

$$
\text { \% }
$$






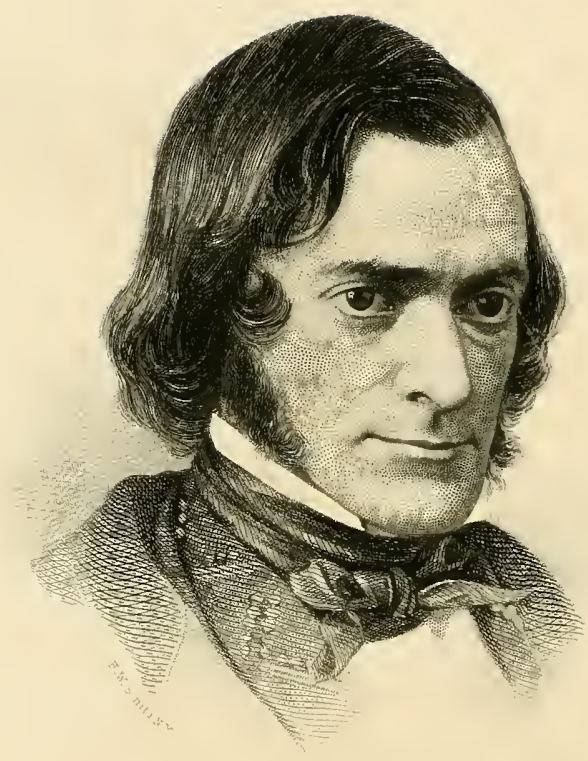




\title{
A TREÁtise
}

ON THE

\section{THEORY AND PRACTICE}

oF

\section{LANDSCAPE \\ GARDENING.}

ADAPTED TO

artortly Americr:

- WITH A VIEW TO THE

\section{IMPROVEMENT OF COUNTRY RESIDENCES.}

\author{
COMPRISING
}

MISTORICAL NOTICES 1 ND GENERAX PRINCIPLES OF THE ART, DIRECTIONS FOR LAYING OUT GROUNDS AND ARRANGING PLANTATIONS, THE DESCRIPTION $\triangle N D$ CULTIVATION OF HARDY TREES, DECORATIVE ACC JMPANIMENTS OF TIE HOUSE AND GROUNDS, THE FORMATION OF

PIECES OF ARTIFICIAL WATER, FLOWER GARDENG, ETC.

WITI

REMARKS ON RURAL ARCHITECTURE.

BY THE LATE A. J. DOWNING, ESQ.

EIGHTH EDTTION.

ENLARGED, REVISED, AND NEWLY ILLTSTRATED.

\section{WITH A SUPPLEMENT,}

CONTAINING SOME REMARKS ABOUT COUNTRY PLACES, AND THE BEST METHODS OF MAETNO THEM; ALSO, AN ACCOUNT OF THE NEWER DECIDUOUS AND EVERGREEN PLANTS, LATRLY INTRODUCED INTO CULTIVATION, BOTH HARDY AND HALF-HARDY.

BY

HENRY WINTHROP SARGENT.

NEW-YORK:

ORANGE JUDD \& COMPAN 245 BROADWAY. 


\section{SB47I \\ - I7 \\ 1859}

Extered, according to Act of Congress, in the year 1559,

BY A. O. MOORE \& CO.,

In the Clerk's Ofice of the District Court of the Enited States, in and for the Southern District of New York.

Jolin A. Grat \& Green, Printerg,

16 if 15 Jacob Street. N. $\mathrm{X}$.

$$
\begin{aligned}
& \text { By tramafol } \\
& 17 \text { ly! }
\end{aligned}
$$$$
\therefore \quad \vdots
$$ 


\section{JOHN QUINOY ADAMS, LL.D.,}

EX-PRESIDENT OF THE UNITED STATES,

THE LOVER OF RURAL PURSUITS,

AS WELL AS

IHE IISINGUISIED PATIIOT, STATISHAN,

$$
\text { A N D SA GE; }
$$

\section{THIS VOLUME}

BY PERMISSION,

IS PESPECTFULLY AND AFFECTIONATELY

I) $\mathrm{E} \mathrm{D} \mathrm{I} \mathrm{A} \mathrm{T} \mathrm{E} \mathrm{,}$

BY HIS FRIEND,

THIS AUTHOR, 



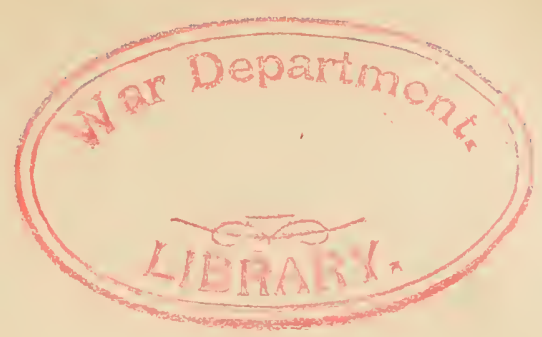

\section{P R E F A E}

TO TIIE FOURTIL EDITION.

IT is even more gratifying to the author of this work to know, from actual observation, that the public taste in Rural Embellishment has, within a few years past, made the most rapid progress in this country, than to feel assured by the call for a fourth edition, that his own imperfect labors for the accomplishment of that end have been most kindly appreciated.

In the present edition considerable alterations and amendments have been made in some portions-especially in that section relating to the nature of the Beautiful and the Picturesque. The difference among critics regarding natural expression and its reproduction in Landscape Gardening, has led him more carefully to examine this part of the subject, in order, if possible, to present it in the clearest and most definite manner.

The whole work has also been revised, and more copiousily illustrated, and is now offered in a more com. plete form than in any previous edition.

A. J. D.

Newburgh, New York, Jan. $1 \varepsilon 49$. 



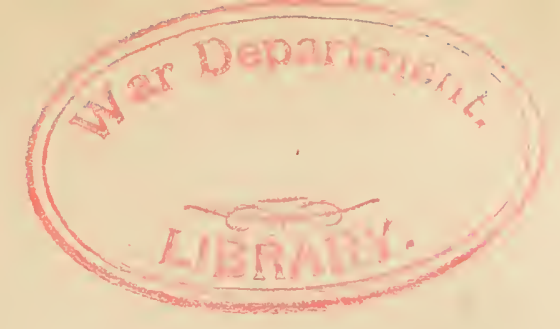

PRE F A E E.

A. TASTE for rural improvements of every descriptior is advancing silently, but with great rapidity in this country. While yet in the far west the pioneer constructs his rude hut of logs for a dwelling, and sweeps away with his axe the- lofty forest trees that encumber the ground, in the older portions of the Union, bordering the Atlantic, we are surrounded by all the luxuries and refinements that belong to an old and long cultivated country. Within the last ten years, especially, the evidences of the growing wealth and prosperity of our citizens have become apparent in the great increase of elegant cottage and villa residences on the banks of our noble rivers, along our rich valleys, and wherever nature seems to invite us by her rich and varied charms.

In all the expenditure of means in these improvements. amounting in the aggregate to an immense sum, professional talent is seldom employed in Architecture or Landscape Gardening, but almost every man fancies himself an amateur, and endeavors to plan and arrange his own residence. With but little practical knowledge, and few correct principles for his guidance, it is not surprising that we witness much incongruity and great waste of time and money. Even those who are familiar with foreign works on the subject in question, labor under many obstacles in practice, which grow out of the difference in our soil and climate, or our social and political position.

These views have so often presented themselves to me of late, and have been so frequently urged by persons desiring advice, that I have ventured to prepare the present volume, in the hope of supplying, in some degree, the 
desideratum so much felt at present. While we have treatises, in abundance, on the various departments of the arts and sciences, there has not appeared even a single essay on the elegant art of Landscape Gardening. Hundreds of individuals who wish to ornament their grounds and embellish their places, are at a loss how to proceed, from the want of some leading principles, with the knowledge of which they would find it comparatively easy to produce delightful and satisfactory results.

In the following pages I have attempted to trace out such principles, and to suggest practicable methods of embellishing our Rural Residences, on a scale commensurate to the views and means of our proprietors. While I have availed myself of the works of European authors, and especially those of Britain, where Landscape Gardening was first raised to the rank of a fine art, I have also endeavored to adapt my suggestions especially to this country and to the peculiar wants of its inhabitants.

As a people descended from the English stock, we inherit much of the ardent love of rural life and its pursuits which belongs to that nation; but our peculiar position, in a nerv world that required a population full of enterprise and energy to subdue and improve its vast territory, has, until lately, left but little time to cultivate a taste for Rural Embellishment. But in the older states, as wealth has accumulated, the country become populous, and society more fixed in its character, a return to those simple and fascinating enjoyments to be found in country life and rural pursuits, is witnessed on every side. And to this innate feeling, out of which grows a strong attachment to natal soil, we must look for a counterpoise to the great tendency towards constant change, and the restless spirit of emigration, which form part of our national character ; and which, though to a certain extent highly necessary to our national pros,erity, are, on the other hand, opposed to social and domestic happiness. "In the midst of the continual movement which agitates a democratic community," says the most philosophical writer who has yet discussed our institutions, "the tie which unites one generation to another is relaxed or broken; every man 
readily loses the trace of the ideas of his forefathers, or takes no care about them."

The love of country is inseparably connected with the love of home. Whatever, therefore, leads man to assemble the comforts and elegancies of life around his habitation, tends to increase local attachments, and render domestic life more delightful; thus not only augmenting his own enjoyment, but strengthening his patriotism, and making him a better citizen. And there is no employment or recreation which affords the mind greater or more permanent satisfaction, than that of cultivating the earth and adorning our own property. "God Almighty first planted a garden; and, indeed, it is the purest of human pleasures," says Lord Bacon. And as the first man was shut out fiom the garden, in the cultivation of which no alloy was mixed with his happiness, the desire to return to it seems to be implanted by nature, more or less strongly, in every heart.

In Landscape Gardening the country gentleman of leisure finds a resource of the most agreeable nature. While there is no more rational pleasure than that derived from its practice by him, who

"Plucks life's roses in his quiet fields,"

the enjoyment drawn from it (unlike many other amusements) is unembittered by the after recollection of pain or injury inflicted on others, or the loss of moral rectitude. In rendering his home more beautiful, he not only contributes to the happiness of his own family, but improves the taste, and adds loveliness to the country at large. There is, perhaps, something exclusive in the taste for some of the fine arts. A collection of pictures, for cxample, is comparatively shut up from the world, in the private gallery. But the sylvan and floral collections,the groves and gardens, which surround the country residence of the man of taste,- - are confined by no barriers narrower than the blue heaven above and around them. The taste and the treasures, gradually, but certainly, creep beyond the nominal boundaries of the 
estate, and re-appear in the pot of flowers in the window: or the luxuriant, blossoming vines which clamber over the porch of the humblest cottage by the way side.

In the present rolume I hare sought, by rendering familiar to the reader most of the beautiful, sylran materials of the art, and by describing their peculiar effects in Landscape Gardening. to encourage a taste among general readers. And I have also endearored to place before the amateur such directions and guiding principles as, it is hoped, will assist him materially in laying out his grounds and arranging the general scenery of his residence.

The lircly interest of late manifested in Rural Architecture, and its elose comexion with Landscape Gardening, have induced me to derote a portion of this work to the consideration of buildings in rural scenery.

I take pleasure in acknowledging my obligations and returning thanks to my ralued correspondent, l. C. Loudon, Esq., F. L. S., etc., of London, the most distinguished gardening author of the age, for the illustrations and description of the English Submban Cottage in the Appendix; to the sereral gentlemen in this country who have lindly furnished me with plans or drawings of their residences: and to A. J. Davis, Esq., of New York, and J. Notman, Esq., of Philadelphia, architects, for architectura! druwings and descriptions. 


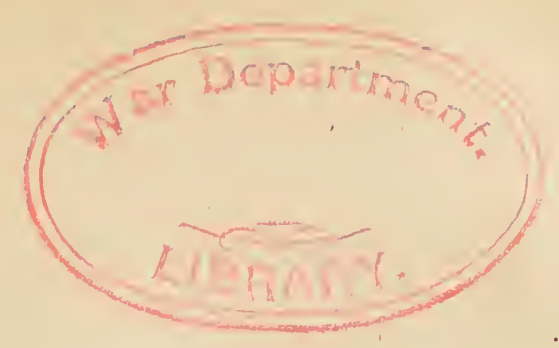

\section{PREFACE TO SIXTH EDITION.}

Artuodgr our advance in rural life has not attained, and may never reach, the extent mentioned by Mr. DownING, in his account of his visit to Woburn Abbey, where he says, " there are 20,000 country houses in England, each lirger than the President's house at Washington;" yet our progress has been very great-partly, perhaps, from the increasing discomfort and expense of our large cities, and the great facilities which our numerous railways and steamers offer to business persons to reside permanently in the country; but more, let us hope, from an improving taste, and love for rural life, which is always one of the agreeable and graceful accompaniments of increasing civilization.

As a country advances in age, she improves in a taste for all the elegant and artistic pursuits of life, which naturally follow in the train of wealth and refinement. The sword is turned into the prining-look, while "arma cedunt togoe."

If one could compare the extremely crude condition of our rural knowledge, upon the first appearance of this book, with the vast progress since made, both in the useful and ornamental cultivation of the soil, it would seem difficult to realize that a nation could move with snch giant strides. Still, though much has been done, much yet remains to do. Those who have already put their hand to the plough, do not desire to turn back, they wish only to know how to go on; want of further information, like the cry of Ajax,

"Give me to see-"

pervades the whole land. 
"What shall I plant?" seems one of the great inquiries, in attempting to answer which, the Editor of this New Edition has endearored to give a list of such of the newer trees and shrubs as have come into notice within the past ten years, with such descriptions of their habits and character as his own information, together with the experience of others (both, he regrets to say, very meagre), will enable him to give.

With regard to the acclimatizing of Evergreens, he would have pieferred to have the experience of another year, in order to test still further, certain varieties, as jet comparatively untried; but perhaps some future edition may enable him to do this.

In conclusion, he would beg to acknowledge the assistance he has derived, in the identification and classification of new and donbtfnl varieties, from $\mathrm{Mr}$. Gordon's excellent work on "The Pinetum," and also from the very complete and thorough "Traité Général des Conifères," par M. Carrière.

To those gentlemen, in this country, who have given him the result of their experience in acclimatizing Erergreens, he desires also to make his acknowledgments.

H. W. S.

Wodenethe, Fishill Landing, Duchess Co.,

New York, January, 185 . 


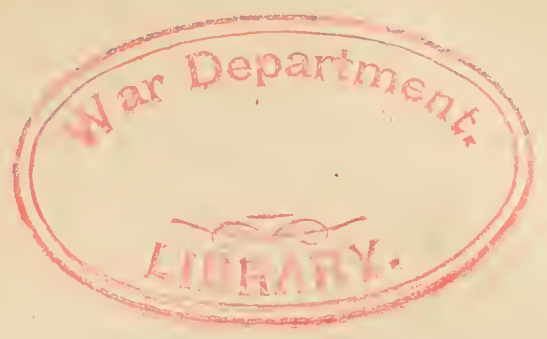

C O N T E N T S.

\section{SECTION I.}

HISTORICAL SKETCHES.

OBJECTs of the art. Origin of the modern and natural style. Influence of the English poets and writers. Examples of the art abroad. Landscape Gardening in North America, and examples now existing.

\section{SECTION II.}

BEAUTIES OF LANDSCAPE GARDENING.

Capacities of the art. The beauties of the ancient style. The Beautiful and the Picturesque. Nature and principles of Landscape Gardening as an imitative art. The Production of Beautiful Landscape. Of Picturesque do. Simple beauty of the art. The principles of Unity, Harmony, and Variety.

\section{SECTION III.}

WOOD AND PLANTATIONE.

The beauty of trees in rural embellishments. Pleosure resulting from their cultivation. Plantations in the ancient style. In the modern style. Grouping trees. Arrangement and grouping in the Graceful school. In the Picturesque school. Illustrations in planting villa, ferme ornée, and cottage grounds. General classification of trees as to forms, with leading characteristics of each class.

\section{SECTION IV.}

DECIDUOUS ORNAMENTAL TREES.

The history and description of all the finest hardy, deciduous trees, Remarks on their effeets in Landscape Gardening, individually and in romposition ; their cultivation, etc.

\section{SECTION $V$.}

EVERGREEN ORNAMTENTAL TREES.

The history and description of all the finest hardy, evergreen trees. Remarks on their effects in Landscape Gardening, individually and in composition. Their cultivation, etc. 


\section{SECTION VI.}

VINES AND OLIMRING PLANTS.

Value of this kind of regetation; fine natural effects. ReInarks on the proper mode of introducing vines. Beautiful effects of climbing plants in connection with buildings.

\section{SECTION TII.}

TREATMENT OF GROUND-FORMATRON OF WALES.

Nature of operations on ground. Treatment of flowing and of irregular surfaces to heighten their expression. Of flats or level surfaces. Rocks as materials in landscape. Laying out roads and walks; the approach. Rules by Repton. The drive and minor ralks. The introduction of fences. Verdant hedges.

\section{SECTION VIII.}

TREATMEXT OF THTER.

Beautiful effects of this clement iu nature. In what cases it is desirable to attempt the formation of artificial pices of water. Regular forms unpleasing. Directions for the formation of ponds or lakes in the irregular manner. Study of natural lakes. Islands. Planting the margin. Treatment of natural brooks and rirulets. Cascades and water-falls. Legitimate sphere of the art in this department.

\section{SECTION IX.}

\section{LANDSCAPE OR RURAL ARCHITECTEIE.}

Difference between a city and country houso. The characteristic features of a country house. Examination of the leading principles in Rural Architecture. The harmonious union of buildings and scenery. The different styles. The Grecian style. Its defects for domestic purposes. The Roman style. The Italian style. Swiss style. The pointed or Gothic style. Castellated buildings. The Tudor mansion. The Elizabethan strle. The old English cottage. Entrance lodges.

\section{SECTION $X$.}

EMBELLISHUENTS; ARCHITECTUT.LL, FUSTIC, AND FLORAL.

Value of a proper connection between the house and grounds. Beauty of the architectural terrace, and its application to rillas and cottages. Use of rases of different descriptions. Architectural flower-garden. Irregulir flower-garden. French flower-garden. English flower-garden Mingled flower-garden. Selections of showy plants, flowering in succes. sion. Arrangement of the shrubbers. The conservatory and greenlouse. Open and corered seats, Parilions. Prospect towers. Bridges. Rockwork. Fountains of rarious descriptions. Judicious introduction of decorations. 


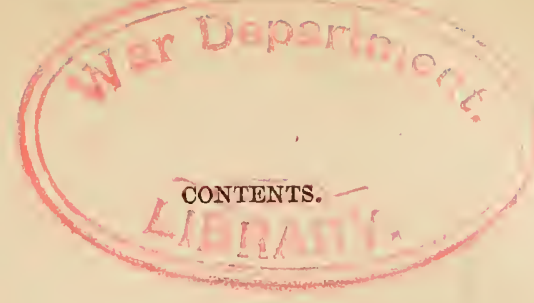

\section{A P P E N D I X.}

Notes on transplanting trees. Reasons for frequenc failures in removing large trees. Directions for performing this operation. Preparing trees for removal. Transplanting evergreens.

On the treatment of Lawns. Use of machines for mowing the Lawn.

\section{S UPPLEMENT.}

\section{SECTION I.}

Progress of Landscape Gardening since Mr. Downing's death. Formation of new places. Common errors. The Lawn.

\section{SECTION II.}

How to make a Country Place. Commencing without trees. Commencing in a wood. History of Wodenethe. History of Welleslex. Italian scenery.

\section{SECTION III.}

The newer deciduous ornamental trees aud shrubs.

\section{SECTION IV.}

The newer half-hardy Evergreen trees and shrubs. Acclimatizing and employing them. Tabular view of Hardihood in different parts of the United States.

\section{SECTION $\mathrm{V}$.}

Historical notices. Examples of Landscape Gardening, and Rural Architecture in the United States.

\section{SECTION VI.}

Historical notices continued. Rural Cemeteries. Central Park, Ner York. Llewellyn PARK, New Jersey. Clinton PARK, etc.

\section{N D E X.}




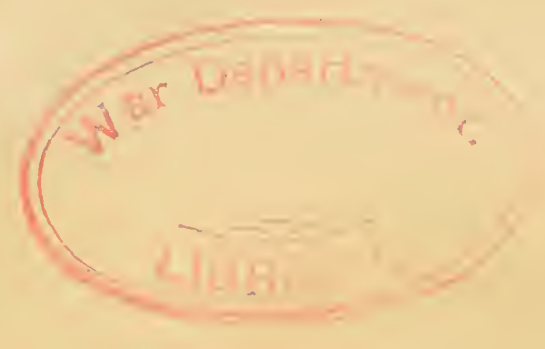

I IST OF ILIUSTRATION S.

ENGRATINGS ON BTELL.

Purtrait of $\Delta$ T. Dowxisg. Frontispiece.

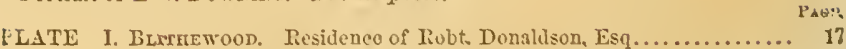

II. Wonexerue. Residence of II. W. Sargent, Esq............ 425

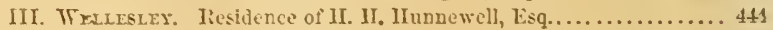

IV. Frracu Fantrum at Wellesley. ..................... \$ts

Y. ITAIAN GARDEx at Wellesler........................... 45.

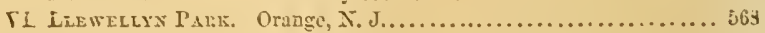

EXGRAYINGB ON TOOD.

Fig. 1. Tiew at IIrde Park........ Pגe. 29 2. Manor of Liringston..........

3. i. Iontgomery Place........... 31

6. Bearerwyck .............. 35

. Residence of $1 \%$ i. Aspinwall................... हi

s. Belmont.................... ss

9. Cottage of Jir. Dunn....... ss

1i. liesilenee of Mr. Shenf......

11. Resilence of Mrs. Camale.... 43

18. Example of the Bentiful.... is

14. Example of the Pieturesque. is

82. Tho European Linden...... 143

35. The ifeeping Larch........ 242

sti. The Magnolis .............. 242

8i. Tho licea pectinata.......... 257

8. The Cedar of Lebanon...... 282

15. Resitence of Mr. Paulding.. 34

49. Resitence of A. J. Downing. $34 t$

50. Tesidence of Mr. Rathbone.. 847

51. Residence of Mr. Lyon...... 84i

52. Mansiun in Elizab. style..... s4

63. Residence of Rer. R. Bolton. sti

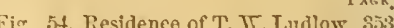
55. Residenco of Wishington Irving............... 353

73. Conserratory at Munt gomery l'lace................ $39 !$ ss. Fiow from Library, irodenethe............... ts

89. View from Breakfist Room, IV odenethe.............4 410 90. Tiew Across the Park, Wodenetho ............ 448 91. The 1)wate llorse Chestmut 4is 92. The Weeping Elm........ 459 93. Tho Weeping Iminer..... 50 s 94. Tho Scaled Juniper....... 508 95. Pinus patuls............. 503 96. Torreya.................

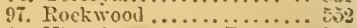
101. Viow in (EXTRAL PARK... B bit? 10:. The Same, propused ettect. $56: 3$ 103. Tlew of Watel Terrace in Cextral Park.......... 56 101. Same, befure improvement. 555

\section{EXGEATIXGS ON STONE.}

rig. 9\&. Plon of Cextrat PARk... 50 99. Original Condition of the Gruunds............ . 561 105. Entrance to Liewelex PAxk...............5 5:0
Fig. 106. N. W. part of LLEmFLIYs park. 10\%. Arcade Cuttige Gromnds.. 57s 10s. Do. Working Flan.... 573 


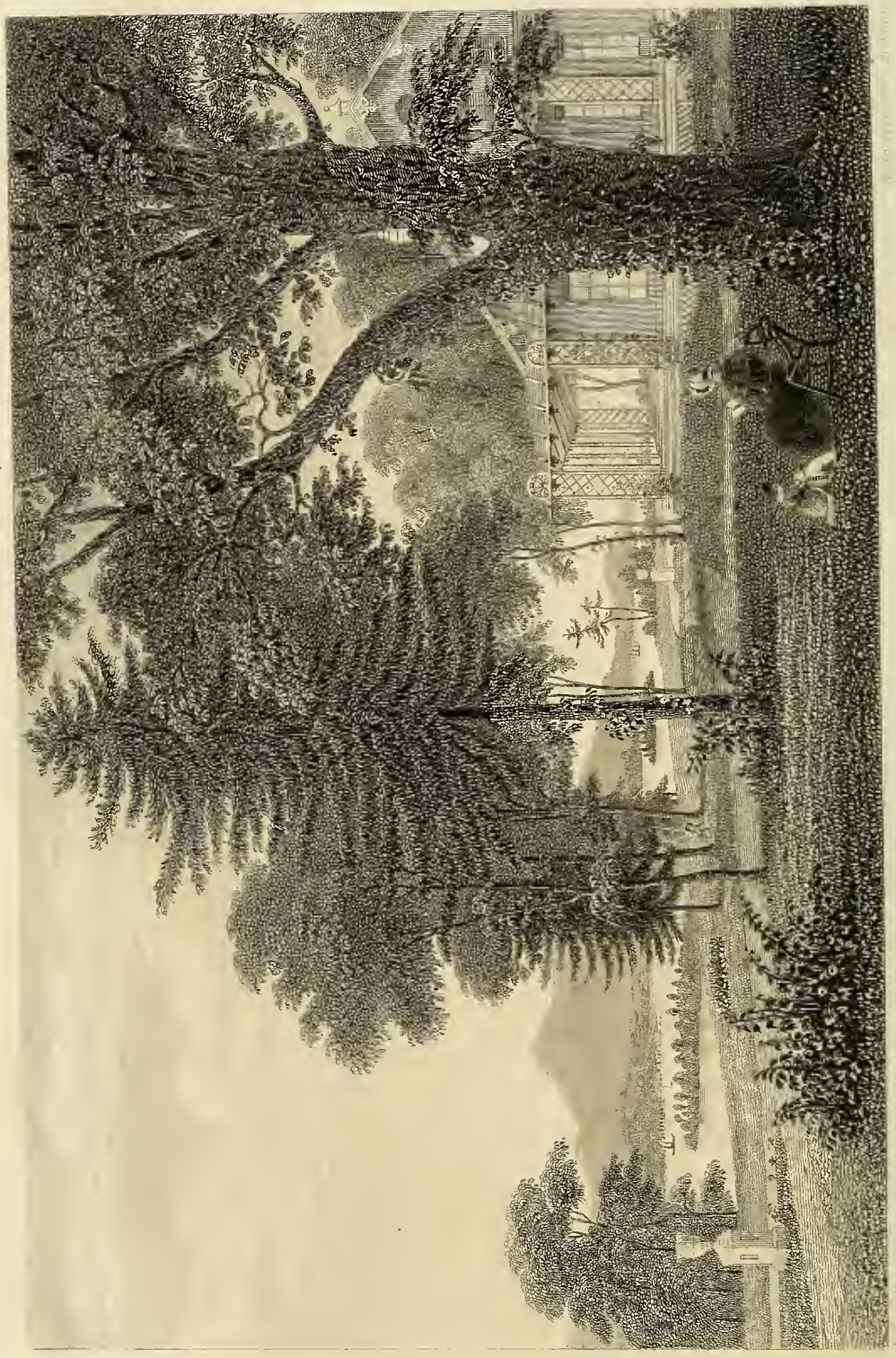


refined perceptions of beauty are combined with them.' And we may add to this, that Landscape Gardening, which is an artistical combination of the beautiful in nature and art-an union of natural expression and harmonious cultivation-is capable of affording us the highest and most intellectual enjoyment to be found in any cares or pleasures belonging to the soil.

The development of the Beautiful is the end and aim of Landscape Gardening, as it is of all other fine arts. The ancients sought to attain this by a studied and elegant regularity of design in their gardens; the moderns, by the creation or improvement of grounds which, though of limited extent, exhibit a highly graceful or picturesque epitome of natural beauty. Landscape Gardening differs from gar dening in its common sense, in embracing the whole scene immediately about a country house, which it softens and refines, or renders more spirited and striking by the aid of art. In it we seek to embody our ideal of a rural home; not through plots of fruit trees, and beds of choice flowers, though these have their place, but by collecting and combining beautiful forms in trees, surfaces of ground, buildings, and walks, in the landscape surrounding us. It is, in short, the Beautiful, embodied in a home scene. And we attain it by the removal or concealment of everything uncouth and discordant, and by the introduction and preservation of forms pleasing in their expression, their outlines, and their fitness for the abode of man. In the orchard, we hope to gratify the palate; in the flower garden, the eye and the smell; but in the landscape garden we appeal to that sense of the Beautiful and the Perfect, which is one of the highest attributes of our nature.

This embellishment of nature, which we call Landscape 
Gardening, springs naturally from a love of country life, an attachment to a certain spot, and a desire to render that place attractive-a feeling which seems more or less strongly fixed in the minds of all men. But we should convey a false impression, were we to state that it may be applied with equal success to residences of every class and size, in the country. Lawn and trees, being its two essential elements, some of the beauties of Landscape Gardening may, indeed, be shown wherever a rood of grass surface, and half a dozen trees are within our reach; we may, even with such scanty space, have tasteful grouping, varied surface, and agreeably curved walks; but our art, to appear to advantage, requires some extent of surface-its lines should lose themselves indefinitely, and unite agreeably and gradually with those of the surrounding country.

In the case of large landed estates, its capabilities may be displayed to their full extent, as from fifty to five hundred acres may be devoted to a park or pleasure grounds. Most of its beauty, and all its charms, may, however, be enjoyed in ten or twenty acres, fortunately situated, and well treated; and Landscape Gardening, in America, combined and working in harmony as it is with our fine scenery, is already beginning to give us results scarcely less beautiful than those produced by its finest efforts abroad. The lovely villa residences of our noble river and lake margins, when well treated-even in a few acres of tasteful fore-ground,-seem so entirely to appropriate the whole adjacent landscape, and to mingle so sweetly in their outlines with the woods, the valleys, and shores around them, that the effects are often truly enchanting.

But if Landscape Gardening, in its proper sense, cannot be applied to the embellishment of the smallest cottage 
residences in the country, its principles may be studied with advantage, even by him who has only three trees to plant for ornament; and we hope no one will think his grounds too small, to feel willing to add something to the general amount of beauty in the country. If the possessor of the cottage acre would embellish in accordance with propriety, he must not, as we have sometimes seen, render the whole ridiculous by aiming at ambitious and costly embellishments; but he will rather seek to delight us by the good taste evinced in the tasteful simplicity of the whole arrangement. And if the proprietors of our country villas, in their improvements, are more likely to run into any one error than another, we fear it will be that of too great a desire for display-too many vases, temples, and seats, and too little purity and simplicity of general effect.

The inquiring reader will perhaps be glad to have a glance at the history and progress of the art of tasteful gardening; a recurrence to which, as well as to the history of the fine arts, will afford abundant proof that, in the first stage or infancy of all these arts, while the perception of their ultimate capabilities is yet crude and imperfect, man. lind has, in every instance, been completely satisfied with the mere exhibition of design or art. Thus in Sculpture, the first statues were only attempts to imitate rudely the form of a human figure, or in painting, to represent that of a tree: the skill of the artist, in effecting an imitation suc. cessfully, being sufficient to excite the astonishment and admiration of those who had not yet made such advances as to enable them to appreciate the superior beauty of expression.

Landscape Gardening is, indeed, only a modern word, first coined, we believe, by Shenstone. 
The most distinguished English Landscape Gardeners of recent date, are the late Humphrey Repton, who died in 1818; and since him John Clandius Loudon better known in this country, as the celebrated gardening author. Repton's taste in Landscape gardening was cultivated and elegant, and mary of the finest parks and pleasure grounds of England, at the present day, bear witness to the skill and harmony of his designs. His published works are full of instructive hints, and at Cobham Hall, one of the finest seats in Britain, is an inscription to his memory, by Lord Darnley.

Mr. Loudon's* writings and labors in tasteful gardening, are too well known, to render it necessary that we should do more than allude to them here. Much of what is known of the art in this country undoubtedly is, more or less directly, to be referred to the influence of his published works. Although he is, as it seems to us, somewhat deficient, as an artist, in imagination, no previous author ever deduced, so clearly, sound artistical principles in Landscape Gardening and Rural Architecture ; and fitness, good sense, and beauty, are combined with much unity of feeling in all his works.

As the modern style owes its origin mainly to the English, so it has also been developed and carried to its greatest perfection in the British Islands. The law of primogeniture, which has there so long existed, in itself, contributes greatly to the continual improvement and embellishment of those vast landed estates, that remain perpetually in the hands of the same family. Magnificent

* While we are revising the second edition, we regret deeply to learn the death of Mr. Loudon. His herculean labors as an author have at last destroyed him; and in his death we lose one who has done more than any other person that ever iived, to popularize, and render universal, a taste for Gardening and Domestic Architecture. 
buildings, added to by each succeeding generation, who often preserve also the older portions with the most scrupulous care; wide spread parks, clothed with a thick velvet turf, which, amid their moist atmosphere, preserves during great part of the year an emerald greennessstudded with noble oaks and other forest trees which number centuries of growth and maturity; these advantages, in the hands of the most intelligent and the wealthiest aristocracy in the world, have indeed made almost an entire landscape garden of "merry England." Among a multitude of splendid examples of these noble residences, we will only refer the reader to the celebrated Blenheim, the seat of the Duke of Marlborough, where the lake alone (probably the largest piece of artificial water in the world) covers a surface of two hundred acres : Chatsworth, the varied and magnificent seat of the Duke of Devonshire, where there are scenes illustrative of almost every style of the art: and Woburn Abbey, the grounds of which are full of the choicest specimens of trees and plants, and where the park, like that of Ashbridge, Arundel Castle, and several other private residences in England, is only embraced within a circumference of from ten to trienty miles.

On the continent of Europe, though there are a multitude of examples of the modern style of landscape gardening, which is there called the English or natural style, yet in the neighborhood of many of the capitals, especially those of the south of Europe, the taste for the geometric or ancient style of gardening still prevails to a considerable extent; partially, no doubt, because that style admits, with more facility, of those classical and architectural accompaniments of vases, statues, busts, etc.; 
the passion for which pervades a people rich in ancient and modern sculptural works of art. Indeed, many of the gardens on the continent are more striking from their numerous sculpturesque ornaments, interspersed with fountains and jets-d'eau, than from the beauty or rarity of their vegetation, or from their arrangement.

In the United States, it is highly improbable that we shall ever witness such splendid examples of landscape gardens as those abroad, to which we have alluded. Here the rights of man are held to be equal; and if there are no enormous parks, and no class of men whose wealth is hereditary, there is, at least, what is more gratifying to the feelings of the philanthropist, the almost entire absence of a very poor class in the country; while we have, on the other hand, a large class of independent landholders, who are able to assemble around them, not only the useful and convenient, but the agreeable and beautiful, in country life.

The number of individuals among us who possess wealth and refinement sufficient to enable them to enjoy the pleasures of a country life, and who desire in their private residences so much of the beauties of landscape gardening and rural embellishment as may be had without any enormous expenditure of means, is every day increasing. And although, until lately, a very meagre plan of laying out the grounds of a residence, was all that we could lay claim to, yet the taste for elegant rural improvements is advancing now so rapidly, that we have no hesitation in predicting that in half a century more, there will exist a greater number of beautiful villas and country seats of moderate extent, in the Atlantic States, than in any country in Europe, England alone excepted. With us, a 
feeling, a taste, or an improvement, is contagious; and once fairly appreciated and established in one portion of the country, it is disseminated with a celerity that is indeed wonderful, to every other portion. And though it is necessarily the case where amateurs of any art are more numerous than its professors, that there will be, in devising and carrying plans into execution, many specimens of bad taste, and perhaps a sufficient number of efforts to improve without any real taste whatever, still we are convinced the effect of our rural embellishments will in the end be highly agreeable, as a false taste is not likely to be a permanent one in a community where everything is so much the subject of criticism.

With regard to the literature and practice of Landscape Gardening as an art, in North America, almost everything is yet before us, comparatively little having yet been done. Almost all the improvements of the grounds of our finest country residences, have been carried on under the direction of the proprietors themselves, suggested by their own good taste, in many instances improved by the study of European authors, or by a personal inspection of the finest places abroad. The only American work previously published which treats directly of Landscape Gardening, is the American Gardener's Calendar, by Bernard McMahon of Philadelphia. The only practitioner of the art, of any note, was the late M. Parmentier of Brooklyn, Long Island.

MI. André Parmentier was the brother of that celebrated horticulturist, the Chevalier Parmentier, Mayor of Enghien, Holland. He emigrated to this country about the year 1824, and in the Horticultural Nurseries which he established at Brooklyn, he gave a specimen of the natural 
style of laying out grounds, combined with a scientific arrangement of plants, which excited public curiosity, and contributed not a little to the dissemination of a taste for the natural mode of landscape gardening.

During M. Parmentier's residence on Long Island, he was almost constantly applied to for plans for laying out the grounds of country seats, by persons in various parts of the Union, as well as in the immediate proximity of New York. In many cases he not only surveyed the demesne to be improved, but furnished the plants and trees necessary to carry out his designs. Several plans were prepared by him for residences of note in the Southern States; and two or three places in Upper Canada, especially near Montreal, were, we believe, laid out by his own hands and stocked from his nursery grounds. In his periodical catalogue, he arranged the hardy trees and shrubs that flourish in this latitude in classes, according to their height, etc., and published a short treatise on the superior claims of the natural, over the formal or geometric style of laying out grounds. In short, we consider M. Parmentier's labors and examples as having effected, directly, far more for landscape gardening in America, than those of any other individual whatever.

The introduction of tasteful gardening in this country is, of course, of a very recent date. But so long ago as from 25 to 50 years, there were several country residences nighly remarkable for extent, elegance of arrangement, and the highest order and keeping. Among these, we desire especially to record here the celebrated seats of Chancellor Livingston, Wm. Hamilton, Esq., Theodore Lyman, Esq., and Judge Peters.

Woodlands, the seat of the Hamilton family, near 
Philadelphia, was, so long ago as 1805 , highly celebrated for its gardening beauties. The refined taste and the wealth of its accomplished owner, were freely lavished in its improvement and embellishment; and at a time when the introduction of rare exotics was attended with a vast deal of risk and trouble, the extensive green-houses and orangeries of this seat contained all the richest treasures of the exotic flora, and among other excellent gardeners employed, was the distinguished botanist Pursh, whose enthusiastic taste in his favorite science was promoted and aided by Mr. Hamilton. The extensive pleasure grounds were judiciously planted, singly and in groups, with a great variety of the finest species of trees. The attention of the visitor to this place is now arrested by two very large specimens of that curious tree, the Japanese Ginko (Salisburia), 60 or 70 feet high, perhaps the finest in Europe or America, by the noble magnolias, and the rich park-like appearance of some of the plantations of the finest native and foreign oaks. From the recent unhealthiness of this portion of the Schuylkill, Woodlands has fallen into decay, but there can be no question that it was, for a long time, the most tasteful and beautiful residence in America.

The seat of the late Judge Peters, about five miles from Philadelphia, was, 30 years ago, a noted specimen of the ancient school of landscape gardening. Its proprietor had a most extended reputation as a scientific agriculturist, and his place was also no less remarkable for the design and culture of its pleasure-grounds, than for the excellence of its farm. Long and stately avenues, with vistas terminated by obelisks, a garden adorned with marble vases, busts, and statues, and pleasure grounds filled with 
the rarest trees and shrubs, were conspicuous features here. Sorne of the latter are now so remarkable as to attract strongly the attention of the visitor. Among them, is the chestnut planted by Washington, which produces the largest and finest fruit; very large hollies; and a curious old box-tree, much higher than the mansion near which it stands. But the most striking feature now, is the still remaining grand old avenue of hemlocks (Abies canadensis). Many of these trees, which were planted 100 years ago, are now venerable specimens, ninety feet high, whose huge trunks and wide-spread branches are, in many cases, densely wreathed and draped with masses of English Ivy, forming the most picturesque sylvan objects we ever beheld.

Lemon Hill, half a mile above the Fairmount waterworks of Philadelphia, was, 20 years ago, the most perfect specimen of the geometric mode in America, and since its destruction by the extension of the city; a few years since, there is nothing comparable with it, in that style, among us. All the symmetry, uniformity, and high art of the old school, were displayed here in artificial plantations, formal gardens with trellises, grottoes, spring-houses, temples, statues, and vases, with numerous ponds of water, jets-d'eau, and other water-works, parterres and an extensive range of hothouses. The effect of this garden was brilliant and striking; its position, on the lovely banks of the Schuylkill, admirable; and its liberal proprietor, $\mathrm{Mr}$. Pratt, by opening it freely to the public, greatly increased the popular taste in the neighborhood of that city.

On the Hudson, the show place of the last age was the still interesting Clermont, then the residence of Chancellor Livingston. Its level or gently undulating lawn, four $\boldsymbol{o x}$ 
five miles in leugth, the rich native roods, and the long vistas of planted aremues, added to its fine water riew, rendered this a noble place. The mansion, the greenhouses, and the gardens, show something of the French taste in design, which Mr. Liringston's residence abroad, at the time when that mode was popular, no doubt, led him to adopt. The finest yellow locusts in America are now standing in the pleasure-grounds here, and the gardens contain many specimens of fruit trees, the first of their sorts introduced into the Union.

Waltham House, about nine miles from Boston, was, 25 rears ago, one of the oldest and finest places, as regards Landscape Gardening. Its ormer, the late Hon. T. Lyman, was a highly-accomplished man, and the grounds at Waltham House bear witness to a refined and elegant taste in rural improrement. A fine level park, a mile in length, emiched with groups of English limes, elms, and oaks, and rich masses of mative wood, watered by a fine stream and stocked with deer, were the leading features of the place at that time; and this, and Woodlands, were the two best specimens of the modern. style, as Judge Peters' seat, Lemon Hill, and Clermont, were of the ancient style, in the earliest period of the history of Landscape Gardening among us.

There is no part of the Union where the taste in Land. scape Gardening is so far adranced, as on the middle portion of the Hudson. The natural scenery is of the finest character, and places but a mile or two apart often possess, from the constantly rarying forms of the water, shores, and distant hills, widely different kinds of home landscrpe and distant view. Standing in the grounds of some of the finest of these seats, the eyce beholds only the 



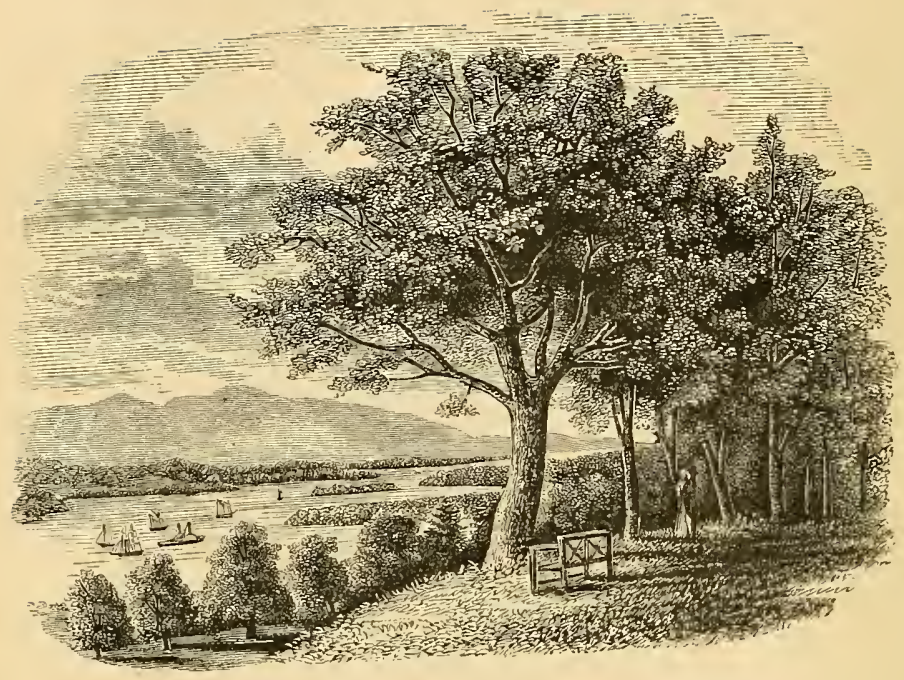

Fig. 1.-View in the Grounds at Hycle Park

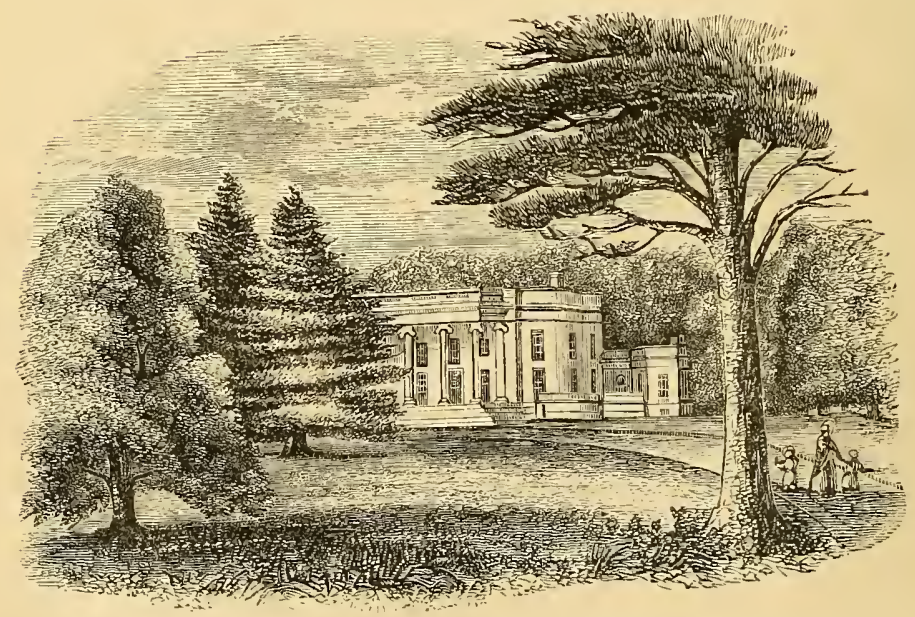

Ful, 2.-The Manor of Livingston. 
soft foreground of smooth lawn, the rich groups of trees shutting out all neighboring tracts, the lake-like expanse of water, and, closing the distance, a fine range of wooderl mountain. A residence here of but a hundred acres, so fortunately are these disposed by nature, seems to appropriate the whole scenery round, and to be a thousand in extent.

At the present time, our handsome villa residences are becoming every day more numerous, and it would require much more space than our present limits, to enumerate all the tasteful, rural country places within our knowledge, many of which have been newly laid out, or greatly improved within a few years. But we consider it so important and instructive to the novice in the art of Landscape Gardening to examine, personally, country seats of a highly tasteful character, that we shall venture to refer the reader to a few of those which have now a reputation among us as elegant country residences.

Hyde Park, on the Hudson, formerly the seat of the late Dr. Hosack, now of W. Langdon, Esq., has been justly eelebrated as one of the finest specimens of the modern style of Landscape Gardening in America. Nature has, indeed, done much for this place, as the grounds are finely varied, beautifully watered by a lively stream, and the views are inexpressibly striking from the neighborhood of the house itself, including, as they do, the noble Hudson for sixty miles in its course, through rich valleys and bold mountains. (See Fig. 1.) But the efforts of art are not unworthy so rare a locality; and while the native woods, and beautifully undulating surface, are preserved in their original state, the pleasure-grounds, roads, walks, drives, and new plantations, have been laid out in such a judi- 
clous manner as to heighten the charms of nature. Large and costly hot-houses were erected by Dr. Hosack, with also entrance lodges at two points on the estate, a fine bridge over the stream, and numerous pavilions and seats commanding extensive prospects; in short, nothing was spared to render this a complete residence. The park, which at one time contained some fine deer, afforded a delightful drive within itself, as the whole estate numbered about seren hundred acres. The plans for laring out the grounds were furnished by Parmentier, and architects from New York were employed in designing and erecting the buildings. For a long time, this was the finest seat in America, but there are now many rivals to this claim.

The DLanor of Livingston, lately the seat of Mrs. Mary Livingston (but now of Jacob Le Roy, Esq.), is seren miles east of the city of Hudson. The mansion stands in the midst of a fine park, rising gradually from the level of a rich inland country, and commanding prospects for sixty miles around. The park is, perhaps, the most remarkable in America, for the noble simplicity of its character, and the perfect order in which it is kept. The turf is, everywhere, short and relvet-like, the gravel-roads scrupulously firm and smooth, and near the house are the largest and most superb erergreens. The mansion is one of the chastest specimens of the Grecian style, and there is an air of great dignity about the whole demesne.

Blithewood, formerly the seat of R. Donaldson, Esq., (now John Bard, Esq.), near Barrytorn, on the Hudson, is one of the most charming villa residences in the Union. The natural scenery here, is nowhere surpassed in its enchanting mion of softuess and dignity -the river being four miles wide, its placid bosom broken only by islands and gleaming sails, and the horizon 



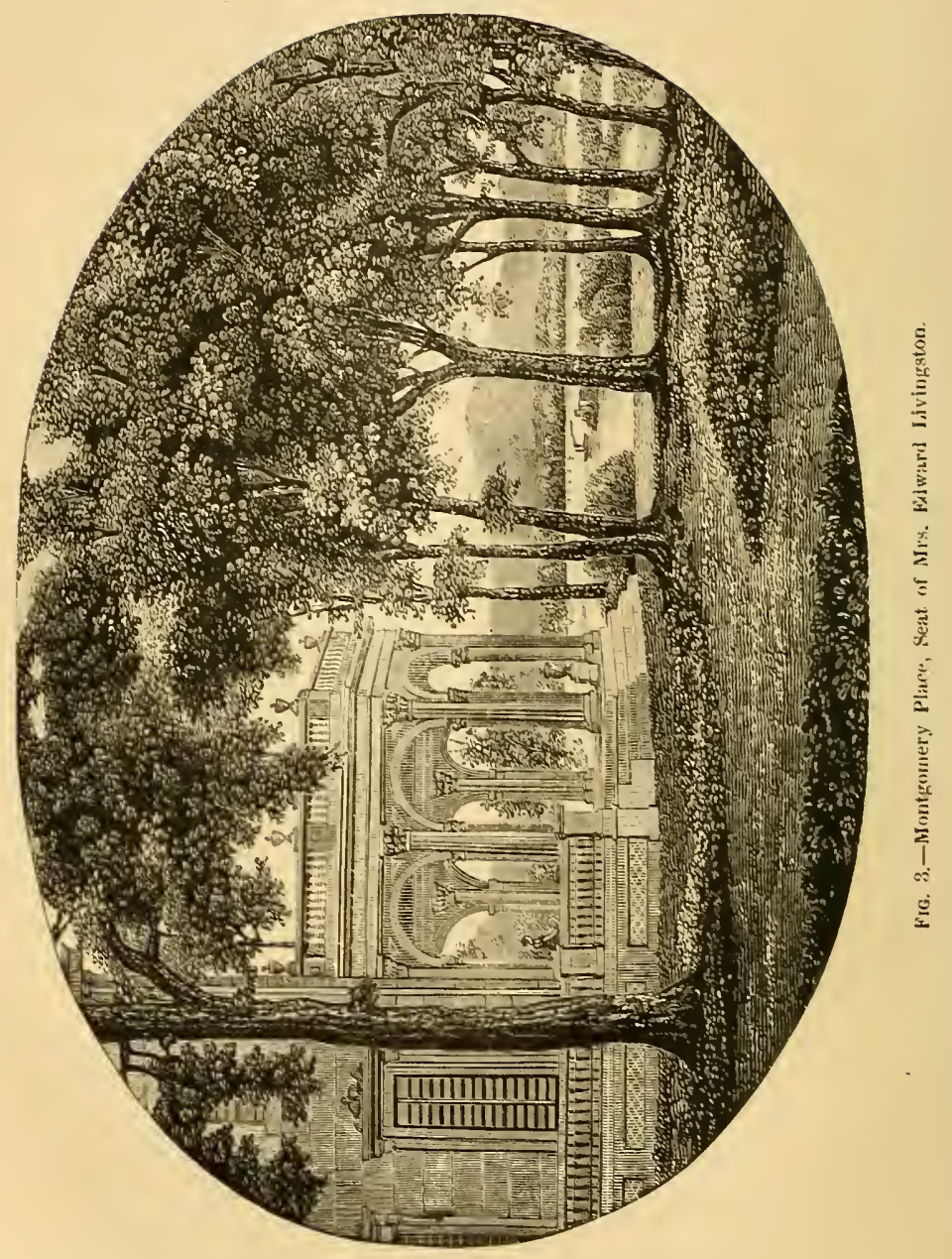


grandly closing in with the tall blue summits of the distant Kaatskills. The smiling, gently varied lawn is studded with groups and masses of fine forest and ornamental trees, beneath which are walks leading in easy curves to rustic seats and summer houses placed in secluded spots, or to openings affording most lovely prospects. (See Frontispiece.) In various situations near the house and upon the lawn, sculptured vases of Maltese stone are also disposed in such a manner as to give a refined and classic air to the grounds.

$\Lambda$ s a pendant to this graceful landscape, there is within the grounds scenery of an opposite character, equally wild and picturesque-a fine, bold stream, fringed with woody banks, and dashing over several rocky cascades, thirty or forty feet in height, and falling altogether a hundred feet in a distance of half a mile. There are also, within the grounds, a pretty gardener's lodge, in the rural cottage style, and a new entrance lodge by the gate, in the bracketed mode; in short, we can recall no place of moderate extent, where nature and tasteful art are both so harmoniously combined to express grace and elegance. Montgomery Place, the residence of Mrs. Edward Livingston, which is also situated on the Hudson, near Barrytown, deserves a more extended notice than our present limits allow, for it is, as a whole, nowhere surpassed in America, in point of location, natural beauty, or the landscape gardening charms which it exhibits.

It is one of our oldest improved country seats, having been originally the residence of Gen. Montgomery, the hero of Quebec. On the death of his widow it passed into the hands of her brother, Edward Livingston, Esq., the late minister to France, and up to the present moment has 
always received the most tasteful and judicious treat, ment.

The lever of the expressive in nature, or the beamtiful in art. will fimd here immumerable subjects for his study. The natural semery in many portions approaches the character of gramdemr. and the foreground of rich woods and lawns, stretehing out on all sides of the mountin, completes a heme landscape of dignified and clegant seclusion, rarely smpassed in amy country.

Among the fine features of this estate are the wilderabes. a thickly wooded and highly picturesyue valley, filled with the richest growth of trees. and threaded with dark, intricate, and mazy walks. along which are placed a

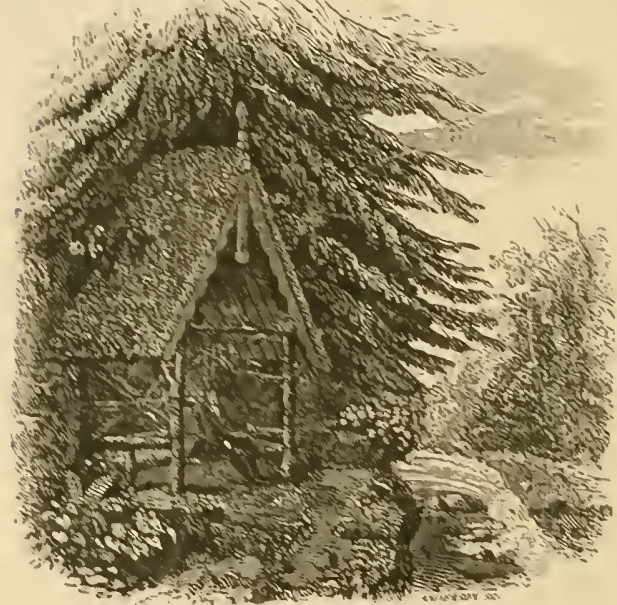

Fiv. 4. One of the kustle seats at Mentgumery llizes] variety of rustic stats, (ricis. 4). 'This valloy is musical with the somul of watertills. of which there are sereral fine ones in tho bold impetuons streinn which fints its course? through the low. er part of the wildermess. Near the fiurther end of the valley is a heantifall lake (Fiv. 5). half of which lies cool and dark under the shadow of tall trees while the other halt grlesms in the गpen sunlight.

In a part of the lawn. near the house, yet so surrounded by a dark setting of trees and shrubs as to form a rich 
picture by itself, is one of the most perfect flower gardens in the country, laid out in the arabesque manner, and glowing with masses of the gayest colors-each bed being composed wholly of a single hue. $\Lambda$ large conservatory, an exotic garden, an arboretum, etc., are among the features of interest in this admirable residence. Including a drive through a fine bit of natural wood, south of the mansion, there are five miles of highly varied and picturesque private roads and walks, through the pleasure-grounds of Montgomery Place.

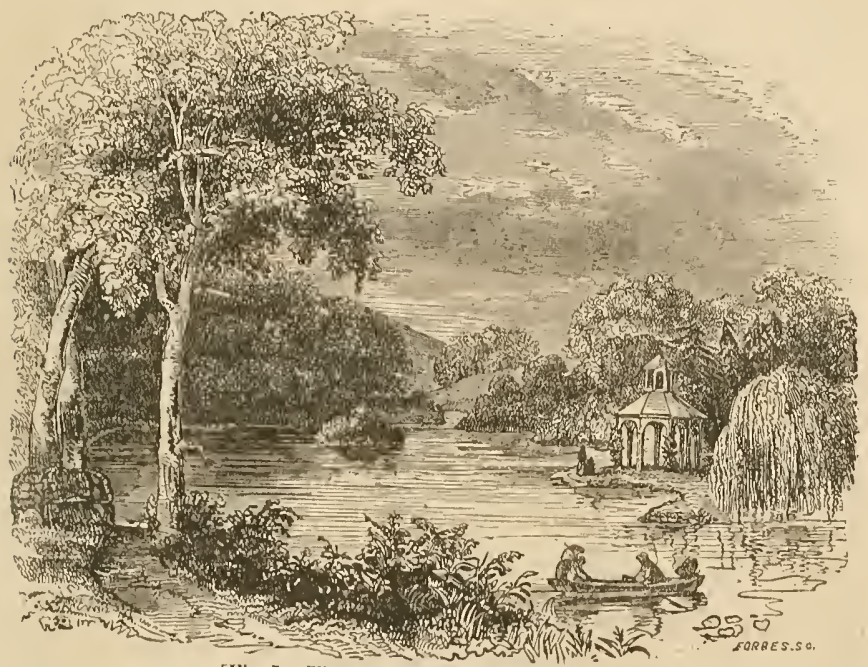

[Fig. 5. The Lake at Montgomery Place.]

Ellerstie is the seat of William Kelly, Esq. It is three miles below Rhinebeck. It compruses over six hundred acres, and is one of our finest examples of high keeping and good management, both in an ornamental and an agricultural point of view. The house is conspicuously placed on a commanding natural terrace, with a fair foreground of park surface below it, studded with beautiful groups of elms and oaks, and a very fine reach of river and 
distant hills. This is one of the most celebrated places on the Hudson, and there are few that so well pay the Ioves of improved landscape for a visit.

Just below Ellerslie are the fine mansion and pleasing grounds of Wm. Emmet, Esq.,-the former a stone edifice, in the castellated style, and the latter forming a most agreeable point on the margin of the river.

The seat of Mrs. Gardiner Howland, near New Hamburgh, is not only beantiful in situation, but is laid ont with great care, and is especially remarkable for the many rare trees and shrubs collected in its grounds.

Thodenethe, near Fishkill landing, is the seat of H. W. Sargent, Esq., and is a bijou full of interest for the lorer of rural beanty; abounding in rare trees, slurubs, and plants, as well as rases, and objects of ruml cmbeliishment of all kinds.

Kienwood, formerly the residence of J. Rathbone, Esq., is one mile south of Aibany. Ten years ago, this spot was a wild and densely wooded hill, almost inaccessible. With great taste and industry Mr. Rathbone has converted it into a country residence of much picturesque beanty, erected, in the Tudor style, one of the best villas in the country, with a gate-lodge in the same mode, and laid out the grounds with remarkable skill and good taste. There are about 1200 acres in this estate, and pleasure grounds, forcing houses, and gardens, are now flourishing where all was so lately in the rudest state of nature; while, by the judicious preservation of natural wood, the effect of a long cultivated demesne has been given to the whole.

The Manor House of the "Patroon" (as the eldest son of the Van Rensselaer family is called) is in the northern suburbs of the city of Albany. The mansion, greatly 


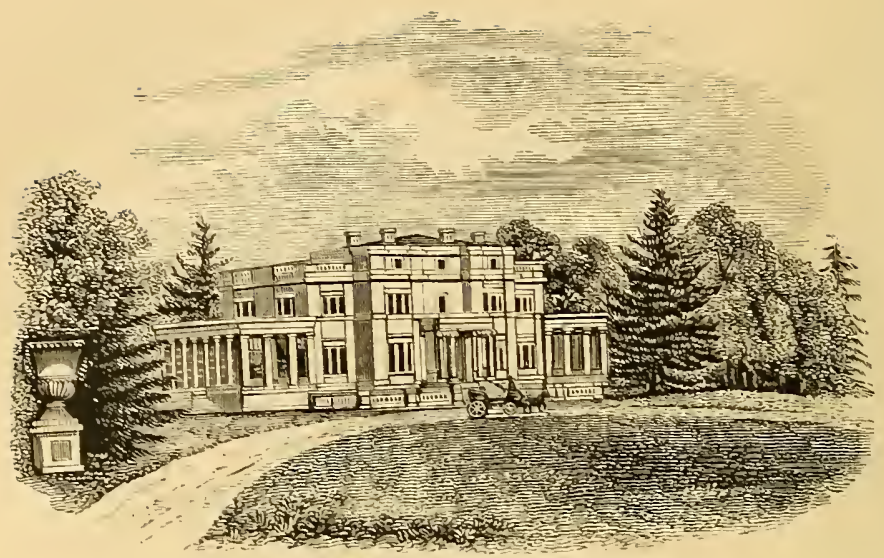

Fic. 6.-Beaverwyck, the Seat of Wm. P. Van Rensselaer, Esq.

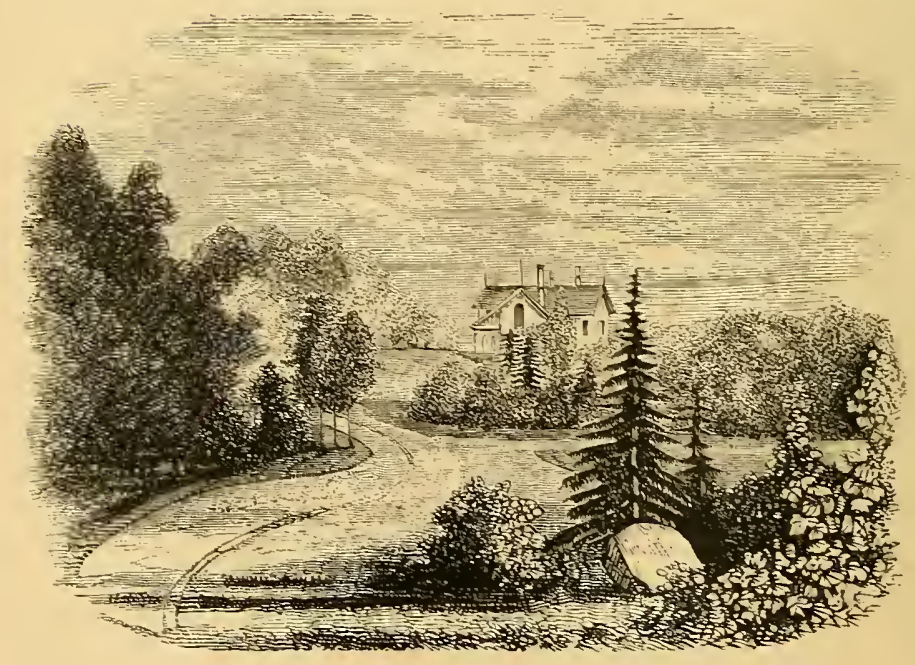

Fzc. T.-Cottage Residence of $\mathrm{Wm}$. H. Aspinmall, Esq. 
enlarged and improved a few years since, from the designs of Upjohn, is one of the largest and most admirable in all respects, to be found in the country, and the pleasuregrounds in the rear of the house are tasteful and beautiful.

Beaverwyck, a little north of Albany, on the opposite bank of the river, was formerly, the seat of Wm. P. Van Rensselaer, Esq. The whole estate is ten or twelve miles square, including the village of Bath on the river shore, and a large farming district. The home residence embraces several hundred acres, with a large level lawn. bordered by highly varied surface of hill and dale. The mansion, one of the first class, is newly erected from the plans of Mr. Diaper, and in its interior-its hall with mosaic floor of polished woods, its marble staircase, frescoed apartments, and spacious adjoining conservatory -is perhaps the most splendid in the Union. The grounds are yet newly laid out, but with much judgment; and six or seven miles of winding gravelled roads and walks have been formed-their boundaries now leading over level meadows, and now winding through woody dells. The drives thus afforded, are almost unrivalled in extent and variety, and give the stranger or guest, an opportunity of seeing the near and distant views to the best advantage.

At Tarrytown, is the cottage residence of Washington Irving, which is, in location and accessories, almost the beau ideal of a cottage ornée. The charming manner in which the wild foot-paths, in the neighborhood of this cottage, are conducted among the picturesque dells and banks, is precisely what one would look for here. A little below, Mr. Sheldon's cottage (now Mr. Hoag's), with its pretty lawn and its charming brook, is one of the best specimens 
ing admirable hints for a class of residence like y to become more numerous than any other in this conntry-the tasteful suburban cottage. The owner of a small cottage residence may have almost every lind of beauty and enjoy. ment in his grounds that the largest estate will afford, so far as regards the interest of trees and plants, tasteful arrangement, recreation and occupation. Indeed, we have little doubt that he, who directs personally the curve of every walk, selects and plants crery shrub and tree, and watches with solicitude every evidence of beauty and pro. gress, succeeds in extracting from his tasteful grounds of half a dozen acres, a more intense degree of pleasure, than one who is only able to direct and enjoy, in a general sense, the arrangement of a rast estate.

Belmont, the seat of J. P. Cushing, Esq., is a residence of more note than any other near Boston; but this is, chiefly, on account of the extensive ranges of glass, the forced fruits, and the high culture of the gardens. A new and spacious mansion has recently been erected here, and the pleasure-grounds are agreeably viried with fine groups and masses of trees and shrubs on a pleasing lawn. (Fig. s.)

The seat of Col. Perkins, at Brookline, is one of the most interesting in this neighborhond. The rery beautiful lawn here, abounds with exquisite trees, fmely disposed; among them, some larches and Norway firs, with many other rare trees of uncommon beauty of form. At a short distance is the villa residence of Theodore Lyman, Esq., remarkable for the unusually fine arenue of Elms leading to the house, and for the beautiful architectural taste dis. played in the dwelling itself. The seat of the Hon. Johu 


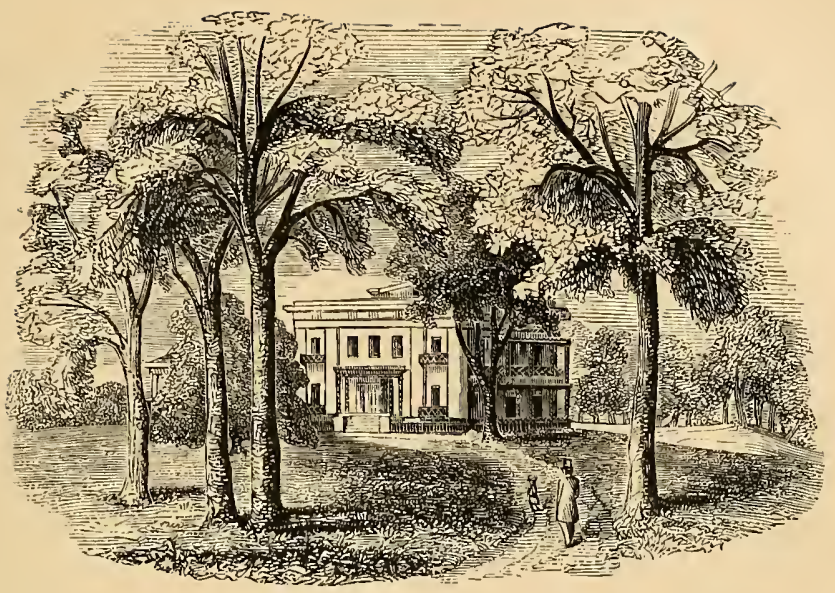

Frg. 8.-Belmont Place, near Boston, the seat of J. P. Cushing, Esq.

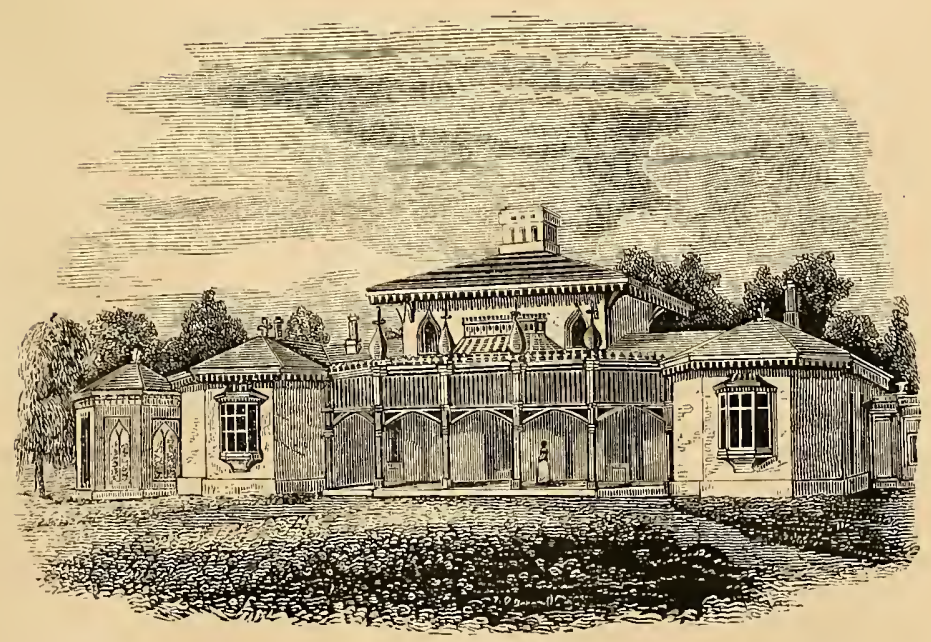

Fis, 9.-Mr. Dunn's Cottage, Mount Holly, N. J. 

Lowell, at Roxbury, possesses also many interesting gardening features.*

Pine Bank, the Perkins estate, on the border of Jamaica lake, is one of the most beautiful residences near Boston. The natural surface of the ground is exceedingly flowing and graceful, and it is varied by two or three singular little dimples, or hollows, which add to its effect. The perfect order of the grounds; the beauty of the walks, sometimes skirting the smooth open lawn, enriched with rare plants and shrubs, and then winding by the shadowy banks of the water; the soft and quiet character of the lake itself,-its margin richly fringed with trees, which conceal here and there a pretty cottage, its firm clean beach of gravel, and its water of crystal purity; all these features make this place a little gem of natural

* We Americans are proverbially impatient of delay, and a few years in prospect appear an endless futurity. So much is this the feeling with many, that we verily believe there are hundreds of our country places, which owe their bareness and destitution of foliage to the idea, so common, that it requires " an age" for forest trees to "grow up."

The middle-aged man hesitates about the good of planting what he imagines he shall never see arriving at maturity, and even many who are younger, conceive tha $\hat{\imath}$ it requires more than an ordinary lifetime to rear a fine wood of planted trees. About two years since, we had the pleasure of visiting the seat. of the late Mr. Lowell, whom we found in a green old age, still enjoying, with the enthusiasm of youtl, the pleasures of Horticulture and a country life. For the encouragement of those who are ever complaining of the tardy pace with which the growth of trees advances, we will here record that we accompanied Mr. L. through a belt of fine woods (skirting part of his residence), nearly half a mile in length, consisting of almost all our finer hardy trees, many of them apparently full grown, the whole of which had been planted by him when he was thirty-two years old. At that time, a solitary elm or two were almost the only trees upon his estate. We can hardly conceive a more rational source of pride or enjoyment, than to be able thus to walk, in the decline of years, beneath the shadow of umbrageous woods and groves, planted by our own hands, and whose growth has become almost identified with our own progress and existence. 
and artistical harmony and beauty. Mr. Perkins has just rebuilt the house, in the style of a French maison de campagne: and Pine Bank is now adorned with a most complete residence in the latest continental taste, from the designs of M. Lémoulnier.

On the other sicle of the lake is the cuttage of Thomas Lee, Esq. Enthusiastically fond of botany, and gardening in all its departments, Mr. Lee has here formed a residence of as much rariety and interest as we ever saw in so moderate a compass-about 20 acres. It is, indeed, not only a most instructire place to the amateur of landscape gardening, but to the naturalist and lorer of plants. Erery shrub seems placed precisely in the soil and aspect it likes best, and native and foreign Rhododendrons, Kalmias, and other rare shrubs, are seen here in the finest condition. There is a great deal of variety in the surface here, and while the lawn-fiont of the house has a polished and graceful air, one or two other portions are quite picturesque. Near the entrance gate is an English oak, only fourteen yars planted. now forty feet high.

The whole of this neighborhood of Brookline is a kind of landscape garden, and there is nothing in America, of the sort, so inexpressibly charming as the lanes which lead from one cottage, or villa, to another. No animals are allowed to run at large. and the open gates, with tempting vistas and glimpses under the pendent boughs, gire it quite an Arcadian air of rural freedom and enjorment. These lanes are clothed with a profusion of trees and wild shrubbery, often almost to the carriage tracks, and curve and wind about, in a mamner quite bewildering to the stranger who attempts to thread them alone; and there are more bints here for the lorer of the picturesque in lanes, than 
we ever saw assembled together in so small a compass.

In the environs of New Bedford are many beautiful residences. Among these, we desire particularly to notice the residence of James $\Lambda$ rnold, Esq. There is scarcely a smalk place in New England, where the pleasure-grounds are so full of variety, and in such perfect order and keeping, as at this charming spot; and its winding walks, open bits of lawn, shrubs and plants grouped on turf, shady bowers, and rustic seats, all most agreeably combined, render this a very interesting and instructive suburban seat. (Fig. 11.)

In New Jersey, the grounds of the Count de Survilliers, at Bordentown,were veryextensive; and although the surface is mostly flat, it has been well varied by extensive plantations. At Mount Holly, about twenty miles from Camden, is $\mathbf{M r}$. Dunn's unique, semi-oriental cottage, with a considerable extent of pleasure ground, newly planted. after the designs of $\mathrm{Mr}$. Notman. (Fig. 9.)

About Philadelphia there are several very interesting seats on the banks of the Delaware and Schuylkill, and the district between these two rivers.

The country seat of George Sheaff, Esq., one of the most remarkable in Pennsylvania, in many respects, is twelve miles north of Philadelphia. The house is a large and re. spectable mansion of stone, surrounded by pleasure-grounds and plantations of fine evergreen and deciduous trees. The conspicuous ornament of the grounds, however, is a magnificent white oak, of enormous size, whose wide stretching branches, and grand head, give an air of dignity to the whole place. (Fig. 10.) Among the sylvan features here, most interesting, are also the handsome evergreens, chiefly Balsam or Balm of Gilead firs, some of which are now 
much higher than the mansion. These trees were planted by Mr. Sheaff twenty-two years ago, and were then so small, that they were brought by him from Philadelphia, at rarious times, in his carriage-a cireumstance highly encouraging to despairing planters, when we reflect how comparatively slow growing is this tree. This whole estate is a striking example of scienee, slill, and taste, applied to a country seat, and there are few in the Union, taken as a whole, superior to it.*

Cottage residence of Mrs. Camac. 'This is one of the most agreeable places within a few miles of Philadelphia. The house is a pieturesque cottage, in the rural gothic style, with very charming and appropriate pleasure grounds, comprising many groups and masses of large and finely grown trees, interspersed with a handsome collection of shrubs and plants; the whole very tastefully arranged. (rig. 11.) The lawn is prettily raried in surfice, and there is a conservatory attached to the house, in which the plants in pots are hidden in beds of soft green moss, and which, in its whole effect and management, is more tasteful and clegant than any plant house, comnected with a dwel!. ing, that we remember to have seen.

* The farm is 300 acres in extent, and, in the time of De Writt Clinton, was pronounced by him the model farm of the United States. At the present time we know nothing superior to it; and Capt. Barclay, in his agricultural tour, says It was the only instance of regular, scientific system of husbandry in the English nanner, he saw in America. Indeed, the large and regular fields, filled with luxuriant crops, everywhere of an exact evemness of growth, and everywhere free from weeds of any sort; the perfect system of manuring and eliture; the simple and complete fences; the fine stock; the very spacioue barns, every senson newly whitewashed internally and extemally, paved with wood, and as clean as a gentleman's stable (with stalls to fatten 90 head of cattle); these, and the masterly way in which the whole is managed, both as regards culture and profit, render this estate one of no common interest in an agricultural, as well as ornamental point of view. 


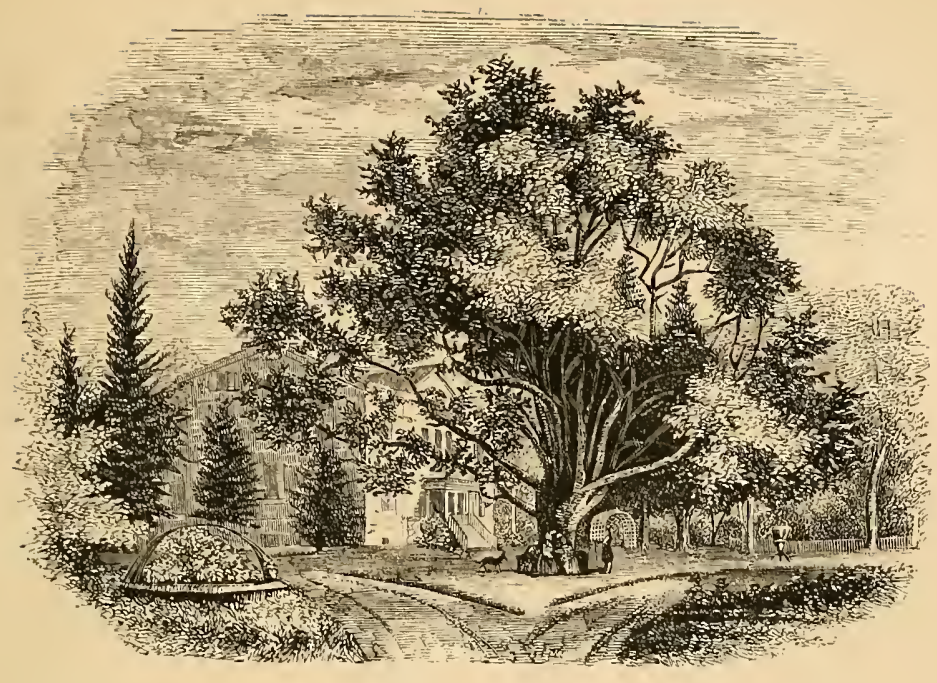

Fig. 10.--The Seat of Cieorge Shear, Esq.

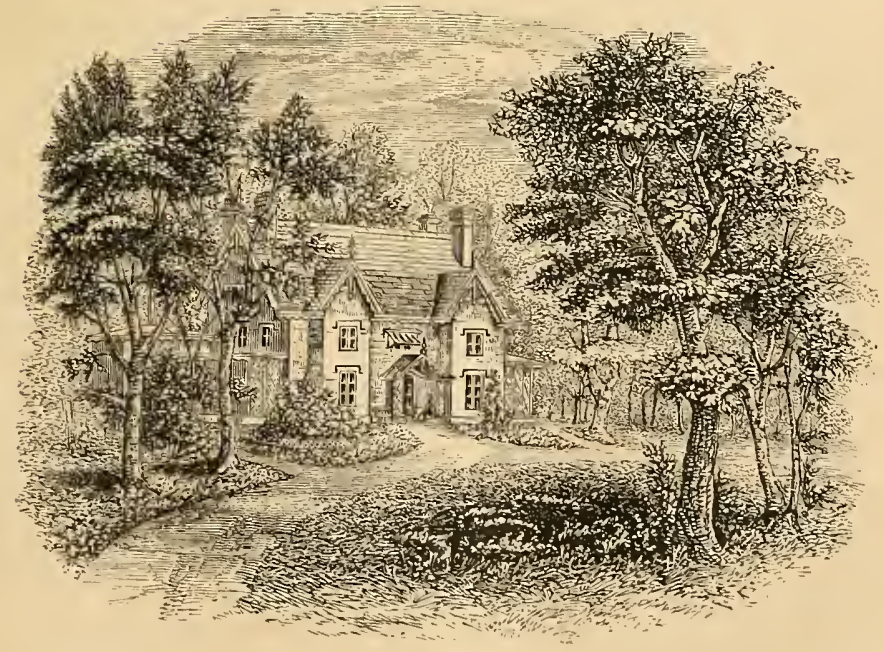

Fis. 11.-Mrs, Camac's Residence 

Stenton, near Germantown, four miles from Philadelpliia, is a fine old place, with many picturesque features. The farm consists of 700 acres, almost without division fencesadmirably managed-and remarkable for its grand old avenue of the hemlock spruce, 110 years old, leading to a family cemetery of much sylvan beauty. There is a large and excellent old mansion, with paved halls, built in 1731, which is preserved in its original condition. This place was the seat of the celebrated Logan, the friend of William Penn, and is now owned by his descendant, Albanus Logan.

The villa residence of Alexander Brown, Esq., is situated on the Delaware, a few miles from Philadelphia. There is here a good deal of beauty, in the natural style, made up chiefly by lawn and forest trees. A pleasing drive through plantations of 25 years' growth, is one of the most interesting features-and there is much elegance and high keeping in the grounds.

Below Philadelphia, the lover of beautiful places will find a good deal to admire in the country seat of John R Latimer, Esq., near Wilmington, which enjoys the reputa. tion of being the finest in Delaware. The place has all the advantages of high keeping, richly stocked gardens and conservatories, and much natural beauty, heightened by judicious planting, arrangement, and culture.

At the south are many extensive country residences remarkable for trees of unusual grandeur and beauty, among which the live oak is very conspicuous; but they are, in general, wanting in that high keeping and care, which is so essential to the charm of a landscape-garden.

Of smaller villa residences, suburban chiefly, there are great numbers, springing up almost by magic, in the borders of our towns and cities. Though the possessors of 
these can scarcely hope to introduce anything approach ing to a landscape garden style, in laying out their limited grounds, still, they may be greatly benefited by an acquaintance with the beauties and the pleasures of this species of rural embellishment. When we are once master of the principles, and aware of the capabilities of an art, we are able to infuse an expression of tasteful design, or an air of more correct elegance, even into the most humble works, and with very limited means.

While we shall endeavor, in the following pages, to give such a vierw of modern Landscape Gardening, as will enable the improver to proceed with his fascinating operations, in embellisining the country residence, in a practical mode, based upon what are now generally received as the correct principles of the art, we would desire the novice, after making himself acquainted with all that can be acquired from written works within his reach, to strengthen his taste and add to his knowledge, by a practical inspection of the best country seats among us. In an infant state of society, in regard to the fine arts, much will be done in violation of good taste; but here, where nature has done so much for us, there is scarcely a large country residence in the Union, from which useful hints in Landscape Gardening may not be taken. And in nature, a group of trees, an accidental pond of water, or some equally simple object, may form a study more conrincing to the mind of a true admirer of natural beauty, than the most carefully drawn plan, or the most elaborately written description. 


\title{
SECTION II.
}

\author{
BEAUTIES AND PRINCIPLES OF TIIE ART.
}

Capacities of the art. The beauties of the ancient style. The modern style. The Beautiful and the Picturesque: their distinctive characteristics. Illustrations drawn from Nature and Painting. Nature and principles of Landscape Gardening as an Imitative art. Distinction between the Beautiful and Picturesque. The principles of Unizy, IJarmony, and Variety.

" Here Nature in her unaffected dresse,

Plaited with vallies and imbost with hills,

Enchast with silver streams, and fringed with woods,

Sits lovely."-

Chamierriayne.

"Il est des soins plus doux, un art plus enchanteur,

C'est peu de charmer l'œil, il faut parler au cœur.

Avez-vous donc connu ces rapports invisibles,

Des corps inanimés et des êtres sensibles?

Avez-vous entendu des eaux, des prés, des bois,

La muette éloquence et la secrète voix?

Rendez-nous ces effets."

Les Jardins, Book I.

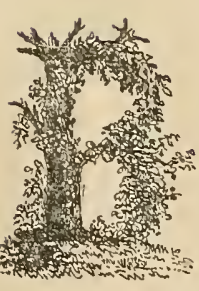

EFORE we proceed to a detailed and more practical consideration of the subject, let us occupy ourselves for a moment with the consideration of the different results which are to be sought after, or, in other words, what kinds of beauty we may hope to produce by Landscape Gardening. To attempt the smallest work in any art, without knowing either the capacities of 
that art. or the schools, or moles ly which it has previous ly been characterized, is but to be groping about in a dim wilight. without the power of knowing. eren shouk we be suecessiul in our efforts. the real exeellence of oug production: or of judying its merit. companatively as a work of faste and imagrination.

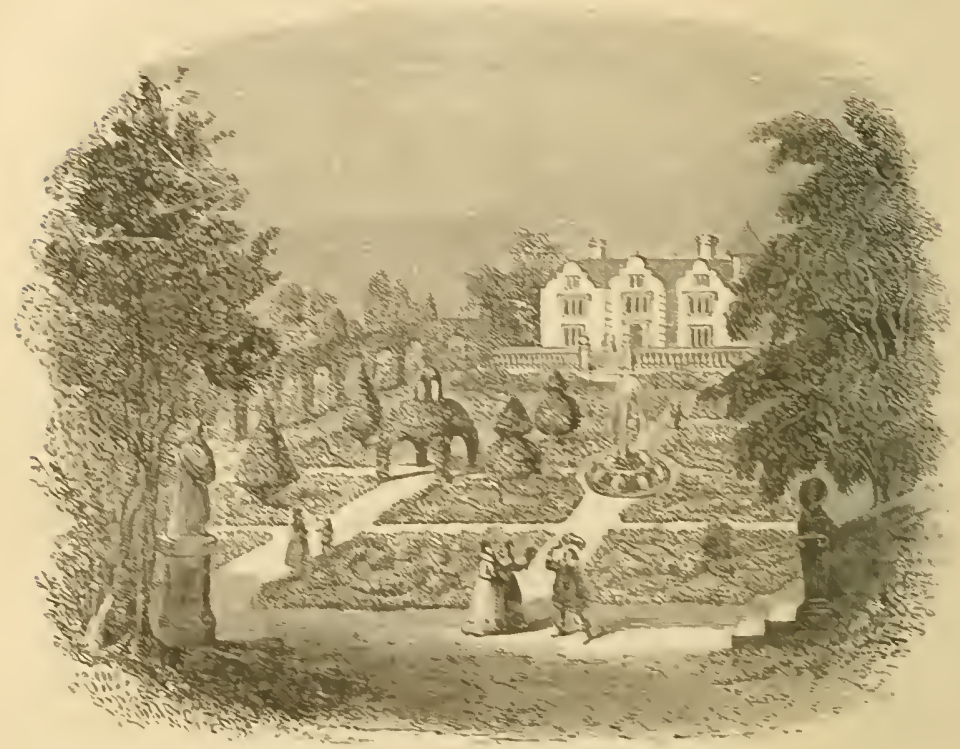

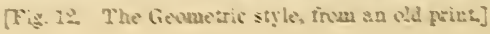

The beames elicited by the ancient style of gradening were those of regularity symmenty and the display of labored ant. These were attained in a merely mechanieal mamer. and usually imvolved little wr no theory. The ereomertical form and lines of the buthtings were only extended and earricd on in the granden. In the best classical models the art of the sculptor conterred digniry and ele. gance on the granden. by the fine forms of marble rases and statues : in the more intricate and labored specimens of the 
Dutch school, prevalent in England in the time of William IV. (Fig. 12), the results evince a fertility of odd conceits, rather than the exercise of taste or imagination. Indeed, as, to level ground naturally uneven, or to make an avenue, by planting rows of trees on each side of a broad walk, requires only the simplest perception of the beauty of mathematical forms, so, to lay out a garden in the geometric style, became little more than a formal routine, and it was only after the superior interest of a more natural manner was enforced by men of genius, that natural beauty of expression was recognised, and Landseape Gardening was raised to the rank of a fine art.

The ancient style of gardening may, however, be introduced with good effect in certain cases. In public squares and gardens, where display, grandeur of effect, and a highly artificial character are desirable, it appears to us the most suitable; and no less so in very small gardens, in which variety and irregularity are out of the question. Where a taste for imitating an old and quaint style of residence exists, the symmetrical and knotted garden would be a proper accompaniment; and pleached alleys, and sheared trees, would be admired, like old armor or furniture, as curious specimens of antique taste and custom.*

* Thero has been a great revival of this kind of garden in England the past ten yenrs-more, perhaps, inclining to the Italian selsool than the Dutel. Chatsworth, Woburu Abbey, Castle Howard, Bowood, Eaton Hall, and, in fact, most of the great places, have more or less adopted the Italian or Arehitcetural school on one or more sides of the house, as a sort of eonnection between art and nature. Trentham (the Duke of Sutherland's) is, wo believe, especially rich in arehiteetural gardens. Both here and at the other places above-mentioned, the grade between the honse and the park is let down, as it were, by $n$ serics of terraees, ench divided from the other by heavy stone balustrades, surmounted, at regular intervals, witl vases, planted either with Geraniums, or with Yucea, Aloe, Bonapartias, and other formal plants. Fiights of broad, heavy stone or marble steps conduct from one terrace to the other, and finally 
The earliest professors of modern Landscape (xardening have generally agreed upon two variations, of which the art is capable-variations no less certainly distinct, on the one hand, than they are capable of intermingling and combining, on the other. These are the beautiful and the picturesque: or, to speak more definitely, the beauty characterized by simple and flowing forms, and that expressed by striking, irregular, spirited forms.

The admirer of nature, as well as the lover of pictures and engrarings, will at once call to mind examples of scenery distinctly expressire of each of these kinds of beauty. In nature, perhaps some gently undulating plain. covered with emerald turf, partially or entirely encompassed by rich, rolling outlines of forest canopy,-its wildest expanse here broken occasionally, by noble groups of roundheaded trees, or there interspersed with single specimens whose trunks support heads of foliage flowing in outline, or drooping in masses to the rery turf beneath them. In such a scene we often behold the azure of hearen, and its silvery clouds, as well as the deep verdure of the luxuriant and shadorry branches, reflected in the placid bosom of a silvan lake; the shores of the latter swelling out, and receding, in gentle curved lines; the banks, sometimes corered with soft turf sprinkled with flowers, and in other portions clothed with luxuriant masses of verdant shrubs. Here are to the Park. The flat of the terrace, being laid out either in the most formal and precise parterre, or in extremely rich and intricate beds of arabesque patterns in serolls, to resemble carpets. In either case, great nse is made of statues and fountains, very elaborately and artistically designed and executed, and of Portugal Laurel, trimmed up to imitate orange-trees in tubs; as, also, of the Irish and Golden Iew, and other prramidal evergreens, either planted in the gronnd, or in boxes, ard, also, of different-colored gravel in the division of the beds, the whole prodneing, when seen from the windows of the house, a brilliant combination, which, with the soft, verdant park as a baekgromu, is inexpressibly gay and effective.-H. T. S. 
all the elements of what is termed natural beauty, -or a landscape characterized by simple, easy, and flowing lines

For an example of the opposite character, let us take a stroll to the nearest woody glen in your neighborhood-perhaps a romantic valley, half shut in on two or more sides by steep rocky banks, partially concealed and overhung by clustering vines, and tangled thickets of deep foliage. Against the sky outline breaks the wild and irregular form of some old, half decayed tree near by, or the horizontal and unique branches of the larch or the pine, with their strongly marked forms. Rough and irregular stems and trunks, rocks half covered with mosses and flowering plants, open glades of bright verdure opposed to lark masses of bold shadowy foliage, form prominent objects in the foreground. If water enlivens the scene, we shall hear the murmur of the noisy brook, or the cool dashing of the cascade, as it leaps over the rocky barrier. Let the stream turn the ancient and well-worn wheel of the old mill in the middle ground, and we shall have an illustration of the picturesque, not the less striking from its familiarity to every one.

To the lover of the fine arts, the name of Claude Lorraine cannot fail to suggest examples of beauty in some of its purest and most simple forms. In the best pictures of this master, we see portrayed those graceful and flowing forms in trees, foreground, and buildings, which delight so much the lover of noble and chaste beauty,-compositions emanating from a harmonious soul, and inspired by a climate and a richness of nature and art seldom surpassed.

On the other hand, where shall we find all the elements of the picturesque more graphically combined than in the vigorous landscapes of Salvator Rosa! In those rugged 
scenes, even the lawless aspects of his favorite robbers and handitti are not more spirited, than the bold rocks and wild passes by which they are surrounded. And in the productions of his pencil we see the influence of a romantic and vigorous imagination, nursed amid scenes teeming with the grand as well as the picturesque-both of which he embodied in the most striking manner.

In giving these illustrations of beautiful and of picturescue scenes, we have not intended them to be understood in the light of exact models for imitation in Landscape Gardening-only as striking examples of expression in natural scenery. Although in nature many landscapes partake in a certain degree of both these kinds of expression, yet it is no doubt true that the effect is more satisfactory, where either the one or the other character predominates. The accomplished amateur should be able to seize at once upon the characteristics of these two species of beauty in all scenery. To assist the reader in this kind of discrimination, we shall keep these expressions constantly in view, and we hope we shall be able fully to illustrate the difference in the expression of eren single trees, in this respect. A few strongly marked objects, either picturesque or simply beautiful, will often confer their character upon a whole landscape; as the destruction of a single group of bold rocks, corered with wood, may render a scene, once picturesque, completely insipid.

The early writers on the modern style were content with trees allowed to grow in their natural forms, and with an easy assemblage of sylvan scenery in the pleasure-grounds, which resembled the usual woodland features of nature. The effect of this method will always be interesting, and an agreeable result will always proceed from following the 
simplest hints derived from the free and luxuriant furms of nature. No residence in the country can fail to be pleasing, whose features are natural groups of forest trees, smooth lawn, and hard gravel walks.

But this is scarcely Landscape Gardening in the true sense of the word, although apparently so understood by many writers. By Landscape Gardening, we understand not only an imitation, in the grounds of a country residence, of the agreeable forms of nature, but an expressive, harmonious, and refined imitation.* In Landscape Gardening, we should aim to separate the accidental and extraneous in nature, and to preserve only the spirit, or essence. This subtle essence lies, we believe, in the expression more or less pervading every attractive portion of nature. And it is by eliciting, preserving, or heightening this expression, that we may give our landscape gardens a higher charm, than even the polish of art can bestow.

Now, the two most forcible and complete expressions to be found in that kind of natural scenery which may be reproduced in Landscape Gardening, are the Beautiful and the Picturesque. As we look upon these as quite distinct, and as success in practical embellishment must depend on our feeling and understanding these expressions beforehand, it is necessary that we should attach some definite meaning to terms which we shall be continually obliged to employ. This is, indeed, the more requisite, from

* "Thus, there is a beauty of nature and a beauty of art. To copy the beauty of nature cannot be called being an artist in the highest sense of the word, as a mechanical talent only is requisite for this. The beautiful in art depends on ideas; and the true artist, therefore, must possess, together with the talent for technical execution, that genial power which revels freely in rich forms, and is capable of producing and animating them. It is by this, that the merit of the artist and his production are to be judged; and these cannot bo 
the vague and conflicting opinions of most preceding writers on this branch of the subject; some, like Repton, insisting that they are identical; and others, like Price, that they are widely different.

Gilpin defines Picturesque objects to be "those which please from some quality capable of being illustrated in painting."

Nothing can well be more vague than such a definition We have already described the difference between the beautiful landscapes of Claude and the picturesque scenes painted by Salrator. No one can deny their being essentially distinct in character; and no one, we imagine, will deny that they both please from "some quality capable of being illustrated in painting." The beantiful female heads of Carlo Dolce are widely different from those of the picturesque peasant girls of Gerard Douw, yet both are favorite subjects with artists. A symmetrical American elm, with its wide head drooping with garlands of graceful foliage, is very different in expression from the wild and twisted larch or pine tree, which we find on the steep sides of a mountain; yet both are farorite subjects with the painter. It is clear, indeed, that there is a widely different idea hidden under these two distinct types, in material forms.

Beauty, in all natural objects, as we conceive, arises from their expression of those attributes of the Creatorinfinity, unity, symmetry, proportion, etc.-which he has stamped more or less risibly on all his works; and a beautiful living form is one in which the individual is a harmo.

properly estimated among those barren copyists which we find so many of our lower, landscape, and portrait painters to be. But the artist stands much higher in the scale, who, though a copyist of visible nature, is capable of seizing it with poetic feeling, and representing it in its more dignified sense; sucb, for examule, as Raphael, Poussin, Claude, Ac."-Weirbredxer. 
nious and well balanced development of a fine type. Thus, taking the most perfect specimens of beauty in the human figure, we see in them symmetry, proportion, unity, and grace-the presence of everything that could add to the idea of perfected existence. In a beautiful tree, such as a fine American elm, we see also the most complete and perfect balance of all its parts, resulting from its growth under the most favorable influences. It realizes, then, perfectly, the finest form of a fine type or species of tree.

But all nature is not equally Beautiful. Both in living things and in inorganized matter, we see on all sides evidences of nature struggling with opposing forces. Mountains are upheaved by convulsions, valleys are broken into fearful chasms. Certain forms of animal and vegetable life instead of manifesting themselves in those more complete and perfect forms of existence where the matter and spirit are almost in entire harmony, appear to struggle for the full expression of their character with the material form, and to express it only with difficulty at last. What is achieved with harmony, grace, dignity, almost with apparent repose, by existences whose type is the Beautiful, is done only with violence and disturbed action by the former. This kind of manifestation, in nature, we call the Picturesque.

More concisely, the Beautiful is nature or art obeying the universal laws of perfect existence (i. e. Beauty): easily, freely, harmoniously, and withuut the display of power. The Picturesque is nature or art obeying the same laws rudely, violently, irregularly, and often displaying power only. 
Hence we find all Beautiful forms characterized by curved and flowing lines-lines expressive of infinity, ${ }^{*}$ of grace, and willing obedience: and all Picturesque forms characterized by irregular and broken lines-lines expressive of violence, abrupt action, and partial disobedience, a struggling of the idea with the substance or the condition of its being. The Beautiful is an idea of beauty, calmly and harmoniously expressed; the Picturesque, an idea of beauty or power, strongly and irregularly expressed. As an example of the Beautiful in other arts we refer to the Apollo of the Vatican; as an example of the Picturesque, to the Laocoon or the Dying Gladiator. In natuie we would place before the reader a finely formed elm or chestnut, whose well balanced head is supported on a trunk full of symmetry and dignity, and whose branches almost sweep the turf in their rich luxuriance ; as a picturesque contrast, some pine or larch, whose gnarled roots grasp the rocky crag on which it grows, and whose wild and irregular branches tell of the storm and tempest that it has so often struggled against. $\dagger$

In pictures, too, one often hears the Beautiful confounded with the Picturesque. Yet they are quite distinct; though in many subjects they may be found harmoniously combined. Some of Raphael's angels may be taken as perfect illustrations of the Beautiful. In their serene and heavenly

* Hogarth called the curve the line of beauty, and all artists have felt instinct. ively its power, but Mr. Ruskin (in Modern Painters) was, we believe, the first to suggest the cause of that power-that it expresses in its varying tendencies, the infinite.

t This also explains why trees, though they retain for the most part their characteristic forms, vary somewhat in expression according to their situation. Thus the larch, though always picturesque, is far more so in mountain ridges where it is exposed to every blast, than in sheltered lawns where it only findo soft airs and sunshine. 
countenances we see only that calm and pure existence of which perfect beauty is the outward type ; on the other hand, Murillo's beggar boys are only picturesque. What we admire in them (beyond admirable execution) is not their rags or their mean apparel, but a certain irregular struggling of a better feeling within, against this outward poverty of nature and condition.

Architecture borrows, partly perhaps by association, the same expression. We find the Beautiful in the most symmetrical edifices, built in the finest proportions, and of the purest materials. It is, on the other hand, in some irregu. lar castle formed for defence, some rude mill nearly as wild as the glen where it is placed, some thatched cottage, weather stained and moss covered, that we find the Picturesque. The Temple of Jupiter Olympus in all its perfect proportions was prized by the Greeks as a model of beauty; we, who see only a few columns and broken architraves standing with all their exquisite mouldings obliterated by the violence of time and the elements, find them Picturesque.

To return to a more practical view of the subject, we may remark, that though we consider the Beautiful and the Picturesque quite distinct, yet it by no means follows that they may not be combined in the same landscape. This is often seen in nature; and indeed, there are few landscapes of large extent where they are not thus harmoniously combined.

But it must be remembered, that while Landscape Gardening is an imitation of nature, yet it is rarely attempted on so large a scale as to be capable of the same extended harmony and variety of expression; and also, that in Landscape Gardening as in the other fine arts, we shall be more successful by directing our efforts towards the production 
of a leading character or expression, than by endeavoring to join and harmonize several.

Our own views on this subject are simply these. When a place is small, and only permits a single phase of natural expression, always endearor to heighten or to make that single expression predoninate; it should, clearly, either aim only at the Beautiful or the Picturesque.

When, on the contrary, an estate of large size comes within the scope of the Landscape Gardener, he is at liberty to give to each separate scene its most fitting character; he will thus, if he is a skilful artist, be able to create great variety both of beautiful and picturesque expression, and he will also be able to give a higher proof of his power, viz. by uniting all those scenes into one whole, by bringing them all into harmony. An artist who can do this has reached the ultimatum of his art.

Again and again has it been said, that Landscape Gar. dening and Painting are allied. In no one point does it appear to us that they are so, more than in this-that in proportion to the limited nature of the subject should simpli. city and unity of expression be remembered. In some of the finest smaller compositions of Raphael, or some of the Landscapes of Claude, so fully is this borne in mind, that erery object, howerer small, seems to be instinct with the same expression; while in many of the great historical pictures, unity and harmony are wrought out of the most complex variety of expression.

We must not be supposed to find in nature only the Beautiful and the Picturesque. Grandeur and Sublimity are also expressions strongly marked in many of the noblest portions of natural landscape. But, except in very rare instances, they are wholly beyond the powers of the landscape gardener, at least in the comparatively limited scale 
of his operations in this country. All that he has to do, is to respect them where they exist in natural landscape which forms part of his work of art, and so treat the latter, as to make it accord with, or at least not violate, the higher and predominant expression of the whole.

There are, however, certain subordinate expressions which may be considered as qualities of the Beautiful, and which may originally so prevail in natural landscape, or be so elicited or created by art, as to give a distinct character to a small country residence, or portions of a large one. These are simplicity, dignity, grace, elegance, gaiety, chasteness, \&c. It is not necessary that we should go into a labored explanation of these expressions. They are more or less familiar to all. A few fine trees, scattered and grouped over any surface of smooth lawn, will give a character of simple beauty; lofty trees of great age, hills covered with rich wood, an elevation commanding a wide country, stamp a site with dignity; trees of full and graceful habit or gently curving forms in the lawn, wallss, and all other objects, will convey the idea of grace; as finely formed and somewhat tall trees of rare species, or a great abundance of bright climbers and gay, flowering shrubs and plants, will confer characters of elegance and gaiety.

He who would create in his pleasure grounds these more delicate shades of expression, must become a profound student both of nature and art; he must be able, by his own original powers, to seize the subtle essence, the half disclosed idea involved in the finest parts of nature, and to reproduce and develope it in his Landscape Garden.

Leaving such, however, to a broader range of study than a volume like this would afford, we may offer what, perhaps, will not bo unacceptable to the novice-a more de- 
tailed sketch of the distinctive features of the Beautiful and the Picturesque, as these expressions should be embodiea in Landscape Gardening.

The Beautiful in Landscape Gardening (Fig. 13) is produced by outlines twhose curves are flowing and gradual, surfaces of softness, and growth of richness and luxuriance. In the shape of the ground, it is evinced by easy undulations melting gradualiy into each other. In the form of trees, by smooth stems, full, round, or symmetrical heads of foliage, and luxuriant branches often drooping to the ground,- which is chiefly attained by planting and grouping, to allow free development of form; and by selecting trees of suitable character, as the elm, the ash, and the like. In walks and roads, by easy flowing curres, following natural shapes of the surface, with no sharp angles or abrupt turns. In water, by the smooth lake with curved margin, embellished with flowing outlines of trees, and full masses of flowering shrubs-or in the easy winding curves of a brook. The keeping of such a scene should be of the most polished kind,-grass mown into a softness like relvet, gravel walks scrupulously firm, dry, and clean; and the most perfect order and neatness should reign throughout. Among the trees and shrubs should be conspicuous the finest foreign sorts, distinguished by beauty of form, foliage, and blossom ; and rich groups of shrubs and flowering plants should be arranged in the more dressed portions near the house. And finally, considering the house itself as a feature in the scene, it should properly belong to one of the classical modes; and the Italian, Tuscan, or Venetian forms are preferable, because these have both a polished and a domestic air, and readily admit of the graceful accompaniments of vases, urns, and other harmonious accessories. Or, if we are to have a plainer dwelling, 


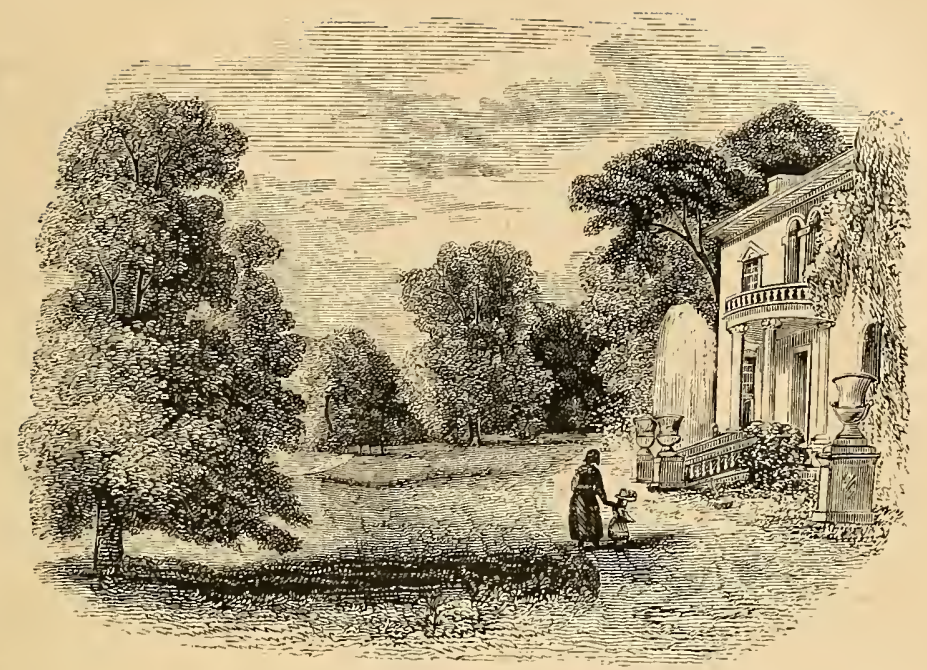

Fig. 13.-Example of the Beautiful in Landscape Gardening.

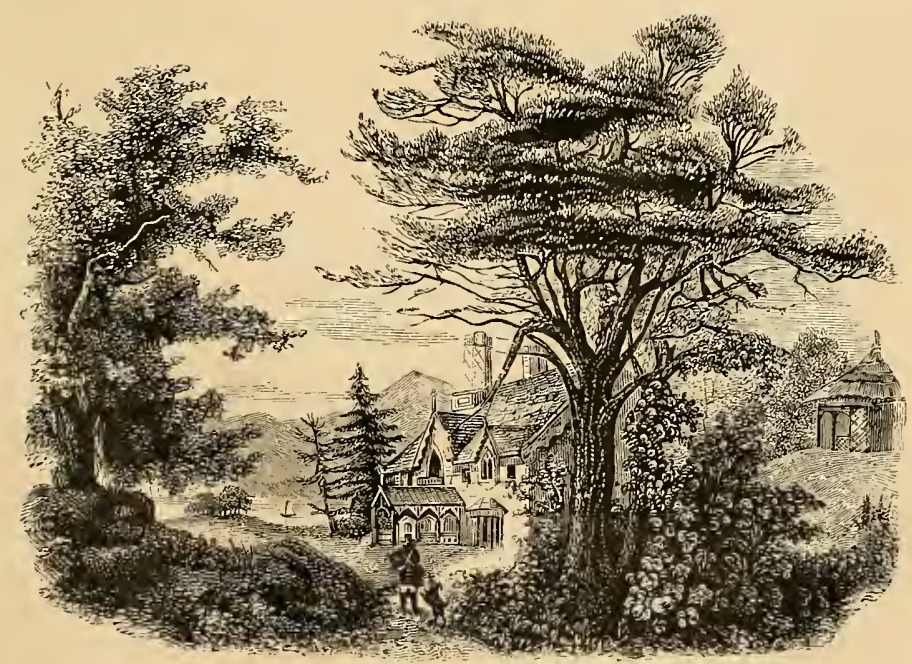

FIg. 16.-Example of the Picturesque in Landscape Gardening. 


$$
0
$$


it should be simple and symmetrical in its character, and its veranda festooned with masses of the finest $c$ imbers.

The Picturesque in Landscape Gardening (Fig. 14) aims at the production of outlines of a certain spirited irregularity, surfaces comparatively abrupt and broken, and growth of a somewhat wild and bold character. The shape of the ground sought after, has its occasional smoothness varied by sudden variations, and in parts runs into dingles, rocky groups, and broken banks. The trees should in many places be old and irregular, with rough stems and bark; and pines, larches, and other trees of striking, irregular growth, must appear in numbers sufficient to give character to the woody outlines. As, to produce the Beautiful, the trees are planted singly in open groups to allow full expansion, so for the Picturesque, the grouping takes every variety of form; almost every object should group with another; trees and shrubs are often planted closely together; and intricacy and variety-thicketsglades-and underwood-as in wild nature, are indispensable. Walks and roads are more abrupt in their windings, turning off frequently at sudden angles where the form of the ground or some inviting object directs. In water, all the wildness of romantic spots in nature is to be imitated or preserved; and the lake or stream with bold shore and rocky, wood-fringed margin, or the cascade in the secluded dell, are the characteristic forms. The keeping of such a landscape will, of course, be less careful than in the graceful school. Firm gravel walks near the house, and a general air of neatness in that quarter, are indispensable to the fitness of the scene in all modes, and indeed properly evince the recognition of art in all Landscape Gardening. But the lawn may be less frequently mown, the edges of 
the walks less carefully trimmed, where the Picturesque prevails; while in portions more remored from the house, the walks may sometimes sink into a mere footpath without gravel, and the lawn change into the forest glade or meadow. The architecture which belongs to the picturesque landscape, is the Gothic mansion, the old English or the Swiss cottage, or some other striking forms, with bold projections, deep shadows, and irregular outlines. Rustic baskets, and similar ornaments, may abound near the house, and in the more frequented parts of the place.

The recognition of art, as Loudon justly observes, is a first principle in Landscape Gardening, as in all other arts ; and those of its professors have erred, who supposed that the object of this art is merely to prodice a fac-simile of nature, that could not be distinguished from a wild scene. But we contend that this principle may be fully attained with either expression-the picturesque cottage being as well a work of art as the classic villa; its baskets, and seats of rustic work, indicating the hand of man, as well as the marble rase and balustrade; and a walk, sometimes narrow and crooked, is as certainly recognised as man's work, as one always regular and flowing. Foreign trees of picturesque growth are as readily obtained as those of beautiful forms. The recognition of art is, therefore, always apparent in both modes. The evidences are indeed stronger and more multiplied in the careful polish of the Beautiful landscape,* and hence many prefer this

* The beau ideal in Landscape Gardening, as a fine art, appears to us to be embraced in the creation of scenery full of expression, as the benutiful or picturesque, the materiais of which are, to a certain extent, different from those in wild nature, being composed of the floral and arboricultural riches of all climates, as far as possible; aniting in che same scene, a richness and a variety never to 
species of landscape, not, as it deserves to be preferred, because it displays the most beautiful and perfect ideas in its outlines, the forms of its trees, and all that enters into its composition, but chiefly because it also is marked by that careful polish, and that completeness, which imply the expenditure of money, which they so well know how to value.

If we declare that the Beautiful is the more perfect expression in landscape, we shall be called upon to explain why the Picturesque is so much more attractive to many minds. This, we conceive, is owing partly to the imperfection of our natures, by which most of us sympathize more with that in which the struggle between spirit and matter is most apparent, than with that in which the union is harmonious and complete; and partly because from the comparative rarity of highly picturesque landscape, it affects us more forcibly when brought into contrast with our daily life. Artists, we imagine, find somewhat of the same pleasure in studying wild landscape, where the very rocks and trees seem to struggle with the elements for foothold, that they do in contemplating the phases of the passions and instincts of human and animal life. The manifestation of power is to many minds far more captivating than that of beauty.

All who enjoy the charms of Landscape Gardening, may perhaps be divided into three classes : those who have arrived only at certain primitive ideas of beauty which are found in regular forms and straight lines; those who in the Beautiful seek for the highest and most perfect

be found in any one portion of nature ; - a scene characterized as a work of art, by the variety of the materials, as foreign trees, plants, \&c., and by the polish and keeping of the grounds in the natural style, as distinctly as by the uniform and symmetrical arrangement in the ancient style. 
development of the idea in the material form ; and those who in the Pieturesque enjoy most a certain wild and incomplete harmony between the idea and the forms in which it is expressed.

As the two latter classes embrace the whole range of modern Landscape Gardening, we shall keep distinctly in view their two governing principles-the Beautiful and the Picturesque, in treating of the practice of the art.

There are always circumstances which must exert a controlling influence over amateurs, in this country, in choosing between the two. These are, fixed locality, expense, indiridual preference in the style of building, and many others which readily occur to all. The great variety of attractive sites in the older parts of the country, afford an abundance of opportunity for either taste. Within the last five years, we think the Picturesque is begimning to be prelerred. It has, when a suitable locality offers, great advantuges for us. The raw materials of wood, water, and surface, by the margin of many of our rivers and brooks, are at once appropriated with so much effect, and so little art, in the picturesque mode; the annual tax on the purse too is so comparatively little, and the charm so great!

While, on one hand, the residences of a country of level plains usually allow only the beauty of simple and graceful forms; the larger demesne, with its swelling hills and noble masses of rood (may we not, prospectively, say the rolling prairie too?), should always, in the hands of the man of wealth, be made to display all the breadth, raliety, and harmony of both the Beautiful and the Picturesque.

There is no surface of ground, howerer bare, which has not, maturally, more or less tendency to one or the other of these expressions. And the improver who detects the true 
character, and plants, builds, and embellishes, as he should constantly aiming to elicit and strengthen it-will soon arrive at a far ligher and more satisfactory result, than one who, in the common manner, works at random. The latter may succed in producing pleasing grounds-he will undoubtedly add to the general beauty and tasteful appearance of the country, and we gladly accord him our thanks. But the improver who unites with pleasing forms an expres. sion of sentiment, will affect not only the common eye, but much more powerfully, the imagination, and the refined and delicate taste.

But there are many persons with small cottage places, of little decided character, who have neither room, time, nor income, to attempt the improvement of their grounds fully, after either of those two schools. How shall they render their places tasteful and agreeable, in the easiest manner? We answer, by attempting only the simple and the natural; and the unfailing way to secure this, is by employing as leading features only trees and grass. A soft verdant lawn, a few forest or ornamental trees, well grouped, walks, and a few flowers, give universal pleasure ; they contain in themselves, in fact, the basis of all our agreeable sensations in a landscape garden (natural beauty, and the recognition of art); and they are the most enduring sources of enjoyment in any place. There are no country seats in the United States so unsatisfactory and tasteless, as those in which, without any definite aim, everything is attempted; and a mixed jumble of discordant forms, materials, ornaments, and decorations, is assembled-a part in one style and a bit in another, without the least feeling of unity or congruity. These rural bedlams, full of all kinds of absurdities, without a leading character or expression of any sort, cost their 
owners a vast deal of trouble and money, without giving a tasteful mind a shadow of the beauty which it feels at the first glimpse of a neat cottage residence, with its simple, sylran character of well kept lawn and trees. If the latter does not rank high in the scale of Landscape Gardening as an art, it embodies much of its essence as a source of enjoyment-the production of the Beautiful in country residences.

Besides the beauties of form and expression in the different modes of laying out grounds, there are certain universal and inherent beauties, common to all styles, and, indeed, to every composition in the fine arts. Of these, we shall especially point out those growing out of the principles of UNITY, HARMONY, and VARIETY.

UNiTx, or the production of a whole, is a leading principle of the highest importance, in every art of taste or design, without which no satisfactory result can be realized. This arises from the fact, that the mind can only attend, with pleasure and satisfaction, to one object, or one composite sensation, at the same time. If two distinct objects, or classes of objects, present themselves at once to us, we can only attend satisfactorily to one, by withdrawing our attention for the time from the other. Hence the necessity of a reference to this leading principle of unity.

To illustrate the subject, let us suppose a building, partially built of wood, with square windows, and the remainder of brick or stone, with long and narrow windows. However well such a building may be constructed, or however nicely the different proportions of the edifice may be adjusted, it is evident it can never form a satisfactory whole. The mind can only account for such an absurdity, by supposing it to have been built by two 
individuals, or at two different times, as there is nothing indicating unity of mind in its composition.

In Landscape Gardening, violations of the principle of unity are often to be met with, and they are always indicative of the absence of correct taste in art. Looking upon a landscape from the windows of a villa residence, we sometimes see a considerable portion of the view embraced by the eye, laid out in natural groups of trees and shrubs, and upon one side, or perhaps in the middle of the same scene, a formal avenue leading directly up to the house. Such a view can never appear a satisfactory whole, because we experience a confusion of sensations in con. templating it. 'There is an evident incongruity in bringing two modes of arranging plantations, so totally different, under the eye at one moment, which distracts, rather than pleases the mind. In this example, the avenue, taken by itself, may be a beautiful object, and the groups and connected masses may, in themselves, be elegant; yet if the two portions are seen together, they will not form a whole, because they cannot make a composite idea. For the same reason, there is something unpleasing in the introduction of fruit trees among elegant ornamental trees on a lawn, or even in assembling together, in the same beds, flowering plants and culinary vegetables-one class of vegetation suggesting the useful and homely alone to the mind, and the other, avowedly, only the ornamental.

In the arrangement of a large extent of surface, where a great many objects are necessarily presented to the eye at once, the principle of unity will suggest that there should be some grand or leading features to which the others should be merely subordinate. Thus, in grouping trees, there should be some large and striking masses to which the others appear to belong, however distant, instead of 
scattered groups, all of the same size. Even in arranging walks, a whole will more readily be recognised, if there are one or two of large size, with which the others appear connected as branches, than if all are equal in breadth, and present the same appearance to the ere in passing.

In all works of art which command universal admiration, we discover an unity of conception and composition, an unity of taste and execution. To assemble in a single composition forms which are discordant, and portions dissimilar in plan, can only afford pleasure for a short time to tasteless minds, or those fond of trifling and puerile conceits. The production of an accordant whole is, on the contrary, capable of affording the most permanent enjoyment to educated minds, everywhere, and at all periods of time.

After unity, the principle of VARIETr is worthy of consideration, as a fertile source of beauty in Landscape Gardening. Tariety must be considered as belonging more to the details than to the production of a whole, and it may be attained by disposing trees and shrubs in numerous different ways; and by the introduction of a great number of different species of regetation, or kinds of walks, ornamental objects, buildings, and seats. By producing intricacy, it creates in scenery a thousand points of interest, and elicits new beauties, through different arrangements and combinations of forms and colors, light and shades. In pleasuregrounds, while the whole should exhibit a general plan, the different scenes presented to the eye, one after the other, should possess sufficient variety in the detail to keep alire the interest of the spectator, and awaken further curiosity.

HARMorr may be considered the principle presiding orer variety, and preventing it from becoming discordant. It, indeed, always supposes contrasts, but neither so strong nor 
so frequent as to produce discord; and variety, but not so great as to destroy a leading expression. In plantations, we seek it in a cumbination of qualities, opposite in some respects, as in the color of the foliage, and similar in others more important, as the form. In embellishments, by a great variety of objects of interest, as sculptured vases, sun-dials, or rustic seats, baskets, and arbors, of different forms, but all in accordance or keeping with the spirit of the scene.

To illustrate the three principles, with reference to Land. scape Gardening, we may remark, that, if unity only were consulted, a scene might be planted with but one kind of tree, the effect of which would be sameness; on the other hand, variety might be carried so far as to have every tree of a different kind, which would produce a confused effect. Harmony, however, introduces contrast and variety, but keeps them subordinate to unity, and to the leading expression; and is, thus, the highest principle of the three.

In this brief abstract of the nature of imitation in Landscape Gardening and the kinds of beauty which it is possible to produce by means of the art, we have endeavored to elucidate its leading principles, clearly, to the reader. These grand principles we shall here succinctly recapitulate, premising that a familiarity with them is of the very first importance in the successful practice of this elegant art, viz. :

The Imitation of the Beauty of Expression, derived from a refined perception of the sentiment of nature: ThE Recognition of Art, founded on the immutability of the true, as well as the beautiful: And the Production of Unity, Harmony, and VARIETy, in order to render complete and continuous, our enjoyment of any artistical work. 
Neither the professional Landscape Gardener, nor the amateur, can hope for much success in realizing the nobler effects of the art, unless he first make himself master of the natural character or prerailing expression of the place to be improred. In this nice perception, at a glance, of the natural expression, as well as the capabilities of a residence, lies the secret of the superior results produced even by the improver, who, to use the words of Horace Walpole, "is proud of no other art than that of softening nature's harsh. ness, and copying her graceful touch." TVhen we discover the picturesque indicated in the grounds of the residence to be treated, let us take advantage of it ; and while all harshness incompatible with scenery near the house is remored, the original expression may in most cases be heightened, in all rendered more elegant and appropriate, without lowering it in force or spirit. In like manner good taste will direct us to embellish scenery expressire of the Beautiful, by the addition of forms, whether in trees, buildings, or other objects, harmonious in character, as well as in color and outline. 


\title{
SECTION III.
}

\author{
ON TWOD.
}

The beauty of Trees in Rural Embellishments. Pleasure resulting from their cultivation. Plantations in the Ancient Style; their formality. In the Modern Style ; grouping trees. Arrangement and grouping in the Graceíul school; in the Picturesque school. Illustrations in planting villa, ferrue ornée, and cottage grounds. General classification of trees as to forms, with leading characteristics of each class.

"He gains all points, who pleasingly confounds, Surprises, varies, and conceals the bounds. Calls in the country, catches opening glades, Joins willing woods, and varies shades from shades; Now breals, or now directs the intending lines; Paints as you plant, and, as you work, designs."

POPE.

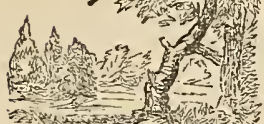

$\mathrm{MON}$ G all the materials at our disposal for the embellishment of country residences, none are at once so highly oruamental, so indispensable, and so easily managed, as trees, or wood. We introduce them in every part of the landscape, -in the foreground as well as in the distance, on the tops of the hills and in the deptlis of the valleys. They are, indeed, like the drapery which covers a somewhat ungainly figure, and while it conceals its defects, communicates to it new interest and expression.

A tree, undonbtedly, is one of the most beantiful objects in natme. Airy and delicate in its youth, Iuxmiant and majestic in its prime, venerable and picturesque in its old 
age, it constitutes in its various forms, sizes, and develop. ments, the greatest charm and beauty of the earth in all countries. The most raried outline of surface, the finest combination of picturesque materials, the stateliest country house would be comparatively tame and spiritless, without the inimitable accompaniment of foliage. Let those who have passed their whole lives in a richly wooded country, -whose daily visions are deep leafy glens, forest-clad hills. and plains luxuriantly shaded,-transport themselves for a moment to the desert, where but a few stunted bushes raise their heads above the earth, or those wild steppes where the eye wanders in vain for some "leafy garniture,"-where the sun strikes down with parching heat, or the wind sweeps over with unbroken fury, and they may, perhaps estimate, by contrast, their beauty and ralue.

We are not now to enumerate the great usefulness of trees,-their value in the construction of our habitations, our navies, the various implements of labor, -in short, the thousand associations which they suggest as ministering to our daily wants; but let us imagine the loreliest scene, the wildest landscape, or the most enchanting valley, despoiled of trees, and we shall find nature shorn of her fair proportions, and the character and expression of these favorite spots almost entirely destroyed.

Wood, in its many shapes, is then one of the greatest sources of interest and character in Landscapes. Variety, which we need scarcely allude to as a fertile source of beauty, is created in a wonderful degree by a natural arrangement of trees. To a pile of buildings, or even of ruins, to a group of rocks or animals, they communicate new life and spirit by their irregular outlines, which, by partially concealing some portions, and throwing others 
into stronger light, contribute greatly to produce intricacy and variety, and confer an expression, which, without these !atter qualities, might in a great measure be wanting. By shutting out some parts, and inclosing others, they divide the extent embraced by the eye into a hundred different landscapes, instead of one tame scene bounded by the horizon.

The different seasons of the year, too, are inseparably connected in our minds with the effects produced by them on woodland scenery. Spring is joyous and enlivening to us, as nature then puts on her fresh livery of green, and the trees bud and blossom with a renewed beauty, that speaks with a mute and gentle eloquence to the heart. In summer they offer us a grateful shelter under their umbrageous arms and leafy branches, and whisper unwritten music to the passing breeze. In autumn we feel a melancholy thoughtfulness as

"We stand among the fallen leaves,"

and gaze upon their dying glories. And in winter we see in them the silent rest of nature, and behold in their leafless spray, and seemingly dead limbs, an annual type of that deeper mystery-the deathless sleep of all being.

By the judicious employment of trees in the embellishment of a country residence, we may effect the greatest alterations and improvements within the scope of Landscape Garden. ing. Buildings which are tame, insipid, or even mean in appearance, may be made interesting and often picturesque, by a proper disposition of trees. Edifices, or parts of them that are unsightly, or which it is desirable partly or wholly to conceal, can readily be hidden or improved by wood; and walks and roads, which otherwise would be but simple 
ways of approach from one point to another, are, by an clegant arrangement of trees on their margins, or adjacent to them. made the most interesting and pleasing portions of the residence.

In Geometric gardening, trees disposed in formal lines exhibit as strongly art or design in the contriver, as regu. lar architectural edifices: whilc, in a more elevated and enlightened tasto, wo are able to dispose them in our pleasure-grounds and parks, around our houses, in all the rariety of groups, masses, thickets and single trees, in such a manner as to rival the most beautiful scenery of general nature: producing a portion of lindscape which unites, with all the comforts and conveniences of rural habitation, the superior charm of refined arrangement. and natural beauty of expression.

It it were necessary to present any other inducement to the country gentlemian to form plantations of trees. than the great beanty and ralue which they add to his estate. we might find it in the pleasure which all derive from their cultivation. Inlike the pleasure arising from the gratification of our taste in architecture, or any other of the arts whose productions are offered to us perfect and complete, the satistaction arising fiom planting and roaring trees is never weakened. "We look," says a writer, "upon our trees as our offspring: and nothing of inamimate nature can be more gratifying than to see them grow and prosper under our care and attention,nothing more interesting than to examine their progress, and mark their sereral peculiarities. In their progress from plants to trees, they erery rear unfold new and characteristic marks of their ultimate beauty, which not only compensate for past cares and troubles, but like the 
returns of gratitude, raise a most delightful train of sensations in the mind; so innocent and rational, that they may justly rank with the most exquisite of human enjoyments."

" Happy is he, who in a country life

Shuns more perplexing toil and jarring strife;

Who lives upon the natal soil he loves,

And sits beneath his old ancestral groves."

To this, let us add the complacent feelings with which a man in old age may look around him and behold these leafy monarchs, planted by his boyish hands and nurtured by him in his youthful years, which have grown aged and venerable along with him;

"A wood coeval with himself he sees,

And loves his own contemporary trees."

Plantations in the Ancient Strule. In the arrangement and culture of trees and plants in the ancient style of Landscape Gardening, we discover the evidences of the formal taste,-abounding with every possible variety of quaint conceits, and rife with whimsical expedients, so much in fashion during the days of Henry and Elizabeth, and until the eighteenth century in England, and which is still the reigning mode in Holland, and parts of France. In these gardens, nature was tamed and subdued, or as some critics will have it, tortured into every shape which the ingenuity of the gardener could suggest; and such kinds of vegetation as bore the shears most patiently, and when carefully trimmed, assumed gradually the appearance of verdant statues, pyramids, crowing cocks, and rampant lions, were the especial favorites of the gardeners of the old school. 
It has been remarked, that the geometric style would always be preferred in a new country, or in any country where the amount of land under cultivation is much less than that covered with natural woods and forests; as the inhabitants being surrounded by scenery abounding with natural beauty', would always incline to lay out their gardens and pleasure-grounds in regular forms, because the distinct exhibition of art rould give more pleasure by cons. trast, than the elegant imitation of beautiful nature. That this is true as regards the mass of uncultivated minds, we do not deny. But at the same time we aflirm that it evinces a meagre taste, and a lower state of the art, or a lower perception of beauty in the individual who employs the geometrical style in such cases. A person, whose place is surı ounded by inimitably grand or sublime scenery, would undoubtedly fail to excite our admiration, by attempting a fac-simile imitation of such scenery on the small scale of a park or garden; but he is not, therefore, obliged to resort to right-lined plantations and regular grass plots, to produce something which shall be at once sufficiently different to attract notice, and so beautiful as to command admiration. All that it would be requisite for him to do in such a case, would be to employ rare and foreign ornamental trees; as for example, the horse-chestnut and the linden, in situations where the maple and the sycamore are the principal trees,--elegant flowering shrubs and beautiful creepers, instead of sumacs and hazels,-and to have his place kept in high and polished order, instead of the tangled wildness of general nature.

On the contrary, w̧ere a person to desire a residence newly laid out and planted, in a district where all around is in a high state of polished cultivation, as in the suburbs 
of a city, a species of pleasure would result from the imitation of scenery of a more spirited, natural character, as the picturesque, in his grounds. His plantations are made in irregular groups, composed chiefly of picturesque trees, as the larch, \&c.-his walks would lead through varied scenes, sometimes bordered with groups of rocks overrun with flowering creepers and vines; sometimes with thickets or little copses of shrubs and flowering plants; sometimes through wild and comparatively neglected portions; the whole interspersed with open glades of turf.

In the majority of instances in the United States, the modern style of Landscape Gardening, wherever it is ap. preciated, will, in practice, consist in arranging a demesne of from five to some hundred acres, - or rather that portion of it, say one half, one third, etc., devoted to lawn and pleasure-ground, pasture, etc.-so as to exhibit groups of forest and ornamental trees and shrubs, surrounding the dwelling of the proprietor, and extending for a greater or less distance, especially towards the place of entrance from the public highway. Near the house, good taste will dictate the assemblage of groups and masses of the rarer or more beautiful trees and shrubs; commoner native forest trees occupying the more distant portions of the grounds.*

* Although we love planting, and avow that there are few greater pleasures than to see a darling tree, of one's own placing, every year stretching wider its feathery head of foliage, and covering with a darker shadow the soft turf beneath $\mathrm{i} i$, still, we will not let the ardent and inexperienced hunter after a location for a country residence, pass without a word of advice. This is, always to make considerable sacrifice to get a place with some existing wood, or a few ready grown trees upon it; especially near the site for the house. It is better to yield a little in the extent of prospect, or in the direct proximity to a certain 
Plantations in the Modern Strue. In the Modern Style of Landscape Gardening, it is our aim, in plantations, to produce not only what is called natural beauty, but even higher and more striking beauty of expression, and of individual forms, than we see in nature; to create variety and intricacy in the grounds of a residence by various modes of arrangement; to give a highly elegant or polished air to places, by introducing rare and foreign species; and to conceal all defects of surface, disagreeable views, unsightly buildings, or other offensive objects.

As uniformity, and grandeur of single effects, were the aim of the old style of arrangement, so variety and harmony of the whole are the results for which we labor in the modern landscape. And as the Avenue, or the straight line, is the leading form in the geometric arrangement of plantations, so let us enforce it upon our readers, the Grovr is equally the key-note of the Modern style. The smallest place, haring only three trees, may hare these pleasingly connected in a group; and the largest and finest park-the Blenheim or Chatsworth, of seven miles square, is only composed of a succession of groups, becoming masses, thickets, woods. If a demesne with the most beautiful surface and riews has been for some time stiflly and

locality, than to pitch your tent in a plain,-desert-like in its bareness-on which your leafy sensibilities must suffer for half a dozen years at least, before you can hope for any solace. It is doubtful whether there is not almost as much interest in studying from one's window the curious ramifications, the variety of form, and the entire harmony to be found in a fine old tree, as in gazing from a site where we have no interruption to a panorama of the whole horizon; and we have generally found that no planters have so little courage and faith, as those who have commenced without the smallest group of large trees, as a nuclens for their plantations. 
awkwardly planted, it is exceedingly difficult to give it a natural and agreeable air; while many a tame level, with scarcely a glimpse of distance, has been rendered lovely by its charming groups of trees. How necessary, therefore, is it, in the very outset, that the novice, before he begins to plant, should know how to arrange a tasteful group!

Nothing, at first thought, would appear easier than to arrange a few trees in the form of a natural and beautiful group,-and nothing really is easier to the practised hand. Yet experience has taught us that the generality of persons, in commencing their first essays in ornamental planting, almost invariably crowd their trees into a close, regular clump, which has a most formal and unsightly appearance, as different as possible from the easy, flowing outline of the group.

"Natural groups are full of openings and hollows, of trees advancing before, or retiring behind each other; all productive of intricacy, of variety, of deep shadows and brilliant lights."

The chief care, then, which is necessary in the formation of groups, is, not to place them in any regular or artificial manner, -as one at each corner of a triangle, square, octagon, or other many-sided figure; but so to dispose them, as that the whole may exhibit the variety, connexion and intricacy seen in nature. "The greatest beauty of a group of trees," says Loudon, "as far as respects their stems, is in the varied direction these take as they grow into trees; but as that is, for all practical purposes, beyond the influence of art, all we can do, is to vary as much as possible the ground plan of groups, or the relative positions which the stems have to each other where they spring from the earth. This is considerable, 
even where a very few trees are used, of which any person may convince himself by placing a few dots on paper. Thus two trees (fig. 15), or a tree and shrub, which is the smallest group $(a)$, may be placed in three different positions with reference to a spectator in a fixed point; if he moves round them, they will first rary in form separately, and next unite in one or two groups, according to the position of the spectator. In like manner, three trees may be placed in four different positions; four trees may be placed in eight different positions (b); five trees may be grouped in ten different ways, as to ground plan: six may be placed in twelre different ways (c), and so on." Encyclopcedia of Gard.)
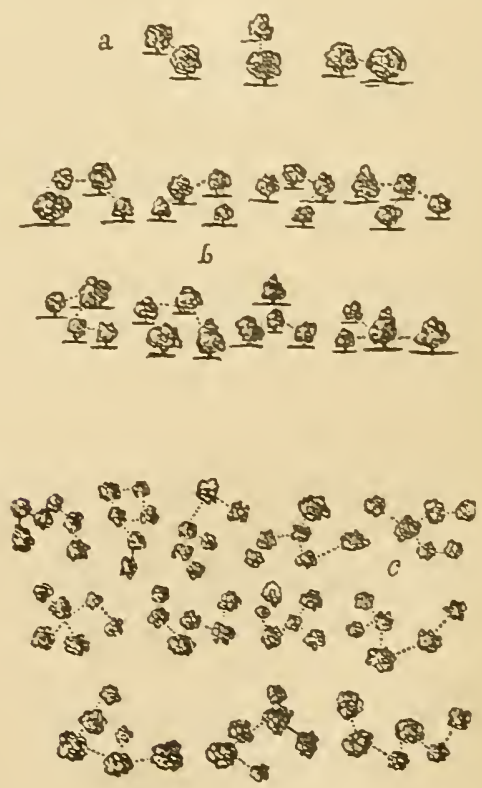

[Fig. 15. Grouping of Trees.]

In the composition of larger masses, similar rules must 
be cbserved as in the smaller groups, in order to prevent them from growing up in heavy, clumpish forms. The outline must be flowing, here projecting out into the grass, there receding back into the plantation, in order to take uff all appearance of stiffness and regularity. Trees of medium and smaller size should be so interspersed with those of larger growth, as to break up all formal sweeps in the line produced by the tops of their summits, and occasionally, low trees should be planted on the outer edge of the mass, to connect it with the humble verdure of the surrounding sward.

In many parts of the union, where new residences are being formed, or where old ones are to be improved, the grounds will often be found, partially, or to a considerable extent, clothed with belts or masses of wood, either previously planted, or preserved from the woodman's axe. How easily we may turn these to advantage in the natural style of Landscape Gardening ; and by judicious trimming when too thick, or additions when too much scattered, elicit often the happiest effects, in a magical manner!

Where there are large masses of wood to regulate and arrange, much skill, taste, and judgment, are requisite, to enable the proprietors to preserve only what is really beautiful and picturesque, and to remove all that is superfluous. Most of our native woods, too, have grown so closely, and the trees are consequently so much drawn up, that should the improver thin out any portion, at once, to single trees, he will be greatly disappointed if he expects them to stand long; for the first severe autumnal gale will almost certainly prostrate them. The only method, therefore, is to allow them to remain in groups of considerable size at first, and to thin them out as is finally desired, when they have made stronger roots and become more inured to the influence of the sun and air. 
But to return to grouping; what we hare already endearored to render familiar to the reader, mar be called grouping in its simple meaning-for general effect, and with an eye only to the natural beauty of pleasing forms. Let us now explain, as concisely as we may, the mode of grouping in the two schools of Landscape Gardening herewofore defined, that is to say, grouping and planting for Beautiful effect, and for Picturesque effect; as we wish it understood that these two different expressions, in artificial bundscape, are always to a certain extent under our control.

Penting and Grouping to prodece the Besutiful. The elementary features of this expression, our readers will remember to be fulness and softness of outline, and perfectly luxuriant development. To insure these in plantations, we must commence by choosing. mainly, trees of graceful habit and flowing outlines: and of this class of irees hereafter more fully illustrated, the American elm and the maple may be taken as the type. Next, in dis. posing them, they must usually be planted rather distant in the groups, and often singly. We do not mean by this, that close groups may not occasionally be formed, but there should be a predominance of trees grouped at such a distance from each other, as to allow a full development of the branches on every side. Or, when a close group is planted, the trees composing it should be usually of the same or a similar kind, in order that they may grow up together and form one finely rounded head. Rich creepers and blossoming rines, that grow in fine luxuriant wreaths and masses, are fit accompaniments to occasional groups in this mamner. Fig. 16 represents a plan of trees grouped alıng a road or walk, so as to derelope the Beautiful.

It is proper that we should here remark, that a distinct. species of after treatment is required for the two mcdes. Trees, or groups, where the Beautilul is amed at, should be 


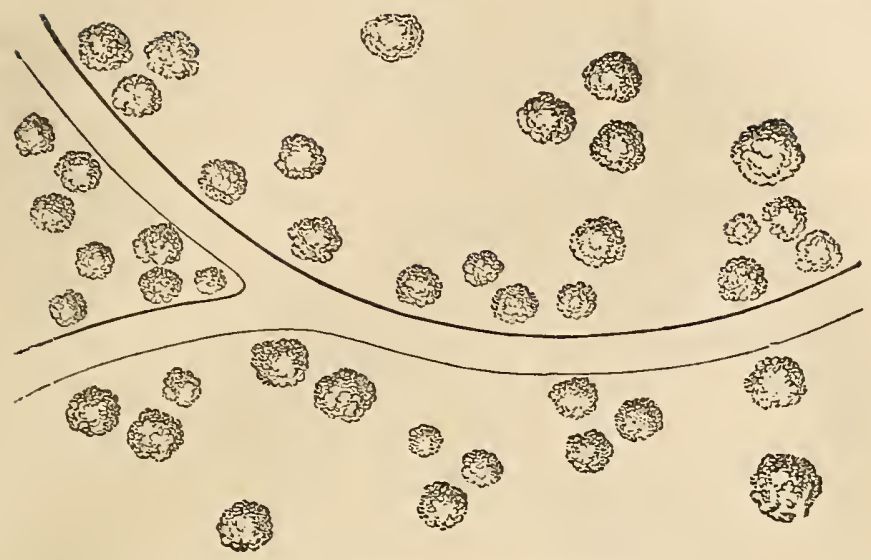

[Fig. 16. Grouping to produce the Beantiful.]

pruned with great care, and indeed scarcely at all, except to remedy disease, or to correct a bad form. Above all, the full luxuriance and development of the tree should be encouraged by good soil, and repeated manurings when necessary; and that most expressively elegant fall and droop of the branches, which so completely denotes the Beautiful in trees, should never be warred against by any trimming of the lower branches, which must also be carefully preserved against cattle, whose browsing line would soon efface this most beautiful disposition in some of our fine lawn trees. Clean, smooth stems, fresh and tender bark, and a softly rounded pyramidal or drooping head, are the characteristics of a Beautiful tree. We need not add that gently sloping ground, or surfaces rolling in easy undulations, should accompany such plantations.

Planting and Grouping to produce tue Picturequue. All trees are armissible in a picturesque place, but a predominance must be used by the planter of what are truly calied picturesque trees, of which the larch and fir tribe. 
and some species of oak, may be taken as examples. In Picturesque plantations everything depends on intricacy

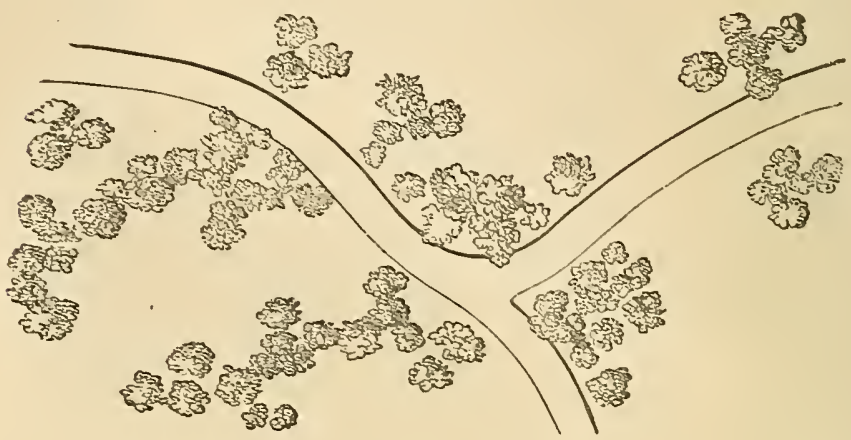

[Fig. 17. Gromping to produce the Picturesque.]

and irregularity, and grouping, therefore, must often be done in the most irregular manner-rarely, if ever, with single specimens, as erery object should seem to connect itself with something else; but, most frequently, there should be irregular groups, occasionally running in to thickets, and always more or less touching each other: trusting to after time for any thinning, should it be necessary. Fig. 17 may, as compared with Fig. 16, give an idea of picturesque grouping.

There should be more of the wildness of the finest and niost forcible portions of natural woods or forests, in the disposition of the trees; sometimes planting them closely, eren two or three in the same hole, at others more loose and scattered. These will grow up into wilder and more striking forms, the barks will be deeply furrowed and rough, the limbs twisted and irregular, and the forms and outlines distinctly varied. They should often be intermixed with smaller undergrowth of a similar character, as the hazel, hawthorn, etc., and formed into such picturesque and stril-- 
ing groups, as painters love to study and introduce into their pictures. Sturdy and bright vines, or such as are themselves picturesque in their festoons and hangings, should be allowed to clamber over occasional trees in a negligent manner; and the surface and grass, in parts of the scene not immediately in the neighborhood of the mansion, may be kept short by the cropping of animals, or allowed to grow in a more careless and loose state, like that of tangled dells and natural woods.

There will be the same open glades in picturesque as in beautiful plantations; but these openings, in the former, will be bounded by groups and thickets of every form, and of different degrees of intricacy, while in the latter the eye will repose on softly rounded masses of foliage, or single, open groups of trees, with finely balanced and graceful heads and branches.

In order to know how a plantation in the Picturesque mode should be treated, after it is established, we should reflect a moment on what constitutes picturesqueness in any tree. This will be found to consist either in a certain natural roughness of bark, or wildness of form and outline, or in some accidental curve of a branch of striking manner of growth, or perhaps of both these conjoined. A broken or crooked limb, a leaning trunk, or several stems springing from the same base, are frequently peculiarities that at once stamp a tree as picturesque. Hence, it is easy to see that the excessive care of the cultivator of trees in the graceful school tc obtain the smoothest trunks, and the most sweeping, perfect, and luxuriant heads of foliage, is quite the opposite of what is the picturesque arboriculturist's ambition. He desires to encourage a certain wildness of growth, and allows his trees to spring up occasionally in thickets 
to assist this effect; he delights in occasional irregularity of stem and outline, and he therefore suffers his trees here and there to crowd each other; he admires a twisted limb or a moss-covered branch, and in pruning he therefore is careful to leave precisely what it would be the aim of the other to remore; and his pruning, where it is at all necessiury, is directed rather towards increasing the naturally striking and peculiar habit of the picturesque tree, than assisting it in developing a form of unusual refinement and symmetry. From these remarks we think the amateur will easily divine, that planting, grouping, and culture to produce the Beautiful, require a much less artistic eye (though much more care and attention) than performing the same operations to elicit the Picturesque. The charm of a refined and polished landscape-garden, as we usually see it in the Beautiful grounds with all the richness and beauty developed by high culture, arises from our admiration of the highest perfection, the greatest beauty of form, to which erery object can be brought; and, in trees, a judicious selection, with high cultiration, will always produce this effect.

But in the Picturesque landscape-garden there is risible a piquancy of effect, certain bold and striking growths and combinations, which we feel at once, if we know them to be the result of art, to be the production of a peculiar species of attention-not merely good, or even refined ornamental gardening. In short, no one can be a picturesque improver (if he has to begin with young plantations) who is not himself something of an artist-who has not studied nature with an artistical eye-and who is not capable of imitating, eliciting, or heightening, in his plantations or other portions of his residence, the picturesque 
in its many variations. And we may add here, that efficient and charming as is the assistance which all ornamental planters will derive from the study of the best landscape engravings and pictures of distinguished artists, they are indispensably necessary to the picturesque im prover. In these he will often find embodied the choicest and most captivating studies from picturesque nature; and will see at a glance the effect of certain combinations of trees, which he might otherwise puzzle himself a dozen years to know how to produce.

After all, as the picturesque improver here will most generally be found to be one who chooses a comparatively wild and wooded place, we may safely say that, if he has the true feeling for his work, he will always find it vastly easier than those who strive after the Beautiful; as the majority of the latter may be said to begin nearly anewchoosing places not for wildness and intricacy of wood, but for openness and the smiling, sunny, undulating plain, where they must of course, to a good extent, plant anew.

After becoming well acquainted with grouping, we should bring ourselves to regard those principles which govern our improvements as a whole. We therefore must call the attention of the improver to the two following principles, which are to be constantly in view: the production of a whole, and the proper connexion of the parts.

Any person who will take the trouble to reflect for a moment on the great diversity of surface, change of position, aspects, views, etc., in different country residences, will at once perceive how difficult, or, indeed, how impossible it is, to lay down any fixed or exact rules for arranging plantations in the modern style. What would be precisely adapted to a hilly rolling park, would often be found entire- 
to assist this effect; he delights in occasional irregularity of stem and outline, and he therefore suffers his trees here and there to crowd each other; he admires a twisted limb or a moss-covered branch, and in pruning he therefore is careful to leave precisely what it would be the aim of the other to remove; and his pruning, where it is at all necessary, is directed rather towards increasing the naturally striking and peculiar habit of the picturesque tree, than assisting it in developing a form of unusual refinement and symmetry. From these remarks we think the amateur will easily divine, that planting, grouping, and culture to produce the Beautiful, require a much less artistic eye (though much more care and attention) than performing the same operations to elicit the Picturesque. The charm of a refined and polished landscape-garden, as we usually see it in the Beautiful grounds with all the richness and beauty developed by high culture, arises from our admiration of the highest perfection, the greatest beauty of form, to which every object can be brought; and, in trees, a judicious selection, with high cultivation, will always produce this effect.

But in the Picturesque landscape-garden there is visible a piquancy of effect, certain bold and striking growths and combinations, which we feel at once, if we know them to be the result of art, to be the production of a peculiar species of attention-not merely good, or even refined ornamental gardening. In short, no one can be a picturesque improver (if he has to begin with young plantations) who is not himself something of an artist-who has not studied nature with an artistical eye-and who is not capable of imitating, eliciting, or heightening, in his plantations or other portions of his residence, the picturesque 
in its many variations. And we may add here, that efficient and charming as is the assistance which all ornamental planters will derive from the study of the best landscape engravings and pictures of distinguished artists, they are indispensably necessary to the picturesque improver. In these he will often find embodied the choicest and most captivating studies from picturesque nature; and will see at a glance the effect of certain combinations of trees, which he might otherwise puzzle himself a dozen years to know how to produce.

After all, as the picturesque improver here will most generally be found to be one who chooses a comparatively wild and wooded place, we may safely say that, if he has the true feeling for his work, he will always find it vastly easier than those who strive after the Beautiful; as the majority of the latter may be said to begin nearly anewchoosing places not for wildness and intricacy of wood, but for openness and the smiling, sunny, undulating plain. where they must of course, to a good extent, plant anew.

After becoming well acquainted with grouping, we should bring ourselves to regard those principles which govern our improvements as a whole. We therefore must call the attention of the improver to the two following principles, which are to be constantly in view: the production of a whole, and the proper connexion of the parts.

Any person who will take the trouble to reflect for a moment on the great diversity of surface, change of position, aspects, views, etc., in different country residences, will at once perceive how difficult, or, indeed, how impossible it is, to lay down any fixed or exact rules for arranging plantations in the modern style. What would be precisely adapted to a hilly rolling park, would often be found entire- 
a charming variety in the scenc, either when seen from a given point or when examined in detail. It must not be forgotten that, as a general rule, the grass or surface of the lawn answers as the principal light, and the roods or plantations as the shadows, in the same manner in nature as in painting; and that these should be so managed as to lead the eye to the mansion as the most important object when seen from without, or correspond to it in grandeur and magnitude, when looked upon from within the house. If the surface is too much crowded with groups of foliage, breadth of light will be found wanting; if left too bare, there will be felt, on the other hand, an absence of the noble effect of deep and broad shadows.

One of the loreliest charms of a fine park is, undoubtedIy, rariation or undulation of surface. Ererything, accordingly, which tends to preserve and strengthen this pleasing character, should be kept constantly in view. Where, therefore, there are no obrious objections to such a course, the eminences, gentle swells, or hills, should be planted, in preference to the hollorrs or depressions. By planting the elerated portions of the grounds, theis apparent height is increased; but by planting the hollows, all distinction is lessened and broken up. Indeed, where there is but a trifling and scarcely perceptible undulation, the importance of the swells of surface already existing is surprisingly increased, when this course of planting is adopted; and the whole, to the eye, appears finely raried.

Where the grounds of the residence to be planted are level, or nearly so, and it is desirable to comfine the view; on any or all sides, to the lawn or park itself, the boundary groups and masses must be so connected together as from 
the most striking part or parts of the prospect (near he house for example) to answer this end. This should be done, not by planting a continuous, uniformly thick belt of trees round the outside of the whole; but by so arranging the various outer groups and thickets, that when seen from the given points they shall appear connected in one whole In this way, there will be an agreeable variation in the margin, made by the various bays, recesses, and detached projections, which could not be so well effected if the whole were one uniformly unbroken strip of wood.

But where the house is so clevated as to command a more extensive view than is comprised in the demesne itsclf, another course should be adopted. The grounds planted must be made to connect themselves with the surrounding scenery, so as not to produce any violent contrast to the eye, when compared with the adjoining country. If then, as is most frequently the case, the lawn or pleasure-ground join, on either side or sides, cultivated farm lands, the proper connexion may be kept up by advancing a few groups or even scattered trees into the neighboring fields. In the middle states there are but few cultivated fields, even in ordinary farms, where there is not to be seen, here and there, a handsome cluster of saplings or a few full grown trees; or if not these, at least some tall growing bushes along the fences, all of which, by a little exercise of this leading principle of connexion, can, by the planter of taste, be made to appear with few or trifling additions, to divaricate from, and ramble'out of the park itself. Where the park joins natural woods, connexion is still easier, and where it bounds upron one of our noble rivers, lakes, or other large sheets of water, of course connexion is not expected ; for 
sudden contrast and transition is there both ratural and beautiful.

In all cases good taste will suggest that the more polished parts of the lawns and grounds should, whatever character is attempted, be those nearest the house. There the rnost rare and beautiful sorts of trees are displayed, and the entire plantations agree in elegance with the style of art evinced in the mansion itself. When there is much extent, however, as the eye wanders from the neighborhood of the residence, the whole evinces less polish; and gradually, towards the furthest extremities, grows ruder, until it assimilates itself to the wildness of general nature around. This, of course, applies to grounds of large extent, and must not be so much enforced where the lawn embraced is but moderate, and therefore comes more directly under the eje.

It will be remembered that, in the foregoing section, we stated it as one of the leading principles of the art of Land. scape Gardening, that in every instance where the grounds of a country residence have a marked natural character, whether of beautiful or picturesque expression, the efforts of the improver will be most successful if he contributes by his art to aid and strengthen that expression. This should ever be borne in mind when we are commencing any improvements in planting that will affect the general expression of the scene, as there are but few country residences in the United States of any importance which have not naturally some distinct landscape character; and the labors of the improver will be productive of much greater satisfaction and more lasting pleasure, when they aim at effects in keeping with the whole scene, than if no regard be paid to this important point. This will be felt almost 
intuitively by persons who, perhaps, would themselves be incapable of describing the cause of their gratification, but would perceive the contrary at once; as many are unable to analyse the pleasure derived from harmony in music, while they at once perceive the introduction of discordant notes.

We do not intend that this principle should apply so closely, that extensive grounds naturally picturesque shal! have nothing of the softening touches of more perfect beauty; or that a demesne characterized by the latter expression should not be occasionally enlivened with a few' "smart touches" of the former. This is often necessary, indeed, to prevent tame scenery from degenerating into insipidity, or picturesque into wildness, too great to be appropriate in a country residence. Picturesque trees give new spirit to groups of highly beautiful ones, and the latter sometimes heighten by contrast the value of the former. All of which, however, does not prevent the predominance of the leading features of either style, sufficiently strong to mark it as such; while, occasionally, something of zest or elegance may be borrowed from the opposite character, to suit the wishes or gratify the taste of the proprietor.

Ground plans of ornamental plantations. To llustrate partially our ideas on the arrangement of plan. tations we place before the reader two or three examples, premising that the small scale to which they are reduced prevents our giving to them any character beyond that of the general one of the design. The first (Fig. 20) represents a portion, say one third or one half of a piece of property selected for a country seat, and which has hitherto been kept in tillage as ordinary farm land. The public 


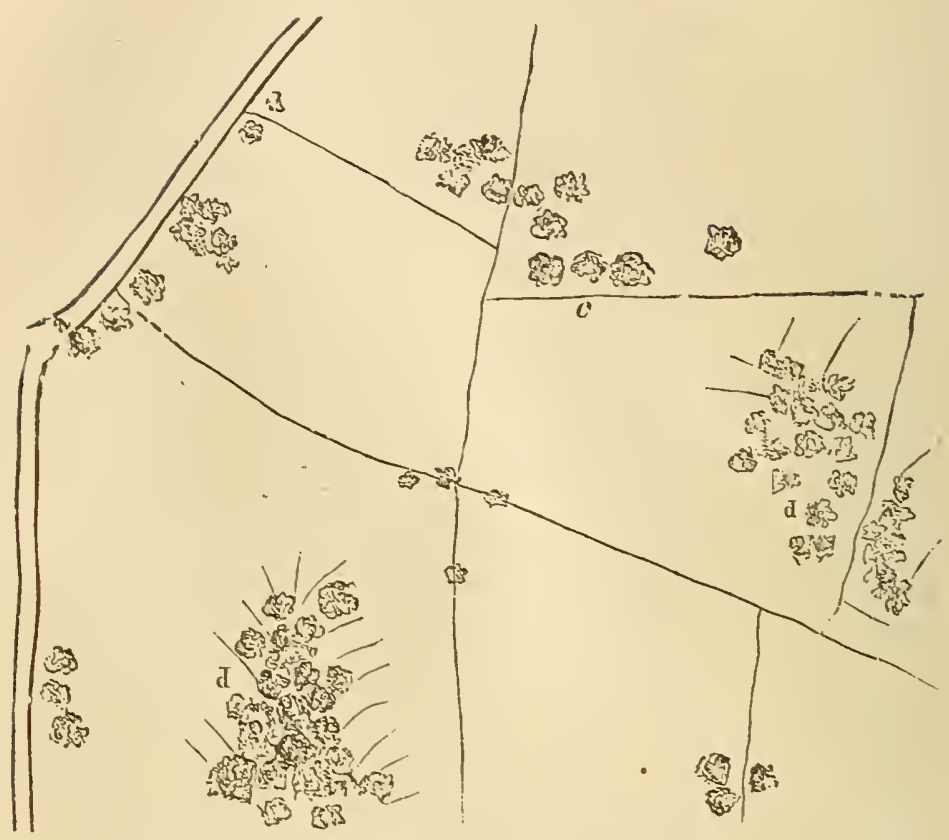

[Fig. 18. Plan of a common Farm, before any improvements.]

road, $a$, is the boundary on one side : $d d$ are prettily wooded dells or hollows, which, together with a few groups near the proposed site of the house, $c$, and a few scattered single trees, make up the aggregate of the original woody embellishments of the locality.

In the next figure (Fig. 19) a ground plan of the place is given, as it would appear after having been judiciously laid out and planted, with several years' growth. At $a$, the approach road leares the public highway and leads to the

- house at $c$ : from whence paths of smaller size, $b$, make the circuit of the ornamental portion of the residence, taking advantage of the wooded dells, $d$, origginally existing, which offer some scope for varied walks concealed from each other by the intervening masses of thicket. It will 


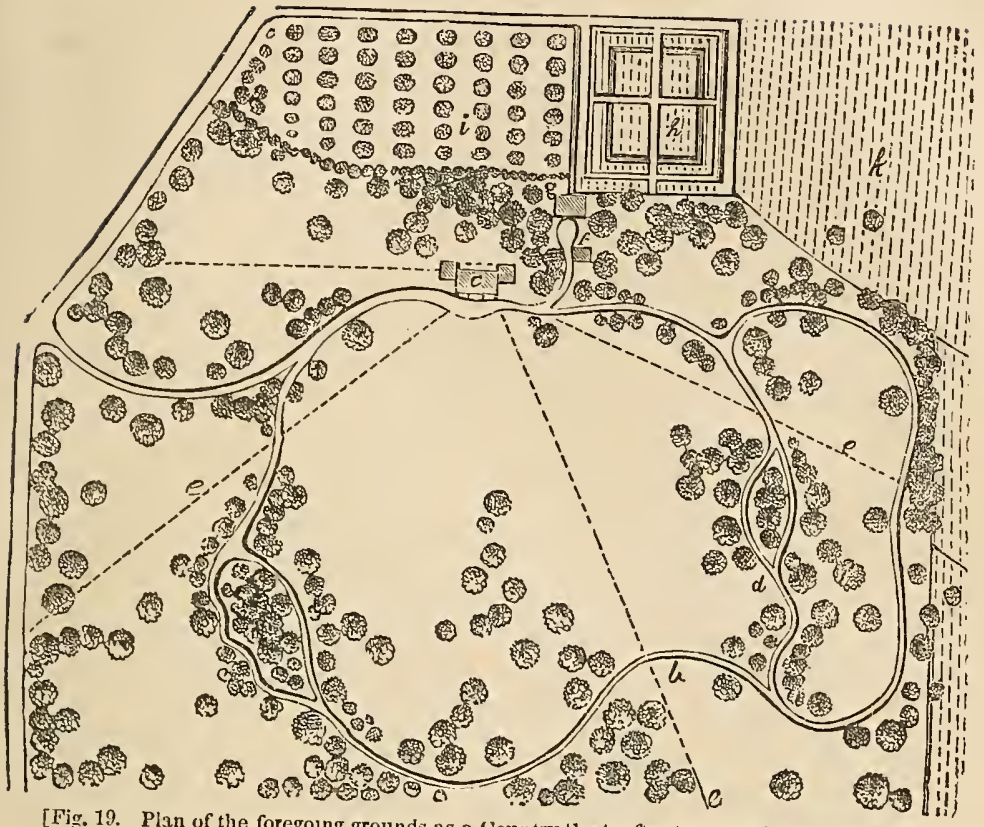

[Fig. 19. Plan of the foregoing grounds as a Country seat, rfter ten years' improvement.]

be seen here, that one of the largest masses of wood forms a background to the house, concealing also the out-buildings; while, from the windows of the mansion itself, the :rees are so arranged as to group in the most pleasing and effective manner: at the same time broad masses of turf meet the eye, and fine distant views are had through the vistas in the lines, $e e$. In this manner the lawn appears divided into four distinct lavns or areas bounded by grours of trees, instead of being dotted over with an unmeaning confusion of irregular masses of foliage. The form of these areas varies also with every change of position in the spec. tator, as seen from different portions of the grounds, or differ. ent points in the walks; and they can be still further varied at pleasure by adding more single trees or small grours, which should always, to produce variety of outline, be 
placed opposite the salient parts of the rood, and not in the recesses, which latter they would appear o diminish or clog up. The stables are shown at $f^{\prime}$; the barn at $g$, and the kitchen garden adjacent at $h$; the orchard at $i$; and a small portion of the farm lands at $k$; a back entrance to h.e out-buildings is shown in the rear of the orchard. The pian has been given for a place of seventy acres, thirty of which include the pleasure grounds, and forty the adjoining farm lands.

Figure 20 is the plan of an American mansion

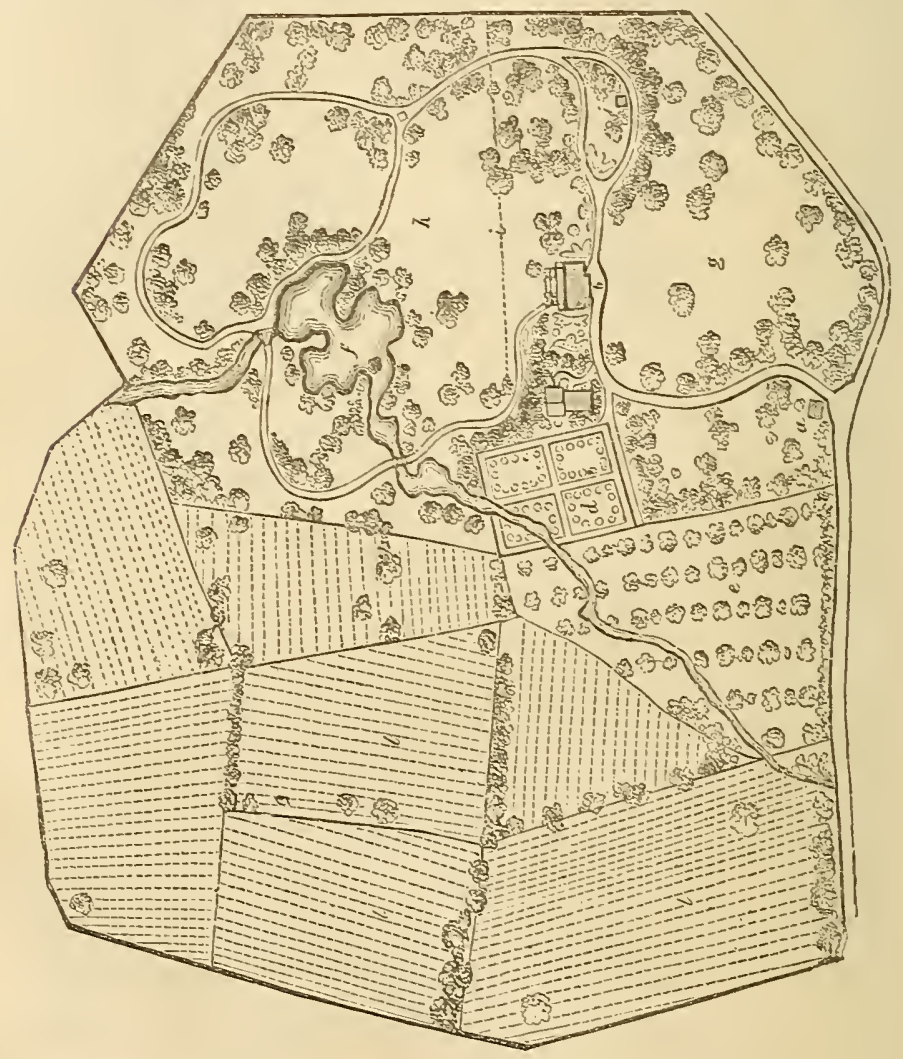

[Fiss. 20. Plau of a Mausion Residence, laid out in the natural stylin] 
residence of considerable extent, only part of the farm lands, $l$, being here delineated. In this residence, as there is no extensive view worth preserving beyond the bounds of the estate, the pleasure grounds are surrounded by an irreguiar and picturesque belt of wood. A fine natural stream or rivulet, which ran through the estate, has been formed into a handsome pond, or small lake, $f$, which adds much to the interest of the grounds. The approach road breaks off from the highway at the entrance lodge, $a$, and proceeds in easy curves to the mansion, $b$; and the groups of trees on the side of this approach nearest the house, are so arranged that the visitor scarcely obtains more than a glimpse of the latter, until he arrives at the most favorable position for a first impression. From the windows of the mansion, at either end, the eye ranges over groups of flowers and shrubs; while, on the entrance front, the trees are arranged so as to heighten the natural expression originally existing there. On the other front, the broad mass of light reflected from the green turf at $k$, is balanced by the dark shadows of the picturesque plantations which surround the lake, and skirt the whole boundary. At $i$, a light, inconspicuous wire fence separates that portion of the ground, $g$, ornamented with flowering shrubs and kept mown by the scythe, from the remainder, of a park-like character, which is kept short by the cropping of animals. At $c$, are shown the stables, carriage--house, etc., which, though near the approach road, are concealed by foliage, though easily accessible by a short curved road, returning from the house, so as not to present any road leading in the same direction, to detract from the dignity of the approach in going to it. \& prospect tower, or rustic pavilion, on a little eminence 
orerlooking the whole estate, is shown at $j$. The small arabesque beds near the house are filled with masses of choice flowering shrubs and plants; the kitchen garden is shown at $d$, and the orchard at $c$.

Suburban villa residences are, every day, becoming more numerous; and in laying out the grounds around them, and disposing the sylvan features, there is often more ingenuity, and as much taste required, as in treating a country residence of several hundred acres. In the small area of from one half an acre to ten or twelre acres, surrounding often a villa of the first class, it is desirable to assemble many of the same features, and as much as possible of the enjoyment, which are to be found in a large and elegant estate. To do this, the space allotted to rarious purposes, as the litchen garden, lavn, etc., must be judicionsly portioned out, and so characterized and divided by plantations, that the whole shall appear to be much larger than it really is, from the fact that the spectator is never allowed to see the whole at a single glance; but while each portion is complete in itself, the plan shall present nothing incongruous or ill assorted.

An excellent illustration of this species of residence, is afforded the reader in the accompanying plan (Fig. 21) of the grounds of Riverside Filla. This pretty rilla at Burlington, New Jersey (to which we shall again refer), was lately built, and the grounds, about sir or eight acres in extent, laid out, from the designs of John Notman, Esq., architect, of Philadelphia; and while the latter promise a large amount of beauty and enjorment, scarcey anything which can be supposed necessary for the conrenience or wants of the family, is lost sight of.

The house, $a$, stands quite near the bank of the rirer, 


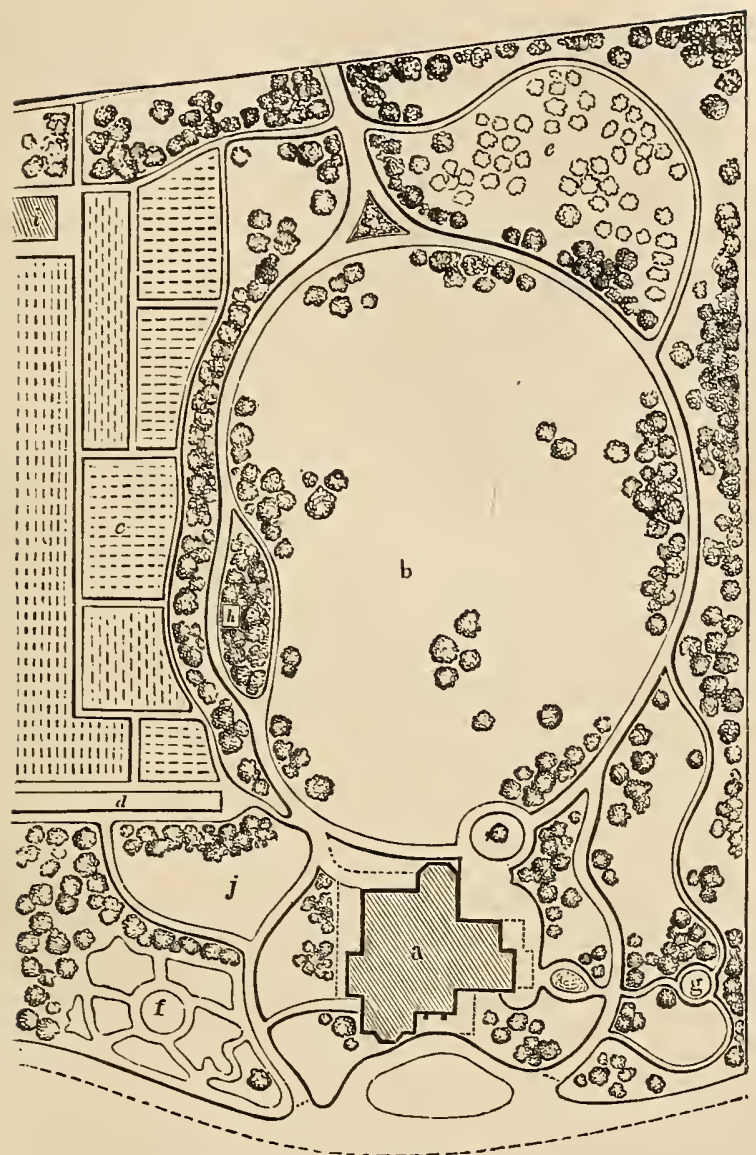

[Fig. 21. Plan of a Suburban Villa Residence.]

while one front commands fine water views, and the other looks into the lawn or pleasure grounds, $b$. On one side of the area is the kitchen garden, $c$, separated and concealed from the lawn by thick groups of evergreen and deciduous trees. At $e$, is a picturesque orchard, in which the fruit trees are planted in groups instead of straight lines, for the sake of effect. Directly under the windows of the drawing-room is the flower garden, $f$; and 
at $g$, is a seat. The walk around the lawn is also a carriage road, affording entrance and egress from the rear of the grounds, for garden purposes, as well as from the front of the house. At $h$, is situated the ice-house; $d$, hot-beds ; $j$, bleaching green; $i$, gardener's house, etc. In the rear of the latter are the stables, which are not shown on the plan.

The embellished farm (ferme ornée) is a pretty mode of combining something of the beauty of the landscape garden with the utility of the farm, and we hope to see small country seats of this lind become more general. As regards profit in farming, of course, all modes of arranging or distributing land are inferior to simple square fields; on account of the greater facility of working the land in rectangular plots. But we suppose the owner of the small ornamental farm to be one with whom profit is not the first and only consideration, but who desires to unite with it something to gratify his taste, and to give a higher charm to his rural occupations. In Fig. 22, is shown part of an embellished farm, treated in the picturesque style throughout. The various trees, under grass or tillage, are divided and bounded by winding roads, $a$, bordered by hedges of buckthorn, cedar, and hawthorn, instead of wooden fences; the roads being wide enough to afford a pleasant drive or walk, so as to allow the orvner or visitor to enjoy at the same time an agreeable circuit, and a glance at all the various crops and modes of culture. In the plan before us, the approach from the public road is at $b$; the dwelling at $c$; the barns and far:n-buildings at $d$; the kitchen-garden at $e$; and the orchard at $f$. About the house are distributed some groups of trees, and here the fields, $g$, are kept in grass, and are either mown 


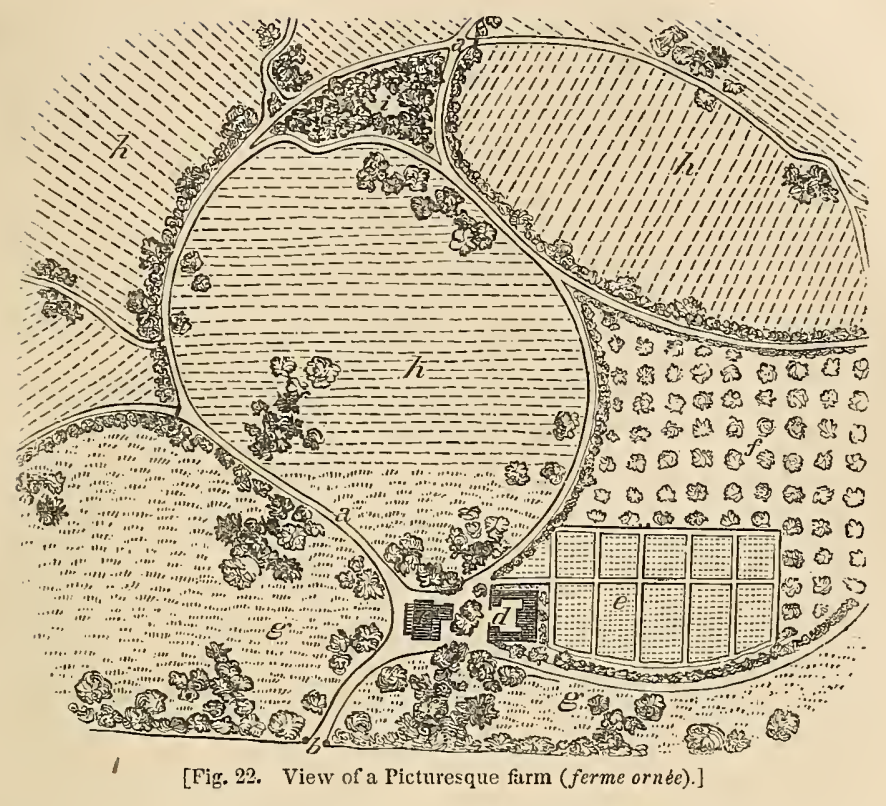

or pastured. The fields in crops are designated $h$, on the plan; and a few picturesque groups of trees are planted, or allowed to remain, in these, to keep up the general character of the place. A low dell, or rocky thicket, is situated at $i$. Exceedingly interesting and agreeable effects may be produced, at little cost, in a picturesque farm of this kind. The hedges may be of a great variety of suitable shrubs, and, in addition to those that we have named, we would introduce others of the sweet brier, the Michigan or prairie rose (admirably adapted for the purpose), the flowering crab, and the like-beautiful and fragrant in their growth and blossoms. These hedges we would cause to grow thick, rather by interlacing the branches, than by constant shearing or trimming, which would give them a less formal, and a more free and natural air. The winding lanes traversing the farm need 
only be gravelled near the house, in other portions being left in grass, which will need little care, as it will generally be kept short enough by the passing of men and vehicles over it.

A picturesque or ornamental farm like this would be an agreeable residence for a gentleman retiring into the country on a small farm, desirous of experimenting for himself with all the new modes of culture. The small and irregular fields would, to him, be rather an advantage, and there would be an air of novelty and interest about the whole residence. Such an arrangement as this would also be suitable for a fruit farm near one of our large towns, the fields being occupied by orchards, vines, grass, and grain. The house and all the buildings should be of a simple, though picturesque and accordant character.

The cottage ornée may have more or less ground attached to it. It is the ambition of some to have a great house and little land, and of others (among whom we remember the poet Cowley) to have a little house and a large garden. The latter would seem to be the more natural taste. When the grounds of a cottage are large, they will be treated by the landscape gardener nearly like those of a villa residence; when they are smaller a more quiet and simple character must be aimed at. But even where they consist of only a rood or two, something tasteful and pretty may be arranged.* In Fig. 23, is shown a small piece of ground on one side of a cottage, in which a picturesque character is attempted to be maintained. The plantations here are made mostly with shrubs instead of trees, the latter being

* For a variety of modes of treating the grounds of small places, see our Designs for Cottage Residences. 
only sparingly introduced for the want of room. In the disposition of these shrubs, however, the same attention to picturesque effect is paid as we have already pointed out in our remarks on grouping; and by connecting the thickets and groups here and there, so as to conceal one walk from the other, a surprising variety and effect will frequently bo produced in an exceedingly limited spot.

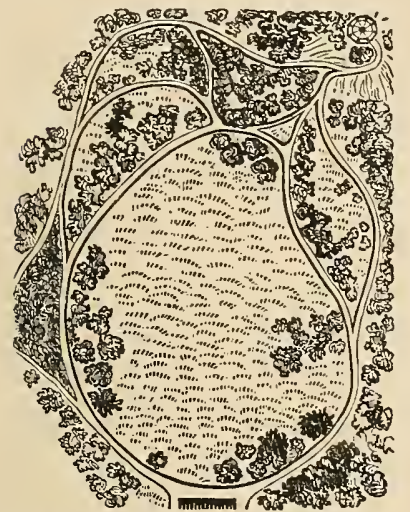

The same limited grounds might be planted so as to produce the Beautiful ; choosing, in this case, shrubs of symmetrical growth and fine forms, planting and grouping them somewhat singly, and allowing every specimen to attain its fullest luxuri. ance of development.

In making these arrangements, [Fig. 23. Grounds of a Cottage ornee.] even in the small area of a fourth of an acre, we should study the same principles and endeavor to produce the same harmony of effects, as if we were improving a mansion residence of the first class. The extent of the operations, and the sums lavished, are not by any means necessarily connected with successful and pleasing results. The man of correct taste will, by the aid of very limited means and upon a small surface, be able to afford the mind more true pleasure, than the improver who lavishes thousands without it, creating no other emotion than surprise or pity at the useless expenditure incurred; and the Abbé Delille says nothing more true than that,

"Ce noble emploi demand un artiste qui pense,

Prodigue de génie, et non pas de dérense." 
From the inspection of plans like these, the tyro may learn something of the manner of arranging plantations, and of the general effect of the natural style in particular cases and situations. But the knowledge they afford is so far below that obtained by an inspection of the effects in reality, that the latter should in all cases be preferred where it is practicable. In this style, unlike the ancient, it is almost impossible that the same plan should exactly suit any other situation than that for which it was intended. for its great excellence lies in the endless variety produced by its application to different sites, situations, and surfaces; ieveloping the latent capacities of one place and heightening the charms of another.

But the leading principles as regards the formation of plantations, which we have here endeavored briefly to elucidate, are the same in all cases. After beconing familiar with these, should the amateur landscape-gardener be at a loss how to proceed, he can hardly do better, as we have before suggested, than to study and recur often to the beautiful compositions and combinations of nature, displayed in her majestic groups, masses, and single trees, as well as open glades and deep thickets; of which, fortunately, in most parts of our country, checkered here and there as it is with beautiful and picturesque scenery, there is no dearth or scarcity. Keeping these fer principles in his mind, he will be able to detect new beauties and transfer them to his own estate; for nature is truly inexhaustible in her resources of the Beantiful.

Classification of trees as to expression. The amateur who wishes to dispose his plantations in the natural style of Landscape Gardening, so as to produce graceful or picturesque landscape, will be greatly aided by a study 
of the peculiar expression of trees individually and in com. position. The effect of a certain tree singly is often ex. ceedingly different from that of a group of the same trees. To be fully aware of the effect of groups and masses requires considerable study, and the progress in this study may be greatly facilitated by a recurrence from groups in nature to groups in pictures.

As a further aid to this most desirable species of information we shall offer a few remarks on the principal varieties oi character afforded by trees in composition.

Almost all trees, with relation to forms, may be divided into three kinds, viz. round-headed trees, oblong or pyramidal trees, and spiry-topped trees; and so far as the expressions of the different species comprised in these distinct classes are concerned, they are, especially when viewed at a distance (as much of the wood seen in a prospect of any extent necessarily must be), productive of nearly the same general effects.

Round-headed trees compose by far the largest of these divisions. The term includes all those trees which have

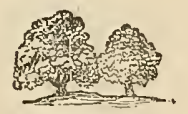
an irregular surface in their boughs, more or less varied in outline, but exhibiting in the [Fig. 24 . Round- whole a top or head comparatively round:
headed Trees. as the oak, ash, beech, and wahut. They are generally beautiful when young, from their smoothness, and the elegance of their forms; but often grow picturesque when age and time have had an opportunity to produce their wonted effects upon them. In general, however, the different round-headed trees may be considered as the most appropriate for introduction in highly-cultivated scenery, or landscapes where the character is that of graceful or polished beauty; as they harmonize with almost all scenes, 
buildings, and natural or artificial objects, uniting well with other forms and doing riolence to no expression of scenery From the numerous breaks in the surface of their foliage, which reflect differently the lights and produce deep shadows, there is great intricacy and variety in the heads of many round-topped trees; and therefore, as an outer surface to meet the eye in a plantation, they are much softer and more pleasing than the unbroken line exhibited by the sides of oblong or spiry-topped trees. The sky outline also, or the upper part of the head, raries greatly in round-topped trees from the irregularity in the disposition of the upper branches in different species, as the oak and ash, or even between indiridual specimens of the same kind of tree, as the oak, of which we rarely see two trees alike in form and outline, although they have the same characteristic expression; while on the other hand no two rerdant objects can bear a greater general resemblance to each other and show more sameness of figure than two Lombardy poplars.

"In a tree," says Uredale Price, "of which the foliage is, everywhere, full and unbroken, there can be but little variety of form; then, as the sun strikes only on the surface, neither can there be much rariety of light and shade; and as the apparent color of objects changes according to the different degrees of light or shade in which they are placed, there can be as little variety of tint; and lastly; as there are none of these openings that excite and nourish curiosity, but the eye is everywhere opposed by one miform leafy screen, there can be as little intricacy as variety." From these remarks, it will be perceived that eren among round-headed trees there may be great difference in the comparative beauty of 
different sorts; and judging from the excellent standard here laid down, it will also be seen how much in the eye of a painter a tree with a beautifully diversified surface, as the oak, surpasses in the composition of a scene one with a very regular and compact surface and outline, as the horse-chestnut. In planting large masses of wood, therefore, or even in forming large groups in park scenery, round-headed trees of the ordinary loose and varied manner of growth cornmon in the majority of forest trees, are greatly to be preferred to all others. When they cover large tracts, as several acres, they convey an emotion of grandeur to the mind; when they form vast forests of thousands of acres, they produce a feeling of sublimity; in the landscape-garden when they stand alone, or in fine groups, they are gracejul or beautiful. While young they have an elegant appearance; when old, they generally become majestic or picturesque. Other trees may suit scenery or scenes of particular and decided characters, but round-headed trees are decidedly the chief adornment of general landscape.

Spiry-topped trees (Fig. 25) are distinguished by straight leading stems and horizontal branches, which are comparatively small, and taper gradually to a point. The foliage is generally evergreen, and in most trees of this class [Fig. 25. Spiry-topped hangs in parallel or drooping tufts from the branches. The various evergreen trees, composing the spruce and fir families, most of the pines, the cedar, and among deciduous trees, the larch, belong to this division. Their hue is generally much darker than that of deciduous trees, and there is a strong similarity, or 
almost sameness, in the different linds of trees which may properly be called spiry-topped.

From their sameness of form and surface, this class of trees, when planted in large tracts or masses, gives much less pleasure than round-headed trees; and the eye is soon wearied with the monotony of appearance presented by long rows, groups, or masses, of the same form, outline, and appearance; to say nothing of the eflect of the uniform dark color, unrelieved by the warmer tints of deciduous trees. Any one can bear testimony to this, who has travelled through a pine, hemlock, or fir forest, where he could not fail to be struck with its gloom, tediousness, and monotony, especially when contrasted with the rariety and beauty in a natural wood of deciduous, round-headed trees.

Although spiry-topped trees in large masses cannot be generally admired for ornamental plantations, yet they hare a character of their own, which is very striking and peculiar, and we may add, in a high degree valuable to the Landscape Gardener. Their general expression when single or scattered is extremely spirited, wild and picturesque; and when judicionsly introduced into artificial scenery, they produce the most charming and unique effects. "The situations where they hare most effect is among rocks and in rery irregular surfaces, and especially on the steep sides of high mountains, where their forms and the direction of their growth seem to harmonize with the pointed rocky summits." Fir and pine forests are extremely dull and monotonous in sandy plains and smooth surfaces (as in the pine barrens of the southern states); but among the broken rocks, craggy precipices, 
and otherwise endlessly varied surfaces (as in the Alp;, abroad, and the various rocky heights in the Highlands of the Hudson and the Alleghanies, at home) they are full of variety. It will readily be seen, therefore, that spiry-topped trees should always be planted in considerable quantities in wild, broken, and picturesque scenes, where they will appear perfectly in keeping, and add wonderfully to the peculiar beauty of the situation. In all grounds where there are abruptly varied surfaces, steep banks, or rocky precipices, this class of trees lends its efficient aid to strengthen the prevailing beauty, and to complete the finish of the picture. In smooth, level surfaces, though spiry-topped trees cannot be thus extensively employed, they are by no means to be neglected or thought valueless, but may be so combined and mingled with other roundheaded and oblong-headed trees, as to produce very rich and pleasing effects. A tall larch or two, or a few spruces rising out of the centre of a group, give it life and spirit, and add greatly, both by contrast of form and color, to the force of round-headed trees. A stately and regular white pine or hemlock, or a few thin groups of the same trees peeping out from amidst, or bordering a large mass of deciduous trees, have great power in adding to the interest which the same awakens in the mind of the spectator. Care must be taken, however, that the very spirited effect which is here aimed at, is not itself defeated by the over anxiety of the planter, who, in scattering too profusely these very strongly marked trees, makes them at last so plentiful, as to give the whole a mingled and confused look, in which neither the graceful and sweeping outlines of the round-headed nor the picturesque summits of the spiry-topped trees predominate; as the former decidedly 
should, in all scenes where an expression of peculiarly irregular kind is not aimed at.

The larch, to which we shall hereafter recur at some length, may be considered one of the most picturesque trees of this division; and being more rapid in its growth than most erergreens, it may be used as a substitute for, or in conjunction with them, where eflect is speedily desired.

Oblong-headed trees show heads of foliage more lengthened out, more formal, and generally more tapering, than

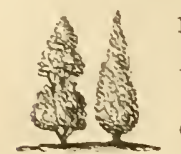
round-headed ones. They differ from spirytopped trees in having upright branches instead of horizontal ones, and in forming a conical or [Fig. "t. Oblong- pyramidal mass of foliage, instead of a spiry,
lesded trees.] tufted one. They are mostly deciduous: and approaching more nearly to round-headed trees than spiry-topped ones do, they may perhaps be more frequently introduced. The Lombardy poplar may be considered the representative of this dirision, as the oak is of the first, and the larch and fir of the second. Abroad, the oriental cypress, an evergreen, is used to produce similar effects in scenery.

The great use of the Lombardy poplar, and other similar trees in composition, is to relieve or break into groups, large masses of rood. This it does very effectually, when its tall summit rises at intervals from among round-headed trees, forming prramidal centres to groups where there was only a swelling and flowing outline. Formal rows, or groups of oblong-headed trees, howerer, are tiresome and monotonous to the last degree; a straight line of them being scarcely better in appearance than a tall, stiff, gigantic hedge. Examples of this can be 
easily found in many parts of the Uniont where the crude and formal taste of proprietors, by leading them to plant long lines of Lombardy poplars, has had the effect of destroying the beauty of many a fine prospect and building.

Conical or oblong-headed trees, when carefully employed, are very effective for purposes of contrast, in conjunction with horizontal lines of buildings such as we see in Grecian or Italian architecture. Near such edifices, sparingly introduced, and mingled in small proportion with round-headed trees, they contrast advantageously with the long cornices, flat roofs, and horizontal lines that predominate in their exteriors. Lombardy poplars are often thus introduced in pictures of Italian scenery, where they sometimes break the formality of a long line of wall in the happiest manner. Nevertheless, if they should be indiscriminately employed, or even used in any considerable portion in the decoration of the ground immediately adjoining a building of any pretensions, they would inevitably defeat this purpose, and by their tall and formal growth diminish the apparent magnitude, as well as the elegance of the house.

Drooping trees, though often classed with oblongheaded trees, differ from them in so many particulars, that they deserve to be ranked under a separate head. To this class belong the weeping willow, the weeping birch, the drooping elm, etc. Their prominent characteristics are gracefulness and elegance; and we consideı them as unfit, therefore, to be employed to any extent in scenes where it is desirable to keep up the expression of a wild or highly picturesque character. As single objects, or tastefully grouped in beautiful landscape, they 
are in excellent lieeping, and contribute much to give value to the leading expression.

When drooping trees are mixed indiscriminately with wher round-headed trees in the composition of groups or masses, much of their individual character is lost, as it depends not so much on the top (as in oblong and spiry trees) as upon the side branches, which are of course concealed by those of the adjoining trees. Drooping trees, therefore, as elms, birches, etc., are shown to the best advantage on the borders of groups or the boundaries of plantations. It must not be forgotten, but constantly kept in mind, that all strongly marked trees, like bright colors in pictures, only admit of occasional employment; and that the very object aimed at in introducing them will be defeated if they are brought into the lawn and park in masses, and distributed heedlessly on every side. An English author very justly remarks, therefore, that the poplar, the willorv, and the drooping birch, are "most dangerous trees in the hands of a planter who has not considerable knowledge and good taste in the composition of a landscape." Some of them, as the native elm, from their abounding in our own woods, may appear oftener; while others which have a peculiar and exotic look, as the weeping willow, should only. be seen in situations where they either do not disturb the prevailing expression, or (rvhich is better) where they are evidently in good keeping. "The weeping willow," says Gilpin, with his usual good taste, "is not adapted to sublime objects. We wish it not to screen the broken buttress and Gothic windows of an abbey, or to overshadow the battlements of a ruined castle. These offices it resigns to the oak, whose dignity can 
support them. The weeping willow seeks an humble scene-some romantic footpath bridge, which it half conceals, or some grassy pool over which it hangs its streaming foliage,

\section{'And dips \\ Its pendent boughs, as if to drink." "*}

The manner in which a picturesque bit of landscape can be supported by picturesque spiry-topped trees, and its expression degraded by the injudicious employment of graceful drooping trees, will be apparent to the reader in the two accompanying little sketches. In the first (Fig.

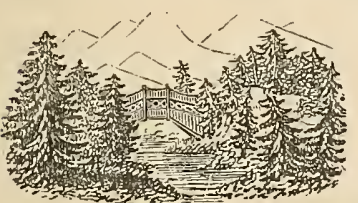

27), the abrupt hill, the rapid mountain torrent, and the distant Alpine summits, are in fine keeping with the tall spiry larches and [Fig. 27. Trees in keeping.] firs, which, shooting' up on either side of the old bridge, occupy the foreground. In the second (Fig. 30), there is evidently something discordant in the scene which strikes the spectator at first sight; this is the misplaced introduction of the large willows, which belong to a scene very different

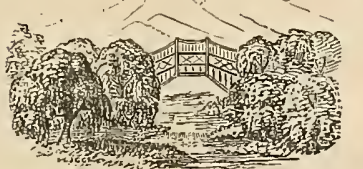
in character. Imagine a removal of the surrounding hills, and let the rapid stream spread out into a [Fig. 23. Trees out of keeping.] smooth peaceful lake with gradually retiring shores, and the blue summits in the distance. and then the willows wili harmonize admirably.

Having now described the peculiar characteristics of these different classes of round-headed, spiry-topped oblong, and drooping trees, we should consider the projer 
method by which a harmonious combination of the different forms composing them, may be made, so as not to violate correct principles of taste. An indiscriminate mixture of their different forms would, it is erident, produce anything but an agreeable effect. For example, let a person plant together in a group, three trees of totally opposite forms and expressions, viz. a weeping willow, an oak, and a poplar; and the expression of the whole would be destroyed by the confusion resulting from their discordant forms. On the other hand, the mixture of trees that exactly correspond in their forms, if these forms, as in oblong or drooping trees, are sinilar, will infallibly create sameness. In order then to produce beautiful variety which shall neither on the one side run into confusion, nor on the other verge into monotony, it is requisite to gire some little attention to the harmony of form and color in the composition of trees in artificial plantations.

The only rules which we can suggest to govern the planter are these: First, if a certain leading expression is desired in a group of trees, together with as great a variety as possible, such species must be chosen as harmonize with each other in certain leading points. And, secondly, in occasionally intermingling trees of opposite characters, discordance may be prevented, and harmonious expression promoted, by interposing other trees of an intermediate character.

In the first case, suppose it is desired to form a group of trees, in which gracefulness must be the leading expression. 'The willow alone would have the effect; but in groups, willow's alone produce sameness: in order therefore, to give variety, we must choose other trees 
which, while they differ from the willow in some particulars, agree in others. The elm has much larger and darker foliage, while it has also a drooping spray ; the weeping birch differs in its leaves, but agrees in the pensile flow of its branches; the common birch has few pendent boughs, but resembles in the airy lightness of its leaves: and the three-thorned acacia, though its branches are horizontal, has delicate foliage of nearly the same hue and floating lightness as the willow. Here we have a group of five trees, which is, in the whole, full of gracefulness and variety, while there is nothing in the composition inharmonious to the practised eye.

To illustrate the second case, let us suppose a long sweeping outline of maples, birches, and other light, mellow-colored trees, which the improver wishes to vary and break into groups, by spiry-topped, evergreen trees. It is evident, that if these trees were planted in such a manner as to peer abruptly out of the light-colored foliage of the former trees, in dark or almost black masses of tapering verdure, the effect would be by no means sc satisfactory and pleasing, as if there were a partial transition from the mellow, pale green of the maples, etc., to the darker hues of the oak, ash, or beech, and finaily the sombre tint of the evergreens. Thus much for the coloring; and if, in addition to this, oblong-headed trees or pyramidal trees were also placed near and partly intermingled with the spiry-topped ones, the unity of the whole composition would be still more complete.*

* We are persuaded that very few persons are aware of the beauty, varied and endless, that may be produced by arranging trees with regard to their coloring. It requires the cye and genius of a Claude or a Poussin, to develope all these hidden beautizs of harmonious combination. Gilpin rightly 
Contrasts, again, are often admissible in woody secnery; and re rould not wish to lose many of our most superb tress because they could not be introduced in particular portions of landseape. Contrasts in trees may be so violent as to be displeasing; as in the example of the groups of the three trees, the willow; poplan, and oak or they may be such as to produce spirited and pleasing efleets. This must be ellected by planting the different dirisions of trees, tirst, in small leading groups, and then by oflecting a union between the groups of diflerent character, by intermingling these of the nearest similarity into and near the groups: in this way by eas transitions from the drooping to the round-headed, and from these to the tapering trees, the whole of the folinge and forms tarmonize well.

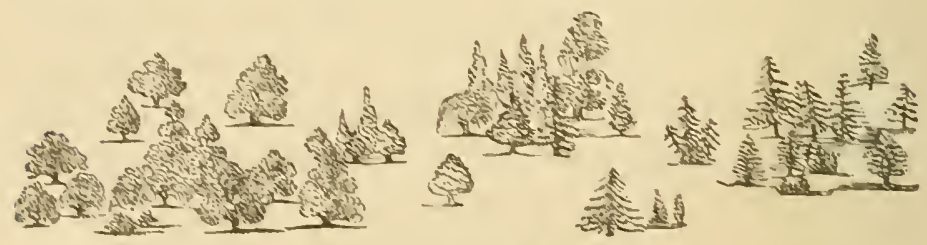

[Fig. o.9. Example in groupins.]

"Trees." observes Mrr. Whately, in his elegant treatise on this subject. "which diffor in but one of these circumstances, of shape, green, or growth, though they acree in every other. are sutficiently distinguished for the

says, in speaking of the dark Seotch fir, "with rearal to color in general, I think I speak the languago of painting, when I asert that the picturesque eyp makes little distinction in this matter. It has no attuchment to one color in prefience to ancther. but comsiders the beanty of all coloring ns nesulting, not from the colors themselves, but almost entingly from their harmony with other colors in their neightorthow. So, that as the scotch fir tree is combined or stationed, it forms a beantifil umbrage or a murkỵ spot." 
purpose of variely; if they differ in two or three, they become contrasts : if in all, they are opposite, and seldom group well together. Those, on the contrary, which are of one character, and are distinguished only as the characteristic mark is strongly or faintly impressed upon them, form a beautiful mass, and unity is preserved without sameness." **

There is another circumstance connected with the color of trees, that will doubtless suggest itself to the improver of taste, the knowledge of which may sometimes be turned to valuable account. We mean the effects produced in the apparent coloring of a landscape by distance, which painters term aërial perspective. Standing at a certain position in a scene, the coloring is deep, rich, and full in the foreground, more tender and mellow in the middle-ground, and softening to a pale tint in the distance.

"Where to the eye three well marked distances Spread their peculiar coloring, vivid green, Warm brown, and black opake, the foreground bears

Conspicuous: sober olive coldly marks

The second distance; thence the third declines In softer blue, or lessening still, is lost In fainted purple. When thy taste is call'd To deck a scene where nature's self presents All these distinct gradations, then rejoice As does the Painter, and like him apply Thy colors; plant thou, on each separate part Its proper foliage."

Advantage may occasionally be taken of this peculiarity in the gradation of color, in Landscape Gardening, by the creation as it were, of an artificial distance. In grounds

* Observations on Modern Gardening. 
and scenes of limited extent, the apparent size and brearth may be increased, by planting a majority of the trees in the foreground, of dark tints, and the boundary with foliage of a much lighter hue.

An acquaintance, individually, with the different species of trees of indigenous and foreign growth, which may be cultirated with success in this climate, is absolutely essential to the amateur or the professor of Landscape Gardening. The tardiness or rapidity of their growth, the periods at which their leaves and flowers cxpand, the soils they love best, and their various habits and characters, are all subjects of the highest interest to him. In short, as a love of the country almost commences with a knowledge of its peculiar characteristics, the pure air, the fresh enamelled turf, and the Juxuriance and beauty of the whole landscape; so, the taste for the embellishment of Rural Residences, must grow out of an admiration for beautiful trees, and the delightful effects they are capable of producing in the hands of persons of taste and lovers of nature.

Admitting this, we think, in the comparatively meagre state of general information on this subject among us, we shall render an acceptable service to the novice, by giving a somewhat detailed description of the character and habits of most of the finest hardy, forest and ornamental trees. Among those living in the country, there are many who care little for the beauties of Landscape Gardening, who are yet interested in those trees which are remarkable for the beauty of their forms, their foliage, their blossoms, or their useful purposes. This, we hope, will be a sufficient explanation for the apparently disproportionate number of pages which we shall devote to this part of our subject. 


\section{SECTION IV.}

\section{DECIDUOUS ORNAMENTAL TREES.}

The History and Deseription of all the finest hardy Deciduous Trees. Remarks on THEIR EFFECTS IN LANDSCAPE GARDENING, INDIVIDUALLY AND IN COYPOSITION Their Cultivation, etc. The Oak. The Elm. The Ash. The Linden. The Beech. The Poplar. The llorse-chestnut. The Birch. The Aider. The Maple. The Locust. The Three-thorned Acacia. The Judas-tree. The Chestnut. " The Osage Orange. The Mulbery. The Paper Mulberry. The Sweet Gum. The Walnut. The Hickory. The Mountain Ash. The Ailantus. The Kentucky Coffee. The Willow. The Sassafras. The Catalpa. The Persimon. The Pepperidge. The Thorn. The Magnolia. The Tulip. The Dogwood. The Salisburia. The Paulonia. The Virgilia. The Cypress. The Larch, etc.

O gloriosi spiriti de gli boschi,

0 Eco, o antri foschi, o chiare linfe,

$O$ faretrate ninfe, o agresti Paui, o Satiri e Silvani, o Fauni e Driadi, Naiadi ed Amadriadi, o Semidee Oreadi e Napee.-

SANNAZZARo.

"O spirits of the woods,

Echoes and solitudes and lakes of light;

0 quivered virgins bright, Pan's rustical

Satyrs and sylrans all, dryads and ye

That up the mountains be; and ye beneath

In meadow or in flowery heath,"

Thu OAк. Quercus.

Nat. Ord. Corylaceæ.

Lin. Syst. Monceia, Polyandı ia.

H E Arcadians beliered the oak to have been the first created of all trees; and when we consider its great and surpassing utility and benuty, we are fully disposed to concede it the first rank among the denizens of the 
forest. Springing up with a noble trunk, and stretching out its broad limbs over the soil,

"These monarehs of the wood,

Dark, gnarled, centennial oaks,"

seem proudly to bid defiance to time; and while generations of man appear and disappear, they withstand the storms of a thousand winters, and seem only to grow more venerable and majestic. They are mentioned in the oldest histories; we are told that Absalom was caught by his hair in "the thick boughs of a great oak;" and Herodotus informs us that the first oracle was that of Dodona, set up in the celebrated oak grore of that name. There, at first, the oracles were delivered by the priestesses, but, as was afterwards believed, by the inspired oaks themselres-

"Which in Dodona did enshrine,

So faith too fondly deemed, a roice divine."

Acorns, the fruit of the oak, appear to have been held in considerable estimation as an article of food among the ancients. Not only were the swine fattened upon them, as in our own forests, but they were ground into flour, with which bread was made by the poorer classes. Lucretius mentions, that before grain was known they were the common food of man; but we suppose the fruit of the chestnut may also have been included under that term.

"That oake whose acornes were our foode before

The Cerese seede of mortal man was knowne."

SPENSER.

The civic crown, given in the palmy days of Rome to the most celebrated men, was also composed of oak leaves. 
It should not be forgotten that the oak was worshipped by the ancient Britons. Baal or Yiaoul (whence Yule) was the grod of fire, whose symbol was an oak. Hence, at his festival, which was at Christmas, the ceremony of kindling the Yule log was performed among the ancient Druids. This fire was kept perpetual throughout the year, and the hearths of all the people were annually lighted from these sacred fires every Christmas. We believe the curious custom is still extant in some remote parts of England, where the "Yule log" is ushered in with much glee and rejoicing once a year.

As an ornamental object we consider the oak the most varied in expression, the most beautiful, grand, majestic, and picturesque of all deciduous trees. The enormous size and extreme old age to which it attains in a favorable situation, the great space of ground that it covers with its branches, and the strength and hardihood of the tree, all contribute to stamp it with the character of dignity and grandeur, beyond any other compeer of the forest. When young, its fine foliage (singularly varied in many of our native species) and its thrifty form render it a beautiful tree. But it is not until the oak has attained considerable size that it displays its true character, and only when at an age that would terminate the existence of most other trees that it exhibits all its magnificence. Then its deeply furrowed trunk is covered with mosses; its huge branches, each a tree, spreading out horizontally from the body with great boldness, its bole of huge dimension, and its "high top, bald with dry antiquity ;" all these, its true characteristics, stamp the oak, as Virgil has expressed it in his Georgics- 
"Jove's own tree,

That holds the woods in awful sovereignty ;

For length of ages last 3 his happy reign, And lives of mortal man contend in vain. Full in the midst of his own strength he stands, Stretching his brawny arms and leafy hands, His shade protects the plains, his head the hills commands."

Dryden's Trans.

"The oak," says Gilpin, "is confessedly the most pictu. resque tree in itself, and the most accommodating in com. position. It refuses no subject, either in natural or in artificial landscape. It is suited to the grandest, and may with propriety be introduced into the most pastoral. It adds new dignity to the ruined tower and the Gothic arch; and by stretching its wild, moss-grown branches athwart their ivied walls, it gives them a lind of majesty coeval with itself; at the same time its propriety is still preserved if it throws its arms over the purling brook or the mantling pool, where it beholds

"Its reverend image in the expanse below."

Milton introduces it happily even in the lowest scene-

"Hard by, a cottage chimney smokes,

From between two aged oalss."

The oak is not only one of the grandest and most picturesque objects as a single tree upon a lawn, but it is equally unriralled for groups and masses. There is a breadth about the lights and shadows reflected and embosomed in its foliage, a singular freedom and boldness in its outline, and a pleasing richess and intricacy in its luge ramification of branch and limb, that render it highly adapted to these purposes. Some trees, as the willow or the spiry poplar, 
though pleasing singly, are monotonous to the last degree, when planted in quantities. Not so, howerer, with the oak, as there is no tree, when forming a wood entirely by itself, which affords so great a variety of form and dispo. sition, light and shade, symmetry and irregularity, as this king of the forests.

To arrive at its highest perfection, ample space on every side must be allowed the oak. A free exposure to the sun and air, and a deep mellow soil, are highly necessary to its fullest amplitude. For this reason, the oaks of our forests,

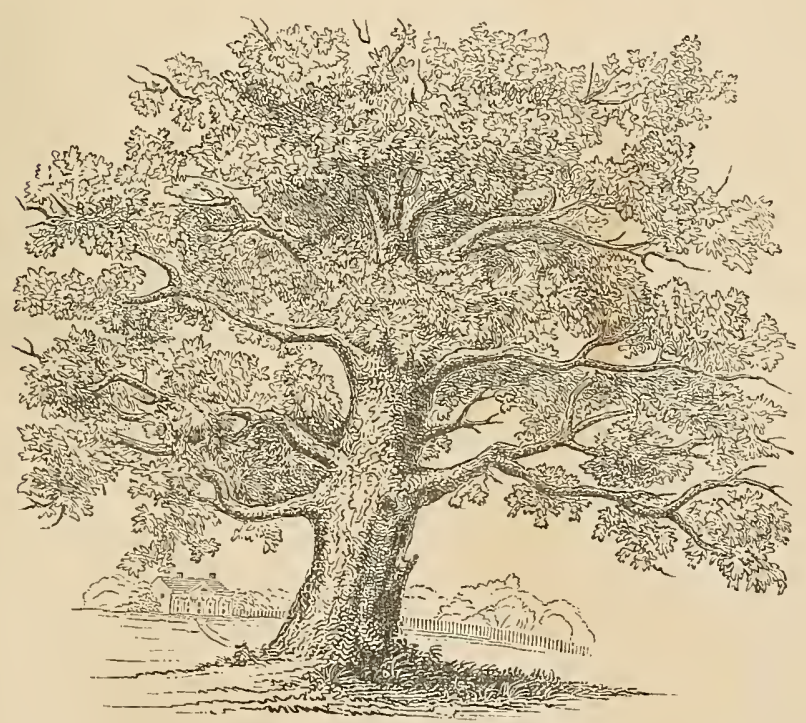

[Fig. 30. The Charter Oak, Hartford.]

being thickly crowded, are seldon of extraordinary size; and there are more truly majestic oaks in the parks of England than are to be found in the whole cultivated portion of the United States. Here and there, however, throughout our country, may be seen a solitary oak of great 
age and immense size, which attests the fitness of the soil and climate. and displays the grandeur of our native species The Wadsworth Oak near Geneseo, N. Y., of extraordinary dimensions, the product of one of our most fertile valleys. has attracted the admiration of hundreds of travellers on the route to Niagina. Its trunk measures thirty-six fect in circumference. The celebrated Charter Oak at Hartford, which has figured so conspicuously in the history of New England, is still existing in a green old age, one of the most interesting monuments of the past to be found in the country.

Near the village of Flushing, Long Island, on the farm of Judge Lawrence, is growing one of the noblest oaks in the comtry. It is truip park-like in its dimensions, the circumference of the trunk being nearly thirty feet, and its majestic head of corresponding dignity. In the deep allurial soil of the western ralleys, the oak often assumes a grand aspect, and bears witness to the wonderful fertility of the soil in that region.

Different species of Oak. This country is peculiarly rich in various kinds of oak; Michaux enumerating no less than forty species indigenous to North America. Of these the most useful are the Live oak (Quercus virens). of such inestimable value for ship-building: the Spanish oak $(Q$. falcata): the Red oak (Q. mbra), etc., the bark of which is extensively used in taming; the Quercitron or Black oak, which is lighly valuable as affording a fine yellow or brown dye for rool, silks, paper-hangings, etc.; and the White oak, which is chiefly used for timber. We shall 
here describe only a few of those which are most entitled to the consideration of the planter, either for their valuable properties or as ornamental trees, and calculated for planting in woods or single masses.

The White oak. (Quercus alba.) This is one of the most common of the American oaks, being very generally distributed over the country, from Canada to the southern states. In good strong soils it forms a tree 70 or 80 feet high, with wide extending branches; but its growth depends much upon this circumstance. It may readily be known, even in winter, by its whitish bark and by the dry and withered leaves which often hang upon this species through the whole of that season. The leaves are about four inches wide and six in length, divided uniformly into rounded lobes without points; these lobes are deeper in damp soils. When the leaves first unfold in the spring they are downy beneath, but when fully grown they are quite smooth, and pale green on the upper surface and whitish or glaucous below. The acorn is oval and the cup somewhat flattened at the base. This is the most valuable of all our native oaks, immense quantities of the timber being used for various purposes in building; and staves of the white oak for barrels are in universal use throughout the Union. The great occasional size and fine form of this tree, in some natural situations, prove how noble an object it would become when allowed to expand in full vigor and majesty in the open air and light of the park. It more nearly approaches the English oak in appearance than any other American species.

Rock Chestnut oak. (Q. Prinus Monticola.) This is one of the most ornamental of our oaks, and is found in considerable abundance in the middle states. It has the 
peculiar advantage of growing well on the most barren and rocky soils, and can therefore be advantageously employed by the landscape gardener, when a steep, dry, rocky bank is to be covered with trees. In deep, mellow soil, its growth is wonderfully vigorous, and it rapidly attains a height of 50 or 60 , feet, with a corresponding diameter. The head is rather more symmetrical in form and outline than! most trees of this genus, and the stem, in free, open places, shoots up into a lofty trunk. The leares are five or six inches long, three or four broad, oval and uniformly denticulated, with the teeth more regular but less acute than the Chestnut white oak. When beginning to open in the spring they are covered with a thick down; but when fully expanded they are perfectly smooth and of a delicate texture. Michaux.

Chestnut White oak. (Quercus Prinus palustris.) This species much resembles the last, but diflers in having longer leaves, which are obovate, and decply toothed. It is sparingly found in the northern states, and attains its greatest altitude in the south, where it is often seen 90 feet in height. Though generally found in the neighborhood of swamps and low grounds, it grows with wonderful rapidity in a good, moderately dry soil, and from the beauty of its fine spreading head, and the quickness of its growth, is highly deserving of introduction into our plantations.

The Lellow oak. (Q. Prinus acuminata.) The Yellow oak may be found scattered through our woods over nearly the whole of the Union. Its leaves are lanceolate, and regularly toothed, light green above, and whitish beneath; the acorns small. It forms a stately tree, 70 feet high; and the branches are more upright in 
their growth, and more clustering, as it were, round the central trunk, than other species. The beauty of its long pointed leaves, and their peculiar mode of growth, recommend it to mingle with other trees, to which it will add variety.

The Pin oak. (Q. palustris.) The Pin oak forms a tree, in moist situations, varying in height from 60 to 80 feet. The great number of small branches intermingleu with the large ones, have given rise to the name of this variety. It is a hardy, free growing species, particularly upon moist soils. Loudon considers it, from its "far" extending, drooping branches, and light and elegant foliage," among the most graceful of oaks. It is well adapted to small groups, and is one of the most thrifty growing and easily obtained of all our northern, oaks.

The Willow oak. (Q. Phellos.) This remarkable species of oak may be recognised at once by its narrow, entire leaves, shaped almost like those of the willow, and about the same size, though thicker in texture. It is not found wild north of the barrens of New Jersey, where it grows plentifully, but thrives well in cultivation much further north. The stem of this tree is remarkably smooth in every stage of its growth. It is so different in appearance and character from the other species of this genus, that in plantations it would never be recognised by a person not conversant with oaks, as one of the family. It deserves to be introduced into landscapes for its singularity as an oak, and its lightness and elegance of foliage individually.

The Mossy-cup oak. (Q. oliveformis) This is Sc. ealled because the scales of the cups terminate in a long, moss-like fringe, nearly covering the acorn. It is auite a 
rare species, being only found on the upper banks of the Hudson, and on the Grenesee river. The foliage is fine, large, and deeply cut, and the lower branches of the tree droop in a beautiful manner when it has attained some considerable size. Quercus macrocarpa, the Orer-cup Thite oak, is another beautiful kind found in the restern states, which a good deal resembles the Mossy-cup oak in the acorn. The foliage, howerer, is uncommonly fine, being the largest in size of any American species; fifteen inches long. and eight broad. It is a noble tree, with fine deep green foliage; and the growth of a specimen planted in our grounds has been remarkably rigorous.

Scarlet oak. (Quercus coccinea.) A native of the middle states; a noble tree, often eighty feet high. The leares. borne on long petioles, are a bright lively green on both surfaces. with four deep cuts on each side, widest at the bottom. The great and peculiar beauty of this tree, we conceire to be its property of assuming a deep scarlet tint in autum. At that period it may, at a great distance, be distinguished from all other oaks, and indeed from every other forest tree. It is highly worthy of a place in erery plantation.

The Lire oak. (Quercus rirens.) This fine species will not thrive north of Tirginia. Its imperishable timber is the most raluable in our forests; and, at the south, it is a fine park tree, when cultirated, growing about 40 feet high, with, howerer, a rather wide and low head. The thick, oral leares are erergreen, and it is much to be regretted that this noble tree will not bear our northern winters.

The English Royal oak. (Q.robur.) This is the great representatire of the family in Europe, and is one of the 
most magnificent of the genus, growing, ofter, in the fine old woods and park's of England, to eighty and one hundred feet in height. The branches spread over a great surface. "The leaves are petiolated, smooth, and of a uniform color on both sides, enlarged towards the summit, and very coarsely toothed." As a single tree for park scenery, this equals any American species in majesty of form, though it is deficient in individual beauty of foliage to some of our oaks. It is to be found for sale in our nurseries, and we hope will become well known among us. The timber is closer grained and more durable, though less elastic than the best American oak; and Michaux, in his Sylva, recommends its introduction into this country largely, on these accounts.

The Turkey oak. (Q. Cerris.) There are two beautiful hybrid varieties of this species, which have been raised in England by Messrs. Lucombe and Fulham, which we hope will yet be found in our ornamental plantations. They are partially evergreen in winter, remarkably luxuriant in their growth, attaining a height of seventy or eighty feet, and elegant in foliage and outline. The Lucombe and Fulham oaks grow from one to five feet in a season; the trees assume a beautiful pyramidal shape, and as they retain their fine glossy leaves till May, they would form a fine contrast to other deciduous trees.

We might here enumerate a great number of other fine foreign oaks; among which the most interesting are the Holly or Holm oak (Quercus Ilex); and the Cork oak (Q. Suber), of the south of France, which produces the cork of commerce (both rather too tender for the north); the Kermes oak (Q. coccifera), from which a scarlet dye 
is obtained; and the Italian Esculent oak (Q. Esculus), with sweet, nutritious acorns. Those, howerer, who wish to inrestigate them, will pursue this subject further in European rorks; while that splendid treatise on our forest trees, the North American Sylva of Michaux, will be found to give full and accurate descriptions of all our numerous indigenous varieties, of which many are peculiar to the southern states.

The oak flourishes best on a strong loamy soil, rather moist than dry. Here at least, the growth is most rapid. although, for timber, the rood is generally not so sound on a moist soil as a diy one, and the tree goes to decay more rapidly. Among the American kinds, however. some may be found adapted to every soil and situation, though those species which grow on upland soils, in stony, clayey, or loamy bottoms, attain the greatest size and longevity. When immense trees are desired, the oals should either be transplanted rery young, or, which is preferable, raised from the acom somn where it is finally" to remain. This is necessary on account of the very large tap roots of this gemus of trees, which are either entirely destroyed or greatly injured by remoral. Transplanting this genus of trees should be performed either early in autumm, as soon as the leares fall or become brown, or in spring, before the abundant rains commence.

\section{The Elis. Ulmus}

INat. Ord. Ulmacer.

Lin. Syst. Pentandria, Digynia.

We have ascribed to the oak the character of pro- 
sminent dignity and majesty among the trees of the forest. Let us now claim for the elm the epithets graceful and elegant. This tree is one of the noblest in the size of its trunk, while the branches are comparatively tapering and slender, forming themselves; in most of the species, into long ana graceful curves. The flowers are of a choculate or purple color, and appear in the month of April, before the leaves. The latter are light and airy, of a pleasine light green in the spring, growing darker, however, as the season advances. The elm is one of the most common trees in both continents, and has been well known for its beauty and usefulness since a remote period. In the south of Europe, particularly in Lombardy, elm trees are planted in vineyards, and the vines are trained in festoons from tree to tree in the most picturesque manner. Tasso alludes to this in the following stanza:

\footnotetext{
" Come olmo, a cui la pampinosa pianta

Cupida s'avviticchi e si marite ;

Se ferro il tronea, o fulmine lo schianta

Trae seco a terra la compagna vite."
}

Gerusalemme Liberata, 2. 326.

It is one of the most common trees for public walks and avenues, along the highways in France and Germany, growing with great rapidity, and soon forming a widely extended shade. In Europe, the elm is much used for kesls in ship-building, and is remarkably durable in water; more extensive use is made of it there than of the American kinds in this country, though the wood of the Red American elm is more valuable than any other in the United States, for the blocks used in ship rigging.

For its graceful beanty the elm is entitled to high 
regard. Standing alone, as a single tree, or in a group of, at most, three or four in number, it derelopes itself in all its perfection. The White American elm we consider the most beautiful of the family, and to this we more particularly allude. In such situations as we have just mentioned, this tree derelopes its fine ample form in the most perfect manner. Its branches first spring up embracing the centre, then bend off in finely diverging lines, until in old trees they often sweep the ground with their loose pendent foliage. With all this lightness and peculiar gracefulness of form, it is by no means a meagre looking tree in the body of its foliage, as its thick tufted masses of leaves reflect the sun and embosom the shaciows as finely as almost any other tree, the oak excepted. We consider it peculiarly adapted for planting, in scenes where the expression of elegant or classical beauty is desired. In autumn the foliage assumes a lively yellow tint, contrasting well with the richer and more glowing colors of our native woods. Even in winter it is a pleasing object, from the minute division of its spray and the graceful droop of its branches. It is one of the most generally esteemed of our native trees for ornamental purposes, and is as great a farorite here as in Europe, for planting in public squares and along the highways. Beautiful specimens may be seen in Cambridge, Mass., and very fine avenues of this tree are growing with great luxuriance in and about New Haven.* The charming villages of New England, among which Northampton and Springfield are pre-eminent, borrow from the superb and wonderfully luxuriant elms which decorate their fine

* The great elm of Boston Common is 22 feet in circumference 
streets and avenues, the greater portion of their peculiar loveliness. The elm should not be chosen where large groups and masses are required, as the similarity of its form in different individuals might then create a monotony; but, as we have before observed, it is peculiarly well calculated for small groups, or as a single object. The roughness of the bark, contrasting with the lightness of its foliage and the easy sweep of its branches, adds much also to its effect as a whole.

We shall briefly describe the principal species of the elm.

The American White elm. (Ulmus Americana.) This is the best known and most generally distributed of our native species, growing in greater or less profusion over the whole of the country included between Lower Canada and the Gulf of Mexico. It often reaches 80 feet in height in fine soils, with a diameter of 4 or 5 feet. The leaves are alternate, 3 or 4 inches long, unequal in size at the base, borne on petioles half an inch to an inch in length, oval, acuminate, and doubly denticulated. The seeds are contained in a flat, oval, winged seed-vessel, fringed with small hairs on the margin. The flowers, of a dull purple color, are borne in small bunches on short footstalks at the end of the branches, and appear very early in the spring. This tree prefers a deep,rich soil, and grows with greater luxuriance if it be rather moist, often reaching, in such situations, an altitude of nearly 100 feet. It is found in the greatest perfection in the alluvial soils of the fertile valleys of the Connecticut, the Mississippi, and the Ohio rivers.

The Red or Slippery elm. (U. fulva.) A tree of 
lower size than the White elm, attaining generally only 40 or 50 feet. According to Michaux, it may be distinguished from the latter; even in winter, by its buds, which are larger and rounder, and which are covered, a fortnight before their development, with a russet down. The leares are larger, rougher and thicker than those of the White clm; the seed-ressels larger, destitute of fringe; the stamens short, and of a pale rose color. 'This tree bears a strong likeness to the Duteh elm, and the bark abounds in mucilage, whence the name of Slippery elm. The branches are less drooping than those of the White elm.

The Wahoo elm ( $U$. alata) is not found north of - Virginia. It may at onee be known in every stage of its growth by the fungous, cork-like substance which lines the bramehes on both sides. It is a very singular and curious tree, of moderate stature, and grows rapidly and well when cultivated in the northern states.

The common European elm. (U. campestris.) This is the most commonly eultivated forest tree in Europe, next to the oak. It is a more upright growing tree than the White elm, though resembling it in the easy disposition and delicacy of its branches. The flowers, of a purple color, are produced in round bunches close to the stem. The leaves are rough, doubly serrated, and much more finely cut than those of our elms. It is a fine tree, 60 or 70 feet high, growing with rapidity, and is easily entivated. The timber is more valuable than the American sort, though the tree is inferior to the White elm in beauty. There are some dozen or more fine rarieties of this species cultivated in the English nurseries, among which the most remarkable are 
the Twisted $\operatorname{clm}$ (U.c.tortuosa), the trunk of which is singularly marked with hollows and protuberances, and the grain of the wood curiously twisted together: the Kidbrook elm (U.c. virens), which is a sub-evergreen: the Gold and Silver striped elms, with variegated leaves, and the Narrow-leaved elm (U. c. viminalis), which resembles the birch: the Cork-barked elm (U.c. suberosa), the young branches of which are covered with cork, etc.

The latter is one of the hardiest and most vigorous of all ornamental trees in this climate. It thrives in almost every soil, and its rich, dark foliage, which hangs late in autumn, and its somewhat picturesque form. should recommend it to every planter.

The Scotch or Wych elm. (U.montana.) This is it tree of lower stature than the common European elm, its average height being about 40 feet. The leaves are broad, rough, pointed, and the branches extend more horizontally, drooping at the extremities. The bark on the branches is comparatively smooth. It is a grand tree, "the head is so finely massed and yet so well broken, as to render it one of the noblest of park trees; and when it grows wild, amid the rocky scenery of its native Scotland, there is no tree which assumes so great or so pleasing a variety of character." In general appearance, the Scotch elm considerably resembles our White elm, and it is a very rapid grower. Its most ornamental varieties are the Spiry-topped elm (U. m. fastigiata), with singularly twisted leaves, and a very upright growth: the weeping Scotch elm ( $U$. m. pendula), a very remarkable variety, the branches of which droop in a 
fan-like manner: and the Smooth-leaved Scotch elm ( $U$ m. glabra).

There is scarcely any soil to which some of the different elms are not adapted. The European species prefer a deep, dry soil; the Scotch or Wych elm will thrive well even in rery rocky places; and the White elm grows readily in all soils, but most luxuriantly in moist places. All the species attain their maximum size when planted in a deep loam, rather moist than dry. They bear transplanting remarkably well, suffering but little eren from the mistaken practice of those persons who reduce them in transplanting to the condition of bare poles, as they shoot out a new crop of branches, and soon become beautiful young trees in spite of the mal-treatment. As the elm scarcely produces a tap root, eren large trees may be remored, when the operation is skilfully performed. In such cases, the recently-remored tree should be carefully and plentifully supplied with water until it is well established in its new situation. The elm is also easily propagated by seed, layers, or, in some species, by suckers from the root.

The Plane or Buttontrood Tree. Platanus.

Nat. Ord. Platanacex.

Lin. Syst. Monceia, Polyandria.

The plane, Platanus, derives its name from $\pi \lambda$ asus, broad, on account of the broad, umbrageous nature of its branches. It is a well known tree, of the rery largest 
size, common to both hemispheres, and greatly prized for the fine shacle afforded by its spreading head, in the warmer parts of Europe and Asia. No tree was in greater esteem with the ancients for this purpose; and we are told that the Academic groves, the neighborhood of the public schools, and all those favorite avenues where ihe Grecian philosophers were accustomed to resort, were planted with these trees; ' and beneath their shade Aristotle, Plato, and Socrates, delivered the choicest wisdom and eloquence of those classic days. The Eastern plane (Platanus orientalis) was first brought to the Roman provinces from Persia, and so highly was it esteemed that, according to Pliny, the Morini paid a tribute to Rome for the privilege of enjoying its shade. 'To that author we are also indebted for the history of the great plane tree that grew in the province of Lycia, which was of so huge a size, that the governor of the province, Licinius Mutianus, together with eighteen of his retinue, feasted in the hollow of its trunk.

In the United States, the plane is not generally found growing in great quantities in any one place, but is more or less scattered over the whole country. In deep, moist, alluvial soils, it attains a size scarcely, if at all, inferior to that of the huge trees of the eastern continent; forming at least, in the body of its trunk, a larger circumference than any other of our native trees. The younger Michaux (Sylva, 1, 325) measured a tree near Marietta, Ohio, which, at four feet from the ground, was found to be forty-seven feet in circumference; and a specimen has lately been cut on the banks of the Genesee river, of such enormous size, that a section of the trunk was hollowed nut and furnished as a small room, capable of containing 
fourteen persons.* On the margins of the great western rivers it sometimes rises up serenty feet, and then expands into a fine, lofty head, surpassing in grandeur all its neighbors of the forest. The large branches of the plane shoot out in a horizontal direction; the trumk generally ascending in a regular, stately, and unintermpted mamer: The blossoms are small, greenish balls, appearing in spring, and the fertile ones grow to an inch in diameter, assuming a deep brownish color, and hang upon the tree during the whole winter. A striking and peculiar characteristic of the plane, is its property of throwing off or shedding continually, the outer conting of bark here and there, in patches. Professor Lindley (Introduction to the Natural System, 2d ed. 187) says this is owing to its deficiency in the expansive power of the fibre common to the bark of other trees, or, in other words, to the rigidity of its tissue: being therefore incapable of stretching with the growth of the tree, it bursts open on different parts of the trunk, and is cast off. This gives the trunk quite a lively and picturesque look, extending more or less eren to the extremity of the branches; and makes this tree quite conspicuous in winter. Bryant, in his address to Green River, says :

"Clear are the depths where its eddies play,

And dimples deepen and whirl awar,

And the plane tree's spccklcd arms o ershoot

The swifter current that mines its root."

The great merit of the plane, or buttonwood, is its

* A buttonwood on the Montezuma estate, Jefferson, Caynga Co., N. Y. is forty-seven and a half feet in eireumference; and the diameter of the hollow two feet from the ground, is fifteen feet. (T. I. Mcd. Reposilory, [1. 4.27.) 
extreme vigor and luxuriance of growth. In a good soil it will readily reach a height of thirty-five or forty feet in ten years. It is easily transplanted; and in new residences, bare of trees, where an effect is desired speedily, we know of nothing better adapted quickly to produce abundance of foliage, shelter and shade. When the requisite foliage is obtained, and other trees of slower growth have reached a proper size, the former may be thinned out. As the plane tree grows to the largest size, it is only proper for situations where there is considerable ground, and where it can, without inconvenience to its fellows, have ample room for its full development. Then, soaring up and extending its wide-spread branches on every side, it is certainly a very majestic tree. The color of the foliage is of a paler green than is usual in forest trees; and although of large size, is easily wafted to and fro by the wind, thereby producing an agreeable diversity of light, pleasing to the eye in summer. In winter the branches are beautifully hung, even to their furthest ends, with the numerous round russet-balls, or seed-vessels, each suspended by a slender cord, and swinging about in the air. The form of the head is pleasingly irregular, and its foliage against a sky outline is bold and picturesque. It is not a tree to be planted in thick groves by itself, but to stand alone and detached, or in a group with two or three. In avenues it is often happily employed, and produces a grand effect. It also grows with great vigor in close cities, as some superb specimens in the square of the State-house, Pennsylvania Hospital, and other places in Philadelphia, fully attest.

There is but a trifling difference in general effect between 
our plane or buttonwood and the Oriental plane. Fur the purposes of shade and shelter, the American is the finest, as its foliage is the longest and broadest. The Oriental plane (Platanus orientalis) has the leaves lobed like our native kind ( $P$. occidentalis), but the segments are much more deeply cut; the footstalks of its leaves are green, while those of the American are of a reddish hue, and the fruit or ball is much smaller and rougher on the outer surface, when fully grown. Both species are common in the nurseries, and are worthy the attention of the planter; the Oriental, as well for the interesting associations connected with it, being the favorite shade-tree of the east, etc., as for its intrinsic merits as a lofty and majestic tree.

Two of the varieties of $\mathrm{P}$. occidentalis are sometimes cultivated, the chief of which is the Maple-leaved plane (P.O. acerifolia).

\section{The Ash Tree. Fraxinus.}

Nat. Ord. Oleaceæ.

Lin. Syst. Polygamia, Diœcia.

The name of the ash, one of the finest and most useful of forest trees, is probably derived from the Celtic asc, a pike-as its wood was formerly in common use for spears and other weapons. Homer informs us that Achilles was slain with an ashen spear. In modern times the wood is in universal use for the various implements of husbandry, for the different purposes of the wheelwright and carriagemaker, and in short for all purposes where great strength and elasticity are required; for in these qualities the ash is 
second to no tree in the forest, the hickory alone excepted. The ash is a large and lofty tree, growing, when surrounded by other trees, sixty or seventy feet high, and three or more in diameter. When exposed on all sides it forms a beautiful, round, compact head of loose, pinnated, light green foliage, and is one of the most vigorous growers among the hard-wooded trees. The American species of ash are found in the greatest luxuriance and beauty on the banks and margins of rivers, where the soil is partially dry, yet where the roots can easily penetrate down to the moisture. The European ash is remarkable for its hardy nature, being often found in great vigor on steep rocky hills and amid crevices, where most other trees flourish badly. Southey alludes to this in the following lines :-

\section{"Grey as the stone to which it clung, half root, Half trunk, the young ash rises from the rock."}

As the ash grows strongly, and the roots, which extend to a great distance, ramify near the surface, it exhausts the soil underneath and around it to an astonishing degree. For this reason the grass is generally seen in a very meagre and starved condition in a lawn where the ash tree abounds. Here and there, a single tree of the ash will have an excellent effect, seen from the windows of the house; but we would chiefly employ it for the grand masses, and to intermingle with other large groups of trees in an extensive plantation. When the ash is young,it forms a well rounded head; but when older, the lower branches bend towards the ground, and then slightly turn up in a very graceful manner. We take pleasure in quoting what that great lover and accurate delineator of forest beauties, Mr. Gilpin, says of the ash. "The ash generally carries its principal 
stem higher than the oak, and rises in an easy flowing line. But its chief beauty consists in the lightness of its whole appearance. Its branches at first keep close to the trunk and form acute angles with it ; but as they begin to lengthen they generally take an easy sweep, and the looseness of the leaves corresponding with the lightness of the spray, the whole forms an elegant depending foliage. Nothing can have a better effect than an old ash hanging from the corner of a rood, and bringing off the heaviness of the other foliage with its loose pendent branches."-(Forest Scenery. p. 8.)

The highest and most charncteristic beauty of the American White ash (and we consider it the finest of all the species) is the coloring which its leaves put on in autumn. Gilpin complains that the leaf of the European ash "decays in a dark, muddy, unpleasing tint." Not so the White ash. In an American wood, such as often lines and overhangs the banks of the Hudson, the Connecticut, and many of our noble northern streams, the ash assumes peculiar beauty in autumn, when it can often be distinguished from the surrounding trees for four or five miles, by the peculiar and beautiful deep brownish purple of its fine mass of foliage. This color, though not lively, is so full and rich as to produce the most pleasing harmony with the bright yellows and reds of the other deciduous trees, and the deep green of the pines and cedars.

The ash, unlike the elm, starts into vegetation late in the spring, which is an objection to planting it in the immediate vicinity of the house. In winter the long greyish white or ash-colored branches are pleasing in tint, compared with those of other deciduous trees. 
The White ash. (Fraxinus Americana) This species, according to Michaux, is common to the colder parts of the Union, and is most abundant north of the Hudson. It owes its name to the light color of the bark, which on large stocks is deeply furrowed, and divided into squares of one to three inches in diameter. The trunk is perfectly straight, and in close woods is often undivided to the height of more than 40 feet. The leaves are composed of three or four pairs of leaflets, terminated by an odd one; the whole twelve or fourteen inches long. Early in spring they are covered with a light down which disappears as summer advances, when they become quite smooth, of a light green color above and whitish beneath. The foliage, as well as the timber of our White ash, is finer than that of the common European ash, and the tree is much prized in France and Germany.

The Black ash ( $F$. sambucifolia), sometimes called the Water ash, requires a moist soil to thrive well, and is seen in the greatest perfection on the borders of swamps. Its buds are of a deep blue; the young shoots of a bright green, sprinkled with dots of the same color, which disappear as the season advances. It may readily be distinguished from the White ash by its bark, which is of a duller hue and less deeply furrowed. The Black ash is altogether a tree of less stature than the preceding.

The other native sorts are the Red ash ( $F$. tomentosa), with the bark of a deep brown tint, found in Pennsylvania: the Green ash (F. viridis), which also grows in Pennsylvania, and is remarkable for the brilliant green of both sides of the leaves: the Blue ash (F. Quadrangulata), a beautiful tree of Kentucky, $\mathbf{7 0}$ feet high, distinguished by the four opposite membranes of a greenish color, found on the young 
shoots: and the Carolina ash ( $F$. platycarpa), a small tree, the leaves of which are corered with a thick down in spring.

The common European ash (F. excelsior) strongly resembles the White ash. It may, however, easily be known by its very black buds, and longer, more serrated leaflets, which are sessile, instead of being furnished with petioles like the White ash. This fine tree, as well as the White ash, grows to 80 or 90 feet in height, with a rery handsome head.

The Teeping ash, Fig. 31, is a rery remarkable variety

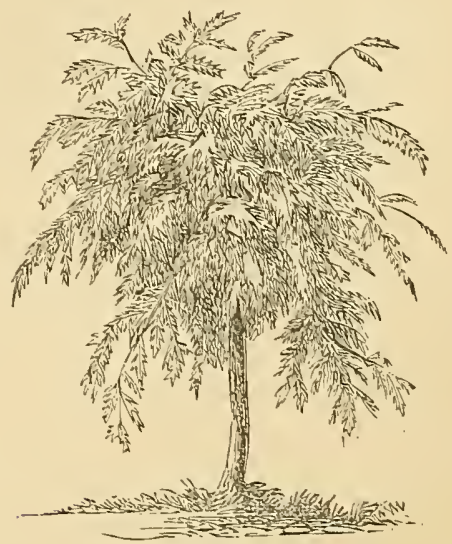

[Fig. 31. The Weeping Ash.]

of the European ash, with pendulous or weeping branches: and is worthy a place in every lawn for its curions ramification, as well as for its general beauty. It is generally propagated by grafting on any common stock, as the White ash, 7 or $S$ feet high, when the branches immediately begin to turn down in a very striking and peculiar manner. The droop of the branches is hardly a graceful one, yet it is so 



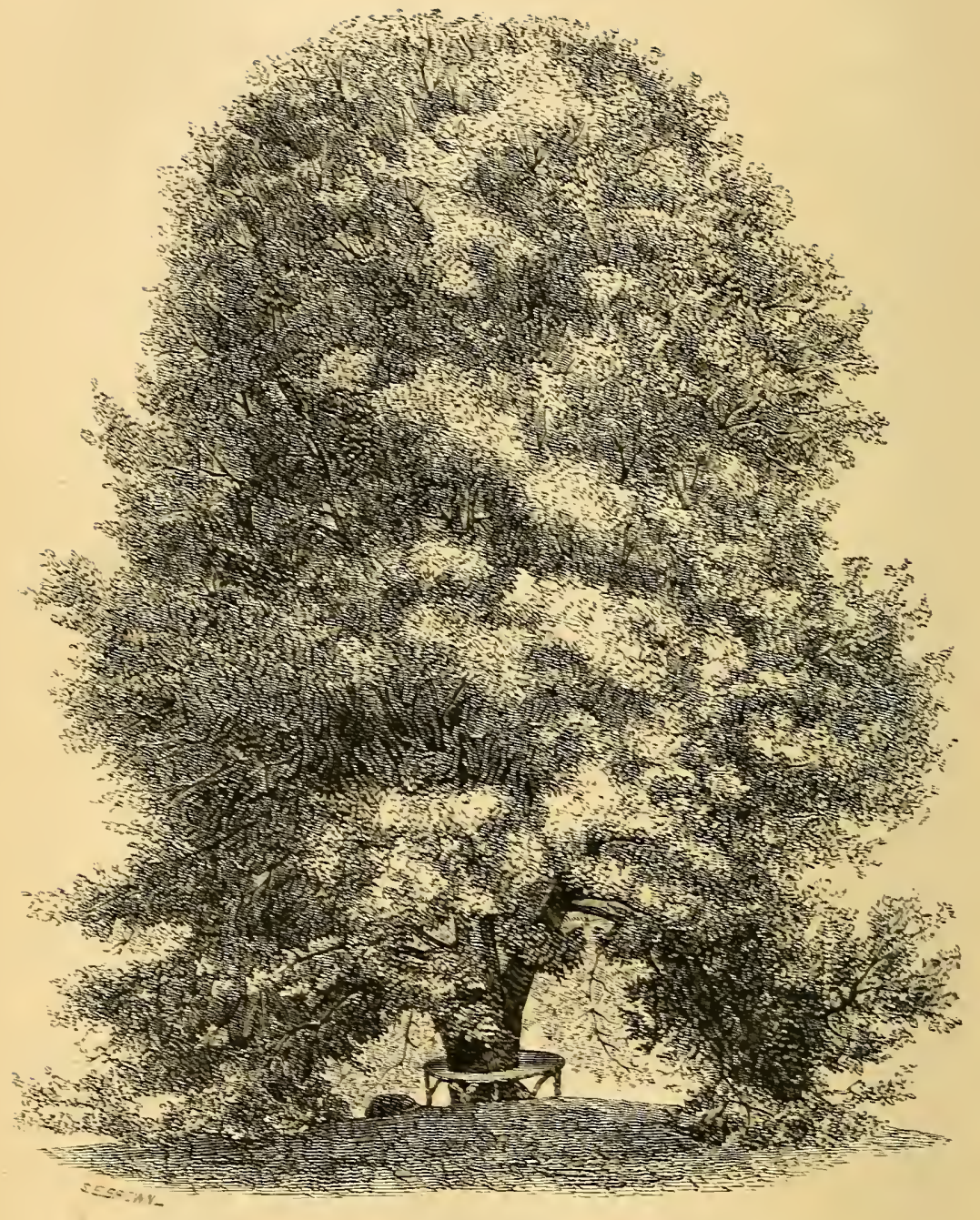

Fro. S2.-The Ergopsas Lrspex, at Presquille, the Residence of Mrs. Denning. - 
unique, either when leafless, or in full foliage, that it has long been one of our greatest favorites.

The Flowering ash (Fraxinus Ornus*) is a small tree of about 20 feet, growing plentifully in the south of Europe, and is also found sparingly in this country. Its chief beauty lies in the beautiful clusters of pale or greenish-white flowers, borne on the terminal branches in May and June. The foliage and general appearance of the tree are much like those of the common ash; but when in blossom it resembles a good deal the Carolina Fringe tree. In Italy a gummy substance called manna exudes from the bark, which is used in medicine.

\section{The Line or Linden Tree. Tilia}

Nat. Ord. Tilaceæ.

Lin. Syst. Polyandria, Morrogynia.

This tree, or rather the American sort, is well known among us by the name of basswood. It is a rapidly growing, handsome, upright, and regularly shaped tree ; and all the species are much esteemed, both in Europe and this country, for planting in avenues and straight lines, wherever the taste is in favor of geometric plantations. In Germany and Holland it is a great favorite for bordering their wide and handsome streets, and lining their long and straight canals. "In Berlin," Granville says in his travels, "there is a celebrated street called 'unter der Linden,' (under the lime trees,) a gay and splendid avenue, planted with double

* Ornus Europæus of Persoon, and the European botanists. Beck remarks that the American kind is so little known, that it is difficult to determino whether it is a different species or only a mere variety of the European. 
rows of this tree, which presented to my view a scene far more beantiful than I had hitherto witnessed in any town, either in France, Flanders, or Germany." In this country the European lime is also much planted in our cities; and some arenues of it may be seen in Philadelphia, particu. larly before the State-house in Chestnut-street. The bassrood is a very abundant tree in some parts of the middle states, and is seen growing in great profusion, forming thick woods by itself in the interior of this state. With us the wood is considered too solt to be of much value, but in England it was formerly in high repute as an excellent material for the use of carvers. Some very beantiful specimens of old carring in lime rood may be seen in Windsor Castle and Trinity College.* The Russian bass mats, which find their way to every commercial country, are prepared from the inner bark of this tree. The sap affords a sugar like the maple, although in less quantities; and it is stated in the Encyclopredia of Plants (p. 467) "that the honey made from the flowers of the lime tree is reckoned the finest in the world. Near Knowno, in Lithuania, there are large forests chiefly of this tree, and probably a distinct rariety. The honey produced in these forests sells at more than double the price of any other, and is used extensively in medicine and for liqueurs."

* The art of earring in wood, brought to such perfection by Gibbons, is now, we believe, much given up; therefore the line has lost a most important branch of its usefulness. Perhaps the finest specimens of the works of Cribbons are to be seen at Chatsworth, the seat of the Duke of Devonshire, in Derbyshire. The execution of the flowers, fish, gane, nets, ete., on the panelling of the walls is quite wonderful. It was of him that Walpole justly said, "that he was the first artist who garo to rood the loose and airy lightness of flowers, and chained twgether the various productious of the elements, with a free disorder natural to eacl'species.' The lime tree is still, however, used by the carver, and we hopo that the art of wood carring may gradually be restored."-Sir T. D. Lauder. 
The leaves of the lime are large and handsome, heartshaped in form, and pleasing in color. The flowers, which open in June, hang in loose, pale yellow cymes or clusters, are quite ornamental and very fragrant.

\section{- Sometimes}

A scent of violets and blossoming limes

Loitered around us; then of honey cells, Made delicate from all white flower bells.

KEATS.

It was a favorite tree in the ancient style of gardening, as it bore the shears well, and was readily clipt into all manner of curious and fantastic shapes. When planted singly on a lawn, and allowed to develope itself fully on every side, the linden is one of the most beautiful of trees. Its head then forms a fine pyramid of verdure, while its lower branches sweep the ground and curve upwards in the most pleasing form. For this reason, though the linden is not a picturesque tree, it is very happily adapted for the graceful landscape, as its whole contour is full, flowing, and agreeable. The pleasant odor of its flowers is an additional recommendation, as well as its free growth and handsome leaves. Were it not that of late it is so liable to insects, we could hardly say too much in its praise as a fine ornament for streets and public parks. There, its regular form corresponds well with the formality of the architecture; its shade affords cool and pleasant walks, and the delightful odor of its blossoms is doubly grateful in the confined air of the city. Our basswood has rather less of uniformity in its outline than the European lindens, but the general form is the same.

The American lime, or basswood (Tilia Americana), is the most robust tree of the genus, and produces much 
more rigorous shoots than the European species. In prefers a deep and fertile soil, where the trunk grows remarkibly straight, and the branches form a handsome, well-rounded summit. The flowers are borne on long stalks, and are pendulous from the branches. The leaves are large, heart-shaped, finely cut on the margin, and terminated by a point at the extremity. The seeds, which ripen in autumn, are like small peas, round and grevish.

The white lime ( $T$. albci) is rare in the eastern states, but common in Pennsylyania and the states south of it. It is not a tree of the largest size, but its flowers are the finest of our native sorts. The leares are also rery large, deep green on the lipper surface, and white belor; they are more obliquely heart-shaped than those of the common basswood. The young branches are corered with a smooth, silvery bark. This species is rery common on the Susquehanuah rirer.

The lowny lime tree. (T. pubescens.) The under side of the leares, and the fruits of this species, are, as its name denotes, covered with a short down. Its flowers are nearly white; the serratures of the leaves wider apart, and the base of the leaf obliquely truncated. It is a handsome, large tree, a native of Florida, though hardy enough, as experience proves, to bear our northern minters.

The European lime ( $T$. Europea) is distinguished from the American sorts, by its smaller and more regularly cordate and rounded leares. Enlike our native species, the flowers are not furnished with inner scale-like petals. The foliage is rather deeper in hue than the native sorts, and the branches of the head rather 
more regular in form and disposition. There are two pretty varieties of the English lime which are well known in this country, viz. the Red-barked, or corallina (var. rubra), with red branches; and the Golden-barked (var. (aurea), with handsome yellow branches. These trees are peculiarly beautiful in winter, when a few of them, mingled with other deciduous trees, make a pleasing variety of coloring in the absence of foliage. The broadleaved European lime is the finest for shade and ornament. The whitish foliage of Tilia alba, which probably is also a variety, has a beautiful appearance, somewhat like the Abele tree, in a gentle breeze.

These trees grow well on any good friable soil, and readily endure transplantation. They bear trimming remarkably well; and when but little root is obtained the head may be shortened in proportion, and the tree will soon make vigorous shoots again. All the species are easily increased by layers.

\section{The Beech Tree. Fagus.}

Nat. Ord. Corylaceæ. Lin. Syst. Monæcia, Polyandria.

The Beech is a large, compact, and lofty tree, with a greyish bark and finely divided spray, and is a common inhabitant of the forest in all temperate climates. In the United States, this tree is generally found congregated in very great quantities, wherever the soil is most favorable; hundreds of acres being sometimes covered with this single kind of timber. Such tracts are familiarly known 
as "beech woods." The leares of the beech are remarkably thin in texture, glazed and shining on the upper surface, and so thickly set upon the numerous branches, that it forms the darkest and densest shade of any of our deciduous forest trees. It appears to have been highly valued by the ancients as a shade tree; and Virgil says in its praise, in a well-known Eclogue:

"Tityre, tu patulæ recubans sub tegmine fagi,

Sylvestrem tenui nusam meditaris avena."

It bears a small compressed nut or mast, oily and sweet, which once was much valued as an article of food. The most useful purpose to which we have heard of their being applied, is the manufacture of an oil, scareely inferior to olive oil. This is produced from the mast of the beech forests, in the department of Oise, France, in immense quantities; more than a million of sacks of the nuts haring been collected in that department in a single season. They are reduced, when perfectly ripe, to a fine paste, and the oil is extracted by gradual pressure. The product of oil, compared with the crushed nuts, is about sixteen per cent. (Michaux, N. American Sylva.)

In Europe, the wood of the beech is much used in the manufacture of rarious utensils; but here, where our forests abound in woods rastly superior in strength. durability, and firmness, that of the beech is comparatirely little esteemed.

The beech is quite handsome and graceful when young. and when large it forms one of the heariest and grandest of beautiful park trees. From this massy quality, how. ever, it is excellently adapted to mingle with other trees when a thick and impenetrable mass of foliage is desired; 
and, on account of its density, it is also well suited to shut out unsightly buildings, or other objects.

The leaves of many beech trees hang on the tree, in a dry and withered state, during the whole winter. This is chiefly the case with young trees; but we consider it as greatly diminishing its beauty at that season, as the tree is otherwise very pleasing to the eye, with its smooth, round, grey stem, and small twisted spray. A deciduous tree, we think, should as certainly drop its leaves at the approach of cold weather, as an evergreen should retain them; more especially if its leaves have a dead and withered appearance, as is the case with those of the beech in this climate.

The White beech (Fagus Sylvatica) is the common beech tree of the middle and western states. It is found in the greatest perfection in a cool situation and a moist soil. The bark is smooth and grey, even upon the oldest stocks. The leaves oval, smooth, and shining, coarsely cut on the edges, and margined with a soft down in the spring.

The Red beech ( $F$. ferruginea), so called on account of the color of its wood, loves a still colder climate than the other, and is found in the greatest perfection in British America. The leaves are divided into coarser teeth on the margin than the foregoing species. The nuts are much smaller, and the whole tree forms a lower and more spreading head.

The European beech ( $F$. sylvatica) is thought by many botanists to be the same species as our white beech, or at most only a variety. Its average height in Europe is about fifty feet; the buds are shorter, and the leaves not so coarsely toothed as our native sorts. The Purple beech is a very ornamental variety of the European beech, common 
in the gardens. Both surfaces of the leares, and even tho young shoots, are deep purple; and although the growth is slow, yet it is in every stage of its progress, and more particularly when it reaches a good size, one of the strangest anomalies among trees, in the hue of its foliage. There is also a variety called the copper-colored beech, with paler purple leares; $;$ and a more rare English variety ( $F . s . p e n$. $d u l_{a}$ ), the Weeping beech, with graceful pendent branches.

The Hornbean (Carpinus Americana), and the Iromwoov (Ostrya Tirginica), are both well known, small trees, belonging to the same natural family as the beech. They are of little value in ormamental plantations; but from their thick foliage, they might perhaps be employed to advantage in making thick rerdant screens for shelter or concealment.

The Poplar Tree. Populus.

Nat. Ord. Salicacer.

Lin. Syst. Diœcia, Octandria.

Arbor Populi, or the people's tree, was the name giren in the ancient days of Rome to this tree, as being peculiarly appropriated to those public places most frequented by the people: some ingenious authors have still further justified the propriety of the name, by adding, that its trembling leares are like the populace, always in motion.

The poplars are light-wrooded, rapid-growing trees; many

* 'The finest Copper Beech in America is growing in the grounds of Thomas Ash, Esq., Throgs Neck, Westehester Co., N. Y. It is more than fifty fed high, with a broad and finely formed head. 
of them of huge size, and all with pointed, heart-shaped leaves. The tassel-like catkins, or male blossoms, of a red or brownish hue, appear early in the spring. Some of the Anserican kinds, as the Balsam and Balm of Gilead poplars, have their buds enveloped in a fragrant gum; others, as the Silver poplar, or Abele, are remarkable for the snowy whiteness of the under side of the foliage; and the Lom. bardy poplar, which

"Shoots up its spire, and shakes its leaves in the sun,"

Proctor.

for its remarkably conical or spire-like manner of growth. 'The leaves of all the species, being suspended upon long and slender footstalks, are easily put in motion by the wind. This, however, is peculiarly the case with the aspen, the leuves of which may often be seen trembling in the slightest breeze, when the foliage of the surrounding trees is motionless. There is a popular iegend in Scotland respecting this tree, which runs thus:

"Far off" in the Highland wilds 'tis said

(But truth now laughs at fancy's Jore),

'I'hat of this tree the cross was made,

Which erst the Lord of Glory bore;

And of that deed its leaves confess,

E'er sinee, a troubled consciousness."

In Landscape Gardening the poplar is not highly esteemed; but it is a valuable tree when judiciously employed, and produces a given quantity of foliage and shade sooner perhaps than any other. Some of the American kinds are majestic and superb trees when old, particularly the Cottonwood and Balsam poplars. One of the handsomest sorts is the Silver poplar. At some distance, the downy under surfaces of the leaves, trined up by the wind, give it very 
much the aspect of a tree corered with white blossoms. This effect is the more striking, when it is sitnated in front of a group or mass of the darker foliage of other trees. It is raluable for retaining its leares in full beanty to the latest possible period in the autumn. Its growth is very rapid, forming a tine, rounded head of thirty feet in height, in six or eight years.

The Lombardy poplar is a beautiful tree, and in certain situations produces a rery elegant effect; but it has been planted so indiscriminately, in some parts of this country, in close monotonous lines before the rery doors of our houses, and in many places in straight rows along the highways for miles together, to the neglect of our fine native trees, that it has been tiresome and disgusting. This tree may, howerer, be employed with singular adrantage in giving life, spirit and rarietr, to a scene composed entirely of round-headed trees, as the oak, ash, etc.,-when a tall poplar, emerging here and there, from the back or centre of the group, often imparts an air of elegance and animation to the whole. It may, also, from its marked and striking contrast to other trees, be employed to fix or direct the attention to some particular point in the landscape. When large poplars of this kind are growing near a house of but moderate dimensions, they have a very bad effect by completely orerpowering the building, without imparting any of that grandeur of character conferred by an old oak, or other spreading tree. It should be introduced but sparingly in landscape composition, as, the moment it is made commo: 1 in any scene, it gires an air of sameness and formality, and all the spirited effect is lost which its sparing introduction among other trees produces. The Lombardy poplar 
is well adapted to confined situations, as its branches require less lateral room than those of almost any other large deciduous tree.

It is an objection to some of the poplars, that in any cultivated soil they produce an abundance of suckers. For this reason they should be planted only in grass ground, or in situations where the soil will not be disturbed, or where the suckers will not be injurious. Indeed, we conceive them to be chiefly worthy of introduction in grounds of large extent, to give variety to plantations of other and more valuable trees. They grow well in almost every soil, moist or dry, and some species prefer quite wet and springy places.

The chief American poplars are the Tachamahaca or Balsam poplar (Populus balsamifera), chiefly found in Northern America; a large tree, $\$ 0$ feet high, with fragrant gummy buds and lanceolate-oval leaves; the Balm of Gilead poplar ( $P$. candicans), resembling the foregoing in its buds, but with very large, broad, heart-shaped foliage. From these a gum is sometimes coilected, and used medicinally for the cure of scurvy. 'The American aspen ( $P$. tremuloides), about 30 feet high, a common tree with very tremulous leaves and greenish bark; the large American aspen ( $P$. grandidentata), 40 feet high, with large leaves bordered with coarse teeth or denticulations; the Cotton tree ( $\boldsymbol{P}$. argentea), 60 or 70 feet, with leaves downy in a young state; the American Black poplar, of smaller size, having the young shoots covered with short hair; the Cottonwood (P. Canadensis), found chiefly in the western part of this state, a fine tree, with smooth, unequally-toothed, wide cordate leaves; and the Carolina poplar ( $P$. angulata). 
an enormous tree of the swamps of the south and west, considerably resembling the Cotton tree, but without the resinous buds of that species.

Among the European kinds, the most ornanental, as we have already remarked, is the Silver aspen, White poplar, or Abele tree (P.alba). which groms to a great size on a deep loamy soil, in a rery short time. The leares are divided into lobes, and toothed on the margin, smooth and rery deep green abore, and densely corered with a soft, close, white down beneath. There are some rarieties of this species known abroad, with leares more or less downy, etc. Sir J. E. Smith remarlis in his English Flori, that the rood, though but little used, is much firmer than that of any other British poplar; making as handsome floors as the best Norway fir, with the additional adrantage that they will not readily take fire, iike any resinous wood.

The English aspen ( $P$. tremula) considerably resembles our mative aspen; hut the buds are somewhat gummy. The Athenian poplar (P. Graca) is a tree about 40 feet high, with smaller, more rounded, and equally serrated foliage. The common Black European poplar (P. nigra) is also a large, rapidly growing tree, with pale-green leaves slightly notched: the buds expand later than most other poplars. and the roung leaves are at first somewhat reddish in colcr. The Necklace-bearing poplar (P. monilifera), so called firm the circumstance of the catins being arranged somewhat like beads in a necklace, is supposed to have been derired from Camada, but there are some doubts respecting its crigin: in the south it is generally called the Tirginia poplar.

The Lombardy poplar ( $P$. dilatata), a matire of the banks of the Po, where it is sometimes called the Cypress poplar 
from its resembance to that tree, is too well known among us to need any description. Only one sex, the female, has hitherto been introduced into this country; and it has consequently produced no seeds here, but has been entirely propagated by suckers from the root.

The Horse-chestrut Tree. AEsculus.

Nat. Ord. Esculacex. Lin. Syst. Feptandria, Monogynia.

A large, showy, much admired, ornamental tree, bearing large leaves composed of seven leaflets, and, in the month of May, beautiful clusters of white flowers, delicately mottled with red and yellow. It is a native of Middle Asia, but flourishes well in the temperate climates of both hemispheres. It was introduced into England, probably from Turkey, about the year $\mathbf{1 5 7 5}$ : in that country the nuts are often ground into a coarse flour, which is mixed with other food, and given to horses that are broken-winded; and from this use the English name of the tree was derived.

A starch has been extracted in considerable quantity from the nuts. The wood is considered valueless in the United States.

The Horse-chestnut is by no means a picturesque tree, being too regularly rounded in its outlines, and too compact and close in its surface, to produce a spirited effect in light and shade. But it is nevertheless one of the most beautiful exotic trees which will bear the open air in this climate. The leaves, each made of clusters of six or seven leaflets. ure of a fine dark-green color; the whole head of foliage 
has much grandeur and richness in its depth of hue and massiness of outline; and the regular, rounded, pyramidal shape, is something so different from that of most of our indigenous trees, as to strike the spectator with an air of norelty and distinctness. The great beauty of the Horsechestnut is the splendor of its inflorescence, surpassing that of almost all our native forest trees: the huge clusters of gay blossoms, which erery spring are distributed with such luxuriance and profusion orer the surface of the foliage, and at the extremity of the branches, gire the whole tree the aspect rather of some monstrous flowering shrub, than of an ordinary tree of the largest size. At that season there can be no more beautiful object to stand singly upon the lawn, particularly if its branches are permitted to grow low down the trunk, and (as they naturally will as the tree adrances) sweep the green sward with their drooping foliage. Like the lime tree, howerer, care must be taken, in the modern style, to introduce it rather sparingly in picturesque plantations, and then only as a single tree, or upon the margin of large groups, masses, or plantations ; but it may be more freely used in grounds in the gracefiul style, for which it is highly suitable. When handsome arenues or straight lines are wanted, the Horse-chestnut is again admirably suited, from its symmetry and regularity. It is, therefore, much and justly ralued for these purposes in our towns and cities, where its deep shade and beauty of blos. som are peculiarly desirable, the only objection to it being the early fall of its leares. The Horse-chestnut is rery interesting in its mode of growth. The large buds are thickly corered in winter with a resinous gum, to protect them from the cold and moisture; in the spring these burst open, and the whole growth of the roung shoots, leares, 
flowers, and all, is completed in about three or four weeks. When the leaves first unfold, they are clothed with a copious, cotton-like down, which falls off when they have attained their full size and development.

The growth of the Horse-chestnut is slow for a soft. wooded tree, when the trees are young; after five or six years, however, it advances with more rapidity, and in twenty years forms a beautiful and massy tree. It prefers a strong, rich, loamy soil, and is easily raised from the large nuts, which are produced in great abundance.

There are several species of Horse-chestnut, but the common one (Esculus Ifippocastanum) is incomparably the finest. The American sorts are the following: ( $E s$ culus Ohioensis,) or Ohio Buckeye, as it is called in the western states; a small sized tree, with palmated leaves consisting of five leaflets, and pretty, bright yellow flowers, with red stamens. The fruit is abost half the size of the exotic species. The Red-flowered Horse-chestnut (AEsculus rubicunda) is a small tree with scarlet flowers; and the Smooth-leaved (AE. glabra) has pale yellow flowers. All the foregoing have prickly fruit. Besides these are two small Horse-chestnuts with smooth fruit, which thence properly belong to the genus Pavia, viz. the Yellow-flowered Pavia ( $P$. lutea) of Virginia and the southern states; and the Red-flowered ( $P$. rubra), with pretty clusters of reddish flowers; both these have leaves resembling those of the Horse-chestnut, except in being divided into five leaflets, instead of seven. There are some other species, which are, however, rather shrubs than trees. 
The Birch Tree. Betula.

Nat. Ord. Betulaceæ. Lin. Syst. Monceia, Polyandria.

The Birch trees are common inhabitants of the forests of all cold and elevated countries. They are remarkable for their smooth, silvery-white, or reddish colored stems, delicate and pliant spray, and small, light foliage. There is no deciduous tree which will endure a more rigorous climate, or grow at a greater elevation above the level of the sea. It is found growing in Greenland and Kamschatka, as far north as the 5sth and 60th degree of latitude, and on the Alps in Switzerland, according to that learned botanist, M. DeCandolle, at the elevation of 4,400 feet. It is, undoubtedly, the most useful tree of northern climates. Not only are cattle and sheep sometimes fed upon the leaves, but the Laplander constructs his hut of the branches; the Russian forms the bark into shoes, baskets, and cordage for harnessing his reindeer; and the inhabitants of Northern Siberia, in times of scarcity, grind it, to mix with their oatmeal for food. In this country the birch is no less useful. The North American Indian, and all who are obliged to travel the wild, unfrequented portions of British America,who have to pass over rapids, and make their way through the wilderness from river to river,-find the canoe made of the birch bark, the lightest, the most durable, and convenient vessel, for these purposes, in the world.*

* The following interesting description of their manufacture, we quote from Michaux. "The most important purpose to which the Canoe birch is applied, and one in which its place is supplied by no other tree, is the construction of 
The wood of our Black birch is by far the finest; and, as it assumes a beautiful rosy color when polished, and is next in texture to the wild Cherry tree, it is considerably esteemed among cabinet-makers in the eastern states, for chairs, tables, and bedsteads.

In Europe, the sap of the birch is collected in the spring, in the same manner as that of the maple in this country, boiled with sugar and hops, and fermented with the aid of yeast. The product of the fermentation is called birch wine, and is described as being a remarkably pleasant and healthy beverage.

Though perhaps too common in some districts of our country to be properly regarded as an ornamental tree, yet in others, where it is less so, the birch will doubtless be esteemed as it deserves. With us it is a great favorite; and we regard it as a very elegant and graceful tree, not less on account of the silvery white bark of several species, than from the extreme delicacy of the spray, and the pleasing lightness and airiness of the foliage. In all the species, the branches have a tendency to form those graceful curves which contribute so much to the beauty

canoes. To procure proper pieces, the largest and smoothest trunks are selected; in the spring, two circular incisions are made several feet apart, and two longitudinal ones, on opposite sides of the tree: after which, by in:roducing a wedge, the bark is easily detached. Theze plates are usually ten or twelve feet long, and two feet nine inches broad. To form canoes, they are stitched together with fibrous roots of the white spruce, about the size of a quill, which are deprived of the bark, split, and suppled in water. The seams are coated with resin of the Balm of Gilead. Great use is made of these cunves by the savages, and the French Canadians, in their long journeys through tho interior of the country: they are light, and very easily transported, on the shoulders, from one lake to another, which is called the portage. A canoe calculated for four persons, with their baggage, weighs from forty to fifty pouuds ; and some of them are made to carry fifteen passengers." 
of trees; but the European reeping birch is peculiarly pleasing as it grows old, on that account. It is this rariety which Coleridge pronounces.

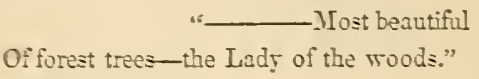

And Bernard Barton, speaking of our native species, says,

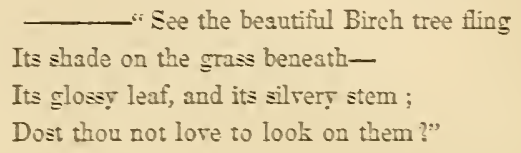

The American sorts, and particularly the Black birch: start into leaf very early in the spring, and their tender green is agreeable to the ere at that season; while the swelling buds and roung foliage in mant kinds, gire out a delicious, though faint perfume. Eren the blossoms, which hang like little brown tassels from the drooping branches, are interesting to the lorer of nature.

"The fragrant bireh abore him hung

Her tassels in the sky,

And many a remal blossom sprung,

And nodded careless by."s

BэรA.т.

Tothing can well be prettier, seen from the windows of the drawing-room, than a large group of trees, whose depth and distance is made up br the heart and deep masses of the ash, oak, and maple; and the portions nearest the ere or the lawn terminated br a few birches, with their sparkling white stems, and delicate, airy, drooping foliage. Our White birch, being a small tree, is very handsome in such situa. tions, and offers the most pleasing rariet! to the eye, wher 
seen in connexion with other foliage. Several kinds, as the Yellow and the Black birches, are really stately trees, and form fine groups by themselves. Indeed, most beautiful and varied masses might be formed by collecting together all the different kinds, with their characteristic barks, branclies, and foliage.

As an additional recommendation, many of these trees grow on the thinnest and most indifferent soils, whether moist or dry; and in cold, bleak, and exposed situations, as well as in warm and sheltered places.

We shall enumerate the different kinds as follows :-

The Canoe birch, Boleau à Canot, of the French Canadians (B. papyracea), sometimes also called the Paper birch, is, according to Michaux, most common in the forests of the eastern states, north of latitude $43^{\circ}$, and in the Canadas. There it attains its largest size, sometimes seventy feet in height, and three in diameter. Its branches are slender, flexible, covered with a shining, brown bark, dotted with white; and on trees of moderate size, the bark of the trunk is of a brilliant white; it is often used for roofirig houses, for the manufacture of baskets, boxes, etc., besides its most important use for canoes, as already mentioned. The leaves, borne on petioles four or five lines long, are of a middling size, oval, unequally denticulated, smooth, and of a dark green color.

The White birch ( $B$. populifolia) is a tree of much smaller size, generally from twenty to thirty-five feet in height: it is found in New York and the other middle states, as well as at the north. The trunk, like the foregoing, is covered with silvery bark: the branches are slender, and generally drooping when the tree attains considerable size. The leaves are smooth on both surfaces, 
heart-shaped at the base, rery acuminate, and donbly and irregularly toothed. The petioles are slightly twisted, and the leares are almost as tremulous as those of the aspen It is a beatiful small tree for ornamental plantations.

The common Black or Sweet birch. (B. lenta.) This is the sort most generally linown by the name of the bireh. and is widely dillised orer the middle and southern states. In color and appearance the bark much resembles that of the cherry tree; on old trees, at the close of winter, it is frequently detached in transverse portions, in the form of hard ligneous plates. six or eight inches broad. The leares, for a fortnight after their appearance, are corered with a thick silvery down, which disappears soon after. They are about two inches long, serrate, heart-shaped at the base, acuminate at the summit, and of a pleasing tint and fine texture. The wood is of exeellent quality, and Michaux recommends its introduction largely into the forests of the north of Europe.

The Lellow birch (B. lutea) grows most plentifully in Nora Seotia. Maine, and New Brunswick, on cool, rich soils, where it is a tree of the largest size. It is remarkable for the color and arrangement of its outer bark, which is of a brilliant golden yellow; and is freçuonty seen diviled into fine strips rolled backwards at the cnd, but attached in the middle. The leares are about three and a halt inches long, two and a half broad, orate, acuminate, and bordered with sharp and irregular teeth. It is a bealitiful tree, with a trunk of nearly uniform diameter, straight, and destitute of branches for thirty or forty feet.

The Red birch (B. rubra) belongs chiefly to the south, being scarcely ever seen north of Tirginia. It prefers the most soll of river banks, where it reaches a noble height. 
It takes its name from the cinnamon or reddish color of the outer bark on the young trees; when old, it becomes rough, furrowed, and greenish. The leaves are light green on the upper surface, whitish beneath, very pointed at the end, and terminated at the base in an acute angle. The twigs are long, flexible, and pendulous; and the limbs of a brown color, spotted with white.

The European White birch. (B. alba.) This species, the common birch tree of Europe, is intermediate in appear. ance and qualities between our Canoe birch and White birch. The latter it resembles in its foliage, the former; in its large size and the excellence of its wood. There is a distinct variety of this, to which we have alluded, called the Weeping birch (Var. pendula), which is very rapid in its growth, and highly graceful in its form. From the great beauty of our native species, this is, perhaps, the only European sort which it is very desirable to introduce into our collections

\section{The Alder Tree. Alnus.}

Nat. Ord. Betulaceæ. Lin. Syst. Monœcia, Tetrandria.

The alder tree is a native of the whole of Europe, where it grows to the altitude of from thirty to sixty feet. Our common Black alder (A. glauca), and Hazel-leaved alder (A. serrulata), are low shrubs of little value or interest. This, however, is a neat tree, remarkable for its love of moist situations, and thriving best in places even too wet for the willows; although it will also flourish on dry and elevated soils. The leaves are roundish in form, wavy, and 
serrated in their margins, and dark green in color. 'The tree rapidly forms an agreeable, pyramidal head of foliage when growing in damp situations. As it is a foreign tree, we shall quote from Gilpin its character in scenery. "The alder," says he, "lores a low, moist soil, and frequents the banks of rivers, and will flourish in the poorest forest swampso where nothing else will grow. It is, perhaps, the most picturesque of any of the aquatic tribe, except the weeping willow. He who would see the alder in perfection must follow the banks of the Mole in Surrey, through the sweet vales of Dorking and Mickleham, into the groves of Esher. The Mole, indeed, is far from being a beautiful river; it is a silent and sluggish stream, but what beauty it has, it owes greatly to the alder, which everywhere fringes its meadows, and in many places forms rery pleasing scenes. It is always associated in our minds with river scenery, both of that tranquil description most frequently to be met with in the vales of England, and with that wider and more stirring cast which is to be found amidst the deep glens and rarines of Scotland; and nowhere is this tree found in greater perfection than on the wild banks of the river Findhorn and its tributary streams, where scenery of the most romantic description every where prevails." *

Although the beauty of the alder is of a secondary kind, it is worth occasional introduction into landscapes where there is much water to be planted round, or low running streams to cover with foliage. In these damp places, like the willow; it grows very well from truncheons or large limbs, stuck in the ground, which take root and become trecs speedily. There are two principal rarieties, the 
common alder (A. glutinosa), and the cut-leaved alder (4. glutinosa laciniata). The latter is much the handsomer tree, and is also the rarest in our nurseries.

The Maple Tree. Acer.

Nat. Ord. Aceracex.

Lin. Syst. Polygamia, Monœcia.

The great esteem in which the maples are held in the middle states, as ornamental trees, although they are by no means uncommon in every piece of woods of any extent, is a high proof of their superior merits for such purposes. These consist in the rapidity of their growth, the beauty of their form, the fine verdure of their foliage, and, in some sorts, the elegance of their blossoms. Among all the species, both native and foreign, we consider the Scarletflowering maple as decidedly the most ornamental species. In the spring this tree bursts out in gay tufts of red blossoms, which enliven both its own branches and the surrounding scene, long before a leaf is seen on other deciduous trees, and when the only other appearances of vegetation are a few catkins of some willows or poplars swelling into bloom. At that season of the year the Scarlet maple is certainly the most beautiful tree of our forests. Besides this, it grows well either in the very moist soil of swamps, or the dry one of upland ridges, forms a fine clustering head of foliage, and produces an ample and delightful shade; while it is also as little infected by insects of any description as any other tree. The latter advantage, the Sugar maple and our other varieties equally possess. As a handsome, 
spreading tree perhaps the White maple deserves most maise, its outline and surface being. in many cases, quite picturesque. There is no quality, howerer, for which the American maples are entitled to higher consideration as desirable oljects in scenery, than for the exquisite beanty which their foliage assumes in autumu, as it fiades and gradually dies oft. It the first approach of cold we cau just perceire a bright rellow stealing orer the leares, then a deeper golden tint, then a few fint blushes. until at length the whole mass of foliage becomes one blaze of crimson or oriange.

- Tints that the maplo wookds diselose,

Like opening buls or fading rose,

Or rarious as those hues that dye

The clouds that deck a euneet sky."."

The contrast of coloring exhibited on many of our fine river shores in a warm dry autum, is perhaps superior to anrthing of the lind in the world: and the leading and most brilliant colors, riz. orange and scarlet, are produed by maples. Eren in Europe, they are highly ralued for this autumnal appearance, so different from that of most of the trees of the old rrorld. Terr beautiful effects can be produced by planting the Scarlet and Sugar maples in the near neighborhood of the ash, which, as we hare already noticed, assumes a fine brownish purple: of the sycamore. which is yellow, and some of the oaks, which remain green for a long time: if to these we add a few erergreens, as the White pine and hemlock, to produce depth, we shall have a lind of kaleidoscope ground, harmo. nious and beautiful as the rainborr.

When the maple is planted to grow singiy on the lawn. or in small groups, it should never be trimmed up ten or 
twenty feet high, a very common practice in sume places, as this destroys half its beauty; but if it be suffered to branch out quite low down, it will form a very elegant head. The maple is well suited to scenes expressive of graceful beauty, as they unite to a considerable variation of surface, a pleasing softness and roundness of outline. In bold or picturesque scenes, they can be employed to advantage by intermingling them with the more striking and majestic forms of the oak, etc., where variety and contrast are desired. The European sycamore, which is also a maple, has a coarser foliage, and more of strength in its growth and appearance: it perhaps approaches nearer, in general expression and effect, to the plane tree, than to our native maples.

It is unnecessary for us to recommend this tree for avenues, or for bordering the streets of cities, as its general prevalence in such places sufficiently indicates its acknowledged claims to beauty, shade, and shelter. It bears pruning remarkably well, and is easily transplanted, even when of large size, from its native woods or swamps. The finest trees, however, are produced from seed.

The Sugar maple (Acer saccharinum) is a very abundant tree in the northern states and the Canadas, where it sometimes forms immense forests. The bark is white; the leaves four or five inches broad, and five-lobed; varying: however, in size, according to the age of the tree. The flowers are small, yellowish, and suspended by slender drooping peduncles. The seed is contained in two capsules united at the base, and terminated in a membranous wing; they are ripe in October. From certain parts of the trunks of old Sugar maples, the fine wood called bird's-eye maple 
is taken, which is so highly prized by the cabinet-makers; and the sap, which tlows in abundance from holes bored in the stem of the tree early in March, produces the rellknomm maple sugar. This can be clarified, so as to equal that of the cane in llaros and appearance: and it has been demonstrated that the planting of maple orchards, for the production of sugar: would be a profitable investment.

The Scarlet-flowering maple (A. mbrum) is found chiefly on the borders of rivers, or in swamps; the latter place appears best suited to this tree, for it there often attains a rery large size: it is firequently called the Soft maple or Swamp naple. The blossoms come out about the middle of April, while the branches are yet bare of leares, and their numerons little peudulous stamens appear tike small tufts of scarlet or purple threads. The leares somewhat resemble those of the Sugur maple, but are rather smaller, and only three or four lobed, glancons or whitish underneath, and inregularly toothed on the margin. This tree may easily be distinguished when young from the tormer, by the bark of the trunk, which is grey, with largo whitish spots. It trunk, in the choicest parts, fimnisbes the beantiful wood linown as the curled maple.

The White or Silver-leaved maple. (1. crioctrpum.) This species somewhat resembles the Scarlet-tlowering maple. West of the Alleglany momntains it is seen in perfection, and is well known as the Thite maple. Its Howers are pale: the leares are dirided into fonr lobes. and have a beantiful white under surfice. MCichanx. spealing of this tree, sars: "In no part of the United States is it more multiplied than in the westem country, and nowhere is its regetation more luxmiant than on the banks of the Otio. There, sometimes alone and sometimes mingled with the willow, which is fomd along these waters. 
it contributes singularly, by its magnifieent foliage, to the embellishment of the scene. The brilliant white of the leaves beneath, forms a striking contrast with the bright green above; and the alternate reflection of the two surfaces in the water, heightening the beauty of this wonderful moving mirror, aids in forming an enchanting picture, which, during my long excursions in a canoe, in these regions of solitude and silence, I contemplated with unwearied admiration."':* There, on those fine, deep, alluvial soils, it often attains twelve or fifteen feet in circumference.

As an ornamental variety, the Silver-leaved maple is one of the most valuable. It is exceedingly rapid in its growth, often making shoots six feet long in a season; and the silvery hue of its foliage, when stirred by the wind, as well as its fine, half drooping habit, render it highly interesting to the planter. Admirable specimens of this speeies may be seen in the wide streets of Burlington, N. J.

The Moose-wood, or Striped maple (A. striatum), is a small tree with beautifully striped bark. It is often seen on the mountains which border the Hudson, but abounds most profusely in the north of the continent. Acer nigrum $\dagger$ is the Black sugar tree of Genesee. A. Negundo, the Ashleaved maple, has handsome pinnated foliage of a light green hue; it forms a pleasing tree of medium size. These are our principal native species. \&

* N. A. Sylva, i. 214.

† This variety differs from $A$. saccharinum, in having much larger leaves, and the bark of a darker color; besides which, the sap is more abundant, and much sweeter, and is considered at the West mueh the finer tree of the two.-H. W. S.

$\ddagger$ Negundo fraxinifolium.

$\$$ Mr. Douglas has discovered a very superb maple (A. macroplyyllum), on the Columbia river, with very large leaves, and fine fragrant yellow blossores. 
Among the finest foreign sorts, is the Norway maple, (1. platenoides) with leares intermediate in appearanee between those of the plane tree and Sugar maple. The bark of the trunk is brown, and rougher looking tham our maples, and the tree is more loose and spreacling in its growth; it also grows more rapidly, and strongly resembles, at a little distance, the button-irood in its young state. Another interesting species is the syeamore tree or Great maple (1. pseudo-platanus). The latter also considerably rescmbles the plane; but the leares, like those of the common maple, are smoother. They are fire-lobed, acute in the divisions, and are placed on much longer petioles than those of most of the species. The flowers, strung in clusters like those of the common currant, are greenish in color. It is much esteemed as a shade-trce in Scotiand and some parts of the Continent, and grows with vigor: producing a large head, and widely spreading branches.

\section{The Locust Tree, Robinia.}

Tat. Ora. Lregumiuosa. Lin. Syst. Diadelphia, Decandna.

This is a well-known American tree, found growing wild in all of the states west of the Delaware River. It is a tree of secondary size, attaining generally the height of forty or fifty feet. The leares are pimnated, bluish-green in color, and are thinly scattered orer the branches. The white blossoms appear in $J$ une, and are highly fragrant and beantiful; and from them the Paris perfumers distil an 
extrait which greatly resembles orange-flower water, and is used for the same purposes.

As an ornamental tree we do not esteem the locust highly. The objections to it are, first its meagreness and lightness of foliage, producing but little shade; seeondly, the extreme brittleness of its branches, which are liable to be broken and disfigured by every gale of wind ; and lastly, the abundance of suckers which it produces. Notwithstanding these defects, we would not entirely banish the locust from our pleasure-grounds; for its light foliage, of a fresh and pleasing green, may often be used to advantage in produeing a variety with other trees; and its very fragrant blossoms are beautiful, when in the beginning of summer they hang in loose pendulous clusters from among its light foliage. These will always speak suffieiently in its favor to cause it to be planted, more or less, where a variety of trees is desired. It should, however, be remembered that the foliage comes out at a late period in spring, and falls early in autumn, which we consider objec. tions to any tree that is to be planted in the close vicinity of the mansion. It is valuable for its extremely rapid growth when young; as during the first ten or fifteen years of its life it exceeds in thrifty shoots almost all other forest trees: but it is comparatively short-lived, and in twenty years' time many other trees would completely overtop and outstrip it. It is easily propagated by seed, which is by far the best mode of raising it, and it prefers a deep, rich: sandy loam.

The locust can be cultivated to advantage, as a timber tree, only upon deep, mellow, and rather rich, sandy soils ; there, its growth is wonderfully vigorous, and an immense rumber may be planted upon a small area of ground.

There are but two distinet species of locust winch attain 
the size of trees in this country, viz. the Yellow locust (R.pseud-acacia), so called from the color of its wood; and the Honey locust ( $R$. viscosa), a smaller tree, with reddish flowers, and branches covered with a viscid, honey-like gum. Some pretty rarieties of the former have been originated in gardens abroad, among which the Parasol locust (Tar. smbraculifera) is decidedly the most interesting. We recollect some handsome specimens which were imported by the late M. Parmentier, and grew in his garden at Brooklyn, Long Island. They were remarkable for their unique, rounded, umbrella-like heads, when grafted ten or twelve feet high on the common locust.

There are two pretty distinct varieties of the common Yellow locust, cultirated on the Hudson. That most frequently seen is the White rariety, which forms a tall and uarrow head; the other is the Black locust, with a broad and more spreading head, and larger trunk; the latter may be seen in fine condition at Clermont. It is a much finer ornamental tree, and appears less liable to the borer than the White rariety.

The Three-thorned Acacia Tree. Gleditschia.

Nat. Ord. Leguminosæ. Lin. Syst. Polygamia, Diœcia.

This tree is often called the Three-thorned locust, from some resemblance to the latter tree. Its delicate, doubly pinnate leaves, howerer, are much more like those of the Acacias, a family of plants not hardy enough to bear our climate. It is a much finer tree in appearance than the common locust, although the flowers are greenish, and inconspicuous, instead of possessing the beauty and fra- 
grance of the latter. There is, however, a peculiar ele. gance about its light green and beautiful foliage, which wafts so gracefully in the summer breeze, and folds up on the slightest shower, that it stands far above that tree in our estimation, for the embellishment of scenery. The branches spread out rather liorizontally, in a fine, broad, and lofty head; there are none of the dead and unsightly limbs, so common on the locust; and the light, feathery foliage, lit up in the sunshine, has an airy and transparent look, rarely seen in so large a tree, which sometimes produces very happy effects in composition with other trees. The bark is of a pleasing brown, smooth in surface, the branches are studded over with curious, long, triply-pointed thorns, which also often jut out in clusters, in every direction, from the trunk of the tree, to the length of four or five inches, giving it a most singular and forbidding look. In winter, these and the long seed-pods, five or six inches in length, which hang upon the boughs at that season, give the whole tree a very distinct character. These pods contain a sweetish substance, somewhat resembling honey; whence the tree has in some places obtained the name of Honey locust, which properly belongs to Robinia viscosa.

Another recommendation of this tree, is the variety of picturesque shapes which it assumes in growing up; sometimes forming a tall pyramidal head of 50 or 60 feet, sometimes a low, horizontally branched tree, and at others, it expands into a wide, irregular head, quite flattened at the summit. It does not produce suckers, like the locust, and may therefore be introduced into any part of the grounds. When but a limited extent is devoted to a lawn or garden, this tree should be among the first to obtain a place; as one or two Three-thorned Acacias, mingled with other 
larger and heavier foliage, will at once produce a charming rariety.

The Three-thorned Acacia has been strongly recom. mended for hedges. It is too liable to become thin at the bottom, to serve well for an outer inclosure, but if kept well trinmed, it forms a capital farm fence and protection against the larger animals, groving up in much less time than the hawthorn. Like the locust, it has the disadvantage of expanding its foliage late in the spring. In the strong rich soils which it prefers, it grows very vigorously, and is easily propagated from seeds.

The Three-thorned Acacia (G. triacanthos) is the principal species, and is indigenous to the states rest of the Alleghanies. G. monosperma is another kind, which is scarcely distinguishable from the Three-thorned, except in haring one-seeded pods. The seedlings raised from $G$. triacanthos are often entirely destitute of thorns.

There is a finespeciesocalled the Chinese, (G. horrida), with larger and finer foliage, and immense triple thorns, which is interesting from its great singularity. A tree of his lind which we imported, has stood our coldest winters perfectly uninjured, and promises to be beautiful and very nardy. Some noble specimens of the common Threethorned Acacia may be seen upon the larrn at Hyde Park, the fine seat of the late Dr. Hosack.

\section{The Judas Tree. Cercus.}

Nat. Ord. Leguminosx. Tizr. Syst. Decandra, Monogynia.

A handsome low tree, about 20 feet in height, which is 
found scattered sparsely through warm sheltered valleys, along the IIudson and other rivers of the northern sections of the United States, but most abundantly on the Ohio. It is valuable as an ornamental tree, no less on account of its exceedingly neat foliage, which is exactly heart-shaped, or cordiform, and of a pleasing green tint, than for its pretty pink blossoms. These, which are pea-shaped, are produced in little clusters close to the branches, often in great profusion, early in the spring, before the leaves have expanded. From the appearance of the limbs at that period, it has in some places obtained the name of Redbud. It is then one of the most ornamental of trees, and, in company with the Dog-wood, serves greatly to enliven the scene, and herald the advent of the floral season. These blossoms, according to Loudon (Encycl. of Plants), having an agreeable poignancy, are frequently eaten in salads abroad, and pickled by the French families in Canada. The name of Judas tree appears to have been whimsically bestowed by Gerard, an old English gardener, who described it in 1596, and relates that "this is the tree whereon Judas did hange himselfe; and not upon the elder tree, as it is said."

There are two species in common cultivation; the American (C. Canadensis) and the European (C. Sili. quastrum). The latter much resembles our native tree. The flowers, however, are deeper in color; the leaves darker, and less pointed at the extremity. It also produces blossoms rather more profusely than the American tree. Both species are highly worthy of a place in the garden, or near the house, where their pleasing vernal influences may be observed. 


\section{The Chestrut Tree. Castanea.}

Nat. Ord. Lorylneex. Lin. Syst. Monceia, Polyaudria.

The chestmut, for its qualities in Landscape Gardening ranks with that king of the forest, the oak. Like that tree, it attains an enormous size, and its longevity in some cases is almost equally remarkible. Its fine massy foliage, and sweet nuts, have rendered it a farorite tree since a very remote period. Among the ancients, the latter were a common article of food.

\section{"Sunt nobis mitia pouma, Castaner molles, et pressi copia laetis."}

FIRG. EcL. 1.

They appear to have been in general use, both in a raw and cooked state. In times of scarcity, they probably supplied in some measure the place of bread-stuffs, and were thence highly ralued:

" As for the thrice three angled beech nut shell, Or Chestnut's armed huske and hid kernell, No squire durst toneh, the law would not afford, Fiept for the court, and for the king's own board."

Bp. Hall, Sat. B. III. 1.

Eren to this day, in those parts of France and Italy nearest the great chestnut forests of the Appenines, these nuts form a large portion of the food which sustains the peasantry, where grain is but little cultirated, and potatoes almost unknown. There a sweet and highly nutritious flour is prepared from them, which makes a delicious bread. Large quantities of the fruit are therefore annually collected in those countries, and dried and stored 
\&way for the winter's consumption. Old Evelyn says, "the bread of the flour is exceedingly nutritive : it is a robust food, and makes women well complexioned, as I have read in a good author. They also make fritters of chestnut flour, which they wet with rose-water, and sprinkle with grated parmigans, and so fry them in fresh butter for a delicate." The fruit of the chestnut abounds in saccharine matter; and we learn from a French periodical, that experiments have been made, by which it is ascertained that the kernel yields nearly sixteen per cent. of good sugar.

As a timber tree, this is greatly inferior to the oak, being looser grained, and more liable to decay; and the American wood is more open to this objection than that produced on the opposite side of the Atlantic. It is, however, in general use among us, for posts and rails in fencing; and when the former are charred, they are found to be quite durable.

The finest natural situations for this tree appear to be the mountainous slopes of mild climates, where it attains the greatest possible perfection. Michaux informs us, that the most superb and lofty chestnuts in America are to be found in such situations, in the forests of the Carolinas. Abroad, every one will call to mind the far-famed chestnuts of Mount Etna, of wonderful age and extraordinary size. The great chestnut there, has excited the surprise of numerous travellers; at present, however, it appears to be scarcely more than a mere shell, the wreck of former greatness. When visited by M. Houel (Arboretum Brit.), it was in a state of decay, having lost the greater part of its branches, and its trunk was quite hollow. A house was erected in the interior, and some country people resided in 
it, with an orew, in which, according to the eustom of the country, they dried chestmuts, filberts and other frnits which they wished to preserve for winter lise; using as fucl. when they could find no other, picess cut with a hatehet from the interior of the tree. In Brydones tims. in 1970. this tree measured two hundred and four feet in cireunferenes. Ho says it had the appearance of five distinet trees: but he was assured that the space was once filled with solid timber, and there was no bark on the inside. This cireumstance of an old trunk, hollow in the interior, beeoming separated so as to hare the appearance of being the remains of sereral distinet trees is trequently met with, in the cilse of very old mulberry trees in Great Britain, and olive treas in Iraly. Kircher, about a century botore Brydone. afinms that an entire thek of sheep might be inclosed within the Etura chestunt. as in a fold.* ( $A$ r. boretum Brit. p. 19s:)

* ()ne of the most celebrated Chestuut trets on revont, la that ealled the

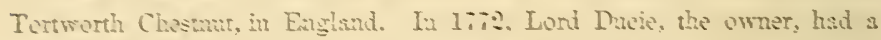
portatit of it taken. which was acompaniet by the following description: " The cast rew of the smetent Chestnut tres at Tortwoth. in the county of

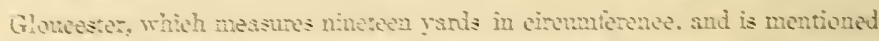
by Sir Robert Alikins in his history of that comaty as a famous tree in Kivg

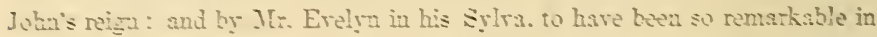
the reign of King Siphen. 1133, as theu to be exlled the grent Chestmut of Tormorth: then whid it way reasonaly be prosumed is kire teen standing letore the Conguest. $1060 . "$ This tree is still standing.

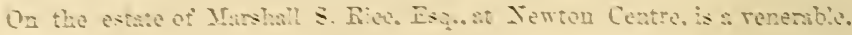

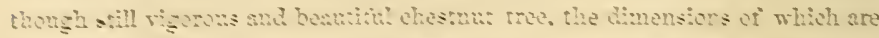

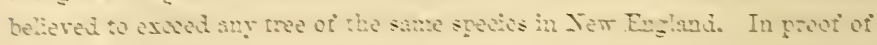

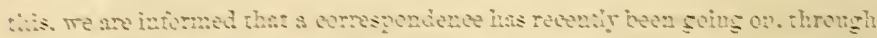

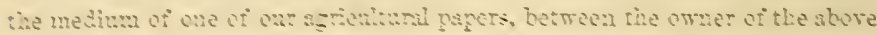

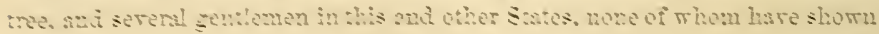

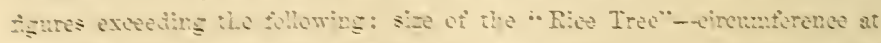

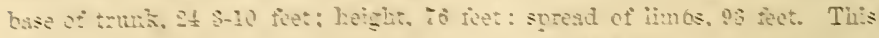

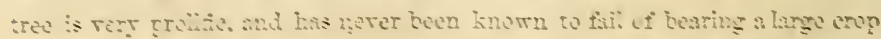

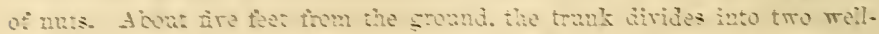

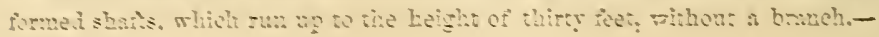
H. IT. S. 
In cunsidering the chestnut as highly adapted to wrnament the grounds of extensive country residences, much that we have already said of the oak will apply to this tree. When young, its smooth stem, clear and bright foliage, and lively aspect, when adorned with the numerous light, greenish yellow blossoms, which project beyond the mass of leaves, render it a graceful and beautiful tree.

It has long been a favorite with the poets, for its graieful shade; and as the roots run deep, the soil beneath it is sufficiently rich and sheltered to afford an asylum for the minutest beauties of the woods. Tennyson sweetly says :-

"That slope beneath the chestnut tall

Is wooed with choicest breaths of air, Methinks that I could tell you all

The cowslips and the king eups there."

When old, its huge trunk, wide-spread branches, lofty head, and irregular outline, all contribute to render it a picturesque tree of the very first class. In that state, when standing alone, with free room to develope itself on every side, like the oak, it gives a character of dignity, majesty, and grandeur, to the scene, beyond the power of most trees to confer. It is well known that the favorite tree of Salvator Rosa, and one which was most frequently introduced with a singularly happy effect into his wild and picturesque compositions, was the chestnut; sometimes a massy and bold group of its verdure, but oftener an old and storm-rifted giant, half leafless, or a barren trunk coated with a rich verdure of mosses and lichens.

The chestnut in maturity, like the oak, has a great variety of outline; and no trees are better fitted than these for the formation of grand groups, heavy masses, 
or wide outlines of foliage. A higher kind of beauty, with more dignity and variety, can be formed of these two genera of trees when disposed in grand masses, than with any other forest trees of temperate climates; perhaps we may say of any climate.

There is so little difference in the common Sweet chestnut (Castanea vesca) of both hemispheres, that they ure generally considered the same species. Varieties hare been produced in Europe, which far surpass our common chestnuts of the woods in size, though not in delicacy and richness of flavor. Those cultirated for the table in France, are known by the name of marrons. These improred sorts of the Spanish chestnut bear fruit nearly as large as that of the Horse-chestnut, inferior in sweetness, when raw, to our wild species, but delicious when roasted. The Spanish chestnut thrives well, and forms a large tree, south of the Highlands of the Hudson, but is rather tender north of this neighborhood. A tree in the grounds at Presque Isle, the seat of William Denning, Esq., Dutchess Co., is now 40 feet high. They may be procured from the nurseries, and we can hardly recommend to our planters more acceptable additions to our nut-bearing forest trees.

The Chinquapin, or Drarf chestnut (C. pumila), is a curious, low bush, from four to sir feet high. The leaves are nearly the size of the ordinary chestnut, or rather smaller, and the fruit about two-thirds as large. It is indigenous to all the states south of Pennsylrania, and is often found in great abundance. It is a curious little tree, or more properly a shrub, and merits a place in the garden; or it may be advantageously planted for underwood in a group of large trees. 
As the chestnut, like the oak, forms strong tap-roots, it is removed with some difficulty. The finest trees are produced from the nut, and their growth is much more rapid when young, than that of the transplanted tree. It prefers a deep sandy loam, rather moist than dry; and will not, like many forest trees, accommodate itself to wet and low situations.

\section{The Osage Orange Tree. Maclura.}

Nat. Ord. Urticaceæ. Lin. Syst. Diœcia, Tetrandria.

'j"his interesting tree is found growing wild on the Arkansas River, and other western tributaries of the Mississippi, south of St. Louis, where, according to Mr. Nuttall, it attains the height of 50 or 60 feet. The branches are rather light-colored, and armed with spines (produced at every joint) about an inch and a half long. The leaves are long, ovate, and acuminate, or pointed at the extremity; they are deep green, and more glossy and bright than those of the orange. The blossoms are greenish; and the fruit is about the shape and size of a large orange, but the surface much rougher than that fruit. In the south, we are told, it assumes a deep yellow color, and, at a short distance, strikingly resembles the common orange; the specimens of fruit which we have seen growing in Philadelphia, did not assume that fine color; but the appearance of the tree laden with it, is not unlike that of a large orange tree. It was first transplanted into our gardens from a village of the Osage tribe of Indians, whence the common name of Osage orange. The introduction of this tree was one of the favorable results of 
Lewis and Clarke's Expedition. It was named by them in honor of the late Im. Maclure, Esq., President of the American Academy of Natural Sciences.

The rood is fine grained, yellow in color, and takes a brilliant polish. It is also very strong and elastic, and on this account the Indians of the wide district to which this tree is indigenous, employ it extensirely for bows, greatly preferring it to any other timber. Hence its common name among the white inhabitants is Bodac, a cor ruption of the term bois darc (bow-wood), of the French settlers. A fine yellow dye is extracted from the wood, similar to that of the Fustic.

As the Osage orange belongs to the monœcious class of plants, it does not perfect its finit unless both the male and lemale trees are growing in the same neighborhood. Manc have beliered the firuit to be eatable, both from its fine appearance, and from its affinity with, and resemblance to that of the bread-fruit; but all attempts to render it pleasant, either cooked or in a raw state, have hitherto failed: it is therefore probably inedible, though not injurious. Perhaps when fully ripened, some mode of preparing it by baking or otherwise, may render it palatable.

As an ornamental tree, the Osage orange is rather too loose in the disposition of its wide-spreading branches, to be called beautiful in its form. But the bright glossy hue of its foliage, and especially the unique appearance of a good sized tree when covered with the large, orange-like fruit, render it one of the most interesting of our natire trees; while it has the same charm of rarity as an exotic, since it was introduced from the far west, and is yet but little planted in the United States. On a small lawn, where but few trees are needed, and where it is desirable that the 
species employed should all be as distinct as possible, to give the whole as much variety as can be obtained in a limited space, such trees should be selected as will not only be ornamental, but combine some other charm, association, or interest. Aniong such trees, we would by all means give the Osage orange a foremost place. It has the additional recommendation of being a fine shade tree and of producing an excellent and durable wood.*

The stout growth and strong thorns of this tree have been thought indicative of its usefulness for the making of hedges: a method of fencing, which sooner or later must be adopted in many parts of this country; and from the experiments which we have seen made with plants of the Osage orange, we think it likely to answer a very valuable purpose; especially in the middle and southern states. The Messrs. Landreth of Philadelphia have lately offered many thousands of them to the public at a low rate, and we hope to see the matter fairly tested in various parts of the Union.

A rich deep loam is the soil best adapted to the growth of this tree; and as it is rather tender when young (though quite hardy when it attains a considerable size) it should, as far as possible, be planted in a rather sheltered situation. A dry soil is preferable, if it must be placed in a cold

* A very superb effect may be produced with this tree, by cutting it sererely back for several years, and compelling it, as the English eall it, to stole, by sending out a dozen leading shoots, instead of one; a plant treated in this way, beeomes, after a few years, a gigantic bush, round-headed, and most luxuriant, and when covered with its golden fruit, peeping out liom amidst its exquisitely green foliage, it is the most superb floral ornament to a lawn that can be coneeived. We recollect a surprisingly fine specimen of an Osage Orange treated in this way, at the late Dr. Edmondston's, near Baltimore, where a plant about twenty-fnur years old measured in eircumference, one hundred and sixty-five feet! the limbs lying about with a profusion of growth positively wonderful, and covered with fruit.-II. W. S. 
aspect, as all plants not perfectly hardy are much injured by the late growth, caused by an excess of moisture and consequent upon an immature state of the wood, which is unable to resist the effects of a severe winter.

\section{The Mulberry Tree. Morus.}

Nat. Ord. Urticaceæ. Lin. Syst. Monœcia, Tetrandria.

The three principal species of the Mulberry, are the common Red American, the European Black, and the White mulberries. None of them are truly handsome in scenery; and the two latter are generally low, spreading trees, valued entirely for the excellency of the fruit, or the suitableness of the foliage for feeding silkworms. Our common mulberry, however, in free, open situations, forms a large, wide-spreading, horizontally branched, and not inelegant tree: the rough, heart-shaped leaves with which it is thickly clothed, afford a deep shade; and it groups well with the lime, the catalpa, and many other round-headed trees. We consider it, therefore, duly entitled to a place in all extensive plantations; while the pleasant flavor of its slightly acid, dark red fruit, will recommend it to those who wish to add to the delicacies of the dessert. The timber of our wild mulberry tree is of the very first quality, when fully seasoned, it takes a dull lemon-colored hue, and is scarcely less durable than the locust or Live oak. Like those trees, it is much valued by ship-builders; and at Philadelphia and Baltimore it commands a high price, for the frame-rvork, knees, floor-timbers, and tree-nails of vessels. The Red mulherry is much slower in its growth 
than the locust; but, so far as we are aware, it is not liable to the attacks of any insect destructive to its timber ; and it would probably be found profitable to cultivate it as a timber tree. The locust, it will be remembered, grows thriftily only on peculiar soils, loose, dry, and mellow; the Red mulberry prefers deep, moist, and rich situations.. No extensive experiments, so far as we can learn, have been made in its culture; but we would recommend it to the particular attention of those who have facilities for plantations of this kind.

The Black mulberry of Europe (Morus nigra)*is a low, slow-growing tree, with rough leaves, somewhat resembling those of our Red mulberry, but more coarsely serrated, and often found divided into four or five lobes; while the leaves, which are not heart-shaped on our native species, are gene. rally three-lobed. The European mulberry bears a fruit four or five times as large as the American, full of rich, sweet juice. It has long been a favorite in England, and is one of the most healthy and delicious fruits of the season, Glover says :

\footnotetext{
"There the flushing peach,

The apple, citron, almond, pear, and date,

Pomegranates, purple mulberry, and fig,

From interlacing branches, mix their hues

And sccnts, the passengers' delight."
}

LEONID. B. II.

We regret that so excellent a fruit should be so little cultivated here. It succeeds extremely well in the middle

* Further experience has shown, that this tree is not to be depended upon, at east as far north as the middle portion of the Hudson River. An admirable substitute for the fruit, is Downing's Seedling Mulberry, raised some years ago by Mr. Charles Downing, of Newburgh, and while being an excellent frnit, has, we believe, the additional merit of being ever-bearing. $-\mathrm{H}$. W. S. 
states; and as it ripens at the rery period in midsummer when fints are scarcest, there can be no more welcome addition to our pomonal treasures, thin its deep purple and luscions herries. According to Loudon, it is a tree of great durability; in proof of which he quotes a specimen at Sim Ilouse, 300. rears old, which is supposed to hare been plinted in the 16th century by the botanist 'Tumer.

The White mulbery (M. albu) is the species upon the leares of which the silkworms are fed. The fruit is insipid and tasteless, and the tree is but little cultivated to embellish ornamental plantations, though one of the most useful in the world. when its importance in the production of silk is taken into account. There are a great mumber of rarieties of this species to be found in the different murseries and silk plantations: among them the Chinese mulberry (M. multicautis) grows rapidly, but scaredy forms mone than a large shrub at the north; and its rery large, tencler, and solt green folinge is interesting in a large collection. The fruit is, we believe, of no importance; but it is the most raluable of all mulberrics is food for the silkworm, while its growth is the most rigorous, and its leares more easily gathered than those of any other tree of the genus.

The Paper Muluerri Tren. Broussonetia.

Nüt. Ord. Urticacen. Lin. Siyst. Diacia, Tetmundria.

The Paper mulbery is an exotic tree of a low growth, rarely cxceeding twenty-fire or thirty feet, indigenous to Japan and the South Sar Islands, but very common in our gardens. It is remarkable for the great rariety of forms exhibited in its foliage; as upon roung trees it is almost 
irr possible to find two exactly alike, though the prevailing outlines are either heart-shaped, or more or less deeply cut or lobed. 'I'hese leaves are considered valueless for feeding the silkworm; but in the South Seas, the bark is woven into dresses worn by the females; and in China and Japan, extensive use is made of it in the manufacture of a paper of the softest and most beautiful texture. This is fabricated from the inner bark of the young shoots, which is first boiled to a soft pulp, and then submitted to processes greatly similar to those performed in our paper-mills. This tree blossoms in spring and ripens its fruit in the month of August. The latter is dark scarlet, and quite singular and minamental, though of no value. The genus is diœcious; and the reason why so few fruit-bearing trees are seen in the United States, is because we generally cultivate only one of the sexes, the female. IVI. Parmenticr, however, who introduced the male plant from Europe, disseminated it in several parts of the country; and the beruty of the tree has thereby been augmented by the interest which it possesses when laden with its long, hairy berries.

The value of the Paper mulberry, in ornamental plantations, arises from its exotic look, as compared with other trees, from the singular diversity of its foliage, the beauty of its reddish berries, and from the rapidity of its growth. It is deficient in hardiness for a colder climate than that of New York; but further south, it is considerably esteemed as a shade-tree for lining the side-walks in cities. In winter; its light fawn or ash-colored bark, mottled with patches of a darker grey, contrasts agreeably with other trees. It has little picturesque beauty, and should never be planted in quantities, but only in scattered specimens, to give interest and variety to a walk in the lawn or shrubbery. 
'The Sweet Gum Tree. Liquidambar.

Nat. Ori. Platanneex.

Lin. Syst. Moncecia, Polyandria.

According to Michaux,* the Sweet gum is one of our most extensively diffused trees. On the seashore it is seeis as far north as Portsmouth; and it extends as far south as the Gulf of Mexico and the Isthmus of Darien. In many of the southern states it is one of the commonest trees of the forest: it is rarely seen, howerer, along the banks of the Hudson (except in New Jersey), or other large streams of New York. It is not unlike the maple in generial appearance, and its palmate, fire-lobed leares are in outline much like the Sugar maple, though dinker in color and firmer in texture. It may also be easily distinguished from that tree, by the curions appearance of its secondary branches, which hare a peculiar roughness, owing to the bark attaching itself in plates edgewise to the trunk, instead of laterally, as in the usual manner. The fruit is globular, somewhat resembling that of the buttonwood, but much rougher, and bristling with points. The male and female catkins appear on diflerent branches of the same tree early in spring.

This tree grows in great perfection in the forests of New Spain. It was first described by a Spanish naturalist, Dr. Hernandez, who observed that a fragrant and transparent gum issued from its trunk in that country, to which, from its appearance, he gave the name of liquid amber. This is now the common name of the tree in Europe ; and the gum is at present an article of export from Mexico, being chiefly ralued in medicine as a styptic, and for its healing and balsamic properties. "This substance, which in the shops

* N. A. Sylra, i. 315 . 
is sometimes called the white balsam of Peru, vr liquid storax, is, when it first issues from the tree, perfectly liquid and clear, white, with a slight tinge of yellow, quite balsamic ; and having a most agreeable fragrance, resembling that of ambergris or styrax. It is stimulant and aromatic, and has long been used in France as a perfume, especially for gloves."* In the middle states a fragrant substance sometimes exudes from the leaves, and, by incision, small quantities of the gum may be procured from the trunk; but a warmer climate appears to be necessary to its production in considerable quantities.

We hardly know a more beautiful tree than the Liquid amber, in every stage of its growth and during every season of the year. Its outline is not picturesque or graceful, but simply beautiful, more approaching that of the maple than any other: it is, therefore, a highly pleasing, round-headed or tapering tree, which unites and harmonizes well with almost any others in composition; but the chief beauty lies in the foliage. During the whole of the summer months it preserves, unsoiled, that dark glossy freshness which is so delightful to the eye ; while the singular, regularly palmate form of the leaves readily distinguishes it from the common trees of a plantation. But in autumn, it assumes its gayest livery, and is decked in colors almost too bright and vivid for foliage; forming one of the most brilliant objects in American scenery at that period of the year. The prevailing tint of the foliage is then a deep purplish red, unlike any symptom of decay, and quite as rich as is commonly seen in the darker blossoms of a Dutch parterre. This is sometimes varied by a shade deeper or lighter, and occasionally an orange tint is assumed. When planted in the 
neigiaberhood of our fine maples ashes, and other tres remarkable for their antummal coloring. the ettect, in a watm, dry atutum, is almost magieal. Whereve has tratrolled thromgh what are ealled the pine barrens of New Jersey in such a seison. must have been struck with the fury tints of the numberless forest trees. which line the rouk through those sumty plains, and with the conspicuons wemty of the Sweet grmm. or Liquidamber.

'The bark of this tree when fill grown, or nearly so, is axcedingly rough and fumowed. like that of the oak. The wood is finc-gramed, and talies a good polish in cabinet work: thengh it is not so durible, nor so much esteemed for such purposes, as that of the Blatek walmut and some other native twes. 'The average height of tull grown trees is about 35 or -10 tect.

liquidambar styracilua is the only North American species. It grows most rapidly in moist or even wot situr. tions, though it will aceommodate itself to a drier soil.

\section{The Warut Trias. Juglans.}

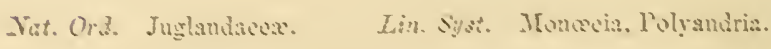

The the tress which properly come mater this leat and belong to the genus Juglans, are the Black walnut. the European walumt, and the Buttermut.

'The Black wilnut is one of the larresest trees of our mative forests. In good soils it often attains a stature of 60 or 70 feet. and a diameter of three or four feet in the trunk, with a corresponding amplitude of branches. The leares, about a foot or eighteen inches in length, are composed of six or 
eight pairs of opposite leaflets, terminated by an odd one. They contain a very strong aromatic odor, which is emitted plentifully when they are bruised. 'The large nut, always borne on the extremity of the young shorts, is round, and covered with a thick husk; which, instead of separating into pieces, and falling off, like those of the lickory; rots away and decays gradually. 'The kernel of the Black walnut, too well known to need any description here, is highly esteemed, and is even considered by some persons to possess a finer flavor than any other wahnut.

The timber of this tree is very valuable : when well seasoned it is as durable as the White oak, and is less liable to the attaeks of sea-worns, etc., than almost any other; it is, therefore, highly esteemed in naval architecture for certain purposes. But its great value is in eabinet work. Its color, when exposed to the air, is a fine, rich, dark brown, beautifully veined in certain parts; and as it takes a brilliant polish, it is coming into general use in the United States for furniture, as well as for the interior finishing of houses.

'The Black walnut has strong claims upon the Landseape Gardener, as it is one of the grandest and most massive trees which he can employ. When full grown it is scarcely inferior in the boldness of its ramification or the amplitude of its head to the oak or chestnut; and what it lacks in spirited outline when compared with those trees, is fully compensated, in our estimation, by its superb and heavy masses of foliagre, which catch and throw off the broad lights and shadows in the finest manner. When the Black walnut stands alone on a deep fertile soil it becomes a truly majestic tree; and its lower branches often sweep the ground in a graceful curve, which gives additional beauty to its whole expression. It is admirably adapted to exten- 
sire lawns, parks, or plantations, where there is no want of room for the attaimment of its full size and fair proportions. Its rapid growth and umbrageous foliage also recommend it for wide public strects and arenues.

The European walnut (J. regiu* ${ }^{*}$ or, as it is generally termed here, the Madeira mut, is one of the most common cultirated trees of Europe, where it was introduced originally from Persia. It diflers from our Black walnut (which, however, it much resembles) in the smooth, grey bark of the stem, the leares composed of three or four pair of leaflets, and in the very thin-shelled fruit, which, though not exceeding the Black waluut in size, ret contains a much larger kernel, which is generally considered more delicate in tlaror. In the interior of France, orehards of the walnut are planted, and a considerable commerce is carried on in its products, consisting chictly of the fruit, of which large quantities are consumed in all parts of Europe. The wood is greatly used in the manuficture of gun-stocks, and in cabinet-making (though it is much inferior to the American walnut for this purpose) ; and the oil extracted from the kernel is in high estimation for mixing with delicate colors used in painting and other purposes.

The European walnut is a noble tree in size, and thickly clad in foliage. It is much esteemed as a shade tree by the Dutch : and Erelyn, who is an enthusiastic admirer of its beanties, mentions their fondness for this tree as in the highest degree praiseworthy. "The Bergstras [Bergstrasse], which extends from Heidelberg to Darmstadt, is all planted with walnuts; for as by an ancient law the Bor.terers were obliged to nurse up and take care of them, and that chiefly for their ormament and shade, so as a man may ride for

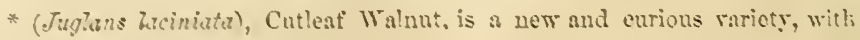
large scalloped leares, - H. W. S. 
many miles about that country under a continual arbor or close walk,-the traveller refreshed with both the fruit and shade. How much such public plantations improve the glory and wealth of a nation! In several places betwixt LIanau and Frankfort in Germany, no young farmer is jermitted to marry a wife till he bring proof that he hath planted, and is the father of a stated number of walnut trees." 湔

The nuts are imported into this country in great quantities; and as they are chiefly brought from Spain and the Madeiras, they are here almost entirely known by the name of the Madeira nut. The tree is but little cultivated among us, though highly deserving more extensive favor, both on account of its value and beauty. It grows well in the climate of the middle states, and bears freely; a specimen eighteen or twenty years old, in the garden of the author, has reached thirty-five feet in height, and bears two or three bushels of fine fruit annually; from which we have already propagated several hundred individuals. It is not perfectly hardy north of this.

As an ornamental tree, Gilpin remarks, that the warm russet hue of its young foliage makes a pleasing variety among the vivid green of other trees, about the end of May; and the same variety is maintained in summer, by the contrast of its yellowish hue, when mixed in any quantity with trees of a darker tint. It stands best alone, as the early loss of its foliage is then of less consequence, and its ramification is generally beautiful.

The Butternut ( $J$. cathartica) belongs to this section, and is chiefly esteemed for its fruit, which abounds in oil, and is very rich and sweet. The foliage somewhat 
resembles that of the Black walnut, though the leatlets are smaller and narrower. The form of the nut, howerer, is strikingly different, being oblong, oral, and narrowed to a point at the extremity. Cinlike the walnut, the husk is corered with a sticky gum, and the surface of the nut is much rougher than any other of the walnut gems. The bark of the butternut is grer. and the tops of old trees generally have a tlattened appearance. It is frequently an uncouth, ill-shapen, and ngly tree in form, though occasionally, also, quite striking and picturesque. Ind it is well worthy of a place, for the excellence of its fruit.*

The Hichory Tree, Carya.

Tat. Ord. Iuglandacese. Lin. Syst. Monceis, Folyanuma.

The hickories are fine and lofty North American trees: highly raluable for their wood, and the excellent fruit borne by some of the species. The timber is extremely elastic, and rery heary, possessing great strength and tenacity. It is not much employed in architecture, as it is peculiarly liable to the attacks of worms and decays quickly when exposed to moisture. But it is rerrextensirely employed for all purposes requiring great elasticity. and strength; as for axletrees, screws, the wooden rings used upon the rigging of ressels, whip-handles, and axe-

* Loudon ers gresty in his Arbonetum, in supposing the buternut to be hentival with the Black waluut : no trees in the whole Ameriesn forest sne nore easily distinguished at first sight. He slso states the fruit to he rocid and of little ralue; but to Anterion lsd of s dozen reas, will secosd with bin in this opinion. 
handles; and an immense quantity of the young poles are cirployed in the manufacture of hoops, for which they are adrnirably adapted.

For fiel, no American wood is equal to this in the brilliancy with which it burns, or in the duration or arnount of heat given out by it : it therefore commands the highest price in market for that purpose.

'I'he lickories are nearly allied to the walnuts; tho chief botanical distinetion consisting in the covering to the nut, or husk; which, in the hickories, separates into four valves, or pieces, when ripe, instearl of adhering in a homogeneous coat, as upon the Black walnut and butternut. In size and appearance, the hickories rank with the first class of forest trees; most of them growing vigorously to the height of 60 or 80 feet, with fine straight trunks, well balanced and arnple heads, and handsome, lively, pinnated foliagre. When confined among other trees in the forest, they shoot up 50 or 60 , feet without hranches; but when standing singly, they expand into a fine head near the ground and produce a noble, lofty pyramid of foliage, rather rounded at the top. They have ill the qualities which are necessary to constitute fine, graceful park trees, and are justly entitled to a place in every considerable plantation.

'The most ornamental species are the Shellbark hickory, the Pignut, and the P'ecan-nut. The former and the latter produce delicious nuts, and are highly worthy of cultivation for their fruit alone; while all of them assume very handsome shapes during every stage of their growth, and ultimately become noble trees. Varieties of the Shellbark hickory are sometimes seen producing nuts of twice or thrice the ordinary size; and we have not the least doubt that the fruit might be so improved in size and 
delicacy of flaror, by careful cultivation, as greatly to supass the European walnut, for the table. This result will probably be attained by planting the nuts of the finest rarieties found in our woods, in rich moist soil, kept in high cultiration; as all improved rarieties of fruit hare heen produced in this way, and not, as many suppose, by cultirating the original species. These remarks also apply to the Pecan-nut; a western sort, which thrives well in the middle states, and which produces a nut more delicate in flaror than any other of this continent.

These trees form strong tap-roots, and are, therefore, somewhat difficult to transplant; but they are easily reared from the nut; and, for the reason stated abore, this method should be adopted in preference to any other, except in particular cases.

The principal species of the hickory are the following:

The Shellbark hickory (C. alba), so called on account of the roughness of its bark, which is loosened from the trunk in long scales or pieces, bending outwards at the exiremity, and remaining attached by the middle; this takes place, howerer, only on trees of some size. The leares are composed of two pair of leaflets, with an odd or terminal one. The scales which corer the buds of the Shellbark in winter, adhere only to the lower half, while the upper half of the bud is left uncorered, by which this surt is readily distinguished from the other species. The hickory nuts of our markets are the product of this tree; they are much esteemed in erery part of the Union, and are exported in considerable quantities to Europe. Among many of the descendants of the original Dutch settlers of 
New York and New Jersey, the fruit is commonly known by the appellation of the Kisky-tom nut.*

The Pecan-nut (Pacainer of the French), (C. olivaformis) is found only in the western states. It abounds on the Missouri, Arkansas, Wabash, and Illinois Rivers, and a portion of the Ohio: Michaux states that there is a swamp of 800 acres on the right bank of the Ohio, opposite the Cumberland river, entirely covered with it. It is a handsome, stately tree, about 60 or 70 feet in height, with leaves a foot or eighteen inches long, composed of six or seven pairs of leaflets much narrower than those of our hickories. The nuts are contained in a thin, somewhat four-sided husk; they are about an inch or an inch and a half long, smooth, cylindrical, and thin-shelled. The kernel is not, like most of the hickories, divided by partitions, and it has a very delicate and agreeable flavor. They form an object of petty commerce between Upper and Lower Louisiana. From New Orleans, they are exported to the West Indies, and to the ports of the United States. $†$

Besides these two most valuable species, our forests produce the Pignut hickory (C. porcina), a lofty tree with five to seven pairs of leaflets, so called from the comparative worthlessness of its fruit; which is very thick-shelled, and generally is left on the ground for the swine, squirrels, etc., to devour. It is easily distinguished in winter by the smaller size of its brown shoots, and its small oval buds. Its wood is considered the toughest and strongest of any of the trees of this section. The thick Shellbark hickory

* In some parts, pleasant social parties which meet at stated times during the winter season, are called Kisky-toms, from the regular appearance of these zuts among the refreshments of the evening.

† N. A. Sylva, i. 168. 
(C. laciniosa) resembles much in size and appearance the common Shellbark; but the nuts are double the size, the shell much thicker and yellowish, while that of the latter is white. It is but little lnown except west of the Alleghanies. The Mockernut hickory (C.tomentosa) is so called from the deceptive appearance of the nuts, which are generally of large size, but contain only a very small liernel. The leares are composed of but four pairs of sessile leaflets, with an odd one at the end. The trunk of the old trees is very rugged, and the wood is one of the best for fuel.

The Bitternut hickory ( $C$. amara), sometimes called the White hickory, grows 60 feet high in New Jersey. The husk which corers the mut of this species, has four winged appendages on its upper half, and nerer hardens like the other sorts, but becomes soft and decars. The shell is thin, but the kernel is so bitter that eren the squirrels refuse to eat it. The Water Bitternut (C. aquatica) is a rery inferior sort, growing in the swamps and rice fields of the southern states. The leaflets are serrated, and resemble in shape the leares of the peach tree. Both the fruit and timber are much inferior to those of all the other hickories.

\section{The Mountair Ash Tree. Pyrus.*}

Now. Ord. Rosaceæ. Lin. Syst. Icosandria, Di-Pentagynia.

The European Mountain ash (Pyrus aucuparia) is an elegant tree; of the medium size, with an erect stem,

* Sorbus of the old Botanists. 
smooth bark, and round head. The leaves are pinnated, four or five inches in length, and slightly resemble those of the ash. The snow-white flowers are produced in large flat clusters, in the month of May, which are thickly suattered over the outer surface of the tree, and give it it lively appearance. These are succeeded by numerous bunches of berries, which in autumn turn to a brilliant scarlet, and are then highly ornamental. For the sake of these berries, this tree is a great favorite with birds; and in Germany it is called the Vogel Beerbaum, i. e. bird's berry tree, and is much used by bird catchers to bait their springs with.

Twenty-five feet is about the average height of the Mountain ash in this country. Abroad, it grows more vigorously; and in Scotland, where it is best known by the name of the Roan or Rowan tree, it sometimes reaches the altitude of 35 or 40 feet. The lower classes, throughout the whole of Britain, for a long time attributed to its branches the power of being a sovereign charm against witches; and Sir Thomas Lauder informs us that this superstition is still in existence in many parts of the Highlands, as well as in Wales. It is probable that this tree was a great favorite with the Druids; for it is often seen growing near their ancient mystical circles of stones. The dairymaid, in many parts of England, still preserves the old custom of driving her cows to pasture with a switch of the roan tree, which she believes has the power to shield them from all evil spells.* "Evelyn mentions that it is cusiomary in Wales to plant this tree in churchyards; and Miss Kent, in her Sylvan Sketches, makes the following remarks:- In former times this tree was supposed to be 
possessed of the property of driving away witches and evls spirits; and this property is alluded to in one of the stanzas of a very ancient song, called the Laidley Worm of Spindlcton's Heugins.

- Their spells were vain ; the boys return'd

To the Queen in sorrowful mood,

Crying that "witches have no power

Where there is rowan-tree wood?"

"The last line of this stanza leads to the true ruading of a stanza in Shakspeare's tragedy of Macbeth. The sailor's wife, on the witch's requesting some chestnuts, hastily' answers, 'A rown-tree, witch!'-but many of the editions have it, 'aroint thee, witch!' which is nonsense, and evidently a corruption."*

The European Mountain ash is quite a favorite with cultivators here, and deservedly so. lts foliage is extremely neat, its blossoms pretty, and its blazing red berries in autumn communicate a cheerfulness to the season, and harmonize happily with the gay tints of our native forest trees. It is remarkably well calculated for small plantations or collections, as it grows in almost any soil or situation, takes but little room, and is always interesting. "In the Scottish Highlands," says Gilpin, "on some rocky mountain covered with dark pines and waving birch, which cast a solemn gloom on the lake below, a few Mountain ashes joining in a clump and mixing with them, have a fine effect. In summer, the light green tint of their foliage, and in autumn, the glowing berries which hang clustering upon them, contrast beautifully with the deeper green of the pines : and if they are happily blended, and not in too large a proportion, they add some of the most picturesque furni-

* Arboretum et Friticetum, p. 918. 
ture with which the sides of those rugged mountains are invested." We have seen the Mountain ash, here, display. ing itself in great beauty, mingled with a group of hemlocks, from among the deep green foliage of which, the coral berries of the former seemed to shoot out; their color heightened by the dark back ground of evergreen boughs.

The American Mountain ash (Pyrus Americana) is a native of the mountains along the banks of the Hudson, and other cold and elevated situations in the north of the United States : on the Catskill we have seen some handsome specimens near the Mountain House ; but generally, it does not grow in so comely a shape, or form so handsome a tree as the foreign sort. In the general appearance of the leaves and blossoms, however, it so nearly resembles the European as to be thought merely a variety by some botanists. The chief difference between them appears to be in the color of the fruit, which, on our native tree, is copper colored or dull purplish red. It may probably assume a handsome shape when cultivated.

The Sorb or Service tree (Pyrus Sorbus) is an interesting species of Pyrus, a native of Europe, which is sometimes seen in our gardens, and deserves a place for its handsome foliage and its clusters of fruit, which somewhat resemble those of the Mountain ash, and are often eaten when in a state of incipient decay. The leaves are coarser than those of the Mountain ash, and the tree is larger, often attaining the height of 50 or 60 feet, in its native soil.

The White Beam (Pyrus Aria) is another foreign species, also bearing bunches of handsome scarlet berries, and clusters of white flowers. The leaves, however, are not pinnated, but simply serrated on the margin. It grows $\mathbf{3 0}$ feet 
high, and as the foliage is dark green on the upper side, and downy white beneath, it presents an effect greatly resem. bling that of the Silver poplar in a slight breeze. Abroad, the timber is considered raluable; but here it is chiefly planted to produce a pleasing rarietr among other trees, by its peculiar foliage, and scarlet autumnal fruit.

All the foregoing trees grow naturall in the highest. most exposed, and often almost barren situations. When, howerer, a rapid growth is desired, ther should be planted in a more moist and genial soil. They are easily propagated from the seed. and some of the sorts may be grafted on the pear or hawthorn. The seeds, in all cases, should be sown in autumn.

\section{The Arlintes Tree. Ailantus.}

Mat. Ord. Innthorylacee. Lin. Syst. Folrgamia, Monceia.

Ailanto is the name of this tree in the Moluceas, and is said to signify Tree of Hearen; an appellation probably bestorred on account of the rapidity of its growth, and the great height which it reaches in the East Indies, its native country. When quite roung it is not unlike a sumac in appearance; but the exlreme rapidity of its growth and the great size of its pinnated leares. four or five feet long. soon distinguish it from that shrub. During the first half dozen rears it outstrips almost ant other deciduous tree in rigor of growth. and we hare measured leading stems which had grown twelve or fifteen feet in a single season. In four or five years, therefore, it forms quite a bulky head, but after that period it advances more slowly, and in 20 rears would probably be orertopped by the poplar, the plane, or any other fast growing tree. There are, as yet, no specimens 
in this country more than 70 feet high; but the trunk shoots up in a fine column, and the head is massy and irregular in outline. With us it is planted purely for ornament, but we learn that in Europe its wood has been applied to cabinet work; for which, from its close grain and bright satin-like lustre, it is well adapted.* The male and female flowers are borne on separate trees, and both sexes are now common, especially in New York. The male forms the finer ornamental tree, the female being rather low, and spreading in its head.

In New York and Philadelphia, the Ailantus is more generally known by the name of the Celestial tree, and is much planted in the streets and public squares. For such situations it is admirably adapted, as it will insinuate its strong roots into the most meagre and barren soil, where few other trees will grow, and soon produce an abundance of foliage and fine shade. It appears also to be perfectly free from insects; and the leaves, instead of dropping slowly, and for a long time, fall off almost immediately when frost commences.

The Ailantus is a picturesque tree, well adapted to produce a good effect on the lawn, either singly or grouped; as its fine long foliage catches the light well, and contrasts strikingly with that of the round-leaved trees. It has a troublesome habit of producing suckers, however, which must exclude it from every place but a heavy sward, where the surface of the ground is never stirred by cultivation.

The branches of this tree are entirely destitute of the small spray so common on most forest trees, and have a singularly naked look in winter, well calculated to fix the attention of the spectator at that dreary season.

* Annales de la Societé d'Horticulture. 
The largest Ailantus trees in America are growing in Rhode Island, where it was introduced from China, under the name of the Tillou tree. It has since been rapidly propagated by suckers, and is now one of the commonest ornamental trees sold in the nurseries. The finest trees, however, are those raised from seed.*

\section{The Kentuch Cofree Tree. Giymocladus.}

Nat. Ord. Leguminosæ. Lin. Syst. Diœcia, Decandria.

This unique tree is found in the western part of the State of New York, and as far north as Montreal, in Canada But it is seen in the greatest perfection, in the fertile buttoms of Kentucky and Tennessee. Sixty feet is the usual height of the Coffee tree in those soils; and judging from specimens growing under our inspection, it will scarcely fall short of that altitude, in well cultivated situations, anywhere in the middle states.

When in full foliage, this is a very beautiful tree. The whole leaf, doubly compound and composed of a great number of bluish-green leaflets, is generally three feet long, and of two-thirds that width on thrifty trees; and the whole foliage hangs in a well-rounded mass, that would look almosî too heary, were it not lightened in efiect by

* We think public opinzon has rery much ehanged abont this tree, since the early editions of this work. Being then but nemly introduced, and haring (to Americuns) the very great merit of growing with renarkable rapidity, it was very much songlut after, and is now, we thiuk, as universally neglected. 'Tho exceedingly disagreenble odor of its flowers and ronug wood, and the troublesome habit of suekering, hare quite thrown it into disfaror, especially since uts place can be now supplied by a mueh more effectire tree, from the same conntry (Japan): the Paulocnia-growing with equal rapidity, and having an early Spring bloom, of grent beanty and streetness of perfume. - H. W. S. 
the loose, tufted appearance of each individual leaf. The flowers, which are white, are borne in loose spikes, in the beginning of summer; and are succeeded by ample brown pods, flat and somewhat curved, which contain six or seven large grey seeds, imbedded in a sweet, pulpy substance. As the genus is diœcious, it is necessary that both sexes of this tree should be growing near each other, in order to produce seed.

When Kentucky was first settled by the adventurous pioneers from the Atlantic States, who commenced their career in the primeval wilderness, almost without the necessaries of life, except as produced by them from the fertile soil, they fancied that they had discovered a substitute for coffee in the seeds of this tree, and accordingly the name of Coffee tree was bestowed upon it: but when a communication was established with the seaports, they gladly relinquished their Kentucky beverage for the more grateful flavor of the Indian plant; and no use is at present made of it in that manier. It has, however, a fine, compact wood, highly useful in building or cabinet-work.

The Kentucky Coffee tree is well entitled to a place in every collection. In summer, its charming foliage and agreeable flowers render it a highly beautiful lawn tree; and in winter, it is certain y one of the most novel trees, in appearance, in our whole native sylva. Like the Ailantus, it is entirely destitute of small spray, but it also adds to this the additional singularity of thick, blunt, terminal branches, without any perceptible buds. Altogether it more resembles a dry, dead, and withered combination of sticks, than a living and thrifty tree. Although this would be highly monotonous and displeasing, were it the common appearance of our deciduous trees 
in winter ; yet, as it is not so, but a rare and very unique exception to the usual beautiful diversity of spray and ramification, it is highly interesting to place such a tree as the present in the neighborhood of other full-sprayed species, where the curiosity which it excites will add greatly to its, value as an interesting object at that period of the year.*

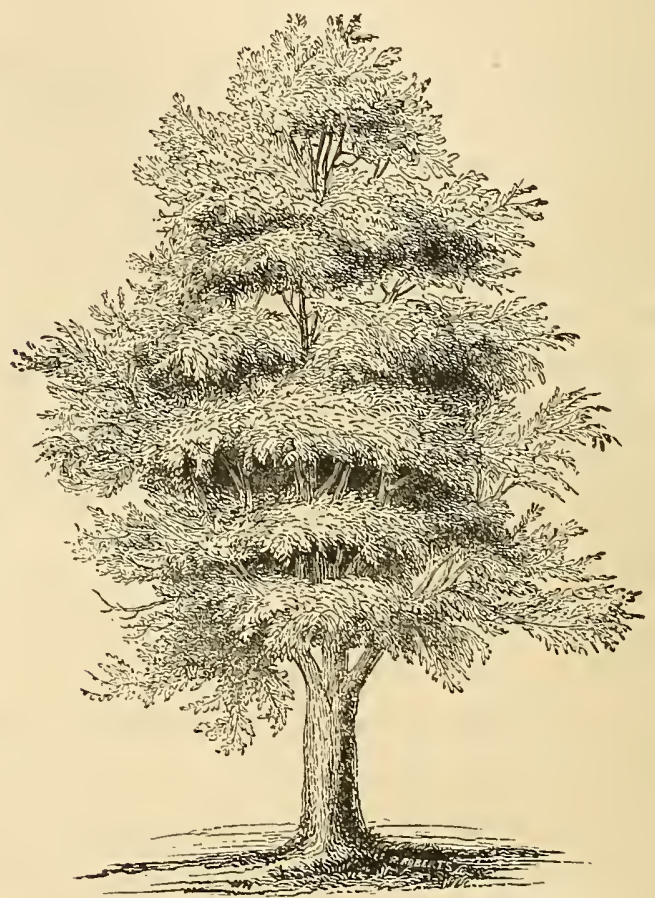

[Fig. 33. The Kentucky Coffee Tree.]

The seeds vegetate freely, and the tree is usually propagated in that manner. It prefers a rich, strong soil, like most trees of the western states.

* There are some very fine specimens upon the lawn, at Dr. Hosack's ceat, IIyde Park, N. Y., which have fruited for a number of years. See Fig. 33. 


\section{The Willow Tree. Salix.}

Nat. Ord. Salicaceæ. Lin. Syst. Diœeia, Diandria.

A very large genus, comprising plants of almost every stature, from minute shrubs of three or four inches in height, to lofty and wide-spreading trees of fifty or sixty feet.* They are generally remarkable for their narrow leaves, and slender, round, and flexible branches.

There are few of these willows which are adapted to add to the beauty of artificial scenery; but among them are three or four trees, which, from their peculiar character, deserve especial notice. These are the Weep. ing, or Babylonian willow (Salix Babylonica), the White, or Huntington willow (S. alba), the Golden willow (S. vitellina), the Russell willow (S. Russelliana), and the profuse Flowering willow (S. caprea).

The above are all foreign sorts, which, however (except the last), have long ago been introduced, and are now quite common in the United States. All of them except the first, have an upright or wavy, spreading growth, and form lofty trees, considerably valued abroad for their timber. The White willow and the Russell willow are very rapid in their growth, and have a pleasing, light green foliage. The Golden willow is remarkable for its bright yellow bark, which renders it quite ornamental, even in winter. It is a middle sized tree, and is often seen growing along the road-sides in the eastern and middle states. Salix caprea is deserving a place in collections for the beauty of its abundant blossoms at an early and cheerless period in the spring.

* Dr. Barratt, of Middletown, Conn., who has paid great attention to the willow, enumerates 100 species, as growing in North America, either indigenous or introduced. 
The chief, and indeed almost the only value of these willows in Landscape Gardening, is to embellish low grounds, streams of water, or margins of lakes. When mingled with other trees, they often harmonize so badly from their extremely different habits, foliage, and color, that unless very sparingly introduced, they cannot fail to have a bad effect. On the banks of streams, howvever, they are extremely appropriate, hanging their slender branches over the liquid element, and drawing genial nourishment from the moistened soil.

"Le saule incliné sur la rive penchante,

Balançant mollement sa tête blanchissante."

In the middle distance of a scene, also, where a stream winds partially hidden, or which might otherwise wholly escape the eye, these trees, if planted along its course, connected as they are in our minds with watery soils, will not fail to direct the attention and convey forcibly the impression of a brook or river, winding its way beneath their shade.

In landscapes, the Weeping willow is peculiarly express. ive of grace and softness. Although a highly beautiful tree, great care must be used in its introduction, to preserve the harmony and propriety of the whole; as nothing could be more strikingly inappropriate than to intermix it frequently with trees expressive of dignity or majesty, as the oak, etc.; where the violent contrast exhibited in the near proximity of the two opposite forms, could only produce discord. The favorite place, where it is most true to nature and itself, is near water, where 
There, when properly introduced, not in too great abundance, hanging over some rustic bridge, or cool, jutting spring, and supported, and brought into harmony with surrounding vegetation by such other graceful and lightsprayed trees as the Birch and Weeping elm, its effect is often surpassingly beautiful and appropriate. There it is one or the first in the vernal season to burst its buds, and mirror its soft green foliage in the flood beneath, and one of the last in autumn to yield its leafy vesture to the chilling frosts, or fitful gusts of approaching winter.

We consider the Weeping willow ill calculated for a place near a mansion which has any claims to size, magnificence, or architectural beauty; as it does not in any way contribute by its form or outline to add to or strengthen such characteristics in a building. The only place where it can be happily situated in this way, is in the case of very humble or inconspicuous cottages, which we have seen much ornamented by being completely hidden, as it were, beneath the soft veil of its streaming folinge.

There is a very singular variety of the Weeping willow cultivated in our gardens, under the name of the Ringlet willow; which is so remarkable in the form of its foliage, and so different from all other trees, that it is well worth a place as a curiosity. Each leaf is curled round like a ring or hoop, and the appearance of a branch in full foliage is not unlike a thinly curled ringlet; whence its common na!ne. It forms a neat, middle-sized tree, with drooping branches, though hardly so pendent as the Weeping willow.

The uses of the willow are extremely numerous. Abroad, it is extensively cultivated in coppices, for timber and fuel, 
ior heops lies ete. : and we are intermed, that in the nortis.

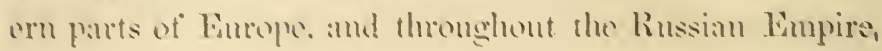
the twigs are cmployod in mimutatming domestio ntensils, hamess. cables. and even for the homses of the peat santry themsolves. From the tibes of the batk, it is satid that a durable choth is woren ly the 'latrtars: and the birk is used for tamming in valrious parts of the casterm continent.

But by tall the most extensive use to which this plant is applied, is in the mambiteture of baskets. From the

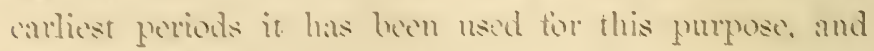
large plantations of osicedieds, as they ate called, are devoted to the culture of partienlar linds for this cond, both in Eumere and Ameriea. 'Ihe common basket willow. an Eurepen species (s. vimimetis), is the sort msmally. gerown for this purpuse, but several others are also compleyed. For the culture of the basket willews a deep. most. though not inmudated soil, is meessary" : such as is generally found on the mangius of small streams, or low lands. "liopes and baskets made fiom willow twigs, were problably" among the very earliest manutietures in comntries where these trees abound. I'le liomans med the twigs for binding their vines. and tying their reds in bundles and made all sorts of baskets of them. I crop of willows wis considered so valuable in the time of Cate, that he ramks the Silietmo. or willow field. next in value to the vinegard and the garden. (Art. Salix. A, B. Brit.)

Among us the buropean Basket willow is extensirely cultivated, and rery limge plantations are to be seen in the low grounds of SNew Jersey and l'ensylyania. The wood of some of the tree willows and particularly that of the Yollow willow; and the shining willow (S. lucilde). is 
greatly used in making charcoal for the manufacture of gurnpowder.

It is almost unrecessary to say that all the willows grow readily firm slips or truncherons planted in the ground. So tenacious of life are they, that examples are known where small trees have been taken up and completely inverted, by planting the branches and leaving the roots exposed, which have nevertheless thrown out new roots from the former tops, and the roots becoming branches, the tree grew again with its ordinary vigor.

'Tine Sassafras 'T'ene. Jaurus.

Nat. Ord. Lauraces. Lin. Syst. Enneandria, Monogynia.

The Sassafras is a neat tree of the rriddle size, belonging to the same furrily as the European laurel or Sweet bay; it is found, more or less pleritifully, through the whole territory of the United States. In favorable soils, along the banks of the Iludson, it often grows to 40 or 50 feet in height; but in the woods it seldorn reaches that altitude. The flowers are yellow, and appear in small clusters in May, and the fruit is a small, deep blue berry, seated on a red footstalk or cup. The bark of the wood and roots has an agrecable smell and taste, and is a favorite ingredient, with the branches of the spruce, in the small beer made by the country pcople. Medicinally, it is considered antiscorbutic and sudorific; and is thought efficacious in purifying the blood. It was formerly in great repute with practitioners abroad, and large quantities of the bark of the roots were shipped to England; but the demand has of late greatly decreased. 
The Sassafras is a very agreeable tree to the eye, decked as it is with its glossy, deep green, oval, or three-lobed leaves. When fully grown, it is also quite picturesque for a tree of so moderate a size; as its branches generally have an irregular, somewhat twisted look, and the head is partially flattened, and considerably varied in outline. After ten years of age, this tree always looks older than it really is, from its rough, deeply cracked, grey bark, and rather crooked stem. It often appears extremely well on the borders of a plantation, and mixes well with almost any of the heavier; deciduous trees. As it is by no means so common a tree as many of those already noticed, it is generally the more valued, and may frequently be seen growing along the edges of cultivated fields and pastures, appearing to thrive well in any good mellow soil.

\section{The Catalpa Tree. Catalpa.}

Nat. Ord. Bignoniaceæ. Lin. Syst. Diandria, Monogyna.

A native of nearly all the states south and west of Virginia, this tree has become naturalized also throughout the middle and eastern sections of the Union, where it is generally planted for ornament.

In Carolina it is called the Catawba tree, after the Catawba Indians, a tribe that formerly inhabited that country; and it is probable that the softer epithet now generally bestowed upon it in the north, is only a corruption of that original name.

The leaves of this tree are very large, often measuring six or seven inches broad; they are heart-shaped in form, 
smooth, and pale green on the upper side, slightly downy beneath. The blossoms are extremely beautiful, hanging, like those of the Horse-chestnut, in massy clusters beyond the outer surface of the foliage. The color is a pure and delicate white, and the inner part of the corolla is delicately sprinkled over with violet, or reddish and yellow spots; indeed, the individual beauty of the flowers is so great when viewed closely, that one almost regrets that they should be elevated on the branches of a large forest tree. When these fall, they are succeeded by bean-like capsules or seed-vessels, which grow ten or twelve inches long, become brown, and hang pendent upon the branches during the greater part of the winter.

The Catalpa never, or rarely, takes a symmetrical forms when growing up; but generally forms a wide-spreading head, forty or fifty feet in diameter. Its large and abundant foliage affords a copious shade, and its growth is quite rapid, soon forming a large and bulky tree. In ornamental plantations it is much valued on account of its superb and showy flowers, and is therefore deserving a place in every lawn. It is generally seen to best advantage when standing alone, but it may also be mingled with other large round-leaved trees, as the basswood, etc., when it produces a very pleasing effect. The branches are rather brittle, like those of the locust, and are therefore somewhat liable to be broken by the wind. Accustomed to a warmer climate, the leaves expand late in the spring, and wither hastily when frost approaches; but the soft tint of their luxuriant vegetation is very grateful to the eye, and it appears to be uninjured by the hottest rays of summer. North of this place, the Catalpa is rather too tender for exposed situations. 
We have seen the Catalpa employed to great advaritage in fixing and holding up the loose soil of river banks, where, if planted, it will soon insinuate its strong roots, and retain the soil firmly. In Ohio, experiments hare been made with the timber for the posts used in fencing; and it is stated on good authority that it is but little inferior, when well seasoned, to that of the locust, in durability.

Michaux mentions that he has been assured that the honey collected from the flowers is poisonous; but this we are inclined to doubt; or at least we have witnessed no ill effects from planting it in abundance in the middle States, in those neighborhoods where bees are kept in considerable numbers.

The Catalpa is rery ensily propagated from seeds sown in any light soil; and the growth of the young plants is extremely rapid. C. syringafolia is the only species.*

\section{The Persimon Tree. Diospyros.}

Nat. Ord. Ebenaceæ. Lin. Syst. Poḷ̦gamia, Diœcia.

The Highlands of the Hudson, and about the same latitude on the Connecticut, may be considered the northern limits of this small tree. It generally forms a spreading, loose head, of some twenty or thirty feet high, in good soils in the middle states; but we have seen a

* This was quite true when the abore chapter was written. Since rhen, we haro C. bungei, C. Kcemferi, and C. himmalayensis - the first two being dwarfs. 
specimen of nearly eighty feet, in the old Bartram Garden at Philadelphia; and fifty feet is probably the average growth on deep fertile lands in the southern states.

The Persimon bears a small, round, dull red fruit, about an inch in diameter, containing six or seven stones; it is insufferably austere and bitter, until the autumnal frosts have mellowed it and lessened its harshness, when it becomes quite palatable. Considerable quantities of the fruit are annually brought into New York market and its vicinity, from New Jersey, and sold : the produce is very abundant, a single tree often yielding several bushels. A strong brandy has been distilled from them; and in the south they are said to enter into the composition of the country beer. For the latter purpose they are pounded up with bran, dried, and kept for use till wanted.

The foliage of the Persimon is handsome; the leaves being four or five inches long, simple, oblong, dark green, and glossy, like those of the orange. The blossoms are green and inconspicuous.

The Persimon has no importance, as a tree, to recommend it; but it may be admitted in all good collections, for its pleasing, shining foliage, and the variety which its singular fruit adds to the productions of a complete country residence. The common sort (D. Virginiana) grows readily from the seed.

There is an European Species (Dyosporus Lotus), with yellow fruit about the size of a cherry, rather less palatable than our native kind. The specimens of this tree, which we have imported, appear too tender to bear our winters unprotected, so that it will probably not prove hardy in the northern states. 


\section{The Peperidge Tree, Nyssa.}

Tat. Ond. Santalaceæ. Lin. Syst. Foḷ̦gamia, Dicecia.

The Peperidge, Tupelo, or sour gun tree, as it is called in rarious parts of the Lnion, grows to a moderate size, and is generally found in moist situations, though we hare seen it in Ner York State, thriving very well in dry upland soils. The diameter of the trunk is seldom more than eighteen inches, and the general height is about forty or fifty feet. The flowers are scarcely perceptible, but the fruit borne in pairs, is about the size of a pea, deep blue, and ripens in October.

The leares are oral, smooth, and hare a beautiful gloss on their upper surface. The branches diverge from the main trunk almost horizontally, and sometimes even bend downwards: like those of some of the Pine family, which gires the tree a rery marked and picturesque character.

The Peperidge, when of moderate size. is not difficult to transplant, and we consider it a very fine tree, both on account of its beautiful, dark green, and lustrous foliage in summer, and the brilliant, fiery color which it takes when the frost touches it in autumn. In this respect it is fully equal in point of beauty to that of the Liquidambar or Swreet gum, and the maples which we have already described; and so fine a feature do we consider this autumnal beauty of foliage that we would by all means adrise the introduc. tion of such trees as the Peperidge into the landscape for that reason alone, were it not also valuable for its peculiar form and polished leares in summer.

Besides the Peperidge, there are three other Mrssas, natires of this continent, riz. the Black gum (N. Sylvatica): 
a tree of greater dimensions, and larger, more elongated leaves, whose northern boundary is the neighborhood of Philadelphia; the Large Tupelo ( $N$. grandidentata), a tree of the largest size, with large, coarsely toothed foliage, and a large blue fruit, three-fourths of an inch long, which is sometimes called the wild olive; and the sour Tupelo (N. capitata), with long, smooth, laurel-like leaves, and light red, oval fruit, called the Wild Lime, from its abounding in a strong acid, resembling that of the latter fruit. Both the latter trees are natives of the southern states, and are little known north of Philadelphia.

The wood of all the foregoing trees is remarkable for the peculiar arrangement of its fibres; which, instead of running directly through the stem in parallel lines, are curiously twisted and interwoven together. Owing to this circumstance it is extremely difficult to split, and is therefore often used in the manufacture of wooden bowls, trays, etc. That of the Peperidge is also preferred, for the same reason, and for its toughness, by the wheelwrights, in the construction of the naves of wheels, and for other similar purposes.

Michaux remarks that he is unable to give any reason why the names of Sour gum, Black gum, etc., have been bestowed upon these trees, as they spontaneously exude no sap or fluid which could give rise to such an appellation. We suspect that the term has arisen from a comparison of the autumnal tints of these trees belonging to the genus Nyssa, with those of the Sweet gum or Liquidambar, which, at a slort distance, they so much resemble in the early autumn.

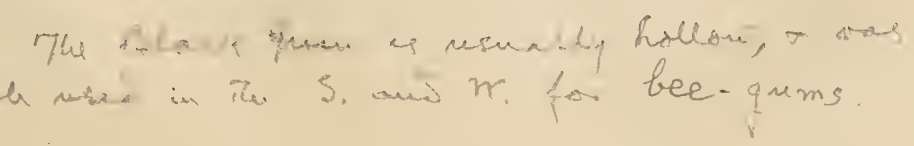




\section{The Thorn Tree. Crategus.}

Nat. Ord. Rosaceæ. Lin. Syst. Icosandria, Di-pentagynia,

A tree of the smallest size; but though many of the sorts attain only the stature of ordinary shrubs, yet some of our native species, as well as the English Hawthorn (C. oxycantha), when standing alone, will form neat, spreading-topped trees, of twenty or thirty feet in height.

Although the thorn is not generally viewed among us as a plant at all conducive to the beauty of scenery, yet we are induced to mention it here, and to enforce its claims in that point of view, as they appear to us highly entitled to consideration. First, the foliage-deep green, shining, and often beautifully cut and diversified in form, -is prettily tufted and arranged upon the branches; secondly, the snowy blossoms-often produced in such quantities as to completely whiten the whole head of the tree, and which in many sorts have a delightful perfume, -present a charming appearance in the early part of the season; and thirdly, the ruddy crimson or purple haws or fruit, which give the whole plant a rich and glowing appearance in and among our fine forests, open glades, or wild thickets, in autumn.

The most ornamental and the strongest growing indigenous kinds are the Scarlet Thorn tree (C. coccinea), and its varieties, the Washington Thorn (C. populifolia), and the Cockspur Thorn (C. crus-galli); all of which, in good soil, will grow to the height of twenty or thirty feet, and can readily be transplanted from their native sites.

The English Hawthorn is not only a beautiful small tree, but it is connected in our minds with all the elegant, 
poetic, and legendary associations which belong to it in England; for scarcely any tree is richer in such than this. With the floral games of May, this plant, from its blooming at that period, and being the favorite of the season, has become so identified, that the blossoms are known in many parts of Britain chiefly by that name. Among the ancient Greeks and Romans, they were dedicated to Flora, whose festival began on the first of that month; and in the olden times of merry England, the May-pole, its top decked with the gayest garlands of these blossoms, was raised amid the shouts of the young and old, assembled to celebrate this happy, rustic festival. Chaucer alludes to the custom, and describes the hawthorn thus :

Marke the faire blooming of the Hawthorne tree,

Which finely cloathed in a robe of white, Fills full the wanton eye with May's delight.

Court of Love.

And Herrick has left us the following lines to "Corrina going a Maying :"

"Come, my Corrina, come; and coming marke

How eche field turns a street, eche street a park

Made green, and trimmed with trees; see how

Devotion gives eche house a bough

Or branch; eche porch, eche doore ere this,

An arke, a tabernacle is,

Made up of Hawthorne, neatly interworo,

As if here were those cooler shacies of iove.".

The following lines descriptive of the English species, we extract from the "Romance of Nature."

"Come let us rest this hawthorn tree beneath, And breathe its luscious fragrance as it flics, 
And wateh the tiuy petals as ther fall, Cireling and wimnowing down our sylvan hall."

The berries, or haus, as they are called, have a rery rich and coral-like look when the tree, standing alone, is completely covered with them in Oetober. There are some elegant varieties of this species, which highly deserre cultiration for the beauty of their florrers and foliage. Among them we may particuiarly notice the Double White, with beautiful blossoms like small white roses; the Pink and the Scarlet flomering, both single and double, and the Tariegated-leaved hawthorn, all elegant trees; as well as the Weeping hathorn, a rarer variety, with pendulous branches.

The Harthorn is most agreeable to the ere in composition, when it forms the undergrowth or thicket, peeping out in all its green fireshmess. gay blossoms, or bright firuit, from beneath and betreen the groups and masses of trees; where, mingled with the hazel, ete., it gires a pleasing intricacy to the whole mass of foliage. But the different species display themselres to most adrantage, and grow also to a finer size, when planted singly, or two or three together, along the walks leading through the different parts of the pleasure-ground or shrubbery.

\section{The Magrolia Tree. Magnolia.}

Hat. Ord. Ingnolisees.

Lin. Syst. Polỵandria, Polygrnnia.

The North American trees composing the genus Magnolia are certainly among the most splendid productions of the forests in any temperate climate; and when twe consider 
the size and fragrance of their blossoms, or the beauty of their large and noble foliage, we may be allowed to doub1 whether there is a more magnificent and showy genus of deciduous trees in the world. With the exception of a few shrubs or smaller trees, natives of China and the mountaing of Central Asia, it belongs exclusively to this continent, as no individuals of this order are indigenous to Europe or Africa. The American species attracted the attention of the first botanists who came over to examine the riches of our native flora, and were transplanted to the gardens of England and France more than a hundred years ago, where they are still valued as the finest hardy trees of that hemisphere.

The Large Evergreen Magnolia ( $M$. grandiflora), or Big Laurel, as it is sometimes called, is peculiarly indigenous to that portion of our country south of North Carolina, where its stately trunk, often seventy feet in height, and superb pyramid of deep green foliage, render it one of the loveliest and most majestic of trees. The leaves, which are evergreen, and somewhat resemble those of the laurel in form, are generally six or eight inches in length, thick in texture and brilliantly polished on the upper surface. The highly fragrant flowers are composed of about six petals, opening in a wide, cup-like form, of the most snowy whiteness of color. Scattered among the rich foliage, their effect is exquisitely beautiful. The seeds are borne in an oval, cone-like carpel or seed-vessel, composed of a number of cells which split longitudinally, when the stony seed, covered with a bright red pulp, drops out. There are several varieties, which have been raised from the seed of this species abroad; the most beautiful is the Exmouth Magnolia, with fine foliage, rusty beneath; it produces its 
flowers much enlier and more abmulantly than the origmal sort.

We regret that this tree is too teuder to bear the open air north of thiladelphia $\mathrm{as}$ it is one of the choinest "rergerens. At the nurseries of the Messrs. Landreth. and at the bartram Botanic Garden of Col. Carr. near that city, some good specimens of this Magnolia and its rarietics are growing thrifily: but in the State of New lork. and at the cast. it can only be considered a greenhouse plimt.

The Cucumber Mangulia (C. arminata), (so called from the appearance of the roung fint, which is not unlike a green cucumber) takes the same place in the north, in point of majesty and eleration. that the Big Laurel occupies in the south. Its morthern limit is Lake Erie: and it ahoumds along the whole range of the Alleghamies to the southward. in rich mountain acelivities, and moist sheltered ralleys. There it often measures three or four fect in diameter, and eighty in height. The leares, which are deciduous. like those of all the Maguolias except the $M$.

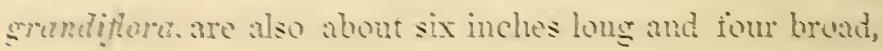
acuminate at the point. of a bluish green on the upper surfice. The flowers aro six inches in diameter, of a pale yellow. mueh like those of the Tulip tree, and slighty tragrant. The truit is about thee inches long. and eylindrical in shape. Most of the inhabitants of the cormtry bordering on the Alleghanies says Michaux grather these cones about midsummer, when they are halt ripe, and steep them in whiskey: the liquor produced, they take as an antidote against the ferers preralent in those districts.

The Lmbrella Magnolia (M. tripetala), though found 
sometimes in the northwest of New York, is rare there, and abounds most in the south and west. It is a smallor tree than the preceding kinds, rarely growing more than thirty feet high. 'The leaves on the terminal shoots are disposed three or four in a tuft, which has given rise to the name of Umbrella tree. 'They aie of fine size, eighteen inches or two feet long, and seven or eight broad, oral, pointed at both ends; the flowers are also large, white, and numerous; and the conical fiuit-vessel containing the secds, assumes a beautiful rose-color in autumn. From its fine tufted foliage, and rapid growth, this is one of the most desirable specics for our pleasure-grounds.

The Large-leaved Magnolia (M. macrophylia) is the larest of the genus in our forests, being only found o.s yet in North Carclina. The leaves grow to an enormous size when the tree is young, often measuring three feet long, and nine or ten inches broad. They are oblong, oval, and heart-shaped at the base. The flowers are also immense, opening of the size of a hat-crown, and diffusing a most agreeable odor. The tree attains only a secondary size, and is distinguished in winter by the whiteness of its bark, compared with the others. It is rather tender north of New York.

The Heart-leaved Magnolia (M. cordata) is a beautiful southern species, distinguished by its nearly round, heartshaped foliage, and its yellow flowers about four inches in diameter. It blooms in the gardens very young, and very abundantly, often producing two crops in a season.

Magnolia auriculata grows about forty feet high, and is also found near the southern Alleghany range of mountains. The leaves are light green, eight or nine inches long, widest at the top, and narrower towards the 
bsse, where they are rounded into lobes. 'The flowers are not so fine as those of the preceding kinds, but still are handsome, pale greenish white, and about four inches in diameter.

Besides these, there is a smaller American Magnolia, which is the only sort that in the middle or eastern sections of the Cnion grows within 150 miles of the seashore. This is the Magnolia of the stramps of New Jersey and the South ( $M$. glauca), of which so many fragrant and beautiful bouquets are gathered in the season of its inflorescence, brought to New Fork and Philadelphia, and exposed for sale in the markets. It is rather a large bush, than a tree; with shining, green, laurel-like leares, four or fire inches long, somewhat mealy or glaucous beneath. The blossoms, about three inches broad, are snowy white, and so fragrant that where they abound in the swamps, their perfume is often perceptible for the distance of a quarter of a mile.

The foreign sorts introduced into our gardens from China, are the Chinese purple (II. purpurea), which produces an abundance of large, delicate purple blossoms, early in the season; the Iulan or Chinese White Magnolia ( $(I$. conspicua), a most abundant bloomer, bearing beautiful white, fragrant flowers in April, before the leaves appear; and Soulange's Magnolia (II. Soulangiana), a hybrid between the two foregoing, with large flowers delicately tinted with white and purple. These succeed well in sheltered situations, in our pleasure-grounds, and add greatly to their beauty early in the season. Grafted on the cucumber tree, they form large and vigorous trees of great beauty.

The Magnolia, in order to thrive well, requires a deep 
rich soil; which in nearly all cases, to secure their luxuriance, should be improved by adding thereto some leaf mould or decayed vegetable matter from the woods. When transplanted from the nursery, they should be preferred of small or only moderate size, as their succulent roots are easily injured, and they recover slowly when large. Most of them may be propagated from seed; but they flower sooner, grow more vigorously, and are much hardier when grafted upon young stocks of the Cucumber Magnolia. This we have found to be particularly the case with the Chinese species and varieties.

All these trees are such superbly beautiful objects upon a lawn in their rich summer garniture of luxuriant foliage, and large odoriferous flowers, that they need no further recommendation from us to insure their regard and admiration from all persons who have room for their culture. If possible, situations somewhat sheltered, either by buildings or other trees, should be chosen for all the species, except the Cucumber Magnolia, which thrives well in almost any aspect not directly open to violent gales of wind.

The White-Wood, or Tulip Tree. Liriodendron.

Nat. Ord. Magnoliaceæ.

Lin. Syst. Polyandria, Polygynia.

The Tulip tree belongs to the same natural order as the Magnolias, and is not inferior to most of the latter in all that entitles them to rank among our rery finest forest trees.

The taller Magnolias, as we have already remarkeả, do 
not grow naturally within 100 or 150 miles of the seacoast; and the Tulip tree may be considered as in some measure supplying their place in the middle Atlantic states. West of the Connecticut river, and south of the sources of the Hudson, this fine tree may be often seen reaching, in warm and deep alluvial soils, 80 or 90 feet iri height. But in the western states, where indeed the growth of forest trees is astonishingly vigorous, this tree far exceeds that altitude. The elder Michaux mentions several which he saw in Kentucky, that were fifteen and sixteen feet in girth; and his son confirms the measurement of one, three miles and a half from Louisville, which, at five feet from the ground, was found to be twenty-two feet and six inches in circumference, with a corresponding elevation of 130 feet.

The foliage is rich and glossy, and has a very peculiar form; being cut off, as it were, at the extremity, and slightly notched and divided into two-sided lobes. The breadth of the leaves is six or eight inches. The flowers, which are shaped like a large tulip, are composed of six thick yellow petals, mottled on the inner surface with red and green. They are borne singly on the terminal shoots, have a pleasant, slight perfume, and are very showy. The seed-vessel, which ripens in October, is formed of a number of scales surrounding the central axis in the form of a cone. It is remarkable that young trees under 30 or 35 feet high, seldom or never perfect their seeds.

Whoever has once seen the Tulip tree in a situation where the soil was favorable to its free growth, can never forget it. With a clean trunk, straight as a column, for 40 or 50 feet, surmounted by a fine, ample summit of rich green foliage, it is, in our estimation, 
decidedly the most stately tree in North America. When standing alone, and encouraged in its lateral growth, it will indeed often produce a lower head, but its tendency is to rise, and it only exhibits itself in all its stateliness and majesty when, supported on such a noble columnar trunk, it towers far above the heads of its neighbors of the park or forest. Even when at its loftiest elevation, its large specious blossoms, which, from their form, one of our poets has likened to the chalice ;

\section{Through the verdant maze \\ The Tulip tree}

Its golden chalice oft triumphantly displays.

Pichering.

jut out from amid the tufted canopy in the month of June, and glow in richness and beauty. While the tree is less than a foot in diameter, the stem is extremely smooth, and it has almost always a refined and finished appearance. For the lawn or park, we conceive the Tulip tree eminently adapted: its tall upright stem, and handsome summit, contrasting nobly with the spreading forms of most deciduous trees. It should generally stand alone, or near the border of a mass of trees, where it may fully display itself to the eye, and exhibit all its charms from the root to the very summit; for no tree of the same grandeur and magnitude is so truly beautiful and graceful in every portion of its trunk and branches. Where there is a taste for avenues, the Tulip tree ought by all means to be employed, as it makes a most magnificent overarching canopy of verdure, supported on trunks almost architectural in their symmetry. The leaves also, from their bitterness, are but little liable to the attacks of any insect. 
This tree was introduced into England about 1668; and is now to be found in almost every gentleman's park on the Continent of Europe, so highly is it esteemed as an ornamental tree of the first class. We hope that the fine native specimens yet standing, here and there, in farm lands along our river banks, may be sacredly preserved from the barbarous infliction of the axe, which formerly despoiled without mercy so many of the majestic denizens of our native forests.

In the western states, where this tree abounds, it is much used in building and carpentry. The timber is light and yellow, and the tree is commonly called the Yellow Poplar in those districts, from some fancied resemblance in the wood, though it is much heavier and more durable than that of the poplar.

When exposed to the weather, the wood is liable to warp, but as it is fine grained, light, and easily worked, it is extensively employed for the panels of coaches, doors, cabinet-work, and wainscots. The Indians who once inhabited these regions, hollowed out the trunks, and made their canoes of them. There are two sorts of timber known; viz. the Yellow and the White Poplar, or Tulip tree. These, however, it is well known are the same species (L. tulipifera); but the variation is brought about by the soil, which if dry, gravelly, and elevated, produces the white, and if rich, deep, and rather moist, the yellow timber.

It is rather difficult to transplant the Tulip tree when it has attained much size, unless the roots have undergone preparation, as will hereafter be mentioned; but it is easily propagated from seed, or obtained from the nurseries, and the growth is then strong and rapid. 


\section{The Dogwood Tree. Cornus.}

Nat. Ord. Cornaceæ. Lin. Syst. Tetrandria, Monogynia.

There are a number of small shrubs that belong to this genus, but the common Dogwood (Cornus florida) is the only species which has any claims to rank as a tree. In the middle states, where it abounds, as well as in most other parts of the Union, the maximum height is thirtyfive feet, while its ordinary elevation is about twenty feet.

The Dogwood is quite a picturesque small tree, and owes its interest chiefly to the beauty of its numerous blossoms and fruit. The leaves are oval, about three inches long, dark green above, and paler below. In the beginning of May, while the foliage is beginning to expand rapidly, and before the tree is in full leaf, the flowers unfold, and present a beautiful spectacle, often covering the whole tree with their snowy garniture. The principal beauty of these consists in the involucrum or calyx, which, instead of being green, as is commonly the case, in the Dogwood takes a white or pale blue tint. The true flowers may be seen collected in little clusters, and are, individually, quite small, though surrounded by the involucrum, which produces all the effect of a fine white blossom.

In the early part of the season, the Dogwood is one of the gayest ornaments of our native woods. It is seen at that time to great advantage in sailing up the Hudson river. There, in the abrupt Highlands, which rise boldly many hundred feet above the level of the river, patches of the Dogwood in full bloom gleam forth in snowy whiteness from among the tender green of the surrounding young. foliage, and the gloomier shades of the dark evergreens 
which clothe with a rich rerdure the rocks and precipices that overhang the moring flood below.

The berries which succeed these blossoms become quite red and brilliant in autumn; and, as they are plentifully borne in little clusters, they make quite a display. When the sharp frosts have lessened their bitterness, they are the food of the robin, which, at that late season, eats them greedily.

The foliage in autumn is also highly beautiful, and must be considered as contributing to the charms of this tree. The color it assumes is a deep lake-red; and it is at that season as easily known at a distance by its fine coloring, as the Maple, the Liquidambar, and the Nyssa, of which we have already spoken. Taking into consideration all these ormamental qualities, and also the fact that it is every day becoming scarcer in our native wilds, we think the Dogwood tree should fairly come under the protection of the picturesque planter, and well deserres a place in the pleasure-ground and shrubbery.

The rood is close-grained, hard, and heary, and takes a good polish. It is too small to enter into general use, but is often employed for the lesser utensils of the farm. The bark has been very successfully employed by physicians in Philadelphia, and elsewhere, and is found to possess nearly the same properties as the Peruvian bark. Bigelow states in his American Botany, that its use in ferers has been hnown and practised in many sections of the Union by the country people, for more than fifty years.

Besides this native species there is an European dogrrood (Cornus mascula), commonly called the Cornelian cherry, which is now planted in many of our gardens, and grows to the height of twenty or thirty feet. The small 
yellow flowers come out close to the branches in March or April, and the whole tree is quite handsome in autumn, from the size and color of its fine oval scarlet berries. These are as large as a small cherry, transparent, and hang for a long time upon the tree. The leaves are much like those of the common Dogwood. Although the blossoms are produced when the plant is quite a bush, yet it must attain some age before the fruit sets. Altogether, the Cornelian cherry is one of the most desirable of small trees.*

The Salisburia, or Ginko Tree.

Nat. Ord. Taxaceæ. Lin. Syst. Monœcia, Polyandria.

This fine exotic tree, which appears to be perfectly hardy in this climate, is one of the most singular in its foliage that has ever come under our observation. The leaves are wedge-shaped, or somewhat triangular, attached to the petioles at one of the angles, and pale yellowish green in color; the ribs or veins, instead of diverging from the central mid-rib of the leaf, as is commonly the case in dicotyledonous plants, are all parallel; in short, they almost exactly resemble (except in being three or four times as large) those of the beautiful Maiden hair fern (Adiantum) common in our woods : being thickened at the edges and notched on the margin in a similar manner. The male flowers are yellow, sessile catkins; the female is seated in a curious kind of cup, formed by the enlargement of the summit of the peduncle. The fruit is a drupe, about an inch in length, containing a nut, which, according to Dr. Abel, is almost always to be seen for sale in the markets of China

* (Cnrnus variegata), the Variegated Dogwood, with leaves curionsly blotched with white, and (C. sanguinea), with its young shoots of a bright searlct-very showy in Winter, are both very desirable varieties.-H. W. S. 
and Japan, the native country of this tree. They are eaten after having been roasted or boiled, and are considered excellent.

The Salisburia was introduced into this country by that zealous amateur of horticulture and botany, the late $\mathrm{Mr}$. Hamilton, of Woodlands, near Philadelphia, who brought it from England in 1784, where it had been received from Japan about thirty years previous. There are several of these now growing at Woodlands ; and the largest measures sixty feet in height, and three feet four inches in circumference. The next largest specimen which we have seen is now standing on the north side of that fine public square, the Boston Common. It originally grew in the grounds of Gardiner Green, Esq., of Boston; but though of fine size, it was, about three years since, carefully removed to its present site, which proves its capability for bearing transplanting. Its measurement is forty feet in elevation, and three in circumference. There is also a very handsome tree in the grounds of Messrs. Landreth, Philadeiphia, about thirty-five feet high and very thrifty.

We have not learned that any of these trees have yet borne their blossoms; at any rate, none but male blossoms have yet been produced. Abroad, the Salisburia has fruited in the South of France, and young trees have been reared from the nuts.

The bark is somewhat soft and leathery, and on the trunk and branches assumes a singular tawny yellow or greyish color. The tree grows pretty rapidly, and forms an exceedingly neat, loose, conical, or tapering head. The timber is very solid and heavy; and the tree is said to grow to enormous size in its native country. Bunge, who accom. panied the mission from Russia to Pekin, states that he saw 
near a Pagoda, an immense Ginko tree, with a trunk nearly forty feet in circumference, and still in full vigor of vegetation.*

Although nearly related to the Pine tribe, and forming, apparently, the connecting link between the conifere and exogenous trees, yet, unlike the former tribe, the wood of the tree is perfectly free from resin.

The Ginko tree is so great a botanical curiosity, and is so singularly beautiful when clad with its fern-like foliage, that it is strikingly adapted to add ornament and interest to the pleasure ground. As the foliage is of that kind which must be viewed near by, to understand its peculiarity, and as the form and outline of the tree are pleasing, and harmonize well with buildings, we would recommend that it be planted near the house, where its unique character can be readily seen and appreciated.

Salisburia adiantifolia is the only species. In the United States it appears to flourish best in a rich fertile soil, rather dry than otherwise. South of Albany it is perfectly hardy, and may therefore be considered a most valuable acquisition to our catalogue of trees of the first class. It has hitherto been propagated chiefly from layers; but cuttings of the preceding year's growth, planted early in the spring, in a fine sandy loam, and kept shaded and watered, will also root without much difficulty. When the old trees already mentioned (which have doubtless been raised from seed) begin to blossom, plants reared from them by cuttings or grafts, will, of course, produce blossoms and fruit much more speedily than when reared from the nut.

* Bull. de la Soc. d'Agr. du départ de l'Herault. Arb. Brit. 


\section{The American Cypress Tree. Taxodium.}

Nut. Ord. Coniferæ.

Lin. Syst. Moncecia, Monadelphia.

The Southern or Deciduous cypress (Taxodium distichum)* is one of the most majestic, useful, and beautiful trees of the southern part of North America. Naturally, it is not found growing north of Maryland, or the south part of Delaware, but below that boundary it becomes extremely multiplied. The low grounds and alluvial soils subject to inundations, are constantly covered with this tree ; and on the banks of the Mississippi and other great western rivers, for more than 600 miles from its mouth, those vast marshes, caused by the periodical bursting and overflowing of their banks, are filled with huge and almost endless growths of this tree, called Cypress swamps. Beyond the boundaries of the United States its geographical range extends to Mexico; and Michaux estimates that it is found more or less abundantly, over a range of country more than $\mathbf{3 0 0 0}$ miles in extent.

"In the swamps of the southern states and the Floridas, on whose deep, miry soil a new layer of vegetable mould is deposited every year by the floods, the Cypress attains its utmost development. The largest stocks are 120 feet in height, and from 25 to 40 feet in circumference above the conical base, which at the surface of the earth is always three or four times as large as the continued diameter of the trunk; in felling them, the negroes are obliged to raise themselves upon scaffolds five or six feet from the ground. The roots of the largest stocks, particularly of such as are

* Cupressus disticha. 
most exposed to inundation, are charged with conical pro. tuberances, commonly from eighteen to twenty-four inches, and sometimes four or five feet in thickness; these are always hollow, smooth on the surface, and covered with a reddish bark, like the roots, which they resemble also in the softriess of their wood; they exhibit no sign of vegetation, and I have never succeeded in obtaining shoots by wounding their surface and covering them with the earth. No cause can be assigned for their existence : they are peculiar to the Cypress, and begin to appear when it is twenty or twenty-five feet in height; they are not made use of, except by the negroes for bee-hives."

"The foliage is open, light, and of a fresh, agreeable tint; each leaf is four or five inches long, and consists of two parallel rows of leaflets, upon a common stem. The leaflets are small, fine, and somewhat arching, with the convex side outwards. In the autumn, they change from a light green to a dull red, and are shed soon after."

"The Cypress blooms in Carolina about the first of February. The male and female flowers are borne separately, by the same tree ; the first in flexible pendulous aments, and the second in bunches, scarcely apparent. The cones are about as large as the thumb, hard, round, of an uneven surface, and stored with small, irregular, ligneous seeds, containing a cylindrical kernel; they are ripe in October, and retain their productive virtue for two years."*

Such is the account given of the Cypress in its native soils. In the middle states it is planted only as an ornamental tree; and while, in the South, its great abundance

* N. A. Sylva. ii. 332 . 
causes it to be neglected or disregarded as such, its rarity here allows us fully to appreciate its beauty. North of the $43^{\circ}$ of latitude it will not probably stand the winter without protection; but sonth of that. it will attain a good size. The finest planted specimen which we have seen, and ono which is probably equal in grandeur to almost any in their native swamps, is growing in the Bartram Botanic Garden, near Philadelphia. That garden was founded by the father of American botanists, John Bartram, who explored the southern and western territories, then rast wilds, at the peril of his life, to furnish the sazans and gardens of Europe, with the productions of the new world, and who commenced the living collection, now unequalled, of American trees, in his own garden. In the lower part of it stands the great Cypress, a tree of noble dimensions, measuring at this time 130 feet in height and $\$ 5$ in circumference. The tree was held by Bartram's son, William, while his father assisted in planting it, ninety-nine years ago. The elder Bartram at the time expressed to his son, the hope that the latter might live to see it a large tree. Long before he died (not many years since), it had become the prodigy of the garden, and great numbers from the neighboring city annually visit it, to admire its rast size, and recline beneath its ample shade.

The foliage of the Cypress is peculiar: for while it has a resemblance to the Hemlock, Jer, and other evergreen trees, its cheerful, bright green tint, and loose, airy tufts of toliage, gire it a character of great lightness and elegance. In young trees, the form of the head is prramidal or pointed; but when they become old, Michaux remarks, the head becomes widely spread, and even depressed, thus assuming a remarkably picturesque aspect. This is also 
heightened by the deep furrows or channels in the trunk, and the singular excrescences or knobs already described, which, jutting above the surface of the ground, give a strange ruggedness to the surface beneath the shadow of its branches. A single Cypress standing alone, like that in the Bartram Garden, is a grand object, uniting with the expression of great elegance and lightness in its foliage, that of magnificence, when we perceive its extraordinary height, and huge stem and branches.

In composition, the Cypress produces the happiest effect, when it is planted with the hemlock and firs, with which it harmonizes well in the form of its foliage, while its soft, light green hue is beautifully opposed to the richer and darker tints of those thickly-clad evergreens. Wherever there is a moist and rather rich soil, the Cypress may be advantageously planted: for although we have seen it thrive well on a fertile dry loam, yet to attain all its lofty proportions, it requires a soil where its thirsty roots can drink in a sufficient supply of moisture. There its growth is quite rapid ; and although it may, at first, suffer a little from the cold at the north, in severe winters, yet it continues its progress, and ultimately becomes a stately tree.

In many parts of the southern states, the timber of this tree, which is of excellent quality, is extensively used in the construction of the framework and outer covering of houses. It is also esteemed for shingles; and a large trade has long been carried on from the south in Cypress shingles. Posts made of this tree are found to be very lasting; and it is also employed for water-pipes, masts of vessels, etc. In the north, its place is supplied by the Pine 
timber, but in many southern cities, particularly New Orleans, it will be found to enter into the composition of almost every building.

In the nurseries, the Cypress is usually propagated from the seed; and as it sends down strong roots, it should be transplanted 'where it is finally to grow, before it attains too great a development.

The European Cypress (Cupressus sempervirens), a beautiful evergreen tree, shaped like a small Lombardy poplar, which is the principal ornament of the churchyards and cemeteries abroad, is unfortunately too tender to endure the winter in any of the states north of Virginia. South of that state, it may probably become naturalized, and serve to add to the catalogue of beautiful indigenous evergreen trees.

From its dark and sombre tint, and perpetual verdure, it is peculiarly the emblem of grief:

"Binde you my brows with mourning Cyparesse, And palish twigs of deadlier poplar tree, Or if some sadder shades ye can devise, Those sadder shades vaile my light-loathing eyes."

Br. Hatx.

\section{The Larch Tree. Larix.}

Nat. Ord. Coniferæ. Lin. Syst. Moncecia, Monadelphia.

The Larch is a resinous, cone-bearing tree, belonging to the Pine family, but differing from that genus in the annual shedding of its leaves like other deciduous trees. In Europe it is a native of the coldest parts of the Alps and Appenines; and in America, is indigenous to the most 
northern parts of the Union, and the Canadas. The leaves are collected in little bunches, and the branches shoot out from the main stem in a horizontal, or, more generally, in a declining position.

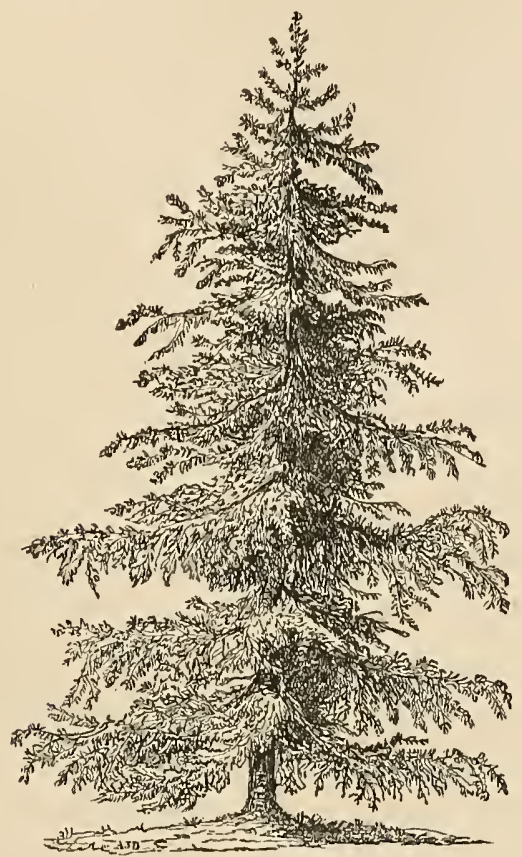

[Fig. 36. The European Larch.]

For picturesque beauty, the Larch is almost unrivalled. Unlike most other trees, which must grow old, uncouth and misshapen before they can attain that expression, this is singularly so, as soon, almost, as it begins to assume the stature of a tree. It can never be called a beautiful tree, so far as beauty consists in smooth outlines, a finely rounded head, or gracefully drooping branches. But it has, what is perhaps more valuable, as being more rare,-the expression of boldness and picturesqueness peculiar to itself, and 
which it seems to have caught from the wild and rugged chasms, rocks, and precipices of its native mountains. There its irregular and spiry top and branches, harmonize admirably with the abrupt variation of the surrounding hills, and suit well with the gloomy grandeur of those frowning heights.

Like all highly expressive and characteristic trees, much more care is necessary in introducing the Larch into artificial scenery, judiciously, than round-headed trees. If planted in abundance, it becomes monotonous, from the similitude of its form in different specimens; it should therefore be introduced sparingly, and always for some special purpose. This purpose may be either to give spirit to a group of other trees, to strengthen the already picturesque character of a scene, or to give life and variety to one naturally tame and uninteresting. All these objects can be fully effected by the Larch; and although it is by far the most suited to harmonize with and strengthen the expression of scenery naturally grand or picturesque, with which it most readily enters into combination; yet, in the hands of taste, there can be no reason why so marked a tree should not be employed in giving additional expression to scenery of a tamer character.

The extremely rapid growth of this tree when planted upon thin, barren, and dry soils, is another great merit which it possesses as an ornamental tree; and it is also a necessary one to enable it to thrive well on those very rocky and barren soils, where it is most in character with the surrounding objects. It is highly valuable to produce eflect or shelter suddenly, on portions of an estate, too thin or meagre in their soil to aftord the sustenance necessary to the growth of many other deciduous trees. 
'I'he Larch is the great timber tree of Europe. Its wood is remarkably heavy, strong, and durable, exceeding in all those qualities the best English oak. To these, it is said to add the peculiarity of being almost uninflammable, and resisting the influence of heat for a long time. Vitruvius relates that when Cæsar attacked the castle of Larignum, wear the Alps, whose gate was commanded by a tower built of this wood, from the top of which the besieged annoyed him with their stones and darts, he commanded his army to surround it with fagots, and set fire to the whole. When, however, all the former were onsumed, he was astonished to find the Larch tower uninjured.*

The Larch is unquestionably the most enduring timber that we have. It is remarkable, that whilst the red wood or heart wood is not formed at all in the other resinous trees, till they have lived for a good many years, the Larch, on the contrary, begins to make it soon after it is planted; and while you may fell a Scotch fir of thirty years old, and find no red wood in it, you can hardly cut down a young Larch large enough to be a walking stick, without fnding just such a proportion of red wood compared to its diameter as a tree, as you will find in the largest Larch tree in the forest, compared to its diameter. To prove the value of the Larch as a timber tree, several experiments were made in the river Thames. Posts of equal thickness and strength, some of Larch and others of oak, were driven down, facing the river wall, where they were aliernately covered with water by the effect of the tide, and then left dry by its fall. This species of alternation is the most trying of all circumstances for the endurance of timber; and accordingly the oaken posts decayed, and were twice renewed in the course of a very few years, 
while those that were made of the Larch remained altogether uncilanged.

Bosides the foregoing species (Larix Europea) "we have wo native sorts much resembling it: which are chiefly found in the states of Maine, Termont, and New Mampsire. These are known by the names of the lied Larch (L. Microcarpa) and the Black Larch (L. pendula). which latter is often called Hackmatack. In the coldest parts of the Union, these often grow to 80 and 100 feet high; but in the middle states they are only seen in the swamps, and appear not to thrive so well except in such situations. For this reason the European Larch is of course greatly preferable when plantations are to be made, either for profit or ormament. The latter is generally increased fiom seed in the nurseries.

The American Larches are well worthy a place where sufficient moisture can be commanded, as the:r peculiar forms are striking, though not so finely picturesque as that of the European species.

* A rery enrions and remarkable addition to the varieties of this gents is (Larix nendala) the Weoping Lareh, difluring from our (Penduha Americana) Ameriean Weeping Lareh, and mueh mere extracdinary. When worked teu or fitteon feet hight, the iuelination of the bimehes and spray is immelintely downward, and when gently strayed by the wind, it is exeessively graceful and pretig. We w not know a more distinetire and striking tree, or one more rare. It secms difhenlt to transylint-at least this is our experienee-and it ean only be increased by grmfting by approneh. Nurserymen are apt to work it too low : it shomld never be grafted at a less distanee than ten to twelve feet - -mal for some rears, it should be supported by a stont stake, as the tree is apt to he top-heary. This enrous rariety was found acedentally, if wo remember rigut, some ten to fifteen years since, in a nursery nen Ifereford, England, by a Mr. Gondsall, and is known in English museries ts Larix commenis pendukr

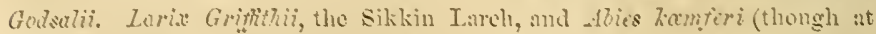
present chased an an flice, we helieve may prove to be Lareh), are two very new ruretice, two cxpensive at present to be genernlly introdneed. A hamferi, known alse as the Golden Pine of China, is very highly extolled for is heantiful green in Snmmer, and gollen eolor in Antmm or Winter.-II. W. S. 

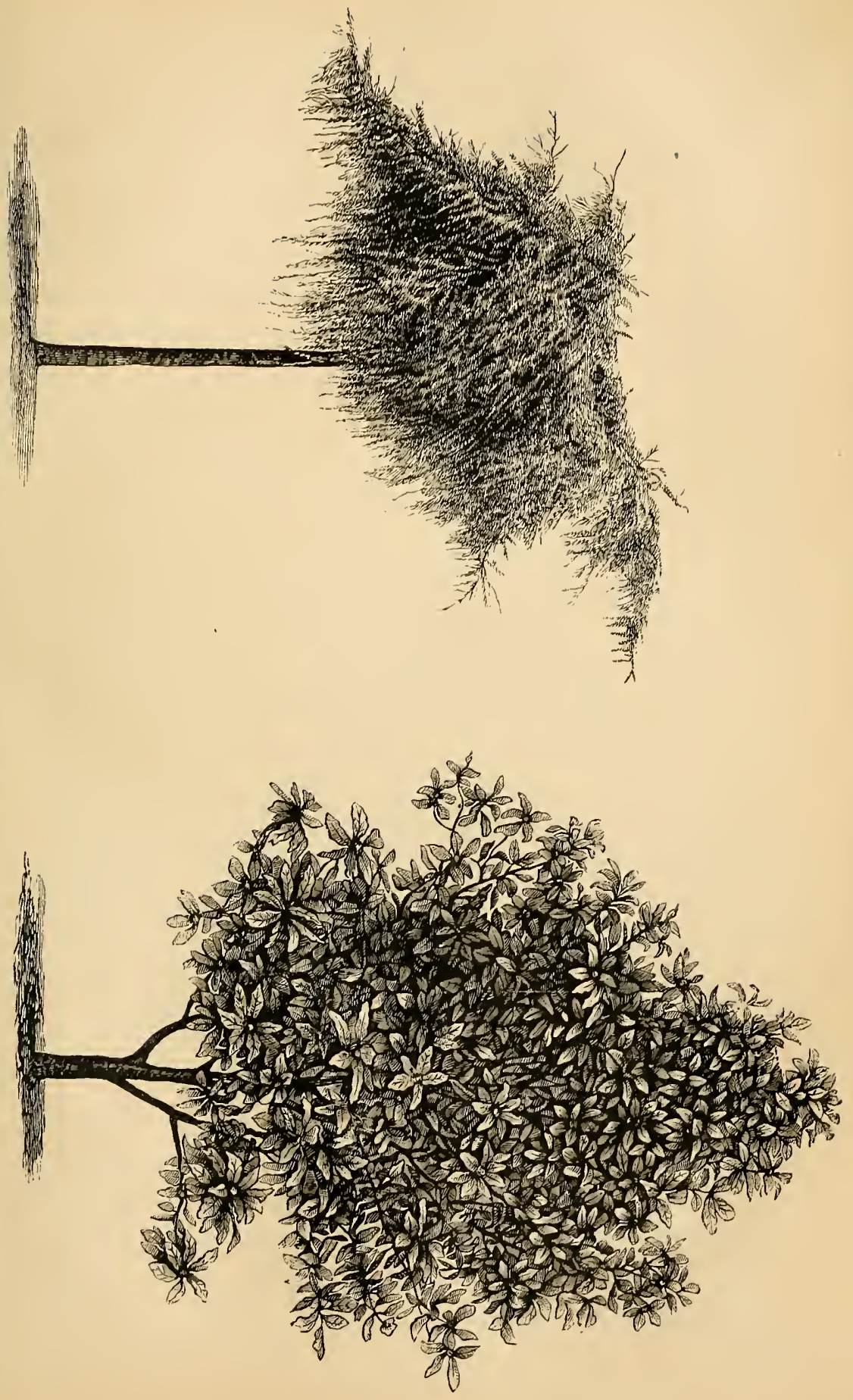

In the upper part of Massachusetts, we nave observed them in their native soils growing 70 or 80 feet high, and assuming a highly pleasing appearance. Their foliage is bluish-green, and more delicate; yet altogether the American Larch appears to be more stiff and formal (except (ar north) than the foreign tree.

\section{The Vrrgrla Tree. Virgilia.*}

Nat. Ord. Leguminacex. Lin. Syst. Decandria, Monogynia.

This fine American tree, still very rare in our ornamental plantations, is a native of West Tennessee, and the banks of the Kentucky river, and in its wild localities seems confined to rather narrow limits. It was named, when first discovered, after the poet Virgil, whose agreeable Georgics have endeared him to all lovers of nature and a country life.

The Virgilia is certainly one of the most beautiful of all that class of trees bearing papilionaccous, or pea-shaped flowers, and pinnate leaves, of which the common locust may serve as a familiar example. It grows to a fine, rather broad head, about 30 or 40 feet high, with dense and luxuriant foliage-much more massy and finely tufted than that of most other pinnated-leaved trees. Each leaf is composed of seven or eight leaflets, three or four inches long, and half that breadth, the whole leaf being more than a foot in length. These expand rather late in the spring, and are, about the middle of May, followed by numerous terminal racemes, or clusters, of the most delicate and charming pea-shaped blossoms, of a pure white. These

* Cladeastris tinctora. Torrey and Gray. 
clusters are six or eight inches in length, aud quite broad, the flowers daintily formed, and aranged in a much more graceful, Joose, and easy manuer, than those of the locust. They have a very agrecable, slight perfume, especially in the erening, and the whole eflect of the tree, when standing singly on a lawn and filled with blossoms, is highly elegant.

When the blossoms disappear, they are followed by the pods, about the fourth of an inch wide, and three or four inches long, containing a few seeds. 'These ripen in July or Augnist.

This tree is frequently called the Fellow-wood in its native haunts-its heart wood abounding in a fine yellow coloring matter, which, however, is said to be rather difficult to fix, or render permanent. The bark is beautifully smooth, and of a greenish grey color. In autumn, the leaves, when they die off, take a lively yellow tint.

'This tree grows pretty rapidly, and is very agreable in its form and foliage, eren while young. It commences flowering when about ten or fifteen feet high, and we can recommend it with confidence to the amateur of choice trees as worthy of a couspicuous place in the smallest collection.

The only species known is Firgilia lutea. It was first described by Michaux, and was sent to England about the year 1812. Quite the finest planted specimens within our knowledge are growing in some of the old seats in the norther suburbs of Philadelphia, where there are several, thirty or forty feet in height, and exceedingly beautiful, both in their form and blossoms. A small specimen on our lawn, eighteen feet high, blossoms now very pro. fusely. 


\section{The Paulownia Trem. Paulownia.}

Nat. Ord. Serophulariacex. Lin. Syst.

The Paulownia is an entirely new ornamental tree, very lately introduced into our gardens and pleasure-grounds, from Japan, and is likely to prove hardy here, wherever the Ailantus stands the winter, being naturally from the same soil and climate as that tree. It is remarkable for the large size of its foliage, and the great rapidity of its growth. The largest leaves are more than two feet in diameter, slightly rough or hairy, and serrated on the edges. They are heart-shaped, and have been likened to those of the Catalpa, but they perlaps, more nearly resemble those of the common Sun-flower.

In its growth, this tree, while young, equals or exceeds the Ailantus. In rich soils, near Paris, it has produced shoots, in a single season, 12 or 14 feet in length. $\Lambda$ fter being two or three years planted, it commences yielding its blossoms in panicled clusters. These are bluish lilac, of an open-mouthed, tubular form, are very abundantly distributed, and, together with the large foliage, and tho robust habit of growth, give this tree a gay and striking appearance. Its flower buds open during the last of $\Lambda$ pril, or early in May, and have a slight, syringa-like perfume.

Should the Paulownia prove as hardy as (from our fine dry summers for ripening its wood) we confidently anticipate * it will beworthy of a prominent place in every arrangement of choice ornamental trees.

* Wo doubt if this trec proves quito as hardy as Mr. Dswning believed. Our own trees, some of the oldest in the country, have missed their bloom for three years-though proviously, they land blossomed rog larly and woll. It is not impossible that, as the treo gets older, and its growth less rampant, it may ripen off its wood better, and thus bo in a better condition to resiat Spring frosts.-II. W. S. 


\title{
SECTION T.
}

\author{
FYELITEEY MIXAMFATAL TIEES.
}

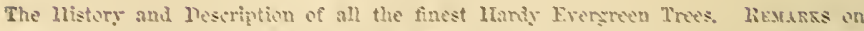

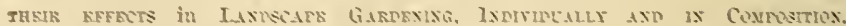

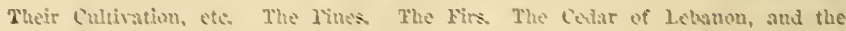

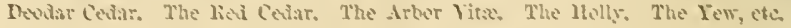

lieneath the finest s skirt I rest.

Whose branching lines rise dark and high, And hear the breves of the W"est

Amone the threaded toliage sigh.

BRTAงt.

The Trve Tues. Pinus.

Miss. Ord. Conitim.

Lin. Sys.. Moncecia, Monodelphia.

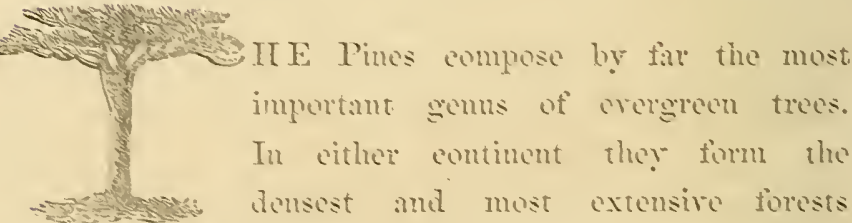

known, and their wood in ciril and naval arehitecture. and for rarions other purposes, is more gemerally usod than any other. In the Luted States and the Canndas. there are ter species: in the territory west of the Mississippi. to the Yacitic induling Mexico, there are fomten: in Emrope fomrosn: in Asia, cight, and in Afriea, two species. All the colder parts of the old world 
-the mountains of Switzerland and the Alps, the shores of the Baltic, vast tracts in Norway, Sweden, Germany, Poland, and Russia, as well as millions of acres in our own country, abound with immense and interminable forests of Pine. Capable of enduring extreme cold, growing on thin soils, and flourishing in an atmosphere, the mean temperature of which is not greater than $37^{\circ}$ or 380 Fuhrenhcit, they are found as far north as latitude 680 in Lapland; while on mountains they grow at a greater elevation than any other arboresecnt plant. On Momt Blane, the Pines grow within 2,800 feet of the line of perpetual snorv.* In Mexico, also, IIumboldt found them higher than any other trec; and Lieut. Glemnic describes them as growing in thick forests on the mountain of Popocatapetl, as high as 12,693 feet, beyond which altitude vegretation ceases cntirely. $\dagger$

The Pines are, most of them, trees of considerable magnitude and lofty growth, varying from 40 to 150 or cven 200 feet in height in favorable situations, rising with a perpendicular trunk, which is rarely divided into branches bearing much proportionate size to the main stem, as in most deciduous trees. The branches are much more horizontal than those of the latter class (excepting the Larch). The leaves are linear or needleshaped, and are always found arranged in little parcels of from two to six, the number varying in the different species. The blossoms are produced in spring, and the seeds, borne in cones, are not ripened, in many sorts, until the following autumn. Every part of the stem abounds in a resinous juice, which is extracted, and forms, in the

* Edinburgh Phil. Journ.

+ Proc. Geological Soc Lond. Arb. Brit. 
rarions shapes of tar, pitch, rosin, turpentine, balsam, etc, a considerable article of trade and export.

As ornamental trees, the Pines are peculiarly valuable for the deep rerdure of their foliage, which, unchanged by the sererity of the seasons, is beautiful at all periods, and especially so in winter; for the picturesque forms which many of them assume when fully grown; and for the effectual shelter and protection which they afiord in cold, bleak, and exposed situations. We shall here particularize those species, natives of either hemisphere, that are most valuable to the plauter, and are also capable of enduring the open air of the middle states.

The Thite Pine (P. strobus), called also Sapling Pine and Apple Pine, in rarions parts of this country, and Weymouth Pine abroad, is undoubtedly the most beautiful North American tree of the genus. The foliage is much lighter in color, more delicate in texture, and the whole tufting of the leaves more airy and pleasing than that of the other species. It is also beautiful in every stage of its growth, from a plant to a stately tree of 150 feet. When it grows in strong soil, it becomes thick and compact in its head; but its most beautiful form is displayed when it stands in a dry and grarelly site; there it shoots up with a majestic and stately shaft, studded every six or eight feet with horizontal tiers of branches and foliage. The hue of the leares is much paler and less sombre than that of the other native sorts; and being less stifly set upon the branches, is more casily put in motion by the wind; the murmuring of the wind among the Pine tops is, poetically thought to give out rather a melancholy sound -

"The pines of Mcenalus were heard to mourn, And sounds of woe along the grove wore borne," 
says Virgil, speaking of the European Pine. But the murnur of the slight breeze among the foliage of the White Pine gives out a remarkably soothing and agreeable sound, which agrees better with the description of Leigh Hunt:

"And then there fled by me a rush of air 'I'hat stirr'd up all the other foliage there, Filling the solitude with panting tongues, At which the Pines woke up into their songs, Shaking their choral locks."

Pickering, one of our own poets, thus characterizes the melody :

\footnotetext{
"Tho overshadowing pines alone, through which I roam, Their verduro keep, although it darker looks;

And hark! as it comes sighing through the grove, The cxhausted gale, a spirit there awakens, That wild and melancholy musie makes."
}

This species-the White Pine-seldom becomes flattenea or rounded on the summit in old age, like many other sorts, but preserves its graceful and tapering form entire. From its pleasing growth and color, we consider it by far the most desirable kind for planting in the proximity of buildings, and its growth, for an evergreen, is also quite rapid.

The leaves of the White Pine are thickly disposed on the branches, in little bundles or parcels of five. The cones are about five inches long: they hang, when nearly ripe, in a pendulous manner from the branches, and open, to shed their seeds, about the first of October. The bark on trees less than twenty years old is remarkably smooth, but becomes cracked and rough, like that of the othes 
Pines, when they grow old, although it never splits and separates itself from the trunk in scales, as in other species.

The great forests of White Pine lie in the northern parts of the Union : and the geographical range of this tree is comprised chicty betroen Now York and the frth degree of north latitude, it being neither eapable of resisting the ficree heat of the south. nor the intense cold of the extreme northern regions. In Maine. New Mampshire, and Termont, the White Pine abounds in rarieus situations, adapting itself to erery variety of soil, from dry, grarelly. upland, to swamps constantly wet. Miehaux measured tro trunks near the rirer Kennebec, one of whieh was 151 feet long, and 51 inches in diameter: the other 111 feet long. and 41 inches in dimeter. at three feet from the ground. Dr. Dwight also mentions a specimen on the Kiattskill 219 feet long, and sereral on the Lnadilla 200 feet long. and three in diameter.* 'These, though they are remarkable specimens, show the stately altitude which this fine species sometimes attains, equalling in majesty the grandest specimens of the old rorld:

\footnotetext{
The rougher rinded l'ine.

The great Argoan ship's brarc ornament.

Which, corcting with his high topis cxtent

To malio the mountuins touch the stars divine,

Decks all the forest with embellishment.
}

STEXSER.

The Jellow Pine ( $P$. mitis) is a fine erergreen, usually reaching a stature of 50 or 60 feet, with a nearly uniform diameter of about 18 inches for two-thirels of its length. 'The branches generally talie a handsome conical shape, and the whole head considerably resembles that of the spruce.

* Dright's Trarels, Vol. jr. p. 21—@6. 
whence it is sometimes called the Spruce l'ine. The term Yellow Pine arises fiom the color of the woorl as contrasted with that of the foregoing sort, which is white. 'The leaves of this species are long and flexible, arranged in pairs upon the branches, and have a fine dark green color. 'The eones are very sinall, scarcely measuring an inch and a lialf in length, and are clothed on the exterior with short spines. The growth is quite slow.

The Yellow Pine is rarely found above Albany to the northward, but it extends as far south as the Floridas. It grows in the greatest abundance in New Jersey, Maryland, and Virginia, and sometimes measures five or six feet in circuinference. In plantations, it has the valuable property to recommend it, of growing on the very poorest lands.

The Pitch Pine (I'. rigida) is a very distinet sort, common in the whole of the United States east of the Alleghanies. It is very stiff and formal in its growth when young, but as it approaches maturity, it becomes one of the most picturesque trees of the genus. Whe branches, which shoot out horizontally, bend downwards at the extremities, and the top of the tree, when old, takes a flattened shape. The, whole air and expression of the tree is wild and romantic, and is harmonious with portions of secnery where these characters predominate. The leaves are collected in threes, and the color of the foliage is a dark green. The cones are pyramidal, from one to three inches long, and armed with short spines.

The bark of this kind of Pine is remarkably rough, black, and furrowed, even upon young trees; and the wood is filled with resinous sap, from which pitch and tar are copionsly supplied. The trees grow in various parts of the country, both on the most meagre scils and in moist 
swamps, with almost equal facility. In the latter situations they are, howerer, comparatively destitute of resin, but tho stems often riso to so feet in eleration.

The foregoing are the finest and most important species of the north. The Red Pine (Pinus rubra) and the Grey Pine are species of small or secondary size, chiefly indigenous to British America. The Jersey l'ine ( $P$. inops) is a dwarfish species, often called the Scrub Pine, which seldom grows more thin 25 feet high.

There are some splendid species that are confined to the southern states, where they grow in great luxuriance. Among the most interestiug of these is the Long-leaver Pine (P. Australis), a tree of 70 feet eleration, with superb wandlike folinge, borne in threes, often nearly a foot in length. The cones are also seren or eight inches long. containing a kernel or seed of agreeable tharor. Is this tree grows as far north as Norfolk in Virginia, we are strongly inclined to believe that it might be naturalized in the elimate of the middle states, and think it would become one of the most raluable additions to our catalogue of evergreen trees. The Loblolly Pine ( $P$. Taeda) of Tirginia has also fine foliage, six inches or more in length, and grows to so feet in height. Besides these already named, the southern states produce the Pond Pine (P. Serotina), which resembles considerably the Pitch Pine, with, howerer, longer leares, and the Table Mountain Pine (P. Pungens), which grows 40 or 50 fect high, and is found exclusirely upon that part of the Alleghany range.

We must not forget in this enumeration of the Pines of North America, the magnificent species of California and the North-West const. The most splendid of these was discovered in Northern California, and named the Pinus 
Tambertiana, in honor of that distinguished botanist, A. B. Lambert, Esq., of London, the author of a superb work on this genus of trees. It is undoubtedly one of the finest cvergreens in the world, averaging from 100 to 200 feet in height. Its discoverer, Mr. Douglass, the indefatigable collector of the Horticultural Society of London, measured one of these trees that had blown down, which was two hundred and fifteen feet in length, and fifty-seven feet nine inches in circumference, at three feet from the root; while at one hundred and thirty-four feet from the root, it was seventeen feet five inches in girth. This, it is stated, is by no means the maximum height of the species. 'The cones of the Lambert Pine, mcasure sixtecn inches in length; and the seeds are eaten by the natives of those regions, either roasted or made into cakes, after being pounded. 'The other species found by Mr. Douglass grow naturally in the mountain valleys of the western coast, and several of them, as the Pinus grandis and nobilis, are almost as lofty as the foregoing sort; while Pinus monticola and P. Sabiniana are highly beautiful in their forms and elegant in foliage. The seeds of nearly all these sorts were first sent to the garden of the London Horticultural Society, where many of the young trees are now growing; and we hope that they will soon be introduced into our plantations, which they are so admirably calculated, by their elegant foliage and stupendous magnitude, to adorn.

The European Pines next deserve our attention. The most common species in the north of Europe is the Scotch Pine (P. sylvestris), a dark, tall, evergreen tree, with bluish foliage, of 80 feet in height, which furnishes most of the deal timber of Europe. It is one of the most rapid of all the Pines in its growth, eren on poor soils, and is therefore 
valuabe in new places. The Stone Pine $(P$. prnea $)$ is a native of the south of lintope, where it is, decidedly, the most pieturesigue erergmen tree of that continent. It belongs peouliarly to laly, and its " vast canopy, supported on a nalied colum of wreat height, torms one of the chief and peenliar beanties in Italian seenery, and in the living lamdscapes of Clamde." Wr regret that it is too tencier to bear our winters, but its place may in a great measure be smpplicd by the Pinaster or Cluster I'ine (P. pinaster), which is quite hatrdy; and sueceds well in the United States. 'lhis has mueh of the same picturesque expression, depressed or rounded head. and tall colmmar stem, which mark the Stone l'me: while its thickly massed foliage, chastering cones, and rough bark, render it distinet and strikingly interesting.

'The Corsican Pine (l'. laricio) is a handsome, regularshaped. primidal tree, with the bramches disposed in tiers, like these of the White l'ine. It grows to a laroge size, and is ralued for its extremely dark green follage, thickly spread upom the branches. It is also one of the most raphid growers among the foreigu sorts, and has been found to thrive remarkithy well upon the barren elnalk downs of England. Pims cembre is a rery slow growing, though valuable kind, indigenons to Switzerland, and hardy here.

These are the principal European species that deserye notice here for their ormamental qualitis. Some splendid aditions hate been made to this gemus, by the discovery of new species on the Himalaya mountains of Asia : and from the great clevation at which they are found grewing wild, we have reason to hope that they will become naturalized in our climate.

We must not leave this extensive fimily of trees without 
adverting to their numerous and important uses. In the United States, full four-fifths of all the houses built are constructed of the White and Yellow Pine, chicfly of the former. Soft, easily worked, light and fine in texture, it is almost universally employed in carpentry, and for all the purposes of civil architecture; while the tall stately trunks furnish masts and spars, not only for our own vessels, but many of those of Fingland. $\Lambda$ great commerce is therefore carried on in the timber of this tree, and vast quantities of the boards, etc., are annually exported to Europe. The Yellow and Pitch Pine furnish much of the enormous supplies of luel consurned by the great number of steamboats employed in navigating our numerous inland rivers. 'The Longleaved l'ine is the great timber tree of the southern states; and when we take into account all its various products, we must admit it to be the most valuable tree of the whole lamily. 'T'le consumption of the wood of this tree in building, in the southern states, is immense; and its sap furnishes nearly all the turpentine, tar, pitch, and rosin, used in this country, or exported to Europe. 'The turpentine flows from large incisions made in the trunk (into boxes fastened to the side of the trees for that purpose) rluring the whole of the spring and summer. Spirit of turpentine is obtained from this by distillation. Tar is procured by burning the dead wood in kilns, when it flows out in a current from a conduit made in the bottom. Pitch is prepared by boiling tar until it is about one half diminshed in bulk; and rosin is the residuum of the distillation when spirit of turpentine is made. 'The Carolinas produce all these in the greatest abundance, and so long ago as $\mathbf{1 8 0 7}$, the exportation of them to England alone amounted to nearly $\$ 800,000$ in that single year. 
The Fu Trues. Abies.

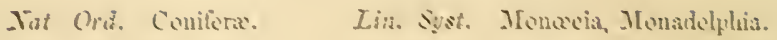

The Fir trees differ from the Pines, to which they are nearly related. in having much sherter leaves, which are placed singly upou the bramches instead of being collected in little bundles or parcels of two. three. or tive, as is the ease in all Pincs. They gencrally gwow in a more conical mamer than the latter, and in ornamental plantations, owe their beauty. in most cases. more to their symmetrical regularity of growth than to pieturesque expression.

The Balsam. or Balm of Gilead Fir (1. balsamea), sometimes also called the Amerion Silyer Fir. is one of the most ormamental of on mative erergreens. It is found most abundmely in Maine and Nora Scotia, but is seatcered more or less on the mountain tops, and in cold swamps, through various other parts of the Tuion. At Pine Orehard, near the Catskill Momtain-house, it homishes well. thengh never seen below the eleration of 1.800 fect. When standing singly; it forms a perfect pyramid of fine dark green toliage, 30 or 10 feet high, resularly elothed from the bottom to the top. The leaves: about halt or three-fourths of an inch long, are silvery white on the under surface, though dark green above: and are inscrted both on the sides and tops of the branches. It is one of the most beantiful crergrecens for planting in grounds near the house, and is perhaps more cultirated for that purpose than amy other in the Lnion. The cones, which are four or five inches long. like those of the European Silver Fir:point uprards. Howerer small the plants of this Fir may be, they are still interesting, as they 



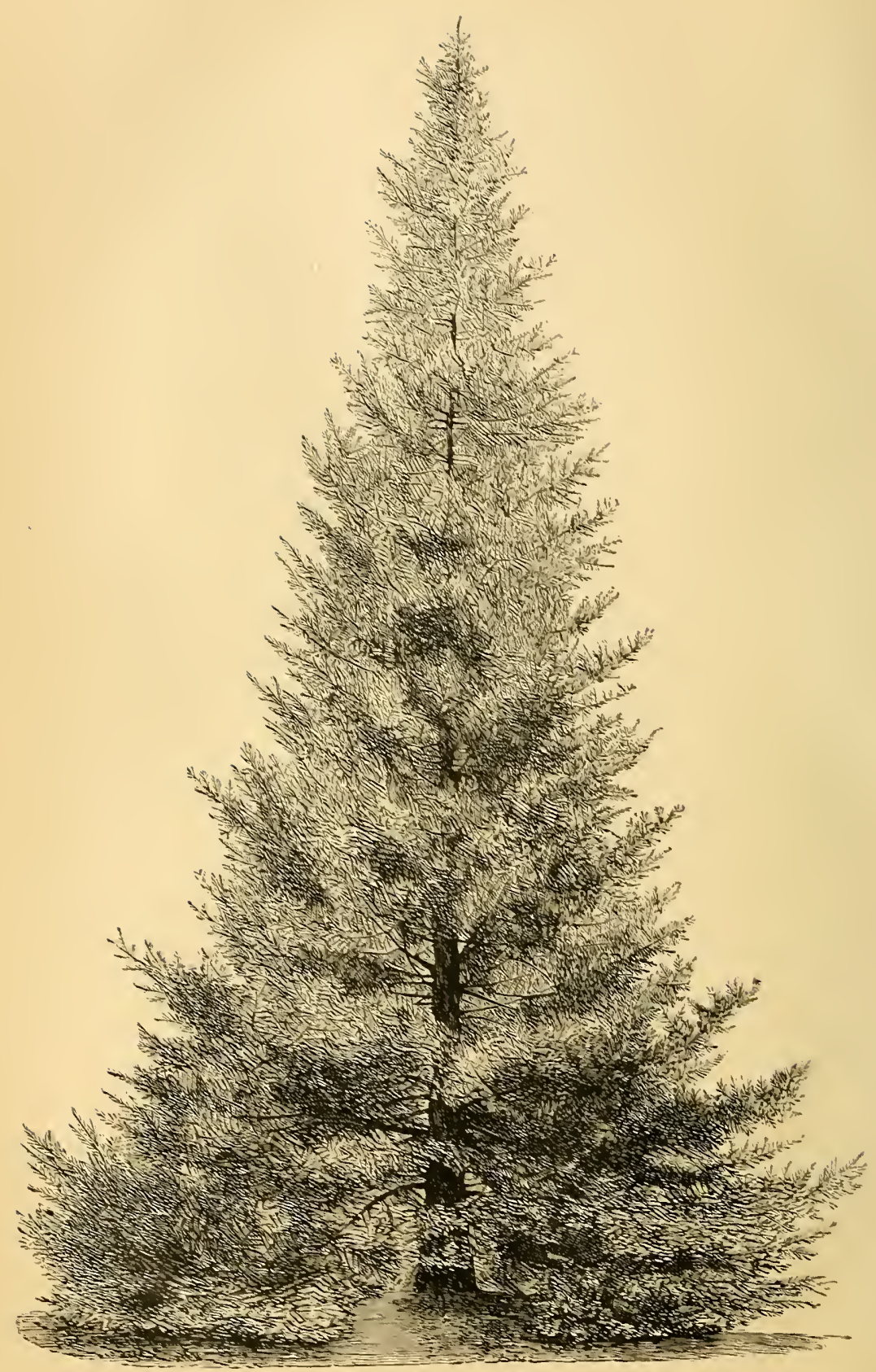

Fa si,-The SiLrer FIR, at the Residence of Dr. Johnson, Germantown, Pa. Age, 57 years. Height, " 00 feet. 
display the ame symmetry as full grown trees. The deep green color of the verdure of the Balm of Gilead Fir is retained unchanged in all its beauty through the severest winters, which causes it to contrast agreeably with the paler tints of the Spruces. On the trunks of trees of this species are found small vesicles or blisters, filled with a liquid resin, which is extracted and sold under the name of Balm of Gilead, * for its medicinal virtues.

The European Silver Fir (A. picea) strongly resembles, when young, the Balsam Fir. But its leaves are longer and coarser, and the cones are much larger, while it also attains twice or three times the size of the latter. In the forests of Germany it sometimes rises over 100 feet; and it always becomes a large tree in a favorable soil. It grows slowly during the first twenty years, but afterwards advances with much more rapidity. It thrives well, and is quite hardy in this comntry.

The Norway Spruce Fir (A. communis $\dagger$ ) is by far the handsomest of that division of the Firs called the Spruces. It generally rises with a perfectly straight trunk, to the beight of from 80 to 150 feet. It is a native, as its name denotes, of the colder parts of Europe, and consequently grows well in the northern states. The branches hang down with a fine graceful curve or sweep; and although the leaves are much paler than those of the foregoing kinds, yet the thick fringe-like tufts of foliage which clothe the branches, give the whole tree a rich, dark appearance. The large cones, too, always nearly six inches long, are

* The true Balm of Gilead is an Asiatic herb, Amyris gilearlensis.

+ Abies excelsa. 
beautifully pendent, and greatly increase the beauty of an old tree of this lind.

The Norway Spruce is the great tree of the Alps; and as a park tree, to stand alone, we scarcely know a more beautiful one. It then, generally, branches not quite down to the ground; and its fine, sweeping, feathery branches harg dorm in the most graceful and pleasing manner. There are some superb specimens of this species in various gardens of the niddle states, 80 or 100 feet high.

The Black, or Double Spruce (A. nigra), sometimes also called the Red Spruce, is very common in the north; and, according to Nichaux, forms a third part of the forests of Termont, Maine, New Hampshire, as well as New Bruns' wick and Lower Canada. The leaves are quite short and stiff, and clothe the young branches around the whole surface; and the whole tree, where it much abounds, has rather a gloomy aspect. In the farorable humid black soils of those countries, the Black Spruce grows 70 feet high, forming a fine tall pyramid of verdure. But it is rarely found in abundance further south, except in swamps, where its growth is much less strong and vigorous. Mingled with other evergreens, it adds to the variety, and the peculiar coloring of its foliage gires value to the livelier tints of other species of Pine and Fir.

The White or Single Spruce (A. alba) is a smaller and less common tree than the foregoing, though it is often found in the same situations. The leaves are more thinly arranged on the young shoots, and they are longer and project more from the branches. The color, however, is a distinguishing characteristic between the two sorts; for while in the Black Spruce it is very dark, in this species it 
is of a light bluish green tint. The cones are also much larger on the White Spruce tree.

The Hemlock Spruce, or, as it is more commonly called, the Hemlock (A. canadensis), is one of the finest and most distinct of this tribe of trees. It is most abundantly multiplied in the extreme northern portions of the Union; and abounds, more or less, in scattered groups and thickets, throughout all the middle states, while at the south it is . confined chiefly to the mountains.

It prefers a soil, which, though slightly moist, is less humid than that where the Black Spruce succeeds best; and it thrives well in the deep, cool shades of mountain valleys. In the Highlands of the Hudson it grows in great luxuriance; and in one locality, the sides of a valley near Crow's nest, the surface is covered with the most superb growths of this tree, reaching up from the water's edge to the very summit of the hill, 1,400 feet high, like a rich and shadowy mantle, sprinkled here and there only, with the lighter and more delicate foliage of deciduous trees.

The average height of the Hemlock in good soils is about ro or 80 feet; and when standing alone, or in very small groups, it is one of the most beautiful coniferous trees. The leaves are disposed in two rows on each side of the branches, and considerably resemble those of the Yew, though looser in texture, and livelier in color. The foliage, when the tree has grown to some height, hangs from the branches in loose pendulous tufts, which give it a peculiarly graceful appearance. When young, the form of the head is regularly pyramidal; but when the tree attains more age, it often assumes very irregular and picturesque forms. 
Sometimes it grorrs up in a thick, dense, dark mass of foliage, only raried by the pendulous branches, which project beyond the grand mass of the tree; at others, it forms a loose, airy, and graceful top, permeable to the slightest breeze, and waring its loose tufts of leares to every passing, breath of air. In almost all cases, it is extremely ornamental, and we regret that it is not more generally employed in decorating the grounds of our residences. It should be transplanted (like all of this class of trees) quite early in the spring, the roots being preserved as nearly entire as possible, and not suffered to become the least dried, before they are replaced in the soil.

The uses of the Fir tree are important. The Norway Spruce Fir furnishes the white deal timber so extensively employed in Europe for all the various purposes of building; and its tall, tapering stems afford fine masts for ressels. The Black Spruce timber is also highly raluable, and is thought by many persons to surpass in excellence that of the Norway Spruce. The young shoots also enter into the composition of the celebrated spruce beer of this country, a delightful and rery healthful bererage. And the Hemlock not only furnishes a rast quantity of the joists used in building frame-houses, but supplies the tamners with an abundance of bark, which, when mixed with that of the oak, is highly esteemed in the preparation of leather.

We regret that the fine evergreen trees both of this country and Europe, which compose the Pine and Fir tribes, have not hitherto receired more of the attention of planters. It is inexpressible, how much they add to the 
beauly of a country residence in winter. At that season, when, during three or four months the landscape is bleak and covered with snow, these noble trees, properly intermingled with the groups in view from the windorv, or those surrounding the house, give an appearance of verdure and life to the scene which cheats winter of hali its dreariness. In exposed quarters, also, and in all windy and bleak situations, groups of evergreens form the most effectual shelter at all seasons of the year, while many of them have the great additional recommendation $\mathrm{ct}$ growing upon the most meagre soils.

In fine country residences abroad, it is becoming customary to select some extensive and suitable locality, where all the species of Pines and Firs are collected together, and allowed to develope themselves in their full beauty of proportion. Such a spot is called a Pinetum ; and the eflect of all the different species growing in the same assemblage, and contrasting their various forms, heights, and peculiarities, cannot but be strikingly elegant. One of the largest and oldest collections of this kind is the Pinetum of Lord Grenville, at Dropmore, near Windsor, England. This contains nearly 100 kinds, comprising all the sorts known to English botanists, that will endure the open air of their mild climate. The great advantage of these Pinetums is, that many of the more delicate species, which, if exposed singly, would perish, thrive well, and become quite naturalized under the shelter of the more hardy and vigorous sorts. 
The Crink of Labaxon 'Tree. Cedruš.

Nat. Orb. Conifore. Lin. Syst. Moncecia, Monadelphia.

'The Cedar of Lebanom is universally admitted by liuropean authors to be the noblest erergreen tree of the old wordd. Its native sites are the elevated ralleys and ridges of Mount Lebanom and the neighboring heights of the lofty groups of Asin Minor. There it once covered immense forests, but it is supposed these have never recovered from the inroads made upon them by the forty seore thousand hewers employed by solomon to procure the timber for the arection of the 'lemple. Modern travellers speak of them as greatly diminished in number. thongh there are still specimens measuring thirty-six fect in circumference. Mount Lebanon is inhabited by numerons Araronite Christians, who hold ammally a colebration of the Transfiguration under the shade of the existing trees, which they call the "Fe'ast of Cedars."

The Cedar of Lebanon is nearly related to the Larch, having its leaves collected in parrels like that tree, but differs widely in the circumstance of its foliage being evergreen. It is remarkable for the wide extension of its branches, and the immense surface corered by its orershadowing canopy of folinge. In the sacred writings it is often alluded to as an emblem of great strength. bonuty" and duration. "Behold the Assrrian was a Cedar in Lebanon, with fair branches, and with a shadowing shrond, and of an high stature; and his top was among the thick boughs. His boughs were multiplicd, and his branches becwne long. 'The fir trees were not like his boughs, nor 


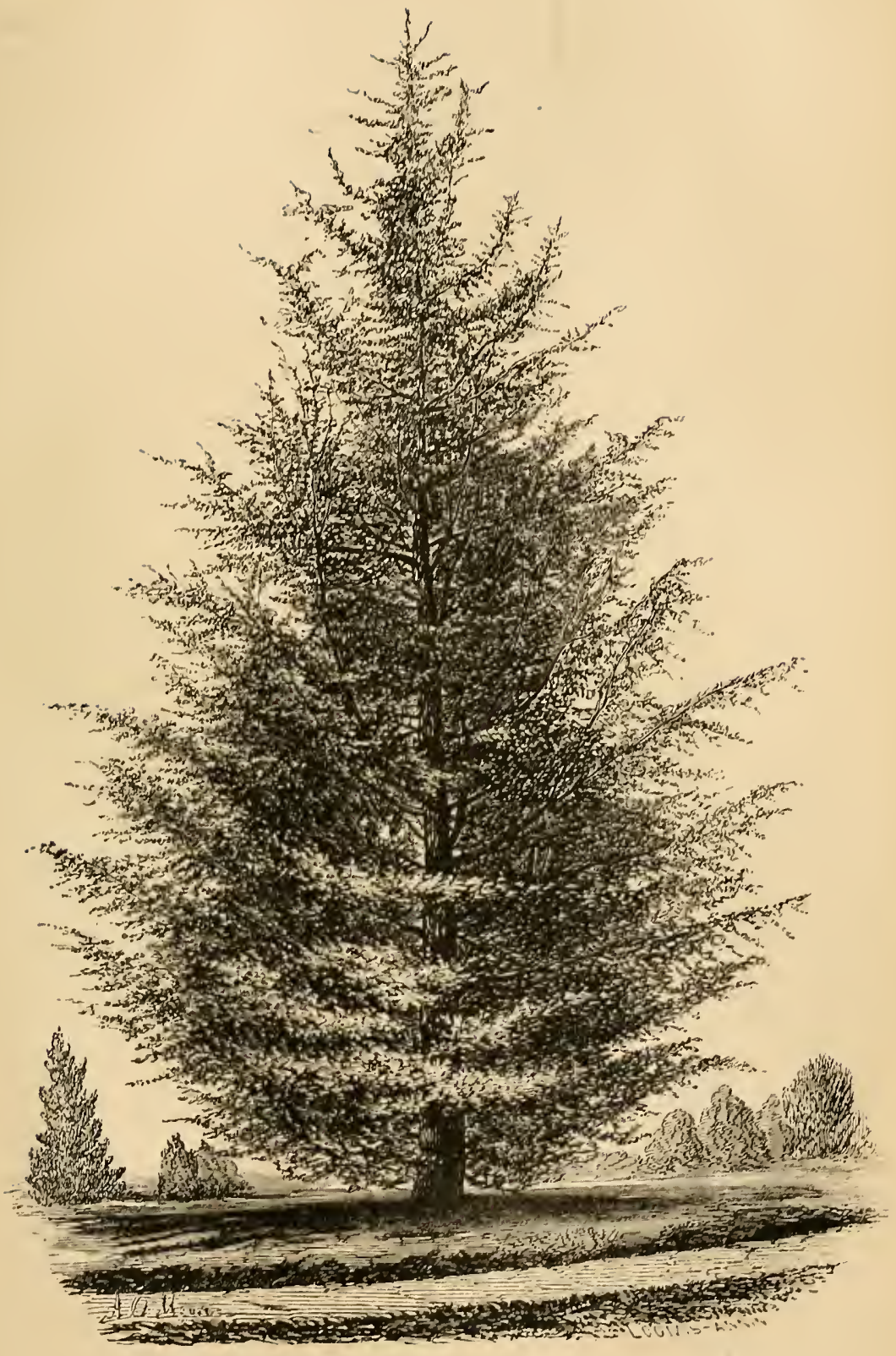

Fis 39,-Cedar or Lebanov, at Woodlawn, ueatr Princeton, N. J. IJejglat, $86 \mathrm{ft}$. 

the chestnut trees like his branches, nor any tree in the garden of God like unto him in beauty."**

In England the Cedar of Lebanon appear's to have become quite naturalized. There it is considered by far the most ornamental of all the Pine tribe,-possessing, when full grown, an air of dignity and grandeur beyond any other tree. To attain the fullest beauty of development, it should always stand alone, so that its far-spreading horizontal branches can have full room to stretch out and expand themselves on every side. Loudon, in his Arboretum, gives a representation of a superb specimen now growing at Sion House, the seat of the Duke of Northumberland, which is 72 feet high, 24 in circumference, and covers an area, with its huge depending branches, of 117 feet. There are many other Cedars in England almost equal to this in grandeur. Sir T. D. Lauder gives an account of one at Whitton, which blew down in 1779 : it then measured 70 feet in height, 16 feet in circumference, and covered an area of 100 feet in diameter. To show the rapidity of the growth of this tree, he quotes three Cedars of Lebanon, which were planted at Hopetoun House, Scotland, in the year 1748. The measurement is the circumference of the trunks, and shows the rapid increase after they have attained a large size.

\begin{tabular}{|c|c|c|c|c|c|c|}
\hline & 1801. & 1820. & 1825. & 1833. & $\begin{array}{c}\text { Incr } \\
32\end{array}$ & $\begin{array}{l}\text { se in } \\
\text { ars. }\end{array}$ \\
\hline $\begin{array}{l}\text { First Cedar, } \\
\text { Second do. } \\
\text { Third do. }\end{array}$ & $\begin{array}{rr}\text { ft. } & \text { in. } \\
10 & 0 \\
8 & 6 \\
7 & 10\end{array}$ & $\begin{array}{rl}\text { ft. } & \text { in. } \\
13 & 1 \frac{1}{2} \\
10 & 9 \frac{1}{3} \\
9 & 9 \frac{1}{2}\end{array}$ & $\begin{array}{ll}\text { ft. } & \text { in. } \\
14 & 0 \\
11 & 4 \\
10 & 8\end{array}$ & $\begin{array}{ll}\mathrm{ft} . & \text { in. } \\
15 & 1 \\
12 & 3 \\
11 & 6\end{array}$ & $\begin{array}{l}\text { ft. } \\
5 \\
3 \\
3\end{array}$ & $\begin{array}{c}\text { in. } \\
1 \\
9 \\
8\end{array}$ \\
\hline \multicolumn{5}{|c|}{ A Chestnut measured at the same periods, only increased } & 2 & 7 \\
\hline
\end{tabular}

Ezekiel xxxi. 
From the above talile, it will be secu how eomgenial even the cold climate of sootland is to the greowth of this tree. Indeed in its native soils, the tops of the surromeling hills atre almost perpetually corered with suow, and it is therefore, one of the rery hadiest of the evererecens of the old world. 'There is no reason why it should not steceed admirably in many parts of the Lnited States: and when we consider its great size, fine dark green foliage, and wido spreading limbs which

\section{“- (Mverarching, frame \\ Mlost solemu domes within,"}

\section{SUBLtex.}

as well as the many interesting associations comnected with it, wo camnot but think it better worth our carly attention. and extensive introduction, tham almost any other foregign tree. Wrergecus are comparatively diflicult to import. and as we have made the experiment of importing Cedars of Lebanon fiom the English murseries with but indifferent suceess. we woukd advise that persons attempting its eultivation should procure the cones containing the seeds from England. when they may bo reared directly in om own soil, which will of course be an additional advantage to the futtire growth of the trec.*

The situations found to be most farorable to this Cedar, in the parks and gardens of Europe, are sandy or gravelly soils, either with a moist subsoil underneath, or in the neighborhood of springs, or bodies of water. In such places it is found to adrance with a rapidity equal to the Lareh,

* The tinest Codar of Ichanou in the Union, is growing in the grounds of T. Ash. Esq. of Westehester Co., X. I. being 50 tiet high and of corresponding breadth. It stands near a l'urplo-leaved Booch, equally large und beantifinl. 
one of the fastest growing timber trees, as we have allealy noticed.

The Deodara, or Indian Cedar (Cedrus Deorlara), is a magnificent species of this tree, recently introduced from the high mountains of Neral and Indo-'Iartary. It stands the climate of Seotland, and appears likely to suceced here wherever the Cedar of Lebanon will flourish. In its native country it is deseribed as being a lolity and majestic tree, frequently attaining the height of 150 feet, with a trunk 30 feet in circumference. 'I'he leaves are larger than those of the Cedar of Ichanon, of a deeper bluish green, covered with a silvery bloow; the eones, borne in pairs, are of a reddish brown color, and axe both longer and brouder than those of the latter species. In some parts of Upper India it is considered a sacred tree (Deodar $u$-tree of God), and is only used to burn as incense in days of higl ceremony; but in others it is leeld in the highest esteem as a timber tree, having all the good qualities of the Cedar of Lebanon -its great durability being attested by its sound state in the roofs of temples of that country, which cannot have been built less than 200 years.

We lave but just introduced the Deodara into the United States, and can therefore say little of its growth or beauty here, though we have little doubt that it will prove one of the noblest evergreen trees for our pleasure grounds. Loudon says, "the specimens in England are yet small; but the feathery lightness of its spreading branches, and the beautiful glaucous hue of its leaves, render it, even when young, one of the most ornamental of the coniferous trees; and all the travellers who have seen it full grown, agree that it unites an extraordinary degree of majesty and grandeur with its beauty. The tree thrives in every part of 
Great Britain where it has been tried, even as far north as Aberdeen, where, as in many other places, it is found hardier than the Cedar of Lebanon. It is readily propagrated by seeds, which preserve their vitality when imported in the cones. It also grows fireely by cuttings, which appear to make as handsome free-growing plants as those raised from seed." The soil and culture for this tree are precisely those for the Cedar of Lebanon.

The Red Cedar Tree. Juniperus.

Sat. Ord. Conifers.

Lin. Syst. Diøcia, Monadelphia.

The Red Cedar is a very common tree, indigenous to this country, and growing in considerable abundance from Maine to Florida ; but thriving with the greatest luxuriance in the sea-board states. When fully grown, the Red Cedas is about 40 feet in height, and little more than a foot in diameter. The leaves, are rery small, composed of minute scales, and lie pretty close to the branches. Small blus berries, borme thickly upon the branches of the female trees in autumn and winter, contain the seeds. These aro corered with a whitish exudation, and are sometimes used, like those of the foreign juniper, in the manufacture of gin.

The Red Cedar has less to recommend it to the eye than most of the evergreens which we have already described. The color of the foliage is dull and dingy at many seasons, and the form of the young tree is too compactly conical to please generally. When old, however, we have seen it throw off this formality, and become an interesting, and indeed a picturesque tree. Then, its branches shooting out 
in a horizontal direction, clad with looser and more penden1 foliage, give the whole tree quite another character. The twisted stems, too, when they become aged, have a singular, dried-looking, whitish bark, which is quite unique and peculiar. There is a very fine natural avenue of Red Cedars near Fishkill landing, in Duchess Co., composed of two rows of noble trees 35 or 40 feet high, which is a very agreeable walk in winter and early spring. This has given the name of Cedar Grove to the country seat in question, where the Red Cedar grows spontaneously upon a slate subsoil with great luxuriance. There the seeds are disseminated widely by the birds, which feed with avidity upon the berries.

The Red Cedar is well known to every person as one of our very best timber trees. It takes its name from the reddish hue of the perfect wood. This has a fragrant odor, and is not only light, fine-grained, and close in texture, but extremely durable. It is therefore much employed (though of late it is becoming scarcer) in conjunction with Live oak, which is too heavy alone, in ship-building. It is also valued for its great durability as posts for fencing; and is exported to Europe, to be used in the manufacture of pencils, and other useful purposes.

\section{The Arbor Vite Tree. Thuja.}

Nat. Ord. Coniferæ.

-Lin. Syst. Monœcia, Monadelphia.

The Arbor Vitæ (Thuja occidentalis), sometimes also called Flat Cedar, or White Cedar, is distinguished from 
most evergreens by its flat foliage, composed of a great number of scales closely imbricated, or overlaying each other, which give the whole a compressed appearance. The seeds are borne in a small cone, usually not more than half'an inch in length.

This tree is extremely formal and regular in outline in almost erery stage of growth; generally assuming the shape of an exact cone or prramid of close foliage, of considerable extent at the base, close to the ground, and narrowing upwards to a shirp point. So regular is their ontline in many cases, when they are growing upon farorable soils, that at a short distance they look as if they had been subjected to the clipping-shears. The sameness of its form precludes the emplorment of this evergreen in so extensive a manner as most others; that is, in intermingling it promiscuously with other trees of less artificial forms. But the $\mathrm{Arbor}$ Tite, from this rery regularity, is well suited to support and accompany scenery when objects of an arowedly artificial character predominate, as buildings, ete., where it may be used with a very happy eflect. There is also no erergreen tree indigenous or introduced, which will make a more effectual, close, and imperrious screen than this: and as it thrires well in almost erery soil, moist, dry, rich, or poor, we strongly recommend it whenerer such thickets are desirable. We hare ourselres tried the experiment with a hedge of it about $\approx 00$ feet long, which was transplanted about five or six feet high from the native habitats of the young trees, and which fully answers our expectations respecting it, forming a perfectly thick screen, and an excellent shelter on the north of a range of buildings at all seasons of the year, growing perfectly thick without trimming, from the very ground upwards. 
The only fault of this tree as an evergreen, is the comparatively dingy green hue of its foliage in winter. But to compensate for this, it is remarkably fresh looking in its spring, summer, and autumn tints, comparing well at those scasons even with the bright verdure of deciduous trees.

The Arbor Vitæ is very abundant in New Brunswick, Vermont, and Maine. In New York, the shores of the Hudson, at Hampton landing, 70 miles above the city of New York, are lined on both sides with beautiful specimens of this tree, many of them being perfect cones in outline; and it is here much more symmetrical and perfect in its growth than we have seen it. Forty feet is about the maximum altitude of the Arbor Vitæ, and the stem rarely measures more than ten or twelve inches in diameter.

The wood is very light, soft, and fine-grained, but is reputed to be equally durable with the Red Cedar. It is consequently employed for various purposes in building and fencing, where, in the northern districts, it grows in sufficient abundance, and of suitable size.

The Chinese Arbor Vitæ ( $T$. orientalis) is a tree of much smaller and more feeble growth. It cannot, therefore, as an ornamental tree, be put in competition with our native species. Bnt it is a beautiful evergreen for the garden and shrubbery, where it finds a more suitable and sheltered site, being rather tender north of New York.

The White Cedar (Thuja spheroida*), which belonge to the same genus as the Arbor Vitæ, is a much loftier

- Cupressus thuyoides of the old botanists. 
tree, often growing so feet high. It can hardly be considered a tree capable of being introduced into cultivated situations, as it is found only in thick swamps and wet grounds. The foliage considerably resembles that of the common Arbor Vitze, though rather narower and more delicate in texture. The cones are small and rugged, and change from green to a bluc or brown tint in autumn. In the south it is often called the Juniper.

The White Cedir furnishes excellent shingles, much more durable than those made of either Pine or Cypress: in Philatelphia the wood is much esteemed and greatly" used in cooperage. "Charcoal," according to Michaux, "highly esteemed in the manuficture of gumpowder, is made of roung stocks, about an inch and a half in diameter, deprired of their bark; and the seasoned rood attiords beautiful lamp-black, lighter and more intensely colored than that obtained from the Pine."

The Americax Holly Tree. Ilex.

Nat. Ord. Aquifoliaces.

Lin. Syst. Dicecia, Tetrandria.

The European Holly is certainly one of the cvergreen glories of the Euglish gardens. There its deep green. glossy foliage, and bright coral berries, which hang on for a long time, are seen enlirening the pleasure-grounds and shrubberies throughout the whole of that leatless and inactive period in regetation-winter. It is also, in our mother tongue, inseparably comnected with the delightful associations of merry Christmas gambols and feastings, when both the churches and the drelling-houses are 
decorated with its boughs. We have much to regret, therefore, in the severity of our winters, which will not permit the European Holly to flourish in the middle or eastern states, as a hardy tree. South of Philadelphia, it may become acclimated; but it appears to suffer greatly further north.

$\Lambda$ beautiful succedancum, however, may, we belicve, be found in the American Holly (Ilex opacu), which indeed very closely resembles the foreign species in almost every particular. The leaves are waved or irregular in surface and outline, though not so much so as those of the latter, and their color is a much lighter shade of green. Like those of the forcign plant, they are armed on the edges with thorny prickles, and the surface is brilliant and polished. The American Holly is seen in the greatest perfection on the eastern shore of Maryland and Virginia, and the lower part of New Jersey. There it thrives best upon loose, dry, and gravelly soils. Michaux says it is also common through all the extreme southern states, and in West Tennessee, in which latter places it abounds on the margins of shady swamps, where the soil is cool and fertile. In such spots it often reaches forty feet in height, and twelve or fifteen inches in diameter.

Although the growth of the Holly is slow, yet it is always beautiful; and we regret that the American sort, which may be easily brought into cultivation, is so very rarely seen in our gardens or grounds. The seeds are easily procured, and if scalded and sowed in autumn, immediately after being gathered, they vegetate frecly. For hedges the Iolly is altogether unrivalled; and it was ilso one of the favorite plants for verdant sculpture, in the ancient style of gardening. Evolyn, in the edition of his 
Sylva, published in London in 1664, thus bursts out in cloquent praise of it: "Above all natural greens which enrich our home-born store, there is none certainly to be compared to the Holly; insomuch that I have often wondered at our curiosity after foreign plants and expensive difficulties, to the neglect of the culture of this vulgar but incomparable tree,-whether we will propagate it for use and defence, or for sight and ornament. Is there under heaven a more glorious and refreshing object of the kind, than an impregnable hedge of one hundred and sixty-five feet in length, seven high, and five in diameter; which I can show in my poor gardens, at any time of the year, glittering with its armed and varnished leaves? The taller standards at orderly distances, blushing with their natural coral. It mocks the rudest assaults of the weather, beasts, or hedge-breaker :-

'Et illum nemo inipune lacessit.'"

The Yew Tree. Táaus.

Nat. Ord. Taxaceæ. Lin. Syst. Monœcia, Monadelphia.

The European Yew is a slow-growing, evergreen tree, which often, when full grown, measures forty feet in height, and a third more in the diameter of its branches. The foliage is flat, linear, and is placed in two rows, like that of the Hemlock tree, though much darker in colcr. The flowers are brown or greenish, and inconspicuous, but they are succeeded by beautiful scarlet berries, about half or three-fourths of an inch in diameter, which are open at the end, where a small nut or seed is deposited. These 
berries have an exquisitely delicate, waxen appearance, and contribute highly to the beauty of the tree.

The growth of this tree, even in its native soil, is by no means rapid. In twenty years, says Loudon, it will attain the height of fifteen or eighteen feet, and it will continue growing for one hundred years; after which it becomes comparatively stationary, but will live many centuries.

When young, the Yew is rather compact and bushy ir its form; but as it grows old, the foliage spreads out in fine horizontal masses, the outline of the tree is irregularly varied, and the whole ultimately becomes highly venerable and picturesque. When standing alone, it generally shoots out into branches, at some three or four feet above the surface of the ground, and is ramified into a great number of close branches.

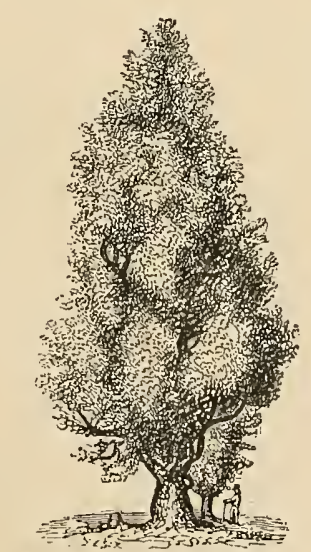

[Fig. 39. The English Yew.]

In England, it has been customary, since the earliest settlement of that island by the Britons, to plant the Yew in churchyards; and it is therefore as decidedly consecrated to this purpose there, as the Cypress is in the souto 
of Europe. For the decoration of places of burial, it is well adapted, from the deep and perpetual verdure of its foliage, which, conjointly with its great longevity, may be considered as emblematical of immortality.

The Yew, like the Holly, makes an excellent evergreen lıedge-close, dark green, and beautiful when clad in the rich scarlet berries. We desire, however, rather to see this tree naturalized in our gardens and lawns as an evergreen tree of the first class, than in any other form. Judging from specimens which we have growing in our own grounds, we should consider it quite hardy anywhere south of the $41^{\circ}$ of latitude. And although it is somewhat slow in its growth, yet, like many other evergreens, it is as beautiful when a small bush or a thrifty young tree, as it is venerable and picturesque when ages or even centuries have witnessed its never failing verdure. It appears to grow most vigorously and thrive best on a rich and heavy soil, and in situations rather shaded than exposed to a burning sun.

There are several beautiful varieties of the Yew (Taxus baccata) cultivated in the nurseries; the Irish Yew (T. $b$. fastigiata), remarkable for its dark green foliage, and very handsome, upright growth, and the Yellow berried Yew (T. b. fructo-flava), are the most ornamental.

The North American Yew (T. canadensis) is a low trailing shrub, scarcely rising above the height of four or six feet, though the branches extend to a considerable distance. In foliage, berries, etc., it so strongly resembles the European plant, that many botanists consider it only a dwarf variety. The leaves are nevertheless shorter and narrower, and the male flowers always solitary. It is found in shady, rocky places, in the Highlands, and various other localities from Canada to Virginia. 


\title{
SECTION VI.
}

\author{
VINES AND CLIMBING PLANTS,
}

Valne of this kind of Vegetation. Fine natural effects. The Euroyean Ivy. The Virginia Creeper. The Wild Grape Vine. The Bittersweet. The Trumpet Creeper. The Pipe Vine, and the Clematis. The Wistarias. The Honeysuckles and Wondbines. The Jasmine and the Periploca. Remarks on the proper mode of introducing vines. Beantiful effects of climbing plants in connexion with buildings.

Quite over-canopied with lush woodbine,

With sweet musk roses, and with eglantine.

Shatspeare.

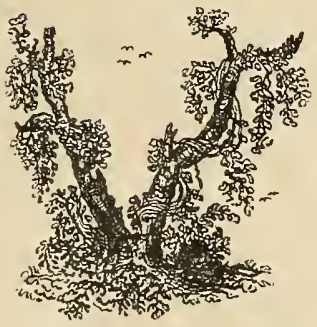

I N E S and climbing plants are objects full of interest for the Landscape Gardener, for they seem endowed with the characteristics of the graceful, the beautiful, and the picturesque, in their luxuriant and ever-varying forms. When judiciously introduced, therefore, nothing can so easily give a spirited or graceful air to a fine or even an ordinary scene, as the various plants which compose this group of the vegetable kingdom. We refer particularly now to those which have woody and perennial stems, as all annual or herbaceous stemmed plants are too short-lived to afford any lasting or permanent addition to the beauty of the lawn or pleas sure-ground. 
Climbing plants may be classed among the adventitious beautics of trees. Who has nut often witnessed with delight in our native forests, the striking beanty of a noble cee, the old trunk and fintastic branches of which were enwreathed with the humiant and pliant shoots and rich loliage of some beatutiful rine, elothing eren its decayed limbs with resdure, and hanging down in gay festoons or loose negligent masses, waving 10 and fro in the air. The Europerm Iry (Hedera Heli.r) is certainly one of the timest, if not the rery finest climbing plant (or more properly, creeping vine, for by means of its littlo fibres or rootlets ou the stems, it will attach itself to trees, walks, or any other substance), with which we are acquainted. It possesses not only rery fine, dark green, palmated foliage in great abumdance, but the foliage has that agrecable property of being evergreen,-which, while it enhanees its value tenfold, is at the same time so rare among rines. The yellow flowers of the Iry are great favorites with bees, from their honied sweetness; they open in autumn, sud the berries ripen in the spring. When planted at the root of a tree, it will often, if the head is not too thickly clad with branches, ascend to the rery topmost limbs: and its dark green foliage, wreathing itsel: about the old and furrowed trunk, and hanging in careless drapery from the lower branches, adds greatly to the elegance of even the most admirable tree. Spenser describes the appear. ance of the Iry growing to the tops of the troes.

"Emongst the rest, the clambing Ivie grew, Kinitting his wanton arms with grasping hold, west that the poplar happely should renew Hor brother's strokes, whoso boughs sho doth enfold With her lythe twigs, till they the top survew, And paint with pallid green her buds of gold." 
The fine contrasts between the dus coloring of the leaves of the Ivy, and the vernal and autumnal tints of the foliage of deciduous trees, are also highty pleasing. 'ndeed this fine climbing plant may be turned to advantage in another way; in reclothing dead trees with verdure Sir T. D. Lauder" says, that "trees often die from eauses which we cannot divine, and there is no one who is master of extensive woods, who does not meet with many such instances of unexpected and unaccountable mortality. Of such dead individuals we have often availed ourselves, and by planting Ivy at their roots, we have converted them into more beautiful objects than they were when arrayed in their own natural foliage."

The Ivy is not only ornamental upon trees, but it is also remarkably well adapted to ornament cottages, and even large mansions, when allowed to grow upon the walls, to which it will attach itself so firmly by the little rootlets sent out from the branches, that it is almost impossible to tear it off. On wooden buildings, it may perhaps be injurious, by causing thein to decay; but on stone buildings, it fastens itself firmly, and holds both stone and mortar together like a coat of cement. The thick garniture of foliage with which it covers the surface, excludes stormy weather, and has, therefore, a tendency to preserve the walls, rather than accelerate their decay. 'This vine is the inseparable accompaniment of the old The Ivy is not a native of America; nor is it by any means a very common plant in our gardens, though we know of no apology for the apparent neglect of so beautiful a climber. It is hardy south of the latitude of $42^{\circ}$, and we have seen it thriving in great luxuriance as far north as Hyde Park, on the Hudson, eighty miles above New York. One of the most beautiful growths of this plant, which has 
vere met one eyes is that upon the old mamsion in the

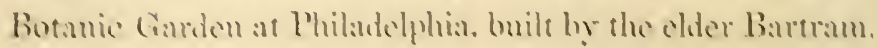
'That pietmespue and yuaint stome huilding is heantifully.

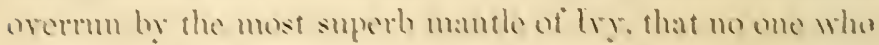

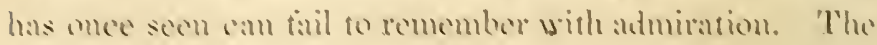
dark arey of the stome-work is tincly oppesed hy the rich verdure of the plamt. Which tills aw: in openings here and

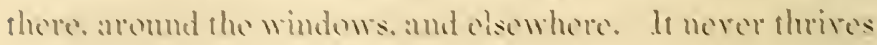
well if sutfired to ramblo alomer the garenud. but needs the support of a troe, a frame, or a wall, wo which it attaches

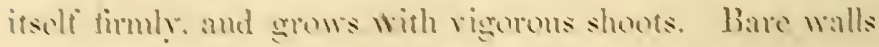
or fences may thes be chethed with verdure and he:mey cynal to the living hedese. in at very shome peried of time. by planting young ly roots at the bise.

The mest desirable varietics of the commen lyy are: the

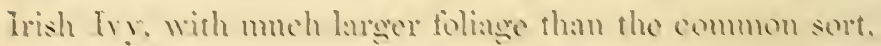
and more rapid in its growth: the silver-striped and the Cold-striped leaved liy. hom of which, thomgh less vigums. are much admired fore the singular colue of their leares. "The common Finglish fry is more hardy than the oflers in me climate.

Mlahough, as wo have sald, the Iry is net a mative of the commery yet we have an indigenoms vine. which, at least iic stmmer, is not inferior to it. We reter to the Virginia Crepper (Ampelopsis hederacers). which is oftem ealled the - meriean by. The leares are as large as the hamed. derply divided info fire lobes and the hessoms are sue. coeded by hamdsome, dark bhe berries. The Tirghinia

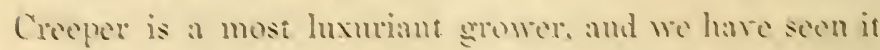
alimbing to the extremities of tress 70 or so feot in heright. Like the Iry. it attaches itself to whaterer it ean lay hold oil. by the litte rootets which spring out of the branches: 
and its loliage, when it colothes thickly a high wall, or folds itself in clustering wreaths around the trunk and branches of an open tree, is extremely handsome and showy. $\Lambda$ Ithough the leaves are not evergreen, like these of the Ivy, yet in auturm they far surpass those of that plant in the rich and gorgeous coloring which they then assume. Numberless trees maty be seen in the country by the roadside, and in the woods, thes decked in autumn in the borrowed glories of the Virginia Crecper; but wo particufarly remember two as being rematably striking objects; one, a wide-spread chn-1he; trunk and graceful diverging branches completely clad in scarlet by this beautiful vine, with which its own leaves harmonized well, in their fince deep yellow dress; the other, a tall and derse Cedar, through whose dask green boughs glearred the rich coloring of the Virginia Crecorer, like a half-eonceated, thengh golowing fire.

In the Anerican forests nothing adds more to the beauty of an occasional tree, than the tall cannpy of verdure with which it is often crowned by the wild Cirape vine. 'There its tall stems wion therraselves about, urstil they reach the very summit of the tree, where they cluster it over, and bask their broad bright green foliage in the sunbeams. $\Lambda \mathrm{s}$ if not content with this, they often completely overhang the head of the tree, falling like ample drapery around on every side, until they sweep the ground. We have seen very beautiful effects produced in this way by the grape in its wild state, and it may easily be innitated. The delicious fragrance of these wild grape vines when in blossom, is unsurpassed in delicacy ; and we can compare it to nothirg but the delightful perfurne which exhales from a huge bed of Mignorrette in full bloom. 'T'He Bittersweet (Celastrus 
scandens) is another well known climber, whicn ornaments our wild trees. Its foliage is rery bright and shining, and the orange-colored seed-ressels which burst open, and display the crinson seeds in winter, are quite ornamental. It winds itself rery closely around the stem. howerer, and we hare lnown it to strangle or compress the bodies of young trees so tightly as to put an end to their growth.

The Trumpet Creeper (Bignonia radicans) is a very picturesque climbing plant. The stem is quite woody, and often attains considerable size; the branches, like those of the Iry and Tirginia Creeper, fasten themselves by the roots thrown out. The leares are pinmated, and the Howers, which are borne in terminal clusters on the ends of the young shoots about midsummer, are exceedingly showy. They are tubes fire or six inches long. shaped like a trumpet, opening at the extremity, of a fine scarlet color on the outside, and orange within. The Trumpet Creeper is a mative of Tirginia, Carolina, and the states further south, where it climbs up the loftiest trees. It is a great farorite in the northern states as a climbing plant, and rery beautiful effects are sometimes produced by planting it at the foot of a tall-stemmed tree, which it will completely surround with a pillar of verdure, and render very ornamental by its little shoots, studded with noble blossoms.

One of the most singular and picturesque climbing shrubs or plants which we cultivate, is the Pipe-rine, or Birthwort (Aristolnchia sipho). It is a native of the Alleghiny mountains, and is one of the tallest of twining plants, growing on the trees there to the height of 90 or 100 teet, though in gardens it is often kept down to a frame of four or five feet high. The leaves are of a noble size, being eight or nine inches broad, and heart-shaped in outline. The 
flowers, about an inch or a little more in length, are very singular. 'They are dark yellow, spotted with brown, in shape like a bent siphon-like tube, which opens at the extremity, the whole flower resembling, as close as possible; a very small Dutchman's pipe, whence the vine is frequently so called by the country people. It flowers in the beginning of summer, and the foliage, during the whole growing season, has a very rich and luxuriant appearance. Aristolochia tomentosa is a smaller species, with leaves and flowers of less size, the former downy or hairy on the under surface.

The various kinds of Clemaris, though generally kept within the precincts of the garden, are capable of adding to the interest of the pleasure ground, when they are planted so as to support themselves on the branches of trees. The common White Clematis or Virgin's Bower (C. virginica) is one of the strongest growing kinds, often embellishing with its pale white blossoms, the whole interior and even the very tops of our forest trees in the middle states. After these have fallen, they are succeeded by large tufts of brown, hairy-like plumes, appendages to the clusters of seeds, which give the whole a very unique and interesting look. The Wild Atragene, with large purple flowers, which blossom early, has much the same habit as the Clematis, to which, indeed, it is nearly related. Among the finest foreign species of this genus are, the Single and Double-flowered purple Clematis (C. viticella and its varieties), which, though slender in their stems, run to considerable height, are very pretty, and blossom profusely. The sweet-scented and the Japan Clematis ( $C$ flammula and C. florida), the former very fragrant, and the latter beautiful, are perhaps too 
tender, except for the garden, where they are highly prized.

The Glycine or Wistaria (Wrsturic pubescens) is a rery beautiful climbing plant, and adds much to the gracefulness of trees, when trained so as to hang from their lower branches. The leaves are pimnate, and the light purple flowers, which bloom in loose clusters like those of the Locust, are universally admired. The Chinese Wistaria (H. sinensis) is a rory elegant species of this plant, which appears to be quite hardy here; and when loaded with its numerous large clusters of pendent blossoms, is highly ornamental. It grows rapidly, and, with but little care, will mount to a great height. These vines with pimated foliage, would be remarkably appropriate when climbing up, and hanging from the branches of such light airy trees as the 'Threct-thorned Acacia, the Locust, etc.

Tre must not forget to enmmerate here the charming family of the Honeysuckles; some of them are natives of the old world, some of our own continent: and all of them are common in our gardens, where they are universally prized for their beanty and fragramee. In their native localities they grow upon trees, and trail along the rocks. The species which ascends to the greatest height, is the common European Wrodbine, * which twines around the stems, and hangs from the ends of the longest branches of trees:

"As Woodbine weds the plaut within her reach. Rough Elm, or smooth-grained Ash, or glossy Beech, In spiral rings ascends the trunk, and lays Ifer golden tassels on the leafy sprays."

Cowfes.

* Woodbind is the original name, derived from the habit of the plant of winding itself around trees, and binding the branehes together. 
The Woodbine (Lonicera periclymenum) has separate, opposite leaves, and buff-colored or paler yellow and red blossoms. 'I'here is a varicty, the common monthly Woodbine, which produces its flowers all summer, and is much the most valuable plant. $\Lambda$ nother (I. p. belgicum), the Dutch Honeysuckle, blossoms quite early in spring; and at third (I. p. quercifolium) has leaves shaped like those of the oak tree.

'The finest of our native sorts are the Red and Yellow

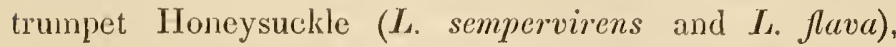
which have the terminal leaves on each branch joined together at the base, or perfoliate, making a single leaf: 'They blossom in the greatest profusion during the whole summer and autumn, and their rich blossom tubes, sprinkled in numerous clusters over the exterior of the foliage, as well as an abundance of scarlet berries in autumn, entitle them to high regard. 'There is also a very strong and vigorous species, called the Orange pubescent Honeysuckle (L. pubescens), with large, lairy, eiliate leaves, and fine large tawny or orange-colored flowers. It is a very luxuriant plant in its liabit, and a very distinct species to the eye. All these native sorts have but very slight fragrance.

The Chinese twining IIoneysuckle ( $L$. flexuosa) is certainly one of the finest of the genus. In the form of the leaf it much resembles the common Woodbine; but the foliage is much darker colored, and is also sub-evergreen, hanging on half the winter, and in sheltered spots, even till spring. It blossoms when the plant is old, several times during the summer, bearing an abundance of beautiful flowers, open at the mouth, red outside, and striped with red, white, or yellow within. It grows 
remarkably fast, climbing to the rery summ t of trees in a short time; and the flowers, which first appear in June, are deliciously fragrant. In all its varieties, the Honer. suckle is a charming plant, either to adorn the porch of the cottage, the latticed bower of the garden-to both of which spots they are especially" dedicated-or to climb the steni of the old forest tree. where-

.. With clasping tendrils it invests the branch, Elso unadornd, with many agay festoon, And fragraut chaplet; reeompensing well The strength it borrows with the graee it lends."

There it dittises through the air a delicious breath, that renders a walk beneath the shade of the tall trees doubly delightful, while its flowers give a gaiety and brightness to the park, which forest trees, producing usually but inconspicuous blossoms. could not alone impart.

Some of the climbing Roses are rery lorely objects in the pleasure-grounds. Many of them, at the north, as the Inultiforas, Noisettes, etc., require some corering in the winter, and are therefore better fitted for the garden. At the south, where they are quite hardy, they are, howerer, most luxuriant and splendid objects. But there are two classes of Roses that are perfectly harty climbers, and may therefore be employed with great adrantage by the Landscape Gardener-the Michiganand the Boursault trees. The single Michigan is a most compact and vigorous grower, and often, in its wild haunts in the west, clambers orer the tops of tall forest trees, and decks them with its abumdant clusters of pale purple flowers. There are now in our gardens several beantiful double rarieties of this, and among them. one, called Beauty of the Prairies, is 
most admired for its large rich buds and blossoms of a deep rose color.

The Boursault roses are remarkable for their pi ofusion of flowers, and for their shining, reddish stems, with few thorns. The common Purple or Crimson Boursault is quite a wonder of beauty in the latter part of May, when trained on the wall of a cottage, being then literally covered with blossoms; and it is so hardy that scarcely a branch is ever injured by the cold of winter. The Blush and the Elegans are still richer and finer varieties of this class of roses, all of which are well worthy of attention.

We have to regret that the inclemency of our winters will not permit us to cultivate the White European Jasmine (Jasminum officinale) out of the garden, as even there it requires a slight protection in winter. Below the latitude of Philadelphia, however, it will probably succeed well. In the southern states they have a most lovely plant, the Carolina Jasmine (Gelseminum), which hangs its beautiful yellow flowers on the very tree tops, and the woods there in spring are redolent with their perfume.

The connoisseur in vines will not forget the curious Periploca, which grows very rapidly to the height of 40 or 50 feet, and bears numerous branches of very curious brown or purple flowers in suinmer; or the Doubleblossoming Brambles, both pink and white, which often make shoots of 20 or 30 feet long; in a season, and bear pretty clusters of double flowers in June. All these fine climbers, and several others to be found in the catalogues, may, in the hands of a person of taste, be made to contribute in a wonderful degree to the variety, elegance, and beauty of a country residence; and to neglect to introduce them would be to refuse the aid of some of the 
most beautiful accessories that are capable of being combined with trees, as well as with buildings, gardens, and fences.

The reader must not imagine, from the remarks which we have here made on the beauty and charms of climbing plants, that we. would desire to see every tree in an extensive park wreathed about and overhung with fantastic vines and creepers. Such is by no means our intention. We should consider such a proceeding something in the worst possible taste. There are some trees whose rugged and ungraceful forms would refuse all such accompaniment ; and others from whose dignity and majesty it would be improper to detract even by adding the gracefulness of the loveliest vine.

Although we are not now writing of buildings, it is not inappropriate here to remark how much may be done in the country, and indeed even in town, by using vines and creepers to decorate buildings. The cottage in this country too rarely conveys the idea of comfort and happiness which we wish to attach to such a habitation, and chiefly because so often it stands bleak, solitary, and exposed to every ray of our summer sun, with a scanty robe of foliage to shelter it. How different such edifices, however humble. become when the porch is overhung with climbing plants.

Almost every man feels prouder of his home when it is a pleasant spot for the eye to rest upon, than when it is situated in a desert, or overgrown with weeds. Besides this, tasteful embellishment has a tendency to refine the feelings of every member of the family; and every leisure hour spent in rendering more lovely and agreeable even the humblest cottage, is infinitely better employed than in lounging about in idle and useless dissipation. 


\title{
SECTION VII.
}

TREATMENT OF GROUND.-FORMATIUN OF WALKS.

Nature of operations on Ground. Treatment of flowing and irregular surfaces to heighten their expression; flats, or level surfaces. Rocks, as materials in Landscape. Laying out Roads and Walks: Directions for the Approach: Rules by Repton. The Drive, and minor walks. The introduction of fences and verdant hedges.

\footnotetext{
"Strength may wield the ponderous spade,

May turn the clod and wheel the compost home;

But elegance, chief grace the garden shows,

And most attractive, is the fair result

Of thought, the creature of a polished mind."
}

COWPer.

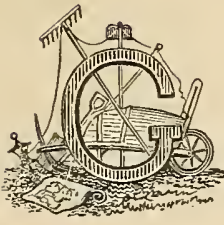

R OUND is undoubtedly the most un. wieldy and ponderous material that comes under the care of the Landscape Gardener. operations of the leveller rarely extending below two or three feet of the surface; but the effect produced by a given quantity of labor expended upon it, is generally much less than when the same has been bestowed in the formation of plantations, or the erection of buildings. 'The achievements of art upon ground appear so trifling, 1no, when we behold the apparent facility with which nature has arranged it in such a variety of forms, that the former sink into insignificance when compared with the latter.
\end{abstract}

For these reasons, the operations to be performed 
upon stomem in this comery will senerally be limited

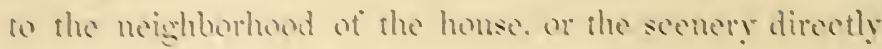
under the aye. Here, hy judicious levelling and smoothing in some eases or by ming gentle cminenes with intepusing hollows in others. much man be dome at at moderate expenso. to improve the beamy of the sumenend. ing limessape.

laceds and walks are so directly comected with opera-

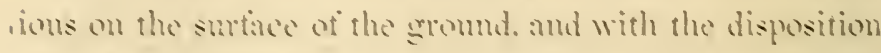
of plantations. wheh we have already mate fimilian to the ceader, that we shall introdneo in this place a few remarks ielative to their direction and formation.

'The dpproesin is by fir the most importam of these routes. It is the private road. leadinge from the public highway, directly to the houso itselt. It should theretore bear a propertionate breadth and size, and exhibit marks of grood keeping. in aceordanes with the dignity of the mansion.

In the ancient style of gardening, the Aproveh was so formed as to chter directly in frome of the homse, attording a full riew of that portion of the cdifice. and mo ofher. A line drawn as directly as pessible, and erenly- hordered on gath side with a tall areme of trees. was the whole expendime of art necessary in its fommion. It is true, the simplieity of design. Was otten more than comuterbalaned by the diffienly of levellings. grading and altering the surtiace. neessary to please the greometric eye; but the mes were as plain and mohangeable as the lines were parallel and auderiating.

In the present move advanced state of Landscape Comdening. the finmation of the Approach has become cqually a matter of arfistical skill with other dotails of the art. The house is generally so approached, that the eye shall frst mect it in an amyalar direction, displaying not 
only the heauty of the anchitectural facede, lout also one of the end clevations, thus giving a rroore complete idea of the size, chancter, or elegance of the building: arod instend of leading in a direct line from thes gate to the hrose, it curves in casy lines through certain portions of tlec park or lawn, until it reaches that objocet.

If the point where the Approach is to start fiorn the lighway be not already dotermined past alteration, it should be so chosen as to affind a sufficient drive through the grourds betore arriving at the house, to give the stranger some idea of the extent of the whole joroperty : to allow an agreeable diversily of surface over which to lead it: and lastly, in such a rmanner as not to interfere with the converience of ready access to and from the mansion.

'This point being decided, and the other being the mansion and adjacent buildings, it remains to lay out the road in strch grarlual curvos as will appear casy and graceful, without verging into rapid turns or formal stiffress. Sinco the modern style las leceome partially known and adopted here, some persors appear to have supposed that nature "has a horror of straight lines," and consequently, believing that they could not possibly ere, they immerliately ran into the other extremo, filling their grounds with zigzag and regularly serpentine roads, still rnore horrible: which can only be compared to the contortions of a wounded snake dragging its way slowly over the earth.

'There are two guiding principles which have been laid down for the formation of $\Lambda$ pproach roads. 'The first, that the curves should never be so great, or learl over surfaces so unequal, as to make it disagrecable to drive upon them; and the second, that the road should never curve without some reason, cither real or apparent. 
The most natural method of forming a winding Approach where the ground is gently undulating, is to follow, in some degree, the depressions of surface, an to curre rotind the eminences. This is an excellent method, so long as it does not lead us in too circuitous a direction, nor, as we betore hinted, make the road itself too uneren. When either of these happens, the easy, gradual flow of the curre in the proper direction, must be maintained by levelling or grading, to produce the proper surface.

Nothing can be more ummeaning than to see an Approach, or any description of road, winding hither and thither, through an extensive level lawn, towards the louse, without the least apparent reason for the curres. Happily, we are not, therefore, obliged to return to the straight line; but gradual curves may always be so arranged as to appear necessarily to wind round the groups of trees, which otherwise would stand in the way. Whererer a bend in the road is intended, a cluster or group, of sreater or less size and breadth, proportionate to the curve, should be placed in the projection formed. These trees, as soon as they attain some size, if they are properly arranged, we may suppose to have originally stood there, and the road naturally to have curred, to aroid destroring them.

This arrangement of trees bordering an extended Approach road, in connexion with the various other groups, masses, and single trees, in the adjacent lawn, will in most cases have the effect of concealing the house from the spectator approaching it, except, perhaps, from one or two points. It has, therefore, been considered a matter worthy of consideration, at what point or points the first 
view of the house shall be obtained. If seen at too great a distance, as in the case of a large estate, it may appear more diminutive and of less magnitude than it should; or: if first viewed at some other position, it may strike the eye of a stranger, at that point, unfavorably. The best, and indeed the only way to decide the matter, is to go over the whole ground covered by the Approach route rarefully, and select a spot or spots sufficiently near to give the most favorable and striking view of the house itself. This, if openings are to be made, can only be done in winter; but when the ground is to be newly planted, it may be prosecuted at any season.

The late Mr. Repton, who was one of the most cele. brated English practical landscape-gardeners, has laid down in one of his works, the following rules on the subject, which we quote, not as applying in all cases, but to show what are generally thought the principal requisites of this road in the modern style.

First. It ought to be a road to the house, and to that principally.

Secondly. If it be not naturally the nearest road possible, it ought artificially to be made to appear so.

Thirdly. The artificial obstacles which make this road the nearest, ought to appear natural.

Fourthly. Where an approach quits the high road, it ought not to break from it at right angles, or in such a manner as to rob the entrance of importance, but rather at some bend of the public road, from which a lodge or gate may be more conspicuous; and where the high road may appear to branch from the approach, rather than the approach from the high road. 
Fifthly. Aiter the approach enters the park, it should aroid skirting along its boundary, which betrays the want of extem or unity of property.

sirthly. The house, mless very large and magnifient, should not be seen at so great a distanee as to make it appear much less than it really is.

Serenthly. The first riew of the honse should be from the most pleasing point of sight.

Eighthly. As soon as the houso is visible from the spproach. there should be no temptation to quit it (which will ever be the casc if the road be at all cirenitous). lanless sutficient obstacles. such is water or inacessible ground, appear to justify its course. *

Although there are many simations where these rules must be greaty modified in practice. yet the improver will do well to ban them in mind, as it is infinitely more easy to make oecasional deviations from general rules, than to carry out a tastefil improrement without any gruiding principles.

There are many fine country residences on the banks of the Hudson, Connecticut, and other rivers, where the proprietors are often much perplexed and puzzled by the situation of their houses: the huilding presenting really two fronts, while they appear to desire only one. Such is the case when the estate is sitmated between the public road on one side, and the river on the other: and we hare otien seen the Approach artificiaily tortured into a long cirenitous route. in order finally to arrive at what the proprietor considers the true front. viz. the side nearest the river. When a building is so situnted. much the most

- Repton's Ingurye into the Changes of Taste in Landsespe Gardening, p. 109. 
elegant effect is produced by having two fronts: one, the entrance fronl, with the porch or portico nearest the road, and the other, the river front, facing the water. The beauly of the whole is often surprisingly enhanced by this arrangtment, for the visitor, after passing by the Approach throug? a considerable portion of the grounds, with perhaps but slight and partial glimpses of the river, is most agreeably surprised on entering the house, and looking from the drawing-room windows of the other front, to behold another beautiful scene totally different from the last, enriched and ennobled by the wide-spread sheet of water before him. Much of the effect produced by this agreeable surprise from the interior, it will readily be seen, would be lost, if the stranger had already driven round and alighted on the river front.

The Drive is a variety of road rarely seen among us, yet which may be made a very agreeable feature in some of our country residences, at a small expense. It is intended for exereise more secluded than that upon the public road, and to show the interesting portions of the place from the carriage, or on horseback. Of course it can only be formed upon places of considerable extent; but it enhanees the enjoyment of such places very highly, in the estimation of those who are fond of equestrian exercises. It generally commences where the approach terminates, viz. near the house: and from thence, proceeds in the same easy curvilinear manner through various parts of the grounds, farm or estate. Sometimes it sweeps through the pleasure grounds, and returns along the very beach of the river, beneath the fine overhanging foliage of its projecting bank; sometimes it proceeds towards some favorite point of view, or interesting spot on the landscape; or at others it 
leaves the lawn and traverses the farm, giving the pro. prietor an opportunity to examine his crops, ol exhibit his agricultural resonrees to his friends.

Walkis are laid ont for purposes similar to Drives, but are much more common, and may be introduced into every scene, howerer limited. They are intended solely for promenades, or exercise on foot, and should therefore be dry and firm, if possible, at all seasons when it is desirable to use them. Some may be open to the south, sheltered with evergreens, and made dry and hard for a warm promenade in winter; others formed of closely mown turf', and thickly shaded by a leafy canopy of verchure, for a cool retreat in the midst of summer. Others again may lead to some sequestered spot, and terminate in a seclucied rustic seat, or conduct to some shaded dell or rugged eminence, where an extensive prospect can be enjoyed. Indeed, the genius of the place must suggest the direction, length, and number of the walks to be laid out, as no fixed rules can be imposed in a subject so everchanging and difierent. It should, however, never be forgotten, that the walk ought always to correspond to the scene it traverses, being rough where the latter is wild and picturesque, sometimes scarcely differing from a common footpath, and more polished as the surrounding objects show evidences of culture and high keeping. In direction, like the approach, it should take easy flowing curves, though it may often turn more abruptly at the interposition of an obstacle. The chie? beauty of curved and bending lines in walks, lies in the new scenes which by means of them are opened to the eye. In the straight walk of half a mile, the whole is seer at a glance, and there is too often but little to excite the spectator to pursue the search; but in the modern style, at 
every few rods, a new turn in the walk opens a new prospect to the beholder, and "leads the eye," as Hogarth graphically expressed it, "a kind of wanton chase," con. tinually atiording new refreshment and variety.

Fences are often among the most unsightly and offensive objects in our country seats. Some persons appear to have a passion for subdividing their grounds into a great number of fields; a process which is scarcely ever advisable, even in common farms, but for which there can be no apology in elegant residences. The close proximity of fences to the house gives the whole place a confined and mean character. "The mind," says Repton, "feels a certain disgust under a sense of confinement in any situation, however beautiful." A wide-spread lawn, on the contrary, where no boundaries are conspicuous, conveys an impression of ample extent and space for enjoyinent. It is frequently the case that, on that side of the house nearest the outbuildings, fences are, for convenience, brought in its close neighborhood, and here they are easily concealed by plantations; but on the other sides, open and unobstructed views should be preserved, by removing all barriers not absolutely necessary.

Nothing is more common, in the places of cockneys who become inhabitants of the country, than a display, immeliately around the dwelling, of a spruce paling of carpentry, neatly made, and painted white or green; an abomination among the fresh fields, of which no person of taste could be guily. To fence off a small plot around a fine house, in the midst of a lawn of fifty acres, is a perversity which we coilc never reconcile, with even the lowest perception of besuty. An old stone wall covered with creepers and climbing plants, may become a picturesque barrier, a 
thousand times superior to such in fence. Bui there is never one instance in a thousand where any barier is necessary. Where it is desirable to separate the louse from the level grass of the lawn, let it be done by an architectural terrace of stone. or a raised flatform of grarel, supported by turf, which will confer importance and dignity upon the building. instead of giring it a petty ar. trifling expression.

Firdant hedges are elegant substitutes for stone o: wooden fences. and we are surprised that their use has not been hitherto more general. The hare ourselres been making experiments for the last ten years with rarious hedge-plants: and hare succeeded in obtaining some hedges which are now highly admired. Fire or six years will, in this climate, under proper care, be sufficient to produce hedges of great beautr, capable of withstanding the attacks of erery hind of cattle; barriers, too, which will outlast many generations. The common trbor Titce (or flat Cedar), which grows in great abundance in many districts, forms one of the most superb hedges, without the least care in trimming: the folinge growing thickly dorn to the rery ground, and being erergreen, the hedge remains clothed the whole rear. Our common Thorns, and in particular those known in the nurseries as the Nerrastle and Tishington thorns, form hedges of great strength and beauty. They are indeed, much better adapted to this climate than the English Hawthorn, wich often suffers from the unclouded radiance of our midsummes sun. In autumn. too, it loses its foliage much sconer than our natire sorts, some of which assume a brilliant scarlet when the foliage is fading in autumn. In New England, the Buckthorn is preferred from its rapid and luxuriant 
srowth; ; and in the middle states, the Maclura, or Osage Orange, is becoming a favorite for its glossy and polished foliage. The Priret, or Prim, is a rapid growing shrub, well fitted for interior divisions. Picturesque hedges are easily formed by intermingling a variety of flowering shrubs, sweet briers, etc., and allowing the whole to grow together in rich masses. For this purpose the Michigan rose is admirably adapted at the north, and the Cherokee rose at the south. In all cases where hedges are employed in the natural style of landscape (and not in close connexion with highly artificial objects, buildings, etc.), a more agreeable effect will be produced by allowing the hedge to grow somewhat irregular in form, or varying it by planting near it other small trees and shrubs to break the outline, than by clipping it in even and formal lines. Hedges may be obtained in a single season, by planting long shoots of the osier willow, or any other tree which throws out roots easily from cuttings.

A simple and pleasing barrier, in good keeping with cottage residences, may be formed of rustic work, as it is termed. For this purpose, stout rods of any of our native forest trees are chosen (Cedar being preferable) with the bark on, six to ten feet in length; these are sharpened and driven into the ground in the form of a lattice, or wrought into any figures of trellis that the fancy may suggest. When covered with luxuriant vines and climbing plants, such a barrier is often admirable for its richness and variety.

* The Buckthorn is perlnaps the best plant wherc a-thick screen is very speedily desired. It is not liable to the attack of insects; grows very thickly at the bottom, at once; and will make an efficient screen sooner than almost any other plant. 
The sunken fence, fosse, or ha-ha, is an English invention, used in separating that portion of the lawn near the house, from the part grazed by deer or cattle, and is only a ditch sufficiently wide and deep to render communication difficult on opposite sides. When the ground slopes from the house, such a sunk fence is invisible to a person near the latter, and answers the purpose of a barrier, without being in the least obtrusive.

In a succeeding section we shall refer to terraces with their parapets, which are by far the most elegant barriers for a highly decorated flower garden, or for the purpose of maintaining a proper comnexion between the house and the grounds, a subject which is scarcely at all attended to, or its importance even recognised as yet among us. 


\section{SECTION VIII.}

'TREATMENT' OF WATER.

Beautiful effects of this element in nature. In what cases it is desirable to attempt the formation of artificial pieces of water. Regular forms unpleasing. Directions for the formation of ponds or lakes in the irregular manner. Study of natural lakes. Isiands. Planting the margin. 'Treatment of nutural brooks and rivulets. Cascades and watct. falls. Legitimate sphere of the art in this department.

The dale

With woods o'erhung, and shagg'd with mossy rocks,

Whence on each hand the gushing waters play,

And down the rough cascade white-dashing fall,

Or gleam in lengthened vista through the trees.

Tromson.

$\mathrm{HE}$ delightful and captivating effects of water in landscapes of every description, are universally known and admitted. The boundless sea, the broad full river, the dashing noisy brook, and the limpid meandering rivulet, are all possessed of their peculiar charms; and when combined with scenes otherwise finely disposed and well wooded, they add a hundred fold to their beauty. The soft and trembling shadows of the surrounding trees and hills, as they fall upon a placid sheet of water-the brilliant light which the crystal surface reflects in pure sunshine, mirroring, too, at times in its resplendent bosom, all the cerulean depth and snowy whiteness of the overhanging sky, give it an almost 
magical effect in a beautiful landscape. The murmur of the babbling brook, that

". In linked sweetness long drawn out,"

falls upon the ear in some quiet secluded spot, is inexpressibly soothing and delightful to the mind; and the deeper sound of the cascade that rushes, with an almost musical dash, over its bed of moss-covered rock, is one of the most fascinating of the many elements of enjoyment in a fine country seat. The simplest or the most monotonous view may be enlivened by the presence of water in any considerable quantity; and the most picturesque and striking landscape will, by its addition, receive a new charm, inexpressibly enhancing all its former interest. In short, as no place can be considered perfectly complete without either a water view or water upon its own grounds, wherever it does not so exist and can be easily formed by artificial means, no man will neglect to take advantage of so fine a source of embellishment as is this element in some of its varied forms.

"___ Fleuves, ruisseaux, beaux lacs, claires fontaines,

Venez, portez partout la vie et la fraîcheur?

Ah! qui peut remplacer votre aspect enchanteur?

De près il nous amuse, et de loin nous invite:

C'est le premier qu'on cherche, et le dernier qu'on quitte.

Vous fécondez les champs ; rous répétez les cieux;

Vous enchantez l'oreille, et vous charmez les yeux."

In this country, where the progress of gardening and improvements of this nature, is rather shown in a simple and moderate embellishment of a large number of villas and country seats, than by a lavish and profuse expenditure on a few entailed places, as in the residences of the English nobility, the formation of large pieces of water 
at great cost and extreme labor, would be cousidered both absurd and uncalled for. Indeed, when nature has so abundantly spread before us such an endless variety of superb lakes, rivers and streams, of every size and descrip. tion, the efforts of man to rival her great works by mera imitation, would, in most cases, only become ludicrous by contrast.

When, however, a number of perpetual springs cluster together, or a rill, rivulet, or brook, runs through an estate in such a manner as easily to be improved or developed into an elegant expanse of water in any part of the grounds, we should not hesitate to take advantage of so fortunate a circumstance. Besides the additional beauty conferred upon the whole place by such an improvement, the proprietor may also derive an inducement from its utility : for the possession of a small lake, well stocked with carp, trout, pickerel, or any other of the excellent pond fish, which thrive and propagate extremely well in clear, fresh water, is a real advantage which no one will undervalue.

There is no department of Landscape Gardening which appears to have been less understood in this country than the management of water. Although there have not been many attempts made in this way, yet the occasional efforts that have been put forth in various parts of the country, in the shape of square, circular, and oblong pools of water, indicate a state of knowledge extremely meagre, in the art of Landscape Gardening. The highest scale to which these pieces of water rise in our estimation, is that of respectable horse-ponds; beautiful objects they certainly are not. They are generally round or square, with perfectly smooth, flat banks on every side, and resemble a huge basin set down in the middle of a green lawn. 
Lakes or ponds are the most beautiful forms in which water can be displayed in the grounds of a country residence.* They invariably produce their most pleasing effects when they are below the level of the house; as, if abore, they are lost to the riew, and if placed on a level with the eye, ther are seen to much less advantage. We conceire that they should nerer be introduced where they do not naturally exist, except with the concurrence of the following circumstances. First, a sufficient quantity of rumning water to maintain at all times an overflow, for nothing can be more unpleasant than a stagnant pool, as nothing is more delightful than pure, clear, limpid water; and secondly, some natural formation of ground, in which the proposed water can be expanded, that will not only make it appear natural, but diminish, a hundred fold, the expense of formation.

The finest and most appropriate place to form a lake, is in the bottom of a small ralley, rather broad in proportion to its length. The soil there will probably be found rather clarey and retentive of moisture ; and the rill or brook, if not already rumning through it, could doubtless be easily diverted thither. There, by damming up the lower part of the ralley with a head of greater or less height, the water may be thrown back so as to form the whole body of the lalie.

The first subject which will demand the attention, after the spot has been selected for the lake or pond, and the

* Owing to the immense scale upon which nature displays this fine element in North America, every sheet of water, of moderate or small size, is almost universally called a pond. And many a beautiful, limpid, natural expanse, which in England would be thought a chaming lake, is here simply a pond. The term mar" be equally correct, but it is by no means as elegant. 
height of the head and consequent depth of water determined upon, is the proposed form or outline of the whole. And, as we have already rejected all regular and geometric forms, in scenes where either natural or picturesque beauty is supposed to predominate, we must turn our attention to examples for imitation in another direction.

If, then, the improver will recur to the most beautiful small natural lake within his reach, he will have a subject to study and an example to copy, well worthy of imitation. If he examine minutely and carefully such a body of water, with all its accompaniments, he will find that it is not only delightfully wooded and overshadowed by a variety of vegetation of all heights, from the low sedge that grows on its margin, to the tall tree that bends its branches over its limpid wave; but he will also perceive a striking peculiarity in its irregular outline. This, he will observe, is neither round, square, oblong, nor any modification of these regular figures, but full of bays and projections, sinuosities, and recesses of various forms and sizes, sometimes bold, and reaching a considerable way out into the body of the lake, at others, smaller and more varied in shape and connexion. In the heights of the banks, too, he will probably observe considerable variety. At some places, the shore will steal gently and gradually away from the level of the water, while at others it will rise suddenly and abruptly, in banks more or less steep, irregular, and rugged. Rocks and stones covered with mosses, will here and there jut out from the banks, or lie along the margin of the water, and the whole scene will be full of interest, from the variety, intricacy and beauty of the various parts. If he witl accurately note in his mind all these varied forms-their separate outlines, the way in which they blcnu into one 
another, and comnect themselves together, and the effeet which. surromding the water, they produce as a whole, he will have some tolerably correct ideas of the way in which an artitieial lake ought to be formed.

Let him go still fiuther now, in imachination, and suppose the banks of this matural lake. without being otherwise altered, entirely demded of grass shmbs trees and rerdure of erery" description, remaining characterized only by their original form and outline: this will give him a more complete view of the method in which his labors must commenee: for, meouth and apparently" mis-shapen as those bauks are and must be. when raw and unclothed, to exhibit all thich raviety and play of light and shadow when verdant and complete, so also must the original form of the banks and margin of the piece of artiticial water. in order funally to assume the beautiful or picturesque, be made to assume outlines equally rough and harsh in their raw and ineomplete state.

It occasionally happens. though rarely, that around the hollow or valley where it is proposed to form the piece of water. the gromd rises in such irregular torm, and is so undulating. recoding, and projecting in rarions parts, that when the water is dammed up by the head below; the natural outline formed by the banks already existing, is sufficionfly raried to produce a pleasing effect without much further preparatory labor. 'This, when it occurs, is exceedingly fortmate: but the examples are so unfiequent, that we must here make our suggestions upon a different supposition.

When, therefore, it is found that the form of the intended latie rould not be such as is desirable, it must be made so by digging. In order to do this with any exactness, the 
improver should take his stand at that part of the ground where the dam or head is to be formed, and raising his levelling instrument to the exact height to which the intended lake will rise, sweep round with his eye upon the surrounding sides of the valley, and indicate by placing marks there, the precise line to which the water will reach. This can easily be done throughout the whole circumference by a few changes of position.

When the outline is ascertained in this way, and marked out, the improver can, with the occasional aid of the leveller, easily determine where and how he can make alterations and improvements. He will then excavate along the new margin, until he makes the water line (as shown by the instrument) penetrate to all the various bays, inlets, and curves of the proposed lake. In making these irregular variations, sometimes bold and striking, at others fainter and less perceptible, he can be guided, as we have already suggested, by no fixed rules, but such as he may deduce from the operations of nature on the same materials, or by imbuing his mind with the beauty of forms in graceful and refined art. In highly polished scenery, elegant curves and graceful sweeps sliould enter into the composition of the outline ; but in wilder or more picturesque situations, more irregular and abrupt variations will be found most suitable and appropriate.

'The intended water outline once fully traced and understood, the workmen can now proceed to form the banks. All this time the improver will keep in mind the supposed appearance of the bank of a natural lake stripped of its vegetation, etc., which will greatly assist him in his progress. In some places the banks will rise but little from the water, at others, one or two feet, and at others, perhaps three, four 
or six times as much. This they will do, not in the same mannere in all portions of the outline, sloping away with a like gradual riso on both sides, for this would ineritably produce tamencss and monotony, but in an irregular and raried manner: sometimes falling back gradually, sometimes starting up perpendicularly, and again orerhanging the bed of the lake itself.

All this can be casily effected while the excarations of those portions of the bed which require deepening are going on. And the better portions of the soil obtained trom the latter, will serve to raise the banks when they are too low:

It is of but little consequence how roughly and irregularly the projections, elevations, etc., of the banks and ontlines are at first made, so that some general form and comexion is preserred. The danger lies on the other side, viz. in producing a whole, too tame and insipid; for we have found by experience, how difficult it is to make the best workmen understand how to operate in any other way than in regular cmres and striight lines. Besides. newly moved earth, by settling and the influence of rains, etc., tends, for some time, iowards greater erenness and equality of surface.

In arranging these outlines and banks, we should study the effect at the points from which they will generally be viewed. Some pieces of water in valleys, are looked down upon from other and higher parts of the demesne; others (and this is most generally the case) are only seen from the adjoining walk, at some point or points where the latter approaches the lake. They are most usually seen 
from one, and seldom from more than two sides. When a lake is viewed from above, its contour should be studied as a whole; but when it is only scen from one or more sides or points, the beanty of the coup d'xil from those positions can often be greatly increased by some trifling alterations in arrangement. A piece of water which is long and comparatively narrow, appears extremely different in opposite points of view; if seen lengthwise from either extremity, its apparent breadth and extent is much increased; while, if the spectator be placed on one side and look across, it will seem narrow and insignificant. Now, although the form of an artificial lake of moderatc size should never be much less in breadth than in length, yet the contrary is sometimes unavoidably the case; and being so, we should by all means avail ourselves of those well known laws in perspective, which will place them in the best possible position, relative to the spectator.

If the improver desire to render his banks still more picturesque, resembling the choicest morceaux of natural banks, he should go a step further in arranging his materials before he introduces the water, or clothes the margin with vegetation. In analysing the finest portions of natural banks, it will be observed that their peculiar characteristics often depend on other objects besides the mere ground of the surrounding banks, and the trees and verdure with which they are clothed. These are, rocks of various size, forrns, and colors, often projecting out of or holding up the bank in various places; stones sometimes imbedded in the soil, sometimes lying loosely along the shore; and lastly, old stumps of trees with gnarled roots, whose decaying hues are often extremely mellow and agreeable to the eye. All these have much to do with the expression of a truly pic- 
turesque bank, and cannot be excluded or taken away from it without detracting largely from its character. There is no reason, therefore, in an imitation of nature, why we should not make use of all her materials to producea similar effect; and although in the raw and rude state of the banks at first, they may have a singular and rather outré aspect, stuck round and decorated here and there with large rocks, smaller stones, and old stumps of trees; yet it must be remembered that this is only the chaotic state, from which the new creation is to emerge more perfectly formed and completed; and also that the appearance of these rocks and stumps, when covered with mosses, and partially overgrown with a profusion of luxuriant vegetation and climbing plants, will be as beautifully picturesque after a little time has elapsed, as it is now uncouth and uninviting.

Islands generally contribute greatly to the beauty of a piece of water. They serve, still further, to increase the variety of outline, and to break up the wide expanse of liquid into secondary portions, without injuring the effect of the whole. The striking contrast, too, between their verdure, the color of their margins, composed of variously tinted soils and stones, and the still, smooth water around them,- - softened and blended as this contrast is, by their shadows reflected back from the limpid element, gives additional richness to the picture.

The distribution of islands in a lake or pond requires some judgment. They will always appear most natural when sufficiently near the shore, on either side, to maintain in appearance some connexion with it. Although islands do sometimes occur near the middle of natural lakes, yet

i the effect is by no means good, as it not only breaks and distracts the effects of the whole expanse by dividing it into 
two distinct parts, but it always indicates a shallowness or want of depth where the water should be decpest.

There are two situations where it is universally admitted that islands may be happily introduced. 'I'hese are, at the irlet and the exit of the body of water. In many cases where the stream which supplies the lake is not remark. able for size, and will add nothing to the appearance of the whole view from the usual points of sight, it may be con. cealed by an island or small group of islands, placed at some little distance in front of it. 'The head or dam of a lake, too, is often necessarily so formal and abrupt, that it is difficult to make it appear natural and in good kecping with the rest of the margin. The introduction of an island or two, placed near the main shore, on either side, and projecting as far as possible before the dam, will greatly diminish this disagrecable formality, particularly if well clothed with a rich tuft of shrubs and overhanging bushes.

Except in these two instances, islands should be generally placed opposite the salient points of the banks, or near those places where small breaks or promontories run out into the water. In such situations, they will increase the irregularity of the outline, and lend it additional spirit and animation. Should they, on the other land, be seated in or near the marginal curve and indentations, they will only serve to $\log$ up these recesses; and while their own figures are lost in these little bays where they are hidden, by lessening the already existing irregularities, they will render the whole ontline tame and spiritless.

On one or two of these small islands, little rustic habitations, if it coincide with the taste of the proprietor, may be made for different aquatic birds or waterfowl, 
which will much enliven the scene by their fine plumage. Among these the sucan is pre-eminent, for its beauty and gracefulness. Abroad. they are the almost constum accompaniments of water in the ground of country residences: and it cannot be denied that, floating ahout in the limpid ware, with their snow-white plumage and superbly curved necks, they are extremely elegant objects. After having arranged the banks, reared up the islands, and completely formed the bed of the proposed lake, the improrer will next proceed, at the proper period, to finish his labors by clothing the newly formed ground, in various parts, with regetation. This may be done immediately, if it be desirable: or if the season be not farorable, it may be deferred until the banks, and all the newly formed earth. hare had time to settle and assume their final forms after the dam has been closed. and the whole basin filled to its intended height.

Planting the margins of pieces of water, if they should be of much extent, must evidently proceed upon the same leading principle that we hare already laid down for ornamental plantations in other situations. That is, there must be trees of difierent heights and sizes, and underwood and shrubs of lower growth, disposed sometimes singly; at others in masses, groups, and thickets: in all of which forms, connizion must be preserred, and the whole unnst be made to blend well together, while the different sizes and contours will prerent any sameness and confusion. On the retreating dry banks, the taller and more sturdy decidnons and erergreen trees, as the oak, ash, etc., may be planted, and nearer br, the different willows, the elm, the alder, and other trees that lore a moister situation, will thrice trell. It is indispensable necessary, in order to 
produce breadth of effect and strong rich contrasts, that underwood shouli be employed to clothe many parts of the banks. Without it, the stems of trees will appear loose and straggling, and the screen will be so imperfect as to allow a free passage for the vision in every direction. For this purpose, we have in all our woods, swamps, and along our brooks, an abundance of hazels, hawthorns, alders, spice woods, winter berries, azaleas, spireas, and a hundred other fine low shrubs, growing wild, which are by nature, extremely well fitted for such sites, and will produce immediate effect on being transplanted. These may be intermingled, here and there, with the swamp button-bush (Cephalanthus), which bears handsome, white, globular heads of blossorns, and the swamp magnolia, which is highly beautiful and fragrant. On cool north banks, among shelves of proper soil, upheld by projecting ledges of rock. our native Kalmias and Rhododendrons, the common and mountain laurels, may be made to flourish. The Virginia Creeper, and other beautiful wild vines, may be planted at the roots of some of the trees to clamber up their stems, and the wild Clematis so placed that its luxuriant festoons shall hang gracefully from the projecting boughs of some of the overarching trees. Along the lower banks and closer margins, the growth of smaller plants will be encouraged, and various kinds of wild ferns may be so planted as partially to conceal, overrun, and hide the rocks and stumps of trees, while trailing plants, as the periwinkle and moneywort (Lysamachia nummularia), will still further increase the intricacy and richness of such portions. In this way, the borders of the lake will resemble the finest portions of the banks of picturesque and beautiful natural dells and pieces of water, and the effect of the whole, wher. 
time has given it the benefit of its softening touches, if it has been thus properly executed, will not be much inferior to those matchless bits of fine landscape. A more striking and artistical effect will be produced by substituting for native trees and shrubs, common on the banks of streams and lakes in the country, only rare foreign shrubs, vines, and aquatic plants of hardy growth, suitable for sucli situations. While these are arranged in the same manner as the former, from their comparative novelty, especially in such sites, they will at once convey the idea of refined and elegant art.

If any person will take the trouble to compare a piece of water so formed, when complete, with the square or circular sheets or ponds now in vogue among us, he must indeed be little gifted with an appreciation of the beautiful, if he do not at once perceive the surpassing merit of the natural style. In the old method, the banks, level, or rising on all sides, without any or but ferv surrounding trees, carefully gravelled along the edge of the water, or what is still worse, walled up, slope away in a tame, dull, uninteresting grass field.. In the natural method, the outline is varied, sometimes receding from the eye, at others stealing out, and inviting the gaze-the banks here slope off gently with a gravelly beach, and there rise abruptly in different heights, abounding with hollows, projections, and eminences, showing various colored rocks and soils, intermingled with a luxuriant vegetation of all sizes and forms, corresponding to the different situations. Instead of allowing the sun to pour down in one blaze of light, without any objects to soften it with their shade, the thick overhanging groups and masses of trees cast, here and there, deep cool shadows. Stealing through the leaves and branches, the sun-beams 
quiver and play upon the surface of the flood, and are reflected back in dancing light, while their full glow upon the broader and more open portions of the lake is relieved, and brought into harmony by the cooler and solter shades mirrored in the water from the surrounding hues and tints of banks, rocks, and vegetation.

Natural brooks and rivulets may often be improved greatly by a few trifling alterations and additions, when they chance to come within the bounds of a country residence. Occasionally, they may be diverted from their original beds when they run through distant and unfrecuented parts of the demesne, and brought through nearer portions of the pleasure grounds or lawn. 'This, however, can only be done with propriety when there is a natural indication in the grounds through which it is proposed to divert it-as a succession of hollows, etc., to form the future channel. Sometimes, a brisk little brook can be divided into smaller ones for some distance, again uniting at a point below, creating additional diversity by its varying form.*

Brooks, rivulets, and even rills may frequently be greatly improved by altering the form of their beds in various places. Often by merely removing a few trifling obstructions, loose stones, branches, etc., or hollowing away the

* The Abbé Délillo has given us a fine image of a brook thus divided, in the following lines:-

“Plus loin, il se sépare en deux ruisseaux agiles,

Qui, se suivant l'un l'autro avec rapidité,

Disputent de vitesse et de limpidité ;

Puis, rejoignant tous deux le lit qui les rassemble,

Murmurent enchantés de voyager ensemble.

Ainsi, toujours errant de détour en détour,

Muet, bruyant, paisible, inquiet tour à tour,

Sous mille aspects divers son cours se renouvelle." 
adjoining bank for a short distance, fine little expanses or pools of still water may be formed, which are happily corktrasted with the more rugged course of the rest of thc stream. Such improvements of these minor water courses are much preferable to widening them into flat, insipid, tame canals or rivers, which, though they present greater surface to the eye, are a thousand times inferior in the impetuosity of motion, and musical, "babbling sound," so delightful in rapid brooks and rivulets.*

Cascades and water-falls are the most charming features of natural brooks and rivulets. Whatever may be their size, they are always greatly admired, and in no way is the peculiar stillness of the air, peculiar to the country, more pleasingly broken, than by the melody of falling water. Even the gurgling and mellow sound of a small rill, leaping over a few fantastic stones, has a kind of lulling fascination for the ear, and when this sound can be brought so near as to be distinctly heard at the residence itself, it is peculiarly delightful. $\nmid \cdot$ Now any one who examines a small cascade at all attentively, in a natural brook, will see that it is often formed in the simplest manner by the interposition of a few large projecting stones, which partially dam up the current and prevent the ready flow of the water. Such little cascades are easily imitated, by following exactly the same

* The most successful improvement of a natural brook that we have ever witnessed, has been effected in the grounds of Henry Sheldon, Esq., of Tarrytown, N.Y. The great variety and beauty displayed in about a fourth of a mile of the course of this stream, its pretty cascades, rustic bridges, rockwork, etc., reflect the highest credit on the taste of that gentleman.

+ The fine stream which forms the south boundary of Blithewood, on the Hudson, the seat of R. Donaldson, Esq., affords two of the finest natural eataracts that we have seen in the grounds of any private residence. Fig. 41 is a view of the larger cascade which falls about 60 feet over a bold, rocky bed. 
course, and damming up the little brook artificially ; studiously avoiding, however, any formal and artificial disposition of the stones or rocks employed.

Larger water-falls and cascades cannot usually be made without some regular head or breastwork, to oppose more firmly the force of the current. Such heads may be formed of stout plank and well prepared clay; ; or, which is greatly preferable, of good masonry laid in water cement. After a head is thus formed, it must be concealed entirely from the eye by covering it, both upon the top and sides, with natural rocks and stones of various sizes, so ingeniously disposed, as to appear fully to account for, or be the cause of the water-fall.

The axe of the original backwoodsman appears to have left such a mania for clearing behind it, even in those portions of the Atlantic states where such labor should be for ever silenced, that some of our finest places in the country will be found much desecrated and mutilated by its careless and unpardonable use ; and not only are fine plantations often destroyed, but the banks of some of our finest streams and prettiest rivulets partially laid bare by the aid of this instrument, guided by some tasteless hand. Wherever fine brooks or water courses are thus mutilated, one of the most necessary and obvious improvements is to reclothe them with plantations of trees and underwood. In planting their banks anew, much beauty and variety can often be produced by employing different growths, and arranging them as we have directed for the margins

* It is found that strong loam or any tenacious earth, well prepared by puddling or beating in water, is equally impervious to water as clay ; and may therefore be used for lining the sides or dams of bodies of made water when such materials are required. 
of laces and ponds. Th some places where easy, beautiful slopes and undulations of groumd border the streams, sravel. sott turt, and a few simple eroups of trees. will be the most natural accompaniments; in others where the borders of the stream are broken into rougher, more rocky, and precipitous ridges, all the rich wildness and intrieney of low shrubs, ferns, creeping and climbing plants. may be brought in to adrantage. Where the extent to be thus improved is considerible, the tronble may be lessoned by planting the larger growth, and sowing the sceds of the smaller plants mingled together. Prepare the materials, and time and mature, with but little oecasional assistance, will mature, and solten, and blend together the whole, in their own matchless and inimitable manner.

From all that we have suggested in these limited remarks, it will be seen that we would ouly attempt in our operations with water, the graceful or pieturesque imitations of natural lakes or ponds, and brooks, rivulets. and streams. Such are the only forms in which this umrivalled element can bo displayed so as to harmonize angreably with matural and picturesque scenery. In the latter, there can be no apology made for the introduction of straight canals, round or oblong pieces of water, and all the regular forms of the geometric mode; becamse they would evidently be in riolent opposition to the whole character and expression of natural laudscape. In arehitectural, or flower gardens (on which we shall hereafter have occasion to offer some remarks), where a different and highly artificial arrangement prevails, all these regular forms, with rarious jets, fountains, ete. may be employed with good taste, and wil' combine well with the other accessories of such 
places. But in the grounds of a residence in the modern style, nulure, if jossible, still more purified, as in the great chefs-d'ouvre of art, by an ideal standard, should be the great aim of the Landscape Gardener. And with water especially, only beatiful when allowed to take its own flowing forms and graceful motions, more than with any other of our materials, all appearance of constraint and formality should be avoided. If art be at all manifest, it should diseover itself only, as in the admirably painted landscape, in the reproduction of nature in her choicest developments. Indeed, many of the most celebrated anthors who have treated of this subject, appear to agree that the productions of the artist in this branch are most perfect as they approach most nearly to fac-similes of nature herself: and though art should lave formed tho whole, its employment must be nowhere discovered by the spectator; or as 'Tasso has more elegantly expressed the islea:

"L'AHTE CHL TUTTO FA, NULTA EI gCOpke." 


\section{SECTION IX.}

\section{LANUSCAPE OR RURAL ARCHITECTURE.}

Difierence between a city and a country house. 'The characteristic features of a country' honse. Examination of the leading principles in Rural Architecture. The different styles. The Grecian style, its merits and defects, and its associations. The Roman and Italian styles. The Pointed or Gothic style. The Tudor Mansion. The English Cottage, or Rural Gothic style. These styles considered in relation to situation or scenery. Individual tastes. Entrance Lodges.

"A house amid the quiet country's shades, With length'ning vistas, ever sunny glades; Beauty and fragrance clustering o'er the wall, A porch inviting, and an ample hall."

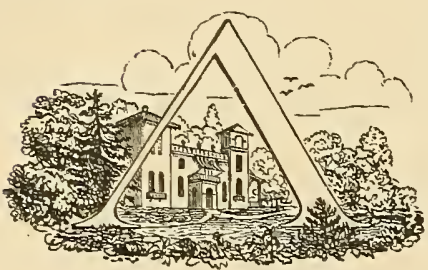

R C H I T E C T U I E, either practically considered or viewed as an art of taste, is a subject so important and comprehensive in itself, that volumes would be requisite 10 do it justice. Buildings of every description, from the humble cottage to the lofty temple, are objects of such constant recurrence in every habitable part of the globe, and are so strikingly indicative of the intelligence, character, and taste of the inhabitants, that they possess in themselves a great and peculiar interest for the mind. To have a "local habitation," - a permanent dwelling, that we can give the impress of our own mind, and identify with our own existence,-appears to be the ardent wish, sooner or later felt, of every man : excepting 
only those wandering sons of Ishmael, who pitch their tents with the same indifference, and as little desire to remain fixed, in the flowery plains of Persia, as in the sandy deserts of Zahara or Arabia.

In a city or town, or in its immediate vicinity, where space is limited, where buildings stand crowded together, and depend for their attractions entirely upon the style and manner of their construction, mere architectural effect, after convenience and fitness are consulted, is of course the only point to be kept in view. There, the façade, which meets the eye of the spectator from the public street, is enriched and made attractive by the display of architectural style and decoration, commen. surate to the magnitude or importance of the edifice; and the whole, so far as the effect of the building is concerned, comes directly within the province of the architect alone.

With respect to this class of dwellings we have little complaint to make, for many of our town residences are highly elegant and beautiful. But how shall we designate that singular perversity of taste, or rather that total want of it, which prompts the man, who, under the name of a villa residence, piles up in the free open country, amid the green fields, and beside the wanton gracefulness of luxuriant nature, a stiff modern "three story brick;" which, like a well-bred cockney with a true horror of the country, doggedly seems to refuse to enter into harmonious combination with any other object in the scene, but only serves to call up the exclamation,

Avaunt, stiff pile! why didst thou stray

From blocks congenial in Broadway!

Yet almost daily we see built up in the country huge 
combinations of boards and shingles, without the least attempt at aaptation to situation; and square masses of brick start up here and there, in the verdant slopes of our village suburbs, appearing as if they had been transplanted, by some unlucky incantation, from the closepacked neighborhood of city residence, and left accidentally in the country, or, as Sir Walter Scott has remarked, "had strayed out to the country for an airing."

What then are the proper characteristics of a rural residence? The answer to this, in a few words, is, such a dwelling, as from its various accommodations, not only gives ample space for all the comforts and conveniences of a country life, but by its varied and picturesque form and outline, its porches, verandas, etc., also appears to have some reasonable connexion, or to be in perfectkeeping, with surrounding nature. Architectural beauty must be considered conjointly with the beauty of the landscape or situation. Buildings of almost every description, and particularly those for the habitation of man, will be considered by the mind of taste, not only as architectural objects of greater or less merit, but as component parts of the general scene; united with the surrounding lawn, embosomed in tufts of trees and shrubs, if properly designed and constructed, they will even serve to impress a character upon the surrounding landscape. Their effect will frequently be good or bad, not merely as they are excellent or indifferent examples of a certain style of building, but as they are happily or unhappily combined with the adjacent scenery. The intelligent observer will readily appreciate the truth of this, and acknowledge the value, as well as necessity, of something besides architectural knowledge. And he will perceive how much 
more likely to be successful are the efforts of him, who, in composing and constructing a rural residence, calls in tc the aid of architecture, the genius of the landscape; whose mind is imbued with a taste for beautiful scenery, and who so elegantly and ingeniously engrafts art upon nature, as to heighten her beauties; while by the harmonious union he throws a borrowed charm around his own creation.

The English, above all other people, are celebrated for their skill in what we consider rural adaptation. Their residences seem to be a part of the scenes where they are situated; for their exquisite taste and nice perception of the beauties of Landscape Gardening and rural scenery, lead them to erect those picturesque edifices, which, by their varied outlines, seem in exquisite keeping with nature; while by the numberless climbing plants, shrubs, and fine ornamental trees with which they surround them, they form beautiful pictures of rural beauty. Even the various offices connected with the dwelling, partially concealed by groups of foliage, and contributing to the expression of domestic comfort, while they extend out, and give importance to the main edifice, also serve to connect it, in a less abrupt manner, with the grounds.

The leading principles which should be our guide in Landscape or Rural Architecture, have been condensed by an able writer in the following heads. "1st, As a useful art, in FITNESS FOR THE END IN VIEW: $2 \mathrm{~d}$, as an art of design in expression of purpose: $3 d$, as an art of taste, in Expression of some particular architec. TURAL STYLE."

The most enduring and permanent source of satisfaction in houses is, undoubtedly, utility. In a country residence, 
therefore, of whatever character, the comfort and con venience of the various members of the family being the first and most important consideration, the quality of fitness is universally appreciated and placed in the first rank. In many of those articles of furniture or apparel which luxury or fashion has brought into use, fitness or convenience often gives way to beauty of form or texture: but in a habitation intended to shelter us from the heat and cold, as well as to give us an opportunity to dispense the elegant hospitalities of refined life-the neglect of the various indispensable conveniences and comforts which an advanced state of civilization requires, would be but poorly compensated for by a fanciful exterior or a highly ornate style of building. Further than this, fitness will extend to the choice of situation; selecting a sheltered site, neither too high, as upon the exposed summit of bleak hills, nor too low, as in the lowest bottoms of damp ralleys; but preferring those middle grounds which, while they aflord a free circulation of air, and a fine prospect, are not detrimental to the health or enjoyment of the occupants. A proper exposure is another subject, worthy of the attention of either the architect or proprietor, as there are stormy and pleasant aspects or exposures in all climates.

However much the principle of fitness may be appreciated and acted upon in the United States, we have certainly great need of apology for the flagrant and almost constant violation of the second principle, viz. the expression of purpose. By the expression of purpose in buildings, is meant that architectural character, $c x$ ensemble, which distinctly points out the particular use or destination for which the edifice is intended. In a 
dwelling-house, the expression of purpose is conveyed by the chimney-tops, the porch or veranda, and those various appendages indicative of domestic enjoyment, which are needless, and therefore misplaced, in a public building. In a church, the spire or the dome, when present, at once stamps the building with the expression of purpose ; and the few openings and plain exterior, with the absence of chimneys, are the suitable and easily recognised characteristics of the barn. Were any one to commit so violent an outrage upon the principle of the expression of purpose as to surmount his barns with the tall church spire, our feelings would at once cry out against the want of propriety. Yet how often do we meet in the northern states, with stables built after the models of Greek temples, and barns with elegant Venetian shutters-to say nothing of mansions with none but concealed climney-tops, and without porches or appendages of ary kind, to give the least hint to the mind of the doubting spectator, whether the edifice is a chapel, a bank, a hospital, or the private dwelling of a man of wealth and opulence!

"The expression of the purpose for which every building is erected," says the writer before quoted, "is the first and most essential beauty, and should be obvious from its architecture, although independent of any particular style; in the same manner as the reasons for things are altogether independent of the language in which they are conveyed. As in literary composition, no beauty of language can ever compensate for poverty of sense, so in architectural composition, no beauty of style can ever compensate for want of expression of purpose." Applying this excellent principle to our own country 
houses and their oflices or out-buildings, we think every reasonable person will, at the first glance, see how lamentably deficient are many of the productions of our architects and builders, in one of the leading principles of the art. The most common form for an American country villa is the pseudo-Greek Temple; that is, a rectangular oblong building, with the chimney-tops concealed, if possible, and instead of a pretty and comfortable porch, reranda, or piazza, four, six, or eight lofty wooden columus are seen supporting a portico, so high as neither to aflord an agreeable promenade, nor a sufficient shelter from the sun and rain.

There are two features, which it is now generally, admitted, contribute strongly to the expression of purpose in a dwelling-house, and especially in a country residence. These are the chimmey-tops and the entrance porch. Chimney-tops, with us, are generally square masses of brick, rising above the roof, and presenting certainly no very elegant appearance, which may perhaps serve as the apology of those who studiously conceal them. But in a climate where fires are requisite during a large portion of the year, chimney-tops are expressive of a certain comfort resulting from the use of them, which characterizes a building intended for a dwelling in that climate. Chimneytops being never, or rarely, placed on those buildings intended for the inferior animals, are also undoubtedly strongly indicative of human habitations. Instead, therefore, of hiding or concealing them, they should be in all dwellings not only boldly avowed, but rendered ornanental; for whatever is a characteristic and necessary feature, should undoubtedly, if possible, be rendered elegant, or at least prevented from being ugly. 
Much of the picturesque effect of the old English and Iialian houses, undoubtedly arises from the handsome and curious stacks of chimneys which spring out of their roofs. These, while they break and diversify the sky outline of the builoing, enrich and give variety to its most bare and unornamented part. Examples are not wanting, in all the different styles of architecture, of handsome and characteristic chimneys, which may be adopted in any of our dwellings of a similar style. The Gothic, or old English chimney, with octagonal or cylindrical flues or shafts united in clusters, is made in a great variety of forms, either of bricks or artificial stone. The former materials, moulded in the required shape, are highly taxed in England, while they may be very cheaply made here.

A Porch strengthens or conveys expression of purpose. because, instead of leaving the entrance door bare, as in manufactories and buildings of an inferior description, it serves both as a note of preparation, and an effectual shelter and protection to the entrance. Besides this, it gives a dignity and importance to that entrance, pointing it out to the stranger as the place of approach. A fine country house, without a porch or covered shelter to the doorway of some description, is therefore as incomplete, to the correct eye, as a well printed book without a title page, leaving the stranger to plunge at once in medias res, without the friendly preparation of a single word of introduction. Porches are susceptible of every variety of form ind decoration, from the embattled and buttressed portal of the Gothic casile, to the latticed arbor porch of the cotiage, around which the festoons of luxuriant climbing plants cluster, giving an. effect not less beautiful than tho richly carved capitals of the classic portico. 
In this country no architectural feature is more plainly expressive of purpose in our dwelling-houses than the veranda, or piazza. The unclonded splendor and fierce heat of our summer sun, render this very general appendage a source of real comfort and enjoyment; and the long veranda round. many of our country residences stands instead of the pared terraces of the English mansions as the place for promenade; while during the warmer portions of the season, half of the days or erenings are there passed in the enjoyment of the cool breezes, secure under low roofs supported by the open colommade, from the solar rays, or the dews of night. The obvious utility of the veranda in this climate (especially in the middle and southern states) will, therefore, excuse its adoption into any style of architecture that may be selected for our domestic uses, although abroad, buildings in the style in question, as the Gothic, for example, are not usually accompanied by such an appendage. An artist of the least taste or invention will easily compose an addition of this lind, that will be in good keeping with the rest of the edifice.

These various features, or parts of the building, with many others which convey expression of purpose in domestic architecture, because they recall to the mind the different uses to which they are applied, and the several enjoyments connected with them, also contribute greatly to the interest of the building itself, and heighten its good effect as part of a harmonious whole, in the landscape The various projections and irregularities, cansed by verandas, porticos, etc., serve to connect the otherwise square masses of building, by gradual transition, with the ground about it.

The reader, who thus recognizes features as expressive 
of purpose in a dwelling intended for the habitation of man, we think, can be at no great loss to understand what would be characteristic in out-buildings or offices, farm-houses, lodges, stables, and the like, which are necessary structures on a villa or mansion residence of much size or importance. A proper regard to the expression of use or purpose, without interfering with the beauty of style, will confer at all times another, viz. the beauty of truth, without which no building can be completely satisfactory; as deceptions of this kind (buildings appearing to be what they are not) always go far towards destroying in the mind those pleasurable emotions felt on viewing any correct work of art, however simple in character or design.

We have now to consider rural architecture under the guidance of the third leading principle, as an art of taste. The expression of architectural style in buildings is uncloubtedly a matter of the first importance, and proper care being taken not to violate fitness and expression of purpose, it may be considered as appealing most powerfully, at once, to the mind of almost every person. Indeed, with many; it is the only species of beauty which they perceive in buildings, and to it both convenience and the expression of purpose are often ignorantly sacrificed.

A marked style of architecture appears to us to have claims for our admiration or preference for rural residences, for several reasons. As it is intrinsically beautiful in itself; as it interests us by means of the associations connected with it ; as it is fitted to the wants and comforts of country life; and as it is adapted to, or harmonizes with, the locality or scenery where it is located.

The harmonious union of buildings and scenery, is a point of taste that appears to be but little understood in 
any country ; and mainly, we believe, because the architect and the landscape painter are seldom combined in the same person, or are seldom consulted together. It is for this reason that we so rarely see a country residence, or cottage and its grounds, making such a composition as a landscape painter would choose for his pencil. But it does not seem difficult, with a slight recurrence to the leading principle of unity of expression, to suggest a mode of immediately deciding which style of building is best adapted to harmo. nize with a certain lind of scenery.

The reader is, we trust, already familiar with our division of landscapes into two natural classes, - the Beautiful and the Picturesque,-and the two accordant systems of improvement in Landscape Gardening which we have based upon these distinct characters. Now, in order to render our buildings perfectly harmonious, we conceive it only to be necessary to arrange (as we may very properly do) all the styles of domestic architecture i: corresponding divisions.

Some ingenious vriter has already developed this idea, and, following a hint taken from the two leading schools of literature and art, has divided all architecture into the Classical and the Romantic schools of design. The Classical comprises the Grecian style, and all its near and direct offspring, as the Roman and Italian modes; the Romantic school, the Gothic style, with its numberless variations of Tudor, Elizabethan, Flemish, and old Fnglish modes.

It is easy to see, at a glance, how well these divisions correspond with our Beautiful and Picturesque phases of Landscape Gardening, so that indeed we might call the Grecian or Classical style, Beautiful, and the Gothic or 
Romantic style, the Picturesque schools in architecture In classical buildings, as in beautiful landscape, we are led to adnire simplicity of forms and outlines, purity of effect, and grace of composition. In the Romantic or Picturesque buildings, we are struck by the irregularity of forms and outlines, variety of effect, and boldness of composition. What, therefore, can be more evident in seeking tc produce unity of effect than the propriety of selecting some variations of the classical style for Beautiful landscape, and some species of romantic irregular building for Picturesque landscape?

In a practical point of view, all buildings which have zonsiderable simplicity of outline, a certain complete and graceful style of ornament, and a polished and refined kind of finish, may be considered as likely to harmonize best with all landscape where the expression is that of simple (r) graceful beauty-where the lawn or surface is level or gently undulating, the trees rich and full in foliage and form, and the general character of the scenery peaceful and beautiful. Such are the Grecian, Roman, Tuscan, and the chaster Italian styles.

On the other hand, buildings of more irregular outline, in which appear bolder or ruder ornaments, and a certain free and more rustic air in finishing, are those which should be selected to accompany scenery of a wilder or more picturesque character, abounding in striking variations of surface, wood, and water. And these are the Castellated, the Tudor, and the old English in all its forms.

There is still an intermediate kind of architecture, originally a variation of the classical style, but which, in becoming adapted to different and more picturesque situations, has lost much of its graceful character, and has 
become quite picturesque in its outlines and effects. Of this kind are the Swiss and the bracketed cottage, and the different highly irregular forms of the Itatian villa. The more simple and regular variations of these modes of building, may be introduced with good effect in any plain country; while the more irregular and artistical forms have the happiest effect only in more highly varied and suitable localities.

The Egyptian, one of the oldest architectural styles, characterized by its heavy colossal forms, and almost sublime expression, is supposed to have had its origin in caverns hewn in the rocks. The Chinese style, easily known by its waving lines, probably had its type in the eastern tent. The Saracenic, or Moorish style, rich in fanciful decoration, is striking and picturesque in its details, and is worthy of the attention of the wealthy amateur.

Neither of these styles, however, is, or can well be, thoroughly adapted to our domestic purposes, as they are wanting in fitness, and have comparatively few charms of association for residents of this country.

The only styles at present in common use for domestic architecture, throughout the enlightened portions of Europe and America, are the Grecian and Gothic styles, or some modifications of these two distinct linds of building. These modifications, which of themselves are now considered styles by most authors, are, the Roman and modern Italian styles, which have grown out of Greek architecture; the Castellated, the Tudor, the Elizabethan, and the rural Gothic or old English cottage styles, all of which are variations of Gothic architecture.

Grecian or classic architecture was exhibited in its purity in those splendid temples of the golden days of 
Athens, which still remain in a sufficient degree of preservation to bear ample testimony to the high state of architectural art among the Greeks. Each of the five orders was so nicely determined by their profound knowledge of the harmony of forms, and admirably executed, that all modern attempts at improving them have entirely failed, for they are, individually, complete models.

As it is admitted, then, that Grecian architecture is intrinsically beantiful in itself, and highly interesting in point of associations, it may be asked, what are the objections, if any, to its common introduction into domestic Rural Architecture?

We have already avowed that we consider fitness and expression of purpose two leading principles of the first importance in Rural Architecture, and Grecian architecture in its pure form-viz., the temple-when applied to the purposes of domestic life, makes a sad blow at both these established rules. The comforts of a country residence are so various, that verandahs, porches, wings of different sizes, and many other little accommodations expressive of purpose, become necessary, and, therefore, when properly arranged, add to the beauty of Rural Architecture. But the admirer of the true Greek models is obliged to forego the majority of these; and to come within the prescribed form of the rectangular parallelogram, his apartments must be of a given size and a limited number, while many things, both exterior and interior, which convenience might otherwise prompt, have to bow to the despotic sway of the pure Greek model. In a divelling of moderate dimensions how great a sacrifice of room is made to enable the architect to display the portico alone! 


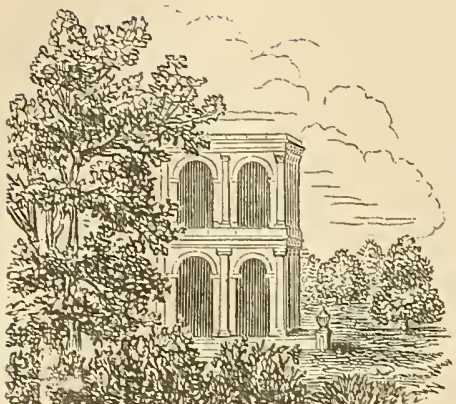

[Fig. 40. Roman Residence.]

It has been well observed by modern critics, that there is no reason to believe the temple form was ever, even by the Greeks, used for private dwellings, which easily accounts for our comparative failure in constructing well arranged, small residences in this style.

The Romans, either unable to compose in the simplo elegance and beauty of the Grecian style, or feeling its want of adaptation to the multifarious usages of a more

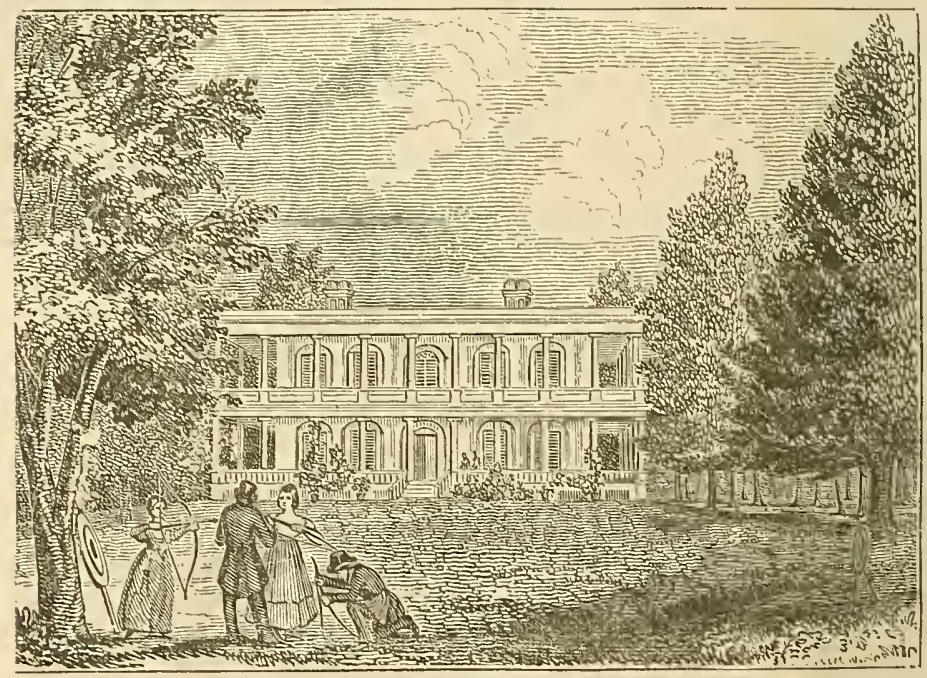

[Fig. 41. View at Presqu, Isle, the residence of Wm. Denning, Esq., Dutchess Co., N.Y.]

luxurious state of society, created for themselves what is generally considered a less beautiful and perfect, yet which is certainly a more rich, varied, and, if we may use the 
term, accommodating style. The Roman style is distinguished from its prototype by the introduction of arched openings over the doors and windows, story piled over story,-often with columns of different orders-instead of the simple unbroken line of the Greek edifices. In decoration, the buildings in this style vary from plain, unornamented exteriors, to the most highly decorated façades; and instead of being confined to the few fixed principles of the Greek, the greatest latitude is often observed in the proportions, forms, and decorations of buildings in the Roman style. These very circumstances, while they rendered the style less perfect as a fine art, or for public edifices, gave it a pliability or facility of adaptation, which fits it more completely for domestic purposes. For this reason, a great portion of the finest specimens of the modern domestic architecture of the other continent is to be found in the Roman style.*

The Italian style is, we think, decidedly the most beautiful mode for domestic purposes, that has been the direct offspring of Grecian art. It is a style which has evidently grown up under the eyes of the painters of more modern Italy, as it is admirably adapted to harmonize with general nature, and produce a pleasing and picturesque effect in fine landscapes. Retaining more or less of the columns, arches, and other details of the Roman style, it has intrinsically a bold irregularity, and strong contrast of light and shadow, which give it a peculiarly striking and painter-like effect.

* Perhaps the finest façade of a private residence, in America, is that of the "Patroon's house," near Albany, the aneient seat of the Van Rensselaer family, lately remodelled and improved by that skilful arehitect, Mr. Upjohn, of New York. 
"The villa architecture of modern Italy," says Mr. Lamb, an able architect, " "is characterized, when on a moderate scale, by scattered irregular masses, great contrasts of light and shade, broken and plain surfaces, and great variety of outline against the sky. The blank wall on which the eye sometimes reposes; the towering campanile, boldly contrasted with the horizontal line of roof only broken by a few straggling chimney-tops : the row of equal sized, closely placed windows, contrasting with the plain space and single window of the projecting balcony; the prominent portico, the continued arcade, the terraces, and the variously formed and disposed out-buildings, all combine to form that picturesque whole, which distinguishes the modern Italian villa from every other." $\dagger$

A building in the Italian style may readily be known at first sight, by the peculiar appearance of its roofs. These are always projecting at the eaves, and deeply furrowed or

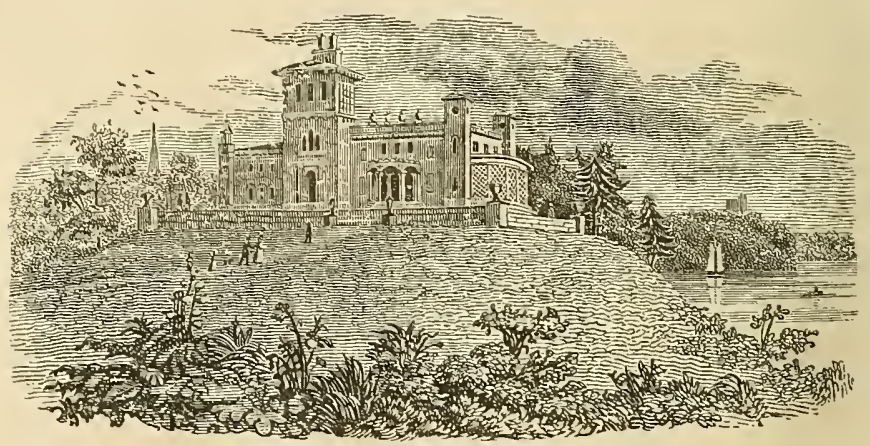

[Fig 42. A Villa in the Italian style.]

ridged, being formed abroad of semi-cylindrical tiles, which give a distinct and highly marked expression to this

* Loudon's Ency. of Arch. p. 951.

+ In this country, owing to the greater number of fires, the effect would be anproved by an additional number of chimney-tops. 
portion of the building.* So many appliances of comfort and enjoyment suited to a warm climate appear, too, in the villas of this style, that it has a peculiarly elegant and refined appearance. Among these are arcades, with the Roman arched openings, forming sheltered promenades; and beautiful balconies projecting from single windows, or sometimes from connected rows of windows, which are charming places for a coup d'œil, or to enjoy the cool breeze-as they admit, to shelter one from the sun, of a fanciful awning shade, which may be raised or lowered at pleasure. The windows themselves are bold, and well marked in outline, being either round-arched at the tops, or finished with a heavy architrave.

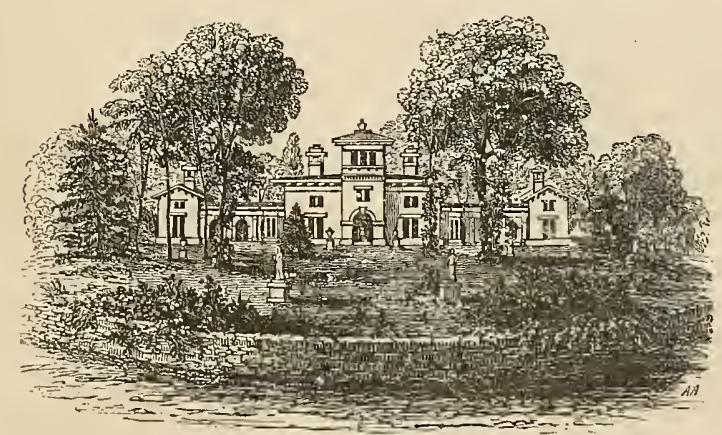

[Fig. 43. Residence of Gov. Morehead, North Carolina.]

All these balconies, arcades, etc., are sources of real pleasure in the hotter portions of our year, which are quite equal in elevation of temperature to summers of the south of Europe; while by increased thickness of walls and

* In some situations in this country, where it might be difficult to procure Liles made in this form, their effect may be very accurately imitated by deeply ridged zinc or tin coverings. The bold projection of the eaves, in the Italian style, offers great protection to a house against storms and dampness. 
closeness of window fixtures, the honses may also be made of the most comfortable description in winter.

The Italian chimney-tops, unlike the Grecian, are alwars openly shown and rendered ornamental; and, as we have already mentioned, the irregularity in the masses of the edifice and shape of the roof, renders the siry outline of a building in this style, extremely picturesque. A villa, howerer small, in the Italian style, may have an elegant and expressive character, without interfering with convenient internal arrangements, while at the same time, this style has the very great merit of allowing additions to be made in almost any direction, without

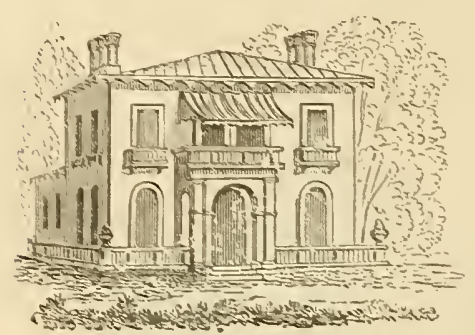

[Fig, 4t. The New Haven Suburban Villa.*] accordance with architecinjuring the effect of the original structure; indeed such is the variety of sizes and forms which the diflerent parts of an Italian villa may take, in perfect tural propriety, that the original edifice frequently gains in beanty by additions of this description. Those who are aware how many houses are erery rear erected in the United States by persons of moderate fortune, who would gladly make additions at some subsequent period, could this be done without injuring the effect or beanty of the main building, will, we think, acknowledge how much,

* New Haren abounds with tasteful residenees. "Hillhouse Arenue," in particular, is remarkable for a neat dispiay of Tusean or Italian Suburban Villas. Moderate in dimension and economical in construction, these exceed. ingly neat edifices may bo eonsidered as models for this kind of dwelling.

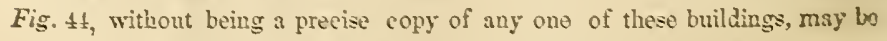
talieu as a pretty aceurate representation of their general appearance. 
even were it in this single point alone, the Italian style is superior to the Grecian for rural residences.

Pleasing associations are connected with Roman and Italian architecture, especially to those who have studied their effect in all the richness and beauty with which they are invested in the countries where they originated; and they may be regarded with a degree of classic interest by every cultivated mind. The modern Italian style recalls images of that land of painters and of the fine arts, where the imagination, the fancy, and taste, still revel in a world of beauty and grace. The great number of elegant forms which have grown out of this long cultivated feeling for the beautiful in the fine arts, -in the shape of fine vases, statues, and other ornaments, which harmonize with, and are so well adapted to enrich, this style of architecture,combine to render it in the fine terraced gardens of Florence and other parts of Italy, one of the richest and most attractive styles in existence. Indeed we can hardly imagine a mode of building, which in the hands of a man of wealth and taste, may, in this country, be made productive of more beauty, convenience, and luxury, than the modern Italian style; so well suited to both our hot summers and cold winters, and which is so easily susceptible of enrichment and decoration, while it is at the same time so well adapted to the material in the most common use at present in most parts of the country,-wood. Vases, and other beautiful architectural ornaments, may now be procured in our cities, or imported direct from the Mediterranean, finely cut in Maltese stone, at very 
moderate prices, and which serve to decorate both the grounds and buildings in a handsome manner.

From the Italian style it is an easy transition to the Swiss mode, a bold and spirited one, highly picturesque and interesting in certain situations. To build an exact copy of a Swiss cottage in a smooth cultivated country, would, both as regards association and intrinsic want of fitness, be the height of folly. But in a wild and mountainous region, such as the borders of certain deep valleys and rocky glens in the Hudson Highlands, or rich bits of the Alleghanies, positions may be found where the Swiss cottage (Fig. 45), with its low and broad roof, shedding off the heary snows, its ornamented exterior gallery, its strong and deep brackets, and its rough and rustic exterior, would be in the lighest degree appropriate.

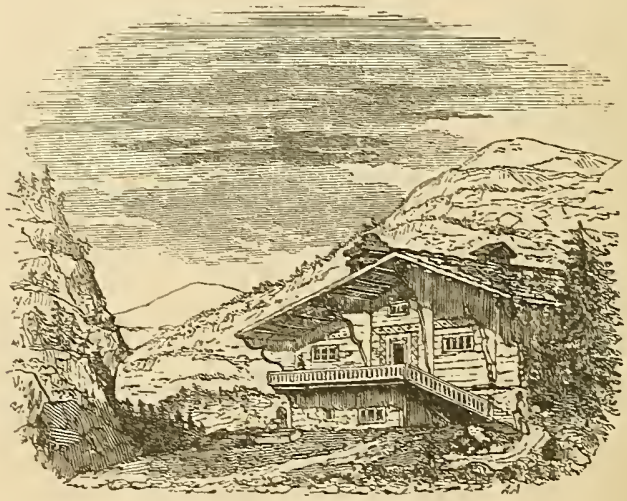

[Fig. 45. The Swiss Cottage.]

A modification, partaking somewhat of the Italian and Swiss features, is what we have described more fully in our "Cottage Residences" as the Bracketed mode. It possesses 
a good deal of character, is capable of considerable picturesque effect, is very easily and cheaply constructed of wood or stone, and is perhaps more entirely adapted to our

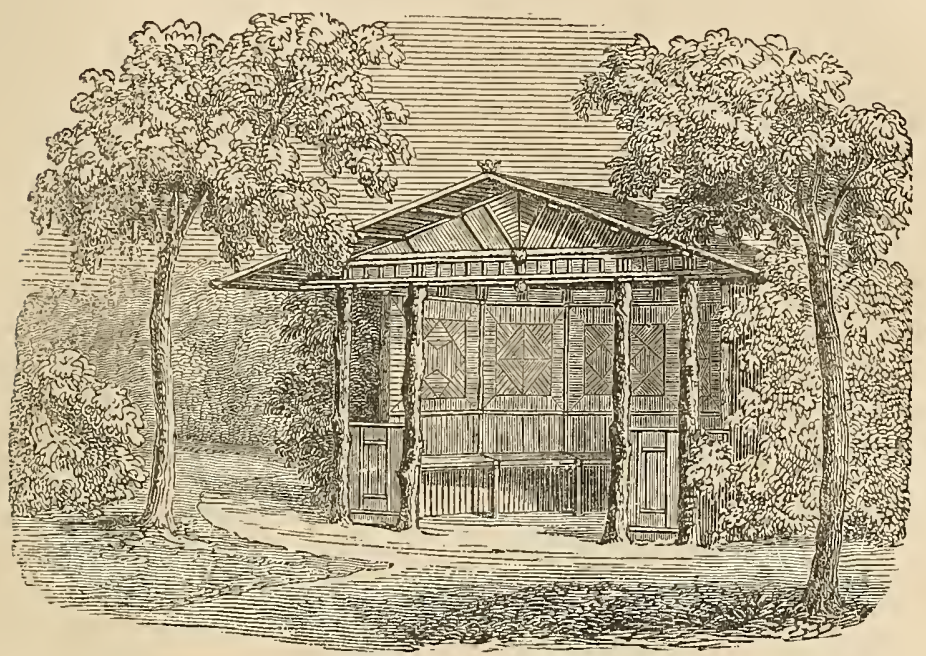

[Fig. 46. The Bracketed Mode.]

hot summers and cold winters than any other equally simple mode of building. We hope to see this Bracketed style becoming every day more common in the United States, and especially in ouj farm and country houses, when wood is the material employed in their construction.

Gothic, or more properly, pointed architecture, which sprang up with the Christian religion, reached a point of great perfection about the thirteenth century; a period when the most magnificent churches and cathedrals of England and Germany were erected. These wonderful structures, reared by an almost magical skill and contrivance, with their richly groined roofs of stone supported in mid-air ; their beautiful and elaborate tracery and carring of plants, finwers, and animate objects ; their large windows 
through which streamed a rich glow of rainbow light; their rarious buttresses and pimnacles, all contributing to strengthen, and at the same time give additional beauty to the exterior; their clustered columns, airy-like, yet firm; and, surmounting the whole, the tall spire, piled up to an almost fearful height torards the heavens, are lasting momuments of the genius, scientific skill, and mechanical ingenuity of the artists of those times. That person, who, from ignorance or prejudice. fully supposes there is no architecture but that of the Greeks, would do well to study one of these unriralled specimens of human skill. In so doing, unless he closes his eyes against the eridences of his senses, he camnot but admit that there is far more genius, and more mathematical skill, erinced in one of these cathedrals, than would hare been requisite in the construction of the most celebrated of the Greek temples. Though they may not exhibit that simplicity and harmony of proportion which Grecian huildings display, they abound in much higher proofs of genius, as is abundantly erinced in the conception and execution of Cathedrals so abounding in unriralled sublimity, rariety, and beauty.

Gothic architecture, in its purity, was characterized mainly by the pouted arch. This novel feature in architecture, which, probably, in the hands of artists of great mathematical skill, was suggested by the inefficiency of the Roman arch first used, has given rise to all the superior boldness and picturesqueness of this style compared with the Grecian; for while the Greek artist was obliged to corer his narrow openings with architrares, or solid blocks of stone, resting on columms at short intervals, and filling up the open space, the Gothic artist, by a single span of his pointed arch, resting on distant pillars, kept the whole 
area beneath free and unencumbered. Applied, too, to openings for the admission of light, which were deemed of comparatively little or no importance by the Greeks, the arch was of immense value, making it possible to pierce the solid wall with large and lofty apertures, that diffused a magical brilliancy of light in the otherwise dim and shadowy interior.

We have here adverted to the Gothic cathedral (as we did to the Greek temple) as exhibiting the peculiar style in question in its greatest purity. For domestic purposes, both, for the same reasons, are equally unfitted; as they were never so intended to be used by their original inventors, and being entirely wanting in fitness for the purposes of habitation in domestic life; the Greek temple, as we have already shown, from its massive porticoes and the simple rectangular form of its interior; and the Gothic cathedral, from its high-pointed windows, and immense vaulted apartments. It would scarcely, however, be more absurd to build a miniature cathedral, for a dwelling in the Gothic style, than to make an exact copy of the Temple of Minerva 30 by 50 feet in size, for a country residence, as we often witness in this country.

The Golhic Style, as applied to Domestic Architecture, has been varied and adapted in a great diversity of ways, to the wants of society in different periods, from the 12 th century to the present time. The baronial castle of feudal days, perched upon its solitary, almost inaccessible height, and built strongly for defence; the Collegiate or monastic abbey of the monks, suited to the rich fertile plains which these jolly ascetics so well knew how to select; the Tudor or Elizabethan mansion, of the English gentleman, surrounded by its beautiful park, filled with old ancestral trees; 
and the pretty, rural, gabled cottage, of more humble pre. tensions; are all rarieties of this multiform style, easily adapting itself to the comforts and conveniences of private life.

Contrasted with Clissic Architecture and its varieties, in which horizontal lines are most prevalent, all the different Gothic modes or styles exhibit a preponderance of rertical or perpendicular lines. In the purer Gothic Architecture, the style is often deternined by the form of the arch predominant in the window and door openings, which in all edifices (except Norman buildings) were lancetshaped, or high pointed, in the 13th century; four centred, or low arched, in the times of Henry VII. and VIII.; and finally square-headed, as in most domestic buildings of later date.

Castellated Gothic is easily known, at first sight, by the line of battlements cut out of the solid parapet wall, which surmounts the outline of the building in every part. These generally conceal the roof, which is low, and were originally intended as a shelter to those engaged in defending the

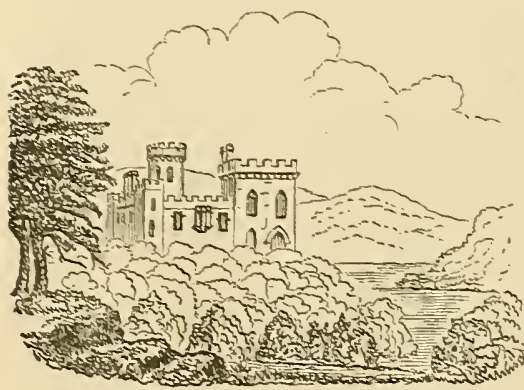
building against assaults. Modern buildings in the castellated style, without sacrificing almost everything to strength, as was once necessary, preserve the general character of the ancient castle, while [Fig. 17. The Castellated Mlode.] they combine with it almost every modern luxury. In their exteriors, we perceive strong and massive octagonal or circular towers, rising boldly, with corbelled or project. ing cornices, above the ordinary level of the building. The 
windows are cither pointed or square-headed, or penhaps a mixture of both. The porch rises into a turreted and embattled gateway, and all the offices and out-buildings connected with the main cdifice, are constructed in a style corresponding to that exhibited in the main body of the building. The whole is placed on a distinct and firm terrace of stone, and the expression of the edifice is that of strength and security.

This mode of building is evidently of too ambitious and expensive a kind for a republic, where landed estates are not secured by entail, but divided, according to the dictates of nature, among the different members of a family It is, perhaps, also rather wanting in appropriateness, castles never having been used for defence in this country. Notwithstanding these objections, there is no very weighty reason why a wealthy proprietor should not erect his mansion in the castellated style, if that style be in unison with his scenery and locality. Few instances, however, of sufficient wealth and taste to produce edifices of this hind, are to be met with among us; and the castellated style is therefore one which we cannot fully recommend for adoption here. Paltry imitations of it, in materials less durable than brick or stone, would be discreditable to any person having the least pretension to correct taste.

The Castellated style never appears completely at home except in wild and romantic scenery, or in situations where the neighboring mountains, or wild passes, are sufficiently near to give that character to the landscape. In such localities the Gothic castle affects us agreeably, because we know that baronial castles were generally built in similar spots, and because the battlements, towers, and other bold features, combine well with the rugged and spirited 
character of the surrounding objects. To place such a building in this country on a smooth surface in the midst of fertile plains, would immediately be felt to be bad taste by every one, as from the style not haring been before our eyes from childhood, as it is in Europe, we immediately refer to its original purposes,-those of security and defence.

A mansion in the Tudor Style affords the best example of the excellence of Gothic architecture for domestic purposes. The roof often rises boldly here, instead of being concealed by the parapet rall, and the gables are either plain or ornamented with crockets. The windows are divided by mullions, and are generally enriched with tracery in a style less florid than that employed in churches, but still sufficiently elegant to gire an appearance of decoration to these parts of the building. Sometimes the low, or Tudor arch, is displayed in the rindow-heads, but most commonly the square-headed window with the Gothic label is employed. Great latitude is allowed in this particular, as well as in the size of the windor, prorided the general details of style are attended to. Indeed, in the domestic architecture of this era, the windows and doors are often sources of great architectural beautr, instead of being left mere bare openings filled with glass, as in the Classic stỵles. Not only is each individual window divided by mullions into compartments whose tops are encircled by tracery; but in particular apartments, as the dining-hall, library, ete., these are filled with richly stained glass, which gires a mellow; pleasing light to the apartment. Added to this, the windors, in the best Tudor mansions, affect a great rariety of forms and sizes. Among these stand conspicuous the bay and oriel windors. The bay- 


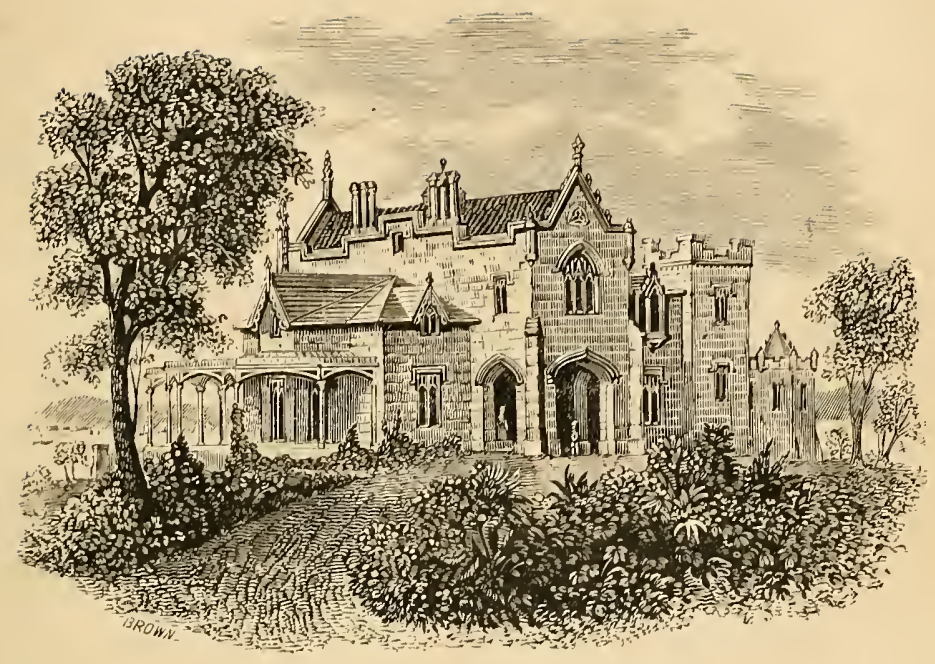

F's. 45.-Mr. Paubling's Residence, 'Tarrytown, N. Y.

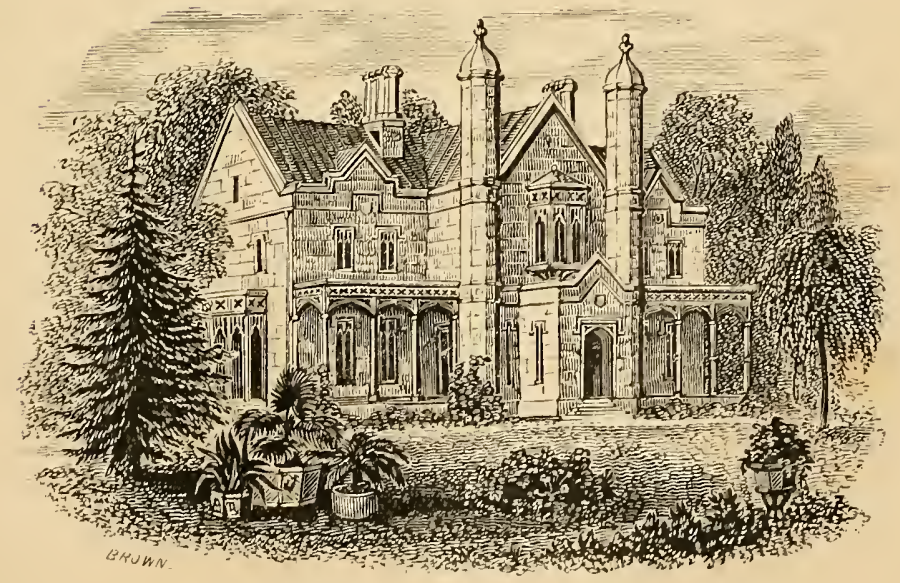

Frg. 49.-Residence of the Author, near Newburgh, N. Y. 

window, which is introduced on the first or principal floor, in most apartments of much size or importance, is a window of treble or quadruple the common size, projecting from the main body of the room in a semi-octagonal or hexagonal form, thereby affording more space in the apartment, from the floor to the ceiling, as well as giving an abundance of light, and a fine prospect in any favorite direction. This, while it has a grander effect than several windows of moderate size, gives a variety of form and outline to the different apartments, that can never be so well attained when the windows are mere openings cut in the solid walls. The oriel-window is very similar to the bay-window, but projecting in a similar manner from the upper story, supported on corbelled mouldings. These windows are not only elegant in the interior, but by standing out from the face of the walls, they prevent anything like too great a formality externally, and bestow a pleasing variety on the different fronts of the building.

The sky outline of a villa in the Tudor Gothic style, is kinghly picturesque. It is made up of many fine features. The pointed gables, with their finials, are among the most striking, and the neat parapet wall, either covered with a moulded coping, or, perhaps, diversified with battlements; the latter not so massive as in the castellated style, but evidently intended for ornament only. The roof line is often varied by the ornamented gablet of a dormer window, rising here and there, and adding to the quaintness of the whole. We must not forget, above all, the highly enriched chimney shaft, which, in the English examples, is made of fancifully moulded bricks, and is carried up in clusters some distance above the roof. How much more pleasing for a dwelling must be the outline of such a building, than 
that of a simple square roof whose summit is one unbroken straight line!*

The inclosed entrance porch, approached by three or four stone steps, with a seat or two for servants waiting, is a distinctive mark of all the cld English houses. This projects, in most cases, from the main body of the edifice, and opens directly into the hall. The latter apartment is not merely (as in most of our modern houses) an entry, uarrow and long, runuing directly through the house, but has a peculiar character of its own, being rather spacious, the roof or ceiling ribbed or groined, and the floor often inlaid with marble tiles. A corresponding and suitable style of finish, with Gothic details, runs through all the different apartments, each of which, instead of being finished and furnished with the formal sameness, here so prevalent, displays, according to its peculiar purposesas the dining-room, drawing-room, library, etc.-a marked and characteristic air.

The hare thus particularized the Tudor mansion, because we believe that, for a cold country like England or the United States, it has strong claims upon the attention of large landed proprietors, or those who wish to realize in a country residence the greatest amount of comfort and enjorment. With the addition, here, of a reranda, which the cool summers of England render needless, we beliere the Tudor Gothic to be the most conrenient and comfortable, and decidedly the most picturesque and striking

* Two miles south of Albany, on a densely wooded hill, is the villa of Jocl Rathbonc, Esq., Fig. 50, one of the most complete specimens of the Tudor style in the United States. It was built from the designs of Daris, and is to the amateur, a rery instructive example of this mode of domestic arelitecture. 


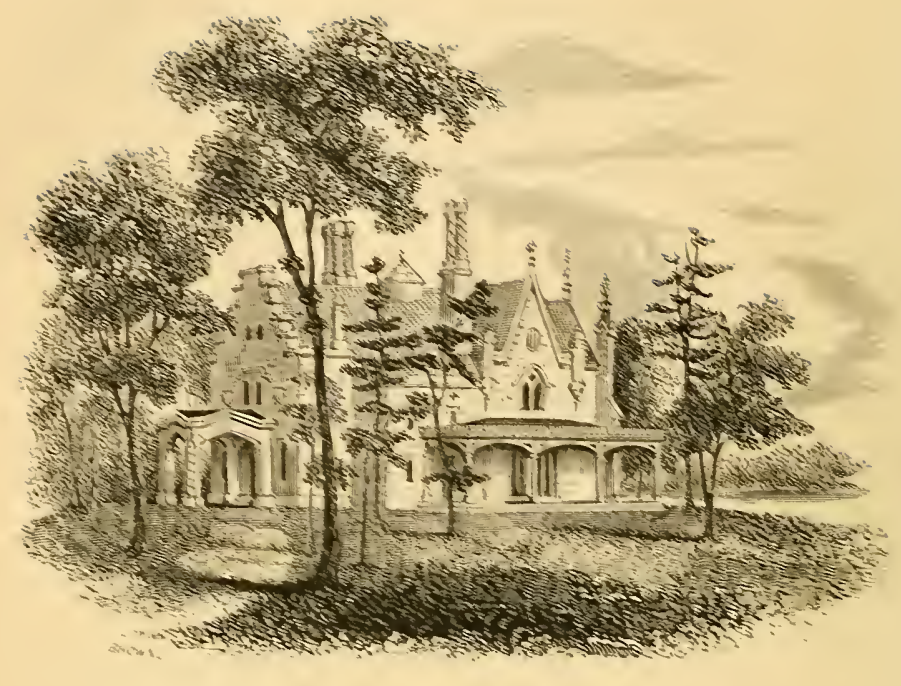

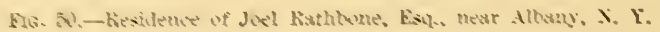

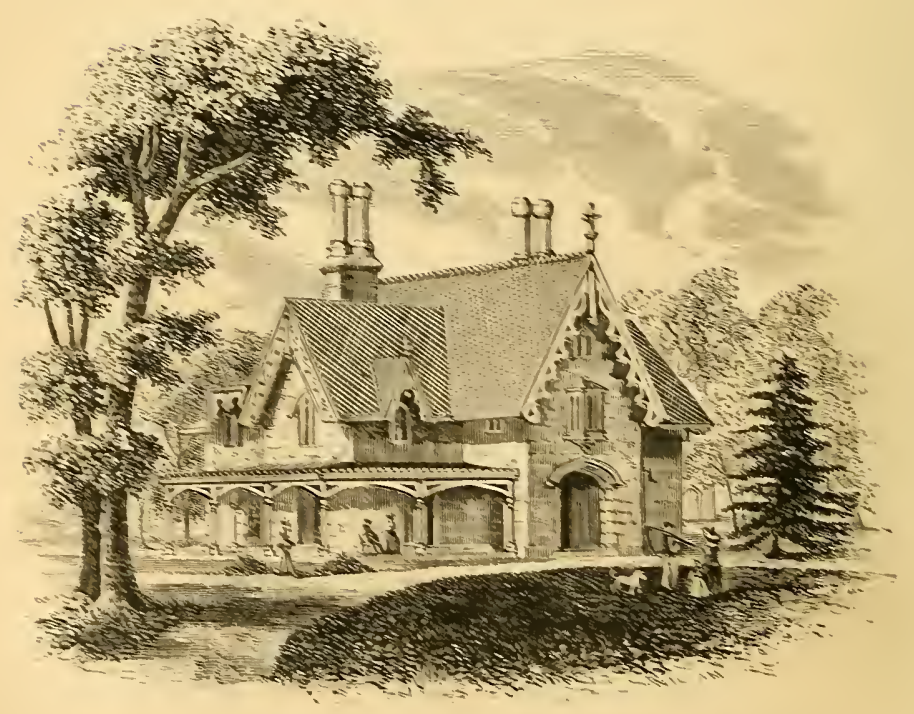

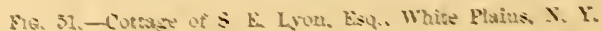




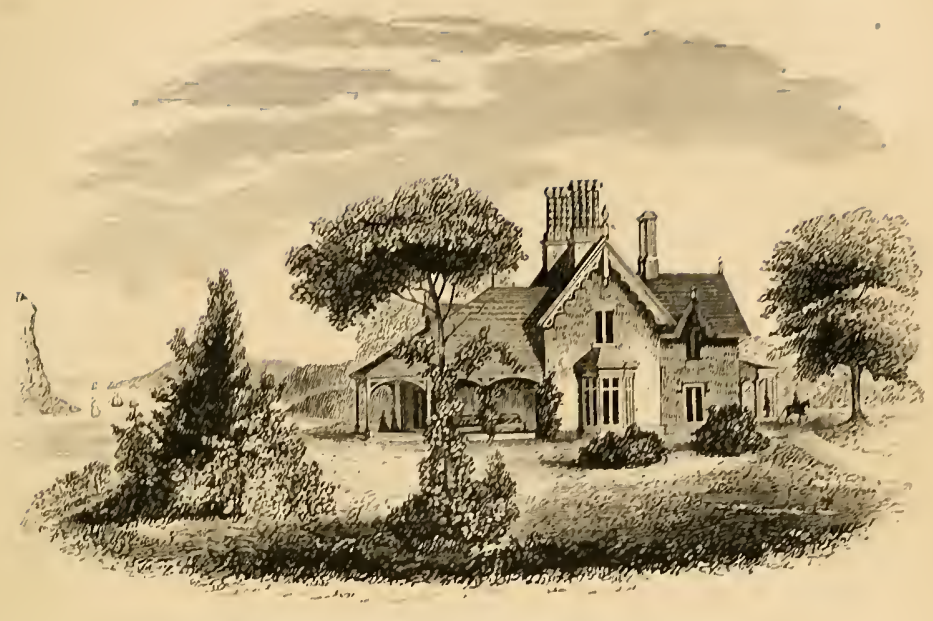

Fia. 52,-Cottage Reshdence of 'Tlumas W. Ludlow, near Yorkers, N Y.

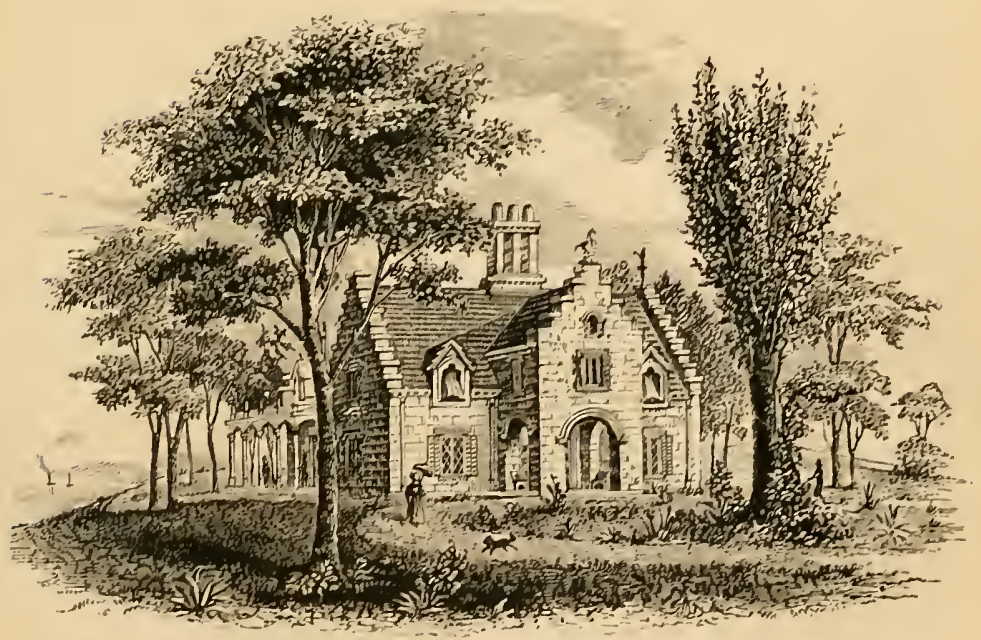

bio. 53.-Sunnyside, Residence of Washiugton Irving, Esg near Tarrytown, N Y 

style, for country residences of a superior class.* The materials generally employed in their construction in England, are stone aud brick; and of late years, brick and stucco has come into very general use.

The Elizabethan Style, that mode of building so common in England in the 17th century, - a mixture of Gothic and Grecian in its details-is usually considered as a barbarous kind of architecture, wanting in purity of taste. Be this as it may, it cannot be denied that in the finer specimens of this style, there is a surprising degree of richness and picturesqueness for which we may look in vain elsewhere. In short it seems, in the best examples, admirably fitted for a bowery, thickly foliaged country, like England, and for the great variety of domestic enjoyments of its inhabitants. In the most florid examples of this style, of which many specimens yet remain, we often meet with every kind of architectural feature and ornament, oddly, and often grotesquely combined--pointed gables, dormer-tvindows, steep and low roofs, twisted columns, pierced parapets, and broad windows with small lights. Sometimes the effect of this fantastic combination is excellent, but often bad. The florid Elizabethan style is, therefore, a very dangerous one in the hands of any one but an architect of profound taste; but we think in some of its simpler forms (Fig. 52), it may be adopted for country residences here, in picturesque situations, with a. quaint and happy effect. $\dagger$

* The residence of Samuel E. Lyon, Esq., at White Plains, N. Y., Fig. 51, is a very pleasing example of the Tudor Cotiage.

The seat of Robert Gilmor, Esq., near Baltimore, in the Tudor style, is a very extensive pile of building.

$+\mathrm{A}$ highly unique residence in the old English syle, is Pelham Priory, the seat of the Rev. Robert Bolton, near New Rochelle, N. Y., Fig. 53. Tho 
The English cottage style, or what we have denominated Rural Gothic, contains within itself all the most striking and peculiar elements of the beautiful and picturesque in its exterior; while it admits of the greatest possible variety of accommodation and convenience in internal arrangement.

In its general composition, Rural Gothic really differs from the Tudor style more in that general simplicity which serves to distinguish a cottage or villa of moderate size from a mansion, than in any marked character of its own. The square-headed windows preserve the same form, and display the Gothic label and mullions, though the more expensive finish of decorative tracery is frequently omitted. Diagonal or latticed lights are also more commonly seen in the cottage style than in the mansion. The general form and arrangement of the building, though of course much reduced, is not unlike that of the latter edifice. The entrance porch is always preserved, and the bay-window jutting out from the best apartment, gives variety, and an agreeable expression of use and enjoyment, to almost every specimen of the old English cottage.

Perhaps the most striking feature of this charming style as we see it in the best old English cottages, is the pointed gable. This feature, which grows out of the high roofs

exterior is massire and picturesque, in the simplest taste of the Elizabethan age, and being built amidst a fine oak wood, of the dark rough stone of the neighborhood, it has at once the appearance of considerable antiquity. The interior is constructed and fitted up throughout in the same feeling,-with harmonious wainscoting, quaint carving, massive chimney pieces, and old furniture and armor. Indeed, we doubt if there is, at the present moment any recent private residence, even in England, where the spirit of the antique is more entirely carried out, and where one may more easily fancy bimsolf in oce of those "mansions builded curiously" of our ancestors in the time of "good Queen Bess," 
adopted, rot only appears in the two ends of the main building, but terminates every wing or projection of almos! any size that joins to the principal body of the house. The gables are either of stone or brick, with a handsome mouided coping, or they are finished with the widely projecting roof of wood, and verge boards, carved in a fancifu. and highly decorative shape. In either case, the point or apex is crowned by a finial, or ornamental octagonal shaft, rendering the gable one of the greatest sources of interest in these dwellings. The projecting roof renders the walls always dry.

The porch, the labelled windows, the chimney shafts, and the ornamented gables, being the essential features in the composition of the English cottage style, it is evident that this mode of building is highly expressive of purpose, for country residences of almost every description and size, from the humblest peasant's cottage, to the beautiful and picturesque villa of the retired gentleman of fortune. In the simple form of the cottage, the whole may be constructed of wood very cheaply, and in the more elaburate villa residence, stone, or brick and cement, may be preferred, as being more permanent. No style so readily admits of enrichment as that of the old English cottage when on a considerable scale ; and by the addition of pointed verandas, bay windows, and dormer-windows, by the introduction of mullions and tracery in the windorv openings, and indeed, by a multitude of interior and exterior enrichments generally applied to the Tudor mansions, a villa in the rural Gothic style may be made a perfect gem of a country residence. Of all the styles hitherto enumerated, we consider this one of the most suitable for this country, as, while it comes within the reach of all persons of moderate 
means, it unites, as we before stated, so much of convenience and rural beauty.*

To the man of taste, there is no style which presents greater attractions, being at once rich in picturesque beauty, and harmonious in connexion with the surrounding forms of vegetation. The Grecian villa, with its simple forms and horizontal lines, seems to us only in good keeping when it is in a smooth, highly cultivated, peaceful scene. But the Rural Gothic, the lines of which point upwards, in the pyramidal gables, tall clusters of chimneys, finials, and the several other portions of its varied outline, harmonizes easily with the tall trees, the tapering masses of foliage, or the surrounding hills; and while it is seldom or never misplaced in spirited rural scenery, it gives character and picturesque expression to many landscapes entirely devoid of that quality.

What we have already said in speaking of the Italian style, respecting the facility with which additions may be made to irregular houses, applies with equal, or even greater force, to the varieties of the Gothic style, just described. From the very fact that the highest beauty of these modes of building arises from their irregularity (opposed to Grecian architecture, which, in its chaste sirmplicity, should be regular), it is evident that additions

* The only objection that can be urged against this mode of building, is that which applies to all cottages with a low second story, viz. want of coolness in the sleeping chambers during mid-summer. An evil which may be remedied by constructing a filse inner-roof-leaving a vacuity between the two roofs of six or eight inches, which being occupied with air and ventilated at the top, will almost entirely obviate the objection.

In our Collage Residences, Design II., we have shown how the comfort of \& full socoad story, suitalle for this climate, may be combined with the expression of the English cotiage style. 
judiciousiy made will tend to increase this beauty, or afford more facility for its display; while it is equally evident that in the interior arrangement, including apartments of every ćescription, superior opportunities are afforded for attaining internal comfort and convenience, as well as external effect.

The ideas connected in our minds with Gothic architecture are of a highly romantic and poetical nature, contrasted with the classical associations which the Greek and Roman styles suggest. Although our own country is nearly destitute of ruins and ancient timeworn edifices, yet the literature of Europe, and particularly of what we term the mother country, is so much our own, that we form a kind of delightful ideal acquaintance with the venerable castles, abbeys, and strongholds of the middle ages. Romantic as is the real history of those times and places, to our minds their charm is greatly enhanced by distance, by the poetry of legendary superstition, and the fascination of fictitious narrative. A castellated residence, therefore, in a wild and picturesque situation, may be interesting, not only from its being perfectly in keeping with surrounding nature, but from the delightful manner in which it awakens associations fraught with the most enticing history of the past.

The older domestic architecture of the English may be viewed in another pleasing light. Their buildings and residences liave not only the recommendation of beauty and complete adaptation, but the additional charm of having been the homes of our ancestors, and the dwellings of that bright galaxy of English genius and worth, which illuminates equally the intellectual firmament of both hemispheres. He who has extended his researches, can 
amore, into the history of the domestic life and habits of those iliustrious minds, will not, we are sure, forget that lowly cottage by the side of the Aron, where the great English bard was wont to dwell; the tasteful resioence of Pope at Twickenham; or the turrets and battlements of the more picturesque Abbotsford; and numberless other examples of the rural buildings of England, once the abodes of renowned genius. In truth, the cottage and villa architecture of the English has grown out of the feelings and habits of a refined and cultivated people, whose devotion to country life, and fondness for all its pleasures, are so finely displayed in the beanty of their dwellings, and the exquisite lieeping of their buildings and grounds.

It is this love of rural life, and this nice feeling of the harmonious union of nature and art, that reflects so much credit upon the English as a people, and which, sooner or later, we hope to see completely naturalized in this country. Our rural residences, evincing that love of the beautiful and the picturesque, which, combined with solid comfort, is so attractive to the eye of every beholder, will not only become sources of the purest enjoyment to the refined minds of the possessors, but will exert an influence for the improrement in taste of every class in our community. The ambition to build "shingle palaces" in starred and meagre grounds, we are glad to see giving way to that more refined feeling which prefers a neat villa or cottage, tastily constructed, and surrounded by its proper accessories, of greater or less extent, of verdant trees and heautiful shrubbery.

It is gratifying to see the progressive improvement in Rural Architecture, which within a few years past has evinced itself in various parts of the country, and par- 



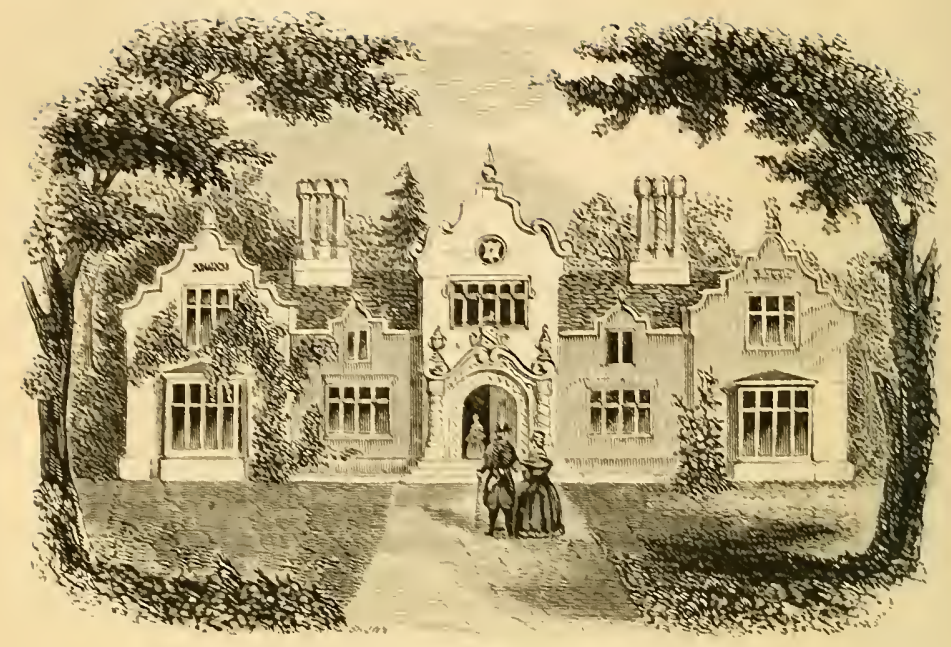

Fu, it,-1 Mansisu in the bilizanethan style.

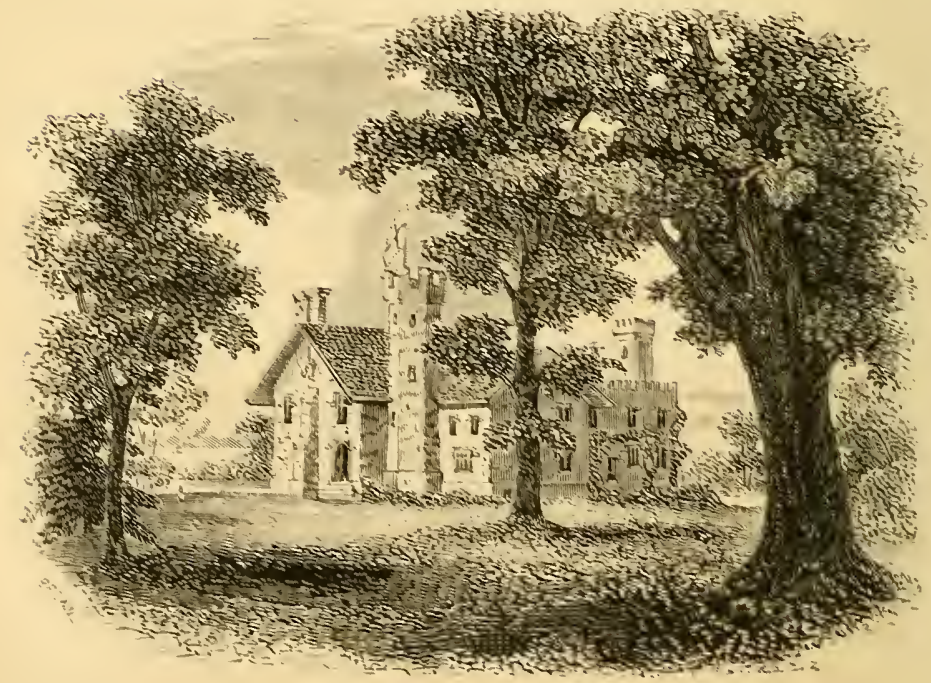

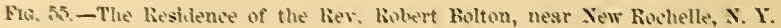


ticularly on the banks of the Hudson and Connecticut Rivers, as well as in the suburbs of our largest cities, Hero and there, beantiful villas and cottages in the Italian or old English styles, are being erected by proprietors who feel the pre-eminent beauty of these modes for domestic architecture. And from the rapidity with which improve. ments having just claims for public favor advance in our community, we have every reason to hope that our Rural Architecture will soon exhibit itself in a more attractive and agreeable form than it has hitherto generally assumed. We take pleasure in referring to a few of these buildings more in detail.

'The cottage of 'Thomas W. Tudlow, Esq., near Yonkers, on the Iludson (Fig. 5t), is one of the most complete examples on this river. The interior is very carcfully and harmoniously finished, the apartments are agreeably arranged, and the general eflect of the exterior is varied and pleasing.

There is scarcely a building or place more replete with interest in $\Lambda$ merien, than the cottage of Washington lrving, near 'T'arrytown (Fig. 55). 'The "Legrend of Sleepy Hollow," so delighttully told in the Sketch-Book, has made every one acquainted with this neighborhood, and especially with the site of the present building, there celebrated as the "Van Tiassel IIouse," one of the most secluded and delightful nooks on the banks of the Hudson. With characteristic taste, Mr. Irving has chosen this spot, the haunt of his early days, since rendered classic ground by his elegant pen, and made it his permanent residence. The house of "Baltis Van Tassel" has been altered and rebuilt in a quaint style, partaking somewhat of the English cottage mode, but retaining strongly marked symptoms of its Dutch origin 'The quaint old weather- 


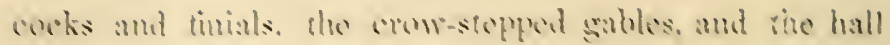

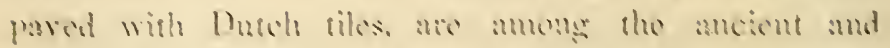
volnerablo ormments of the houses of the origizal

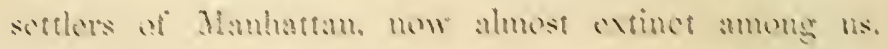

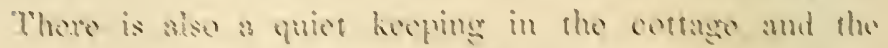
stroneds anome it that assists in making up the cham

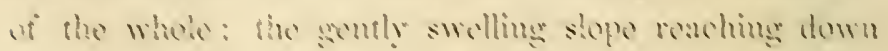

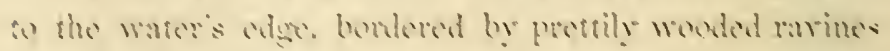

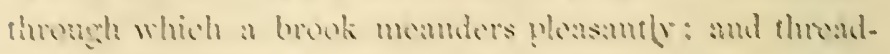

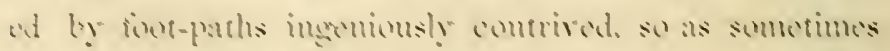

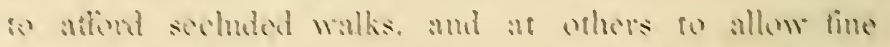

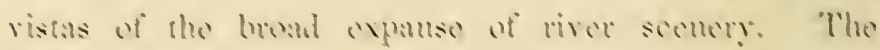

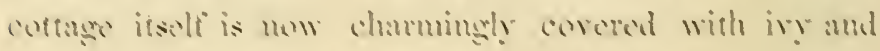

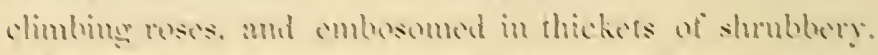

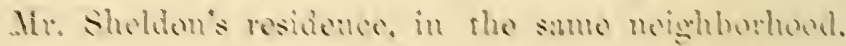

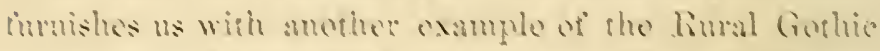

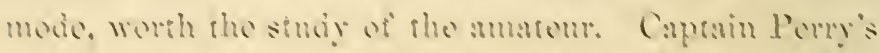

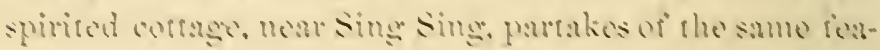

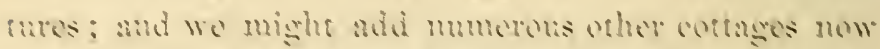

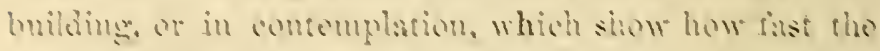
foling for something moro expressiro and pioturesque

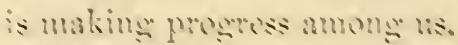

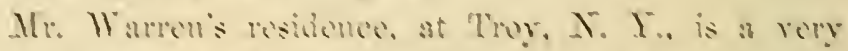

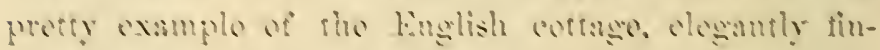

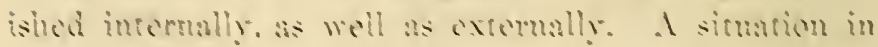
a valley. embosomed wich luxmiant tress. would have

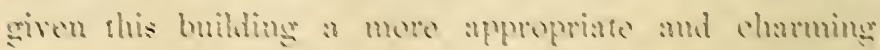

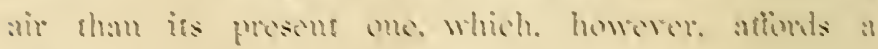

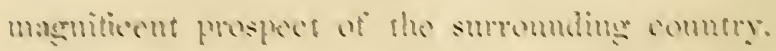

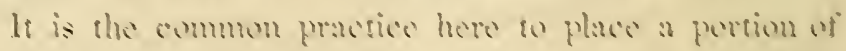

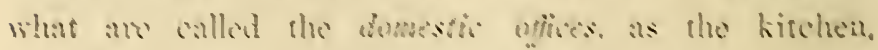
pantries, che, in the bascmem story of the house. 
directly beneath the living rooms. 'This has partly arisen from the circumstance of the comparative econemy of this methed of constructing them under the same roof; and partly from the difliculty of adding wings to the main building for threse purposes, which will not mat hes simplicity and clegance of a Grecian villa. In (he) betere class of houses in Fingland, the domestic; oflices, which include the kitchen and its appurtenances, and also the stable, coach-house, harness-room, etc., aro in the majority of eases attached to the main body of the building on one side. The great advantage of having all these eonveniencess on the sarne floor with the principal rooms, sind communicating in such a way as to be casily accessible at all times without going iroto the open air, is underiable. It must also be adrritted that these domestic offices, extending out from the main huilding, partly visible and partly concealed by trees and foliage, add much to the extent and importance of a villa or marision in the country. In the old Finglish style these appendages are made to unite happily with the lauiding, which is in itself irregular. Picturesque effect is certainly increased by thus extending the pilc and increasing tho varicty of its outline.

$\Lambda$ blind partiality for any one style in building is detrimental to the progress of improvemerit, both in taste and comfort. 'The variety of means, habits, and local feclings, will naturally cause many widely different tastes to arise among us; and it is only by the mears of a number of distinct styles, that this diversity of tastes can le accornmodated. 'There will always be a large class of individuals in every country who prefer a plain square house because it is more economical, and because they have little feeling 
for architoctursh or, indect, amy other species of beaty. But besides such. there will always be fomd some nem of timer natures, who have a sympatnetic appreciation of the beantifin in neture and art. Among these, the classical scholar and gentleman may, from association and the love of antiquity, prefer a villa in the Grectum or homan style. the who has a passionate love of pirtures and especially. the lamksopes, will perhaps, rery naturally, preter the modern Italian style for a comtry residened. 'The wealthy' proprictor, either fiom the romantic and chivalrous assow viations comeeted with the baronial castle, w from desire to display his owm resomees, may indulgo his finme in crecting a castellated drelling. The gentemin whe wishes to realize the bean ideal of a gremme old Euglish comtry residenee, with its rarioms internal comterts, and its spirited exterior. may establish himself in a Tudor villa or mansion: and the lover of nature and rural life, who, with more limited means, takes equal interest in the beamty of his grounds or garden (howerer small) and his housewho is both an atmirser of that kind of beanty called the pretaresque, and has a lively pereeption of the effect of a happy adaptation of buildings to the landseipe, - stuch a person will very naturally make choice of the rural cottage style.

Entrance Lodges are not ouly handsome arehitectural objocts in the scenery of comtry residences of large size. wh are in mam eases excedingly comenient. both to the limily and the guests or visitors haring frequent ingress and egress. The entrance lodge may turther be considered a matter strietly useful, in serving as the dwelling of the 
garderer or firmer and his fimily. In this point of view. arrangements for the comfort and convenience of the inmates should ho regarded as more important than the fincifinl decoration of the exterior-as no exterior, however charming, ean, to a reflective and well regulated mind, apologizo for contrated apartments, and imperfect light and rentilation, in homan habitations.

Among the numerous entrance lodges which we remember 10 have seen in the United States, we searcely recall a single example where the means, or rather the facility, of opening and shutting the gate itself, has been sulliciently considered. Most grenerilly the lodgre is at too great a distance fiom the gatte, consuming too much time in attendance, and exposing the persons attending, generally women or children, to the inclemeneies of the weather. Besides this, service of this kind is less eheerfully performed in this comntry than in binrope, from the very simple reason of the greater equality of conditions here, and therefore overything which tends to lessen labor, is worthy of being taken into account.

For these reasons we would place the gate very near the lodge; it would be preferable if it were part of the same arehitectural composition: and if possible adopt the contrivance now in use at some places abroad, by which the gate, being hming nearest the building, may be opened by the oecupant without the latter being seen, or being searcely obliged to leave his or her employment.* "This

* In Fig. 56 , is shown tho soction of a gate arranged upon this plan. $\Lambda t$ the bottom of the hamgirig pest of the gato, is a bovelled iron pinion, that works into another pinion, $b$, at the ond of tho horizontal shaft, $a$, which shaft is fixed in a squaro box or tumnel muder tho rosd. Tho part to the right of tho partition line, $f$, is the interior of the gatto-keeper's honso; and by turning the winch, e, the npright shaft, $c$, is put in motion, which moves by moans of the bovolled pinions, $s$, d, tho shaft $a$, and thoroforo, fhrough $d$, tho back post of tho gato, 
is cortainly the ultimatum of improvements in gato lodges: and where it camot be attained. something my still be done cowards amelionation. hy placing the gate within sa comenient distmee, instead of halt a dezen tods apart from the lodgere, an is fiequently done.

That the entrance lodge shenld correspend in style with the mansion. is a maxim insisted upen by all writers on limal Arehiteome. Where the latter is built in a mixed style, there is more latitude allowed in the choice of forms for the lontger. which may be comsidered more as a thing by itselt. but where the dwelling is a strictly arehioctural composition. the lodge should correspond in style, and bestr ovidenes of emanating fiom the same mind. A rariation af the same style may be adopted with pleasing eflect. as a

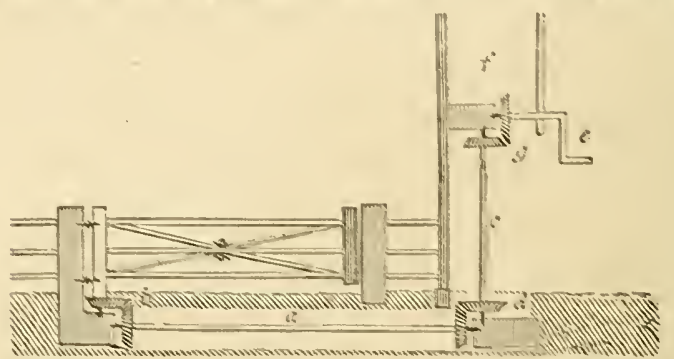

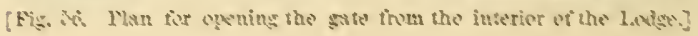

lodge in the form of the old English cottuge for an castellated

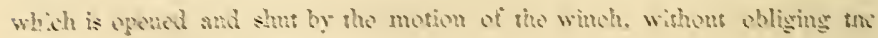
rumstes to lrive the hor:s.

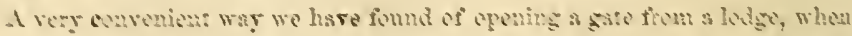

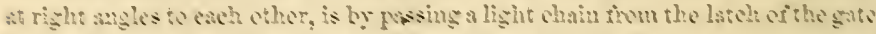

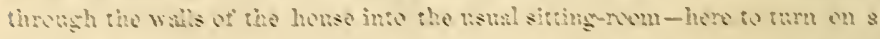

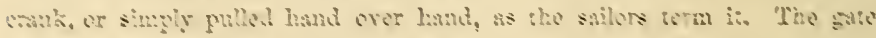

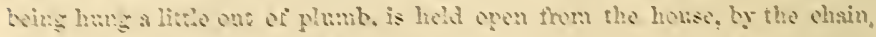

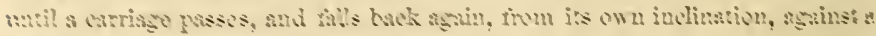

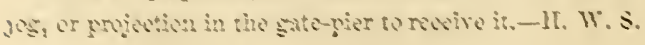


ransıon, or a Dorje lorge for a Corinthian villa ; but never two distinct styles on the same place (a Gothic gate-house and a Grecian residence) without producings in minds imbued with correct prineiples a lecling of incongruity. 'A certain correspondence in size is also agreeable; where the dwelling of the proprietor is simply an ornamenta! eottage, the lodge, if introdueed, should be more simple and unostentatious; and even where the house is magnificent, the lotge should rather be below the general ais of the residence than ahove it, that the stranger who enters at a showy and striking lodge may not be disappointed in the want of correspontence between it and the remaining, portions of the demesne.

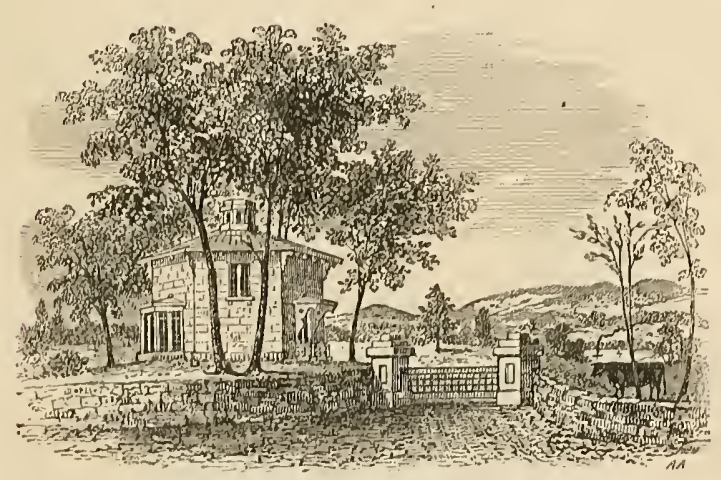

[Fig. 57. The New G'te Lodge at Blithowood.]

The gate-lodge at Blithewood, on the Hudson, the scat of R. Donaldson, Fisq., is a simple and effective cottage in the bracketed style-octagonal in its form, and very compactly arranged internally.

Nearly all the fine seats on the North river have entrance 
lodges-often smple and but little ornamented, or only

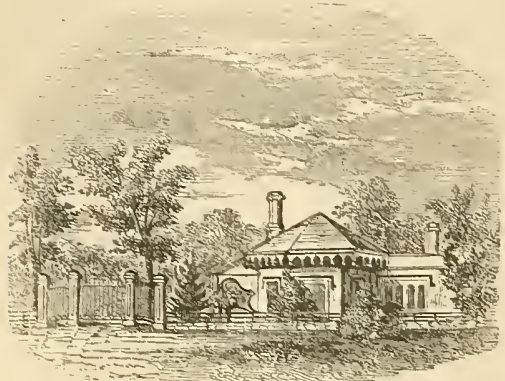

[Fig. 5s. The Gate Lodge at Netherwood.] pleasingly embowered in toliage ; but, occasionally, highly picturesque and striking in appearance.

$A$ riew of the pretty gate lodge at Nether. wood, Duchess County N. I., the seat of Gardiner Howland, Esq., is shown in Fig. 5S. Half a mile north of this seat is an interesting lodge in the Swiss style, at the entrance to the residence of Mrs. Sheafe.

In Fig. 59, is show' an eleration of a lodge in the Italian style, with projecting eares supported by cantilevers or brackets, round-headed windows with balconies, character. istic porch, and other leading features of this style.

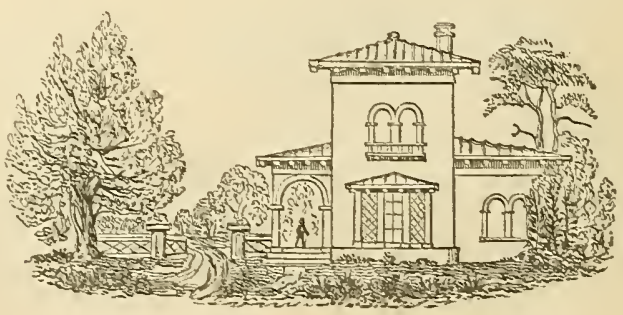

[Fig. 5\%. Gate Lodge in the Italian stryle.]

Mr. Repton has stated it as a principle in the composition of residences, that neither the house should be risible from the entrance nor the entrance from the house, if there be sufficient distance between them to make the approach through raried grounds, or a park, and not immediately into a court-yard. 
Entrance lodges, and indeed all small ornamental buildings, should be supported, and partially concealed, by trees and foliage; naked walls, in the country, hardly admitting of an apology in any case, but especially when the building is ornamental, and should be considered part of a whole grouping with other objects in rural landscape.

Nore.-To readers who desire to cultivate a taste for rural architecture, we take pleasure in recommending the following productions of the English press. Loudon's Encyclopadia of Cottage, Farm, and Villa Architecture, a volume replete with information on every branch of the subject; Robinson's Rural Architecture and Designs for Ornamental Villas; Lugar's Villa Architecture; Goodwin's Rural Architecture; Hunt's Picturesque Domestic Architecture, and Examples of Tudor Architecture; Pugin's Examples of Gothic Architecture, etc. The most sucessful American architects in this branch of the art, with whom we are acquainted, are Alexander J. Davis, Esq., is New York, and John Notman, Esq., of Philadelphia.

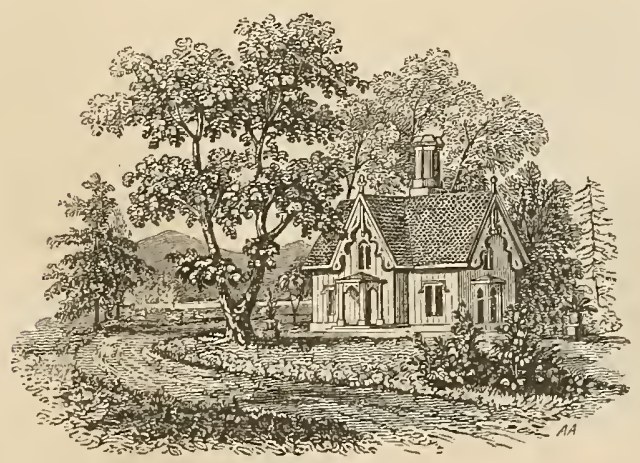

[Fig. 60. The Gardener's House, Blithewood.] 


\section{SECTION $\mathrm{x}$.}

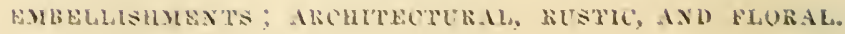

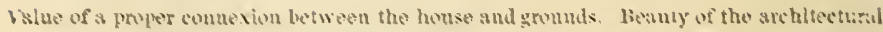
terrsce, and its appliestion to viliss sud contages. l'so of vases of difterent descriptions

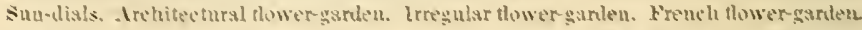

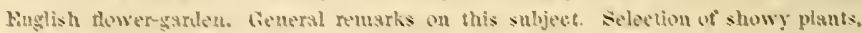
Blowering in sucession. Arrumenent of the shrublery, and selection of ehoice shruhs. Tho conservatury or gresu-hwise. Open and covered seats, liovilions. Rustic seats.

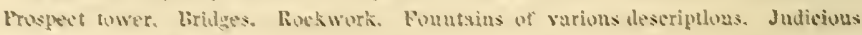
introbuetion of decorations.

Noturo, ssimuing a mow lordy face.

Burrowing a bouty from the werks of grace.

COWLE.

Each odornus, bushy strub

Fenced up the verdant wall ; esch beamteoms dower:

lris all hues, hoses and Jesunimo

Restid high their thotrished heads betwera,

And wroughe Nosuli.

ILนTN.

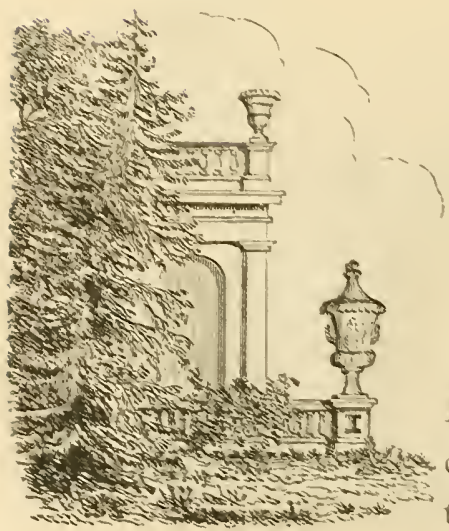

X our finest places. or those or park scenery is kept up, one of the most striking defects is the want of " union between the house and the grounds." 
We are well aware that from the comparative rarity of any. thing like a highly kept place in this courtry, the want of this, which is indeed like the last finish to the residence, is scarcely felt at all. But this only proves the infant state of Landscape Gardening here, and the little attention that has been paid to the highest details of the art.

If our readers will imagine, with us, a pretty villa, conveniently arranged and well constructed, in short, complete. in itself as regards its architecture, and at the same time, properly placed in a smooth well kept lawn, studded with groups and masses of fine trees, they will have an example often to be met with, of a place, in the graceful school of design, about which, nowever, there is felt to be a certain incongruity between the house, a highly artificial object, and the surrounding grounds, where the prevailing expression in the latter is that of beautiful nature.

Let us suppose, for further illustration, the same house and grounds with a few additions. The house now rising directly out of the green turf which encompasses it, we will surround by a raised platform or terrace, wide enough for a dry, firm walk, at all seasons; on the top of the wall or border of this terrace, we will form a handsome parapet, or balustrade, some two or three feet high, the details of which shall be in good keeping with the house, whether Grecian or Gothic. On the coping of this parapet, if the house is in the classical style, we will find suitable places, at proper intervals, for some handsome urns, vases, etc. On the drawing-room side of the house, that is, the side towards which the best room or rooms look, we will place the fower-garden, into which we descend from the terrace by a few steps. This flower-garden may be simply what its name denotes, a place exclusively devoted to th.e culti. 
vation of flowers, or (if the house is not in a very plain style, admitting of little enrichment) it may be an architectural flower-garden. In the latter case, intermingled with the flowers, are to be seen vases, fountains, and sometimes even statues; the effect of the fine colors and deep foliage of the former, heightened by contrast with the sculptured forms of the latter.

If our readers will now step back a few rods with us and take a second view of our villa residence, with its supposed harmonizing accessories, we think they can hardly fail to be impressed at once with the great improvement of the whole. The eye now, instead of witnessing the sudden termination of the architecture at the base of the house, where the lawn commences as suddenly, will be at once struck with the increased variety and richness imparted to the whole scene, by the addition of the architectural and garden decorations. The mind is led gradually down from the house, with its projecting porch or piazzas, to the surrounding terrace crowned with its beautiful vases, and from thence to the architectural flower-garden, interspersed with similar ornaments. The various play of light afforded by these sculptured forms on the terrace; the projections and recesses of the parapet, with here and there some climbing plants luxuriantly enwreathing it, throwing out the mural objects in stronger relief, and connecting them pleasantly with the verdure of the turf beneath; the still further rambling off of vases, etc., into the brilliant flower-garden, which, through these ornaments, maintains an avowed connexion with the architecture of the house; all this, we think it cannot be denied, forms a rich setting to the architecture, and unites 
agreeably the forms of surrounding nature with the more regular and uniform outlines of the building.

The effect will not be less pleasing if viewed from another point of view, viz. the terrace, or from the apartments of the house itself. From either of these points, the various objects enumerated, will form a rich foreground to the pleasure-grounds or park-a matter which painters well know how to estimate, as a landscape is incomplete and unsatisfactory to them, however beautiful the middle or distant points, unless there are some strongly marked objects in the foreground. In fine, the intervention of these elegant accompaniments to our houses prevents us, as Mr. Hope has observed, "from launching at once from the threshold of the symmetric mansion, in the most abrupt manner, into a. scene wholly composed of the most unsymmetric and desultory forms of mere nature, which are totally out of character with the mansion, whatever may be its style of architecture and furnishing." **

The highly decorated terrace, as we have here supposed 1t, would, it is evident, be in unison with villas of a somewhat superior style; or, in other words, the amount of enrichment bestowed upon exterior decoration near the house, should correspond to the style of art evinced in the exterior of the mansion itself. An humble cottage with sculptured vases on its terrace and parapet, would be in bad taste; but any Grecian, Roman, or Italian villa, where a moderate degree of exterior ornament is visible, or a Gothic villa of the better class, will allow the additional enrichment of the architectural terrace and its ornaments. Indeed the terrace itself, in so far as it denotes a raised dry

- Fssay on Ornamental Gardening, by Thomas Hope. 
platform around the house, is a suitable and appropriate appendage to every dwelling, of whatever class.

The width of a terrace around a house may vary from five to twenty feet, or more, in proportion as the building is of greater or less importance. The surromnding wall, which supports its level, may also vary from one to eight feet. 'The terrace, in the better class of Finglish residences, is pared with smooth flag stones, or in place of this, a surfice of firm well-rolled gravel is substituted. In residences where a parapet or balustrade would be thought too expensive, a square stone or plinth is placed at the angles or four corners of the terrace, which serves as the pedestal for a vase or urn. When a more elegant and finished appearance is desirable, the parapet formed of open work of stone, or wood painted in imitation of stone, rises above the level of the terrace two or three feet with a suitably bold coping. On this rases may be placed, not only at the corners, but at regular intervals of ten, twenty, or more feet. Wo have alluded to the good effect of climbers, here and there planted, and suffered to intermingle their rich foliage with the open work of the parapet and its cromuing ormaments. In the climate of Philadelphia, the Giant Iry, with its thick sculptmesque looking masses of foliage, would be admirably suited to this purpose. Or the Virginia Creeper (the Iry of America) may take its place in any other portion of the Union. To these we may add, the Chinese twining Honeysuckle (Lonicera llexuosa) and the Sweet-scented Clematis, both delicioush fragrant in their blossoms, with many other fine climbers which will readily recur to the amateur.

There can be no reason why the smallest cottage, if its occupant be a person of taste; should not have a terrace 
decorated in a suitable manner. 'This is easily and cheaply effected by placing neat flower-pots on the parapet, on border and angles of the terrace, with suitable plants growing in them. For this purpose, the American or Century Aloc, a formal architectural-looking plant, is exceedingly

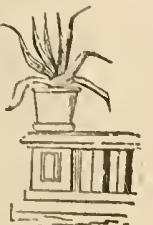

[Fig. 61.] well adapied, as it always preserves nearly the same appearance. $\mathrm{Or}^{\cdot}$ in place of this, the Yuecas, or "Adam's needle and thread," which hare something of the same character; while they also produce beautiful heads of flowers, may be chosen. Yucca flaccida is a tine hardy species, which would look well in such a situation. An aloe in a common flower pot is shown in Fig. 61; and a lucea in an ormamental flower-pot in rig. 6:.

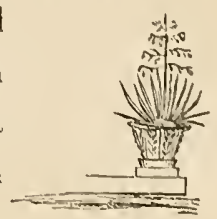

[Fig. 62.]

Where there is a terrace ornamented with urns or rases, and the proprictor wishes to give a corresponding air of elegance to his gromds, vases, sundials, etc., may be placed in various appropriate situations, not only in the architectural flower-garden, but on the lawn, and through the pleasure-grounds in various different points near the house. We say near the house, because we think so highly artificial and architectural an object as a sculptured vase, is never correctly introduced untess it appear in some way connected with buildings, or objects of a like architectural character. To place a beautiful vase in a distant part of the grounds, where there is no direct allusion to art, and where it is accompanied only by natural objects, as the overhanging trees and the sloping turf, is in a measure, doing violence to our reason or taste, by bringing two ohjects so strongly contrasted, in direct union. But when 
we see a statue or a vase placed in any part of the grounds where a near view is obtained of the house (and its accompanying statues or vases), the whole is accounted for, and we feel the distant vase to be only a part of, or rather a. repetition of the same idea,-in other words, that it forms part of a whole, harmonious and consistent.

Vases of real stone, as marble or granite, are decorations of too costly a kind ever to come into general use among us. Vases, however, of equally beautiful forms, are manufactured of artificial stone, of fine pottery, or of cast iron, which have the same effect, and are of nearly equal durability, as garden decorations.

A vase should never, in the open air, be set down upon the ground or grass, without being placed upon a firm base of some description, either a plinth or a pedestal. Without a base of this kind, it has a temporary look, as if it had been left there by mere accident, and without any intention of permanence. Placing it upon a pedestal, or square plinth (block of stone), gives it a character of art, at once more dignified and expressive of stability. Besides this, the pedestal in reality serves to preserve the vase in a perpendicular position, as well as to expose it fairly to the eye, which could not be the case were it put down, without any preparation, on the bare turf or gravel.

Figure 63 is a Gothic, and Figures 64, 65, are Grecian vases, commonly manufactured in plaster in our cities, but which are also made of Romas cement. They are here shown upon suitable pedestals - $a$ being the vase, and $b$ the pedestal. These with many other elegant vases and urns are manufactured in an artificial stone, as durable as inarble, by Austin of London, and together with a great 
variety of other beautiful sculpturesque decorations, may be imported at very reasonable prices.

Figures 64,65 , are beautiful vases of pottery ware manufactured by Peake, of Staffordshire-and which may he imported cheaply, or will be made to order at the Salamander works, in New York. These vases, when colored

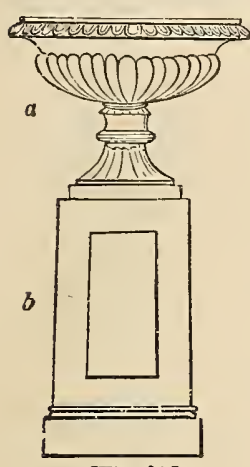

[Fig. 64.]

to imitate marble or other stone, are extremely durable and very ornamental. As yet, we are unable to refer our readers to any manufactory here, where these articles are made in a manner fully equal to the English ; but we are satisfied, it is only necessary that the taste for such articles should increase, and the consequent demand, to induce our artisans to produce them of equal beauty and of greater cheapness.

At Blithewood, the seat of R. Donaldson, Esq., on the Hudson, a number of exquisite vases may bo seen in the pleasure-grounds, which are cut in Maltese stone. These were imported by the proprietor, direct from Malta, at very moderate rates, and are not only ornamental, but very durable. Their color is a warm shade of grey which harmonizes

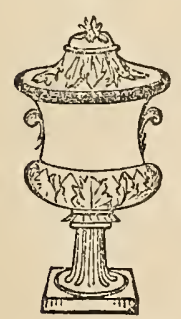

[Fig. 66.] agreeably with the surrounding vegetation.

Large vases are sometimes

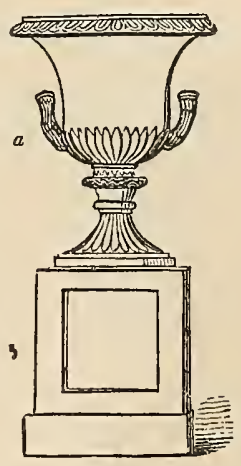

[Fig. 65.] filled with earth and planted with choice flowering plants, and the effect of the blossoms and green leaves growing out of these handsome receptacles, is at least unique and striking. 24 
Loudon objects to it in the case of an elegant sculptured vase, "because it is reducing a work of art to the level of a mere garden flower-pot, and dividing the attention between the beauty of the form of the rase and of its sculptured ornaments, and that of the plant which it contains." This criticism is a just one in its general application, especially when vases are considered as architectural decorations. Occasional deviations, however, may be permitted, for the sake of producing variety, especially in the case of vases used as decorations in the flower-garden.

A very pretty and fanciful substitute for the sculptured vase, and which may take its place in the picturesque landscape, may be found in vases or baskets of rustic work, con-

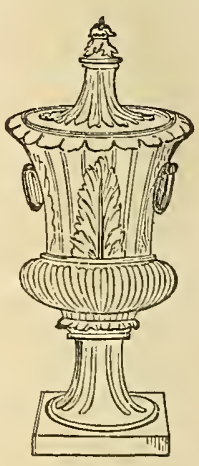

[Fig. 67.] structed of the branches and sections of trees with the

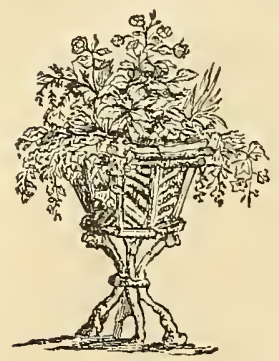

[Fig. 6S.] bark attached. Figure $6 s$ is a representation of a pleasing rustic vase which we have constructed withont difficulty. A tripod of branches of trees forms the pedestal. An octagonal box serves as the body or frame of the vase ; on this, pieces of birch and hazel (small split limbs covered with the bark) are railed closely, so as to form a sort of mosaic covering to the whole exterior. Ornaments of this kind, which may be made by the amateur with the assistance of a common carpenter, are very suitable for the decoration of the grounds and flower-gardens of cottages or picturesque villas. An endless variety of forms will occur to an 
ingenious artist in rustic work, which he may call in to the embellishment of rural scenes, without taxing his purse heavily.

Sundials (Fig. 69) are among the oldest decorations for the garden and grounds, and there are scarcely any which

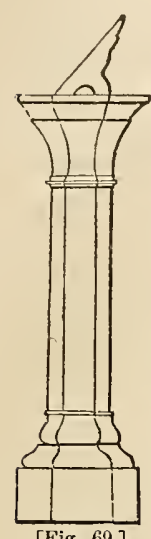

we think more suitable. They are not merely decorative, but have also an useful character, and may therefore be occasionally placed in distant parts of the grounds, should a favorite walk terminate there. When we meet daily in our walks, for a number of years, with one of these silent monitors of the flight of time, we become in a degree attached to it, and really look upon it as gifted with a species of intelligence, beaming out when the sunbeams smile upon its dial-plate.

The Architectural Flower-garden, as we have just remarked, has generally a direct connexion with the house, at least on one side by the terrace. It may be of greater or less size, from twenty feet square to half an acre in extent. The leading characteristics of this species of flower-garden, are the regular lines and forms employed in its beds and walirs. The flowers are generally planted in beds in the form of circles, octagons, squares, etc., the centre of the garden being occupied by an elegant vase, a sundial, or that still finer ornament, a fountain, or jet d'eau. In various parts of the garden, along the principal walks, or in the centre of parterres, pedestals supporting vases, urns, or handsome flower-pots with plants, are placed. When a highly marked character of art is intended, a balustrade or parapet, resembling that of the terrace to which it is connected, is continued round the whole of 
this garden. Or in other cases the garden is surrounded by a thicket of shrubs and low trees, partly concealing it from the eye on all sides but one.

It is evident that the architectural flower-garden is superior to the general flower-garden, as an appendage to the house, on two accounts. First, because, as we have already shown, it serves an admirable purpose in effecting a harmonious union between the house and the grounds. And secondly, because we have both the rich verdure and gay blossoms of the flowering plants, and the more permanent beauty of sculptured forms; the latter heightening the effect of the former by contrast, as well as by the relief they aftord the eye in masses of light, amid surrounding verdure.

There are several varieties of general flower-gardens, which may be formed near the house. Among these we will only notice the irregular flower-garden, the old French flower-garden, and the modern or English flower-garden.

In almost all the different kinds of flower-gardens, two methods of forming the beds are observed. One is, to cut the beds out of the green turf, which is ever afterwards

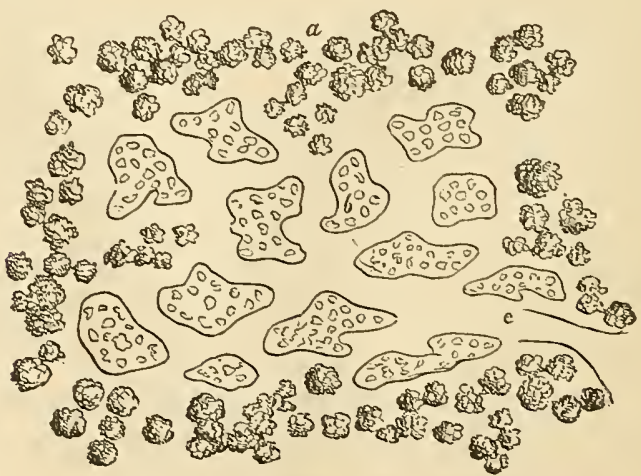

[Fig. 0 . The Irregular Flower-garden.] 
kept well-mown or cut for the walks, and the edges pared; the other, to surround the beds with edgings of verdure, as box, etc., or some more durable material, as tiles, or cut stone, the walks between being covered with gravel. The turf is certainly the most agreeable for walking upon in the heat of summer, and the dry part of the day; while the gravelled flower-garden affords a dry footing at nearly all hours and seasons.

The irregular flower-garden is surrounded by an irregular belt of trees and ornamental shrubs of the choicest species, and the beds are varied in outline, as well as irregularly disposed, sometimes grouping together, sometimes standing singly, but exhibiting no uniformity of arrangement. An idea of its general appearance may be gathered from the accompanying sketch (Fig. 70), which may be varied at pleasure. In it the irregular boundary of shrubs is shown at $a$, the flower-beds $b$, and the walks $e$.

This kind of flower-garden would be a suitable accompaniment to the house and grounds of an enthusiastic lover of the picturesque, whose residence is in the Rural Gothic style, and whose grounds are also eminently varied and picturesque. Or it might form a pretty termination to a distant walk in the pleasure-grounds, where it would be more necessary that the flower-garden should be in keeping with the surrounding plantations and scenery than with the house.

Where the flower-garden is a spot set apart, of any regular outline, not of large size, and especially where it is attached directly to the house, we think the effect is most satisfactory when the beds or walks are laid out in symmetrical forms. Our reasons for this are these: the flower-garden, unlike distant portions of the pleasure. 
ground scenery, is an appendage to the house, seen in the same riew or moment with it, and therefore shonld exhibit something of the regularity which characterizes, in a greater or less degree, all arehitectural compositions; and when a giren scene is so small as to be embraced in a single glance of the eye, regular forms are found to be more satisfactory than irregular ones, which, on so small a scale, are apt to appear ummeaning.

'The French flower-garden is the most fanciful of the I g gular modes of laying out the area deroted to this purpose. The patterns or figures employed are often highly intricate, and require considerable skill in their formation. The walks are either of gravel or smoothly shaven turf, and the beds are filled with choice flowering plints. It is evident that much of the beauty of this kind of flower-garden, or indeed any other where the figures are regular and intricate, must depend on the outlines of the beds, or parterres of cmbroidery, as they are called, being kept distinct and clear. To do this effectually, low growing herbaceous plants or border flowers, perennials and amnuals, should be chosen, such as will not exceed on an arerage, one or two feet in height.

In the English flower-garden, the beds are either in symmetrical forms and figures, or they are characterized by irregular curved outlines. The peculiarity of these gardens, at present so firshionable in England, is, that each separate bed is planted with a single rariety, or at most two varieties of flowers. Only the most striking and showy rarieties are generally chosen, and the effect, when the selection is judicious, is highly brilliant. Each bed, in its season, presents a mass of blossoms, and the contrast of rich colors is much more striking than in any other 
arrangement. No plants sre admitted that are shy bloomers, or which have ugly habits of growth, meagre or starved foliage; the aim being brilliant effect, rather than the display of a great variety of curious or rare plants. To bring this about more perfectly, and to have an elegant show during the whole season of growth, hyacinths and other fine bulbous roots oceupy a certain portion of the beds, the intervals being filled with handsome herbaceous plants, permanently planted, or with flowering annuals and green-house plants renewed every season.

To illustrate the mode of arranging the beds and disposing the plants in an English garden, we copy the plan and description of the elegant flower-garden, on the lawn at Dropmore, the beds being cut out of the smooth turf.

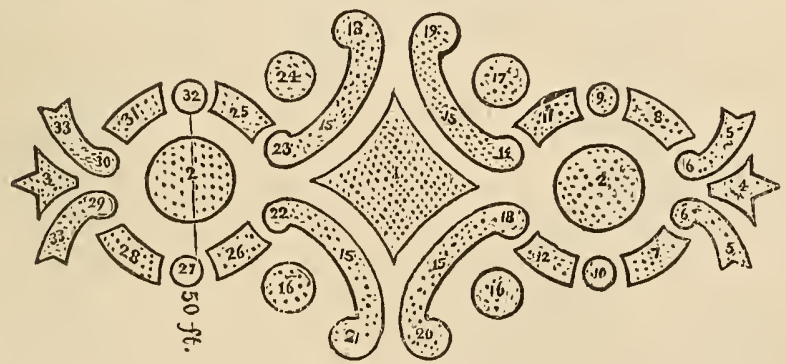

"As a general principle for regulating the plants in this figure, the winter and spring flowers ought, as much as possible, to be of sorts which admit of being in the ground all the year: and the summer crop should be planted at intervals between the winter plants. Or the summer crop, having been brought forward in pots uniler glass, or by nightly protection, may be planted out about the middle of June, after the winter plants in pots are removed. A number of hardy bulbs ought to be potted and plunged in the beds in the months of October and November; and when out of bloom, in May or June, removed to the reserve 
garden and plumged there, in order to pertect their foliage and matme their bulbs for the suceededing seasom." *

There cammot be a question that this method of planting the flower-garden in groups and masses, is productive of by fin the most splendid etlect. In Einglimd, where flower. gardens are carried to their ereatest pericetion, the pre. terence in planting is given to exoties wheh hlossom constantly throughout the season. and which ate lept in the sreen-house during winter. and tumed out in the beds in the early part of the season. where they thower in the greatest puotusion until trost: as Fuchsias, Salvias,

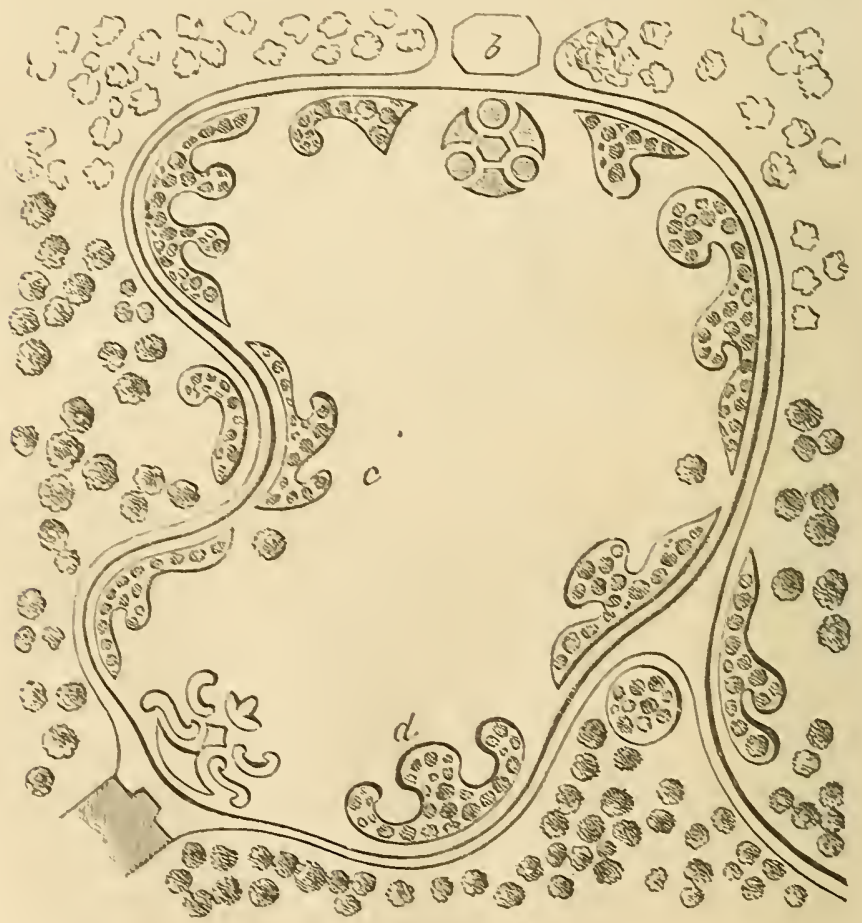

[Fig. is. English Fiower-Ganlen.]

- Eney, of Cardening, 1000. 
Lobelias, Scarlet Geraniums, etc., etc.* This mode can be adopted here where a small green-house or frame is kept. In the absence of these, nearly the same effect miciy be produced by choosing the most showy herbaceous planis, perennial and biennial, alternating them with hardy bulbs, and the finer species of annuals.

In Fig. 72, we give an example of a small cottage or villa residence of one or two acres, where the flower-beds are disposed around the lawn in the English style: their forms irregular, with curved outlines, affording a great degree of variety in the appearance as viewed from different points on the lawn itself. In this, the central portion is occupied by the lawn; $c, d$, are the flower-beds, planted with showy border-flowers, in separate masses; $b$, the conservatory. Surrounding the whole is a collection of choice shrubs and trees, the lowest near the walk, and those behind increasing in altitude as they approach the boundary wall or fence. In this plan, as there is supposed to be no exterior view worth preserving, the amphitheatre of shrubs and trees completely shuts out all objects but the lawn and its decorations, which are rendered as elegant as possible.

Where the proprietor of a country residence, or the ladies of a family, have a particular taste, it may be indulged at pleasure in other and different varieties of the flowergarden. With some families there is a taste for botany,

* In many English residenses, the flower-garden is maintained in neverfading brilliancy by almost daily supplies from what is termed the reserve garden. This is a small garden out of sight, in which a great number of duplicates of the species in the flower-garden are grown in pots plunged in beds. As soon as a vacuum is made in the fluwer-garden by the fading of any flowers, the same are immediately removed and their places supplied by fresh plants just ready to bloom, from the pots in the reservo garden. This, which is the ultimatum of refinement in flower-gardening, has never, to our knowledge, been attempted ' $\mathrm{I}$ this country. 
when a small botanic flower-garden may be preferred-the herbaceous and other plants being grouped or massed in beds after the Linnaan, or the natural method. Some persons have an enthusiastic fondness for florist flowers, as Pansies, Carnations, Dahlias, Roses, etc.; others for bubous roots, all of which may very properly lead to particular modes of laying out flower-gardens.

The desideratum, however, with most persons is, to have a continued display of blossoms in the flower-garden from the opening of the crocus and snowdrop in the spring, until the autumnal frosts cut off the last pale asters, or blacken the stems of the luxuriant dahlias in November. This may be done with a rery small catalogue of plants if they are properly selected: such as flower at different seasons, continue long time in bloom, and present fine masses of flowers. On the other hand, a rery large number of species may be assembled together; and owing to their being merely botanical rarities, and not bearing fine flowers, or to their blossoming chiefly in a certain portion of the season, or continuing but a short period in bloom, the flower-garden will often have but an insignificant appearance. With a group of Pansies and spring bulbs, a bed of erer-blooming China Roses, including the Iste de Bourbon varieties, some few Eschscholtzias, the showy Petunias, Gilias, and other annuals, and a dozen choice double Dahlias, and some trailing Terbenas, a limited spot, of a few yards in diameter, may be made productive of more enjoyment, so far as regards a continued display of flowers, than ten times that space, planted, as we often see flower-gardens here, with a heterogeneous mixture of everything the possesor can lay his hands on, or crowd within the inclosure. 
The mingled flower-garden, as it is termed, is by far the most common mode of arrangement in this country, though it is seldom well effected. The cbject in this is to dispose the plants in the beds in such a manner, that while there is no predominance of bloom in any one portion of the beds, there shall be a general admixture of colors and blossoms throughout the entire garden during the whole season of growth.

To promote this, the more showy plants should be often repeated in different parts of the garden, or even the same parterre when large, the less beautiful sorts being suffered to occupy but moderate space. The smallest plants should be nearest the walk, those a little taller behind them, and the largest should be furthest from the eye, at the back of the border, when the latter is seen from one side only, or in the centre, if the bed be viewed from both sides. A neglect of this simple rule will not only give the beds, when the plants are full grown, a confused look, but the beauty of the humbler and more delicate plants will be lost amid the tall thick branches of sturdier plants, or removed so far from the spectator in the walks, as to be overlooked.

Considerable experience is necessary to arrange even a moderate number of plants in accordance with these rules. To perform it successfully, some knowledge of the habits of the plants is an important requisite; their height, time of flowering, and the colors of their blossoms. When a gardener, or an amateur, is perfectly informed on these points, he can take a given number of plants of different species, make a plan of the bed or all the beds of a flowergarden upon paper, and designate the particular situation of each species. 
The shrubbery is so generally situated in the neighbor. hood of the flower-garden and the house, that we shall here offer a few remarks on its arrangement and distribution.

A collection of flowering shrubs is so ornamental, that to a greater or less extent it is to be found in almost every residence of the most moderate size : the manner in which the shrubs are disposed, must necessarily depend in a great degree upon the size of the grounds, the use or enjoyment to be derived from them, and the prevailing character of the scenery.

It is evident, on a moment's reflection, that shrubs being intrinsically more ornamental than trees, on account of the beauty and abundance of their flowers, they will generally be placed near and about the house, in order that their gay blossoms and fine fragrance may be more constantly enjoyed, than if they were scattered indiscriminately over the grounds.

Where a place is limited in size, and the whole lawn and plantations partake of the pleasure-ground character, shrubs of all descriptions may be grouped with good effect, in the same manner as trees, throughout the grounds; the finer and rarer specics being disposed about the dwelling, and the more hardy and common sorts along the walks, and in groups, in different situations near the eye.

When, however, the residence is of larger size, and the grounds have a park-like extent and character, the intro. duction of shrubs might interfere with the noble and dignified expression of lofty full grown trees, except perhaps they were planted here and there, among large 
groups, as underwood; or if cattle or sheep were allowed to graze in the park, it would of course be impossible to preserve plantations of shrubs there. When this is the case, however, a portion near the house is divided from the park (by a wire fence or some inconspicuous barrier) for the pleasure-ground, where the shrubs are disposed in belts, groups, etc., as in the first case alluded to.

There are two methods of grouping shrubs upon lawns which may separately be considered, in combination with beautiful and with picturesque scenery.

In the first case, where the character of the scene, of the plantations of trees, etc., is that of polished beauty, the belts of shrubs may be arranged similar to herbaceous flowering plants, in arabesque beds, along the walks, as in Fig. 70, page 372. In this case, the shrubs alone, arranged with relation to their height, may occupy the beds; or if preferred, shrubs and flowers may be intermingled. Those who have seen the shrubbery at Hyde Park, the residence of the late Dr. Hosack, which borders the walk leading from the mansion to the hot-houses, will be able to recall a fine example of this mode of mingling woody and herbaceous plants. The belts or borders occupied by the shrubbery and flower-garden there, are perhaps from 25 to 35 feet in width, completely filled with a collection of shrubs and herbaceous plants; the smallest of the latter being quite near the walk; these succeeded by taller species receding from the front of the border, then follow shrubs of moderate size, advancing in height until the background of the whole is a rich mass of tall shrubs and trees of moderate size. The effect of this belt on so large a scale, in high keeping, is remarkably striking and elegant.

Where picturesque effect is the object aimed at in the 
pleasure-grounds, it may be attained in another way; that is, by planting irregular groups of the most vigorous and thrifty growing shrubs in lawn, without placing them in regular dug beds or belts; but instead of this, keeping the grass from growing and the soil somewhat loose, for a few inches round their stems (which will not be apparent at a short distance). In the case of many of the hardier shrubs, after they become well established, even this care will not be requisite, and the grass will only require to be kept short by clipping it when the lawn is mown.

As in picturesque scenes everything depends upon grouping well, it will be found that shrubs may be employed with excelient effect in connecting single trees, or finishing a group composed of large trees, or giving fulness to groups of tall trees newly planted on a lawn, or effecting a union between buildings and ground. It is true that it requires something of an artist's feeling and perception of the picturesque to do these successfully, but the result is so much the more pleasing and satisfactory when it is well executed.

When walks are continued from the house through distant parts of the pleasure-grounds, groups of shrubs may be planted along their margins, here and there, with excellent effect. They do not shut out or obstruct the view like large trees, while they impart an interest to an otherwise tame and spiritless walk. Placed in the projecting bay, lound which the walk curves so as to appear to be a reason for its taking that direction, they conceal also the portion of the walk in advance, and thus enhance the interest doubly. The neighborhood of rustic seats, or resting points, are also fit places for the assemblage of a group or groups of shrubs.

For the use of those who require some guide in the 
selection of species, we subjoin the accomparying list of hardy and showy shrubs, which are at the same time easily procured in the United States. A great number of additional species and varieties, and many more rare, might be enumerated, but such will be sufficiently familiar to the connoisseur already; and what we have said respecting botanical rarities in flowering plants may be applied with equal force to shrubs, viz. that in order to produce a brilliant effect, a few well chosen species, often repeated, are more effective than a great and ill-assorted mélange.

In the following list, the shrubs are divided into two classes-No. 1 designating those of medium size, or low grouth, and No. 2, those which are of the largest size.

\section{Flowerixg in Aprit.}

1. Daphne mezereum, the Pink Mezereum, D. MI. album, the white Mezereum.

2. Shepherdia argentea, the Buffalo berry; yellow.

1. Xanthorhiza apiifolia, the parsley-leaved Yellow-root; brown.

1. Cydonia japonica, the Japan Quinee; searlet.

1. Cydonia japonica alba, the Japan Quinee; white.

2. Amelanchier Botryapium, the snowy Medlar.

1. Ribes aureum, the Missouri Currant; yellow.

1. Coronilla Emerus, the Seorpion Senna ; yellow.

2. ILagnolia conspicua, the Chinese ehandelier Magnolia ; white.

MAY.

2. Crategus oxycantha, the searlet Hawthorn.

3. Cratcgus oxycantha, $f$. pleno, the double white Hawthorn.

2. Chionanthus virginica, the white Fringe tree.

1. Chionanthus latifolius, the broad-leaved Fringe tree; white.

I. Azalea, wany fino varieties; red, white, and yellow.

1. Calycanthus florida, the Sweet-scented-shrub; brown.

1. Magnolia purpurea, the Chinese purple Magnolia.

2. Halesia tetraptera, the silver Bell tree; white.

2. Syringa vulgaris, the common white and red Lilaes.

1. Syringa persica, the Persian Lilac: white and purplo. 
1. Syringa persica laciniata, the Persian eut-leaved Lilac ; purple.

1. Kerria or Corchorus japonica, the Japan Globe flower; yellow.

1. Lonicera tartarica, the Tartarian upright Honeysuckles; red and white.

1. Philadelphus coronarius, the common Syringo, and the double Syringo ; white.

1. Spiraa hypericifolia, the St. Stephen's wreath; white.

1. Spirca corymbosa, the cluster flowering Spirea; white.

1. Ribes sanguineum, the scarlet flowering Currant.

1. Amygdalus pumila, $p l$., the double dwarf Almond; pink.

1. Caragana Chamlagu, the Siberian Pea tree; yellow.

2. Magnolia soulangeana, the Soulange Magnolia; purple.

1. Paonia Moutan banksia, and rosea, the Chinese tree Pæonia; purple.

1. Benthamia frugifera, the red berried Benthamia; yellow.

JUNE.

1. Amorpha fruticosa, the Indigo Shrub; purple.

2. Colutea arborescens, the yellow Bladder-senna.

1. Colutea cruenta, the red Bladder-senna.

1. Cytisus capitatus, the cluster-flowered Cytisus; yellow.

1. Stuartia virginica, the white Stuartia.

1. Cornus sanguinea, the bloody twig Dogwood; white.

1. Hydrangca quercifolia, the oak-leaved Hydrangea; whito.

2. Philadelphus grandiflorus, the large flowering Syringo; white.

2. Viburnum Opulus, the Snow-ball; white.

2. Magnolia glauca, the swamp Magnolia; white.

1. Robinia hispida, the Rose-acacia

JULY.

1. Spirca bella, the beautiful Spirea; red.

2. Sophora japonica, the Japan Sophora; white.

2. Sophora japonica pendula, the weeping Sophora; white.

2. Khus Cotinus, the Venetian Fringe tree; yellow. (Brown tufts.)

1. Ligustrum vulgare, the common Privet; white.

2. Cytisus Laburnum, the Laburnum; yellow.

2. Cytisus l. quercifolia, the oaked-leaved Laburnum; white.

1. Cytisus purpureus, the purple Laburnum.

1. Cytisus argenteus, the silvery Cytisus; yellow.

1. Cytisus nigricans, the black rooted Cytisus; yellow.

2. Kolrcuteria paniculata, the Japan Kolreuteria ; yellow. 


\section{August and Septemras.}

1. Clethra alnifolia, the alder-leaved Clethra; white.

1. Symphoria racemosa, the Snowberry; (in fruit) white.

2. Hibiscus syriacus, the donble purple, double white, double striped duuble blue, and variegated leaved Altheas.

1. Spirca tomentosa, the tomentose Spirea ; red.

2. Magnolia glauba thompsoniana, the late flowering Magnolia white.

1. Baccharis halimifolia, the Groundsel tree; white tufts.

2. Euonymus curopceus, the European Strawberry tree (in fruit), red.

2. Euonymus curopaus alba, the European Strawberry tree; the fruit white.

2. Euonymus latifolius, the broad-leaved Strawberry tree; red.

1. Duphne mezcreum autumnalis, the autumnal Miezereum.

Besides the above, there are a great number of charming varieties of hardy roses, some of which may be grown in the common way on their own roots, and others grafted on stocks, two, three, or four feet high, as standards or treeroses. The effect of the latter, if such varieties as George the Fourth, La Cerisette, Pallagi, or any of the new hybrid roses are grown as standards, is wonderfully brilliant when they are in full bloom. Perhaps the situation where they are displayed to the greatest advantage is, in the centre of small round, oval, or square beds in the flower-garden, where the remainder of the plants composing the bed are of dwarfish growth, so as not to hide the stem and head of the tree-roses.

There are, unfortunately, but few evergreen shrubs that will endure the protracted cold of the winters of the north. ern states. The fine Hollies, Portugal Laurels, Laurustinuses, etc., which are the glory of English gardens in autumn and winter, are not hardy enough to endure the depressed temperature of ten degrees below zero. South of Philadelphia, these beautiful exotic evergreens may be 
acclimated with good suecess, and will add greatly to the interest of the shrubbery and grounds in winter.

Besides the Balsam firs and the Spruce firs, the Arbor Vitæ, and other evergreen trees which we have described in the previous pages of this volume, the following hardy species of evergreen shrubs may be introduced with advantage in the pleasure-ground groups, viz:-

Rhododenaron maximum, the American roso bay or big Laurel; whito and pink, several varieties (in shaded places).

Fialmia latifolia, the eommon Laurel; several colors.

Juniperus suecia, the Swedish Juniper.

Juniperus communis, the Irish Juniper.

Buxus arborescens, the common Tree-box, the Gold striped Tree-bor, and the Silver striped Tree-box.

Mlex opaca, the American Holly.

Crategus pyracantha, the Evergreen Thorn.

Mahonia aquifolium, the Hollv leaved Berberry.

The Conservatory or the Green-House is an elegant and delightful appendage to the villa or mansion, when there is a taste for plants among the different members of a family. Those who have not enjoyed it, can hardly imagine the pleasure afforded by a well-chosen collection of exotic plants, which, amid the genial warmth of an artificial climate, continue to put forth their lovely blossoms, and exhale their delicious perfumes, when all out-of-door nature is chill and desolate. The many hours of pleasant and healthy exercise and recreation aforded to the ladies of a family, where they take an interest themselves in the growth and vigor of the plants, are certainly no trifling considerations where the country residence is the place of labitation throughout the whole year. Often during the inclemency of our winter and spring months, there are cays when either the excessive cold, or the disagreeablo 
state of the weather, prevents in a great measure, many persons, and especially females, from taking exercise in the open air. To such, the conservatory would be an almost endless source of enjoyment and amusement; and if they are true amateurs, of active exertion also. The constant changes which daily growth and development bring about in vegetable forms, the interest we feel in the opening of a favorite cluster of buds, or the progress of the thrifty and luxuriant shoots of a rare plant, are such as serve most effectually to prevent an occupation of this nature from ever becoming monotonous or ennuyant.

The difference between the green-house and conservatory is, that in the former, the plants are all kept in pots and arranged on stages, both to meet the eye agreeably, and for more convenient growth; while in the conservatory, the plants are grown in a bed or border of soil precisely as in the open air.

When either of these plant habitations is to be attached to the house, the preference is greatly in favor of the conservatory. The plants being allowed more room, have richer and more luxuriant foliage, and grow and flower in a manner altogether superior to those in pots. The allusion to nature is also more complete in the case of plants growing in the ground; and from the objects all being on the same level, and easily accessible, they are with more facility kept in that perfect nicety and order which an elegant plant-house should always exhibit.

On the other hand, the green-house will contain by far the largest number of plants, and the same may be more easily changed or renewed at any time; so that for a particular taste, as that of a botanical amateur, who wishes to grow a great number of species in a small space, the 
green-house will be found preferable. Whenever either the conservatory or green-house is of moderate size, and intended solely for private recreation, we would in every case, when such a thing is not impossible, have it attached to the house; communicating by a glass door with the drawing-room, or one of the living rooms. Nothing can be more gratifying than a vista in winter through a glass door down the walk of a conservatory, bordered and overhung with the fine forms of tropical vegetation, golden oranges glorving through the dark green foliage, and gay corollas lighting up the branches of Camellias, and other floral favorites. Let us add the exulting song of a few Canaries, and the enchantment is complete. How much more refined and elevated is the taste which prefers such accessories to a dwelling, rather than costly furniture, or an extravagant display of plate!

The best and most economical form for a conservatory is a parallelogram-the deviation from a square being greater or less according to circumstances. When it is joined to the dwelling by one of its sides (in the case of the parallelogram form), the roof need only slope in one way, that is from the house. When one of the ends of the conservatory joins the dwelling, the roof should slope both ways from the centre. The advantage of the junction in the former case, is, that less outer surface of the conservatory being exposed to the cold, viz. only a side and two ends, less fuel will be required; the advantage in the latter case is, that the main walk leading down the conservatory will be exactly in the line of the vista from the drawing-room of the dwelling.

It is, we hope, almost unnecessary to state, that the roof of a conservatory, or indeed any other house where plants 
are to be well-grown, must be glazed. Opake roofs prevent the admission of perpendicular light, without which the stems of vegetation are drawn up weak and feeble, and are attracted in an unsightly manner towards the glass in front. When the conservatory joins the house by one of its ends, and extends out from the building to a considerable length, the effect will be much more elegant; and the plants will thrive more perfectly, when it is glazed on all of the three sides, so as to admit light in every direction.

The best aspect for a conservatory is directly south; southeast and southwest are scarcely inferior. Even east and west exposures will do very well, where there is plenty of glass to admit light; for though our winters are cold, yet there is a great abundance of sun, and bright clear atmosphere, both far more beneficial to plants than the moist, foggy vapor of an English winter, which, though mild, is comparatively sunless. When the conservatory adjoins and looks into the flower-garden, the effect will be appropriate and pleasing.

Some few hints respecting the construction of a conservatory may not be unacceptable to some of our readers. In the first place, the roof should have a sufficient slope to carry off the rain rapidly, to prevent leakage; from 40 to 45 degrees is found to be the best inclination in our climate. The roof should by no means be glazed with large panes, because small ones have much greater strength, which is requisite to withstand tire heavy weight of snow that often falls during winter, as well as to resist breakage by hail storms in summer. Four or eight inches by six, is the best size for roof-glass, and with this size the lap of the panes need not be greater than one- 
eighth of an inch, while it would require to be one.fourth of an inch, were the panes of the usual size. On the front and sides, the sashes may be handsome, and filled in with the best glass; even plate glass has been used in many cases to our knowledge here.

In the second place, some thorough provision must be made for warming the conservatory ; and it is by far the best mode to have the apparatus for this purpose entirely independent of the dwelling house; that is (though the furnace may be in the basement), the flues and fire should be intended to heat the conservatory alone; for although a conservatory may, if small, be heated by the same fire which heats the kitchen or one of the living rooms, it is a much less efficient mode of attaining this object, and renders the conservatory more or less liable at all times to be too hot or too cold.

The common square flue, the sides built of bricks, and the top and bottom of tiles manufactured for that purpose, is one of the oldest, most simple, and least expensive methods of heating in use. Latterly, its place has been supplied by hot water circulated in large tubes of three or four inches in diameter from an open boiler, and by Perkins's mode as it is called, which employs small pipes of an inch in diameter, hermetically sealed. Economy of fuel and in the time requisite in attendance, are the chief merits of the hot water systems, which, however, have the great additional advantage of affording a more moist and genial temperature.

In a green-house, the flues, or hot water pipes, may be concealed under the stage. In conservatories they should by all means be placed out of sight also. To effect this, they are generally conducted into a narrow, hollow 



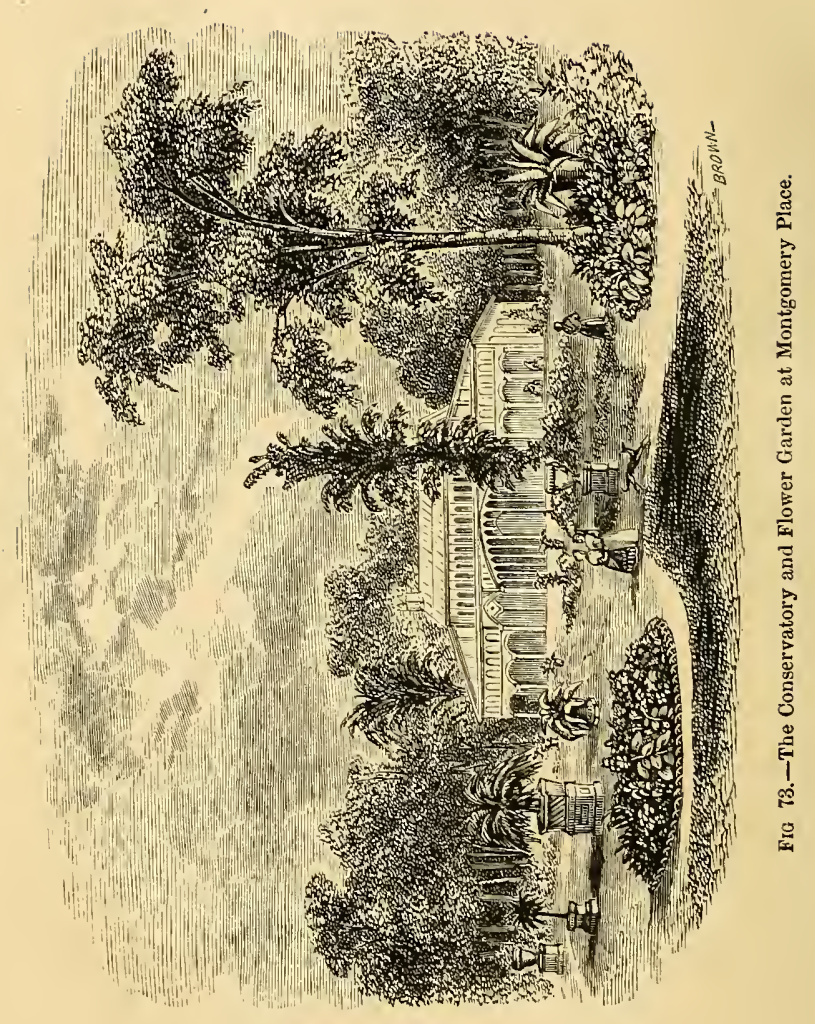


chamber, under the walk, which has perforated sides or a grated top, to permit the escape of heated air.*

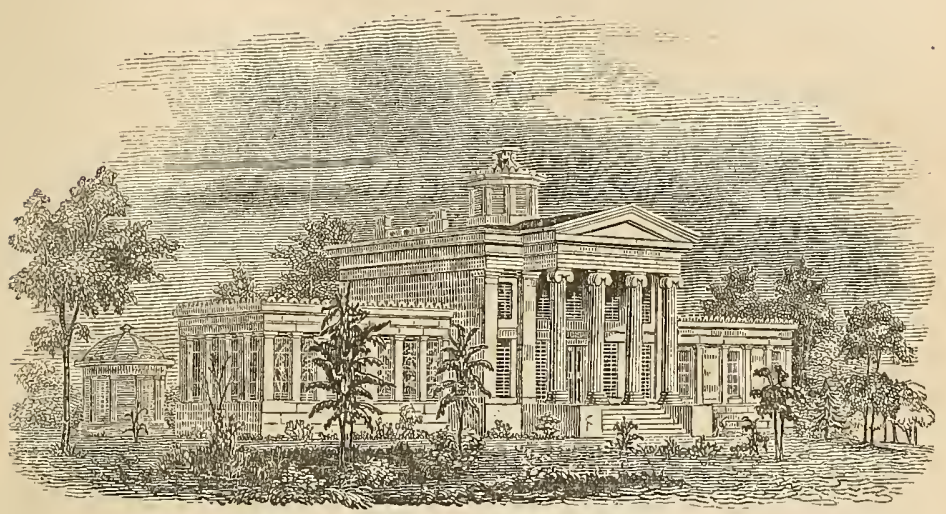

[Fig. 74, Villa at Brooklyn, N. Y., with the Conservatory attached.]

One of the most beautiful conservatories attached to the dwelling, to which we can refer our readers, for an example, is one built by J. W. Perry, Esq., Brooklyn, near New York (Fig. 74), forming the left wing of this elegant villa. Among the most magnificent detached conservatories are those of J. P. Cushing, Esq., at his elegant seat, Belmont Place, Watertown, near Boston; and that at Montgomery Place, the seat of Mrs. Edward Livingston, on the Hudson, Fig. 73.

A conservatory is frequently made an addition to a rectangular Grecian villa, as one of its wings-the other being a living or bed-room. The more varied and irregular outline of Gothic buildings enables them to receive an appendage of this nature with more facility in almost any direction, where the aspect is suitable.

* The circulation of warm air is greatly accelerated when an opening through the outer air is permitted to enter the hot air passage, thus becoming heated and passing inlo the conservatory. 
Whatever be the style of the architecture of the house, that of the conservatory should in every case conform to it, and evince a degree of emrichment according with that of the main building.

Though a conservatory is often made an expensive luxury, attached only to the better class of residences, there is no reason why cottages of more humble character should not have the same source of enjoyment on a more moderate scale. A small green-house, or plant cabinet, as it is sometimes called, eight or ten feet square, communicating with the parior, and constructed in a simple style, may be erected and kept up in such a manner, as to be a source of much pleasure, for a comparatively trifling sum; and we hope soon to see in this country, where the comforts of life are more equally distributed than in any other, the taste for enjoyments of this kind extending itself with the means for realizing them, into every portion of the northern and middle States.

Open and covered seats, of various descriptions, are among the most convenient and useful decorations for the pleasure-grounds of a country residence. Situated in portions of the lawn or park, somewhat distant from the house, they offer an agreeable place for rest or repose. If there are certain points from which are obtained agreeable prospects or extensive views of the surrounding country, a seat, by designating those points, and by affording us a convenient mode of enjoying them, has a double recommendation to our minds.

Open and covered seats are of two distinct kinds; one architectural, or formed after artist-like designs, of stone or wood, in Grecian, Gothic, or other forms; which may, if they are intended to produce an elegant effect, have 
vases on pedestals as accompaniments; the other, rustic, as they are called, which are formed out of trunks and branches of trees, roots, etc., in their natural forms.

There are particular sites where each of these kinds of seats, or structures, is, in good taste, alone admissible. In the proximity of elegant and decorated buildings where all around has a polished air, it would evidently be doing violence to our feelings and sense of propriety to admit many rustic seats and structures of any kind; but architectural decorations and architectural seats are there correctly introduced. For the same reason, also, as we have already suggested, that the sculptured forms of vases, etc., would be out of keeping in scenes where nature is predominant (as the distant wooded parts or walks of a residence), architectural, or, in other words, highly artificial seats, would not be in character: but rustic seats and structures, which, from the nature of the materials employed and the simple manner of their construction, appear but one remove from natural forms, are felt at once to be in unison with the surrounding objects. Again, the mural and highly artistical vase and statue, most properly accompany the beautiful landscape garden; while rustic baskets, or vases, are the most fitting decorations of the Picturesque Landscape Garden.

The simplest variety of covered architectural seat is the latticed arbor for vines of various descriptions, with the seat underneath the canopy of foliage; this may with more propriety be introduced in various parts of the grounds than any other of its class, as the luxuriance and natural gracefulness of the foliage which covers the arbor, in a great measure destroys or overpowers the expression of its original form. Lattice arbors, however, neatly 
formed of rough poles and posts, are much more pictu. resque and suitable for wilder portions of the scenery.

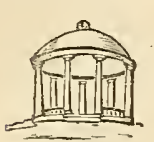

The temple and the pavilion are highly finished forms of covered seats, which are occasionally introduced in splendid places, [Fig. 75.7 where classic architecture prevails. There is a circular pavilion of this kind at the termination of one of the walks at Mr. Langdon's residence, Hyde Park. Fig. 75 .

We consider rustic seats and structures as likely to be much preferred in the villa and cottage residences of the country. They have the merit of being tasteful and picturesque in their appearance, and are easily constructed by the amateur, at comparatively little or no expense.

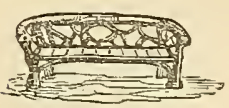

[Fig. 76.]

There is scarcely a prettier or more pleasant object for the termination of a long walk in the pleasure-grounds or park, than a neatly thatched structure of rustic work, with its seat for repose, and a view of the landscape beyond. On finding such an object, we are never tempted to think that there has been a lavish expenditure to serve a trifling purpose, but are gratified to see the exercise of taste and ingenuity, which completely answers the end in view.

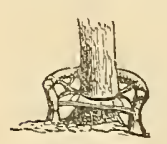

Figure 76 is an example of a simple rustic seat formed of the crooked and curved branches of the oak, elm, or any other of our forest trees

[Fig. 7i.] Fig. 77 is a seat of the same character, made at the foot of a tree, whose overhanging branches afford a fine shade.

Figure 78 is a covered seat or rustic arbor, with a thatched roof of straw. Twelve posts are set securely in the ground, which make the frame of this structure, the 


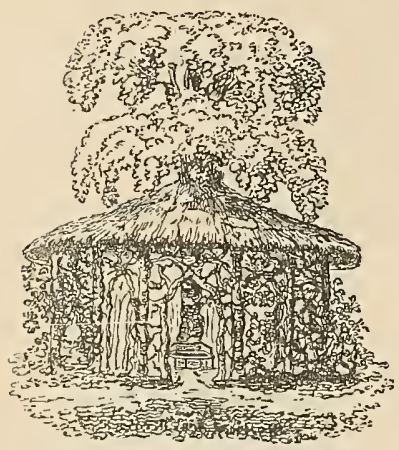

[Fig. 78.]

openings between being filled in with branclies (about three inches in diameter) of different trees-the more irregular the better, so that the perpendicular surface of the exterior and interior is kept nearly equal. In lieu of thatch, the roof may be first tightly boarded, and then a covering of bark or the slabs of trees with the bark on, overlaid and nailed on. The figure represents the structure as formed round a tree. For the sake of variety this might be omitted, the roof formed of an open lattice work of branches like the sides, and the whole covered by a grape, bignonia, or some other vine or creeper of luxuriant growth. The seats are in the interior.

Figure 79 represents a covered seat of another kind.

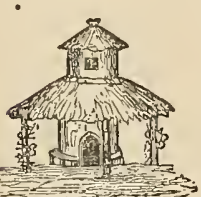

[Fig. 79.]

The central structure, which is circular, is intended for a collection of minerals, shells, or any other curious objects for which an amateur might have a penchant. Geological or mineralogical specimens of the adjacent neighborhood, would be very proper for such a cabinet. The seat surrounds it on the outside, over which is a thatched roof or veranda, supported on rustic pillars formed of the trunks of saplings, with the bark attached. 
Many of the English country places abound with admirable specimens of rustic work in their parks and pleasure-grounds. White Knight's, in particular, a residence of the Duke of Marlborough, has a number of beautiful structures of this kind. Figure 80 is a view of a

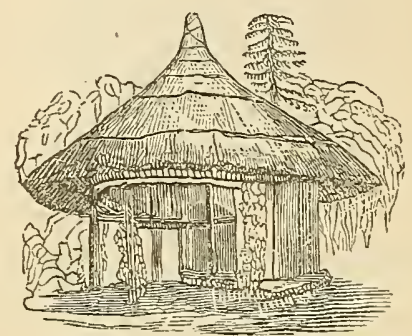

[Fig. 80. Rustic Covered Seat.]

round seat with thatched roof, in that demesne. Three or four rustic pillars support the architrave, and the whole of the exterior and interior (being first formed of frame. work) is covered with straight branches of the maple and larch. The seat on the interior looks upon a fine prospect; and the seat on the back of the exterior fronts the park.

There is no limit to the variety of forms and patterns in which these rustic seats, arbors, summer-houses, etc., can be constructed by an artist of some fancy and ingenuity. After the frame-work of the structure is formed of posts and rough boards, if small straight rods about an inch in diameter, of hazel, white birch, maple, etc., are selected in sufficient quantity, they may be nailed on in squares, diamonds, medallions, $x$ r other patterns, and have the effect of a mosaic of wood.

Among the curious results of this fancy for rustic work, we may mention the moss-house-erected in several placea 
abroad. The skeleton or frame-work of the arbor or house is formed as we have just stated; over this small rods half an inch in diameter are nailed, about an inch from centre to centre; after the whole surface is covered with this sort of rustic lathing, a quantity of the softer wood-moss of different colors is collected; and taking small parcels in the hand at a time, the tops being evenly arranged, the bottoms or roots are crowded closely between the rods with a small wooden wedge. When this is done with some little skill, the tufted ends spread out and cover the rods entirely, showing a smooth surface of mosses of different colors, which has an effect not uniike that of a thick Brussels carpet.

The mosses retain their color for a great length of time, and when properly rammed in with the wedge, they cannot be pulled out again without breaking their tops. The prettiest example which we have seen of a handsome moss-house in this country, is at the residence of Wm. $\mathbf{H}$. Aspinwall, Esq., on Staten Island.

A prospect tower is a most desirable and pleasant structure in certain residences. Where the view is comparatively limited from the grounds, on account of their surface being level, or nearly so, it often happens that the spectator, by being raised some twenty-five or thirty feet above the surface, finds himself in a totally different position, whence a charming coup d'œil or bird's-eye view of the surrounding country is obtained.

Those of our readers who may have visited the delightful garden and grounds of M. Parmentier, near Brooklyn, some half a dozen years since, during the lifetime of that amiable and zealous amateur.of horticulture, will readily remember the rustic prospect-arbor, or tower 


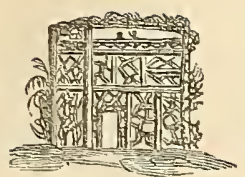

[Fig. S1.]

Fig. 81, which was situated at the extremity of his place. It was one of the first pieces of rustic work of any size, and displaying any ingenuity, that we remember to have seen here; and from its summit, though the garden walks afforded no prospect a beautiful reach of the neighborhood for many miles was enjoyed.

Figure S2 is a design for a rustic prospect tower of three

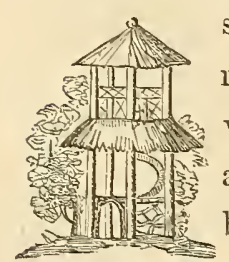

[Fig. 82.] stories in height, with a double thatched roof. It is formed of rustic pillars or columns, which are well fixed in the ground, and which are filled in with a fanciful lattice of rustic branches. A spiral staircase winds round the interior of the platform of the second and upper stories, where there are seats under the open thatched roof.

On a ferme ornée, where the proprietor desires to give a picturesque appearance to the different appendages of the place, rustic work offers an easy and convenient method of attaining this end. The dairy is sometimes made a detached building, and in this country it may be built of logs in a tasteful manner with a thatched roof; the interion being studded, lathed, and plastered in the usual way. Or the ice-house, which generally shows but a rough gable and ridge roof rising out of the ground, might be covered with a neat structure in rustic work, overgrown with vines, which would give it a pleasing or picturesque air, instead of leaving it, as at present, an unsightly object which we are anxious to conceal.

A species of useful decoration, which is perhaps more naturally suggested than any other, is the bridge. Where 
a constant strearn, of greater or less size, runs through the grounds, and divides the banks on opposite sides, a bridge of some description, if it is only a narrow plank over a rivulet, is highly necessary. In pieces of artificial water that are irregular in outline, a narrow strait is often parposely made, with the view of introducing a bridge for eflect.

When the stream is large and bold, a handsome architectural bridge of stone or timber is by far the most suitable ; especially if the stream is near the house, or if it is crossed on the Approach road to the mansion; because a character of permanence and solidity is requisite in such cases. But when it is only a winding rivulet or crystal brook, which meanders along beneath the shadow of tufts of clustering foliage of the pleasure-ground or park, a rustic bridge may

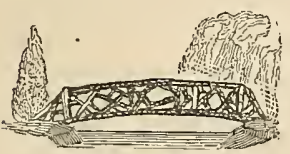

[Fig. ₹3.] be brought in with the happiest effect. Fig. 83 is a rustic bridge erected under our direction. The foundation is made by laying down a few large square stones beneath the surface on both sides of the stream to be spanned; upon these are stretched two round posts or sleepers with the bark on, about eight or ten inches in diameter. The rustic hand-rail is framed into these two sleepers. The floor of the bridge is made by laying down small posts of equal size, about four or six inches in diameter, crosswise upon the sleepers, and nailing them down securely. The bark is allowed to remain on in every piece of wood employed in the construction of this little bridge; and when the wood is cut at the proper season (durable kinds being chosen), such a bridge, well made will remain in excellent order for many years.

Rockwork is another kind of decoration sometimes intro. 
duced in particular portions of the scenery of a residence Fig. St. When well executed, that is, so as to have a natural and harmonious expression, the effect is highly pleasing. We have seen, however, in places where a high

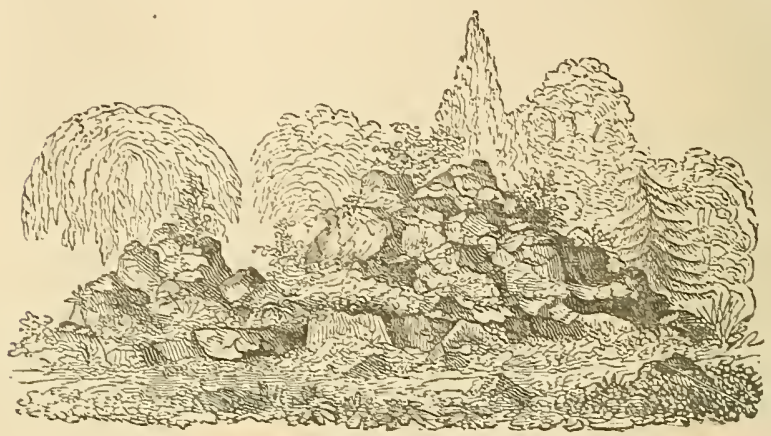

[Fig. St, Rockwork.]

keeping and good taste otherwise prerailed, such a barbarous mélange, or confused pile of stones mingled with soil, and planted over with dwarfish plants dignified with the name of rockwork, that we have been led to believe that it is much better to attempt nothing of the kind, unless there is a suitable place for its display, and at the same time, tha person attempting it is sufficiently an artist, imbued with the spirit of nature in her various compositions and combinations, to be able to produce something higher than a caricature of her works.

'The object of rockwork is to produce in scenery or" por. tions of a scene, naturally in a great measure destitute of groups of rocks and their accompanying drapery of plants and foliage, something of the picturesque effect which such natural assemblages confer. To succeed in this, it is evident that we must not heap up little hillocks of mould 
and smooth stones, in the midst of an open lawn, or the centre of a flower-garden. But if we can make choice of a situation where a rocky bank or knoll already partially exists, or would be in keeping with the form of the ground and the character of the scene, then we may introduce such accompaniments with the best possible hope of success.

It often happens in a place of considerable extent, that somewhere in conducting the walks through the grounds, we meet with a ridge with a small rocky face, or perhaps with a large rugged single rock, or a bank where rocky summits just protrude themselves through the surface. The common feeling against such uncouth objects, would direct them to be cleared away at once out of sight. But let us take the case of the large rugged rock, and commence our picturesque operations upon it. We will begin by collect. ing from some rocky hill or valley in the neighborhood of the estate, a sufficient quantity of rugged rocks, in size from a few pounds to half a ton or more, if necessary, preferring always such as are already coated with mosses and lichens. These we will assemble around the base of a large rock, in an irregular somewhat pyramidal group, bedding them sometimes partially, sometimes almost entirely in soil heaped in irregular piles around the rock. The rocks must be arranged in a natural manner, avoiding all regularity and appearance of formal art, but placing them sometimes in groups of half a dozen together, overhanging each other, and sometimes half bedded in the soil, and a little distance apart. There are no rules to be given for such operations, but the study of natural groups, of a character similar to that which we wish to produce, will afford sufficient hints if the artist is 
"Prodigue de génie,"

and has a perception of the natural beauty which he desires to imitate.

The rockwork once formed, choice trailing, creeping, and alpine plants, such as delight naturally in similar situations, niay be planted in the soil which fills the interstices between the rocks: when these grow to fill their proper places, partly concealing and adorning the rocks with their neat green foliage and pretty blossoms, the effect of the whole, if properly done, will be like some exquisite portion of a rocky bank in wild scenery, and will be found to give an air at once striking and picturesque to the little scene where it is situated.

In small places where the grounds are extremely limited, and the owner wishes to form a rockwork for the growth of alpine and other similar plants, if there are no natural indications of a rocky surface, a rockwork may sometimes be introduced without violating good taste by preparing natural indications artificially, if we may use such a term. If a few of the rocks to be employed in the rockwork are sunk half or three-fourths their depth in the soil near the site of the proposed rockwork, so as to have the appearance of a rocky ridge just cropping out, as the geologists say, then the rockwork will, to the eye of a spectator, seem to be connected with, and growing out of this rocky spur or ridge below: or, in other words, there will be an obvious reason for its being situated there, instead of its presenting a wholly artificial appearance.

In a previous page, when treating of the banks of pieces of water formed by art, we endeavored to show how the natural appearance of such banks would be improved by the judicious introduction of rocks partially imbedded into 
and holding them up. Such situations, in the case of a small lake or pond, or a brook, are admirable sites for rockwork. Where the materials of a suitable kind are abundant, and tasteful ingenuity is not wanting, surprising cffects may be produced in a small space. Caves and grottoes, where ferus and mosses would thrive admirably with the gentle drip from the roof, might be made of the overarching rocks arranged so as to appear like small natural caverns. Let the exterior be partially planted with low shrubs and climbing plants, as the wild Clematis, and the effect of such bits of landscape could not but be agreeable in secluded portions of the grounds.

- In many parts of the country, the secondary blue limestone abounds, which, in the small masses found loose in the woods, covered with mosses and ferns, afords the very finest material for artificial rockwork.*

After all, much the safest way is never to introduce rockwork of any description, unless we feel certain that it will have a good effect. When a place is naturally picturesque, and abounds here and there with rocky banks, etc., little should be done but to heighten and aid the expressions of these, if they are wanting in spirit, by adding something more; or softening and giving elegance to the expression, if too wild, by planting the same with

* Our readers may see an engraving and description of a superb extravaganza in rockwork in a late number of Loudon's Gardener's Magazine. Lady Broughton, of Hoole House, Chester, England, has succeeded in forming, round a natural valley, an imitation of the hills, glaciers, and scenery of a passage in Switzerland. The whole is done in rockwork, the snow-covered summits being represented in white spar. The appropriate plants, trees, and shrubs on a small scale, are introduced, and the illusion, to a spectator standing in the valley surrounded by these glaciers, is said to bo wonderfully strilking and complete. 
beautiful shrubs and climbers. On a tame sandy level, where rocks of any kind are unknown, their introduction in rockworks, nine times in ten, is more likely to give rise to emotions of the ridiculous, than those of the sublime or picturesque.

Fountains are highly elegant garden decorations, rarely seen in this country; which is owing, not so much, we apprehend, to any great cost incurred in putting them up, or any want of appreciation of their sparkling and enlivening effect in garden scenery, as to the fact that there are few artisans here, as abroad, whose business it is to construct and fit up architectural, and other jets d'eau.

The first requisite, where a fountain is a desideratum, is a constant supply of water, either from a natural source or an artificial reservoir, some distance higher than the level of the surface whence the jet or fountain is to rise.

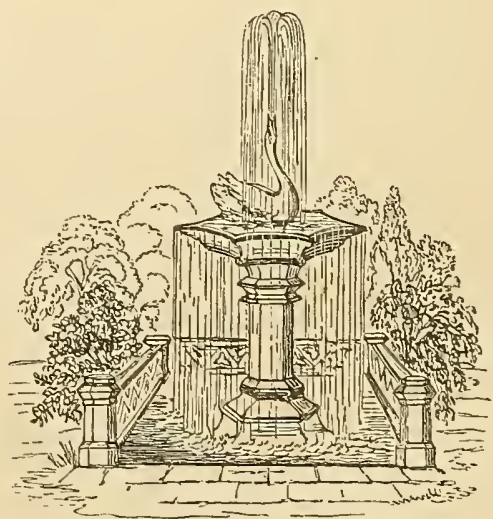

[Fig. 85. Design for a Fountain.]

Where there is a pond, or other body of water, on a higher level than the proposed fountain, it is only necessary to lay pipes under the surface to conduct the supply of water to 
the required spot; but where there is no such head of water, the latter must be provided from a reservoir artificially prepared, and kept constantly full.

There are two very simple and cheap modes of effecting this, which we shall lay before our readers, and one or the other of which may be adopted in almost every locality. The first is to provide a large flat cistern of sufficient size. which is to be placed under the roof in the uppur story of one of the outbuildings, the carriage-house for example, and receive its supplies from the water collected on the roof of the building; the amount of water collected in this way from a roof of moderate size being much more than is generally supposed. The second is to sink a well of capacious size (where such is not already at command) in some part of the grounds where it will not be conspicuous, and over it to erect a small tower, the top of which shall contain a cistern and a small horizontal windmill ; which being kept in motion by the wind more or less almost every day in summer, will raise a sufficient quantity of water to keep the reservoir supplied from the well below. In either of these cases, it is only necessary to carry leaden pipes from the cistern (under the surface, below the reach of frost) to the place where the jet is to issue; the supply in both these cases will, if properly arranged, be more than enough for the consumption of the fountain,during the hours when it will be necessary for it to play, viz. from sunrise to evening.

The steam-engine is often employed to force up water for the supply of fountains in many of the large public and royal gardens; but there are few cases in this country where private expenditures of this kind would be justifiable. But where a small stream, or even the overflow of a 
perpetual spring, can be commanded, the Hydraulic Ram is the most perfect as well as the simplest and cheapest of all modes of raising water. A supply pipe of an inch in diameter is in many cases sufficient to work the Ram and force water to a great distance; and where sufficien to fill a "driving pipe" of two inches diameter can be commanded, a large reservoir may be kept constantly" filled. As the Hydraulic Ram is now for sale in all our cities we need not explain its action.

"In conducting the water from the cistern or reservor to the jet or fountain, the following particulars requre to be attended to: In the first place, all the pipes must be laid sufficiently deep in the earth, or otherwise placed and protected so as to prevent the possibility of their being reached by frost; next, as a general rule, the diameter of the orifice from which the jet of water proceeds, technically called the bore of the quill, ought to be four times less than the bore of the conduit pipe; that is, the quill and the pipe ought to be in a quadruple proportion to each other. There are several sorts of quills or spouts, which throw the water up or down, into a rariety of forms: such as fans, parasols, sheaves, showers, mushrooms, inverted bells, etc. The larger the conduit pipes are, the more freely will the jets display their different forms; and the ferrer the holes in the quill or jet (for sometimes this is pierced like the rose of a watering-pot) the greater certainty there will be of the form continuing the same; because the risk of any of the holes choking up will be less. The diameter of a conduit pipe ought, in no case, to be less than one inch; but for jets of rery large size, the diameter ought to be two inches. Where the conduit pipes are of great length, say upwards of 1000 feet, it is 
found advantageous to begin, at the reservoir or cistern, with pipes of a diameter somewhat greater than those which deliver the water to the quills, because the water, in a pipe of uniform diameter of so great a length, is found (1) lose much of its strength, and become what is technically called sleepy: while the different sizes quicken it, and redouble its force. For example, in a conduit pipe of 1800 feet in length, the first six hundred feet may be laid with pipes of eight inches in diameter, the next 600 feet with pipes of six inches in diameter, and the last 600 feet with pipes of four inches in diameter. In conduits not exceeding 900 feet, the same diameter may be continued throughout. When several jets are to play in severat fountains, or in the same, it is not necessary to lay a fresh pipe from each jet to the reservoir; a main of sufficient size, with branch pipes to each jet, being all that is required. Where the conduit pipe enters the reservoir or cistern, it ought to be of increased diameter, and the grating placed over it to keep out leaves and other matters which might choke it up, ought to be semi-globular or conical; so that the area of the number of holes in it may exceed the area of the orifice of the conduit pipe. The object is to frevent any diminution of pressure from the body of water in the cistern, and to facilitate the flow of the water. Where the conduit pipe joins the fountain, there, of course, ought to be a cock for turning the water off and on; and particular care must be taken that as much water may pass through the oval hole of this cock as passes through the circular hole of the pipe. In conduit pipes, al elbows, bendings, and right angles should be avoided as much as possible, since they diminish the force of the water. In very long conduit pipes, air-holes formed by 
soldering on upright pieces of pipe, terminating in inverted valves or suckers, should be made at convenient distances, and protected by shafts built of stone or brick, and corered with movable gratings, in order to let out the air. IVhere pipes ascend and descend on rery irregular surfaces, the strain on the lowest parts of the pipe is always the greatest; unless care is taken to relieve this by the judicious disposition of cocks and air-holes. Without this precaution, pipes conducted orer irregular surfaces will not last nearly so long as those conducted over a level." Encycl. of Cottage, Farm, and Villa Architecture, page 989.

Where the reservoir is but a short distance, as from a dozen to fifty yards, all that is necessary is to lay the conduit pipes on a regular uniform slope, to secure a steady uninterrupted flow of water. Owing to the friction in the pipes, and pressure of the atmosphere, the water in the fountain will of course, in no case, rise quite as high as the level of the water in the reserroir; but it will rise nearly as high. For example, if the reserroir is ten feet four inches high, the water in the jet will only rise ten feet, and in like proportion for the different heights. The following table*

\begin{tabular}{|c|c|c|c|c|c|c|c|}
\hline \multicolumn{2}{|c|}{$\begin{array}{l}\text { Height of the } \\
\text { Reservoir. }\end{array}$} & \multicolumn{2}{|c|}{$\begin{array}{l}\text { Disuneter of the } \\
\text { Conduit pipes. }\end{array}$} & \multicolumn{2}{|c|}{$\begin{array}{l}\text { Diameters of the } \\
\text { Orifices. }\end{array}$} & \multicolumn{2}{|c|}{$\begin{array}{l}\text { Height the water } \\
\text { will rise to. }\end{array}$} \\
\hline Feet. & Inches. & Inches. & Lines. & Lines. & Parts. & Feet. & Incies \\
\hline 5 & 1 & 0 & 22 & 4 & 0 & 5 & 0 \\
\hline 10 & 4 & 0 & 25 & 5 & 0 & 10 & 0 \\
\hline 15 & 9 & $\approx \frac{1}{4}$ & 0 & 6 & 0 & $1 \overline{5}$ & 0 \\
\hline$? 1$ & 4 & $2 \frac{1}{2}$ & 0 & $6 \frac{1}{2}$ & 0 & 20 & 0 \\
\hline 33 & 0 & 3 & 0 & $i$ & 0 & 30 & 0 \\
\hline 45 & 4 & $4_{2}^{1}$ & 0 & $\tau$ & 8 & 40 & 0 \\
\hline 58 & 4 & 5 & 0 & 8 & 10 & 50 & 0 \\
\hline 72 & () & $5 \frac{1}{2}$ & 0 & 10 & 12 & 60 & 0 \\
\hline 36 & 4 & 6 & 0 & 12 & 14 & 70 & 0 \\
\hline 100 & 0 & $\tau$ & 0 & 12 & 15 & 80 & 0 \\
\hline
\end{tabular}

* Switzer's Introduction to a Gencral Sisten of Hydrostatics. 
shorvs with a given height of reservoirs and diameter of conduit pipes and orifices, the height to which the water will rise in the fountain.

A simple jet (Fig. 86) issuing from a circular basin of water, or a cluster of perpendicular jets (candelabra jets), is at once the simplest and most pleasing of fountains. Such are almost the only kinds of fountains which can be introduced with propriety in simple scenes where the pre[Fig. s6.] dominant objects are sylvan, not architectural.

Weeping, or Tazza Fountains, as they are called, are simple and highly pleasing objects, which require only a

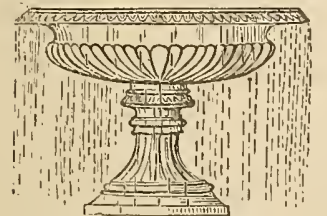

[Fjg. si. Tazza Fountain.] very moderate supply of water compared with that demanded by a constant and powerful jet. The conduit pipe rises through and fills the vase, which is so formed as to overflow round its entire margin. Figure 87 represents a beautiful Grecian vase for tazza fountains. The ordinary jet and the tazza fountain may be combined in one, when the supply of water is sufficient, by carrying the conduit pipe to the level of the top of the vase, from which the water rises perpendicularly, then falls back into the vase and overflows as before.

We might enumerate and figure a great many other designs for fountains; but the connoisseur will receive more ample information on this head than we are akle to afford, from the numerous French works devoted to this branch of Rural Embellishment.

A species of rustic fountain which has a good effect, is made by introducing the conduit pipe or pipes among the groups of rockivork alluded to, from whence (the orifice of 
the pipe being concealed or disguised) the water issues among the rocks, either in the form of a cascade, a weeping fountair, or a perpendicular jet. A little basin of water is formed at the foot or in the niidst of the rockwork; and the cool, moist atmosphere afforded by the trickling streams, would offer a most congenial site for aquatic plants, ferns, and mosses.

Fountains of a highly artificial character are happily situated only when they are placed in the neighborhood of buildings and architectural forms. When only a single fountain can be maintained in a residence, the centre of the flower-garden, or the neighborhood of the piazza or terrace-walk, is, we think, much the most appropriate situation for it. There the liquid element, dancing and sparkling in the sunshine, is an agreeable feature in the scene, as viewed from the windows of the rooms; and the falling watery spray diffusing coolness around is no less delightful in the surrounding stillness of a summer evening.

After all that we have said respecting architectural and rustic decorations of the grounds, we must admit that it requires a great deal of good taste and judgment, to introduce and distribute them so as to be in good keeping with the scenery of country residences. A country residence, where the house, with a few tasteful groups of nowers and shrubs, and a pretty lawn, with clusters and groups of luxuriant trees, are all in high keeping and evincing nice order, is far more beautiful and pleasing than the same place, or even one of much larger extent, where a profusion of statues, vases, and fountains, or rockwork and rustic seats, are distributed throughout the garden and grounds, while the latter, in themselves, show 
slovenly keeping, and a crude and meagre knowledge of design in Landscape Gardening.

Unity of expression is the maxim and guide in this department of the art, as in every other. Decorations can never be introduced with good effect, when they are at variance with the character of surrounding objects. A beautiful and highly architectural villa may, with the greatest propriety, receive the decorative accompaniments of elegant vases, sundials, or statues, should the proprictor choose to display his wealth and taste in this manner; but these decorations would be totally misapplied in the case of a plain square edifice, evincing no architectural style in itself.

In addition to this, there is great danger that a mere lover of fine vases may run into the error of assembling these objects indiscriminately in different parts of his grounds, where they have really no place, but interfere with the quiet character of surrounding nature. He may overload the grounds with an unmeaning distribution of sculpturesque or artificial forms, instead of working up those parts where art predominates in such a manner, by means of appropriate decorations, as to heighten by contrast the beauty of the whole adjacent landscape.

With regard to pavilions, summer-houses, rustic seats, and garden edifices of like character, they should, if possible, in all cases be introduced where they are manifestly appropriate or in harmony with the scene. Thus a grotto should not be formed in the side of an open bank, but in a deep shadowy recess; a classic temple or pavilion may crown a beautiful and prominent knoll, and a rustic covered seat may occupy a secluded, 
quiet portion of the grounds, where undisturbed meditation may be enjoyed. As our favorite Delille says:

“ Sachez ce qui convient ou nuit au caractère.

Unn réduit écarté, dans un lieu solitaire,

Peint mieux la solitude encore et l'abandon.

Montrez-vous donc fidèle à chaque expression;

N'allez pas au grand jour offrir un ermitage:

Ne cachez point un temple au fond d'un bois sauvage."

LES JARDINS.

Or if certain objects are unavoidably placed in situations of inimical expression, the artist should labor to alter the character of the locality. How much this can be done by the proper choice of trees and shrubs, and the proper arrangement of plantations, those who have seen the difference in aspect of certain favorite localities of wild nature, as covered with wood, or as denuded by the axe, can well judge. And we hope the amateur, who has made himself familiar with the habits and peculiar expressions of different trees, as pointed out in this work, will not find himself at a loss to effect such changes, by the aid of time, with ease and facility. 


\title{
A P PENDIX.
}

\section{I.}

\begin{abstract}
Notes on transplanting trees. Reasons for frequent failures in removing large trees, Directions for performing this operation. Selection of subjects. Preparing trees for removal Transplanting evergreens.
\end{abstract}

There is no subject on which the professional horticulturist is more frequently consulted in America, than transplanting trees. And, as it is an essential branch of Landscape Gardening-indeed, perhaps, the most important and necessary one to be practically understood in the improvement or embellishment of new country residences-we shall offer a few remarks here, with the hope of rendering it a more easy and successful practice in the hands of amateurs.

The first and most important consideration in transplanting should be the preseriation of the roots. By this we do not mean a certain bulk of the larger and more important ones only, but as far as possible all the numerous small fibres and rootlets so indispensably necessary in assisting the tree to recover from the shock of removal. The coarser and larger roots serve to secure the tree in its position, and convey the fluids; but it is by means of the small fibrous roots, or the delicate and numerous points of these fibres called spongioles, that the food of plants is imbibed, and the destruction of such is manifestly in the highest degree fatal to the success of the transplanted tree. To avoid this as far as practicable, we should, in removing a tree, commence at such a distance as to include a circumference large enough to comprise the great majority of the roots. At that distance from the trunk we shall find most of the smaller roots, which should be carefully loosened 
from the soil, with as little injury as possible; the earth should be gently and gradually removed from the larger roots, as we proceed onward from the extremity of the circle to the centre, and when we reach the nucleus of roots surrounding the trunk, and fairly undermine the whole, we shall find ourselres in possession of a tree in such a perfect condition, that even when of considerable size, we may confidently hope for a speedy recovery of its former luxuriance after being replanted.

Now to remove a tree in this manner, requires not only a consideraole degree of experience, which is only to be acquired by practice, but also much patience and perseverance while engaged in the work. It is not a difficult task to remove, in a careless manner, four or five trees in a day, of fifteen feet in height, by the assistance of three or four men, and proper implements of removal, while one or two trees only can be removed if the roots and branches are preserved entire or nearly so. Yet in the latter case, if the work be well performed, we shall have the satisfaction of beholding the subjects, when removed, soon taking fresh root, and becoming vigorous healtliy trees, with fine luxuriant heads, while three-fourths of the former will most probably perish, and the remainder struggle for several years, under the loss of so large a portion of their roots and branches, before they entirely recover, and put on the appearance of handsome trees.

When a tree is carelessly transplanted, and the roots much mutilated, the operator feels obliged to reduce the top accordingly; as experience teaches him, that although the leares may expand, yet they will soon perish without a fresh supply of food from the roots. But when the largest portion of the roots are carefully taken up with the tree pruning should be less resorted to, and thus the original symmetry and beauty of the head retained. When this is the case, the leaves contribute as much, by their peculiar action in elaborating the sap, towards re-establishing the tree, as the roots; and indeed the two act so reciprocally with each other, that any considerable injury to the one always affects the other. "The functions of respiration, perspiration, and digestion," says Professor Lindley, "which are the particular offices of leaves, are essential to the health of a plant; its healthiness being in proportion to the degree in which these functions are duly 
performed. The leaf is in reality a natural contrivance for exposing a large surface to the influence of external agents, by whose assistance the crude sap contained in the stem is altered, and rendered suitable to the particular wants of the species, and for returning into the general circulation, the fluids in their matured condition. In a word, the leaf of a plant is its lungs and stomach traversed by a system of veins."** All the pruning, therefore, that is necessary, when a tree is properly transplanted, will be comprised in paring smooth all bruises or accidental injuries, received by the roots or branches during the operation, or the removal of a few that may interfere with elegance of form in the head.

Next in importance to the requisite care in performing the operation of transplanting, is the proper choice of individual trees to be transplanted. In making selections for removal among our fine forest trees, it should never be forgotten that there are two distinct kinds of subjects, even of the same species of every tree, viz. those that grow among and surrounded by other trees or woods, and those which grow alone, in free open exposures, where they are acted upon by the winds, storms, and sunshine, at all times and seasons. The former class it will always be exceedingly difficult to transplant successfully even with the grreatest care, while the latter may always be removed with compariltively little risk of failure.

Any one who is at all familiar with the growth of trees in woods or groves somewhat dense, is also aware of the great difference in the external appearance between such trees and those which stand singly in open spaces. In thick woods, trees are found to have tall, slender trunks, with comparatively few branches except at the top, smooth and thin bark, and they are scantily provided with roots, but especially with the small fibres so essentially necessary to insure the growth of the tree when transplanted. Those, on the other hand, which stand isolated, have short thick stems, numerous branches, thick bark, and great abundance of root and smali fibres. The latter, accustomed to the full infiuence of the weather, to cold winds as well as open sunshine have what Sir Henry Steuart has aptly denominated the "protecting properties," well developed; being robust and hardy, they are well cal.

* Theory of Horticulture. 
sulated to endure the violence of the removal, while trees growing in the midst of a wood sheltered from the tempests by their fellows, and scarcely ever receiving the sun and air freely except at their topmost branches, are too feeble to withstand the change of situation, when remored to an open lawn, eren when they are carefully transplanted.

"Of trees in open exposures," says Sir Henry, "we find that their peciliar properties'contribute, in a remarkable manner, to their health and prosperity. In the first plice, their shortness and greater girth of stem, in contradistinction to other's in the interior of roods, are obviously intended to give to the former greater strength to resist the winds, and a shorter lever to act upon the roots. Secondly, their larger heads, with spreading branches, in consequence of the free aicess of light, are as plainly formed for the nourishment as well as the balancing of so large a trunk, and also for furnishing a cover to shield it from the elements. Thirdly, their superior thickness and induration of bark is, in like manner, bestowed for the protection of the sap-vessels, that lie immediately under it, and which, without such defence from cold, could not perform their functions. Fourthly, their greater number and variety of roots are for the double purpose of nourishment and strength; nourishment to support a mass of such magnitude, and strength to contend with the fury of the blast. Such are the obvious purposes for which the unvarying characteristics of trees in open exposures are conferred upon them. Nor are they conferred equally and indiscriminately upon all trees so situated. They seem, by the economy of nature, to be peculiar adaptations to the cireumstances and wants of each indiridual, uniformly bestowed in the ratio of exposure, greater where that is moro conspicuous, and uniformly decreasing, as it becomes less."*

Trees in which the protecting properties are well developed are frequently to be met with on the skirts of woods; but those standing singly liere and there, through the cultirated fields and meadows of our farm lands, where the roots have extended themselves freely in the mellow soil, are the finest subjects for removal into the lawn, $\mathrm{p}: \mathrm{rk}$, or pleasure ground.

* The Planter's Guide, p. 105. 
The machine used in removing trees of moderate size is of simple construction, consisting of a pair of strong wheels about five feet ligh a stout axle, and a pole about twelve feet long. In transplanting, the wheels and axie are bronght close to the trunk of the tree, the pole is firmly lashed to the stem, and when the soil is sufficiently removed and loosened about the roots, the pole, with the tree attached, is drawn down to a horizontal position by the aid of men and a pair of horses When the tree is thus drawn out of the hole, it is well secured and properly balanced upon the machine, the horses are filstened in front of the mass of roots by gearings attached to the axle, and the whole is transported to the destined lncation.

In order more effectually to insure the growth of large specimens when transplanted, a mode of preparing beforehand a supply of young roots, is practised by skilful operators. This consists in removing the top soil, partially undermining the tree, and shortening back many of the roots; and afterwards replacing the former soil by rich inould, or soil well manured. This is suffered to remain at least one year, and often three or four years; the tree, stimulated by the fresh supply of food, throws out an abundance of small fibres, which render success, when the tirne for removal arrives, comparatively certain.

It may be well to remark here, that before large trees are transplanted into their final situations, the latter should be well prepared by trenching, or digging the soil two or three feet deep, intermingling throughout the whole a liberal portion of well decomposed manure, or rich compost. To those who are in the habit of planting trees of any size in unprepared grounds, or that merely prepared by digging ons spit deep, and turning in a little surfice manure, it is inconceivable how much more rapid is the growth, and how astonishingly luxuriant the appearance of trees when removed into ground properly prepared. It is not too much to affirm, that young trees under favorable circumstances -in soil sn prepared-will advance more rapidly, and attain a larger stature in eight years, than those planted in the ordinary way, withont deepening the soil, will in twenty-and trees of larger size in proportion; a gain of growth surely worth the trifling expense incurred in the first instance. And the same observation will apply to all plantr 
ing. A little extra labor and cost expended in preparing the soil will, for a long time, secure a surprising rapidity of growth.*

In the actual planting of the tree, the chief point lies in bringing every small fibre in cortact with the soil, so that no hollows or interstices are left, which may produce mouldiness and decay of the roots. To avoid this, the soil must be pulverized with the spade before filling in, and one of the workmen, with his hands and a flat dibble of wood, should fill up all cavities, and lay out the small roots before covering them in their natural position. When watering is thought advisable (and we practise it almost invariably), it should always be done while the planting is going forward. Poured in the hole when the roots are just covered with the soil, it serves to settle the loose earth compactly

* There expense is not so muteh an object as success, we cannot too deeply impress upon planters the necessity of making very deep, aud very wide holes, or pits, as they are called in England. These pits should be four to fire feet deep, and not less than ten to sixteen feet in diameter, and neither round nor square, but star-slinped, or cross-shaped, of such a form as would be produced by placing one equilateral triangle upon another, or two parallelograms across each other, so as to form a Greck cros3.
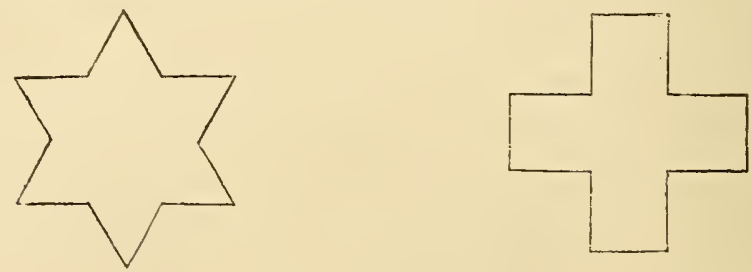

The object of departing from the square, or round form, is to introduce the growing fibres of the young trees into the firm and poor soil, by degrees, and not all at once, as in the round or square-hole manner.

When a tree is planted in the round or square pit, surrounded outside of it by poor, lard soil, it is very mueh in the same situation as if its roots wero confined in a tub or box.

The dove-tailing, so to speak, of the prepared soil, and of the moisture it will retain, with the hard, impenetrable soil by which it is surrounded, will gmdually prepare the latter for being penetrated by the roots of the trees, and prevent the sides of the pit from giving the same check to those roots, which the sicles of the pot or tub do to the plant contained in it. In the preparation of these holes, the lower spot, or hard-pan, shovld bo thrown out, and ten to irelve inehes of stone substituted, for the double purpose of drainage, and retention of moisture in dry weather.-H. W. S. 
around the various roots, and thus both furnishes a supply of moisture, and brings the pulverized mould in proper contact for growtl. Trees well watered when planted in this way, will rarely require it afterwards; and should they do so, the better way is to remove two or three inches of the top soil, and give the lower stratum a copious supply; when the water having been absorbed, the surface should agair: be replaced. There is no practice more mischievous to newly moved trees, than that of pouring.water, during hot weather, upon the surface of the ground above the roots. Acted upon by the sun and wind, this surface becomes baked, and but little water reaches the roots; or just sufficient, perhaps, to afford a momentary stimulus, to be followed by increased sensibility to the parching drought.

With respect to the proper seasons for transplanting, we may remark that, except in extreme northern latitude, autumn planting is generally preferred for large, hardy, deciduous trees. It may commence as soon as the leaves fall, and may be continued until winter. In planting large trees in spring, we should commence as early as possible, to give them the benefit of the April rains; if it should be deferred to a later period, the trees will be likely to sufier greatly by the hot summer sun beforo they are well established.

The transplanting of evergreens is generally considered so much more difficult than that of deciduous trees, and so many persons who have tolerable success in the latter, fail in the former, that we may perhape be expected to point out the reason of these frequant failures.

inost of cur horticultural maxims are derived from English authors ind among them, that of always planting evergreens either in August or late in autumn. At both these seasons, it is nearly impossible to succeed in the temperate portions of the United States, from the different character of our elimate at these seasons. The genial moisture of the English climate renders transplanting comparatively easy at all scasons, but especially in winter, while in this country, our Augusts are dry and hot, and our winters generally dry and cold. If planted in the latter part of summer, evergreens become parched in their foliage, and soon perish. If planted in autumn or early winter, the severe cold that ensues, to which the newly disturbed plant $i$ s peculiarly alive, paralyses vital action, ind the tree is so much enfeebled that, whon 
spring arrives, it survives but a short period. The only period, there fore, that remains for the successful removal of evergreens here, is the spring. When plinted as early as practicable in the spring, so as to have the full benefit of the abundant rains so beneficial to vegetation at that season, they will almost immediately protrude new shoots, and regain their former vigor.

Evergreens are, in their roots, much more delicate and impatient of dryness than deciduous trees; and this should be borne in mind while transplanting them. For this reason, experienced planters always choose a wet or misty day for their removal; and, in dry weather, we would always recommend the roots to be kept watered and covered from the air by mats during transportation. When proper regard is paid to this point, and to judicious selection of the season, evergreens will not be found more difficult of removal than other trees.

Another mode of transplanting large evergreens, which is very successfully practised among us, is that of removing them with frozen balls of earth in mid-winter. When skilfully performed, it is perhaps the most complete of all modes, and is so different from the common method, that the objection we have just made to winter planting does not apply to this case. The trees to be removed are selected, the situaLions chosen, and the holes dug, while the ground is yet open in autumn. When the ground is somewhat frozen, the operator proceeds to dig a trench around the tree at some distance, gradually undermining it, and leaving ail the principal mass of roots embodied in the ball of earth. The whole ball is then left to freeze pretty thoroughly (generally till snow covers the ground), when a large sled drawn by oxen is brought as near as possible, the ball of earth containing the tree rolled upon it, and the whole is easily transported to the hole previously prepared, where it is placed in the proper position, and as soon as the weather becomes mild, the earth is properly filled in around the ball. A tree, either evergreen or decidnous, may be transplanted in this way, so as scarcely to show, at the return of growth, any ill effects from its change of location. 
I.

Note on the treatment of Lawns:

As a lawn is the ground-work of a landscapye-garden, and as the management of a dressed grass surface is still a somerwhat ill-understood subject with us, some of our readers will, perhaps, be gıad to receive a very few hints on this subject.

The unrivalled beauty of the "velvet lawns" of England has passed into a proverb. This is undoubtedly owing, in some measure, to their superior care and keeping, but mainly to the highly favorable climate of that moist and sea-girt land. In a very diy climate it is nearly . impossible to preserve that emerald freshness in a grass surface, that belongs only to a country of "weeping skies." During all the present season, on the Hudson, where we write, the constant succession of showers has given us, even in the heat of midsummer, a softness and verdure of lawn that can scarcely be surpassed in any climate or country.

Our climate, however, is, in the middle states, one of too much heat and brilliancy of sun, to allow us to keep our lawns in the best condition without considerable care. Beautifully verdant in spring and autumn, they are often liable to suffer from drought in midsummer. On sandy soils, this is especially the case, while on strong loamy soils, a considerable drought will be endured without injury to the good appearance of the grass. It therefore is a suggestion worthy of the attention of the lover of a fine lawn, who is looking about for a country residence, to carefully avoid one where the soil is sandy. The only remedy in such a soil is a tedious and expensive one, that of constant and plentiful topdressing with a compost of manure and heavy soil-marsh mud-swamp muck, or the like. Should it fortunately be the case (which is very rare) that the sub-stratum is loamy, deep plougling, or trenching, by bringing up and mixing with the light surface soil some of the heavier earth from below, will speedily tend to remedy the evil.

In almost all cases where the soil is of good strength, a permanent. lavin may be secured by preparing the soil deeply before finally laying it down. This may ke dore readily, at but little outlay, by deep 
ploughing-ia good and cheop substitute for trenching-that is to say making the plough follow three times in the same furrow. This, with manure, if necessary, will secure a depth of soil sufficient to allow the roots of plants to strike below the effects of a surface drought.

In sowing a lawn, the best mixture of grasses that we can recuin. mend for this climate, is a mixture of Red-top and white Clover-two natural grasses found by almost every roadside-in the proportion of three fourths of the former, to one of the latter.

There is a common and very absurd notion current (which we have several times practically disproved), that, in order to lay down a lawn well, it is better to sow the seed along with that of some grain; thus, starving the growth of a small plant by foreing it to grow with a larger and coarser one. A whole year is always lost by this processindeed, more frequently two. Many trials have convineed us that the proper mode is to sow a heavy crop of grass at once, and we advise him who desires to have speedily a handsome turf, to follow the English practice, and sow three to four bushels of seed to the acre. If this is done early in the spring, he will have a lawn-like surface by mid-summer, and a fine close turf the next season.

After this, the whole beauty of a lawn depends on frequent mowing. Once a fortnight at the furthest, is the rule for all portions of the lawn in the neighborhood of the house, or near the principal walks. A longer growth than this will only leave yellow and coarser stubble after mowing, instead of a soft velvet surface. A broad-bladed English scythe (to be had at the shops of the seedsman), set nearly parallel to the surface, is the instrument for the purpose, and with it a clever mower will be able to shave within half an inch of the ground, without leaving any marks. To free the surface from worm casts, etc., it is a common practice to roll the previous evening as much as may be mown the next day.*

* A very great improvement and economy in the keeping of lawns now $-\Omega_{-}$days, is in the employment of the Lawn-cutter, by which one man, with a lorse-nachine, will accomplish, in two or threc hours, more than a dozen men ean in a whole day. The best English lawn-cutters will ent, roll, and gather the grass from one acre, in one hour, where it is good, close turf, and there are no trees to interfere with the action of the machine. 
As the neatness of a well kept lawn depends mainly upon the manner in which it is mown, and as this again can only be well done where there are no inequalities in the ground, it follows that the surface should be kept as smooth as possible. Before sowing a lawn, tor much pains cannot be taken to render its surface smooth and ever. After this, in the spring, before the grass starts, it should le examined, aid all little holes and irregularities filled up, and the same should be looked over at any annual top-dressing that may take place. The

When a lawn is in perfect condition, smooth, free from stones and inequalities, and is cut, as it ought to be, once a week, it is quite surprising how much gratification we derive from what used to be performed with great labor, and often with a very unsatisfactory result. There are very few places in the country where we can have complete lawns by the scythe, because, as the work must be performed early in the morning and late in the afternoon when the dew is on, it follows that a very large force, much larger than is usually kept even in our best places, must be required, to accomplish much in so short a time. In England, this is more easily done, becalse they turn on to the lawn at daylight, ten to thirty men, from all parts of the place, who separate after 8 , or 9, A. M., to their respective and regular duties-to the garden, to the farm, to the forest. We cannot afford to do this, and as our sun is much hotter, and our dew much less time in duration than in England, it follows, that any improvement, which will allow us to cut our lawns thronghont the heat of the day, is very desirable. This the mowing machine does, performing its work better when the dew is off, than on, and allowing us to mow, roll, and gather up, at the same time, and by the same means. All that remains subsequently to do, is to clip with scythe or sickle around the edges and verges, as well as near trees, or masses of shrubs, very close to which the machine should not be allowed to pass. We have found more satisfaction in the use of this machine, than in any other thing we have done since we lived in the country, and liave now got our lawn into such a responsive and genial condition, that (except during May and June, when the growth of grass is more rampant, and has to be gathered), we have removed our box for catching the grins as it falls from the rollers, and permit it to fly in a little shower all over the lawn, as the entting progresses. In this way, the lawn-top dresses itself, by returning all that it produces. By cutting and rolling once a week, this weekly cutting amounts to little more than snipping off the points of shoots half to three-quarters of an inch long, which have projected above the cutting-grade of the machine, and which are seattered in this sort of grassy shower on the lawn, decaying or disappearing in conrse of two to three hours, while all below the grade becomes pressed and matted by the roller into a fine and verdant sod If. W, S. 
oceasional use of a heavy roller, after rain, will also greatly tend to remedy all defects of this nature.

Where a piece of land is long kept in lawn, it must have an oceasional top-dressing every two or three years, if the soil is rich, or every season, if it is poor. As early as possible in the spring is the best time to apply such a top-dressing, which may be a compost of any derayed vegetable or animal matte̊r-heavier and more abounding witl marsh mud, ete., just in proportion to the natural lightness of the soil. Indeed almost every season the lawn should be looked orer, all weeds taken out, and any poor or impoverished spots plentifully top-dressed, and, if neeessary, sprinkled with a little fresh seed. Wood ashes, either fresh or leached, is also one of the most efficient fertilizers of a lawn.

We can already, especially in the finer places on the Hudson, and about Boston, boast of many finely kept lawns, and we hope every day, as the better class of country residences increases, to see this indispensable feature in tasteful grounds becoming better understood and more universal. 


\section{S U P P L E M E N T}

TO THE

\section{SIXTH EDITION}

O F

\section{LANDSCAPE GARDENING:}

CONTAINING

SOME REMARKS ABOUT COUNTRY PLACES, AND THE BEST METHODS OF MAKING THEMr; ALSO, AN ACCOUNT OF THE NEWER DECIDUOUS AND EVERGREEN PLANTS, IATELY INTRODUCED INTO CULTIVATION, BOTH HARDY AND HALF-HARDY.

B Y

HENRY WINTHROP SARGENT.

Navigis pinos, domibus cedros que cupressos que."

GEOR ii. 442 . 



\title{
SUPPLEMENT TO LANDSCAPE GARDENING.
}

\author{
SECTION I.
}

SOME GENERAL REMARKS ON LANDSCAPE GARDENING AND COUNTRY PLACES.

Great as was the impetus given to the public mind by the first appearance of this book in 1841, and great as has been the advantage derived from its publication since, not only in assisting by certain rules as far as it is possible to apply rules to an art, but also in developing and fostering rural tastes, yet, we think, it must be conceded by observing and discriminating persons, that the style of our country places is still vastly inferior to the rery marked improvement in Rural Architecture during the past ten years.

This has arisen partly from the fact that no sensible man attempts to build his own house, and the necessity of employing architects has not only developed much ability in our own professors of this art, but has also given us the additional adviantage of a great deal of foreign talent and skill.

This has not been the case with Landscape Gardening. There laas been no one since Mr. Downing's death who has exactly filled the niche he occupied in the public estimation. We do not mean to say that there are not at present in this country, gentlemen of taste and knowledge, and who are professional Landscape Gardeners of sufficient ability to take any place and to make it all that is desirable; but there is no one, we think, whose judgment and opinions would have, at this moment. such decided and marked influence in all matters of 
rural taste, as the late Mr. Downing exercised at the time of his death.

While, therefore, the excellence of country houses has greatly increased, the improvement in country places is not so evident. A great many persons are either too indolent or too busy to give much attention to the capabilities or wants of their places. The former fall easily into the hands of an inferior class of nurserymen, or job-planters, and become a ready prey to the most tasteless imposition, while the latter crowd into a few hours a day the arrangement and adormment of grounds which should require many months of thought and study.

We Americans are, as a general rule, in too great a hurry "to get through." We are apt to allow ourselves to go into the country without quite understanding what we are to do there, or how we are to live, or whether we have true taste and capacity for country life. Most persons are satisfied while building their house and attempting to arrange their grounds. The first is comparatively easy, for we have only to communicate to an architect our general wishes, and it becomes his duty to carry them out; the second is more perplexing, simply because we do not know what we want, or we want to have everything we have seen that has struck us as desirable. We do not stop to consider whether a certain style of planting or selection of trees, harmonizes either with our house or is in character with our grounds. We have an indefinite idea of the pleasure certain effects gave us in other country places, and we are determined to have those effects in our own, without any reference to propriety or good taste, not from obstinacy, but from ignorance. We have, to be sure, certain rules for planting, but the lazy are too indolent, and the busy are too hurried to read or study them. The suggestions of others are readily taken, and the most incongruous and imperfect results necessar- 
ily ensue. A willow drooping over a rustic bridge, and a pine waving its giant limbs on a rocky eminence, are each charming in its place, becanse in harmony with surrounding nature; but pines and willows alternating around a house, or on a flat approach road, are most discordant and in the rilest taste, and yet we constantly meet with discrepancies in new country places, not a whit less barbarous.

A common error, and we think a very decided one, in our new places, is the anxiety to have flowers and flowering shrubs while the place is still in the rough, and before we know where to put them with propriety.

A very usual employment of new grounds immediately adjacent to the house, is the most injudicious and tasteless admixture of decapitated forest trees and dahlias, with vases, evergreens, roses, altheas, and the various common plants, indiscriminately put together, a few inches, or at most a few feet apart, in the coarse weedy grass, which is the best apology for lawn which could be got up in the time--exposed to the carelessness of workmen, and the depredation of roadside cattle. We have even seen avenues-and in places too, where otherwise there are evidences of good taste-planted with alternate rows of forest trees and dahlias, with an occasional rose tree or geranium. Nothing, we conceive, can be in worse taste than this; for though nothing can well be prettier than a rose in a rose garden properly surrounded by the most refined and ornamental shrubs, like a jewel in an appropriate setting, yet can anything be more improper or discordant than the same rose in a stubble field, or what is quite as inappropriate, in the rough and ill-kept grounds of a raw and unfinished place. Refinement must be associated with and surrounded by refinement, or it loses half its charm. We hear of and sometimes see a rough dia. mond; but no one, we think, will pretend to say that 
the same diamond polished and properly set, is not in. finitely more attractive.

Besides which, no flowers do well under such circum. stances; the ground is hard and rough, and the plants being placed immediately under the drip, and amidst the roots of trees, do not receive the full benefit of either sun, air, or soil, and yield the most unsatisfactory returns for the expenditme of a great deal of time and money.

Whether flowers should or should not be planted at all around a honse, is a question of considerable moment, and as a general rule, we must confess, our own judgment is against it; we think the only exception is where it is desirable to retain the view from the principal windows either within the lawn, or within the immediate surroundings of the house, from the more distant prospect being flat and uninteresting, or containing objects decidedly disagreeable.

In such cases, the more the eye can be prevented from wandering to the distant points, the better, and this can be accomplished in no more pleasing way than by surrounding the house with the most dazzling flower-beds, or the most striking architectural ornaments, snch as vases, sun-dials, terraces, and fountains, or distinctive and remarkable trees or plants.

Where, however, as is most often, we think, the case in this country, the place itself is of snfficient size or elevation to create a distant prospect which is agreeable, or the view beyond the boundaries presents natural features of an attractive character, such as fine monntains, lakes, or rivers, or distant peeps of pastoral comntry, or pretty villages, then it is not desirable to fritter these away by flowers or any objects near the house; but the arrangements of the grounds should be of the most simple character, and partake of that smooth harmonions form, most suggestive of the repose and quiet which we seem always inseparably to associate 
with a well-ordered country place. The trees should be so arranged, that while forming natural and graceful gromps, they should act as it were as frames, through which the distant views or objects of interest on or beyond the place, seem to appear to the greatest advantage. We do not certainly wish to interdict all flowers, or banish them from the vicinity of the honse; far from it. We think, on the contrary, a bed or so of roses, or a mass of the sweet-scented honeysuckle and fragrant elematis immediately under the windows of the drawing room, are most desirable, that we may enjoy their fragrance of a summer evening. We would only so arrange or place them, that they should in no way disturb the view by withdrawing the eye from something much finer beyond.

Nothing can well be prettier or in better taste than an arehitectural flower garden, opening from the breakfast or morning room, or perhaps on a side of the house, where the view is confined and shut in by ornamental shrubs, and which seems, by a judicious transition, to connect the house and the grounds; but we think on those sides where the views are, and especially on the entrance front, there should be nothing but the simplest and most dignified arrangements of trees and grass.

There is another, and we think a very sensible reason, why flowers and flowering shrubs should not be introduced, in profusion at least, either along the borders of the approach road, or in the immediate vicinity of the entrance front.

It is well laid down by the English Landseape Gardener's, that from the time the house is first seen on an approach, it should not be lost sight of. It being the highest arehitectural object on the place, no rural objects, like flowers, or any arehitectural features of lower art, like statnes, or vases, should be permitted to divert the eyc of the visitor, which they wonld be very apt to do, if from no other reason than the care 
and attention necessary to prevent driving over or against them. It is particularly objectionable, therefore, to place rows or masses of green-house plants, as is often done, on either side of the entrance, which are sure to be more or less injured by hungry horses and careless coachmen.

And finally, in this comntry where we have no rural sports as in England, nothing in fact for the ammsement of our friends and visitors, except what is beautifu] or interesting on our grounds or in our gardens, we have always thought it highly desirable not to tell our whole story from the house, but to set aside in different and distant portions of the place all onr objects of interest; a flower garden in one spot, the vegetable garden in another, an arboretum or pinetum in a third, and so make and multiply as it were, various interests in different parts-properly connected, but as widely separated as convenience or space will allow-which shall furnish to our guests excuses for a walk, and give to a small place the appearance of a large one; in other words to afford as much interest and diversion as the capacity of the grounds will allow, and prevent that ennui and fatigue, which nothing to see and nothing to do, produces not only in our visitors, but in our own families. We cannot well imagine anything more dreary than those country places where there is no motive to go out, because everything is gathered and crowded around the house and can be seen from the windows.

Although we know there is nothing prodnced without labor, yet it is not pleasant to be always forced to realize it. Repose is, we think, almost as essential to the highest charm of a comntry place as it is for our own comfort. The clink of the hammer and the sound of the anvil are all very well in their way, yet one does not desire to hear always these evidences of human toil. If therefore we surround our house with a multiplicity 
of objects requiring constant care and attention, we are never free from the labor of life. The highest charm of a country place is the appearance of the most refined culture and beautiful results prodnced without apparent effort.

In fairy tales, or fairy plays upon the stage, the fuscination is in the magic result produced apparently by the touch of the wand. If we are permitted to ger behind the curtain and witness the hurry and vexation of the scene shifters, and the groaning, shrieking process by which to the unconscious spectators a desert suddeuly becomes a paradise, we immediately realize the apples of the Dead Sea. We do not enjoy that which we see is jrodnced through the agency of aching bones and weary limbs-and this is one reason why Nature is so attractive, because she works silently, or as a child once expressed it, "without her shoes."

In the best English places, to such an extent is this feeling carried out, that the entire machinery is kept ont of sight; and flowers bloom, and lawns are shorn, and walks are swept by invisible hands, at such hours as the family is supposed not to come out.

It is told of the late $\mathrm{Mr}$. Beckford, the eccentric and talented anthor of Vathek, that he never allowed any work to be done at Fonthill Abbey during the day; but if he wished a walk cut, or a new plantation made, he used to say nothing in way of preparation, but merely gave orders, perhaps late in the afternoon, that the improvement or alteration should be completed and in a perfect state by the following morning at the time he came ont to take his usual ride. The whole force of the place and the strength of the neighboring village were then put into requisition and employed all night. We mention this, not as an example-for there are very few of us who would or could afford to spend, as Mr. Beckford did at Fonthill, twelve or fifteen millions of dollars -but simply to show how strongly English prejudice is 
against the risible connection of labor with the immediate adornment of their comtry homes. Labor in its proper place-in the forest, or garden, or harvest fieldis a necessary and appropriate feature; but they strire to banish it as much as possible from the repose and quiet and simple beanty aromel the house, by pushing ofi to more distant, and as they think, more suitable localities, those operations with the soil which require the constant snpervision and presence of man. It is principally on this account, besicles the other reasons we have given, that the best examples of English places present a simple dignitied combination of trees and lawn about the honse-certainly on two or three sideswhile the mass of pleasme grounds and flower gardens are usually at some distance.

If we were more willing in this country to follow such good examples, and aim at simplicity and breadth of effect, instead of carving np om grounds about onr houses with "fragmentary picces of misplaced omament," our places would not be so lamentably deficient in character and beanty, or so frittered away into an exceedingly dis. tasteful aud artificial appearance.

Another mistake in American places is the want of a proper termination to the ornamental grounds, or, rather, some intelligible division between the ornmental and practical.

Te use the expression "intelligible," bccanse we all keep (or pretend to) mnder the roller ind scythe, erery two or three weeks, a certuin quantity of lawn, say from one hundred feet to an acre or more, and at the end of the last swiuth starts up a har-field, which is nown orer perhaps twice in the season; but, in most cases, there seems no reason why the lawn should end and the hay-field begin just where they do, instend of ten or one hundred feet one way or the other; in finct there is no good reason; for the length and breadth of the lawn often depends upon the horticultural zeal or 
pecuniary position for the moment. If the first mowing of the season is made under the receipt of an increased or unexpected dividend, the lawn gets a swarth or two more, and a cock or two of hay is subtracted from the harvest; while the next year, under a smaller income, thrift conquers taste, and the lawn, instead of being shorn of its grass, is shorn of its fair proportions.

In order to make some appropriate boundary or division between the lawn and the park, or hay-field ; in other words, between the dressed and nndressed portions of the estate, great use has been made of late years of the wire fence or hurdle. By its adoption we might diminish the amount of lawn now liept under the scythe, obtaining similar results by substituting cattle-especially sheep - and increasing very much the charm of the landscape by the introduction of animated nature.

The keenest eye can hardly detect a wire fence at thirty or forty rods distance; consequently our finest places do not really require a lawn larger than twice this breadth in diameter, provided the grass on the other side of the wire is kept equally short by sheep.

It is quite astonishing in England how very small the proportion of mown lawn is to that part which, by use of invisible wire fencing, is kept equally short and almost in as fine order, by grazing.

At Windsor Castle we donbt if the mown border or strip of grass round the park-side of the castle exceeds fifty to one hundred feet up to the wire fence, beyond which, in the park, are large masses of rhododenrons, laurels, Portngal laurels, etc., protected from thousands of deer and sheep which surround them, by invisible wire fences.

At Longleat, the magnificent seat of the Marquis of Bath-which Charles II. on his return from his exile then considered the finest place in England-there is a strip of three hundred feet of mown lawn planted with 'rare shrubs, between the river and one side only 
of the honse, and separated from six hundred acres, or more, of grazed park by the invisible wire fence. At Wilton House (Lord Pembroke's), Appelder-Conrt, Goodwood (the Duke of Richmond's), Blenheim, Chatsworth, Stowe, and many more of the best examples of English places that we remember, the amount of mown lawn consists really of little more than the grass borders of walks, or the strips which divided or surronnded plantations in the gardens and shrubberies. Three sides of the honses are thrown open, and kept short by deer and sheep.

Althongh grazing is not as profitable in this country as in England, where the soft, mossy grass of the parks is nsually verdant and green all summer, yet much more can be done than is. We know many a fine place where large expenditures have been made on houses and grounds, where the entire effect has been completely destroyed by the most mistaken economy of allowing the fields which surround the house, to grow up for hay, instead of being kept short by grazing as a park.

In order to sare a few hundred dollars of hay, the whole effect of hundreds of thousands of dollars in houses and grounds is completely lost.

If people will persist in this mistaken thrift, they should, at least, plant their grazing or hay-fields in clumps and masses of trees, appropriately and naturally placed for park-like effects, and which wonid not materially interfere with the plongh or the harrow, when necessary to use them.

By surronnding these plantations with invisible wire fences, which are quite lost against the foliage, they could at any time, when in grass, be converted into parks simply by the introduction of cattle and sheep. 


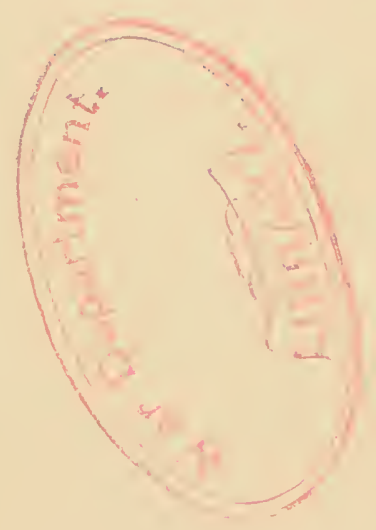




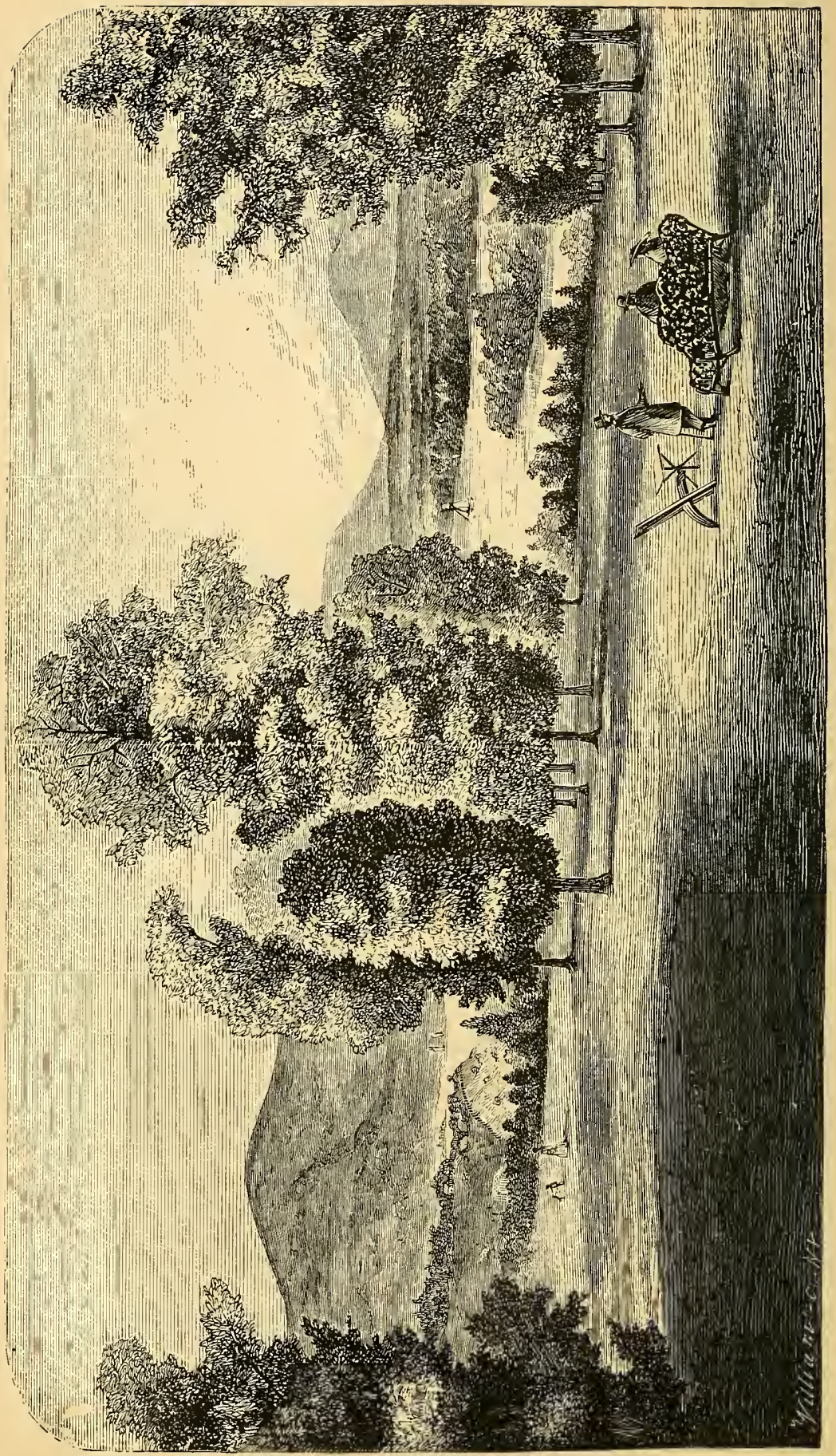

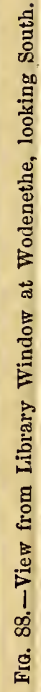




\section{SECTION II.}

HOW TO MAKE A COUNTRY PLACE.

$\mathrm{O}_{N}$ the Continent and in England, it is rarely that a new place is made from the beginning. The taste for country life having existed as long as England herself has existed, the whole kingdom may be said to be one universal garden; all who can, from the sovereign to the cit, live, at least some portion of the year, in the country; in fact, one's respectability is not complete, unless he is a landed proprietor. If, as we said in our preface, there are in England 20,000 country houses, each larger than the White House, at Washington, there are more than twice that number, a great deal smaller.

Places change hands, but few new places are made. This is not the case in this country. We have but few old estates, and those, whenever offered for sale, are generally so run down and desolate as to afford little attraction to the beginner of country life; besides which the universal delusion among $u$ is that we can make a country place, cheaper than we can buy one. While we are alarmed at a sum total, we easily reconcile ourselves to progressive expenditure, until, in the end, wo realize "that fools build houses and wise men live in them."

This is one great reason, we have always thought, why makers of new places so soon become discontented and discouraged, and ready to sell out at a sacrifice. A man who hesitates to give $\$ 20,000$, or $\$ 100,000$ for a 


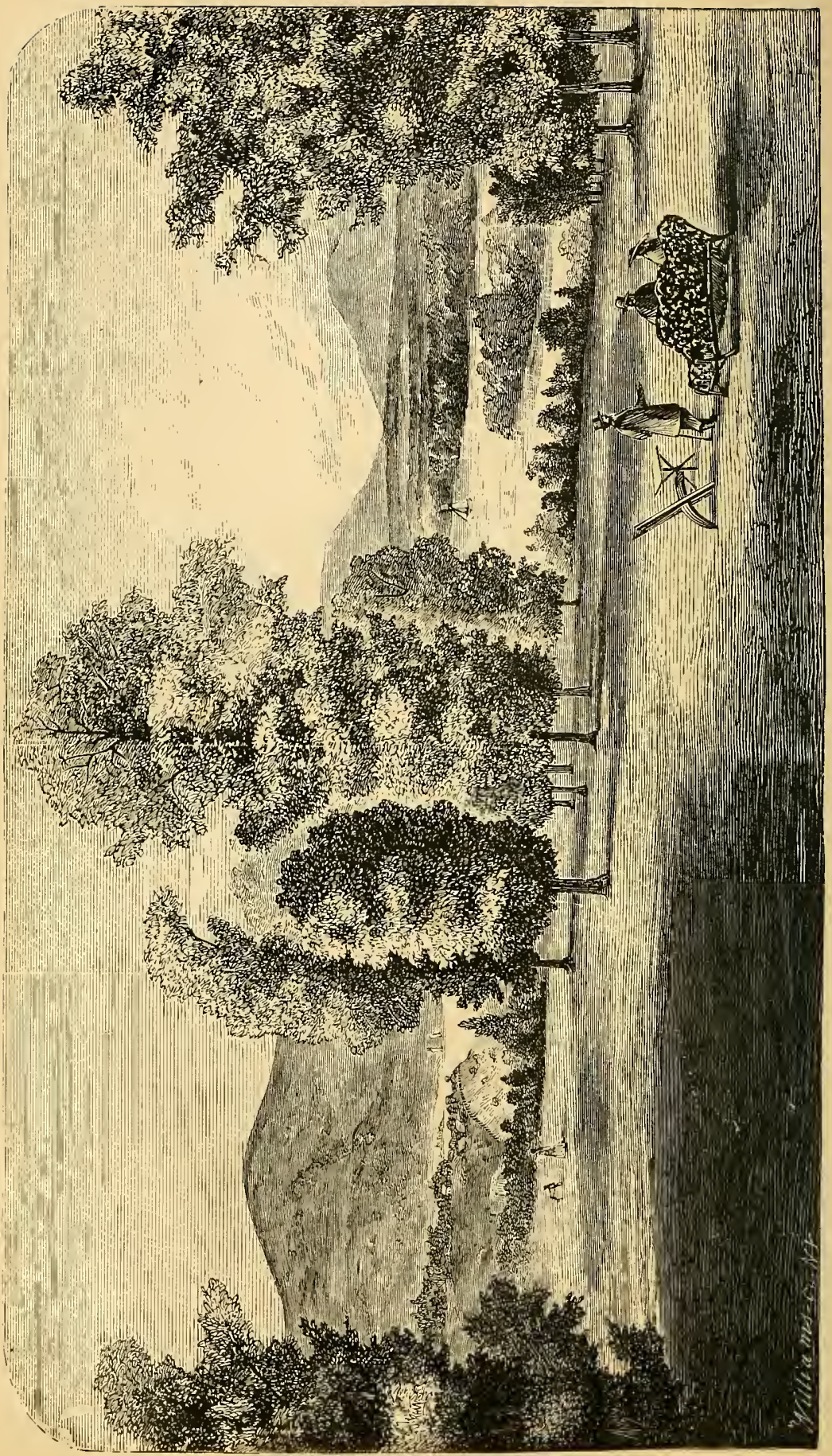

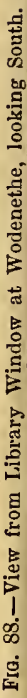


$\mathrm{O}_{\mathrm{N}}$ the Continent and in England, it is rarely that a new place is made from the beginning. The taste for country life having existed as long as England herself has existed, the whole kingdom may be said to be one universal garden; all who can, from the sovereign to the cit, live, at least some portion of the year, in the comntry; in fact, one's respectability is not complete, unless he is a landed proprietor. If, as we said in our preface, there are in England 20,000 country houses, each larger than the White House, at Washington, there are more than twice that number, a great deal smaller.

Places change hands, but few new places are made. This is not the case in this country. We have but few old estates, and those, whenever offered for sale, are generally so run down and desolate as to afford littlo attraction to the beginner of country life; besides which the universal delusion among us is that we can make a country place, cheaper than we can buy one. While we are alarmed at a sum total, we easily reconcile ourselves to progressive expenditure, until, in the end, wc realize "that fools build houses and wise men live in them."

This is one great reason, we have always thought, why maker's of new places so soon become discontented and discouraged, and ready to sell out at a sacrifice. . A man who hesitates to give $\$ 20,000$, or $\$ 100,000$ for a 
comtry place, and eren feels indigmant at the supposition that he conld be guilty of such folly, if he attempts to make his own place, generally ends by spending twice as much.

We refuse to pay $\$ 25,000$ outright, and we hug ourselves with the idea that our land will cosit but $\$ 6,000$, and our house $\$ \$, 000$, and our stable $\$ 1,000$, and sundries $\$ 500$. But, unfortunately, these sundries are the rocks on which much rural enthusiasm is lost. It is the ice-house, and the root-honse, and the gardener's-honse, and the green-house, and the grape-house, with the grading, and road making; and trenching, and digging, and the labor necessary to keep these all up, that exhanst both onr enthusiasm and our purse, and make us see, in the end, what we could not see in the beginning, viz: That it is always better to purchase an improved place, or one partially improred, than to begin one. For, it may be laid down as an ineritable rule, and prevent much subsequent disappointment, whenever any improrements at all are contemplated (and it is dificult, where tre have no amusements or sports, to be contented withont doing something), to remember one fact, that the modern accessories to a country place are at least equiralent to first enst of honse and grounds-that is to say, where the improrements are in keeping with the honse and place, and continued for a series of rears.

There are two styles of new places most commonly, we think, attempted in this country, viz: A place without any foliage, or possibly a few stunted or marailable trees, where all the effects are to be produced by the spade (in planting); and, secondly, a dense wood, where the place is to be made mostly by the axe: and we propose to illustrate these two schools by giving the history of our own residence as a specimen of the latter, and "Wellesley," the residence of H. H. Hun newell, Esq., near Boston, as a specinen of the former We shonld, perhaps, mention here, that it is with much 
hesitation we find ourselves compelled to say so much about these two places, especially our own; but we have known them both from their commencement, with all their sins of omission and commission; and with all the motives and designs for each step taken in their improvement, and the reason why every tree was planted or cut down on either place, which is a knowledge we have of no other place, and more than all, as one was a dense wood and the other a naked field, they are better examples of the two styles than any other places we recollect, even if we had been equally familiar with others.

When we purchased our own place, in 1810 , we found a honse partially built in the midst of a wood, but without any view, though we were aware that we had, or ought to have, a range of mountains on one side, the Hudson River on the other, a valley on the third, and a long range of country on the fourth; but between us and these views, and all more or less around us, were thinly scattered houses, which were far from agreeable accessories to the landscape.

We felt, after studying our position, that our plan ought to be to conceal these offensive objects, by planting them out, and to open up the attractive points of river, valley, and mountain; but how to do this was the question!

The trees, like all trees grown in a forest, were tall and spindling, hiding ont with their heads what they should not have concealed, and opening throngh their naked stems what ought to have been hid; on object therefore, was to get the branches of these trees (principally oaks and hickories) down near the ground, in order to form masses and gromps, not only to hide out our boundaries and these objectionable houses, but also to produce certain effects of light and shade, as the beginning and basis of ornamental planting. We accomplished this in part by topping all the trees which had any signs 
of vitality in their lower branches, as low as there was young wood enough to carry on the circulation. Many trees seventy feet in height, we thus reduced to thirty and forty. This formed a thicket of background from which we took, year by year, the weakest and most misshapen; so that a mass, composed, eighteen years ago, of fifty or sixty trees, seventy or seventy-five feet high, is now leduced to twenty or thirty trees only forty teet high, but denser, and covering much more space than donble the number of original trees. Where necessary to obtain certain extended viers, we cut boldly and irregularly through the mass, producing, after some years growth, the effect as represented in Fig. 8S, entitled, "Viow from Library Window." Where we accomplished two distinct landscapes-the one including a charmingly wooded point called "Presqu-ile," the residence of Mrs. Denning, with a distant view of Idlewild, the residence of N. P. Willis, across the river; and the other a portion of Pollapells' islandwith a fine effect of the Dunderber'g or Storm Iring, as background.

But, in process of time, finding that from the irregular shape of the house-a view of the river side of which appears as frontispiece to this Supplement-we could, by careful planting against the masses forming the boundaries to the view referred to (Fig. 8S), not only produce more agreeable and ornamental effects from the windows, but contine to each window one distinct and separate view, which should be seen from that one window and that alone-while it had also the effect of lengthening and extending the vistas, making, as it were, a series of cabinet pictures-we advanced an irregular plantation of the most ornamental trees in front of these two masses, completely masking them; and while very much extending the view by an apparent and, indeed, an actual elongation, it also substituted from the windows an ornamental grouping between the house 


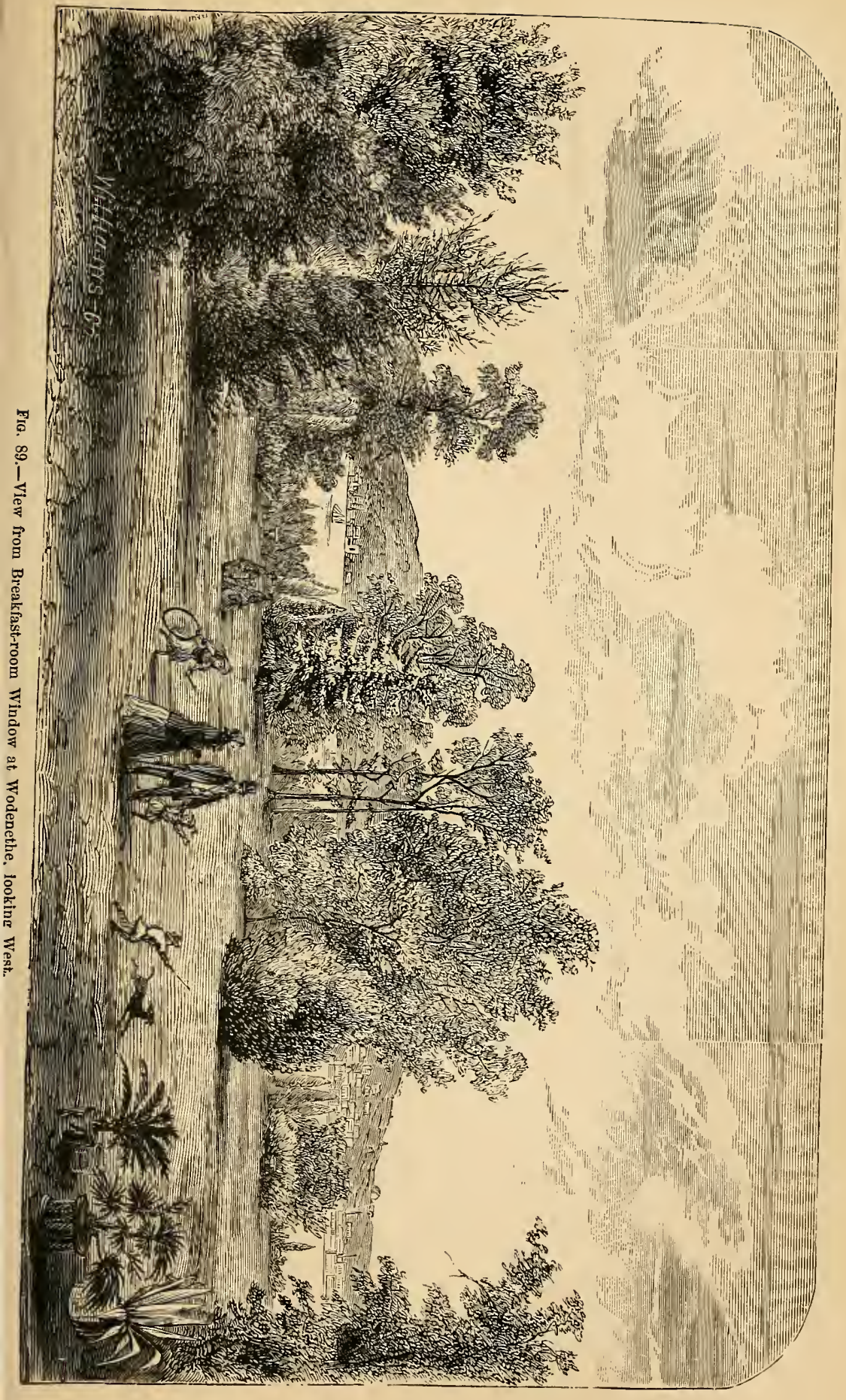



and the ratural grouping, which is, however, omitted in this sketch.

The view from the breakfast-room window (Fig. 89), opened for the purpose of introducing a part of Newburgh and a fine wooded bank below the town, was made in the same way-the decapitated forest trees having in a few years become thick and umbrageous, made an admirable back ground for an ornamental facing of the choicest trees, both deciduous and evergreen, while these various masses, all now more or less surrounded with the rarest trees, are connected together and made to liarmonize by small irregular groups and single trees, blending the different parts into one whole, but so arranged as not to injure the most striking viewsample space being left for the full development of single specimens and loose groups.

On the other side of the house-in the view entitled, "View across the park" (Fig. 90)-our intention was to attempt, with no other aid but the axe, a parklike effect by the grouping and massing of certain native oaks, withont the aid of any artiticial planting. This was effected by selecting the best specimens standing sufficiently near to each other for this purpose, and leaving around them a large circle of forest trees as nurses, which we thinued out from the inside, year by year, giving the permanent trees more and more light and space, until finally they stood alone, and liave since continued to thr" a ; though if we had thinned ont immediately everything about them, they wonld probably have perished from the too sndden removal of their accustomed shelter; but $b_{j}^{-}$diminishing their nurses gradually in successive years, the trees to remain, became by degrrees fortified and strengthened by extended roots, and now stand as well alone as if they had been planted for this purpose.

The boundaries of the place were treated in a similar. manner; the original trees reduced to half or two-thirds their height, and, when thick and bushy, faced with 
ornamental plantations, as an arboretum, with collections of trees in families, and also a portion as a pinetumeach genus being kept by itself-and through which is a walk making the circuit of the place; the whole being dirided by a wire fence from the portion abore described as arranged for a park, which is kept short by cattle and slieep.

All the space necessary for regetable and flower gardens, pinetum, arboretum, orchards, etc., was, of course, taken entirely from the wood-the trees being cut down and their roots grubbed up.

Haring attempted to describe a place made by the axe, out of a wood, we will now gire some account of the other and different style of comtry residence before referred to, entirely by the spade and from the ground.

The whole estate at "Mellesler" consists, we beliere, of two hundred acres, being an mimprored portion of an old family place of many hundred acres.

The part selected by $\mathrm{Mr}$. Humerrell for the ornamental improrement of his grounds comprises about forty acres, originally a flat, sandr, arid plain, which, when he took it in hand, in 1Sš1, only seren years since, was more or less corered with a tangled growtl of dwiluf pitch pine, scrub onk, and birch, all of which were cut down and plonghed up.

The first thing done was to trench orer and thoroughls prepure with composted muck, an acre or more for a nursery; which was planted with large quantities of Normar sprice, white pines, balsams, Austriau pines, Scotch firs, lirch, beech, oaks, elms, maples, etc., mostly imported from England, not orer twelre to fifteen inches high, with some few natire trees of greater age, prerionsly prepared. The lawn was then graded, subsoiled, and a large portion trenched by spade, and after being verry hearily manured and emiched with compost, wias for sereral years cultirated in order to ameliorate and subdue the soil; the boundaries of the place, 

especially on the exposed part towards the public road, were then trenched over twenty to fifty feet broad, heavily composted and planted with a judicions mixture of evergreens and ornamental trees. The border, however, for many years, until the trees were fifteen to twenty feet high, and in many cases touched each other, was amnully emriched and planted in potatoes, the crop being some remuneration for the expense.

The next step after deciding upon the situation of the house, was to form the avenues and plant them; the one from the Boston entrance, with alternating Pinus excelsa, and Magnolia tripetala at one end, and with large masses of rhododendrons, Kalmia latifolia, Mahonias, and other rare evergreen shrubs, as a frontage to a back gronnd of Norway spruces at the other; mintil the road reaches the Italian garden, with a view of the lake on one side, and the honse and lawn on the other, when the avenue effect of the planting ceases - and groups, masses, and single specimens, and the ormamental arrangement, shown in the view, commence.

The other avenue from the Natick entrance is planted with rows of white pine and larch, now, perhaps, twenty to twenty-five feet high, and being all fine trees, the effect is already very marked.

The next step was to plant the lawn of about eight acres with the best specimens selected from the nurseries or border plantations. This has been most cleverly and successfully done, much of it in the winter with frozen. balls and with the most ornamental and choicest trees ; in some cases large specimens twenty to thirty feet ligh were bronght twenty miles, but even after the clumps, masses, and single specimens on the lawn were arranged and planted, it was still annually enriched and cultivated, and the ground around each tree and mass of trees is, even to this day, kept clean to a circle following the drip of the branches.

The house. a front or entrance view of which is given 
in Plate III., was then built, having among other fine features, a hall of $5 \pm \times 1$ feet rmning through it; on one side, the fine extent of simple and dignified lawn, and on the other side is a French parterre or architectural garden (Plate IV.) with fountains, bordered by heavy balustrades, surmounted at intervals by rases, with steps leading through a series of terraces to the lake, a fine sheet of water of about a mile in extent, having a peculiarly varied and beantiful ontline. From this French parterre, stretches off on the right the ormamental or English pleasure-grounds, a part of the same view, showing the summer-house very artistically rusticated, with colored glass windows, producing rery curious effects of contrast by the stained glass.

From this we pass along the lake to the Italian garden, of which we have given a view in Plate $V$., and which is the most snccessful, if not the only one as yet in the country. The effect, especially by moonlight, of the like seen through the balustrades of the parapet, and among the vases and statues which surmount itwith the splashing of the fountain, and the very unique features, at least in this country, of the formally clipped trees and topiary work, quite lead us to suppose we are on the lake of Como.

To MIr. Inunnewell, we believe, is due the merit of having first attempted to clip our white pine, and the lesult shows that it bears the shears quite as well as the hemlock or yew; though in this garden are equally successtinl specimens of clipped Normays, balsams, arbor vitr, the English maple, the beech and Scotch firs.

From the Italian garden we cross the avenue into a wood, through which winds a malk planted on either side with a rery extensive and satisfactory pinetum, containing all the rarest and newest conifers and evergreen shrubs, and which with the slight protection from the winter's sun, seem to thrire exceedingly well. 


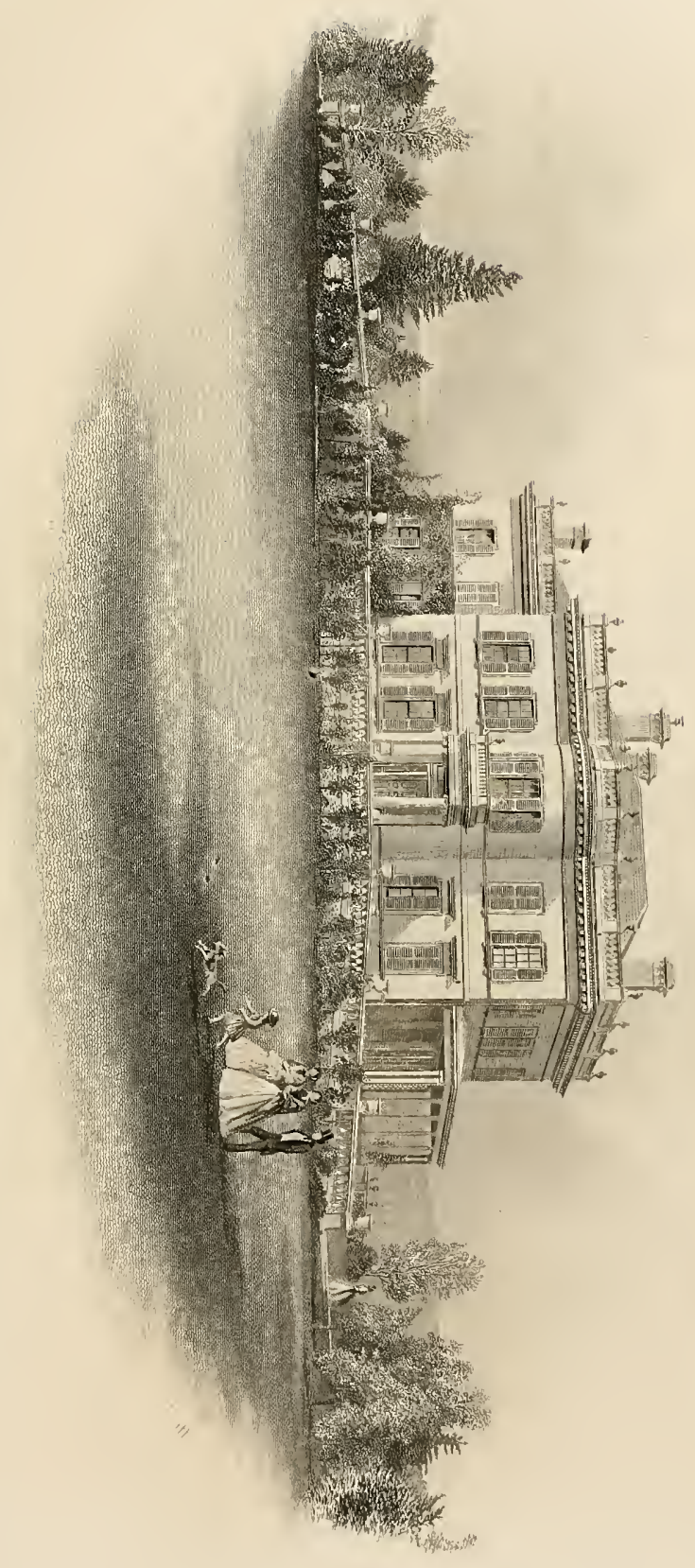





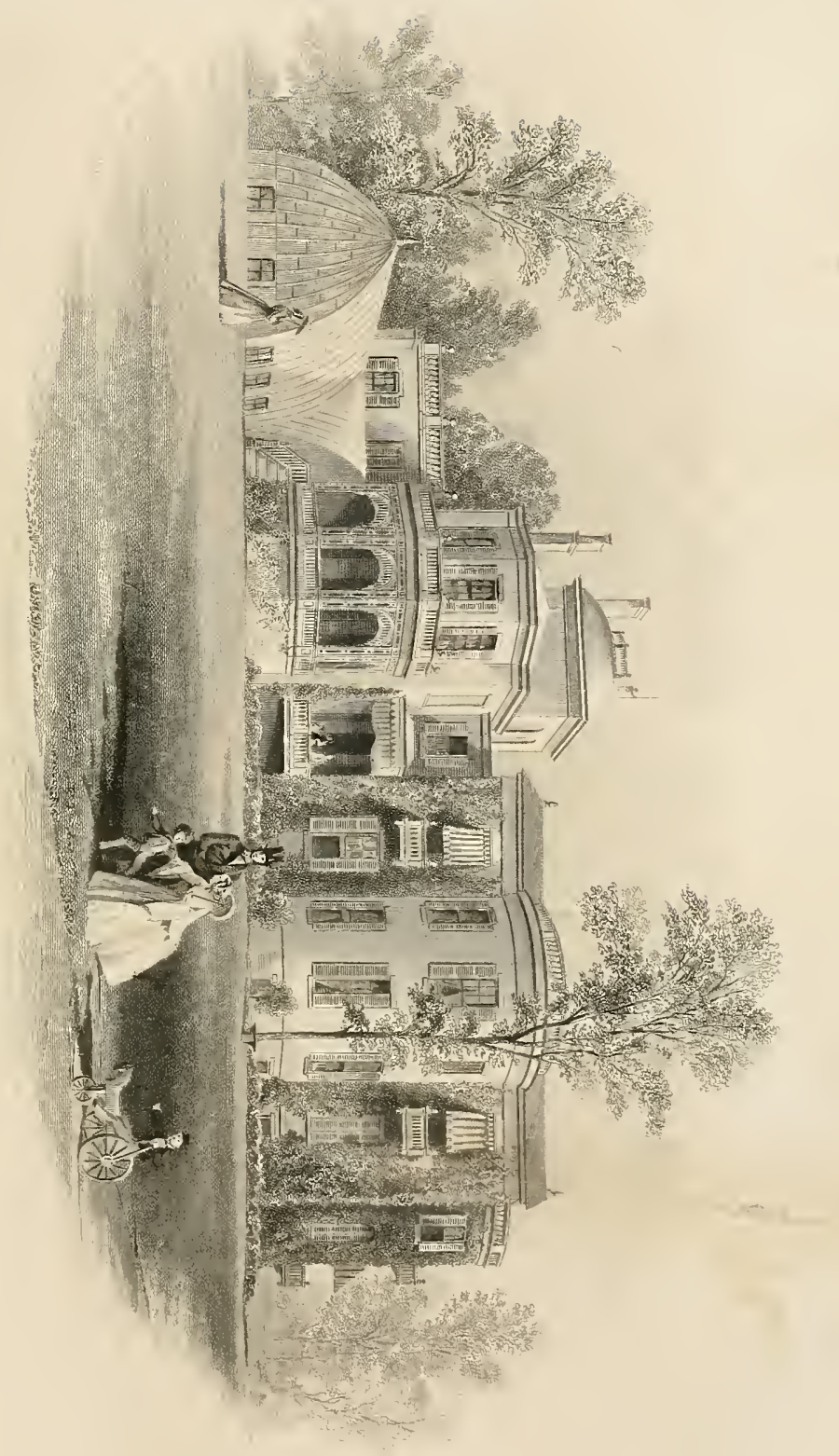




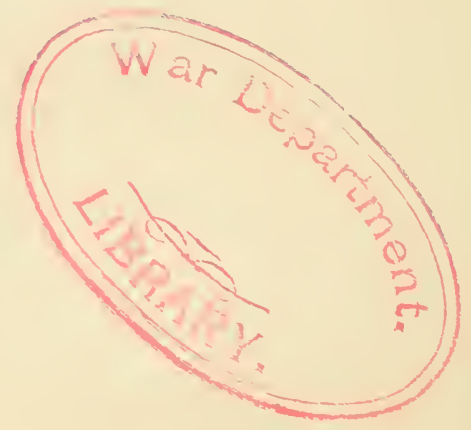


Among other features of this place, and accomplished like everything else, within seven years, are varions vistas throngl different arenues planted for this purpose-some of purple beech, others of white pine-all of which will in a few year's become very interesting and effective.

If to the above we add the extensive and wellconducted vegetable and fruit gardens surrounded by most admirably kept hedges, an abundance of well trained fruit trees, peach, grape, and green-houses, and a steam ongine for forcing water into a reservoir, from which distributing pipes conduct it over all the gardens, we shall, we think, conclude a description of a place almost unequalled in this country, considering the few years only it has existed.

Mr. Hunnewell's suceess has been attributable in the first place, to working on a plan-making no or few mistakes-having little or nothing to undo, and lastly, having the taste and ability to do everything thoronghly and well; always keeping up what has been done, so that neither tree or flower, or lawn, is ever permitted to flag.

Of the two places above described as illustrating the two schools most common in this country, we believe we shall afford consolation to many beginners of naked places by saying that our experience is extremely adverse to all attempts at converting a wood into any thing ornamental.

If two places of the same size were commenced the same day, by persons of equal taste, knowledge, and means, one a wood and the other a maked plain, at the end of ten year's the naked plain would be the finer and more satisfactory.

In the first place, if one in planting, will make his holes wide and deep enongh, and with judicious preparation of the soil; if instead of the ordinary three feet wide by two feet deep, our holes are prepared 
twelve feet wide and six feet deep, it rould be easy enongh to predict the result at the end of fire or six years. Besides which, it is a very simple matter to know the effect certain trees or certain groups of trees are groing to produce by setting up a few stakes, which shall cover the same extent of ground; and it is a rery easy matter to more these groups of stakes until they are rightly and properly placed beyond any question, and then to proceed with our planting. By continuing in this way with all our planting we may, as we hare shown elsewhere, get every thing placed, withont the possibility of error.

It is impossible to do this in a rood. We cannot carve out the views and the gromps and masses, exactly as we wish, becanse we cannot find the trees always ready to assist ns. It often happens that the finest tree is just where we should prefer to have none; and where we want density and bulk to hide unsightly objects, we hare naked poles of fifty feet, with ten feet of brish up in the sky instead of where it should be, on the ground. There is no remedy in such cases but to ent down onr fine tree or abandon the riew it hides, and also to cut down onr unarailable giants and to plant in their places. We are, in this instance, not as well off as our friend withont trees, becanse we have to do all that he does with the additional labor of grubbing np the old stumps and renewing the soil before planting: There are, to be sure, instances as we have mentioned in our own case above, where $\pi$ e can make the natire forest arailable by topping those trees which will admit it, and by 'planting among and in front of them; but eren this, for many years, is not satisfactory. The dignity of the original trees, if any dignity is left, is much injured and frittered away by being sicle by side with om newly planted Norrays and hemlocks of only three feet in height; while these, which, in a few years at least, would have made their mark, if no comparisons conld hare been 
instituted, will now always appear to a disadvantage in connection with the forest, besides the injury to their progress from the roots and drip of their hungry and uncouth companions.

There is, to be sure a certain class or condition of wood which chance or design has from year to year thinned ont, and cattle cleared of undergrowth, resembling the oak openings of the West, which becomes after a while a sort of natural park, most desirable for country residences, but the thick, tangled, inextricable wood which will not readily admit any amelioration, but always returns for your attempted improvement, sickly and dying trees, pointing at you from every direction their weird and skeleton limbs, as if in derision and mockery at your efforts, had better be left alone in its wildness, or no attempts made to reform it.

The proper way, we have always thought, to make a country place, where there are no trees already existing, is, as we have already described as in Mr. Hunnewell's case, to dig an irregular border all round the boundary, or at least on those sides exposed to public roads or disagreeable objects, and to plant this with a.judicions mixtme of decidnous and evergreen trees of two or three feet high, either imported from Enrope for a few dollars the hundred, or purchased from our own nurseries at wholesale prices.

We do not mean by this to be understood as recommending one of those formal belts so much employed in the time of Brown, but a picturesque boundary, with bays and recesses, and projecting curves, occasionally employing the denser and more umbrageous trees where distant and unsightly objects are to be excluded; and agrain the lowest growing shrubs to admit the landscape beyond the boundaries when it is desirable to do so. This border may, the first few years, be employed as a nursery for the purpose of receiving all the trees, shrubs and plants required for the future and entire 
planting and embellishing of the place, and may be thinned ont from year to year as the trees crowd each other, or may be wanted for progressive improvement and separate planting, milil as the place advances and the border becomes annually thinned for this purpose it is at last reduced simply to such a number of plants, (which must be suffered to remain), as are required to prodnce the effects and objects above described.

During the first year or so, the proprietor may, at his leisure, study the planting of his place, withont the loss of that time so precious to all good Americans, as his trees are already growing-not in their final place, but in his border nursery. To do this effectually and properly he must employ a quantity of stakes or poles ten to twelve feet high, and by placing first a stake where he thinks a tree shonld be planted, and then several smaller stakes at such a distance around it as his books or his own knowledge may inform him will be the extension of the tree when full grown. By carefully observing this collection of stakes from his point of view, which, as a general rule shonld be the principal room of the house, he will at once see whether it is in the right place, whether it is too near the road or walk, or will injure a view. When satisfied by many observations-and it would be well if made from many points of view, all, however, subservient to the principal point-that the centre stake is correctly placed, let him substitnte for it a small stake eight or ten inches high, with the name of the tree to be planted there legibly written on it. In the Antumn or Spring, whichever may be the proper time for transplantinglet the hole be ding at leisure, properly and carefully prepared, and let a tree be selected from the border nursery on a damp or rainy day, and is properly and carefully planted. Pursue this conrse with all the single trees, groups, and masses to be planted on the grounds, and if judiciously done the most complete 


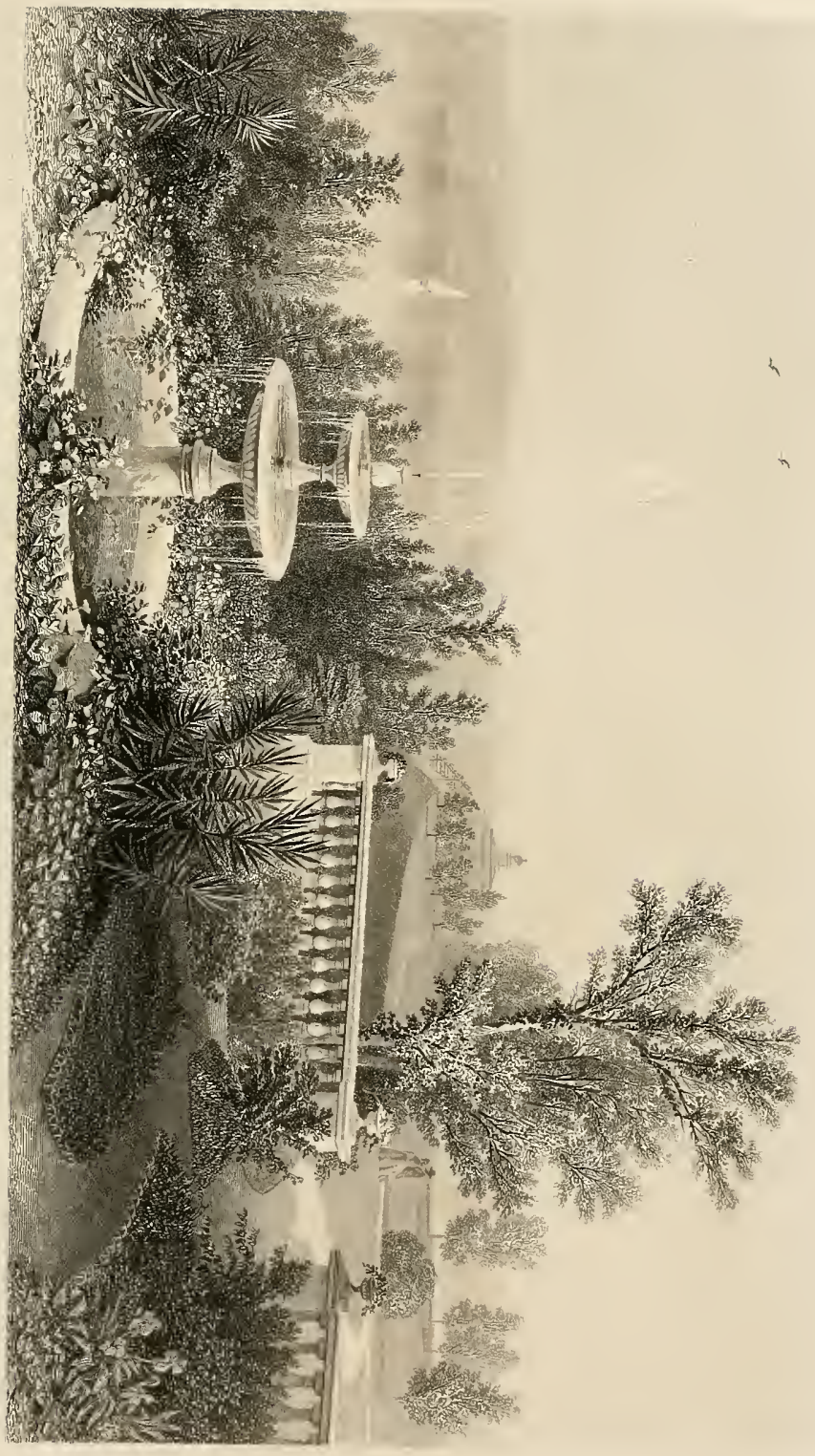



satisfaction will be the result; because one may not only make up their own mind by studying their groups of poles, for weeks or months, even, but they can also have the advantage of criticism from intelligent visitors, and if the poles are wrong it is much easier to remove them than the trees.

If it were our object to make the most thorough place with the greatest expedition and fewest mistakes, we should plant erery group, mass, and single specimen in poles, and allow thein to remain when the trees were both in and out of leaf, in order to be quite certain that the planting worked equally well in all seasons, and also to study and be quite sure we were right in the harmony and selection we made of varieties for forming groups and masses.

Although the process may seem slow and tedions to new beginners, yet we are quite sure a place thus treated will, at the end of four or five years, be far more advanced and much more judiciously and successfully planted than by the more ordinary and hasty method. In the first place, there will be no mistakes-no undoing-on the contrary, the planting of the place is the making of the border: and in the second place, the trees will be better specimens, because we may at our leisure select fiom our border the best plants, and have them much better planted, inasmuch as when the spot for the tree is selected, the hole may be dug months, if necessary, before used-which, for spring planting, is most advantageous, by submitting the soil to the action of the frost. Whereas in the usual method, we go to a nursery and order a certain quantity of plants, and when they arrive, possibly on a disagreeable, windy day, we sct about in the greatest hurry to dig holes and plant our trees, without in the least knowing the effects they are to make or mar when fully grown.

It is this careless method which produces so much bad planting and ruins so many country places. How 
l'arely do we see trees planted at sufficient distance from each other, or from roads, or walls, or houses. One plants a pine or Norway spruce three or four feet high at about the same distance from the margin of a road. There are many approaches that we know of bordered by pines and Norway spruces, with the trees five or six feet only from the border. When these trees get a few year's older they must be remored or trimmed up, and if a pine only ten or twelve year's old is to be trimmed up sufliciently high to admit the passage of carriages uncler it, it is very easy to see how little beanty is left. If in planting arenues one would first plant stakes, they would soon discorer, that to employ pines, firs, beeches, or, in fact, any tree proper for this purpose, the trees shonld be set back at least twenty-fire to forty feet from the margin, so as to be in proper position when fully grown. In order to present the meagre appearance of clmmps or masses, or aremes properly planted for future resnlts, there is no objection to closer planting for immediate effect, care being taken that the latter is cut down or removed from year to year, before they crowd or injure the permanent trees. In this way with judgment and taste, a place may have the appearance of finish within a year or two; the present group and mass producing similar effects except less light and shade, and covering the same ground as will be produced in twenty or thirty years by the two or three permanent trees, which, by that time are all that will be permitted to remain.

By this method of planting, which we recommend, we have an opportunity which is impossible in the ordinary way, of studying the character and habits of the trees, which, later in the season, we propose to substitute for our poles-to learn how they group, how they harmonize in habit, color, or growth, and we are thus enabled to produce some of those charming artistic effects by skillful combinations of color and habit, which 
nature so pleasingly exhibits in her own planting. Very few attempts, to our knowledge, have as yet been made, in this country, in what is called "artistic planting," that is, where reference is had to those effects attained by combination of certain colors ; for instance, in order to increase the effect of a vista or opening, by planting the darker foliage nearest the eye, and the lighter at the more distant point of view, or by planting two trees in the sane lole in order to prodnce pictureaque eflects in contrast to the more formal or gardenesque plauting on the place. We remember to have seen at Ouchy, on the Lake of Geneva, that most graceful tree, the Weeping Silver birch, planted in the same hole with a pretty, drooping, fragile, dark-looking cedar ; and the two (some twenty-five years old) had grown up together like two loving sisters, and their dark and silvery foliage and graceful arms gently entwined together, seemed to eling fondly to cach other for support--the Minna and Brenda of the woods.

A selection and blending of trees with reference to their autumnal colors, is another refinement yet little practiced in this comntry. A group, for example, of our ash, the different maples, the liquid-amber, the sour gum, the dogwood, etc., judicionsly toned down in color, from the darkest and richest to the lightest, will present a combination, which, for brilliancy and gorgeonsness, wonld be hardly credible to those who had not witnessed the result.

In connection with this subject, we have made use of some memoranda of a visit to a place in Italy, some years since, as illustrative of artistic planting, from which, notwithstanding the advantages of climate, it is very easy to see how very far we yet fall short in this sort of perfection.

The place which we have most particularly in our mind, at present, is a bold promontory in the Lake of Como, called Bellagio, belonging to the Duchess of 
Bologna, having a position not very mulike that of West Point on the Hudson-supposing that the rirer forked there, one arm rmming on ench side. You stand on this promontory and look down one lake twenty miles to Como; and this view is similar, though finer, from the mountains being higher and more delicate, to the view down the North River, from Koscinsko's monument; and then on the other side, you look as it might be mpon a portion of the river running between Crow-Nest and. West Point dock, some twenty miles also down the lake to Lecco; you then look up, as if to Newburgh, and see, at about this distance (nine miles) the Alps, in snowclad majesty. The whole promontory does not, we believe, exceed fire acres, rising conically perhaps six hundred feet from the water; but the walks, which are graveled or pared with very small pebbles, are three or four miles in extent, most admirably managed by means of dense plantations, tmmels, and bridges. The promontory from the lake seems hearily wooded; and yet everything has been done by art. The deep shade has been produced by the most charming undergrowth of cypress, lamrel, casuaria, myrtle, and English Jews.

Yon enter throngh a carern into a glen, quite spectral in its midnight darkness, surrounded by immense Italian pines, and an undergrowth of yew; you are then let out, as it were, into diylight, and into a charming peep of one of the lakes, by the most delicate gradations of dark to light, first going through not only the colors bit also the changes of form of the following trees: Cedars of Lebanon. Pims excelsa, deodars, and weeping larches, which actually ware and dance you out into the sunlight.

After these trees, you shortly commence in the midst of a blazing sun, among the most feathery and delicate of the acacias, and grow cooler and darker with the coarser rarieties, and the rose acacia, all enchantingly entangled with the Chinese wistaria, which here flowers 


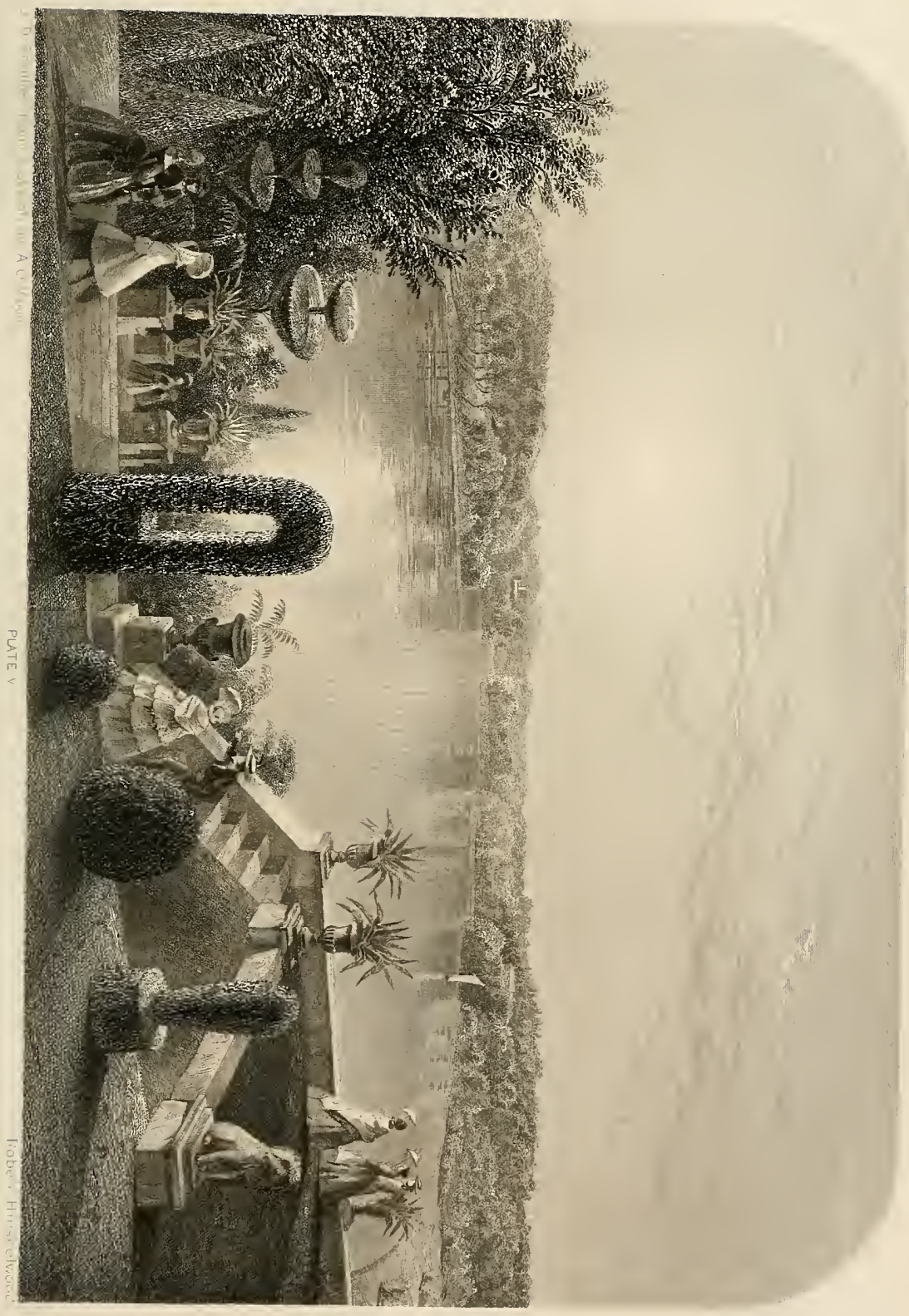


<smiles>C1=CCCCCCCCCCC1</smiles> 
all summer. After struggling throngh purple beeches, and some other dark folinge, you get out through a lovely grove of araucarias, I'inus excelsa, P'inus longifolia, and Abies Donglasii; from this you emerge iisto is little lawn, quite sumpounded by highl elifl's, covered with superb plantations of aloes, bananas, pepper trees, and white and scarlet horse-chestunts, and a collection of rhododendrons, dazzling from their gorgeonsness.

This lawn was devoted to magnolias of every possible variety, of which some eight or ten sorts were, when we saw them, in flower-the air being lieavy with their perfume. 'These were in masses and as single specimens.

Yon left this oasis by the only way it seemed possible to get out-a cavern in the rocks, through which you passed, mutil yon again entered profonnd darknessgradually the light returned-at last you reached a point from which two vistas opened, one down the lake to Como, the other down the lake to Leeco; yor looked at these as at a picture through a darkened tube, for the cavern was formed apparently for this purpose; these tunnels led yon out to a walk bordered by natural rock, perhaps twenty feet high, covered by Lamarque and the Banksian roses in such a profusion of bloom, that the wall had the appearance of being painted white and yellow. On the other side the walk was bordered by masses of choice azalias, in every variety of color, and flowers some eight and ten feet high. . Passing a charming cascade overhung with weeping becches, waving birches, and different varieties of willows, the walk led throngh a maze of Judas trees (pink and white), all the varictios of double thorns, the laburnmm (purple and yellow), and becoming umbrageous and mazy, with purple beeches, purple berberries, and purple filberts; finally came ont again clear and bright through different varieties of heath and acacia, upon a little platform 
looking up the third lake, and to the snowy Alps, and down a perpendicular precipice of some six hundred feet into an exquisite flower garden below, into which, you are prevented from falling, by a parapet interlaced with erery rariety of honeysuckle and clematis.

The other walk from the carern led along a similar mall of rock, pierced with holes, haring an occasional frame of rustic work, covered with air plants (orchids) and parasites. This led by a grand terrace, balustraded and statued, and commanding the three lakes to the palace.

We have attempted to give our recollection of this wonderful spot; not that we expect it to be a model for anything YET to be done in America, but because it is the only place we remember to have seen in any part of the world which we have risited where a great work of art has been produced in a rerr considerable degree by the forms and colors of trees. The dim and sombre effects of the carerns and tunnels hare been marrelonsly extended and increased by the deep, dark, purple colors selected for this purpose, while the gay, graceful, sparkling spray and glitter of the fairy-like acacias, are so blended and interworen with the sunshine that one cannot but feel, how much even nature, grand as she always is, can some times be aided by man. There are many bold and prominent bluffs and promontories in this country on our beantiful and picturesque rivers and majestic lakes where much of the artistic beauty of Bellagio can be accomplished by judicious and tasteful planting, and although we have not a climate which admits hedges of oleander and myrtle, at least at the North, yet when we know the colors, forms and habits of many trees which hare as yet never been employed in ornamental landscape, we shall be surprised to find how much material we have for proaucing the most remarkable and the most pleasing results. 


\section{SECTION III.}

THE NEWER DECIDEOUS ORNAMENTAL TREES AND SHRUBS.

$W_{\mathrm{E}}$ do not intend in this section to occupy the attention of the reader by any preliminary remarks as to the ornamental or practical value of any of the varieties we shall describe. Mr. Downing has already, to a great extent, done this in the preceding portion of the book. It remains for us simply to introduce to planters such new scions and connections of their older friends - the results, sometimes of inter-marriage between the ancient families, producing hybrids and crosses-and sometimes from the new discoveries of trees, which the increased intercourse all over the world has enabled collectors and societies to make. With this introduction we shall proceed at once to describe those trees and plants omitted in the previous edition and which our observation has induced us to believe are well worthy the attention of amateurs.

\section{Acer. The Maple.}

A. Campestre, erroneously campestris of the Catalogues (the Common or English Field maple).-This is a beautiful, compact, round-headed tree, or rather bush, rarely exceeding twenty or twenty-five feet in height, and, if allowed to assume its natural shape, quite as broad as it is bigh. This tree, which is one of the most ornamental of the maples, is very rarely to be met with, though common, we believe, in our best nurseries. It is a tree, above all others of its kind, suited to small lawns, where it should stand alone, or on the outside of loose gardenesque groups, where it is accessible on all sides; since the character 
of its growth is so regular and formal (in shape of a bee-hive), that it does not harmonize with wild or picturesque plantations, but is peculiarly adapted to the neighborhood of the house or to the more formal trees, like the horse-chestnut and linden. The finest specimen we recollect to have seen, is at the late Mr. Downing's, which is nearly fully grown; a specimen at Wodenethe, about fifteen feet high, and nearly as wide, is extremely beautiful. The largest specimens in England are at Kew, fifty years planted, twenty-six feet high; at Milbury Park, one hundred years planted, thirty-eight feet high. It should nerer be trimmed up; on the contrary, if by accident the lower limbs are injured or lost, the tree should be severely headed back to encourage new growth from the ground.

A. c. foliis variegatis (the Variegated maple). - A variety of A. campestre-rery much of its character and habit, though perhaps a little looser. This tree is extremely pretty and effective up to mid-summer, especially when placed on the boundaries of plantations, as it catches the light well; after July, it is apt to burn and get shabby during the dry weather. There is another Striped or Blotched-leared maple, which is a rariety of the A.pserdo platanus, which is still larger and less compact than the preceding, and equally worthy of being planted by those who funcy rariegated-leaved trees.

A. macrophyllum (the Large-leared maple).-This superb tree, a mere mention of which appears in a note to the previous edition of this work, was introduced into England in 1812, and has only within a very few years made its appearance in this country, and we hare, of course, no specimens of any size. It is described in its native state as varying in heiglt from forty to ninety feet, very graceful in form, with branches widely spreading, the wood soft, but beantifully reined; specimens sent home by Mr. Douglas, exhibit a grain scarcely inferior to the finest satin wood. Though the leares rary much in size, yet they are by far the largest of the maples; this, with its hardihood and great size and loftiness, renders it one of the noblest of its kind, and it should invariably be planted where there is sufficient space for its derelopment.

A. Monspessulanum (the Montpelier maple).-This is another of the newer maples but lately introduced here; though of 
small habit of growth, yet it is very ornamental, the leaves resembling somewhat in size and color those of A. campestre : the flowers are pale, and are very attractive to bees. In mild seasons, in Europe, the leaves remain on the tree until midwinter, and on this account it is much planted in France for hedges. It rarely attains a greater height than thirty to forty feet, and is readily propagated by seeds or by layers.

A. p. laciniata (Cut-leaved or eagle's claw).-A very curious low growing tree, with the lobes of its leaves jagged and somewhat resembling, as its name implies, the foot or claw of an eagle. It is one of the varieties of $A$. pseudo-platanus, and comes in well with the cut-leaved ash, beech, and other trees with this peculiar foliage.

A. $p$. foliis purpurcis (the Purple-leaved maple).-Another sport or variety of $A$. pseudo-platanus, very peculiar and striking when the wind blows, the leaves having a fine purple underneath, and being ruffled by the breeze, presenting a curious blending of purple and pale green; the foot-stalks to the leaves are quite distinctly pink. This tree is commonly known in the nurseries as the Purple Jersey maple, it having originated in a nursery in that island in 1828. Plants raised from seed sport so much in color that sometimes they become quite green. On this account, specimens for planting should be selected from the nursery rows while in leaf.

A. p. Turtaricu (Tartarian maple); A. Creticum (Cretan Maple), Hodgkins' Seedling, with yellow blotched leaves; $A$. punctata, with spotted leaves, and several others, are only sports or varieties of $A$. pseudo-platanus, and have not yet, to our knowledge, been planted in the United States.

\section{Alsculus hippocGistanum. THE Horse-chestnut.}

XI. h. Flore pleno (Double-flowering horse-chestnut).-A beautiful variety of $2 E$. Tippocastanum, resembling it in character and foliage, but with the flowers double and very full, not unlike at a distance, a gigantic hyacinth. The tree seems perfectly hardy, and has the additional advantage of flowering when very young. 
A2.h. coccinea (Scarlet-flowering horse-chestnut).-This differs from the Rubicunda simply in color of its flower, being a deep scarlet. It is very hardy, flowers early, and is, perhaps, the most striking floral tree of the season. The specimen we have, about ten feet high, is the only one we have seen in this country, but we hardly know an ornamental tree more deserving of notice.

E. h. variegata (the Variegated horse-chestnut).-This is simply a variety with blotched leaves; in fact, there are two, one mottled with white, the other with yellow; whence, the distinction of gold and silver-leaved. We do not regard either of them as particularly handsome, having more the appearance of disease than a regular blotch; and we consequently would only recommend them for arboretums, or where one has a fancy for variegated trees.

AE. h. laciniata (Cut-leaved horse-chestnut). - A rery distinctive variety, with deeply cut leaves; in certain conditions of growth, the leaves have simply the appearance of threads. This is by far the most curious and interesting of all the cut-leaved trees, and we consider it very desirable even in small collections. It is perfectly hardy, and slould be planted by itself. It is still very rare.

Z2. $\%$. Whitleyi.-Whitley's New Scarlet is a rariety of Rubicunda, as are also $2 E$. Americana, and $2 E$. fol. aurea (Goldenleaved horse-chestnut). They can be had at our nurseries, and are well worthy the attention of planters.

The Pavias are simply varieties of the horse-chestnut, with smooth fruit and leares, and generally of lower growth, most of them are deserving of notice and one of them, Pavia macrostachya (the Dwarf white-flowering horse-chestnut), is rather a slurub than tree; but we hardly know anything more raluabe in the month of July, when covered with its long spikes or flower's, which are agreeably odoriferous.

Its habit of growth is peculiar, stoling from the root, and when standing alone, as it invariably should, making a magnifcent bush, much wider than it is ligh. It is a native, we believe, of North America, growing most abundantly near St. Augustine in Florida, and was only introduced into England in 1820, the largest plants being at "White Knights," twenty- 


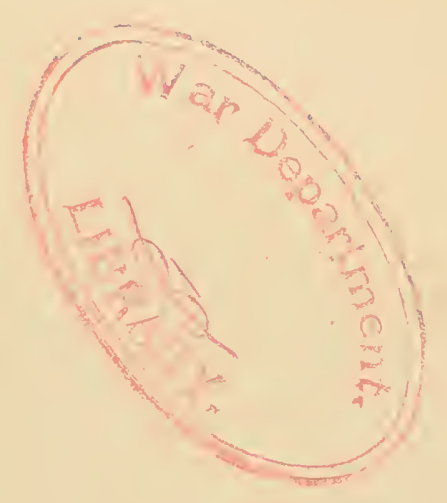




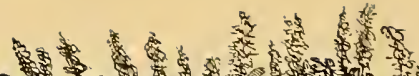

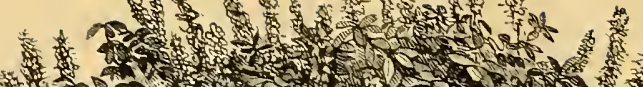

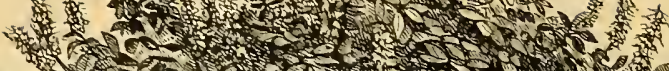

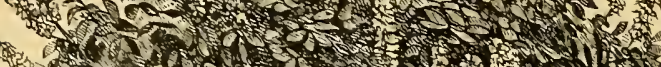

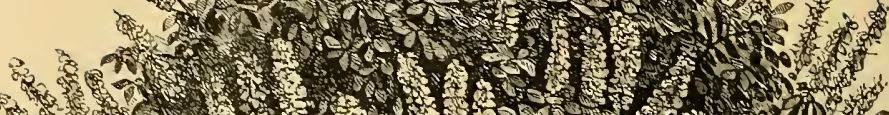
2.

7 .

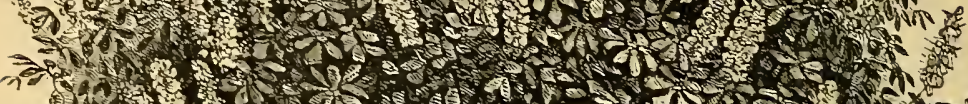

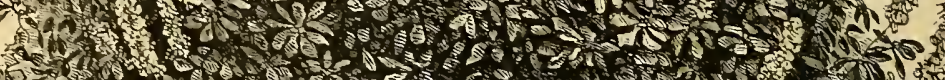

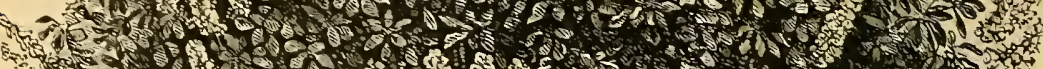

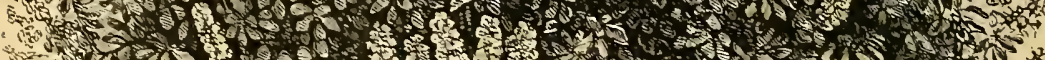

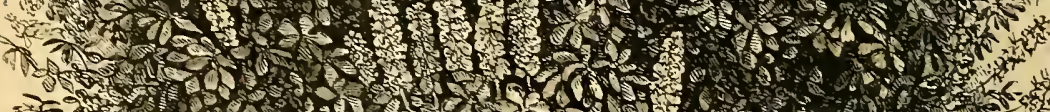
I.

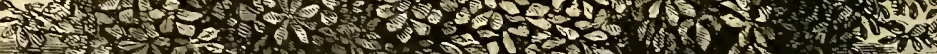

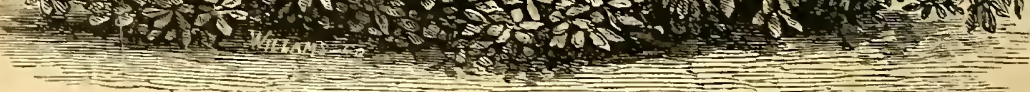

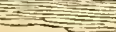
$+2=$

Fig. 91.-Diarf Horse Chestxut, at. Wodenethe. Age, 12 yrs. Ileight, $\mathrm{s} f \mathrm{ft}$ Cir. $60 \mathrm{ft}$.

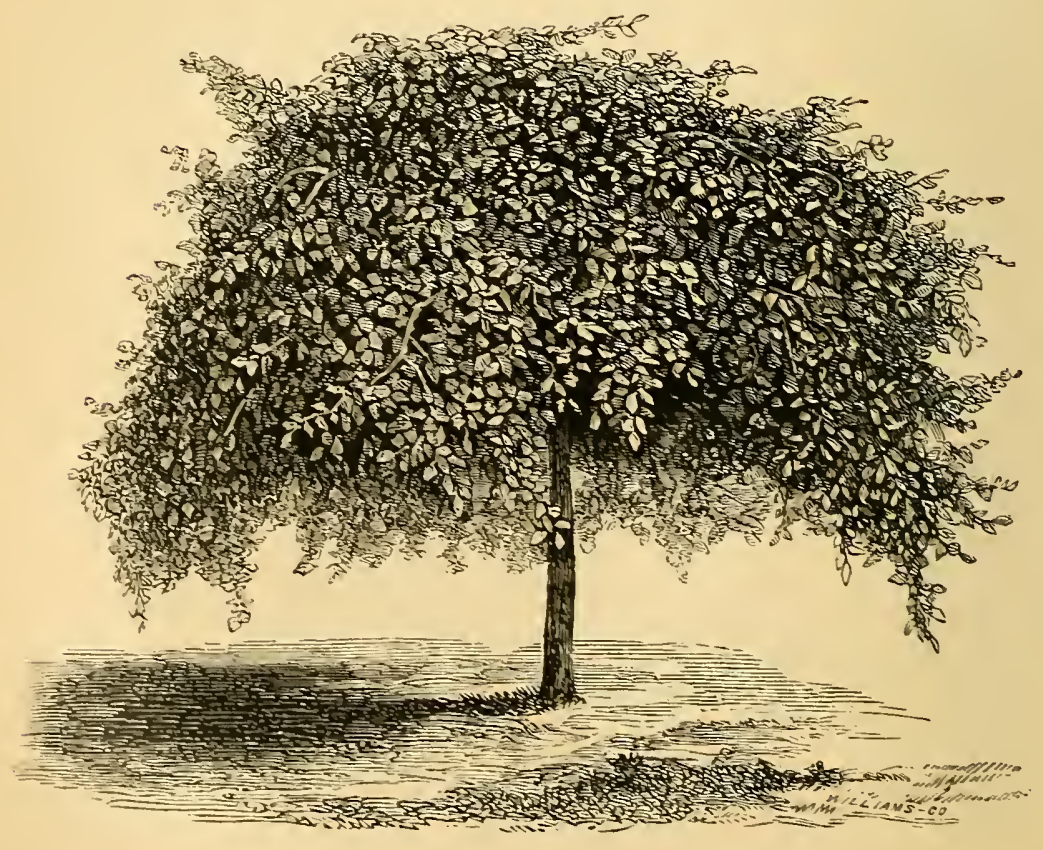

Frg. 92-Scaupstox Wetpixa Ely, at Wodenethe.

Age, 6 yrs. Height, $7 \mathrm{ft}$. Circum., $86 \mathrm{ft}$. 
five years planted, fifteen feet high. At Syon House, near London, there is a specimen, twelve feet. In this country, as yet, it is rarely to be met with in our ornamental places, which is the more remarkable as we do not know a shrub which should be planted before it. It comes into bloom a month or six weeks later than the other horse-clıestnuts, and at a period, too, when very few shrubs are in flower, and continues a long time. Our best plant at Wodenethe--of which Fig. 91 is a sketch-twelve years old, is sixty feet in circumference and about eight feet ligh, and has, at the time we write, between three and four hundred racemes of flowers, the feathery lightness of which, and the fine umbrageous character of the leares render it a most striking and attractive object.

Pavia rubra (Red-flowering), -which is merely mentioned by Mrr. Downing, and which is now better lsnown, is a shrubby tree, seldom exceeding twenty feet, with reddish flowers suffciently distinct to make it desirable-though Pavia humilis pendula (the Weeping red pavia), is even more desirable and attractive. Mr. Loudon considers this one of the most beautiful and interesting forms of Pavia, and recommends hor'se-chestnuts of twenty to thirty year's' growth to be grafted all over with it at the points of the shoots; care being taken afterwards, once or twice every year, to rnb off all the buds from the stock as soon as they appear, so that the entire force of the plant may be directed to the nourishment of the scions.

Paria carnea pubescens (Downy leaf), from the fact of the whole plant, including the young wood, being covered with pubescence.

P. purpurea (Purple); P. rubra atrosanguineca (Dark red); and $P$. carnea superba (Pale red), are all new rarieties to be obtained in this country, and of greater or less merit.

\section{Almus. The Alder.}

The principle additions to this genus, since the previous edition of this work, have been A. cordifolia, (Heart-shaped), a tree of some magnitude, a native of Calabria, with large, deep green, shining leares, rather broad and deeply 
heart-shaped, growing rapidly, and, we beliere, perfectly hardy-at least, we hare found it so at this place-and $A$. quercifolia (the Oak-leaved alder); although MIr. Downing places little value on the A. glauca (our common Swampalder), yet we must confess, we hardly know a more charming plant in the winter, when covered with its bright scarlet berries, especially when placed against hemlocks or other evergreens; and we are quite confident, that planted in this manner it only needs to be seen to be more generally employed.

\section{Betula. BIRch.}

The only new rarieties lately introduced of the birch are:

$B$. daurica (the Daurian birch), from Asiatic Siberia, which is supposed to be only a variety of $B$. alba, not growing as tall as the common birch, nor does the trunk attain the same size, though the wood is both harder and yellower.

Betula laciniata (the Cut-leaf birch), as known in our nurseries; an exceedingly graceful, pretty tree, with a light, airy growth, inferior, however, to a still newer variety $B$. laciniala pendula (Pendulous cut-leaf), which is quite the prettiest and most feathery of the birches.

B. nana and B. pumila (the Dwarf and low growing birch). These two are merely shrubs, both natives of the northern portions of America, and the latter found in Srreden, Norway, and Russia ; and growing only two or three feet high, merely valuable as carrying out the class in arboretums.

\section{Castanea. Chestnut.}

The principle additions to this genus, since the first edition are: Castanea asplenifolia (Cut-leaf chestnut), a rery remarkable and peculiar rariety, with its leares in shreds; and $C$. variegala, foliis-aureis, and follis-argenteis, (the Goldenleared and the Silver-leared chestnuts), both rery striking and showy, especially when planted against or near evergreens, the golden variety being particularly gay. Small plants of this tree hare, at Wodenethe, blossomed when 
only two feet high, but whether this is the habit of this variety, or accidental, we are not prepared to say.

We have also here (received some years ago from Mr. Rivers, we think), a dwarf variety, called Dwarf prolific, which has the merit of fruiting when a small shrub.

\section{Cercis. Judas Tree.}

The only addition to this variety, which has appeared within the past few years, is Cercis foliis-variegatis (the Variegated-leaved Judas); the leaves blotched and streaked with white, and sometimes pink and white splashes; desirable, but at present very rare. We procured our plants, we believe, from France.

\section{Fagus. ВеЕсH.}

There are several varieties of this tree, which have been introduced into cultivation within the last few years, well deserving of notice, and some of them very curious and interesting; among these is, Fagus laciniata, called also $F$. asplenifolia and $F$. incisa, and known in the nursuries as Cut-leaved, Fernleaved and Various-leaved beech. We have all these plants under the different names, but, except the occasional sport, which the beech is peculiarly liable to, we believe them to be identical; sometimes resembling a fern, which is the most usual, and others again with leaves very oddly cut and shredded, as it were, by insects. The Fern-leaved beech, commonly socalled, is a great favorite with us, and we hardly know a prettier or more attractive tree, or one less known or planted; if we could plant but half a dozen trees this would certainly be one of the first. It has the close round habit of the beech with a pleasing green and glaucous color, and the most tiny and delicate foliage, the persistency of which would make it rery desirable for topiary work, as it bears the shears better than any deciduous tree we know of. Its maximum height is forty to fifty feet, but we have seen no specimen in this country over twelve to fifteen feet; its arerage annual growth being twelve to fifteen inches. 
Fugus cristitu (Crosted or Curled-leaved beech), is more "urions than interesting, and is what MIr. Ioudon called a "monstrosity," with leares small, ahmost sessile and erowded into small tuits which oeemr at intervals along the luranches: it mever beromes a large trece.

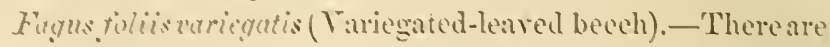
two variories of this, the Colden and silvere: the latter being the most striking.

'There is also another most ahaming variety- $F$. Cuminghamia (the Freregreen beech), with leares emrously small, but which does not stand on climate in this vicinity, but, which in the Sonthern States. we have little donbt, wonld be quite an acequisition to the Evergatentres. In comnetion with the beed we would also mention threa new varieties of Curpinus (Hornbeam). C. perduler. a pretty wereping tree, smd the Golden and silver-leaved varieties, resembling very much, though interior to these same rarieties in the beech.

\section{Fraxinus. AsIr.}

There are tive or six rulieties of this tree, mot mentioned by Mr. Downing: that are woil deservingattemtion: the most striking and ravest. perhaps, is $F$. andugrolia (the Anemba-leared ash). 'The leaves blotehed wirh yellow, like that well-known English shrub, the -tureber fipunicer, and to sneh an extent that at at little distamer' a tree of some age has the appearamee of this plant of extruordinary size : on the edges of plantations it catches the light so well that it works nip to great advantage, and hats so strongs a resemblance to a tree in thower that it is constanty raken for one. The tree is yet very rate. a plint we obtained a year or wo sine from Jessers. Fllwanger and barry is the mily specinem we have seen.

F. enrea (Golden :sh). and $F$. aurea pendulat (Weeping Gohden ash), are both rery desirable varieties : the eolor of the wood of a rich golken yellow, being rery striking in wiuter when contrated with the snow. quite as maked as the Goldan willow: on this acoount it would be well to plant it in sight from the windows of the house. 'The latter tree is, with us. 
quite as hardy as and a great improvement upon the old Weeping ash.

Fr. salicifolia (IVillow-leaved ash). - This is another of those remarkable thin cut-leaved trees, of which we have specimens in the beech, horse-chestnut and even the oak. 'Tlis is a most rapid and robust grower, and would, undoubtedly, be taken for a willow, by persons not very familiar with trees-and though not particularly handsome, still it is well deserving a place in all collections, where striking and eurious plants are desired.

Ir. glubosa viridis or myrtifolia (Myrtle-leaved ash).- $\Lambda$ seedling, if we mistake not, of Messrs. Ellwanger and Barry, from whom we procured the plant some years ago; is wlien grafted standard ligh, a very pretty effective little tree, with a globular - liead of small close, dark green foliage like the myrtle, and comes in very well, standing by itself in small pleasure grounds, or peeping out of low masses of shrubs.

$F$. argentea alba. $-\Lambda$ very singular variety, with leaves entirely white, and when planted with the aucubcefolia, the leaves of which are quite golden, producing a remarkable effect, like gigantic flowering plants. We do not know the history of this singular tree, and have only seen it at Mr. Daniel Brincker. lioff's, in this neighborhood, who has the impression he procured it some years since, from Mr. Rivers of the Sawbridgeworth nurseries in England. It differs from the varieties known in the English nurseries as $F$. argentea, from the peculiar whiteness of its foliage; the argentea being generally streaked with green, though it may be a sport of this tree. It is apt to suffer vely much in June from the insects which, apparently attracted by the white foliage at night, greedily devour the leaves, though all the other ashes standing by escape untouched.

$F$. lentiscifolia and $F$. lentiscifolia pendula, are both desirable trees, with neat, narrow foliage, and rapid growth. The Pendulous-branched we have found the most rapid of the ashes. The Weeping black and Gold-striped weeping, both pretty; $F$. atro-virens, remarkable for its dark foliage; $F$. bosci, with dark glossy foliage, and woolly shoots; $F$. juglandifolia (Walnutleaved); $F$. monophyll , single, instead of pinnate leaves; $F$. 
elonga Japonica pannosa, Nova Anglica, oxyphillas and scolo. pendrifolium, are all new varieties, for arboretums or very full collections.

\section{Magnolia.}

There are several newly introduced varieties of this beautiful tree which deserve attention: anong them may be mentioned, $M$. Thompsoniana, a fine distinct variety, probably a cross between glauca and tripetala, quite as hardy with us as either parent.

M. speciosa, M. gracilis, M. Alexandrina and M. Nortbertiana.-These four varieties so closely resemble $M$. Soulangiana, that we think they can be only seedlings, differing a little in the mingling of the white and purple, which is the color of their flowers.

IT. Nortbertiana, being whiter in its flowers, may probably be a seedling or variety of $M$. conspicua; $M$. gracilis is unquestionably only a more slender delicate variety of $M$. purpurea, having much darker flowers, especially when half expanded; II. Alexandrina flowers earlier than its parent.

Another desirable variety is M. longifolia, which is often confounded with and sold for M. Thompsoniana, and is intermediate in appearance between $M$. tripetala and $M$. glauca; the leaves are acute at both ends, longer than Thompsoniana, and resembling tripetala, but thicker, smaller, and glaucous underneath; the flowers are very sweet but not as large as $M$. Thompsoniana.

MI. galissoniere.-A plant of which we imported from France two years since, is said to be the only variety of the $M$. grandi. flora which will stand our climate, and as it resists the cold of the north of France, it is not impossible it may be acclimatized here. We do not know that it has been sufficiently tested at present to be able to class it among our hardy magnolias. 


\section{Quercus. OAK.}

We have but few additions to make to this genus, and these rather of the fancy order.

Q. laciniata (Cut-leaf oak), known also as $Q$. salicifolia and Q. filicifolia, is a curious variety, with leaves deeply cut at the edges and laciniated.

Q. foliis variegatis (Variegated oak), both gold and silver, with leaves rariegated with white or yellow and occasional streaks of red; well grown, quite showy and ornamental.

Q. purpurea (Purple oak), has the foot-stalks of the leaves and its young shoots quite distinctly tinged with purple-even the young leares, when they first appear, are very dark, as much so as the Purple beech, and, like this tree, becoming greener as the season advances.

But of all the newer varieties recently introduced here, the Q. pendula (Weeping oak), is the most distinctive and remarkable. We have as yet, we believe, no trees of any size in the country. The largest tree known is at Moccas court, in Herefordshire, England, which Mr. Loudon (Arbo: Brit. vol. 3. page 1732), describes as ono of the most extraordinary trees of the oak kind in existence; the height of the trunk to the first kranch is eighteen feet, total height of the trunk seventy-fire feet, with brauches reaching from about the middle of its height to within seven feet of the ground, and hanging down like cords ; many of these branches are thirty feet long and no thicker in any part of their length than a common wagon rope. There is another variety of Weeping oak to be found in our nurseries, and which we have had here, but the inclination of the branches is more rigid and less pendulous and graceful than the Moccas oak, and we much doubt, if we have ever had this species here.

To persons curious in trees, or who are desirous of making plantations of the many dwarfs at present quite the fashion in England, we would suggest here two varieties of oak interesting for this purpose; viz., Quercus humilis (the low growing oak), a native of Europe, where it never exceeds a height of three to four feet, and in the Landes near Bordeaux, not over one foot; and Q. pumila (an American dwarf), which seldom exceeds twenty inclies. 


\section{Salix. Willow.}

There are three or four charming varieties to add to this well known genus. Among them the newest, and perhaps the most remarkable, is the Kilmarnock Weeping, quite distinctive, with a very pendulous but close habit of growth, so much so, that the branches, at least in young trees, are quite hid out by the large glossy leaves, which, at a little distance, are not unlike the apple leaf. It seems perfectly hardy, and, with the one next mentioned, may be very appropriately planted in pleasure grounds, where the other and larger willows would be out of keeping.

S. Americana pendula, an American dwarf variety, with very slender and graceful branches, or rather shoots, which when grafted six or seven feet high, hang down like whipcord ; this variety, we think, was first noticed by the late Mr. Downing in River's' nursery, and very prettily described by him as the Fountain willow, which is a much more expressive and appropriate name than the one it now goes by in the nurseries. It should always be grafted on what is called the Stock willow; if upon its own roots or worked even on itself, standard high, it becomes nothing but an awkward distorted shrub.

S. rosmarifolia (the Rosemary-leaved willow)--Is another exceedingly pretty little lawn tree, with delicate rosemarylike leaves; this should also be worked standard high.

The Huntington willow, with large, beautiful, shining leaves, and a variety we imported from France a year or so ago, called $S$. pentandra, described there (though it has not yet realized its reputation with us), as a beautiful tree, with leaves like the laurel, are all the newer varieties proper for ornamental planting.

\section{Sophora. The Sophora.}

Lin. Syst. Decandria, Monogynia.

This genus, the only hardy variety of which is deciduous, is a native of Japan, and is highly ornamental. There is not, to our knowledge, any large tree of it in this country, and from this fact, perhaps, and from its great rarity, it was classed by 
Mr. Downing among the shrubs. It is in reality a large tree when grown, forty to fifty feet high, with pinnate leaves, and producing large branches of cream colored flowers in August. It is quite distinctive in winter, by the dark green bark of its young wood; and in summer by the dark blue green of its foliage. Near Paris there are some trees sixty feet high. It grows rapidly and is peculiarly adapted to the United States from one remarkable property of its foliage, which is the power it has to retain both its leaves and their color in the very hottest and driest seasons, when locusts and acacias and other pinnated-leaved leguminacece are apt to lose their foliage.

The flowers, it is said, in China make yellow dye of so superior a color, that it is reserved exclusively for the use of the Imperial family.

S. pendula (Pendulous or Weeping sophora), is more commonly met with, perhaps, than the upright sophora, though even this variety is very rare. It has long pendulous shoots; grafted near the ground it becomes a mere straggling plant, but, ten to twenty feet high, we hardly know anything more ornamental or striking; even in winter, the long slender branches of beautiful bright green render it most attractive.

There is a third variety, variegata, but the color of the leaf is sickly, and we do not consider it desirable, except for arboretums.

\section{Pyrus. Modntain Ash.}

A very pretty and marked addition to the rarieties heretofore known, and described is Pyrus pendula (Weeping mountain ash), with extremely pendulous branches bending quite to the ground, and then rambling along it if not stopped; a most rapid grower, more so, we think, than the common mountain ash, and a very great bloomer.

$P$. nana (Dwarf mountain ash).-This is a very stunted variety of slow, close growth, but quite remarkable for the luxuriant corymbs of coral berries in the Autumn.

$P$. quercifolia, a distinct variety with large, hoary, oak leaves; $P$. striata (Striped-leared), $P$. vestita (White-leaved), the young shoots and the under part of the leares being as clearly 
white as the Sirver poplar. The Yellow-berried, the Largefruited gray, the Large-firuited red, and the Large-fruited rose, are all deserving notice where there is ample space for planting.

\section{Tilia. Line or Linden.}

The only varieties of value to add to those previously enu' merated in this book, are T. laciniata (Cut or Jagged-leaf linden), with the leaves curiously cut; and $T$. pendula alba (Weeping White linden), of a very pendulous habit, and the under part of the leaf very silvery. We esteem this one of the most, if not the most ornamental of the lindens.

\section{Ulmus. ELy.}

There are a good many new elms lately introduced, which are quite remarkable in their habit, and distinctive in appearance; among them are two Scotch varieties of weeping elms, the Scampston (of which Fig. 92 is a portrait), and Camperdown, both somewhat allied in appearance, though the first is the most remarkable, having fine large foliage, and the most extraordinary droop to the branches; so much and so regular and formal is their inclination, that it is difficult to believe artificial means have not been resorted to. When grafted as it should be, fifteen to twenty feet high, the branches make a curvilinear droop to the ground, with a growth so regular and symmetrical as to give the whole tree the appearance of a gigantic arbor; regularly trained and trimmed, and by making an arched opening on one side, it can be well used for this purpose, the thick umbragecus character of the leaves producing the most agreeable and dense shade.

The only material difference between this tree and $U$. Camperdown, is that this last is of a more open, loose foliage, and rather less regular in the droop of the branches. They are both, however, very fine trees and well worthy the most prominent positions in the lawn-care being taken that they shall bave ample space for their development. 
U. glabra pendula is another fine variety of Weeping eim, but far inferior, we think, to the two above mentioned.

$U$. montana pendula, and U. rugosa pendula, (the Scotch weeping), and (Rough-leaved weeping), are also very desirable Weeping elms.

The Huntington elm is a rapid growing variety, with a fine large leaf.

The $U$. articofolia, (Nettle-leaved); $U$. variegata; (the Variegated); and $U$. purpurea, (the Purple), are all curious and desirable in large places; as is also U.adianthafolia, a strong rugged variety with corrugated and crimped leaves very peculiar.

\section{THE NEWER ORNAMENTAL DEOIDUOUS SHRUBS.}

Before enumerating the many new and beautiful shrubs which have been introduced into our gardens and pleasure grounds within ten years, we wish to say a few words respecting their employment.

We have before remarked, in another place, that the facilities afforded by railroads and steamboats are now so great, that there is a class, and a large one, of small suburban places and villa residences in the neighborhood of our large cities and rural towns, to which this kind of plant is especially valuable. In residences of a few hundred feet square to an acre or more, shrubs are much more valuable than trees, as the latter, when fully matured, become so large and cumbersome as to interfere very much with a free circulation of air, and often completely shut out all view, and are apt to make the places themselves damp and dreary. There are many of these residences where trees should never be planted, but their place should be supplied by the finer shrubs, as the Weigela, Forsythia, the Fly honeysuckie, the smaller Magnolias (glanca, purpurea, gracilis, conspicua, soulangiana), the Purple berberry, the Purple filbert, the Variegated syringo, the Dwarf horse-chest- 
nut, the Fern-leared beech, the Oak-leaved hydrangen, the Red-twigged dogwood, the Double Japan quince, the Dentzia gracilis, and the different hardy English and Belgic azaleas, among the decidnous shrubs. And among the evergreens, the English and Irish yews, the different Junipers, the different Arbor-ritæ, the Weeping cypress (Cupressus oblonga pendula), the eight or ten rarieties of Dwarf firs, the Thuiopsis borealis, a beatitiful and hardy plant from Baffin's Bay; the Hemlock, if kept clipped and bushy, the various Rhododendrons, especially the Catawbiensis; the Lamrelleared holly (Ilex laurifolia), the American holly, and finally that most raluable of all shrubs, the Berberis mahonia. By a tasteful and judicions massing and grouping of the abore plants, with occasionally a single specimen by itself alone, as the English yer, or Drant horse-chestnut, or Fern-leaf beech, a very pretty and ornamental effect may be produced, without shutting ont the light of hearen, as is too often done by tall sparse trees, with long naked stems, producing no other sensation but a shudder at their ugliness.

In subnitting the annexed list of the newer shrubs, we regret our space will not allow us to do much more than to emmerate their names; merely premising that the most clesirable are those we have already just mentioned abore.

Aralia Japonica, a new rariety of A. spinosa (Hercules' club), but much finer in folinge, and rery highly esteemed in England; hardy.

A. paprripera (the Chinese Rice-paper plant).- To have but recently imported this, and do not yet know its hardihood; it has superb leares some three feet or more in diameter.

Ceanothus.-The ceanothus, of which there are sereral rarieties, are beautifnl shrubs, with white or blue clusters of Howers.

Comus variegala (the Tariegated-leared dogwood). - A rery 
prettily striped leaf, and contrasting agreeably with the othen varielies.

Daphne atro purpureum. - A very marked variety of Mezereum, with purplish leares.

Deutzia gracilis, and D. scabra.-Two very desirable shubs introduced some six or eight years ago; the gracilis being perhaps, the most charming shrub at the period of its inflorescence; it has also the merit of bearing foreing well in a green-house, though perfectly hardy.

Ilea Caroliniu (the Carolina itea).-A charming little shrub which does best in the strade.

Leycesteria formosa (the beautiful leycesteria).

Ligustrum, foliis aureis, and argenteis (the Golden and Silver striped privet).-Very pretty and desirable, mingled with the green privet.

Forsythia viridissima.-The very green Forsythia is certainly one of the most desirable among the new shrubs; its flowers, a bright yellow, appear very early in the spring, succeeded by a deep, dense foliage which in winter is sub-erergreen, hanging on to the plant and retaining its color until long past Christmas. Like the magnolia, it appears to more advantage when planted against evergreens.

Persica vulgaris flore pleno alba (the Double whitefflowering peach).-Beautiful, especially when planted by the Double pink.

Ribes sanguincum fiore pleno, and $R$. speciosum.-Both beautiful varieties of the Flowering eurrant. The first a great improvement on the old $R$. sanguineum, and the last with long pendulous red flowers, like a fuschia.

Sambucus flore pleno, S. foliis aureis, $S$. foliis argenteisNew and striking varieties of the Black or Common elder, as yet very rare. We have found them hardy and most luxuriant growers; the Double-flowering is very striking, but the Silver and Gold-leaved are much more so. We presume they ean now be procured at our nurseries, though we obtained ours from M. Leroy in France.

Spiraa callosa, S. Douglasii, S. Lindleyana, S. Nepalensis, S. prunifolia, S. Reevsii, S. $r$. flore pleno, are all the finest 
among the new Spireas: 'xecedingly haty and desimble, cs-

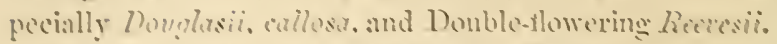

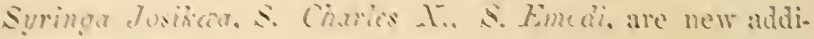
cions to the chamming tamily ot litars.

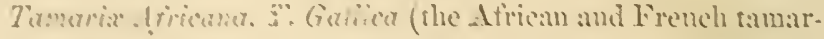
iks). are rery metị amat desirnble.

Wit ser rosea (the liosy weigela) is perhaps, take it all in all, the gareatest acepistion to our hardy shrubs within the past ten vears. We lam dy know a more lowely plant or more abmatams blowmer: the whire and pink thwers resembling apple blossme, almost cover the plant with a sheet of blow. 


\section{SECTION IV.}

IELMATKS ABOU'T' IIALF-MARDY I'LANTS AND 'THE NEWES

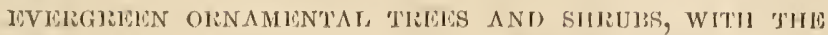
METHOD OF ACOLIMATTZING AN1) EMPLOYING THIST.

Permats in no one way laas the taste for planting more developed itself since the first appearance of Mr. Downing's book, especially during the past four or five years, than in the increasing predilection for evergreens, and prevaling desire not only to plant the better known and more common varicties, but also those of more recent introdnetion.

$\Lambda$ lmost every one, even with the smallest place, now plants not only the Norway spruee, and the Austrian and Scoteh pines, but is even desirons of trying his land upon deodars, eryptomerias and ofher varieties, considered only as lnxuries in Mr. Downing's day.

The cost of many of these plints liaving been redneed from one or two guineas apicee, to filteen or twenty cents, the case with which they may be imported, at little risk, and the fincility with which they live, at least for one or two years, to say nothing of the fashion for evergreens now-il-days, are ecrtainly very strong temptations; but the actual beanty, great variety and contrast in character, habit, and color, and the entire liardihood of a great many new sorts, and the vast addition made by this class of trees to a winter's landscape, much more frequently seen now by owners of comntry places than when the tirst edition even of this work appeared, all combine to make it very desirable that some anthentic information should be given, which 
may be reliable as to what may and what may not be planted.

We have individuals enongh in this conntry who are willing to spend money liberally for trees if they conld find out what to buy, and how and where to plant. The early edition of this work, thongh quite up to the time when it was published, is now singnlarly mengre in its chapters on Evergreens, and there are probably at this moment in this country, collections, in extent and variety (though not in size of trees), greater than was the Pinetum at Dropmore, in England, which Mr. Downing refers to, in 1811 . We are quite sure there are over ninety varieties of evergreens, nearly all quite hardy in this middle portion of the Hudson, which are not mentioned in the first edition, and there are sereral distinct, beantiful, and hardy genera not eren alluded to, such as the piceas, of which there are at present known twelce distinct species, all, we believe, hardy here. Mr. Downing mentions seven abies, and we now have in cultiration, more or less general, twenty-thres more. We have growing in the difierent collections in this country, principally betreen Washington and Boston, twenty more pines, in addition to the fifteen he enumerates, twenty-five junipers, against one in the first edition; ten new (Thujo) arbor vitæ, and seren rews.

It may be objected that these are not all hardy. They may not be in one particular locality, but throughout the length and breadth of our land, we have a sufficient rariety of climate for erery thing, and if one cannot grow a tree on the shores of Lake Erie, one can, perhaps, in Pennsylrania or Virginia, or the Curolinas, or Florida. Besides, as we shall hope to show, a great deal more may be done in planting doubtful trees (than is done) by a judicions selection of site and soil. We further hope to show that in our best places where there is the desire and means to make large collections, that one should 
not discard a tree because his neighbor may have not been successful with it.

There are many reasons which may aperate against the success of a tree this year, and for several years, which may disappear in time. One consideration, and that an important one, is shelter. Plant a deodar cedar in the middle of a large and high field, thoroughly and entirely exposed to every blast that blows, with the full force of a summer, and what is worse, a winter's sun, and it is hardly possible it should survive. Plant the same tree in the same place with the colder winds broken and kept off by masses of evergreens, and shielded from the pernicions effects of the early spring sun, and the chances are your tree will succeed and flourish.

Again, persons are very apt to plant their new evergreens, especially if they are rare and costly, in what are called "well prepared" holes, that is, in holes redolent, perhaps, with guano, and with the richest, compost to be obtained; if the new plant is not killed immediately by over-dosing, it is at any rate so stimulated by excess of food as to make a succulent redundant growth of imperfectly ripened wood, which is sure to be killed back the first winter, and the tree become so enfeebled as to die ontright the second; or the plant may have vitality enough to struggle throngh this surfeit and after staggering for months, or perhaps a year or so, with this indigestion, manage to work into healthy, natural, unprepared soil, and erentually become a tree. Then again, our climate is constantly changing. This, we think, is conceded by every one who has wintered in the country the past five or ten years, and trees which could not or would not stand now, may five years hence; and, lastly, a tree, like a man becomes finally more or less acclimatized - it may get knocked about somewhat at first, but eventually learns to stand up and take care of itself. The Torreya, for instance (and we have 
many such trees upon this place) required an inmense deal of coaxing to reconcile it to to our northern and changeable climate. The first year we left it ont it was protected by a donble box, the interval between the sidings being filled with tan. The second year, the tree was sheathed in straw and protected besides by a single box, with a few air holes on the north; the third year it was open at the north, but protected on the east, south, and west, by a box with three sides. The fourth year a mat was substituted for the box, and the fifth year it passed alone throngh the winter, the extreme tip of some of its more exuberant shoots being a little injured-the wellripened wood being untonched-since when it survires our most severe weather without injury, and now takes its place among the really hardy evergreens. We should feel no more apprehension about its safety in our worst winter's than we should about a pine or hemlock.

A curious fact connected with this tree is, that plants propagated from cuttings before it became acclimatized are still tender, while plants propagated since its hardihood became confirmed, seem quite as hardy as the parent.

We are not prepared to say that a great deal of this care was not a work of supererogation, and that the tree might have done as well with much less protection, and for half the number of winters, but we were working in the dark; the tree was a native of Florida; it never had been tried here, and from the climate whence it originated, we did not suppose it would stand, and felt consequently disposed to take extra pains, for which we are quite compensated by the gain of a new and most exquisite variety, and the certainty of oul knowledge that all torreyas, from this plant at least, are are perfectly hardy in this latitude.

We mention this, simply as one illustration of a great many similar experiments, with results more or less successful, because we are quite sure it is within the 
experience of most persons who have attempted acclimatizing plants, that success not unfrequently is the reward, when from the habits of the plants, and the character of the climate from which they come, a contrary result might be anticipated. We remember in England some ten years since, seeing at Chatsworth a plant of Weigela rosea, in a house built, if we mistake not, expressly for it, because Sir Joseph, then Mr. Paxton, did not think it hardy-judging probably from the country to which it belonged; and now there is no more common and hardier shrub, and, we may add, more beautiful in the season, or one more generally planted in the Northern States. Mr. Loudon very truly observes, "That though the nature of a species cannot be so far altered as to fit an inhabitant of a very hot climate for a very cold one, yet that the habits of individuals admit of considerable variation, and that some plants of warm climates are found to adapt themselves 'much more readily to cold climates than others; thus the common passion flower, according to Dr. Walker, when first introduced into the Edinburgh Botanic Garden, lost its leaves during the winter, but in a few years the same plant retained the greater part of them at that season." The same author relates that plants of the common yew, sent from Paris to Stockholm, to plant certain designs of Le Notre laid out there for the King of Sweden, all died, althongh the yew is a native of that country as well as France.

"Every gardener," he says, "must have observed that the common weeds which have sprung up in pots, in hot-beds, or in hot-houses, when these pots happen to be set out in the open air, during winter or spring, have their leaves killed or injured, whilst the same species growing in the open ground are uninjured."

We have ourselves observed, that peach trees in pots, if by chance they are left out all winter, are destroyed, though the same tree in the ground can resist any 
degree of frost. The obrious conclusion to be drawn from this is, not that peach trees are not hardy, but nuder certain conditions are not hardy; which facts lead to this theory, that the habits of plants admit of a certain degree of change with regard to the climate which they will bear; that the degree in which this power exists in any plant, is only to be ascertained by experiment, by trying in the open air plants usually considered as tender, or which litherto have been kept under glass.

O ur usual method of acclimatizing a plant, is to select some very protected and shady spot, as the north side of a thicket, or what we prefer, the interior of some evergreen rood, and to prepare the holes six feet wide and three deep, with loose but poor soil, well drained with stones for the lower eight or ten inches, with barely compost enough to assist the tree through the summer. For the first two or three years in winter, a little mound of earth, eight or ten inches high, is put around the neck of the plant, to prevent the bad effects of thaming and freezing in a most sensitive part, and cedar or hemlock boughs, are placed round its branches; this corering diminishing year by year, as the tree obtains size and vigor, until it is omitted altogether. The plant, to ensure safety, is moved once or twice rrithin this wood, each time to a more exposed situation, which has also the additional adrantage (like root pruning) of checking all redundancy of growth. When it exhibits sufficient strength, it is transplanted to its final situation on the lawn-its cedar covering being renewed for a couple of winters-and, if it can be reconciled to the climate, it is now supposed to be so.

We have found it very perplexing to arrive at any thorough and satisfactory decision as to comparative hardihood of trees in different portions of the United States, from its being so difficult to reconcile the appa- 
rent diserepancies in the various returns which we have received from these places, and we are led, therefore, to these conelusions, viz: that the hardihood and success of trees depend not exclusively upon elimate, and that a few degrees of latitude, north or south, are of far less importanee than proper soil and sitnation, and that a thorough knowledge of what to do, which experience alone, after many mishaps, can teach, will often enable us to grow trees at the North and East which do not seem to sueeeed now at the West and the South. For instance, in the neighborhood of Natchez, within six miles of that city, and on an elevation of three hundred and twenty-six feet above the river, the Gardenia Florida, the Pittosporum, the Magnolia fuscata, the $\boldsymbol{M}$. grandiflora, the Olea fragrans, the Myrtles in variety, the English lanrel, the Laurestinus, thrive perfeetly.

The Deodar eedar and Cryptomeria Japoniea, never suffer except oceasionally from caterpillars, and become luxuriant trees; there being specimens of the former thirty feet high, and of the latter fifteen feet, with branches in both trees sweeping the ground. Cunninghamia Sinensis is also perfeetly hardy, and has reached a height of fiom fifteen to eighteen feet, and yet the Abies Snithiana is reported as not quite hardy and sometimes injured by spring frosts, though at Newport, the Abies Sninithiana is said to be the hardiest of all the spruces-more so even than the Abies excelsa (the common Norway). Again, in a report from Pennsylvania, in the neighborhood of Warrior's Mark, on the side of one of the Alleghany mountains, at an altitude above the sea of 1,020 feet, and in latitude $40^{\circ} 40^{\prime}$, and where the thermometer has indicated $23^{\circ}$ below zero, where even the Ailanthus, Catalpa, and Paulownia are annually cut to the ground, the Cryptomeria fiourishes, though browned, and the Deodar cedar survives, though making little or no progress, when the cedar of Le- 
banon, the Silver cedar and the Donglas fir are killed ontright. Now at Wodenethe, we find the Silver cedar and the Cedar of Lebanon much hardier than the Deodar, yet at Nemport the Cedar of Lebanon will not stand, and at Philadelphia, Mr. Meehan says the Deodar is killed on dry soil, and uninjured on wet; while at a conntry place near Boston, on a slope facing the south, withont any protection or shelter from other trees, Deodar cedar's plinted in 1S53, have been browned but slightly, though exposed to the sun all the day long. Cedars of Lebanon planted at same time, get more browned.

It is rery evident from all this, we think, that we cannot form any decisire opinion as to what is and what is not truly hardy in any one portion of the comntry, where we receire so many contradictory reports; but it does not follow that a failure for one or two years, unless very complete, shonld disconrage ns so entirely as to prevent on trying the same plant again in other situations and mnder different treatment. Becanse the Indian sprnce (A. Smithiana) suffer's from spring frost near Natchez, when the Cryptomeria and Deodar do not, let us rather hope to aeclimatize it by moring the spruce to a higher or drier situntion, where being more retarded, it will either ripen off its annual growth better, or push later in the spring. If the Indian spruce is hardier at Nerrport, where the thermometer sometimes gets rery low, than the common Norway, there can be little doubt but what it will grow near Natehez, when properly placed. If too, the Deodir cedar, and Cedar of Lebanon thrive near Philadelphia, in wet and low, instead of high and dry soil, it will be rery easy for planters of these trees in that ricinity to adopt this hint; while we, who have found the reve:se of this true, will act in accordance with our experience.

So also of the Crrptomeria-it it his been found to withstand a cold of $23^{\circ}$ below zero, on the Alleghany 
mountains, at an elevation of 1,020 feet above the seawhere eren the Ailanthus was destroyed, we cannot see why this tree may not stand in any other part of the country, at the same elevation, having no greater degree of cold, but always under the same circumstances and conditions. What these are, unfortunately, the tree only linows; possibly a frost, even as severe as this, at a great distance from the sea, may be less injurions than half the amount of frost near salt water' or the severe weather may come and go, gradually, withont the great variations common in the middle States; which variation we have always believed most destructive to regetable, as it is injurious to animal life; and finally, the conclusion we must inevitably come to is that the organism of a plant is as wonderful and mysterious as that of a man, and that, with certain general rules as to planting and treatment, we must grope in the dark until many more years of experience in different parts of the United States, enable us to know what we can and what we cannot grow. We trust, however, that some assistance may be obtained from the reports we have been enabled to procure from different parts of the country, by which planters in those localities will be able to do as well as their neighbors, if they can give their trees the same advantages.

Another reason why we proposed to give in this supplement a more complete account and list of all the evergreens, hardy and half-hardy, which have been introduced into this country of late years is (and we quote again in part from Mr. Loudon), that we think there are few scenes in an ornamental garden or pleasureground, of greater interest to a person having any taste or knowledge of Botany, however slight, than a collection of trees and shrubs, natives of foreign climates, which, though they would be destroyed if exposed in the winter, yet when planted (turned out), or sunk in the ground during the summer, exhibit a degree of 
beauty and luxuriance which they nerer do or could attain in a green-honse or conservatory; and whieh require in the winter simply the protection of a cool green-house, or in most eases of a eold pit suffieiently deep and protected to exclude the frost, and with facilities for oceasionally admitting air for ventilation.

A pit of this description, well drained and dry, and twelve or fifteen feet deep, might accommodate plants ten or twelve feet high, which, when planted out in the pleasure-grounds during the summer, the tub or pots being sunk out of sight in the soil, would produce the most extraordinary and eharming effects. By an introduction and eombination in on1 own grounds of bananas, palms, aloes, the different arundos (a species of bamboo), the different dracenas, the New Zealand flax (Phormium tenax), Bambusc metake (another rariety of bamboo), which we hope will prove hardy, the different Cannas, and a mingling of the rarer evergreens, like the Arancarias (of which Cunninghamii and excelsa are very effective), we have, we think, prodneed a very pleasing effect. These, with the Indian eedars, and Southem and Mexiean long-leaved pines, have quite changed a portion of our grounds from an American to a tropical and oriental landscape.

All these plants we have named, and the newer tender evergreens which we liave not as jet named, would winter saiely (excepting perhaps the arancaria excelsa), in a cold pit or cool green-honse, or a dry cellar, where there was some light and no frost. If we add to these the great variety and number of evergreen shrubs-the different evergreen Magnolias, the Hollies, the Lamrel, the Portugal laurel, the lialf-hardy Rhododendrons, all of which are too tender for our climate, we eannot but believe the time is not far distant when instead of keeping green-honses for the preservation of the ordinary green-house plants, persons of taste will build pits for the presers ation of half-hardy evergreens and ligneons 
plants, which, when judiciously arranged and combined in the summer, will alter the whole character of their grounds. We have in our eye at this moment, many fine places, both on this river and in different parts of the country, where large green-houses and conservatories are kept up all winter, at a great expense, and where the plants literally "waste their fragrance on the desert air," as the families are away in cities at too great a distance to admit their flowers being sent to them.

These rery places in summer present a very unattractive and meagre appearance, being planted simply with the older and less beantiful trees and shrubs-in many cases with little or no flower garden. The Camelias, Azalias, Geraniums, and other plants being stowed away out of sight, until the return of another winter, when they will again bloom for the benefit, solely, of the gardener and his friends.

Were these same houses at a consumption of one-half or one-fifth the amount of fuel and labor, deroted to the cultivation (or rather to the preservation, for they require no cultivation or attention in the winter beyond an occasional watering), of half-hardy evergreens and tender plants, the compensation and enjoyment from them in summer would be ten-fold that derived from the usual occupation of plant-houses; and in cases where families are permanent residents of the country, let them devote a portion of their green-houses to this purpose, or have some arrangement of pits as we hare above described.

We must bear in mind one fact: that as excellent models as the English are in all matters pertaining to country life, yet they use their places only in the winter, and we, as a general rule, only in the summer; while it is, therefore, very important for them to have their grounds and green-honses adorned with those plants and shrmbs which will make it most agreeable and delightful at the season when they are at home, in the winter, 
yet the reverse of this is true with us. Our object should be to make omr places as gay and interesting as possible, at those portions of the year when we live at them. What advantage is it to plant the beautiful varie. ties of double and single thorns, the Judas tree, the Forsythia, or the Magnolias in those places which the fimilies or owners do not reach until the season of their inflorescence is past; where one lives in the country from June to October, the whole force should be applied to those plants, shrubs, and flowers which bloom during these four months; and as a majority of our country gentlemen do not get ont to their places much before June, and are apt to become very restless after the early part of October, we think a selection of those plants should be made most useful and attractive during this time; and we do not know anything more effective than the proper mingling of some of the large showy exotics and tender evergreens we have mentioned. Of course we do not suggest this as general, but merely to those-and their number is now large-who have a taste for planting the newer and more striking conifers.

In concluding this section we will merely add: that with one or two exceptions, we have described only those plants and shrubs which we have ourselves seen, and which, in almost every instance, we have growing upon our own place. We believe that a correctness in description, and an honest statement of the merits and demerits of each plant, will, more than anything else, contribute to the main end we have in view-the extension of the taste for planting the newer deciduous and evergreen trees.

THE NEWER EVERGREEN ORNAMENTAL TREES.

Alies. The Spruce Firs.

Albies alba nana (the Dwarf White spruce fir-or Prostrate White spruce) is only a dwarf variety of our native White 
Spruce fir, seldom growing more than a bush of three or four feet, and perfectly hardy, all over the United States.

A. a. glauca.-A very distinct and striking variety of the American White spruce, with very white, silvery leavesoriginating in England, but hardy here.

A. a. minima.-Another minute English variety, being the dwarfest of all the spruces; and we presume would be hardy in this country.

A. Brunoniana (the Indian hemlock spruce).-Classed by Syn.

$\Lambda$, dumoss.

Carriere among the Tsugas, those kinds with flat leaves, mostly glaucous below.

We are somewhat perplexed in making up our mind about the future condition of this charming tree, as to its availability. If it succeeds at all, it will certainly require a good deal of coaxing. Our own experience has been very various. It has stood some winters well, and others, not as cold but possibly damper, seem to have destroyed it; and yet, Mr. Smith writes us from Newport, it has stood there three years. At Washington it is reported tender, as well as at Philadelphia, Flushing, and at Mr. Reids' nursery at Elizabethtown. We do not, however, see why it may not eventually prove hardy after a little acclimatization, since Dr. Hooker found it in Sikkin at an elevation of nine thousand to ten thousand feet on the side of Kunchinjinga, probably the loftiest peak in the world, where it reaches a height of seventy to eighty feet. Most persons would take it for a hemlock spruce, except that the under part of the leaves is perfectly white, forming, when moved by the wind, a beautiful blending of green and silver.

A. excelsa pygmœe-a very pretty dwarf rariety of the Norway spruce, not exceeding a foot or so in lieight, but spreading very much. The specimens in our grounds do not seem affected by the severest winters.

A. e. monstrosa.-Another hardy variety of Norway spruce, with straggling habit, but destitute of branchlets, somewhat resembling the araucaria imbricata in appearance.

A.e. pendula.-Also a seedling of the Norway spruce, differing only in having its branches more drooping; hardy.

A. e. variegata.-A Variegated variety of our common Norway, pretty, distinctive, and hardy. 
A. e. Clanbrasiliana (Lord Clanbrasil's variety)-Excecdingly dwarf and perfectly hardy; leaves, only half an inch long, and the mature plant not over three feet.

A.e. elegans.-A pretty Dwarf hardy variety, with slender gray foliage reaching the height of four or five feet.

A. e. diffusa, A. e. compacta, A. e. pumila, $A$. e. attenuata -are four Dwarf varieties of the Norway spruce, similar in growth and general appearance to those mentioned abore, and ver'y hardy. In fact, wherever the Norway spruce can be grown, these eight or ten dwarf varieties can, and when grouped with the dwarf pine, $P$. strobus pumilis, and the Dwarf Scotch fir, $P$. sylvestris pumilis, neither, of which ever exceed four or five feet, they make a very interesting and striking plantation.

A. Menziesii-(Menzies' fir) known also $A$. Sitchensis-is a tall tree, with light glaucous-colored foliage, growing sixty to seventy feet high ; a native of northern California and the island of Sitcha; quite hardy here. Our specimens, which have been out some five or six ycars, occasionally get scorched by the summer; in the latitude of Philadelphia it does, likewise, very well, as also at Cincinnati, Newport, Washington, Boston, Flushing, in New Jersey, and even at Clinton, N. Y., when in shade.

A. oborata (Obovate-coned spruce), known and imported by Syn. us as A. Wittmanniana, is as yet comA. Schrenkiana paratively new. Judging from the appearA. Ajanensis. ance of our specimens now, we should suppose it would prove hardy, which is most likely to be the casc with firs coming from so high an altitude as the Altai mountains. It is also found in Siberia. It resembles the common spruce. It is quite hardy at Flushing, which is the only place we can discover where it has been tried.

A. orientalis (Eastern spruce). $-\mathrm{A}$ peculiar tree, with dense short foliage covering the branches on all sides, growing seventy to eighty feet high, and forming a conical-shaped head. A native of the Black Sea, on the loftiest mountains of Imeretia, in Upper Mongrelia; perfectly hardy here, and at Washington; comparatively well at Newport, our youngest specimens here, were untouched even by the winters of $1856-7$. 
A. Smithiana (the Indian spruce).-This magnificent tree syn. is found on the mountains from Bootan to A. Morinda. Kafiristan, at an elevation of from 7,000 to A. Khutrow. 12,000 feet. It resembles somewhat in its size and habit of growth, the finest Norway spruce, though inuch more pendulous and graceful, and with a darker, richer foliage, especially when grown in the shade It occasionally reaches a lieight of 170 feet, though its usual average is 100 to 150 . It is also found in China and Japan, where it is called "Toranowo-momi" (the Tiger's tail). Although we imported this tree some six to eight years ago, we have not as yet succeeded in raising any very fine specimens. When much exposed to the full action of the sun's rays, it becomes a dingy yellow green, and is very apt to lose its leader, and young plants are sometimes killed down to the snow-line. This is also the experience in the neighborhood of Philadelphia, Boston, and Columbus, though hardy at Cincinnati. When planted with us in the shade, however, it secms to do much better in retaining its leader, and we have little donbt it may, after some struggle, eventually be acclimatized, especially when planted in dry, gravelly, well-drained soil. At Chestnut Hill, near Philadelphia, there are perfect specimens, eight to ten feet high, with leaders. We have no specimen at Wodenethe over six feet, though very broad in proportion. At Washington, it is returned to us as hardy and beautiful. The largest specimens in the public grounds, planted by $\mathrm{Mr}$. Downing, in 1852, are five feet. At Newport, it is reported as hardier and finer than A. excelsa. (the Common Norway), though at Messrs. Parsons,' at Flushing, Mr. Hogg's, near Yorkville, and Mr. Reid's, at Elizabethtown, the younger shoots are sometimes injured, and it does better in the shade. At Woodlawn, N. J. (Mr. Field's), the oldest. specimens are seven feet high, and do not now suffer from the winter, perhaps from the redundancy of growth being slightly checked by having been moved several times. They have also borne cones, which at first were erect like the Picea's, but, afterwards pendulous like the Abies', which acconnts for the confusion mentioned by MIr. Loudon, that has cxisted as to whether this tree was an abies or a picen 
A. Douglasii (the Douglas fir).--Another superb tree, reSyin. specting the hardihood of which, very much the Tsuga Donglasii. same remarks we made about the preceding Picea Douglasii. variety (A. Smithiana), will apply. Plants with us, in low, damp ground, suffer occasionally in color, if not in loss of leader, while those grown in the shade, or on an exposed hill-side, in poor, slaty soil, succeed admirably. This is also the case near Boston, at "Wellesley" (Mr. Hunnewell's), where trees, two years planted, are five feet high, and do admirably in the shade; while at Mr. Reid's, at Elizabethtown, it loses its leader in severe winters; and near Philadelphia, Mr. Meehan reports: "that so far it has not been satisfactory." At Washington, perfectly hardy ; at Newport, it wont stand; though at Augusta, Ga., and Cincinnati, it thrives well. The variety originates in the north-western part of North America, and along the banks of the Columbia River, where it is found in immense forests, and also on the Rocky Mountains, on the top of which, it rarely is more than a small bush, but becomes larger and more stately as it descends, until it reaches the altitude of one hundred and fifty to two hundred feet. Its foliage is very dark, and the tree generally resembles a superb balsam fir.

A. Jezoensis (the Jezo fir), found in China, and the Island of Syn.

Jezo, is probably hardy, though we have not

Picea Jezoensis. heard of its being tested sufficiently to pronounce decidedly. It is quite striking. There has been a good deal of confusion in its classification, as to whether it is a spruce or Silver fir, and it would seem to be intermediate, though we believe with persistent cones. Our specimens, which are small, seem quite hardy, and are not very unlike in their general appearance, the Torreya, and also the Cephalo. taxus.

\section{Araucaria.}

This extraordinary and most distinguished genus of plants derives its name from Araucanos, a people of Chili, where the species known as imbricata greatly abounds, its seeds being used for food. 
The only variety which approaches hardihood in this part of the country is the $A$. imbricata, (Chili pine), which when planted in sand and gravel on well drained soil, and in a shady wood, succeeds quite well-that is to say, we have specimens which withstood the severe winters of 1855-6-7, with no other protection than a few hemlock boughs, and came out perfectly bright and green in the spring, even with their leaders uninjured for the past three years. Both sun and wet are fatal to it, and in situations where there are no side-hills sloping to the north, it should be planted on the north of buildings, on little mounds; with at least the lower foot in the holes filled with stones for drainage. Mr. Saunders informs us that there are some fine healthy trees near Baltimore, with upright shoots. At Washington, a specimen planted, in 1852, by Mr. Downing, in the public grounds has succeeded admirably, though a little injured by the winter of 1856 . It does not stand at Newport, and at Flushing, and in New Jersey succeeds only when sheltered; so also at Cincinnati. In Augusta it is eminently successful. The other varieties, A. Bidwili, A. Brasitiensis, A. Cunninghamii, and $A$. excelsa. (the beautiful Norfolk Island pine), are too tender for any but our extreme Southern States, though all thriving, except excelsa, in the open ground at Augusta, Ga.; but for purposes of ornament to cultivated grounds in summer we know nothing more distinguished than these different varieties grown in tubs and protected in winter in a common green-house.

\section{Biota.}

The Chinese or Eastern arbor vitæ, so called to distinguish it from Thuja, the American or WVestern arbor vitæ.

B. orientalis, (Chinese arbor vita), which was but comparatively new, when this book was first published, has not proved quite as hardy or as available as was at first hoped; all our reports, from different parts of the country, speak of it in most cases as not quite laardy, at any rate doing better in protected situations. Even in New Jersey it is sometimes killed to the ground in severe winters. Our best returns are from Washing. ton, where it is reported as very commonly planted and pen fectly successful. At Woodlawn, N. J. (Mr. Field's), there is a 
hedge of it many years planted, which suffered a great deal at first, but of late years, by severe cutting in the spring it seems to have become quite acclimatized.

$B$. orientalis glauca, and $B$. argentea, are new varieties, not yet, we think, introduced; the first a seedling of Messrs. Pince, of Exeter, England, of a very silvery appearance, and the latter resembling the Aurca, being silver instead of gold.

$B$. orientalis aurea, (the Golden arbor vitæ, is a seedling of Messrs. Waterer, in England, we believe from the old $B$. orientalis (the Chinese arbor vitæ). The $B$. aurea is a pretty, dense, and beautifully compact little shrub, growing not over two or three feet high, of an exquisite delicate green in winter, and a golden color at the extremities of its branches in spring.

It is perfectly hardy with us, at Fishkill, though forty miles above us it does not stand well; but we have observed that our trees, now several years old, though untouched by the cold or sun, lose very much the compact pressed appearance so characteristic of the English plants, and its principal charm we think, on this account. In complete collections of evergreens this is one of the varieties we should recommend to be grown in pots and kept in the house during the winter, although there is no doubt of its hardihood here.

B. pendula. (Weeping arbor vitæ).-A bush or small tree, Syn.

Thuja pendula, Thuja filiformis. growing ten to fifteen feet high, with very long, slender, pendulous branches; is one of the greatest acquisitions to our perfectly hardy trees. Our largest specimen, eight to ten feet, has survired our coldest winter's and hottest summers for ten or twelve years, without the slightest protection. Nothing can well be prettier or more graceful than this charming little tree. We do not know why this should not be hardy in our most northern States, though, we understand, it is sometimes killed near Philadelphia; yet near Boston, and at Washington, it does as well as here. It was at one time supposed to be a hybrid between the Common Red cedar and an arbor vitæ, and to have originated in a nursery in England; but Dr. Siebold having discovered the plant wild in China, finally decided the question. 
B. orientalis gracilis.-This variety, which we have received under the latter name, Nepalensis, is perfectly hardy Syn. and much more slender and graceful than the common Chinese. It is found in Nepaul and Northern India. We consider it one of the most interesting of the arbor vite.

B. Turtarica (Tartarian arbor vita).-A dense conical bush Syn.

B. pyramidalis. distinctive. Our specimen, eight feet high, has

Thuja australis. always proved perfectly hardy.

We are inclined to believe that this variety may be often confounded with and sold for what is called the Siberian arbor vitæ, and the place of its origin would seem to justify this; but we do not find, in all our authorities or in any of the English or Frencl catalogues, any mention of the Siberian arbor vitæ, except as a synonym of T. occidentalis (the American arbor vitæ), which, what is known in this country as Siberian, certainly is not. It is also associated with Warreana, though the latter came from Nootka Sound, and would seem to be identical with Don's plicata.

\section{Cedrus. TIIE Cedar.}

C. Allantica (the Mount Atlas cedar), or better known in Syn. this country as the Silver cedar of Lebanon, is only C. argentea. a variety of the ordinary Cedar of Lebanon with glaucous leaves. It is not impossible, however, but what it may be in certain localities hardier, since it thrives perfectly at Newport, when the common Cedar of Lebanon is cut down and not unfrequently killed. This is also the report from Flushing.

As all the remarks, we propose to make about the Cedar of Lebanon, apply to this tree, we shall refer our readers to the succeeding pages.

C. deodara (the Deodar or Indian Cedar).-The anticipations Syn. formed of this most graceful evergreen in the Pinus deodara. first edition of this book, we truly regret to say, have not been generally fulfilled. It grows so readily and sc rapidly, particularly in the later autumn months, that it is with 
great reluctance we feel constrained to admit it is not to be de. pended upon. It is certainly the most delusive of all erergreens. We have upon this place raised specimens twelve to fifteen feet high!, as perfect as could be, but which the winters of 1850 - 6 severely injured, and the subsequent winter finished to the snowline. These trees are now about eight or nine feet high, with several leaders, and nearly fifty feet in circumference, mostly holding their color well so fir this winter, though having been subjected to a temperature, for two days, of $15^{\circ}$ below zero. The fatt of the tree (if so charming a tree can have any firult) is its habit, like the Cryptomeria and Tarodium sempervirens, and many other of the new evergreens, of making a late autumnal growth without ripening off its wood.

'The fitct that the tree below the snow-line almost always appears fresh and green, proves, we think, quite satisfactorily, that some protection, and no or little sun, will go far towards establishing its hardihood. A wood, or the north side of buildings, will accomplish this; and if to this, we add such a preparation of soil as will retard rather than stimulate the tree, so that by accomplishing an early growth it may ripen off its wood, we think we may again hope to acclimatize the Deodar, which as now grown in the Middle States, hardly amounts to more than a bush, annually increasing in amplitude, but not in height. There are portions of this country, in the neighborhood of Tashington possibly, and in Southern Tirginia, and about that latitude, and as far south as Augusta, Ga., where it succeeds admirably. In the extreme south it suffer's from the sun in summer as much as it does here from the sum in winter. There are, however, specimens at $\mathrm{Mr}$. Affleck's, near Natchez, twenty-five to thirty feet high, and feathering to the ground. At Flushing. L. I., in Ohio, in New Jersey, and near New York, it does best in some shelter; though at "Woodlawn," near Princeton, a specimen, ten feet high, and thirty-three in circumference, stands well in the most exposed situations. When first imported, it was supposed to be hardier than the Cedar of Lebanon, but subsequent experience does not confirm this-at least in our case.

C. d:odara viridis (the Green deodar), C. deodara robusta 
(the Robust deodar), are only varieties of the common deodar-the former being of a slenderer habit, and more vivid green, and the latter much coarser and stouter. As these two varieties are out with us for the first time this winter, we can not as yet say how hardy they may prove, and we have no returns from any other plice.

We may as well, perhaps, add here, that Mr. Meehan reports, near Philadelphia, "all Deodars on wet low soils are uninjured, while those on dry are killed outright." This is the contrary of our theory and experienee here certainly, but facts are better than arguments, and time alone will show whether a damp or dry soil is most congenial to this plant.

C. Lebani (Cedar of Lebanon.)-This is another variety of Syn. the genus Cediuts, so distinet and remarkable

Pinus cedrus.

Cedrus Phœnicia. that we regret being compelled to say it has also fallen short of what was expected and hoped of it; and we doubt, if, with a few exceptions, there are more specimens now in this country, or much larger, tban when MIr. Downing wrote his first edition. After the specimen at Throgg's Neck (Mrr. Ashe's), the next best we know of is at Woodlawn (Mr. Field's), at Princeton, N. J., where a specimen (Fig. 38) planted in 1842 is now thirty-six feet high, bearing cones, and may be considered beyond all risk; and also some trees at Laurel Hill Cemetery, near Philadelphia, planted by MIr. J. J. Smith, the founder of that most lovely and interesting of rural cemeteries.

These trees were only slightly browned in the severe winters of 1855-6. But $\mathrm{Mr}$. Field's soil is a light sandy loam, and that of Laurel Hill, a gravel or disentegrated rock, lying high above the surface of the Schuylkill, and so protected by trees as to allow even the Gordonia pubescens to flourish to the height of forty feet, strewing the ground in September with its fragrant blossoms. In both these eases, as in our own, the soil las been dry, and the tree not stimulated by a damp, rich position; and although the winter of 1855-6 reduced, with us, a tree of fifteen feet to eight, yet other specimens, a little less exposed to the full influence of the morning sun, suffered simply a little browning of the leaves, and have since gone through an ordinary winter without any injury, leading us to 
the conclusion that in this latitude, the Cedar of Lebanon may be considered fairly hardy, but "slow;" and though not growing with much rapidity, and occasionally liable to lose a little in the winter of what it has made in the summer, yet on the whole, like the tortoise in the fuble, we beliere it will come out first in the end, and should be much more generally planted.

At Washington. Mr. Saul writes us, it is perfectly hardy, specimens in the Capitol grounds being twelve feet high; and at Yorkville, it is returned as hardy; but at Flushing and at Elizabethtown its reputation is a little qualified, though supposed to become hardy as it advances. At Augusta, Ga., it is straggling and uneertain; and in Ohio, both in the neighborhood of Columbus and Cincinnati, it is very much injured by serere winters.

\section{Cephalotoxus. The Cluster-Flowered Yews.}

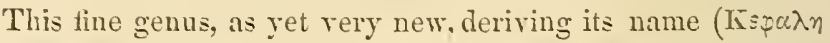
-kephale-a head, and Tass-taxis-arrangement), from the flowers and fruit growing in close, globular heads, is likely, we think, to become a great acquisition in this country. With us it has proved quite as hardy as the Common English yew, and although like that plant, the foliage is much finer and darker in the shade, yet we have had no difficulty, for the past three years, in growing it in the sun.

The only rarieties as yet known here, we think, are:

Cephalotaxus Fortun-mas. and femina-(Fortune's Male and Female cephalotaxus), found by Mrr. Fortune in the north of China, particularly in the province Jang-Sin, and also in Japan, growing from forty to fifty feet high-the foliage, not mlike that of the torreya, is longer and wider than the yew. With us the male plant seems the most hardy, the female having suttered somewhat in the winter of $1856-7$.

C. drupucea-(The Plum-fruited cephalotaxus), is another fine rariety which has proved liardy with us. It resembles very much the Irish yew, and also the Taxus, or more properly" the Podocarpus Juponica. Mr. Carriere, in his excellent work on Conifers, makes it a synonrm of the Female eephalotaxus Fortuni, but our plant certainly differs much from this, in having both darker and shorter foliage; grows about 20 feet high.

Cephalotaxus pedunculata, and $C$. umbraculitera, are the 
two remaining varieties of the genus, and we think, are likely to prove as hardy as the preceding ones.

\section{Chamcecyparis. The White Cedar.}

Chamrecyparis sphceroida variegata-sometimes called both Thuja and Cupressus variegata-is, beyond doubt, we think, a beautiful golden variety of the White cedar, great use of which is made in England, combined with the Golden and Silver yews, and the Golden and Variegated arbor vitæ. We have liad it out but one winter, but we see no reason why it should not prove hardy.

\section{Cryptomeria. The Japan Cedar.}

Cryptomeria.-(The Japan cedar); from Kruptos, hidden, and Meris, a part.

C. Japonica.-This exquisite tree, deservedly called the "Queen of Evergreens," is a native of China, growing sixty to one hundred feet high. It was discovered in 1784, by Professor Thunbergh, and only introduced into England by Mr. Fortune, in 1844, where it succeeds perfectly well and is the, or certainly one of the most charming of the newer evergreens. With us, in the Southern States, it succeeds admirably; but farther north it is apt to suffer from our severe winters. At Wodenethe we have little trouble in growing it in a wood, and we have one specimen, which we are in the habit of starving in very poor soil, and on a side hill quite exposed to the strong west winds, which has been out five years and does not even brown. This tree has a worse habit than the Deodar, of growing late into the autumn. Where this can be partially prevented, by thin, light soil, especially with some shade from a wood or buildings, we believe, as far north as Fishkill, it can be grown, though, perhaps, never to develop its full and graceful beauties. Near Philadelphia, at Chestnut Hill, it sometimes suffers, though last winter not at all; and at Laurel Hill it has stood for several severe winters, without injury, under the shade of other trees. At Newport, it is tolerably hardy, there being specimens ten feet high. Near Boston, the roots keep alive, but no progress is made in the tree. At Washington, there is a specimen in Ia Fayette Square, planted by Mr. Downing in 1852, and never protected, which lsas reached fourteen 
feet, and is rery beautiful. At Elizabethtown, it succeeds when sheltered. At Flushing, the extremities of the branches suffer in severe winters, and at Yorkville, near New York, it is considered hardy under favorable circumstances, as also at "Woodlawn," N. J., the residence of MIr. Field, where there are specimens twenty-nine feet in circumference, though not proportionally high. In Ohio, it is killed to the ground in severe winters. This is another of those evergreens, which grown in tubs, ten to fifteen feet high, and planted (plunged) out in summer, would produce most agreeable effects in orna. mental grounds, with no care in winter beyond removing it to a cellar or cool green-house.

C. Japonica viridis, C. Japonica lobbii, C. Japonica nana.These three are only varieties of the one above described, and we presume no more hardy, unless it be Lobbii, introduced from the Dutch Botanic gardens at Batavia. C. nana, which is a mere dwarf-bush, always seems to suffer with us more from the sun in summer than the cold in winter. We have a fourth rariety, received from France, called Pendula, rather more slender and pendulous than Japonica.

\section{Cunnivgmamia.}

Cunninghamia.-A small tree, native of Japan and China, named after its discoverer, Mr. Cunningham. There are but two varieties, of which $C$. Sinensis or $C$. lanceolata, is the one most generally cultirated in this country. In its general character and appearance, it resembles very much Araucaria imbricata, with lance-like leaves, though lighter green. With us it stands generally better than the araucaria, and will make an admirable substitute for this tree, if it should prove hardy.

At Baltimore, we have seen a plant six or eight feet high, and apparently quite vigorous. At Newport, it is also regarded as quite hardy, and a great accession. Specimens there are six feet high, and near Natchez, fifteen to eighteen feet, nearly half its full size, and always untouched by winter. At Flushing it stands about as well as the cryptomeria, and will probably prove about as reliable as this tree; as yet it is comparatively new, and we have but few returns about it.

C. glauca, the remaining variety, differs only in its leares being silvery. 


\section{Cupressus. The True Cypress.}

This fine genus-not mentioned by Mr. Downing in the early edition of bis work, and of which there are now some twenty rarieties known and cultivated in England--seems peculiarly ansuited to this climate. The cypress is found indigenous in the south of Europe, China, Mexico, the East Indies, and a few varieties, erroneously classed among our cedars and junipers; in this country. There are but three varieties which may be considered as fairly hardy, and as some of these are better known under different names, we may say there is not one hardy cypress, distinctly known and recognized as such, that is cultirated in the northern and middle portion of the United States. The half-hardy varieties, such as attenuata, excelsa, sempervirens, Goveniana, Lusitanica, torulosa, and a few others, can probably never be cultivated, unless in pots, except at the extreme south. The only species we can rely upon here will be:

C. Nootkaensis (the Nootka Sound cypress), byt better known sym. here as Thuiopsis Borealis, is a tall everThuiopsis Tchugatskoy. green tree, reaching the height of one hurdred feet, with widely expanded branches, rery flexible; as it advances, the limbs are covered with small b]isters, which, on being punctured, emit a fine aromatic balsam, whence is derived another synonym, abies aromatica. It is also found in Russia, near Lake 'Tschondskoe. It is but yet very new, even in England; our specimens have been out two winters and are perfectly hardy, as it will probably prove to be in every northern part of the United States.

C. pendula.-There are three Weeping cypress, one a synonym of Thuja filiformis, or Biota filiformis (Weeping arbor vitæ), which we have already described as very beautiful and perfectly hardy; a second, a synonym of C. torulosa, a variety of which we have mentioned above as only adapted for the extreme soutl1; * and a third, a synonym of C. funebris.

C. funebris (the Weeping or Funebral cypress), is another tree like the Deodar eedar and cryptomeria, of which much was expected, but little obtained.

It was first noticed, we believe, by Lord McCartney in lis expedition to China, who descrioed it as having the appearance as an immense evergreen Weeping willow, but it was only in-

* Mr. Buist thinks this may prove hardy near Philadelphia. 32 
troduced into England, many years subsequently, by. Mr. Fortune, from the celebrated tea country "Wheychou," in the north of China. It is described as attaining a height of sixty feet, with horizontal branches, sweeping upwards with its graceful curves and chropping again at the points. We observe, from our returns, it has been tried in many parts of the United States, but, so far, has only succeeded well at Augusta, Ga, where both Messrs. Berckmans and Mr. Redmond report most favorably as to its hardihood; with us it has succeeded but indifferently, though having had every advantage from poor soil and a protecting wood. Even in Washington, it is too tender to be relied on.

C. Lazosoniana (Lawson's cypress), the most beautiful of the cypress, if not of trees, raised from seed in 1857, collected and sent to England by MIr. Murray. It grows one hundred feet high, and is found along the banks of streams and in the vallies of the mountains of Northern California, in latitude $40^{\circ}$ to $42^{\circ}$.

There is one very distinctive characteristic about it, which we hare observed, and by which it can readily be recognized, the drooping of the leading sloots like the Deodar. The tops of the branches hang down like an ostrich feather. It is said to resemble the C. Nutkaensis (Thuiopsis Borealis), described above, but our plants are much more slender and graceful.

We have strong hopes this charming evergreen may be acclimatized. Our trees are out for their first winter. It is also on trial at Cincinnati. It is still very rare and expensive; small plants, eight to ten inches high, costing a guinea.

\section{Dacrydium. Dacryolun.}

A very rare genus, found only in New Zealand and the East Indies, and so tender as hardly worth while being mentioned, except that a new variety, lately introduced into. England. promises to be hardy there, and may consequently be in certain parts of the United States. This variety, D. Franklinii (Huon pine), is found in Van Dieman's Land, and becomes a tree of one hundred feet high, thickly covered with spray; the branches 
are numerous, dense, long, and very flexible in our plants (in pots) like whip-cords. We have not received any reports of this tree.

D. Cupressinum (the Cypress-like dacrydium), though not hardy, is well worthy of cultivation in pots. It is exceedingly graceful and pretty, with slender, delicate, almost thread-like, drooping shoots, thickly clothed with small, spiny leaves. A specimen we have, about eight feet high, is much admired. There are several other varieties for the conservatory.

\section{Filz Roya Patagonia. The Patagonian Fitz Roya.}

A large evergreen tree, found in the mountains of Patagonia growing one hundred feet high, but introduced within the past three years into England, where so far it stands well. Our specimens are out for their first winter. WVe have every reason to suppose this may survive our climate; since in its native country it diminishes from one hundred feet in the valleys, to only a few inches on the borders of perpetual congelation.

\section{Glyptostrobus. The Embossed Crpress.}

This new genus, which has been but lately introduced under this name (derived from "Glypho," embossed, and "strobus," a (cone), but has been previously by some botanists regarded as a Taxodium; is a native of China, where it is called the Water pine.

The only variety of this genus, apparently recognized as distinct by the English, is G. Teterophyllus, known also as Thuja pensilis, and Taxodium Japonicum; although Endlicher has another and very beautiful variety, which we have found perfectly hardy at Wodenethe, more so even than $G$. heterophyllus. This is the Glyptostrobus sinensis pendulus, which is also recognized under this name by the French arboriculturists, though in the English Pineturns, and by Gordon, in his rery excellent work on Conifers, it is classed as a Taxodium; and we have imported it fiom France as Glyptostrobus sinensis pendulus; from England, as Taxodium sinense pendulum; while in 
our nurseries, it is sold as the Weeping deciduous cypress; and we think it is generally regarded by those who have it in this country (which are very few), as identical with our Southern deciduous or Swamp cypress, and only a pendulous and more delicate variety of it; this is also the classification of the English. Under this embarrassment, we sent specimens of the three rarieties to that distinguished botanist, Dr. Gray, who replied that, in his opinion, "the Genus Glyptostrobus will be adopted as distinct from Taxodium, though most resembling it;" that Glyptostrobus s. pendulus and Taxodium s. pendulum are the same thing, under different names; "while G. heterophyllus is the allied species, and probably not distinct."

The Taxodium pendutum is one of the most graceful and exquisite little trees, which will survive the rigor of our nortlern winters. With us, as before stated, it is untouched by the severest weather.

The resemblance to the Southern deciduous or Swamp cypress, which has led to its being confounded with this variety is chiefly in the autumn, when the leares are expanded and spread out very much like it; but in the earlier spring montls, they are twisted and compressed around the stem, having a very peculiar wavy and curled appearance.

At Newport, in New Jersey, and at Flushing, this tree is returned as hardy and very superb.

\section{Juniperus. The Juniper.}

Of this large and important family of plants, $J$. Virginiana, commonly called the Red Cedar, was the only variety mentioned by Mr. Downing. The name itself is derived from the Celtic word Juneprus, meaning rough or rude, from the stiff character of the plants, or from Juniores pariens, the old and young leaves and berries being on the plant at the same time. There are some twenty-six to thirty varieties known and cultivated in Europs, of which nineteen or twenty have reached the collections in this country.

Of these, alphabetically, the first on the list is $J$. Bedfordiana, a slencler variety of $J$. Virginiana, found on 
the island of Barbadoes, and the Windward Islands, and Syn.

J. Barbadensis.

J. Gossainthania. erroneously cultivated by these three names, by each of which we have it. We observe from our returns, that this tree, under these three names, is also pretty generally cultivated at the principal nurseries in this country; and while $J$. Gossainthania is generally considered perfectly hardy, and $J$. Bedfordiana nearly as much so at Newport, Washington, and New Jersey, $J$. Barbadensis is reported as tender in the one or two places where tried, from which, it is evident, there is some confusion in the synonym. It is a pretty, graceful, slender tree, with drooping branches; when fully grown, some fifty feet high.

J. Californica (Californian juniper).-Is an extremely pretty, delicate variety from California, with glaucous leaves, attaining an altitude, in its native country, of forty feet. We received this variety from MEssrs. Ellwanger \& Barry two years since, and have not yet ventured it out. It is more rare in England than here, being classed among those of which little is known.

$J$. Canadensis (Canadian or Common juniper). - This well Syn. known species in our Northern States, and the J. depressa, northern parts of North America, Labrador, NewJ. nana. foundland, \&c., is merely a bush, with a loose open head, from three to five feet high. It is sometimes confounded with the Dwarf juniper of Europe, but has a smaller and lighter foliage, with rather more of an upright tendency; perfectly hardy.

J. Chinensis (Chinese juniper).-A very great acquisition, Syn. from China and Japan, perfectly hardy with us J. Thrmbergii. in the most severe winters, and a most beautiful variety. It is dicecious, the male plant being distinguished with male flowers of a bright yellow color in the spring, and very showy when fully grown, attaining a height of fifteen to twenty feet. The female variety, known and sold also as $J$. Reevesiana, and $J$. flagelleformis, is rather smaller than the male; berries small, of a glaucous violet brown when ripe. We strongly recommend these trees, especially the male, as being perhaps, the finest of the really liardy junipers. 
J. communis (Common juniper).-This plant, which is the Syni. ordinary juniper of Europe, is not the same as

J. Cracovia. the $J$. communis, or Canadensis of this country. J. vulgaris. It is found generally on the Continent, and in England, a loose, spreading tree orbush, of twelve to eighteen feet high ; while on tops of mountains it becomes a straggling shrub. There are three varieties of the common European or' English juniper, all well known, and cultivated in the United States, riz.:

J. communis Suecica (Swedish juniper).-A native of Norway, Denmark, Sweden, and Russia, a conical, upright growing bush, of from twelve to twenty feet, very hardy, we believe, in every part of the country:

J. communis Hibernica (Irish jmiper).-A neat, pretty, slender variety, found on the mountains of Ireland, more upright and delicate than the Swedish, though resembling it. It sometimes suffers with us from the sun in midsummer, but rarely from the cold, and this we see by our returns, is its character generally.

$J$. communis compressa-which we imported some years since, as Hispanica, or Spanish juniper-seems quite as hardy with us as either of the other rarieties, being compact and close in its habit, but with a less vivid green; it comes from the Apennines. There is another Spanish juniper, called J. thuripera, from the mountains of Spain, forming a dense, handsome, pyrumidal tree, tapering to a point, and growing to the height of thirty feet, which we also find entirely hardy.

J. Japonica (Japan juniper)-is a small, hardy, bush from Syn.

Chinensis procumbens. the mountains of Japan, not growing ores one or two feet high, and distinct.

J. nana (the Dwarf juniper).-Common all orer Europe, syn. England, Scotland; seldom growing orer one foot J. Alpina, high, but spreading. It is so often taken for $J$. J. sibiriea, Canadensis of this country, as to be constantly conothers. founded and grown for it.

J. oblunga pendula (Weeping juniper)-unquestionably the syn. most attractive of the junipers; a small tree r. peadula vera fifteen to twenty feet high, from the Hakone ridge of mountains in the island of Niphon in Japan ; perfectly 



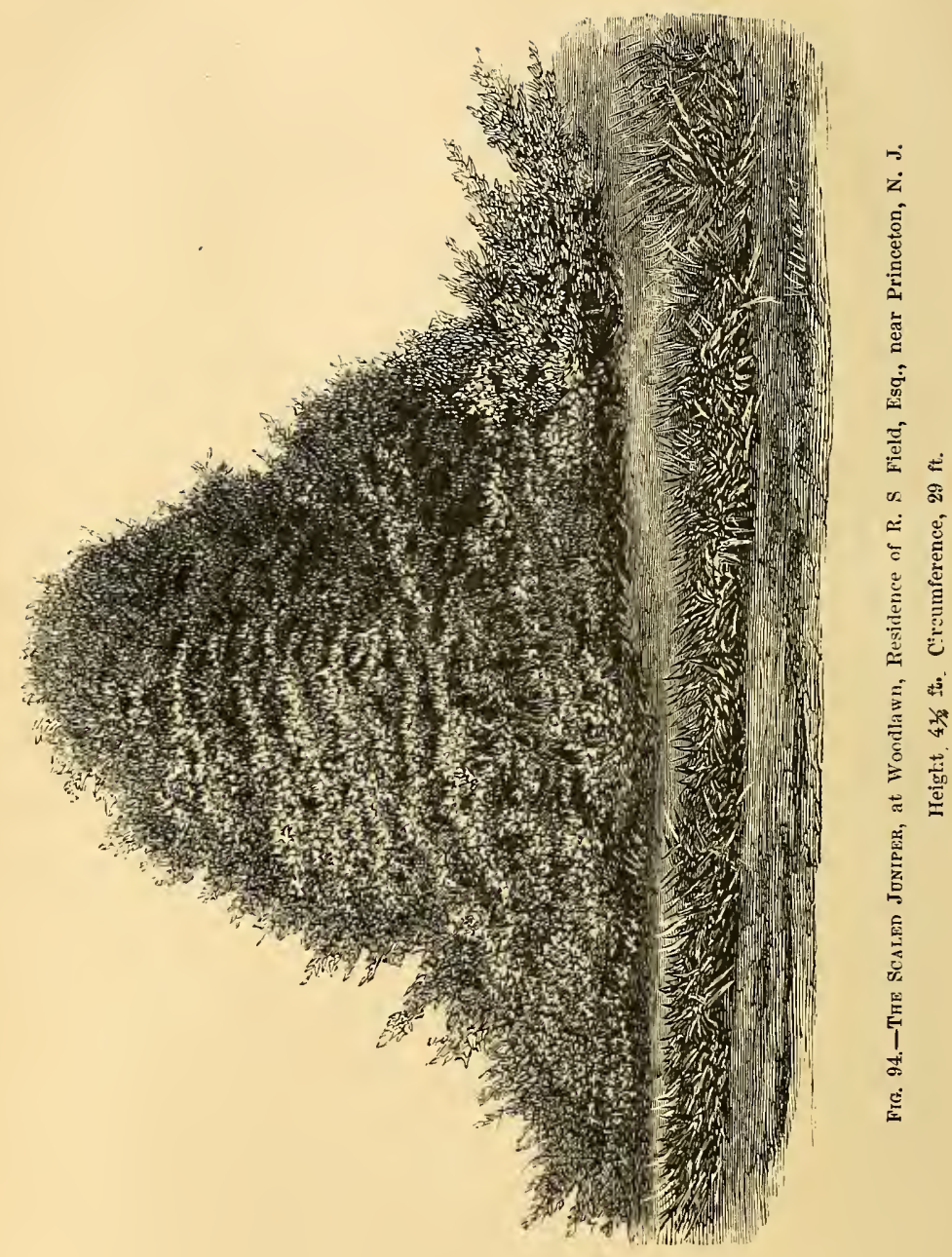


hardy with us, and the most graceful and pendulous of evergreens. Our best specimen (Fig. 93) has been planted ten years-it is nearly six feet high, though only a few inches when set out. We find it transplants badly and recovers slowly, and when necessary to be moved, should be balled in winter, or moved with greatest care. It takes several years to get under way, and often dies back from sun, but, when once started, succeeds admirably.

J. occidentalis (Western juniper).-We doubt very much if " Syn. the variety is, in this country, correct, at any rate we J. excelsa. have no retums about it; and if here at all it may be under its synonym of excelsa, with which it, and many other junipers, are frequently confounded. It is found, at an elevation of five thousand feet, on the Klamet mountains in Oregon, and also on the Rocky mountains, where it becomes an umbrella-shaped tree of forty feet, with a pretty silver bloom; it will, no doubt prove quite hardy here.

J. oxycedrus (Priekly juniper). - This variety is reported as Sym. bardy in Jersey. Our plants are out for the J. monspeliensium. first winter, and we cannot, therefore, report upon them now. It is found on the Apennines, at an elevation of three thousand feet, in France, also in Spain, and Portugal. Our specimens are attractive from being more or less glaucous on both sides of their leaves; the branches are angular and rather pendant: it grows eight to ten feet ligh, and its berries are used in flavoring gin.

J. Phcenicia (Phœnician juniper).-This speeies, forming a bush of fifteen to twenty feet in height, of a beautiful pyramidal shape, is found on the rocks along the shores of the Mediterranean, near Nice and Calabria. We have favorable reports of its hardihood from New Jersey; we have not tried it. There is another rariety, $J$. $P$. Lycia (Lyeian juniper), a much smaller bush than the preceding, and greener foliage, originating in the Levant, but also found, according to Prof. Pallas, in Siberiait having been introduced in the Russian gardens as juniperus duvurica. This is the juniper from which the gum called olibanum is eollected, so mucis used for ineense in religious ceremonies on the Continent. This, no doubt, will prove hardy in the Urited States 
J. prostrata (Prostrate-branch juniper).-_'This interesting Syn. species, so well known all over the Middle and

J. repens,

J. humilis,

J. sabina prostrata. Northern States, need hardly be described; with us t $t$ is a common road-side plant, and very much neglected in consequence. We do not really know a finer object than this juniper, well grown in ornamental grounds where it has ample space to develop itself There are two specimens at Mr. Field's in Princeton, truly superb, resembling immense great evergreen beds, not over two feet high, but thirty leet in circumference.

J. recure (Weeping Indian juniper).-This is certainly a Syn. very charming rariety, and we wish we could say

J. Nepalensis. it is perfectly liardy; with us, heretofore, in the winter, it becomes very shabby and dingy, haring much the clouded look produced by the web of the red spider; this, lrowever, is where it has been exposed to the winter's sun. We have now some specimens planted in a wood, and well protected, which we hope may do better.

Mr. Hogg writes us that at Yorkville, when sheltered, it may be regarded as hardy; and this is reported also from Flushing, L. I., and in New Jersey; at Washington it did well until in jured by the winter of $1855-6$. The only unqualified return of entire success is from Augusta, Gri., where it is grown without trouble. J. recurve densa is the male form of this variety; with us, the male is more dwarf, and of much closer and thicker habit. The plant itself originates in Nepaul and in Bhotan, at an elevation of eight to ten thousand feet, where it makes a small and beautiful tree; at greater eleration it becomes a straggling bush.

$J$ religiosa (the Pencil or Incense juniper). Whe beliere $s y n$. there is no question of the hardihood of this J. excelsa.

IPerhaps the tall Tuniper of the American nurseries.] juniper; although no Indian conifer seems to have been more confused than this species Tre presume, however, that the J. excelsa (the Tall juniper) of our American nurseries is not properly the $J$. excelsa of the Indian botanists, which is the true $J$. religiosa. The first is undoubtedly harily, becoming a handsome, pyramidal tree, thirty to forty feet high; a native of the islanis in the Grecian Archipelago, Syria, Armenia, and 
Georgia ; the second is quite hardy with us; and we have no report from any other place. It resembles very much the Chinese Juniper, and it is often confounded with Cupressus torulosa. It obtains its name from its wood being burned in temples on festivals, and also from being used in cedar pencils.

It is a native of Nepaul, where it rarely descends below an altitude of ten thousand feet; above an elevation of fifteen thousand feet, it degenerates into a scraggy bush; while in favorable situations, it forms a large, magnificent tree of sixty to eighty feet. It gets its name of religiosa from being usually employed for the Buddhist temples, and in their religious ceremonies.

J. sabina (the Common savin), a low, loose-growing bush, not, as it strikes us, particularly handsome, growing six or seven feet high, and native of the Lower Alps, $\Lambda$ ppenines, and the Altain and Taurian mountains. There is another and prettier variety, J.s. variegatce (Variegated savin), with its leaves curiously striped or blotched with yellow, and intermingling with the green, making a striking contrast. We have grown these many years without any protection.

$J$ squamata (Scaly-lenved juniper), a large, procumbent, Syn. many branched shrub, growing four or five J. dumosa Lambertina. feet high, and very spreading, from the mountains of Nepaul and the Bhotan AIps, also in Cashmere. It seems to thrive on the loftiest mountains at elevations of eleven, twelve, and even fifteen thousand feet, forming extensive beds or masses like carpets, covering immense spaces; the foliage is a bright, vivid green, and large glossy, purplish black fiuit.

The finest specimen we know in this country, and one of the most extraordinary and striking objects we ever saw among evergreens, is the $J$. squamata, at Woodlawn, N. J., Mr. Field's (Fig. 94), which was obtained from Mr. Buist, in Philadelphia, in the spring of 185 ó ; and though only seren years planted, is now a bush of twenty-nine feet in circumference, having one leading shoot which, after ascending perpendicularly four and a half to five feet, as suddenly descends again at an acute angle to the ground, resembling somewhat an elongated ox-bow, the lower branches radiating from the stem. 
and spreading in every direction with a marvellous profusion into a perfect circle. It is unquestionably hardy all over the colder portion, at least, of the United States.

\section{Pseudo-larix komferi. Golden or Chinese Larch.}

This properly belongs to the deciduous class of trees; though when first sent to England by Mr. Fortune, Syn.

Abies kcemferi.

Pinus do. it was supposed to be a fir, and Mr. Lambert classed it among the pines. It is still very rare and very expensive; plants only two inches high costing seven dollars in England. We know of but one other specimen in this country, besides our own, which was too small to venture out this winter, though we intend doing so next. It will, no doubt, prove hardy, coming as it does from the northern provinces of China. The leaves are a beautiful bright green, when young, but before autumn assume a fine golden yellow. There being no specimens in England over a foot high, we have no further description of this tree.

\section{Libocedrus. Incense CEDAR.}

This exquisite genus (for all the rarieties are alike beautiful) is another of Mr. Endlicher's introductions fiom Chili and Nevi Zealand. The name is derived from libanos, incense, and cedrus, the cedar. It is found upon the Andes of Chili, where it grows to the height of sixty to eighty feet, and bears so close a resemblance to the arbor vitæ, as, by many, to be classed with this tree, haring the same pyramidal habit, thickly clothed with beautifully delicate, glaucous and light green imbricated leaves from its very base.

Therc are but four varieties, three of which have been im. ported, by collectors of evergreens, into this country, viz.: Chitiensis, Doniana and decurrens, of which the first and last only approach to some hope of being acclimatized.

L. Chilitnsis, we have had several years. Our oldest plant survived three winters on ail open lawn, protected simply by 
. cedar boughs, but was destroyed by the serere weather of ' $55-6$. At Elizabethtown, N. J., there are specimens five feet high, and, it is reported to us, as nearly hardy there. At Washington, and on Long Island it has not been sufficiently tested to be pronounced upon. The only unqualified return of entire success is from Augusta, Ga., where it stands admirably and becomes one of their most lovely evergreens.

L. Doniana (Don's arbor vitæ)--even more than the preceding resembles an arbor vitæ, and is more Syn.

Thuja Doniana, generally known and sold as a Thuja than a Libocedrus; it has the appearance of a most exquisite fern, being of a peculiarly soft yellowish green, and most delicate habit. There is no hope, we fear, of acclimatizing this beautiful variety, except, perhaps, in the Southern States; but nothing can well be prettier or more attractive than this and the preceding variety (L.Chiliensis), grown in pots or tubs.

$L$. decurrens, the third and last variety, being more properly an arbor vitæ, has been removed to that genus, we shall therefore describe it under its appropriate head of Thuja.

\section{Picea. The Silver Fir.}

In contradistinction to Abies, the Spruce fir is derived from pix (pitch) - this variety producing an abundance of resin, and having theircones erect and nearly cylindrical, while the cones of the Alies (Spruce fir) are pendant and persistent for a long time. They are found in Europe, Asia, and North America and are, we believe, without exception perfectly hardy in the middle and northern portions of the United States, and a very great addition to our ornamental evergreens.

P. amabilis (the lovely Silver fir)-one of the latest addin tions to this tribe of plants, still rare and very Syn.

P. lasiocarpa. costly. There are no plants of any size in

Pinus lasiocarpa. his country. It stands well at Beach Clyffe, the residence of MIr. Kane, at Newport, and also at Flushing, and we presume it may prove hardy at Boston. It is a magnificent tree in its native forests on the mountains of Northern California, reaching an altitude of two hundred 
and fifty feet, with a naked stem of sixty feet. It was discov. ered by Mr. Jeffrey.

P. balsamea (the Balm of Gilead fir), has already been deseribed in the early edition of this work, and is too well known as the common Balsam fir of the country to require further remarks.

$P$. butsamea longifolia, is a much finer and equally hardy variety, with longer leaves, introduced from Booth's nursery, at Hamburgh.

P. balsamea variegaia-A variegated variety of our Common balsam-pretty and hardy-the new growth being yellow; though attractive in the spring, yet when the new shoots become ripened, the bright yellow becomes a little dingy, and we should hardly give it a prominent place in plantations. We have also a variety with a silvery instead of a golden variegation.

P. Bracteata (Leafy-bracted Silver fir).-This is a very rare variety as yet in this country, and will probably Syn. Abies Bracteata. prove as hardy as P. Webbiana, and, like it, be apt to lose its leader. It was discorered by Douglas on the mountains of Columbia river, and afterwards in Upper California. It is a tall, slender-ģrowing tree, onc hundred and twenty feet high, straight as an arrow, and only two or three feet in diameter; sometimes only the upper third of the tree is clothed with branches.

P. Ceplatonica (Mount Enos fir).-This is perhaps one of the finest and most reliable of the new Silver firs. We have specimens eight and ten feet high, perfectly untouched by the remarkable winters of $18550-6$, and without any advantages of position or protection.

It is called the Wild cedar by the Greeks, and was first sent home by General Napier, when Governor of Cephalonia. It has since been discovered on the different mountains of Greece, on the Sacred Apollo, on Mount Parnassus, on Mount Itna, and also on Mount Olympus; it has, consequently, among its other merits, at least that of having early classical associations. A full grown tree is about sixty feet high.

P. Fraseri (Fraser's Silver fir).-A rariety probably of our Syn. common Balsam fir, a little lighter, we think, in Pinus Fraseri. color; supposed to have originated in the mounAbies do. tains of Carolina and Pennsylvania. Neither 
Carriere nor Gordon seem to place it anywhere else; though we have trees sent to us from Vermont, by rresident Wheeler, of Burlington, which he thinks identical with the southern variety; and we must confess we quite coincide with him, though they may prove some sport of our ordinary double spruce. At any rate, both varieties are as hardy as possible.

P. Fraseri Hudsonica (Hudson Bay Silver fir).-A pretty, flattish Dwarf rariety of $P$. Fraseri, forming a dense close bush, never over three or four feet high, and, of course, a perfectly hardy tree, coming, as it does, from the Hudson Bay Company's territories.

P. nobilis (Noble Silver fir).-This superb variety well deSyn. Serves its name, reaching as it does an altitude of two Pinus nobilis. hundred feet, with regularly horizontal and spreading Abies do. branches, and cinnamon-colored bark, forming immense forests upon the mountains of California. It was a discovery of MIr. Jeffrey, and proves unquestionably hardy wherever it has been tried. We have had it five or six years; but our trees being raised from seed, instead of being grafted, were very small (three inches only) when planted, and are not over two to three feet high now ; and though fine in color and habit, do not yet show that grand characteristic which induced Mr. Downing, when in England, to describe it as the most majestic of evergreens. At Elvaston Castle, there are specimens, says Mr. Buist (in his account of his visit to that remarkable place), finer than the Araucaria excelsa (the Norfolk Island pine). It is perfectly hardy near Boston, at Flushing, New York, Baltimore, \&c.; and will prove equally so in all the middle portions, at least, of the United States.

P. Nordmanniana (Nordmann's Silver fir).-Another superb Syn. Silver fir, quite as hardy as the preceding, Abies Nordmanniana. and as fine; indeed, we think even finer, Pinus do. when young. We have had it at Wodeneihe four or five years, and it has never suffered in our severest winters. It comes from the mountains of the Crimea, and reaches a growth of one hundred feet.

$P$. pectinata (Common Silver fir).-A lofty tree, growing one hundred to one hundred and fifty feet high, found all over the Alps, and also on the Apennines and Pyrenees; and yct, 
strange to say, it is somewhat capricious in the United States, and among our returns, we find in many places it is apt to lose its leader. This we believe, however, only takes place in young, and consequently succulent plants, which, as they advance in age, acquire a habit of solidifying, as it were, their growth, and escape injury. We have specimens fifteen to eighteen feet high, which are very perfect, and never suffer. The finest specimen we know in the country is one near Germantown, Pa. (Fig. 37.)

P. pectinata pendula (Weeping Silver fir)-Is a distinct and very rare variety of the Common Silver fir, which we had for many years-perfectly hardy, with peculiarly drooping branches. It is of French origin, we believe.

$P$. pectinata variegata (Variegated Silver fir)-Is very similar (though distinct) to the P. Fraseri variegata; hardy.

$P$. pectinata nana (Dwarf Silver fir) - A pretty little shrub, quite hardy, and only growing two or three feet high.

$P$. grandis (Great Silver fir).-Another of the grand discoveries of Mr. Jeffrey, on Fraser's River-a superb tree, growing to the height of two hundred and eighty feet, and resembling in its character and habits the Common Silver fir, but much finer and more gigantic. Our specimens are only eight to ten inches ligh, and we do not know of any others in the country any or much larger; and although from its description we have every reason to suppose it will prove hardy, still we have no authority for saying so. The tree is still too young and costly (two guineas each), to make the attempt quite yet. The only report of it is from Washington, where there are plants in Mr. Corcoran's grounds, two feet high, perfectly hardy.

P. pichta (Pitch or Siberian Silver fir).-Although this tree Syn. does not become so majestic as the preceding, P. Eiberica. yet it is a remarkably fine variety, and well worthy extensive cultivation. It is perfectly hardy, and has a superb luxuriant growth, which is most refreshing. It is not very unlike a very fine Balsam fir, though much denser, softer, and deeper foliage. It is found in the mountains of Siberia and Altai, and rarely exceeds twenty-five to thirty feet. There 
is another variety, with longer and more glaucous leaves, called P. longifolia.

P. Pindrow (Upright Indian Silver fir) - A fine tree, growSyn.

Abies Webtiana. ing from eighty to one hundred feet, and

Taxus Lambertiana, found on the mountains of Bootan, at an elevation of eleven to twelve thousand feet. In this country, this variety has been constantly confounded with $P$. Webbiana, which it so closely resembles as to require the nicest scrutiny to detect the difference. It also, like the Webbiana, suffers from losing its leader, and on this account, even in England, it is recommended to be planted on the north of woods or buildings; with this protection it may be classed as tolerably hardy.

P. Pinsapo (Pinsapo fir).-This is a Spanish fir, very disSign. tinctive, and perfectly hardy everywhere, as Aises Pinsapo. far as tried. Our best specimen is ten feet Pinus do. ligh, and exceedingly fine, being as regular and symmetrical as the Balsarn fir. Its greatest altitude is seventy to eighty feet. It is found in Spain, on the mountains between Ronda and Malaga; also in Granada, and on the jighest parts of the Sierra de la Nieve-eren near the summits, where snow lies at least five months in the year.

$P$. Webbiana (Webb's Indian fir) - A superb tree, growing Syn. from seventy to eighty feet high; discovered on abies spectabilis. the Himmalayas above an elevation of ten thouA. densa.

Pinus striata, etc. sand, and Dr. Hooker found it in Sikkin at an elevation of thirteen thousand feet. A beautiful dye of an exquisite violet tint is extracted from the cones, whence the name by which it is known in this country, "Webb's Purple coned fir :" like P. Pindrow, it suffers in its leader, if exposed, but does pretty well in a wood.

\section{Pinus. The Pine.}

Of this, the largest and most important family of evergreens, there are, at present, known and cultivated in England and in collections on the Continent, about sixty varieties; twenty-four of which have proved hardy in the United States, or, at least, in our portion of it on the Hudson River-and there are a few 
more; besides, which may possibly become acclimatized in a few years. Six of these have already been described by Mr. Downing, in his early editions, leaving a gain of eighteen new varieties-a great many for so valuable a genus, and in so short a time as ten years.

In our Southern States, the whole sixty varieties now known abroad, could undoubtedly be grown with cntire success; we therefore propose, in describing the twenty-four varieties which we have ourselves tested, to give some brief mention of the most prominent and desirable of the others, which at the North can only be cultivated in tubs, and kept in green-houses during the winter.

$P$. australis (Southern pine),-This superb tree, more comSyn. monly known as the Georgia pine, is found from P. Palustris, Virginia to Georgia, growing to the height of

P. Georgica. sixty to seventy feet, with a bright green foliage, nearly a foot long in young plants. We have great hope that this tree may be acclimatized here. In Philadelphia, Mr. Buist regards it as hardy; at Elizabethtown it succeeds when sheltered by evergreens, there being specimens there six feet high. There is another variety, with much longer leaves, and said to be much hardier, withstanding the coldest weather in Germany, and coming from the northwest coast of America, which would, no doubt, prove entirely hardy, since it was raised, as we believe, from seed in Messrs. Booths' nurseries at Hamburgh, where we remember we were informed peach trees would not stand.

P. Apulcensis (Apulco pine).-This variety, from the vallies of Mexico, is likely to prove too tender for any but our Southern States; it reaches a height of forty to fifty feet.

P. Ayacahnite (Ayacahnite pine).- This pretty and effective pine, with a soft, vivid foliage, has been out with us, two or three years, in a sheltered position, and seems tolerably hardy; it somewhat resembles our native White pine, only is much softer and brighter. It is from the mountains of Mexico.

P. Austriaca (Austrian pine).-This valuable tree, perfectly Syn. hardy everywhere, is found on the mountains in P. nigra, P. laricio. Austria, Styria, Transylvania, \&c., and reaches a height of one hundred to one hundred and twenty 
feet. Take it all in all, we do not know a finer or more a rail. able evergreen. It grows in any soil and has a strong, ram. pant, healthy look, which is positively refreshing when surrounded by its more delicate companions, the half-hardy ones It is very rapid in its progress, and has a firm, stocky growth, retaining its fine green color during our hottest summers anci coldest winters. In Austria it is very much esteemed for charcoal, and the wood is said to resist the alternations of moisture and dryness better, even, than the Lareh. By some, it is supposed to be only a variety of laricio.

P. Banksiana (Sir Joseph Banks' pine)-Is a stunted, Syn. serubby, straggling bush, from five to ten feet P. Hudsonica. high; in good soil it reaches, sometimes, fifteen feet. It is found in the most northern parts of North America, in Maine, Nova Scotia, Labrador, \&c., and is only valuable to complete a collection.

P. Bermasleyi.-We are inclined to think both these trees are identical, and are synonymous with $P$. ponsyn.

P. Craigeana. derosa, though they are sold as distinct in the English nurseries, and in ours also. They belong to what are called the "Long-leaved Californians," such as Benthamiana, Ponderosa, Maerocarpa, \&cc., and when young, they resemble each other so closely that we must confess we are puzzled to tell them apart, and are not surprised at the confusion. Carriere, in his Histoire Genéral des Coniferes, makes Beardsleyi a distinet variety, but does not deseribe it, merely saying, it was introduced in seed in 1855, from North America; but Gordon, who seems the more thorough as well as the latest writer, regards them as synonyms of Ponderosa. In the absence of any more light, or until the trees get larger, so as to show the difference, if it exists, we shall adopt this elassifieation, and refer our readers to our subsequent deseription of Ponderosa, for what may prove, presently, to answer for these trees.

$P$. Benthamiana (Bentham's pine).-This superb tree, said to be the grandest of the "Long-leaved CaliforSyn. sinclairi. nians," was found by Mr. Hartweg, on the mountains of Vera Cruz, where he diseovered specimens two hundred to two hundred and twenty feet high, with stems 
twenty-eight feet in cireumference. It seems peculiarly a mountain pine, flourishing above the region of $\mathrm{P}$. Sabiniana, and in the greatest abundance, near MIonterey, and on the monntains abore Bear Creek. The timber is said to be the most valuable of the pines, though at five dollars apiece for small plants eight to twelve inches high, we are not likely to test this excellence for some years. It proves very hardy at Wodenețhe. Our specimens, but slightly protected, have stood for three years without injury.

It is also hardy at "Wellesley," near Boston, the residence of Mr. Munnewell. In the public grounds at Washington, there are fine specimens three and four feet high. At Yorkville, it is lardy, though the plants being very small, are often under the snow. At Flushing, on the contrary, it is returned "not hardy," and it may belong to those pines which do not flourish near the sea. Being still rery rare and costly, it has not yet been much planted.

P. Brutia (Calabrian Cluster pine). - A fine lofty tree of sixty to serenty feet, and bright green foliage, Sym.

P. conglomerata. with spreading head, found in Calabria, and closely resembling $P$. Halepensis (the Aleppo pine). It is not unlike, in its general appearance, some of the numerous varieties of Maritima; it proves perfectly hardy with us, having been out several winters.

$P$. Canariensis (Canary Island pine).-A charming, graceful, slender pine, with long pendulous leares, growing seventy to eighty feet, in its own country, but too tender for any thing but pot-culture here, though it might do at the extreme South.

P. Cembra (Sriss Stone pine).-All travellers who have Syn. crossed Mount Cenis and the Tyrol, must have

P. II lelvetica. been struck with the rast forests of this tree,

P. montana, ite. which abound in those stupendous regions. It is the pine of the Alps; and as such must prove hardy anywhere at the North. It grows about fifty feet high, but very slowly, though always forming a pretty, compact tree. There are many synonyms, and two rarieties; the Siberian Stone pine, with shorter, denser, and greener leares, and the Dwarf Cembran pine, found on the rocks of the Ural MLountains. The seeds of all three of these varieties are eatable. 
P. Devoniana (Duke of Devonshire pine)-A fine, delicate, pendulous tree, with a charming green foliage, resyn.

P. Blanco. sembling very much our $P$. palustris - called also, Pino real, or Royal pine, from its majestio character. It is from Mexico, growing 80 feet high-tolerably hardy in England, and perhaps in our Southern States, but too tender for us at the Nortb, except for pot-culture.

P. excelsa (Lofty Bhotan pine).-We hardly know what Syn. to say of this splendid tree, called by Mr. P. pendula. Downing, that " affectedly pretty pine." It is

P. Nepalensis. universally returned to us as hardy, from all
fc., dc. parts of the country, though sometimes suffering from sun in summer. Near Boston, this is the case, and at Natchez, where plants have to be shaded from the summer sun. Mr. Barry writes us from Rochester, it is hardy there, but will not make an old tree. Our own trees at Wodenethe, which perhaps are some of the oldest in the country, being, or rather having been, sixteen and eighteen feet high, certainly sufier from sun and not cold. The winter of ' 55 and ' 56 , which destroyed some and damaged many other white pines here, and even road-side cedars, produced no effect upon this tree, which was entirely unprotected and uninjured; and yet often in midsum. mer, it will become ruptured in its leading shoots, and die back. This may be on the principle of the frozen sap-blast in fruit trees, where the damage done in winter, does not develope the injury before the succeeding summer; but we are more inclined to believe, that the tree, if planted in rich looles, overgrows, and a sort of apoplexy supervenes. We form this theory, from observing that, where a great redundancy of growth has taken place, and the leading shoot is three or four feet long and extremely succulent, this rupture is most often the result, when the sun being hot, activity of eirculation is excessive; when, however, the exuberance of growth is checked by poor, thin soil, the tree grows enough, and seems to mature its wood as it advances through the summer-at any rate sufficient to withstand what might be called determination of sap to the head; so that in future we shall always plant Excelsas in poor soil. The variety itself is found in Nepaul, in the mountains, and in Bhotan, above the region of the Deodar. It reaches a 
height of one hundred and fifty feet. It is sometimes called the Himalayan Weeping fir. Take it all in all, it has been the greatest favorite, and the most successful of all the new conifers-having a charmingly graceful habit, and soft, pretty glaucous foliage.

P. filifolic (Thread-leaved pine).-Certainly this and $I$. patula are the most delicate and graceful of pines, syn.

P. Skinneri. exquisite for pot-culture, but too tender for any portion of this country, except the extreme Soutl. It is a native of Guatemala, growing there to the lieight of forty to sixty feet, and resembling very mueh our Georgia pine $(P \cdot$ palustris $)$, with its long, beautiful, thready leaves; twelve to fourteen inches in length.

P. flexilis (Contorted-branched pine).-This curious tree was found by MIr. Jeffery, at an elevation of nine thousand feet, and even fourteen thousand, in the neighborhood of Fraser's river, where it makes a small tree of forty feet high, with a peculiarly flattened head; and on the highest portion of the mountain, where it degenerates into a shrub of only three feet high, it beeomes so eompact that a person may walk on the top of it. It has not been introdueed here yet, and hardly into England; but from its being found so near the snow-line, we should suppose it might prove hardy.

P. Fremontiana (Colonel Fremont's pine).-This pine was Sy: diseovered by Col. Fremont, during his explorP. monophylla. ing expedition, when crossing the Sierra Nevada, P. Llareana. growing on both sides, extending over the top of that great, snowy chain. It does not reach a size of over twenty feet, is very spreading in its habits, and will probably prove perfectly hardy in this country, sinee Col. Fremont often found the thermometer at two degrees below zero, at night, and four feet of snow where the tree grew. The seeds are eatable, and are quite an article of commerce with the Indians, in the season, under name of Nut pine.

P. Gerardiana (Gerard's pine).-A slow-growing but vigorSy/n. ous variety from the mountain of Kunawar, in

P. Neoza. India, reaching the height of fifty feet, and

P. Aucklandii. forming a elose, compact head; the leaves of

P. Chilghosa. these are stiff, and of a bluish green. We had this 
twelve years ago as (if we are not mistaken) "The Short-leaved Weymouth," which we never thought correct, but there was so little to distinguish it from an ordinary pine that we replaced it by something more valuable. It was perfectly hardy.

$P$. Halepensis (Aleppo, or Jerusalem pine).-This variety Syn resembles the Brutia (which we have P. Hierosolymitana. already described) so much as to be often $\mathrm{P}$ genuensis. sold for it. We cannot quite, as yet, malie up our mind whether it will stand our climate here, or not. It does very well in a wood, and a specimen more exposed, docs equally well, if it is true; but the resemblance to Brutia is so great that it may be this variety; Maritima is often confounded with it. Messr's. Hovey, in Boston, report it as liardy and fine there; but their plants, like our's, may prove Brutias, or something else. It is found on the east and west sides of the Apennines, and in Sicily, among the rocks in Lybia, and in Greece, growing to be a tree of thirty feet.

P. Hartwegii (Hartweg's pine).-This is a fine variety that $s_{y y}$. we remember to have struck us very forcibly ten P. resinosa. years ago, in England (when very small), from P. Standishi, the fine, dense color of the foliage. It is one of the Mexican pines, forty to fifty feet high, and beginning on the mountains at ten thousand feet elevation, where the Picea religiosa ceases. We have tried it for several years with but indifferent success, and have abandoned it as too tender for any climate north of Virginia. It is too coarse for pots.

$P$. inops (The New Jersey pine).-This variety, too well Sinn. known to need description, is found from Carolina P. variabilis, to the Hudson River, but does, we think, extend beyond it. It has a spreading top, and is thirty to forty feet high, and, of course, must be planted in collections, though hardly otherwise would be selected by the amateur.

$P$. insignis (the Remarkable pine).-We regret that this Syn.

P. Californica, of Loisel. $P$. minteragensis. certainly most beautiful pine will not resist our winters, even in a wood; though it will, no doubt, do well and prove a very great acquisition in our Southern States. It is so attractive in its appearance, that it was one of the earliest of the new conifers tried here, but without any success. It is 
found in many portions of California, growing to the height of eighty to one bundred feet.

$P$. Jeffreyi (Jeffrey's pine).-We doubt if this has becu tried at all in this country yet. Our own plants are extremely small, and not yet out. It is a majestie tree, one hundred anr? fifty feet high, from Northern California.

$P$. Lambertiana (Lambert's pine).-This superb variety, reach ing an altitude of one hundred and fifty to two hundred feet, and twerity to sixty feet in girth near the ground, is from the norihern parts of California ; and is, without doubt, perfectly hardy in this lititude. Our plants have eseaped injury the

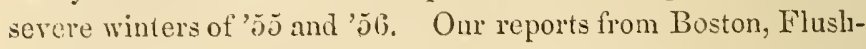
ing, New Jersey, and Washington all coineide as to its hardihood; so that we may place this among the "safe trees." Its resemblance to the Pinus strolus (White pine) hits been stated as an objection, but it might resemble a worse tree; besides, we do not think this is quite so. To us it is very distinctive; and it has long been a great filvorite with us for its tine, deep green, and rigorous, healthy habit. It has this merit, to say the least, even if its eharacter is not as marked as many of the less robust pines.

P. Taricio (the Corsican pine). - This tree with many synSym.

P. maritima.

P. Corsicana pyramidalis, dre. onyms, is a native, as its name implies, of Corsica, though found also in Europe, Greece, and Spain; and is the great tree upon Mount Aitna, growing rapidly to a height of cighty to one hundred and thirty feet. It is quite as bardy as Lambertiana, or Austriaca, all over the country, having somewhat the robust habit of the latter, only a less vivid green. Some of our speeimens of this variety made leading shoots last year of five feet.

P.l. Culabrica (the Calabrian pine), P. I. Caramanica (the Car:amanian pine), P. l. pygmea (the Dwarf Corsican), and $P$. l. contorta (the Twisted Corsican), are only varieties.

$P$. leiophylla (the Smooth-leaved Mexican pine). - A large tree, with an irregular open head, rertical branches, and drooping foliage, growing sixty to one hundred feet high; from the mountains of Angangueo, in Mexico, and is called by the natives "Ocote Chino," from its abundance of resin, and being 
used for torches and candles. The wood is so hard, as to resist the plane. The tree is too tender for the Middle States, but would doubtless succeed south of Virginia.

$P$. Lindleyana ( $\mathrm{Dr}^{\mathrm{r}}$. Lindley's pine).-This variety, often consyn. founded with Montezuma, and as such, imported P. Nontezumx. by us some year or so ago, is really quite distinct, and is a robust, bushy looking tree of forty feet; found near the "Sumate," on the mountains of Mexico. It will, no doubt, prove hardy, coming from so high an elevation. We do not know that it las as yet been tried, nor do we think it very desirable, except in very full collections.

$P$. longifolia (the Long-leaved pine).-This is one of the syn. class of exquisite pines, of which $P$. filifolia, P. serenagensis. patula, Canariensis, and even Australis are also representatives. They are all, except Australis (Palustris), too tender even for the climate of Great Britain, and will not of course do at all here, except in Georgia, the Carolinas, and our Southern States, where no greater addition to ornamental plantations can be made; they are charming for pot-culture with us, which is the only way they grow them in England generally. The timber of Longifolia is excellent, and full of resin, which is another recommendation for the South. The foliage is of an exquisite light green, and the leaves, tweive to fourteen inches long, delicate and thready.

It comes from the lower ranges of the Himmalayan mountains, fiom Bootan to Afrghan, growing forty to one hundred feet high, with a peculiar spiral arrangement of bark and fibre, like a cork-screw.

The chips are used in India for candles, and are called "Chamsiug" (niglut lights). According to Dr. Hooker, ink is made in Sikkin from the charcoal of the burnt leaves mixed with water. It is also remarkable for its fiagrance.

P. macrocarpa (Dr. Coulter's pine).-.This is a grand tree, Fin. which we have had several years under each of P. Coulteri. the above names; though now we believe cultiP. macrocarpa. vators have settled down upon macrocarpa and Coulteri, as the proper ones. Our best specimens would have been eight to ten feet high, having worked through the winters of ' 55 and ' 56 , with very trifling injury, when, unfortunately, 
all the terminal buds were eaten off by sheep; and though the trees might hare stood climate alone, yet they were unable to resist both climate and sheep, and they consequently perished. It has rugged, stiff leares, ten or twelre inches long, and becomes a rery striking tree, eighty to one lundred feet high; from the momntains of Santa Lueia, in California, at an elevation of three or four thousand feet.

$P$. macrophylla (the Long-leared Mexican).-An uncomSym. . monly tine rariety, which we lost in the winter of $P$ Leroyi. 1855 , in a rery exposed situation, though we are not prepared to say it would hare stood better in a protected cne. It is a rery striking tree, from one of the highest mountains of Mexico, growing twenty to thirty feet high, with a fine, ample foliage, fifteen inches long. It is almost too stout and coarse for pot-culture. but would be rery ornamental at the South, where it would grow perfectly well.

$P$. maritima (the Maritime pine).-This tree, so called and so sold in our nurseries, is simply a nurseryman's name, there really being no such tree. It is rery curious, but nerertheless true, that the greatest confusion prevails, both in the English and Freach nurseries, abont this variety. 'In England, it is confounded often with P. pinaster, Halepensis, and Laricio; and in Franee, with Pallasiana, Pithyusa (Halepensis), Lariciv, and Pyrenaica, and made synonymons with each ; and in this country, it secms to represent any thing which is unknown.

The specimens we have seen in our neighborhood as Mraritima, are probably Calabriea-a sub-rariety of Laricio-and, we think, most NIaritimas in our nurseries are Laricio or: Pinaster. Representing, as it does, so many different trees, it is dificult to get any reputation about it which is to be depended on. In Boston, it is returned to us as tender, from which we assume that the rariety there may be Pinaster, which is sometimes tender here; while at Rochester, it is reported hardy, and may be Calabrica, or one of the hardy synonyms. At Washington, the variety known as Maritima, does well, and also at Elizabethtomn; but what these trees realiy are at these two places, we hare no means of linowing, except that they are not Maritimas. 
$\int_{1}$ 

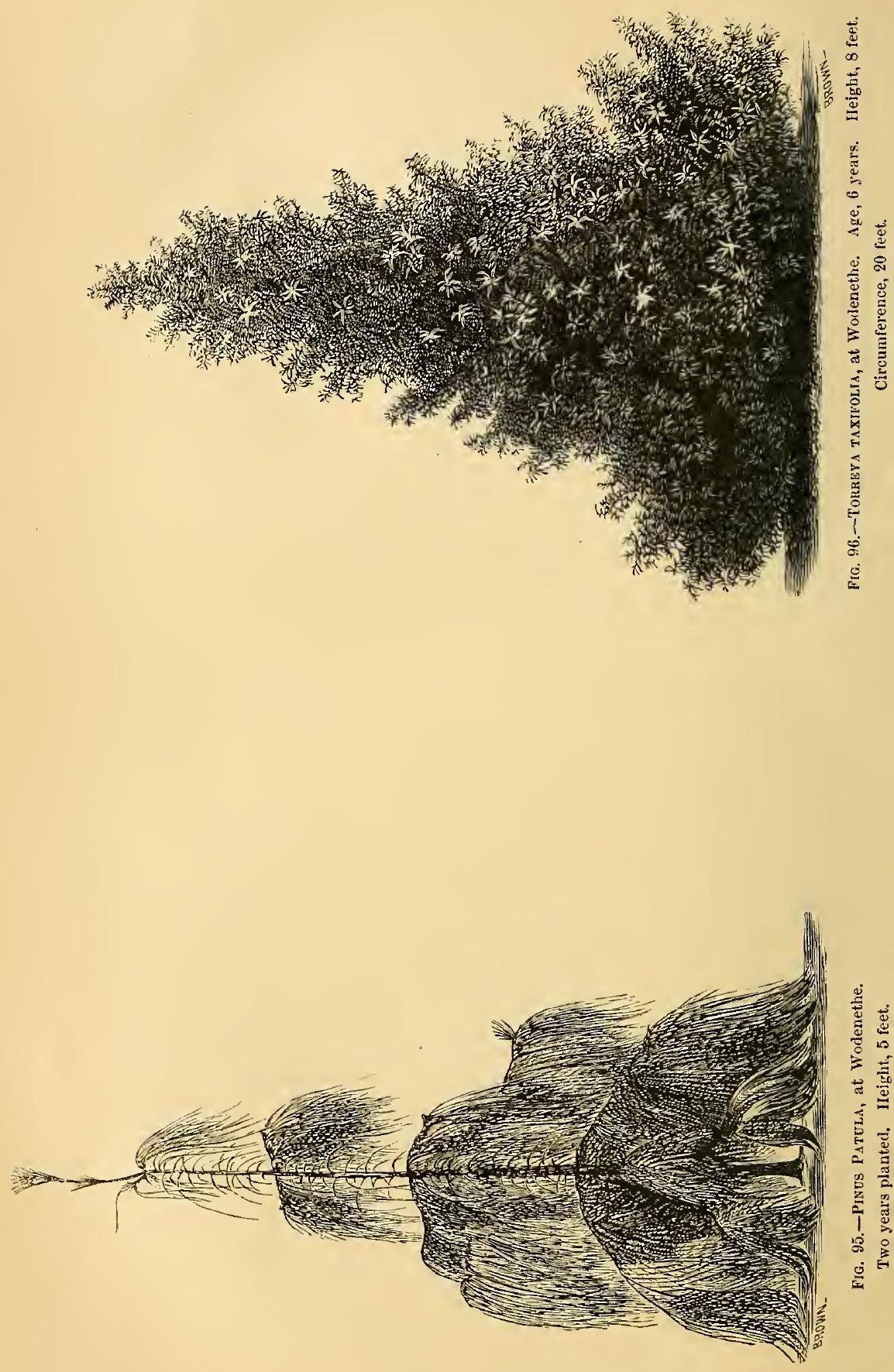


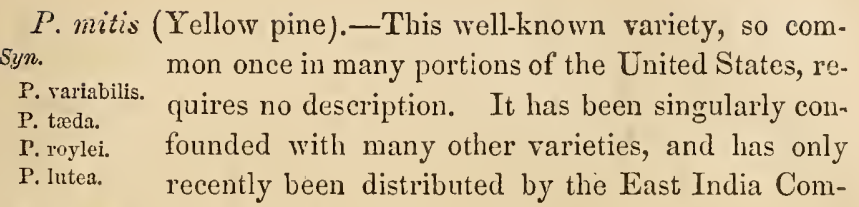
pany, as a new species, under the name of P. roylei, which farther experience shows clearly was the common American yellow pine.

P. monticola (the Mountain pine). - W We have had this tree P. Lambertiana. out for several years. It is quite as hardy as P. brevifolia. our White pine, and so closely resembling it as hardly to pass as distinct. It grows as tall as the White pine, but has a denser head, and shorter and more glaucous foliagefound on Trinity Mountain, in Northern California.

P. Montezuma (Montezuma Mexican pine). - This fine variety has stood out with us several winters, though somewhat protected. It is found on the mountains of Mexico, at an elevation of eleven thousand feet, growing forty to sixty feet high, with a spreading head. This does not appear as yet to be in any of the American collections besides our own.

P. Mugho (the Mugan pine).-A small tree, thirty feet high, P. sylvestris Mugho. from the Alps, perfectly hardy everywhere, P. Mughus.

but not very attractive. There are four varieties, all small, and Mugho nana (Kinee pine), not more than three feet high.

$P$. nivea (the Snow pine)-Is only a variety of our common White pine ( $P$. strobus), with the under part of the leaves, silvery-quite as hardy as its parent.

P. palustris.-Te have already described as Australis.

$P$. patula (the Wide-spreading Mexican pine).-O Of all the pines which we have ever seen, this is beyond measure the most graceful and charming, not only in its growth and habit,a representation of which is given in Fig. 95-but in the nature, softness, and color of its leaves. It resembles a beautiful, delicate green fountain of spun glass, and has a particolor, like shot-silk, which catches the sunlight almost like a kaleidoscope. The leares resemble the silk of maize, being as soft and delicate, and not mnlike it in color. Although found in the colder regions of Mexico, on the Real del Monte 
mountains, it bas not the appearance of being hardy, and wo have not yet attempted to acclimatize it - having but two plants, which are quite beautiful enough for pot-culture to satisfy anybody. It would unquestionably grow at the South. We have no reports about it, and know but one other specimen in the country, which is at Wellesley, near Boston, grown, like ours, in a pot. There are two other varieties, $P$. patula stricta (more erect), and $P$. patula macrocarpa (much larger and taller); neither,' we think, in this country.

P. pinaster (Star or Cluster pine.)-This fine tree, which, Syyn.

P. Nepalensis.

P. maritima.

P. Japonica, and

seven others. when first introdueed, and before thoroughly tested, promised to be the most artistic of pines (at least of available pines)-doing for our landscape what $P$. pinea (the Stone pine) did for Claude in the Italian Landscape-lias, in our latitude, proved itself a little questionable. It will certainly stand uninjured our ordinary winters; but such uncommon ones as those of 1855-6, when, with us, the mercury sank to twenty degrees below zero, destroyed, at Wodenethe, specimens eighteen and twenty feet high, and this seems the experience of our returns.

It is a most admirable tree for planting near the sea-shore, where it thrives wherever the climate will permit, and is to be found all along the Cornish road, bordering the Mediterranean, in Spain, Portugal, Greece, Turkey, Japan, New Holland. From the facility with which it flourishes near the sea, it received its synonym of maritima. No doubt $P$. pinaster Hamiltonii, Lemoniana, minor variegata, are varieties.

$P$. ponderosa (the Heavy-wooded pine.)-The hardiest, we should say, of all pines, not excepting our naSyn.

P. Craigeana.

P. Benrdsleyi. tive White pine, and the fastest grower. We have a specimen, sixteen to eighteen feet high, raised from seed in less than seven years. This variety is gigantic in every sense of the word; the new shoots are two or three times as thick as those of our White pine, and same with the buds. The annual leading shoots exceed a yard. It is from the Northwest coast of America and California, where it grows one hundred feet high. Although a strik- 
ing, it is not a handsome tree, the interval between the tiers of branches being so wide and the foliage so coarse and sparse, as to give it a thin and naked look; besides which, it has an ugly habit of working the erown of the root out of ground, so as to grive the tree the appearance of insecurity. Our tree, though eighteen feet high, and grown from seed where it stands, still requires, or seems to require, support. It is, of course, liardy all over the United States-at least, we doubt if any cold will affect it, though it might suffer from sun in the extreme South.

P. Pullasiana Taurica (Taurian pine.) - A large tree, seventy to eighty feet high, found as yet only in the Crimea and along the coast of the Black Sea. We have specimens which have been out several years without protection; perfectly liardy, though not very distinetive, as it resembles exceeaingly our White pine.

P. prmilis (the Mountain pine.) - A remarkably stiff, unEyn. graceful dwarf, resembling the Scotch fir-in P. Tartarian, some farorable situations, becoming a tree thirty \&c.

feet high, but generally only a low, straggling, slow-growing bush. It is very common on the Alps and the Carpathian Mountains; perfectly hardy.

$P$. pinea (Italian Stone pine).-No one, we think, who has Syn.

P. Latina.

P. domestica.

P. arctica, \&c. ever been to Rome, will have forgotten the Colonna pine, which, together with St. Peter's, eternal city. This superb object, rising abruptly from the midst of the Colonna gardens, is so much associated in our early recollections, with all views of Rome, that now it is gone, ${ }^{*}$ it would really seem as if we had lost an old friend. It is the great tree of Claude, and all the old masters, and no Italian garden would seem quite perfect without it. It is generally, we think, too tender for this climate, though suited well to the South. We have tried many times to acelimatize it; but though it may struggle on for a few years, yet it never would form, pro. oably, the picturesque tree, so valuable for the eomposition of 'certain lanảscape effects.

* Blown down in 1851. 
P. Pyrenaica (Pyrenean pine). - A rery hardy, robust Syn:

P. Hispaniea.

P. Monspeliensis.

P. laricio, ant? nino others. variety from the Pyrenees, perfectly hardy with us, having survived several winters; but. like I. nivea and P. Pallasiana, too nuch resembling our native White pine to be very distinctive.

$P$. radiata (Radiated-cone pine).-This tree, from Upper California, is one of Dr. Coulter's introduetions, closely resembling the. P. insignis; but, being a little denser and stouter, may prove hardier. It seems to thrive near the sen-shore; the specimen found by Dr. Coulter being one liundred feet high, with a straight sten, feathered to the gronnd. The wood is much used at Monterey for boat-building. Not to our knowledge introduced here yet.

P. rigida (Stitf-leared pine).-Another of our" "Native Syn.

P. Canadensis-trifulia. Americans," extending throughout the whole of the United States, as far north as Brunswick, in Maine. Not desirable, except to complete collections.

P. resinosa (Red pine).-An American tree, principally Syn. found in Canada and Nova Scotia; not very mike P. rubri, sc. the Corsican. It abounds in resin, and is esteemed for its strength and durability.

P. Sabiniana (Sabine's pine).-This majestic tree-from the Cordilleras of Mexico, where it grows to the height of one hundred and fifty feet-is very distinctive, and, we believe, will prove hardy. Our trees have been out since the severe winters of $1855-56$, and stand in a protected place thus far very well. The tone of the foliage is peculiarly soft and pleasing, being of a light glancous color.

P. strobus (White or Weymouth pine).-A description of this well-known tree will be found in the first part of the book, under Mr. Downing's section on evergreen trees.

P. syleestris (Scotch fir).-This valuable variety is also too well known to reguire description or eren mention, beyon? the fact that, take it all in all, it is perhaps the most important of all foreign pines. It is perfectly hardy everywhere in this country, and in Europe, where it is cultivated under twenty different names. It is not a beautiful tree, though it assumes, 
with age, a good many picturesque forms. It is very cheapplants, two or three feet high, can be imported from the Eng. lish nurseries, at three or four dollars the hundred-and very raluable as a hack tree for planting out disagreeable objects and making screens. There are a good many varieties; among them are, Variegata, which is with us as hardy as Sylvestris, haring a golden stripe or blotch on the leaves; Pygmea, a dwarf, of two feet or so; Argentea, a silver-leared variety.

$P$. tada (Loblolly pine).-Another of our native trees, Syn. found from Florida to Virginia, forming a tree P. Tirginiana. of eighty feet high, with a spreading head. This P. Pennifolia. is also called the Frankincense pine, and is distinguished by its delightful aroma.

$P$. tuberculata (Tuberculated-cone pine). - We have but Syn. lately had this variety, and by its synonymous P. Californica. name (Californica). It was discovered by Dr. Coulter, immediately on the beach, near Monterey, and after. wards was found on the Santa Cruz mountains, by Mr. Hartweg. Mr. Jeffrey, also, found it on an elevation of five thousand feet. It is said to be slow-growing, reaching a leight of forty feet. Our specimens, so far, resemble P. Sabiniana. We have no reports about it, and never saw any other specimens except our own.

\section{Podocarpus.}

This comparatively rare genus obtains its name from two Greek words, rovs, a foot, and Kapros, a fruit; and is found in Asia, Africa and America, and may be anglicised into the Fruit foot-stalked yew, from which it seems only slightly differing, many varieties being sold as Taxus ( $Y$ ew), instead of Podocarpus. There are about ninety varieties introduced into the collections on the Continent and in England; a great many of these are very tender, even abroad, and we do not, as yet, find mole than four which promise at all well for this country.

Of these, $P$. Japonica (Japan podocarpus), seems the best known as yet, and the hardiest. It is a small tree, from Japan, where it abounds, and is not very unlike Taxus Hibernica (the Irish yew), only with a broader and, perhaps, flatter leaf; our 
specimens have been through two winters without any injury -it is certainly with us quite as hardy as the Irish yerr. It is reported to us as hardy at Flushing and at two different places in. Georgia, but being new and costly it has not as yet been tried anywhere else.

P. Andina (The Andes podocarpus).-Another pretty, small Syn. tree, ten to twenty feet high, from the Alpine P. Tarus spicata. regions of South Chili, with a broader and more leathery leaf than the preceding variety; our specimen is out, for first time, this winter, and we have but one return about it, which is from Augusta, and is satisfactory.

$P$. coriacea (Leathery-leaved podocarpus). - This variety Syn. comes from the Blue Mountains of Jamaica. Taxus lancifolia. and also the Antilles, growing fifty feet high. We have more doubt about this than the two above, and we have but one return, from Flushing, I. I., where it is marked "hardy."

$P$. taxifolia (Yew-leaved podocarpus).-There is no question Syn. we think, of the hardihood of this rariety

Taxus montana.

Torreya Hnmboldii. We have had it out three rears without injury. It resembles still more the Irish Jew, than P. Japonica. It comes from the mountains of Peru, at an elevation of eight thousand feet, where it is a tree of sixty feet. We have no returns.

There is one other variety, not yet received into this country, to our knowledge, which promises better than any of the above. viz.: Podocarpus Nubigena, which is described as one of the finest, as it is unquestionably one of the hardiest and most distinct, of all the conifers introduced within a few years. It is a native of Patagonia and is found also on the Andes, near the Araucaria imbricata, which tree it much resembles-the branches being produced at regular distances like it.

\section{Saxe Gothaca conspicua. Prince Alemrts Yew.} Syn. Tasuz Patrogonica.

A genus by itself, and this the only species; a small bush or tree found on the mountains of Patagonia, growing thirty feat high, with very much the habit and appearance of the common 
yew, but not so fine a color. We have no report about it in this country, and presume it will, at the North, at least, have to be grown in tubs, though we have a specimen out this winter.

\section{Sequoia sempervirens. Californta Red Wood.}

Better known here as Taxodium sempervirens. Found in the 1:orthwest part of North America, forming a majestic tree two hundred to three hundred feet high, and often confounded with Washingtonia gigantea, quite a different thing; the foliage of the Sequoia being flat, two-rowed, and dark green, while that of Washingtonia is needle-shaped, spirally alternate, and on the branchlets very close and regularly imbricated like an Arbor vitæ, besides being a light or yellowish green. The two varieties are probably the most gigantic evergreens in the world. There is a slab of the wood of the Sequoia at St. Petersburgh, measuring fifteen feet in diameter, and having one thousand and eight annual rings to mark its age.

We have tried it many winters, but with hardly any success. It grows too rapidly and too late in the autumn to ripen off its wood, and almost always with us gets killed back to the snowline, though generally shooting up again the next spring to meet a similar fate the succeeding winter. We have no returns about this tree other than tender, except from Waşhington, where a specimen, six feet high, planted by Mr. Downing, in 1852 , is growing beautifully though slightly injured in ' $55-6$. There is no reason why, in our Southern States, it should not succeed perfectly.

\section{Taxodium distichum. Deciduous Cypress.}

Syn. Cupressus Virginiana, \&c., \&c.

Though not an evergreen, yet this valuable genus is closely allied to coniferous trees, and is well known by all planters as the Southern or Swamp cypress, found along the banks of rivers and swamps in vast quantities; in Georgia, Carolina, Florida, and all the Southern States, it reaches the height of one hundred and twenty feet. It is perfectly hardy at the 
North. 'The varieties, fustigiatum, pedulum, nutans, \&c., are described under the head of Glyptostrobus.

\section{Taxus. The TEW.}

Great additions lave been made to this class of evergreens, since the first edition of this book, where only three foreign and one American varieties are mentioned, 1;z.: T. baccata (the Common English), $T$. fastigiata (the Upright yew), and the $T$. fructo-flava (Yellow-berried). Among the new ones which we have found hardy, are:

T. adpressa (Flattened or Creeping yew).-An exceedingly Syn.

Cephalotaxus adpressa,

T. brevifolia. dark, striking bush, never, we believe, exceeding three feet high, but spreading horizontally; with very minute close leaflets and pretty bright red berries, very desirable; like all the yews, doing better in the shade.

$T$. argentea and $T$. aurea (Silver and Golden yew).-These two are very beautiful and desirable varieties of the Common yew; the first having silvery white-striped leaves, and the second golden. They seem perfectly liardy here. We have some Golden Jews grafted standard high on the Green yew, which produces a very pleasing contrast. They are more commonly known in the English nurseries as Taxus elegans and Taxus elegantissima.

T. Dovaston (Dovaston's yew).-A singular Weeping Syn. variety of common Englisl yew, found some years

T. pendula, ago, if we remember aright, in the yard of a cob-
T. horizontalis,

T. horizontalis. bler near Shrewsbury; described as pendulous as a birch or weeping willow; quite hardy with us, and well worth cultivating.

$T$. erecta (the Erect yew) - A slender variety of the comSyn.

T. pyramidalis,

T. stricta. mon English yew, with smaller foliage, and more erect habit of growth; sometimes called Fulham yew. It is thought by some cultivators in this country to be hardier than the common English yew, though the latter with us, especially after a year or 'so, succeeds perfectly well, though possibly a little browned in very severe winters. 
T. ericoides (the Heath-like yew).-A very pretty, slender kinn. variety, with very minute foliage, quite disr. microphylla. tinctive and liardy here, and at Newport.

T. Hibernica (the Irish yew).-'The same as Fastigiata, a very striking pyramidal tree, resembling in its close compact habit, the Lombardy poplar. There are specimens in England twenty-one feet high, though usually twelve to fifteen feet seems its common height; it is also known as the Florence Court yew. It is quite hardy generally, though sometimes a little browned by severe winters. This is a most admirable variety for potculture.

T. nana (Dwarf yew).-A very dwarf, hardy variety, never syn. exceeding two or three feet, but very spreading, T. Foxii. like the Prostrate juniper.

T. variegata (Variegated yew).-A handsome variety, differing a little from the Golden yew, and sometimes sold as T.elegans; hardy here.

\section{Thuiopsis. BroAd-LEAVED ARBor VITz.}

Name derived from Thuia, arbor vitæ, and opsis, like. There is but one variety of this new genus recognized in Gordon's Picetum, viz., Thuiopsis dolabrata. The remaining variety, known in this country as Thuiopsis borealis, is classed by Mr. Gordon among the Cupressi, and has already been described by us as a most valuable and hardy tree, known as Cupressus Nootkaensis. We think, ourselves, it would be better to aldopt the nurserymen's name, Thuiopsis Borealis, by which it is generally invoiced.

\section{Thuja. The Arbor vite.}

So many of this family have been already described under the head of Biota, and Mr. Downing having said all that was necessary upon the common American arbor vita (Thuja occidentalis), but few distinctive Thujas remain for us to mention. Thuja gigantea (Gigantic arbor vitre).-If this succeeds in syn.

T. Craigiana.

T. Libocedrus decurrens. the United States-and there is every reason to be satisfied with its success thus far-it will unquestionably be the 
noblest addition this genus ever received. Accustomed as we are to regard the Arbor vitæ as a small bush, principally available for hedging or single specimens, ten to twenty feet higlt, for small villa-gardens and village-yards, we shall find it difficult to realize that we are to have an arbor vitæ reaching to the dignity of a majestic tree, one hundred and forty feet upright, with a fine umbrella-shaped top and picturesque head. This is, another of the giants from the Columbia river and Nootka sound. Mr. Jeffrey discovered it along the banks of Scott's river, and sent it home to England as Thuja Craigiana. Mr. Nuttall, in his Rocky Mountain expedition, also discovered it, and gave it the name of Thu. gigantea; and finally, Dr. Torrey has classed it as a Libocedrus, and distinguished it as decurrens. It lias since again been discovered in California, in 1853 , by $\mathrm{M}$. Borusier de la Rivière.

It has been discovered so many times, by different people, and received different names, that a good deal of confusion exists about it, and it is often confounded with another Thu. qigantea-so named by Sir William Hooker, in his American Flora-but which, though coming from California, is a more slender tree, not over fifty feet, and is beyond doubt, the true Thu. Menziesii, which is also sometimes called Thu. plicata, and very much resembling the American arbor vitæ. In fact, it would seem as if there often existed among Arbor vites botanical rather than physical differences, which often, as in this case, and that of the Siberian Arbor vitæ, produces great perplexity.

As these two giganteas are completely mixed up, we will describe them separately, with the hope of throwing some light upon their difference.

The real Thu. gigcritea has its branches rather erect, long, slender, and spreading laterally, with numerous smaller ones; branchlets, short, flattened, channeled along the sides; leaves, awl-shaped, lanceolate, loosely imbricated in four rows, the outer pair being the longest, and folded partially over the inner pair on both sides, giring the young shoots a trident-like appearance.

'The Thu. Menziesii, on the contrary, has its branches spreading, flat, more or less horizontal, slender, and of a deep brown 
color, alternately two round, and nearly all the inner side quite straight ; leaves in alternately opposite pairs, closely imbricated, those on the branchlets being much shorter, more rounded, and furnished with a short spiny point; besides which, one forms a tree of one hundred and forty, while the other (Thu. Menziesii) only attains an altitude of forty feet.

We are not yet able to say what either of these trees will do in this country. The real gigantea is said to be hardy, and the false, not. At Elizabethtown, N. J., Mr. Reid writes us, "The true one grows rapidly, and will no donbt prove hardy." At Augusta it stands perfectly well. At Flushing, not quite hardy. These are the only reports we have, and our own plants are out for the first time.

7'tu. macrocarpa.--This is a variety we received, if we mistake not, several years since, from Messrs. Ellwanger \& Barry, of Rochester, and about which we can find no mention in any of the books, nor does it seem to exist in any of the foreign Pinetums, or in any nurserymen or collectors' catalogues. It resembles so much the Thu. giganlea, that we are inclined to think it is this variety under a different name. We have never tried it out, as we could not find anything of its character or habits under this name.

Thu. variegata (Variegated arbor vitæ).-Only a goldenstriped variety of our common arbor vitæ, but pretty and distinctive, and perfectly liardy.

Thu. aurea Americana (American Golden arbor vitæ).-Is an exceedingly pretty and well-marked seedling, found accidentally in a nursery row by our neighbor, Mr. Daniel Brinckenhoff, and named by us as above. The new growth is very distinctly yellow, and the old foilage, which is a bright clear green, tones off so gradually and delicately into the golden hue of the new, as to produce a most pleasing little tree, and perfectly hardy.

Thu. Hoveyi (Hovey's arbor vitæ).-Another American seedling not yet introduced, but which is described to us by Messrs. Hovey (in whose nursery, near Boston, it was found) as a seedling of Occidentalis, as hardy as an oak, haviung never lost a limb in the severe winters of ' 55 and ' 56 . Very nearly of the same habit as Aurea, compact and upright branches; leaves 
as fine as Aurea, making a most superb tree. It holds its color even better than Thu. Siberica, while it is a lively, soft green. brighter than Aurea, and not as sombre as Siberica. It is now, even in midwinter, as green as most arbor vitæs are in summer. Messrs. Hovey have two other seedlings, not as distinct or tine as the above.

Thu. plicata (Nootka Sound arbor vitæ).-These two plants Syn. plicata and Warreana, though often sold by seThu. Warreana parate names, are, beyond question, identical;

Thu. compacta. this is the conclusion both of the English and Thu, robusta.

French authorities; although there is another plicata, a synonym of Thu. Menziesii in the English collections, and another Warreana in some of the French collections, as among "les variétiés horlicoles," but only another name for Thu. occidentalis. The true plicata and true Warreana are one and the same thing.

The Nootka Sound arbor vitæ is found on the western shores of North America, at Nootka Sound, quite hardy, everywhere, and differing from the common American arbor vitæ, in having its brauches shorter, more compact, stouter, and densely covered with small, flattened leaves, bluntly pointed, and with a plaited and jointed appearance.

We have already alluded, under the head of Biota, to the difficulty in recognizing the origin of B. Siberica, which is sometimes confounded with Tatarica, but more generally with Warreana. This latter (Warreana) was named from Mr. Ware, a nurseryman at Coventry, in England, and Mr. Loudon considered it as a distinct variety; but it seems now to be referred back again to Thu. occidentalis; and Siberica adopted as its name without any botanical authority, and simply as a nursery distinction; and we presume, consequently, that all plants grown in this country, as the Siberian arbor vita, are Warreana, or its synonym, plicata.

\section{Torreya. The Torreya.}

Vulgarly, the Stinking Yew.-Small evergreen trees, found in North America, China and Japan, emitting, when bruised, 
a strong, disagreeble smell, and named after Dr. Torrey, the celebrated American botanist.

T. grandis (The Grand Torreya).-Discovered by Fortune in northern part of China, as a large tree with a spreading head, but so resembling a Cephalotaxus (which most of the others do) as to render it uncertain whether it may not yet prove one. It is considered very desirable wbatever it may be, but just introduced into England and not yet, to our knowledge, here.

T. myristica (Californian nutmeg).-A small, bushy tree, twenty to forty feet high, with spreading horizontal branches, found on the Sierra Nevada, in California ; quite hardy in England and likely to prove so here. Our specimens are out for first winter, and we have no returns. Like all the Torreyas, emitting a most disagreeable odor when bruised or burnt, and called by emigrants the Stinking yew or California nutmeg.

T. nucifera (Nut-bearing Torreya).-This is out with us at Wodenethe, for the first winter, and we have no returns about it. It is another small tree, twenty to thirty feet high, found on the mountains of Niphon and Sikok, in Japan, where an oil is made from the kernel of the nuts, used there for culinary purposes. The nut itself, and the leaves and branches, have the distinguishing characteristic of all the Torreyas-a disagreeable odor.

T. taxifolia (Yew-leaved 'Torreya.) - This is one of our Syn.

Taxus montana. greatest accessions in the Middle States-being now perfectly hardy with us, as already described in our introductory chapter on evergreens, and very distinctive.

It is a handsome pyramidal tree, with numerous spreading branches, growing from forty to fifty feet high, found in the middle and northern parts of Florida, where it is commonly known by the inhabitants as Stinking cedar and Wild nutmeg.

Our best specimen (fig. 26 ), is about eight feet high, very dense, showing nothing but foliage, like a thrifty arbor vita, and remarkable, particularly in winter, for the star-like appearance of the extreme tips of its young shoots.

We have returns of this tree from Elizabethtown, N. J., Dobb's Ferry, Yorkville, Flushing and Newport, in all of 
which places it succeeds well, and is considered hardy, except at the last place where it is reported tender.

\section{Washingtonia gigantea. The Mammoth Tree.}

This truly most magnificent of all trees-deciduous or ever. Syn. green-was discovered in a valley at the

Wellingtonis gigantea. Sequoia gigantea.

source of one of the tributaries of the Calaveras, California. Within an area of fifty acres only, ninety two trees of this species were found standing, beyond doubt the most stupendous vegetable products on earth.

They were first discovered in 1850 , by some hunters, whose accounts were considered fabulous until confirmed by actual measurement. The largest tree was one called the "Father of the Forest," four hundred and fifty feet high, one hundred and twelve feet in circumference. The next largest the "Mother of the Forest," three hundred and twenty-seven feet high, and ninety feet in circumference.

'Three trees, growing together, called the "Three Graces," are each three hundred feet high, ninety feet in circumference. There is another which has fallen, and through which a man on horseback may ride serenty-five feet, and twelve feet in the clear. These trees may be truly termed the "Lions of California," and in such estimation are they held, that it has been found sufficiently remunerative to erect a hotel and run a line of stages to Sacramento city and Sonora, for the accommodation of visitors to these great natural curiosities.

The botanical discovery of this genus was, however, probably made by the unfortunate Douglas, in 1831, when he writes to Mr. Hooker : "The splendor of the Californian vegetation consists of a species of Taxodium which gives to the mountains an especial beauty, which I may almost call terrible."

This wonderful tree, which closely resembles, in our plants, the Weeping arbor vitæ (Thuja fliformis), in its imbricated leaves, of a more delicate color than the arbor vitæ, being of a pleasing light green, is, we are happy to say, promising to be hardy in the United States. 
Our own plants have only been out one year, but seem to succeed perfectly well. We have returns from a good many parts of the country where it has not been left out all winter, and also from Mr. Reid, at Elizabethtown, where it was, and who has a specimen four to five feet, perfectly hardy. He thinks, in time, it may prove as common as a Norway spruce, being very rapid in its growth. At Woodlawn, N. J., it stands well, the largest specimen being four to five feet. At Rochester, it is hardy, and also at Augusta.

\section{Widdringtonia. The African Cypress.}

A new, distinct variety of cypress, found at Cape of Good Hope, and Madagascar, and named after Capt. Widdrington, and a variety of which, erroneously called Widdringtonia ericoides, has been imported into this country, and is cultivated with some success, doing very well here in the shade, and also at Washington and Augusta. We hardly know why it comes out to us as a Widdringtonia. In the English collection it is called Retinispora cricoides, and in the French, Chamosyparis ericoides; but, by whatever name it is called, it is a pretty heath-like little shrub, resembling somewhat the Irish juniper. It is cultivated in Japan (its "native country), in pots, and called "Nezu,"-(Dwarf.)

\section{EVERGREEN ORNAMENTAL SHRUBS.}

But very little progress has been made in the planting of evergreen shrubs. As great as has been the advance in trees, especially the coniferous, there has been nothing to correspond with it in the introduction of evergreen shrubs. With the exception of a few varieties of the Berberries-like Japonica, Bealii, Intermedia, \&c., we do not remember any thing available for this 
climate now, which was not well known when Mi: Dorning wrote.

There are, perhaps, a few things, untried ten years ngo, which have been tested the past three or fonl years, and not "found wanting;" such as some of the smaller English shrubs, like the Andromeda-especially Floribunda-the Cotoneaster, of which Buxifolia, with us, proves the hardiest, though Microphylla and Marginata, both do well in the shade. And here let us remark, once for all, that no evergreen shrubs do at all well in this country, in the sun. Every thing, from the yew down to the creeping periwinkle, succeeds vell, only in shade.

If it is impossible or inconvenient, to have these shrubs otherwise than exposed in open lawns, we should recommend only the employment of certain varieties, like the Rhododendron Catawbiensis, Kalmia latifolia, Mahonia aquifolinm, and Ilex laurifolia.

These four shrubs seem to stand any amount of heat and cold. Onr thermometer, while we now write, indicates sixteen below Zero; and last summer they passed through a fiery ordeal of $95^{\circ}$ to $100^{\circ}$ : and this they have done for many years, with no other ill effect than that the very hot weather changes that fine, deep, dense color they universally have in the shade, into a yellowish green, but they survive and grow and flomish and bloom, though certainly less fine than when planted on the north of buildings or woods.

'T'ake it all in all, we consider the Ríahonia (sometimes called Berberis mahonia), the most valuable of all shrubs, deciduous or evergreen.

If there is any exception to our remarks above, about the necessity of growing evergreen shrubs in the shade, we should make it in favor of this variety. It may be imported very cheap. Messrs. Waterer \& Godfrey, Knaphill Nursery, Woking, near London, offer plants, one foot high, at eighty shillings sterling, per 
thousand, and in same proportion for smaller quantities. It is perfectly hardy-a most rapid grower-has a very attractive, yellow flower early in spring, succeeded by fine purplish berries in autumn, which, in England, are used for preserves by the agricultural classes, very much, as in New England, the common Berberry is used for same purpose. It is evergreen, or if not entirely so, it has what is even better, a most superb rich, brown tone, mingled with the most gorgeous scarlet and crimson, like our highest autumnal coloring, and the leaves covered with a brilliant lnstre-like varnish. We believe it does not grow over five or six feet high, and we find the plant is much improved by keeping it back by occasional clipping, as it sometimes has a tendency to straggle. It should be always planted in beds or masses, by itself.

The Rhododendron is too well known to require description. Although the R. Ponticum and many of the hardy hybrids like Nero, Atrosanguineum, Ferrugineum, and a few others are quite satisfactory in the protection of a wood, yet the only truly reliable ones in exposed situations, are the English varieties of the Catawbiensis, of which Messrs. Waterer \& Godfrey (and we presume they can also be procured now at our nurseries) offer thirty varieties in color, all hardy here, one and a half to two feet high, mostly with flower buds, at fifty shillings sterling, per hundred, for plants not named, and ten pounds per hundred (about fifty cents each) for named varieties.

It is perhaps well to say here that Rhododendrons, Azaleas, and most of these evergreen shrubs, do well enough in ordinary garden soil, but are much improved in color and habit, by a soil prepared equally of peat, leaf soil, and sand or sandy loam. There is no more superb plant cultivated than the Rhododendron, and we earnestly recommend the adoption in pots (to be kept in the green-honse during winter) of the varieties below 
mentioned,* too tender to be entirely exposed all tho year.

The Ilex Zaurifolia (Laurel-leaved holly), strikes us, after the Mahonia, as the next most valuable evergreen shrub, even more so here than our native Kalmia, which is very apt to suffer fiom oul hot August weather. We have grown this Ilex many years, both in a wood and in the most open situation, and apparently with equal success; though we presume in certain seasons, with great alternations of heat and cold, those exposed would be apt to scorch. It has a leaf of a color and habit like the Camelia, and even finer; and, if we regard foliage alone without flower (though even this is pretty), we should say we had no finer plant upon this place. It is an exceedingly great favorite of onls, and strange to say, we have never seen it elsewhere.

The Kalmia latifolia (the Broad-leaved Kalmia), or American Sheep-laurel, as it is commonly called, is another very desirable shrub, as well as its varietiesTr. angustifolia (Narrow-leaved Kalmia); K. myrtifolic (Myrtle-leaved); K. carnea (Red-flowering Kalmia), \&c. It is somewhat difficult to more, and although the mountains in our neighborhood abound with them, we have found it less expensive to import plants from England, raised from seed, at fifteen cents apiece, than to transplant the native habitats of the mountains, with their long straggling roots. Thongh it will grow in the sun, yet in the shade it becomes a different plant.

The above, with the different Yews, Arbor vitas, creeping and low-growing Junipers, \&c., are the only dependable evergreen shrubs that we can at this

* Atro sanguineum (Superb Deep maroon); Archimedes (Superb Rose de Chine); Angiola (Superb Cherry pink); Brayamum; Curranum (Superb Iruss lilac rose); Chancellor ; Fastuosum (Mnguifieent Truss lilae); Giganteum; Hannibal; Henry Drummond; Luxidum; Rubrum Maculatum, Lero; Ne Plus Ultra (Fine lilac); Poussin; Reedianum (Small Truss rosepink, but fine); Sir Isaac Newton; Vandyck ; Victoria (Superb Deep lilac); Cleopatra; Invictun; Proserpine; Speciosum. 
moment recommend for general planting in exposed sunny situations.

For amatenrs, who have the advantage of a wood, or a long line of high fence, upon the northern side ot which they may have a shaded border, there are several other things we would suggest: such as the hardy Heaths, the hardy Belgic azalias, costing in England $£ 10$ per hundred (fifty cents apiece), for named vari. eties, in twenty different colors: the different Andromedas, the Rhodora Canadensis, the various Ganltherias, the Ledmus, the pretty family of Menziesias, the Epigxa, the different varieties of Box, the green and the variegated Enonymons.

The Ilex Scottica is represented to us as quite as fine and as hardy as Ilcx laurifolia, thongh we have not yet tried it.

In those parts of the country, too cold to grow the English ivy, we wonld suggest large circular beds, in appropriate parts of the pleasure-grounds, to be planted in ivy; and which, while permitted to fill the bed, shonld be kept within it by clipping. Beds in this way filled (the ground being well covered in) with the different varieties of the Gold-striped, the Silver-striped, and the Dark Giant, are very effective and striking, and when not protected by snow in winter, can readily be so by a few cedar or hemlock boughs thrown over them.

Note.-As this work is passing through the press, we have received a twig, perfectly green and fresh, of an $A$ bies Douglasii, from a tree at Cazenovia, New York, planted in 1853, when only eighteen inches high, and that has now reached the altitude of eight feet, making annual shoots of fifteen to twenty inches, withstanding a temperature in $1855-6-7$, of $25^{\circ}$ to $25^{\circ}$ belowo zero, without the slightest protection or the least injury; while the A. Menziesii is immediately destroyed, and the Silver fir raised with difliculty, and where neither the Cedar of Lebanon, the Pinus excelsa, or Picea pinsapo, succeed at all.

The tree from which the specimen was sent us, is growing in a retentive loam, rarely suffering from drought, but planted on an open lawn, entirely exposed on every side.

This seems conclusire evidenee that cold at least, does not injure the Douglas fir, and that it may be classed "Perfectly hardy" in a climate usually considered the most severe, or one of the most severe, in the State of New York. 


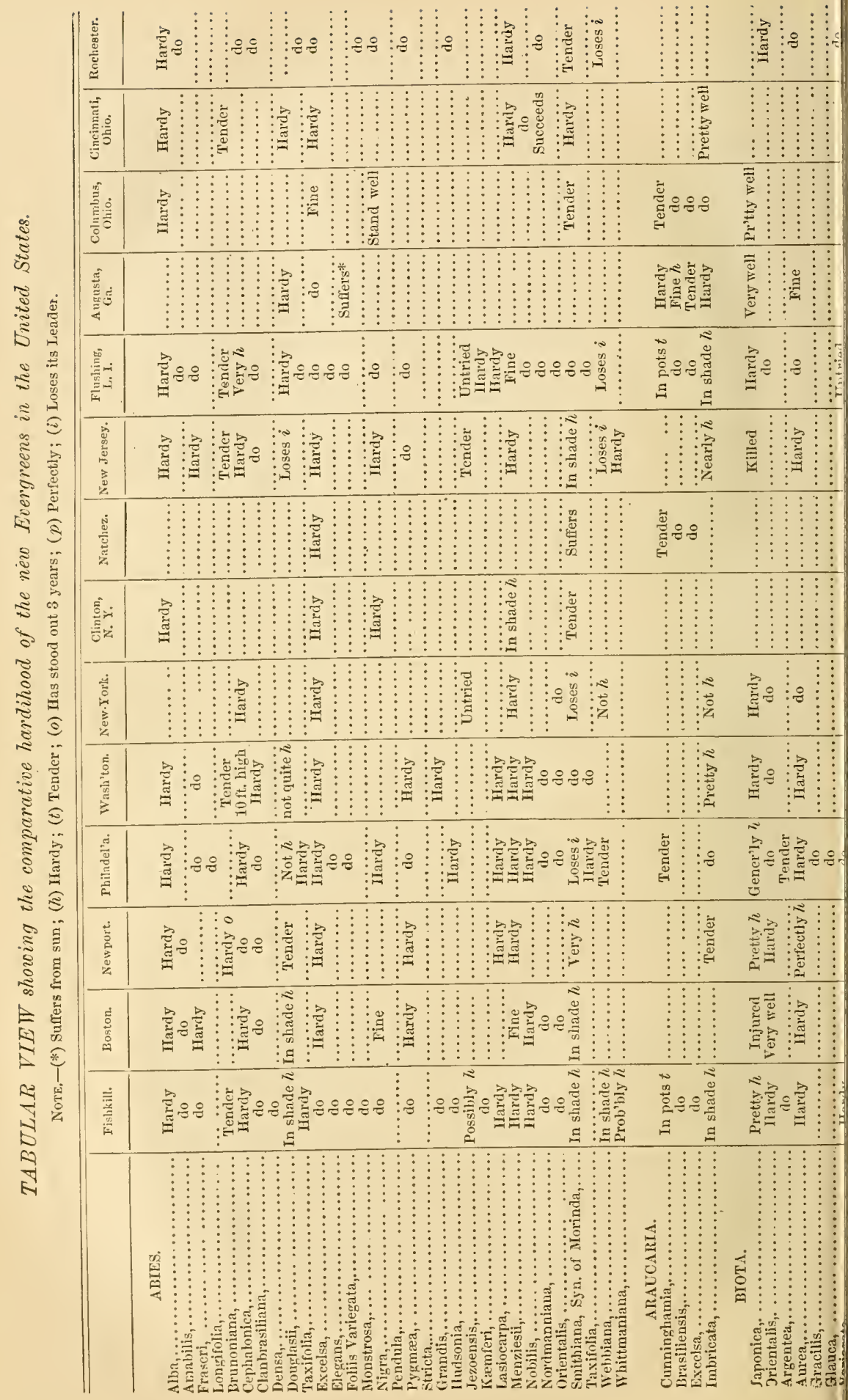




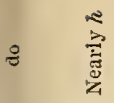

咅!

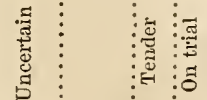

苛。

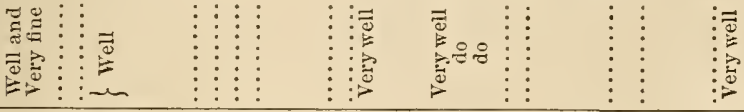

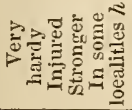

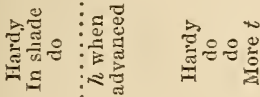

离

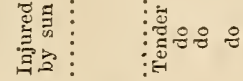

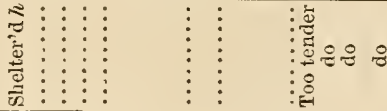

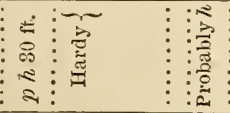

$\vdots$ 剁

$\vdots \vdots$

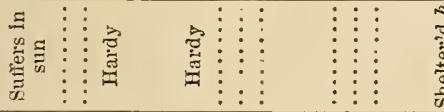

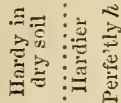

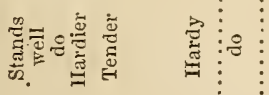

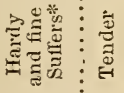

(y)

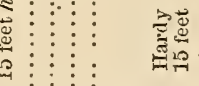




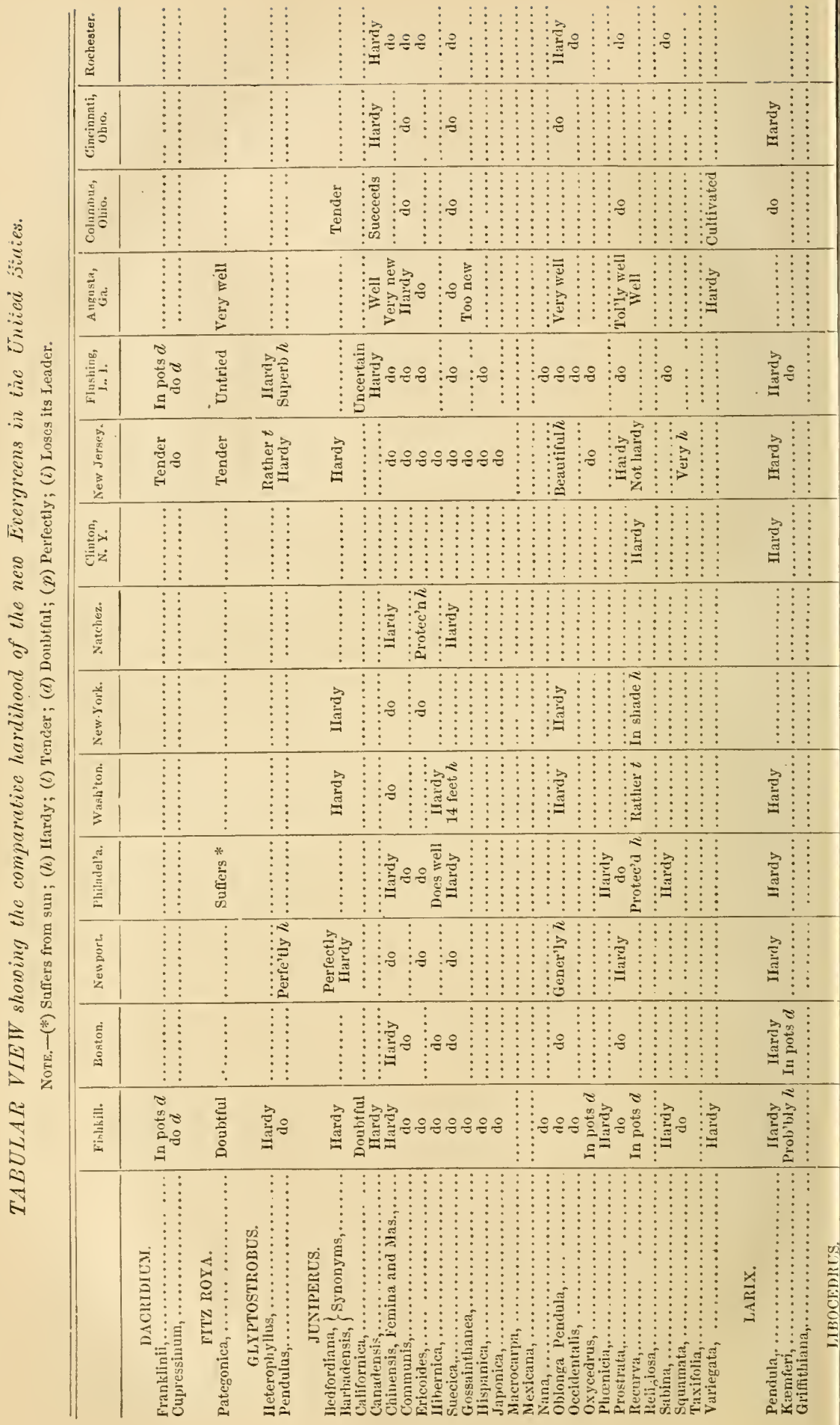




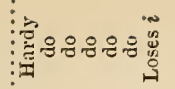
$\vdots$
$\vdots$
$\vdots$
$\vdots$
$\vdots$
$\vdots$
$\vdots$
$\vdots$
$\vdots$

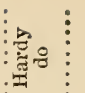

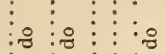

学。

$\vdots$
$\vdots$
$\vdots$
$\vdots$
$\vdots$

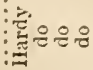

尝

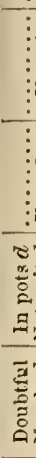

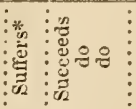

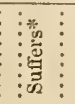

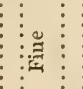

$\begin{array}{ccc} & \vdots \\ \vdots & \vdots \\ \vdots & \vdots \\ \vdots & \vdots \\ \vdots & \vdots \\ \vdots & \vdots \\ \vdots & \vdots\end{array}$

In

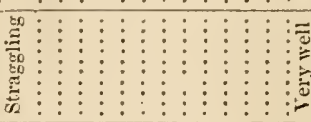

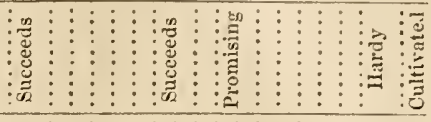

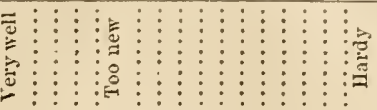

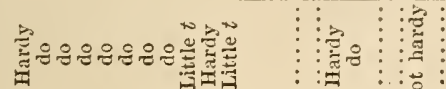

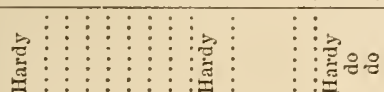

【)

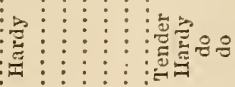

窟

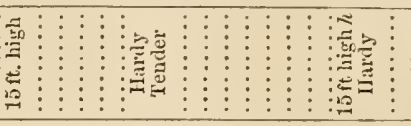

绾。

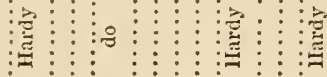

保

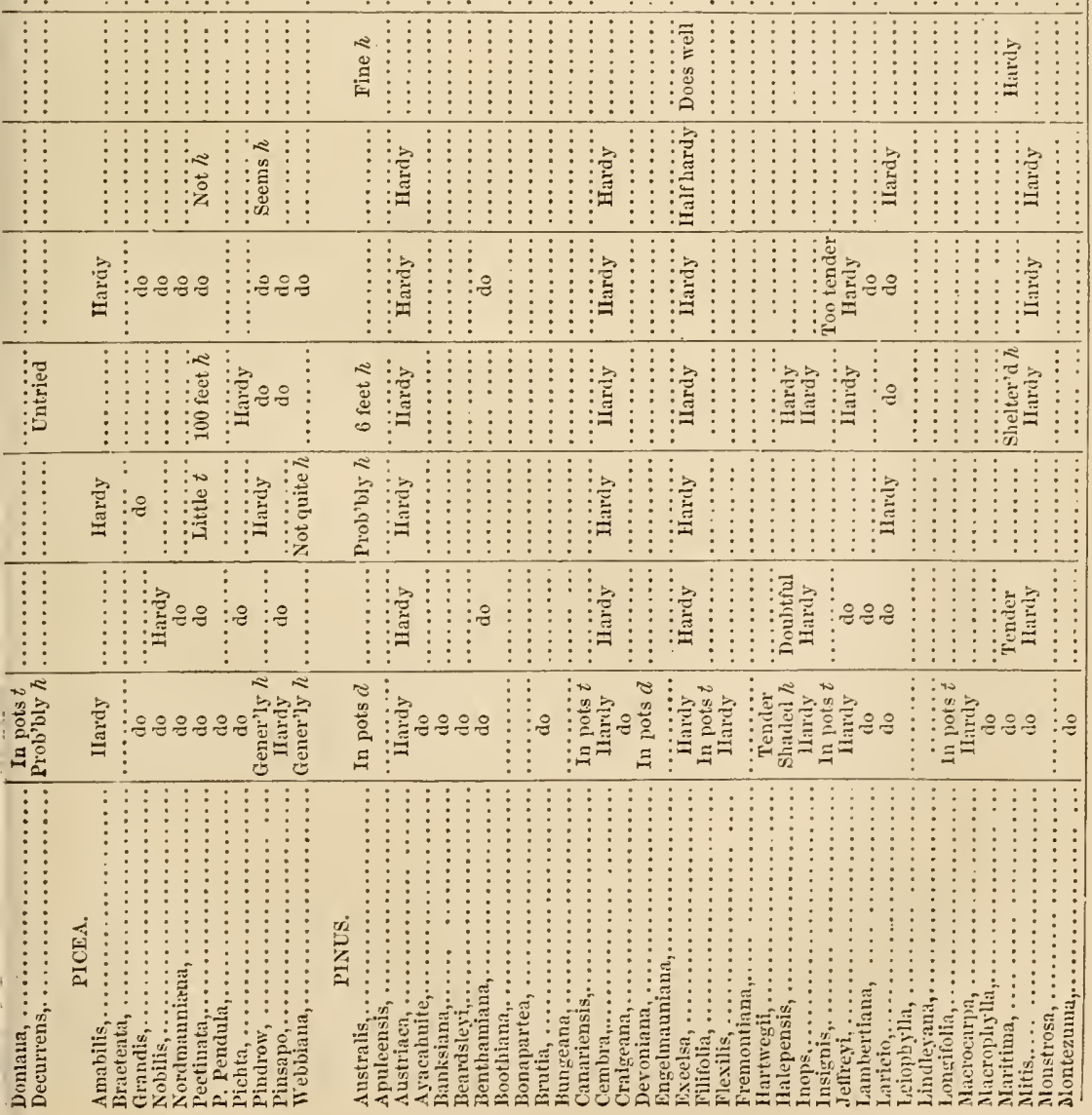




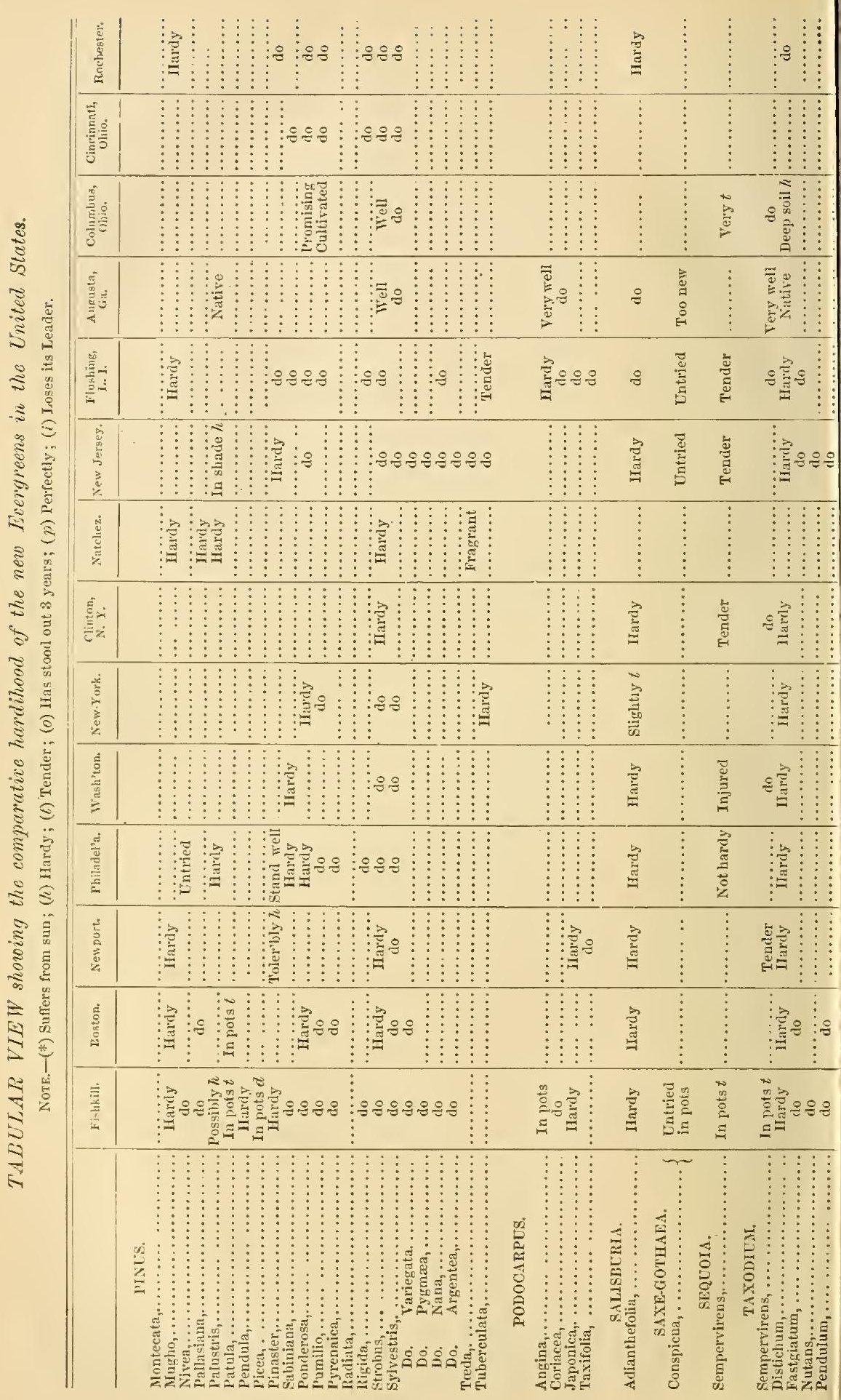


能! :

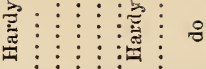

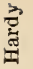

:

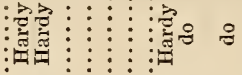

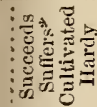

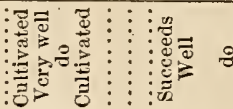

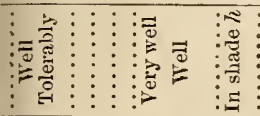

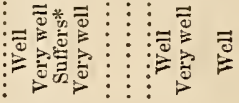

\begin{tabular}{lllll} 
& & & \\
\hline
\end{tabular}

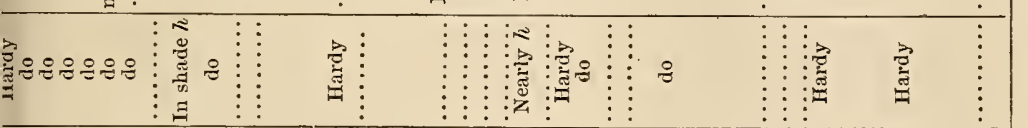

$\vdots$

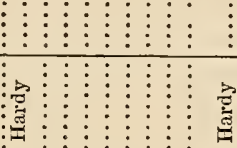

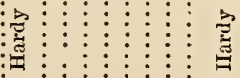

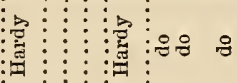

密

到

\begin{tabular}{c:cc}
100 \\
\hdashline
\end{tabular}

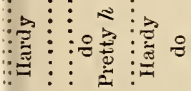

密

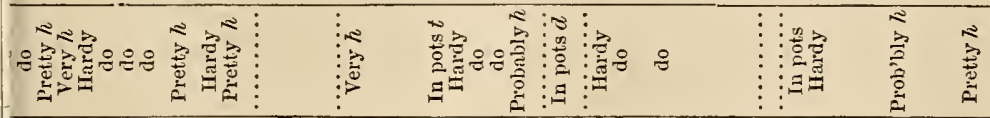

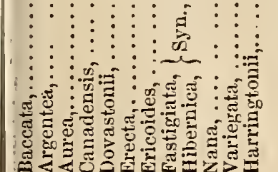

$\frac{u}{u_{1}}$

:

嵁

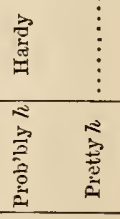

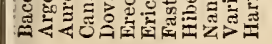

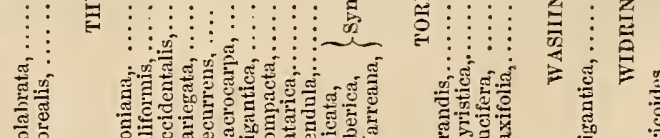

落

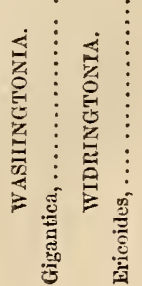

in

$\cong$

5

胥

ङ



:

हี่

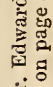

볼

릉

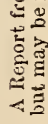

* * 


\section{SECTION V.}

FISTORICAL NOTICES.

Ir is with great reluctance that we undertake this portion of our task, from a consciousness of our entire inability to do justice to the many fine places which exist all over the United States, and which require a greater knowledge than we have of them, as well as more space and time than is allowed us, for the remainder of this supplement.

With Mr. Downing, in his first edition, this labor was comparatively a light one, as, twelve or fifteen years ago, there were only a few marked places in the neighborhood of our large cities, and upon the banks of the Hudson river and Long Island sound, which were so distinguished and prominent as to be easily described; of this class were Col. Perkins' and Mr. Lyman's near Boston; the Manor of Livingston, Montgomery place and Hyde Park, upon the Hudson; the Bartram garden, Stenton, Woodlawn, etc., near Philadelphia; and a few others. Since this period, however, the taste for country life has adranced so rapidly, that, in and about these very neighborhoods, there are, at present, scores of country houses, many of them of the finest and most expensive character, but all partaking more or less of similar disposition and style of grounds, and a similar fashion of planting.

We have already said, in the introduction to this supplement, that since Mr. Downing's time, though the style of country houses had vastly improved, yet an equal improvement was not so evident in Land- 
scape Gardening. This we attributed to the fact that, while an Architect was employed to build the house, no professional artist was employed to arrange the grounds, and great errors and mistakes constantly nccurred-in many cases so gross, as to destroy the entire effect of what would be otherwise a very fine and attractive place.

Althongh there has been great expenditure of money in comtry houses and costly glass-buildings, during the past ten year's, yet, in a great many cases, very inferior arrangement and planting have been exhibited in the grounds. Landscape Gardening is just as much a picture, though a living one, made by trees, as a painted landscape is made by the pencil or brush; both require longyears of study, artistic perceptions, and a knowledge of how to handlo the tools. It would be quite as unreasonable, we think, to expect one of our merchants or lawyers, in active business, to make a landscape, as to paint one. How can a person who has passed his life in the whirl and excitement of active business, or professional ocenpations, be suddenly transferred to the country and be expected to make a garden? It would be just as absurd as to expect that a gardener can be transferred to the counting-room, and become, the next day, a merchant. It is quite as necessary in the one case as in the other to be educated up to whatever you are to succeed in.

It requires more and different qualities to make a country-place than are required for any other profession. For while industry, knowledge, pridence, sagacity, are generally all that are necessary for a merchant, or lawyer, or doctor, the Landscape Gardener must have not only these but also taste-a knowledge of the beantiful, and a perception of the harmony of form and color; in other words, he must be an artist.

The fashion of living in the country has not existed long enough (though rapidly increasing) for this knowledge or' taste to have been very widely extended; for every good 
place there are a great many bad ones, and we eamnot but think that our comntry residenees would be much more agreeable, if artists were allowed to arange the placesat least, to make suggestions, just as artists are allowed to build the honses, or, at any rate, help build them.

The necessary result then, as we have previonsly observed, is that a person going into the eomntry to live, makes his own place thom his neighbor's suggestions, or from ideas derived from his neighbor's place-which maly be rery fianty or of an entirely different eharacter from his own-with the aid, perhaps, of his gardener and a snggestive nurseryman. A great many places are manufinetured from these three sources; and the general charracter ot them all is so much alike, that there is little or no distinction between half a dozen in the same neighborhood, though a competent Landscape Gardener might hare dereloped many different beanties in each.

In the absence, therefore (from haring becn already mentioned in the first part of this book), of any of those rery marked and distinguished residenees which have received the stamp of years, where trees have grown into studies, and the places themselves have beeome schools for the lovers of art, we trust we shall not be thought invidions if we confine omselves to a bricf mention of a few of the prominent places which have come muder on notiee-heing quite aware that they are well deserring of mueh more than we have an opportunity to say. We were in hopes with many of these to have given illnstrations, but here agatin time finled $n s$; cren the oue or two we suceceded in procuring were too late for the engraver.

We are quite aware we shall be forced to onit a great many in more remote parts of the comuty, which we have not yet had the pleasure of seeing, and this makes us the more regret that onr limits and our time will allow us to do so little. 
The neighborhood of Boston was so thoroughly des. cribed in the first portion of the present volume, that but little is left us to add to this accomt. The samo places, more or less, which were prominent then, are quite as distinctive now.

Mr. Lee's lawn, as yet, has no rival, unless perhaps that of Mr. M[udge, at Swamseot, near Lynn. Wellesley, the residence of Mr. Inumewell, we have already deseribed; and though there are a great many other fine houses, the places themselves are yet comparatively newly planted.

Kenwood, the residence of Mr. Peabody, near Salem, has a great deal of quiet pastoral beanty, and much artistic effect is shown in the arrangement of the house and grounds.

Linmere, the residence of R. S. Fay, Esq., has great capabilities, not yet taken advantage of." 'There is here a very valuable collection of rare deciduous and evergreen trees, which, if properly thimned out and planted, would be very effective. The place itself is a fine estate of some five hundred acres ol more, mostly surrounding a lake, and very much resombling Scotch scenery.

The house and grounds of the late John E. Thayer, Esq., inchuding a vast extent of glass, are perhaps the most expensive in the neighborhood of Boston.

The residence of Mr. J. L. Gardener has a pretty sloping lawn, and an attractive flower garden, with many fine Norways and other trees.

The difliculty of procuring suitable residences in the city, has forced many persons into the country, and the consequent high prices have prerented the oceupation of much land by any single individual.

The new residences are, consequently, surburban, but very complete in all the onter acessaries of country life-stables, green and fruit-houses, and very substantial and handsome walls. 
Within a few years, there has been very visible improvement in the style and character of the marine residences in the neighborhood of Boston.

At Lynn, and on what is called the Beverley shore, are the marine villas of $\mathrm{Mr}$. Prescott, Mr. Curtis, Mr. Iawrence, Mr. Jasigi, Mr. J. D. Bates, Mr. Loring, and the late Mr. Dexter-all more or less distinguished by the excellence of their houses, and with most charming views.

Newport, having become, of late years, a very desirable place of residence for people of tortune, abounds, like the neighborhood of Boston, in very tasteful and agreeable villas and cottages, with prettily arranged and well kept grounds, the most snccessful of which, taking grounds with house, is Beachclyffe, the residence of Delancy Kane, Esq. Mr. Kane's honse, a very fine one, is in the style of the French chateanx, with extensive views both inland and seaward, and his lawn is quite as successful as any we know in this country. The place is about twenty acres, and very charmingly planted with a great variety of the most valuable trees. We think the growth of certain varicties unsurpassed in any place we have ever seen; and there is a luxuriance of habit and depth of color in the masses which form his bonndary plantations, which is truly remarkable.

Mr. Kane had a great advantage over many of lis Newport neighbors, in finding quite a number of wellgrown horse-chestnuts, and other ornamental trees, which he has contrived to work, with much good taste, into his own plantations. The gate-lodge here is quite a little gem in its way.

Malbone Place.--The residence of Mr. J. Prescott Hall is a fine house of red or rather brown freestone, commanding an extensive view of Narragansett bay, and surrounded by some most extraordinary Red cedars, of great antiquity, but with their heads, so flattened and 
distorted by the winds as to produce the closest resem. blance to that peculiar horizontal growth which characterizes the Cedar of Lebanon.

Mr. Hall's farm is, we believe, a fine one, and he has great command of water from a hydraulic ram, in the driest seasons, sufficient to irrigate his entire garden.

The celebrated Buffum pear originated on this place, and is still very prolific.

Mr. Wetmore's residence, built of Fall River granite, is the largest and most expensive house at Nerport, with a very successful lodge, and a fine extent of glass, containing a vinery, and a very handsome octagonal conservatory. The view of the sea from this place is very implessive.

Mr. Parish has a fine place in the neighborhood of Mr. Wetmore. The house, of brick and stone trimmings, is a very striking one, and the lawn admirably kept to the water's edge. Adjoining this is the estate of $\mathrm{Mr}$. Cadwallader, where at present there is no house. We believe great and extensive improvements are contemplated in this place; it is still in an unfinished state.

The residence of Mr. King is a handsome brick house, in the Italian style, surrounded by some fifteen acres, with some remarkably fine specimens of Pinus cembra, twelve to fifteen feet high; also some fine Junipers and Purple beeches.

Mr. Calvert's grounds, near the town, contain some fine trees grouped with much taste.

Among other residences of more or less merit, are those of Messr's. Russell, Lyman, Hoppin, Van Rensselaer, Wright, Mason, and Mr. Morgan Gibbes.

Notwithstanding the difficulty which is always sup. posed to exist, in producing any effect by trees so immediately in the neighborhood of the sea, yet experience shows that, at Newport, at least, much is and has been done by judicious planting. Mr. Kane informs us, and 
in this, we believe, $\mathrm{Mr}$. Smith, who is the great antho. rity at Nerport on trees, coincides, that in making an evergreen screen from the sea, the Scotch and Austrian pines should be placed outside, Siberian (Thuja Tarreana) Arbor ritæ, and Pinus cembra next, with perhaps the Common Red cedar; and among deciduous trees, nothing succeeds better than Acer pseudo-platanus and Platames orientalis (the Eastern plane).

Upon the Hudson, the most marked place which has been created since the first edition of this book, is Rockwood, the residence of Edwin Bartlett, Esq., " near Tarrytown. The house (Fig. 97), is truly a princely mansion, with a façade of nearly or quite one hundred and fifty feet, and with its internal arrangements and decorations, we should say, quite the most complete establishment in the United States. The estate itself consists of sereral hundred acres, rery cleverly planted with park-like effect; and the approach, which is quite a long one, so judiciously managed, that it conreys the idea of a very large place, and gives a stranger the most agreeable impression of the house, at the first appearance, when emerging from a ravine or passage between two rocky eminences.

The riews from the house and the platean or terrace around it, are rery superb, and unrivalled, we think, upon the Iudson Rirer.

Very extensive green-houses and conservatories have been erected under the supervision of MIr. Luchars, a builder of great experience; and we do not see wliy, in a fer years, with the taste and liberality of expenditure on the part of the proprietor, Pockwood will not be the, or certainly one of the most distinguished country-seats in America.

With regard to Hyde Park (Mrr. Langdon's), Ellerslie (Mrr. Kelly's), MLontgomery Place (Mrs. Liringston's), and Annandale (late Blithewood), Mrr. Bard's, which we hare always considered the four great places in this

* Now Wm II. Aspinwall Esq., 


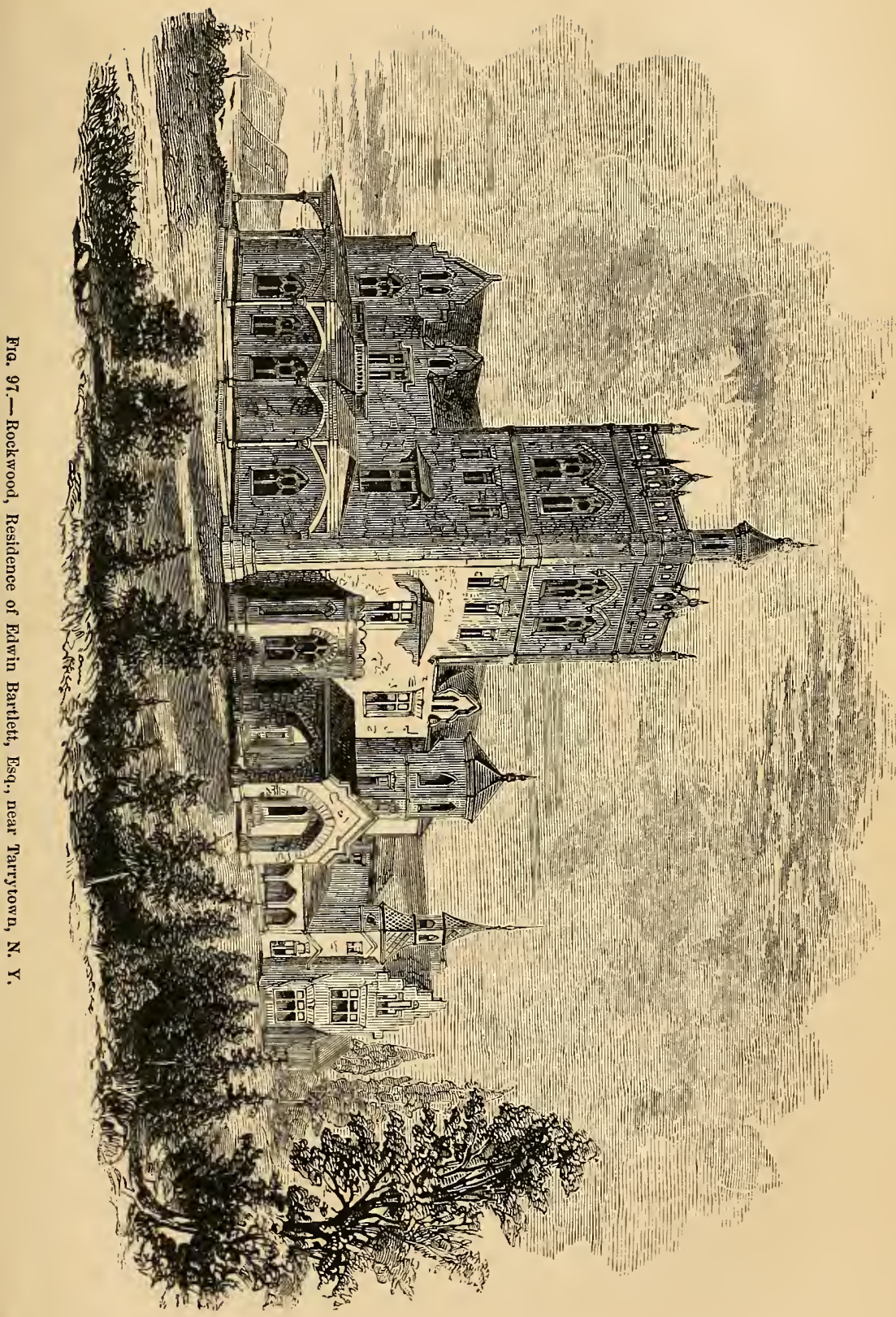



country, we can only refer our reader's to Mr. Downing's remarks about them in the first portion of this volume.

While the hand of time has even still more mellowed their beauties by those touches and effects which Nature alone can produce with years, yet even here the hand of man has not been idle.

At Annandale and Hyde Park, extensive ranges of glass have replaced the old ones of previous owners, * while at Montgomery Place and Ellerslie the most showy and superb conservatories and green-houses have been erected.

At Montgomery Place also, there has been planted within the past ten years, the most complete and satisfactory arboretum in the United States. Neither pains or expense have been spared in obtaining the most entire and thorough collection, or in the peculiar and appropriate preparation of soil for the reception of the different varieties.

In the neighborhood of Rhinebeck, is "Wyndclyffe," the r'esidence of Miss Jones, a very successful and distinctive house, with much the appearance of some of the smaller Scotch castles. This place is still quite new, but the situation is one of great beauty, upon a bold, projecting point of land, in admirable harmony with the style of the house, and with the most extensive and superb views.

Immediately above Hyde Park, is the fine house of Mr. Curtis, one of the most expensive and costly upon the Hudson, possessing very much the same extended views of river and mountain as at Hyde Park.

Roseneath-the residence of C. Mr. Wolcott, Escr., in our own immediate neighborhood, is the creation of the past few years, and we are very much indebted to it for a great many advantages to our own place, which

* At Hyde Park, a very graceful and elegant house of the composite order, designed and built by Platt, of New York, and with a façade of one hundred and fifty feet, has within a few years, replaced the hospitable old mansion of the late Dr. Hosack. 
we should not otherwise possess. By the employment of wire fences, and some careful planting ont of the houses in both places, a great deal of what Nature has done for each, has been appropriated by both.

We know of no other place where such successful masses of Rhododendrons, Azalias, and Mahonias are grown as here, being on the north side of the house, and getting but little or no sun. The graperies, green-house, and gardens, are extensive, and admirably kept. By means of a steam-engine, water can at any moment be forced into the mansion and an outside reservoir, from which it can be distributed over the gardens. In the comparatively small space of sixteen acres, $\mathrm{Mr}$. Wolcott has every attribute of a well-kept country place-several lawns, each distinct from the other, with separate and lovely views; an English flower-garden, a most successful vegetable-garden, green-house, grapery, and forcinghouse, the most charming views, and no apparent boundary but river and mountain.

Idlewild-the residence of N. P. Willis, Esq., across the Hudson, some four miles below Newburgh, is a piece of Nature's Landscape Gardening, where the hand of man should not, and, from the good taste of the owner, lias not been allowed to appear, except in the necessary buildings. In a work like this, for the purpose of showing the progress of Landscape Gardening, this place should, properly, not be mentioned; and we refer to it, simply to show how delicate and refined that taste must be which, appreciating all that Nature has done with so much prodigality of beanty, as at "Idlewild," has the comrage to let her alone.

In the neighborhood of Philadelphia, there are a great many fine places; among them is Medary, the residence of Harry Ingersoll, Esq. A tasteful and substantial house, built by Notman, we believe, with pleasure-grounds of very considerable extent, and of a pretty, graceful character, softly undulating, and well 
planted. The landscape and the character of the country in the ncighborhood of Medary, though deficient in the bolder ontlines of many of our more northern places, yet has, what we confess is a great attraction to ns, the quiet sylvan beauty of English scenery-that pastoral look, which seems to suggest the presence of animated nature; and Mr. Ingersoll has, with great good taste, we think, taken advantage of this lint, by the introduction of fine cattle, which harmonize most pleasingly with the character of the place. There is here a pretty flower-garden, plantcabinet, green-house, vinery, and some new peach and orchard-honses.

Brookwood-the residence of Charles Henry Fisher, Esq.-a very extensive and complete establishment, with a great amount of glass, most charming views, and a great deal of well-kept, ornamental ground, will, in a few years, be one of the most striking places near Philadelphia.

Alverthorpe-the residenee of J. Francis Fisher, Esq., is another superb place, where a vast deal has been accomplished, both with honse and grounds. The parklike view from the front is extensive and exceedingly striking. An effective architectural appearance is produced in connecting the mansion and green-houses by a sort of cloister, or gallery. The collection of trees and shrubs at this place is also large and very choice.

Fern Itill-nearer town, is the residence of J. Pratt McKean, Esq., and is another of those remarkably fine and imposing lonses which have been erected in the neighborhood of I'hiladelphia within a fer years. ITere, also, are fine ranges of glass, and extensive and interesting views, and a great work in process of being accomplished.

There are many other places near Philadelphia (and we think the vicinity of no other city abounds in so many costly comntry residences) which we shall be compelled 
to pass over, from want of time and space, smply with their names: such as the fine and expensive house of Col. Eastwick, on the old Bartram garden; Woodfield. the fine residence of Mr. Swift; Devonshire, the seat of Mr. Blight, remarkable for its evergreens; and Champlost, the most charming old country residence of Charles P. Fox, Esq.

In the vicinity of Princeton, N. J., are some fine residences. The most interesting one to us is Woodlawn, belonging to Richard S. Field, Esq, and which we have alluded to so often in course of this supplement, that we have no right, perhaps, to say anything more. The honse is a very fine one, and the place most successful in certain varieties of evergreens.

There is here a Cedar of Lebanon (Fig. 38) larger than any other in the country, except Mr. Ashe's at Throgg's Neck; a Juniperus squamata, unsurpassed in any collection, and Siberian arbor vitæ (as they are called) though probably the Thuja Warreana, and many other evergreens of matchless size and beanty.

Near Wilmington, Del., is the fine place of Mr. Shiply; and in the neighborhood of Baltinore, is Farmlands, the noble estate of G. W. Lniman, Esq., comprising nearly six liun Hred acres, a large portion of which is cultivated for agricultural purposes, with very remunerating success. The mansion, without any architectural pretension, is one of great comfort and extent, cornmanding varied views over a fine rolling comtry to the city, and adjacent Chesapeake ; a well designed walk leads from the lawn, shaded by majestic oaks, with a few fine and effective cedars, to a pretty valley, bordered by masses and clumps of Rhododendrons, Hollies, Azalias, and other rare and valuable shrubs and trees; the whole terminating in a brilliant French parterre, surmonnted on a terrace by an extensive green-honse, in the rear of which, a gardener's house, a double curvilinear vinery, a frame-yard with several hundred feet of brick pits, a 
well concealed vegetable and fruit garden, complete the modern appliances of a fine country seat.

Hampton, the residence of John Ridgley, Esq., is situated about nine miles north of Baltimore, and belongs more properly to the early edition of this work, than to this supplement, which is intended simply to describe what has been done within ten years. It has been truly said of Hampton that it expresses more grandeur than any other place in America.

It belongs to the stately order of places almost unknown here at the North, situated as it is in the midst of a domain of six thousand acres. The façade of the house is one hundred and eighty feet in length, with offices attached, erected soon after the Revolution, in 1783.

The entrance hall, of great width and dignity, passes the visitor to the sonth front, where is a terraced garden of great antiquity, with clipped cedar hedges of most venerable appearance. The formal terraces of exquisitely kept grass, the long rows of superb lemon and orange trees, with the adjacent orangerie and the foreign air of the house, quite disturb ones ideas of republican America.

Clifton Park, near Baltimore, the residence of John Hopkins, Esq., is unquestionably one of the most elaborate places in this country. We remember no other, where in addition to a fine and costly house, there is so large a range of glass, with such diversified and extensive grounds; the varieties of trees, shrubs, walks, lawns, large pieces of ornamental water, containing numerous islands planted with masses of rhododendrons and evergreen shrubs, and connected by appropriate and tasteful bridges, are all, certainly, much in advance of any other place we know.

Lyndhurst, the country seat of Reverdy Johnson, Esq., has a new and very striking house, with a most extended and superb view.

Carroll Manor is another fine old place, like Hampton, 
with a turf unbroken for nearly two hundred years, and of the softness and thickness of velvet.

Mondawmin, the residence of $\mathrm{Mr}$. Brown, is a very attractive place, prettily laid out and planted.

In concluding our remarks on what has been done the past ten years, in various parts of the United States, as illustrating the progress in country life, we insert a short account of the state of Landscape Gardening in Ohio, extracted from a letter of Robert Buchanan, Esq., a well known enthusiast in rural matters, whose tastefully arranged grounds should, undoubtedly, have a place in the list of beantiful residences in the picturesque environs of Cincinnati.

"Landscape Gardening, according to the modern taste in that beautiful art, is of but recent introduction into the West. Previous to the publication of $\mathrm{Mr}$. Downing's valuable book on that subject, the improvements of public and private grounds were made under the direction of the proprietors, or of some gardener who had strayed out to this new country to better his fortune. There was no system-nothing to copy after; and although all were desirous to improve in good taste, they had no guide, until Mr. Downing's work appeared, and that was at once adopted as the text-book. Since that period, the magic wand of the enchanter has passed over the comntry, and in the vicinity of our cities and towns has transformed the barren hills and vales of their environs into tasteful suburban villas, through the skill of the Landscape Gardener.

"No public or private grounds with any pretensions to elegance, are now undertaken to be improved, without the supervision of a competent master of this art; for no one wishes to have it said, that his improvements were in bad taste.

"In the vicinity of Cincinnati, on the beautiful hills surrounding the city, many fine specimens of well-im. 
proved country seats are to be found. Among others, may be mentioned those of R. B. Bowler, Wm. Resor, W. B. Smith, Griffin Taylor, Thos. Sherlock, S. J. Kellogg, and Henry Probasco, of Clifton; W. W. Scarborough, and his neighbors of East Walnut Hills ; Miles Greenwood, and others, of Avondale; several on College Hill, in the neighborhood of Farmers' College; and Jacob Hoffuer, of Cumminsville, in the valley below.

"In the West, of late years, the establishment of Rural Cemeteries in the vicinity of towns and cities has been introduced with commendable zeal, and with a refining influence on those interested, as well as on the public at large. Among the most prominent of these improvements may be named 'Spring Grove Cemetery,' near Cincinnati; 'Alleghany Cemetery', near Pittsburgh; 'Bell Fountain,' of St. Louis ; 'Cave Hill,' of Louisville; and those of Lexington, Frankfort, Dayton, Columbus, and Cleveland; many of them presenting good specimens of the art of and taste in modern Landscape Gardening.

"The environs of these last-named cities are also adorned with many elegant country residences, too numerous to mention here; but the country seats of John H. Shoenberger, of Pittsburgh; Dr. C. W. Short, of Louisville; and Col. John O'Fallon, of St. Louis, may be given as examples. The latter, for extent and beauty, is excelled by none in the West."

In connection with Landscape Gardening at the West, we feel the importance of impressing upon all planters the great advantage, and even necessity of thick belts and screens of evergreens on the prairies, to shelter orchards, buildings, and stock-yards from the severity of the winter winds.

Mr. Edwards, the Secretary of the Illinois State Horticultural Society, writes us, that in this State, especially in the neighborhood of Lamoille, Bureau County, the 
following evergreens do well: the White, Gray (Banksiana), Austrian, Cembran, and Scotch pines; the Red, Black, White, and Norway hemlock spruces ; also, the Red cedar, the Savin, the Swedish and Irish junipers, the Balsam fir, the American and Siberian Arbor vitæ; that the Pine and Juniper are peculiarly adapted to the high, dry prairies- the Arbor vitæ and Spruce to moist localities; and that the following varieties have been tried, but all need protection in the winter: Araucaria imbricata, Cedar of Lebanon, Pinus excelsa, Pinus maritima, Deodar cedar; Douglas, Menzies, and Pinsapo spruces; English and Irish yews, English Silver fir, Chinese and Golden arbor vitæ; the Tree box, and even the Dwarf box, for edging. 



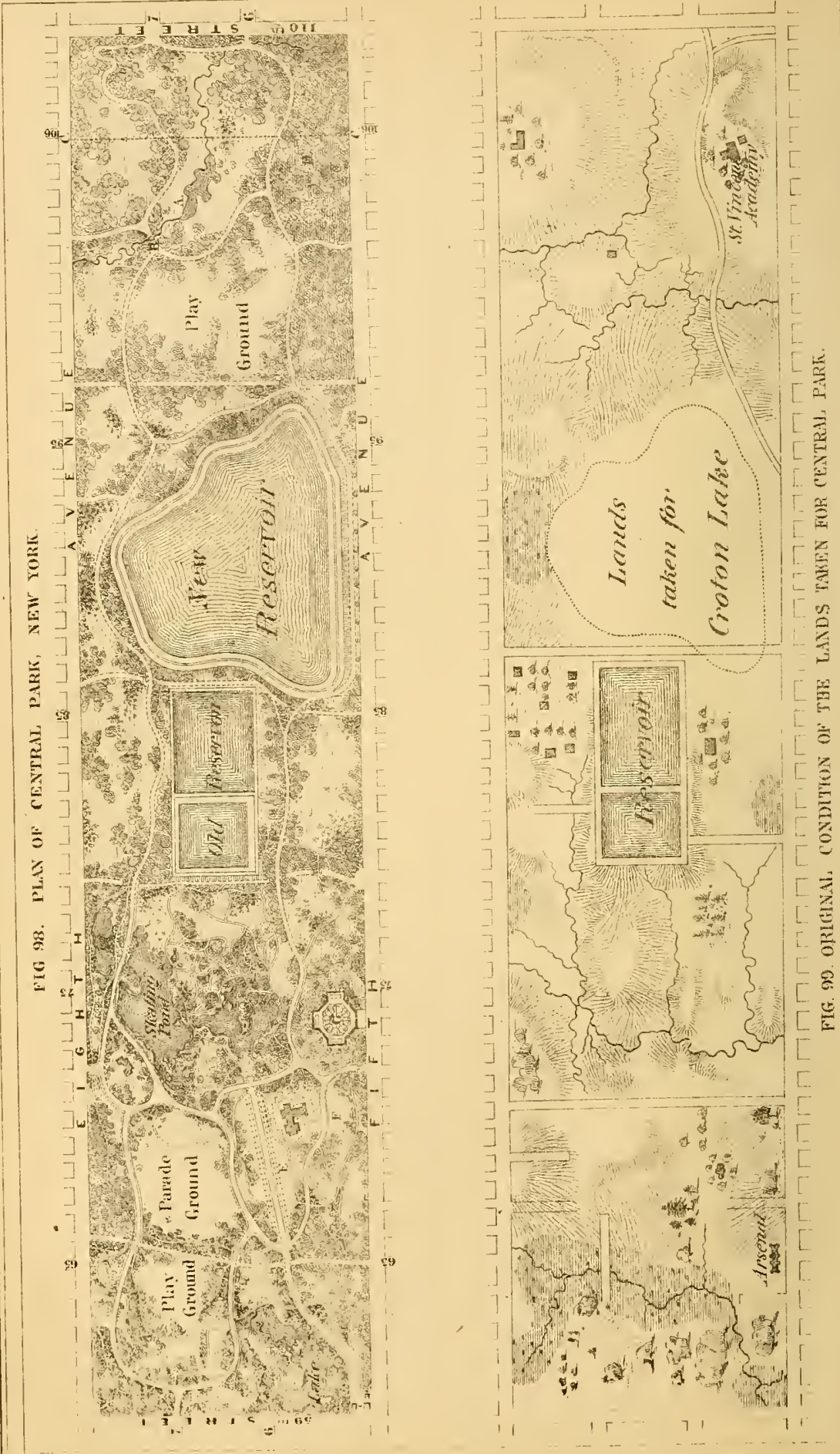




\section{SECTION VI.}

HISTORICAL NOTICES CONTINUED.

Not very many years have passed, since from the crorrded and confined state of our public Burial Grounds within our large cities, the question of extramural interments excited great and earnest consideration, and eventually led to the establishment of Rural Cemeteries.

The fir's one of any importance, was that at Lanre] Hill, near Philadelphia, a most successfnl enterprise, mainly due to the taste and perseverance of Mr. John Jay Smith, of that city. This was followed by the one at New Haven; Mount Auburn, near Boston; Greenwood, at New York; Spring Grove, near Cincinnati; two near Baltimore, \&c., until there is hardly a city or town of any size in the Union which does not possess its Rural Cemetery.

This was one of those grand improvements in civilization, the importance and necessity of which was so apparent, that it has since been universally adopted, and may be fairly considered now one of our institutions.

Another, and the next great step onward which is now exciting much attention thronghout the land, is the establishment of Parks, which may be classified as Public Parks, for the enjoyment of the People of our Cities and larger Towns, as the Central Park in New York, and Hunting Course Park, near Philadelphia; semi-Public Parks, owned and enjoyed by the persons who live around them; and lastly, the Parks, or Ornamental Grounds, attached to our Public Buildings, 
Colleges, \&c. As illustration, we will give from each class one example, selecting such as we happen to be the most familiar with.

The Central Park, in New York, being the most important work of the kind that has been undertaken in America, some slight reference to its plan and general intention will be appropriate here, the more especially, as the editorial articles that appeared in the "Horticulturist," urging its necessity, and setting forth its advantages, unquestionably exercised an important in. fluence in favor of the project.

The ground set aside for the purpose, consisting of about 750 acres (represented by the small diagram, Fig. 99), was appropriated by an Act of Legislature, in the course of the year following Mr. Downing's death. It was not, however, till the close of 1557 , that the actual purchase of the land was completed. Premiums for designs were at this time offered by the Commissioners intrusted with the conduct of the enterprise, and early in June, 1S5s, the plan (Fig. 9S), submitted by Fred. Law Olmsted, and Calvert Vaux, was adopted by the Board. The work was at once actively commenced, under the guidance of the designers, and has since been steadily pressed forward by the Commission-a force of over 2,000 men being employed during the most favorable part of the season.

From the published description of the design, and such other data as have been furnished us, it appears that the Park is two and-a-half miles long and half a mile wide. It is divided into two distinct parts by the old and new Reservoirs-the former a quadrangular basin of mason-work; the latter, of an irregular curved outline, with an earth embankment to retain the water. These two artificial structures oceupy a considerable space, and when complete, will have appropriated about 150 acres of ground ont of the middle of the site; 
<smiles>C1=CCCCCCCCCCCC1</smiles> 

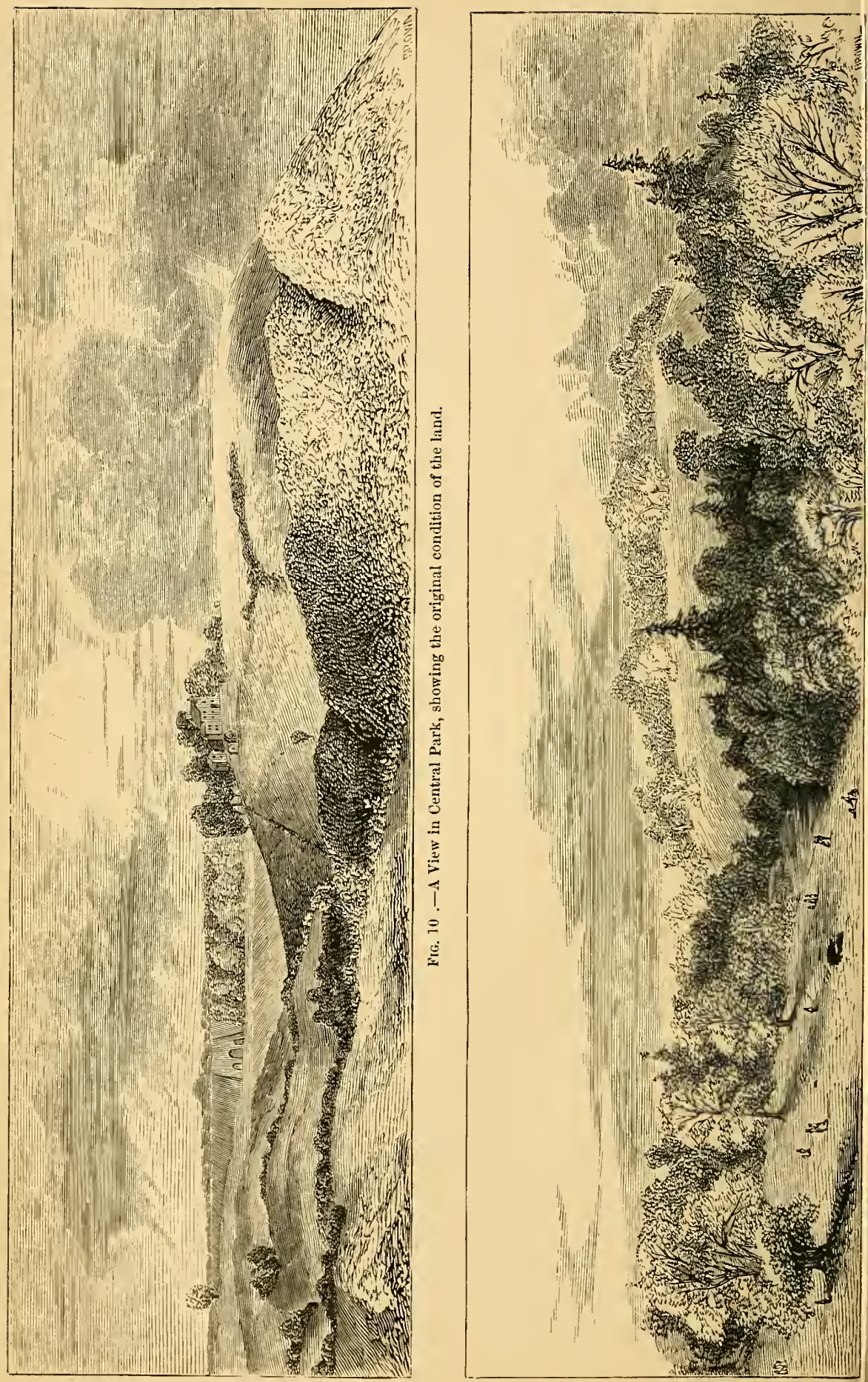
narrow spaces being left on either side, that at certain points become mere connecting links between the upper and lower portions of the Park.

The horizon lines of the upper Park, between the New Reservoir and 106th street, are bold and sweeping, and the slopes have considerable breadth and aniplitude in almost every direction in which they may be viewed. This character is, perhaps, taken altogether, the best that can be desired for a park; and but little alteration of surface is, therefore, needed.

A ravine of considerable extent runs through this section of the Park, in which a small lake $(A)$ may readily be formed, a view of which is given in Fig. 102; and west of this point $(B)$, where the road meets the dip of the two most important hills, a stone bridge is proposed to be erected, so that the main circuit-drive may include in its course a view of all the principal features of interest in the upper Park. The land, for some distance to the north of the boundary line $(C C)$, provided by the Act of the Legislature, should have been included in the original grant, as it commands extensive views that are not obtained within the present limits, and consists of a series of bold and picturesque rocky bluffs, terminating abruptly at 110 th street, which offer the only natural boundary to the Park property. The advisability of making this alteration in the line is now evident to all who visit the locality; and the attention of the city anthorities has been, for some time past, drawn to the subject. It is, therefore, quite possible that the northern boundary may soon be advanced to 110 th street. This will add about sixty acres to the area of the Park.

On the easterly side of the upper Park it is proposed to plant an American Arboretum $(D)$, so that every one who wishes to do so may become acquainted with the trees and shrubs that will flourish in the open air, in the northern and central parts of our country. 
It is not intended to be arranged formally, but so that it may present all the most beautiful features of lawn and woodland landscape, preserving, at the same time, the natiral order of families, as far as practicable. In the erent of the extension of the Park to 110th street being made, the space vecupied by the Arboretum might be considerably enlarged.

The lower Park, between 59th street, and the New Reservoir, is far more heterogeneons in its character, and requires a much more varied treatment. Its most prominent and characteristic feature is the long, rocky hill-side immediately south of the Old Reservoir; and this has been accepted as the central point of landscape attraction, to which the other ornamental arrangements of the plan are to be made more or less subservient. A skating-pond, or lake, of varied ontline, and containing abont fifteen acres, surrounds a considerable portion of the base of this hill, and, in a measure, separates it from the rest of the lower Park. Expanses of lawn are prepared on the table-land forming the summit of the hill, and the side is converted into a ramble, with a labyrinthine arrangement of foot-paths, leading the visitor among groves and shrubbery, rivulets, rocks, and glens, to the prominent points of view that are obtained in this part of the grounds.

A cavernons passage formed by large, overhanging rocks has been discovered, and excavated during the summer, and is an interesting incident heightening the naturally picturesque character of the ramble.

The Promenade $(E)$ is the feature next in importance in the lower Park. It consists of a broad level walk between double rows of elms. The boundaries are to be on all sides irregnlarly planted, so that its formality will scarcely be perceived, except within itself. Its northern extremity is finished architecturally, and, as suggested by the original outline of the surface, is elevater abont twenty feet above the ground immediately to the north, 


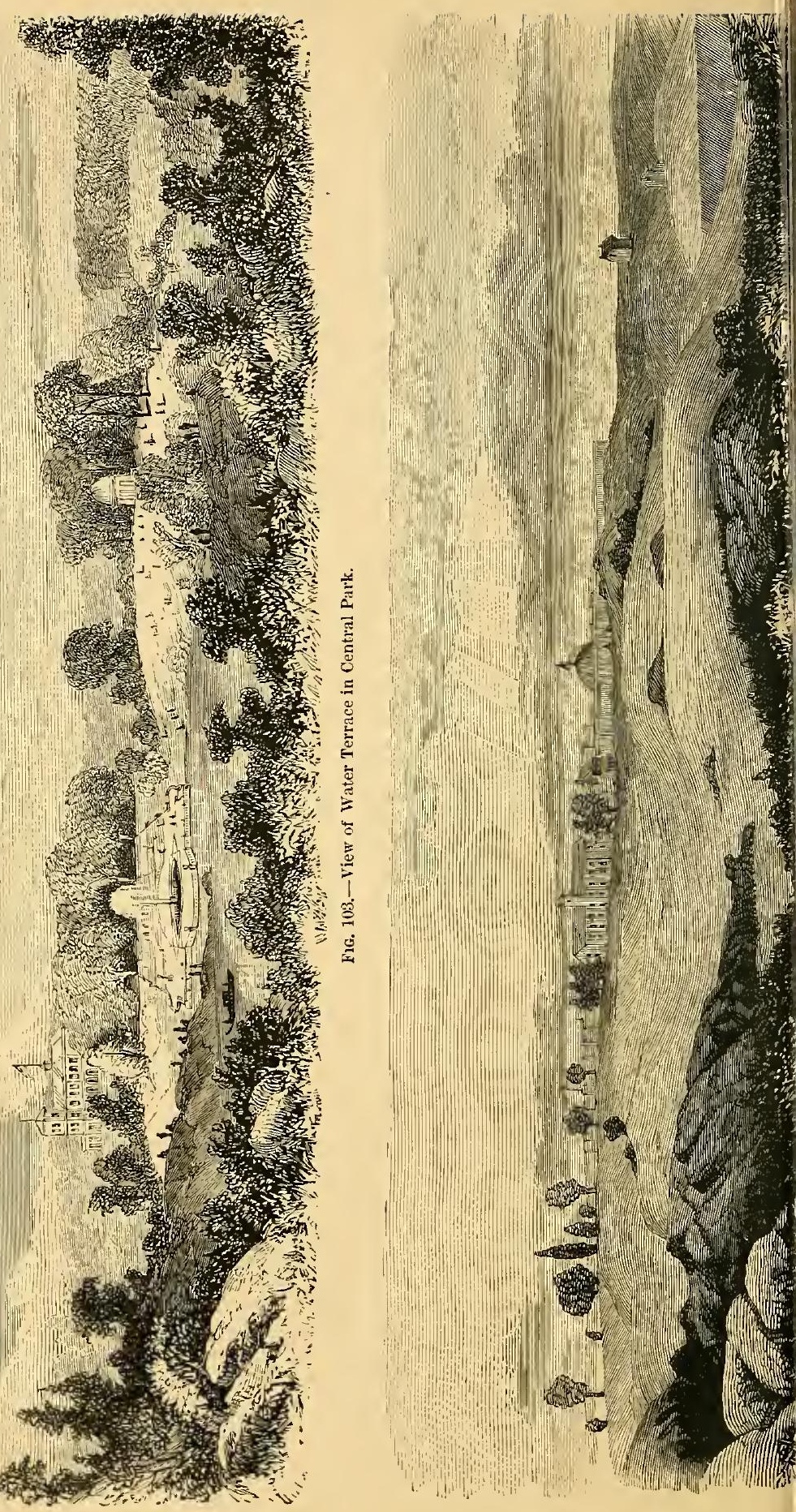
overlooking the hill-side occupied by the ramble, and being connected with the intervening lake by a Water Terrace (see Fig. 103), with which it communicates by flights of stone steps, and also through a spacious corrider passing under one of the carriage-drives.

To the west of the promenade a tract of about twenty-five acres, of nearly level ground, has been prepared, by the removal of rocks and other obstructions, which is intended to be used as a parade-ground.

On the east of the promenade $\left(E^{\prime}\right)$, and partially separated from it by an intervening ridge and plateau, is a stretch of pleasantly undulating ground $(F)$, intended to be carefully cultivated and planted with fine shade trees. 'To the sonthwest of the promenade is the play-ground, containing now about fourteen acres of levelled surface, overlooked by picturesque rocks that offer ample oppor tunity for spectators to view the games.

The southern extremity or entrance to the promenade is approached by roads and foot-paths leading from the different gates at the lower end of the Park, and offers a point of concentration and divergence both for pedestrians and those driving. Commencing at this point, a short circuit or vis-a-vis drive of a mile is provided around the parade and play-grounds, with branches connecting it with the longer circuit-drive that passes through the whole length of the upper and lower Parks.

Between the Fifth and Sixth Avenue entrances, near the southern bonndary of the Park, another lake of abont six acres is provided in low ground that is suggestive of such an arrangement.

Around the New Reservoir it is intended to construct a course for riding, and connecting with it, a bridle road is arranged, that commences with the principal entrance gates, and winds throngh the Park, passing under the roads and foot-paths by bridges, one of which is shown in Fig. 100. 


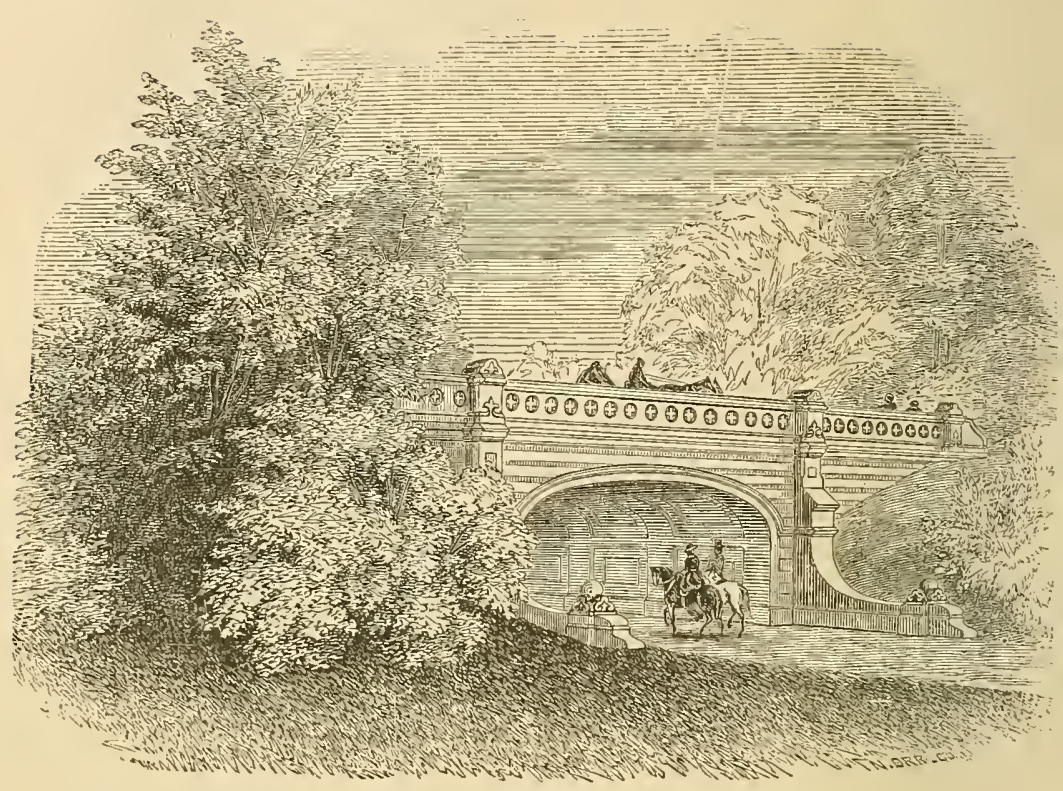

Fig. 100.

Along the westerly side of the Park, for a distance of nearly two miles, there will be a winter-drive, protected by hardy evergreens; and on the easterly side of the lake, a Geometric flower-garden $(G)$ of considerable size is proposed, as will be seen on the diagram of plan. Fig. 99.

In adapting to its present purpose the site selected for the Park, its situation in the probable future heart of the city had to be considered, and transverse roads between the east and west sides of the city were, of course, demanded. The Park being two and-a-half miles in length, it was also evident that these transverse roads would, at no very distant time, become crowded thoroughfares, having nothing in common with the Park proper, but every way at variance with the agreeable sentiments it should inspire. Eight times in a single circuit of the Park, they would oblige a pleasure-drive or 
stroll, to encounter a turbid stream of traffic. Each of these roads has, therefore, been so located and arranged on the adopted plan, that it may be carried through the Park on a grade that will allow the pleasure-drives to pass entirely over it at the necessary points of intersection, withont any obvious elevation or divergenee from their routes. Short tunnels are preferred for this purpose to ordinary bridges, so that the spaces at the sides of the pleasure-drive may be thickly planted, and the riew of-the city-street below shat ont from view. To illustrate still further the treatment of the grounds, we have selected two of the more important points of view (Figs. 101 and 102, 103 and 101), showing the original condition of the land, and the improvements which are contemplated.

In regard to the second description of Parks, we would first remark, that in the United States, the most numerous class from whom the art of Landscape Gardening will receive attention, is composed of persons of moderate means. They are mostly merchants or professional men, who seek a refuge from the confined and unwholesome air of the city, or whose taste leads them to find agreeable recreation in the cultivation and adornment of a country residence; who still maintain their business, or social connection with the adjacent city or town, but whose time and means which can be appropriated to their "place," are more or less limited.

We have, indeed, a rapidly increasing number of men of fortune, whose estates are large enough, and whose means and liberality are adequate for the production of the highest results of the art; but our best efforts must fall far short of the grand effects attainable under the English system of proprietorship, and the great majority of the practical exponents of American Gardening, will always be cultivators of few acres, whose taste, if correctly formed, will lead them to attempt only modest results. 
There are many practical difficulties, which every one must find, who essays to make such country or sub. urban residences. If the selection of a site is to be made, the proximity of nuisances, or the danger that an advancing population from the neighboring city will soon supply them, renders the task one of imuch perplexity. The limits of your place, plant as you may, can not always be concealed, witlout shutting ont the distant prospect; and all breadth of effect, and grace of ontline, is destroyed by the effort to secure yourself from present or anticipated annoyances. High boundary fences, and a separate gate-lodge for each place, scem necessary for protection from maranders-while the idea of even a respectable drive over your own ground, secure from the disagreeable objects of the public hightway, is rarely entertained. These difficulties, and many others, the enthusiastic lorer of a country life will bravely meet, and patiently endure, when they are insurmountable; but the attempt to overcome them has been made with apparent success, by the project before mentioned, of a semi-public, or, as it is, we believe, called a Neighborkood Park. The general plan on which such an enterprise can be based, may perhaps, be best elncidated by the history and description of Ilewellyn Park, * at Orange, New Jersey, in illustration of which, the engraving on steel (Plate VI.), presents a view of the entrance. A Plan of the same is also given in Fig. 105, and the upper and northwestern part of the Park is shown in Fig. 106, the figures being further explained by the Table of References, page 573 .

The site selected for this Park is on the eastern slope of the Orange mountain, which here forms an inclined

* The origin aud exceution of this valuable seheme, is attributable to Mr. L. S. Haskell, a merchant of New York, who has enthusiastieally devoted the past three years to the development of this, his farorite idea. 


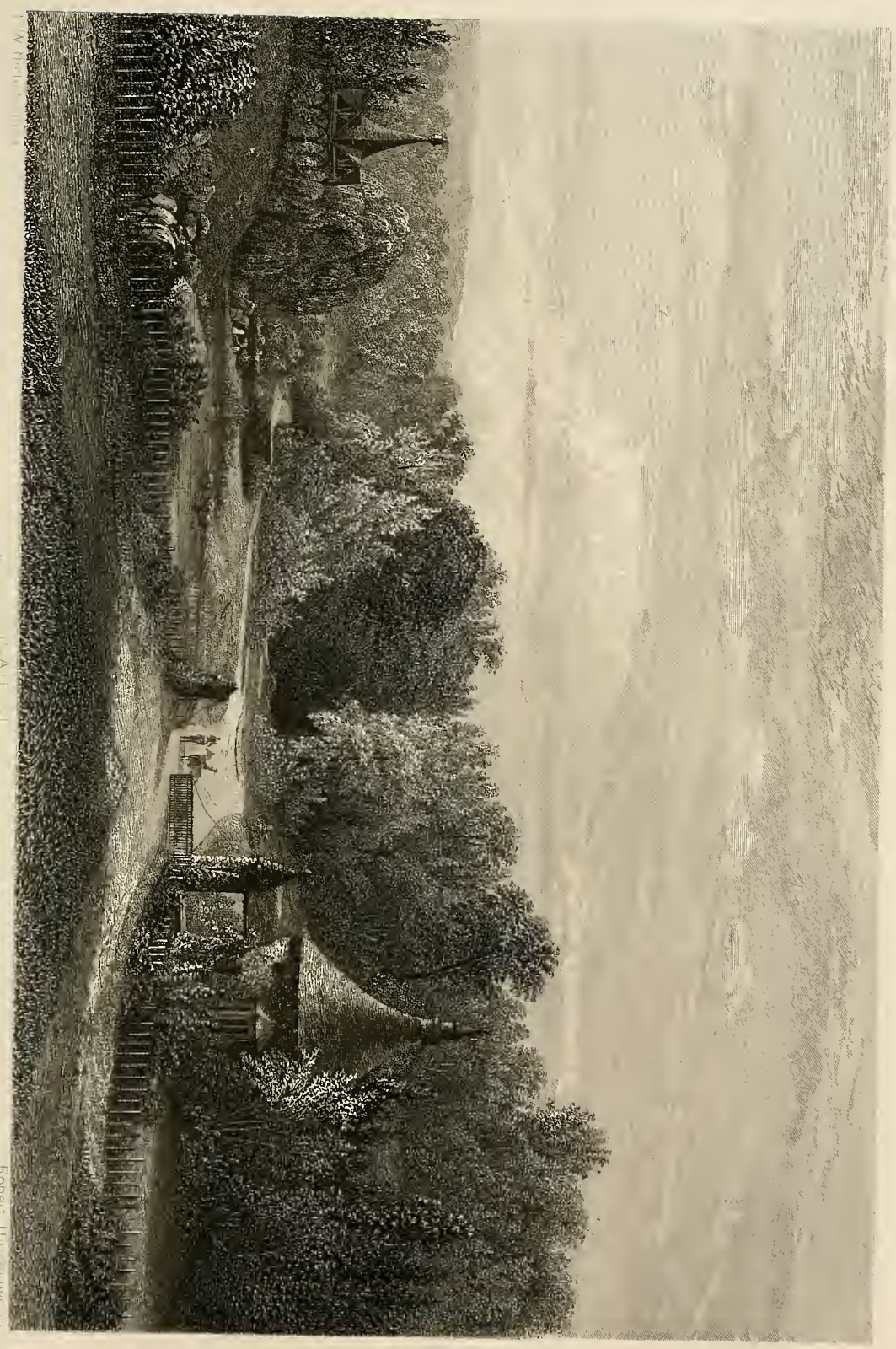



plane, starting from an elevated platean, on which is the village of Orange, and ascending westerly, at a moderate grade, for abont a mile, until surmounted by a rocky cliff of "Trap," which forms the crest of the mountain. The location gives accessibility to New York, by railroad, and to the pleasant village at the base of the mountain. The view from the grounds comprehends the entire area, extending to the city of New York, with a peep of the ocean through the Narrows, on the east; the Highlands of the Hudson on the north; and the receding blue of the New Jersey plains in the sonth; with the intervening cities, villages, forests, and farms. The tract of land procured for the enterprise, consisted of some 350 acres, mostly of half-cultivated or deserted farms-partly forests of oak, hickory, chestnuts, cedar, and pines.

It will usually be found, as in this case, that the most snitable land for such a project is-from the desirable irregularities of surface, the profusion of rocks and ravines, and its elevated position-the least useful for the agriculturist. That portion of the grounds sclected for the Park proper is centrally situated, as regards the whole tract, and in form it is irregular, following the natural indications of the surface-being traversed by a finely wooded ravine, throngh which flows a brook, affording material for ornamental water and cascades, which have been tastefully made throughont its course. It comprises nearly sixty acres-its greatest length measuring one mile-the entire tract being encompassed by a road which gives access to the surrounding residences; and the other drives made for the convenience of those sites not immediatcly contignous to the Park, increase the extent of carriage roads to an aggregate of five miles. The walks, measuring about the same length, lead from the entrance, to the snmmit of the cliff, and to other interesting parts of the grounds; while at suitable points are liosks, seats, and bridges, constructed in rustic- 
work, to be in keeping with the natural character of the surrounding forests. The entrance from the public road is protected by a gate-lodge, and is set back from the highway two hundred and fifty feet; a liberal space here rendering the change from the road to the cultivated grounds of the park less abrupt, and expressing the idea of hospitality. The main avenne from the entrance soon leads the visitor into the ravine, while on either hand diverge the other roads; following Glen Arenue, we emerge from the ravine, by a picturesque turn up the precipitous bauk. The somewhat laby-. rinthian drives which now offer themselves, lead in graceful curves throughout the estate, the mity of which is not marred by interior fences; for though the proprietor's are not restricted in this respect by any rule, they have, by common consent, thus far avoided the erection of any barriers, excepting those necessary to enclose the whole tract. The Park itself and all the private places, seem like one large estate, enlivened by the dwellings and embellishments which, at intervals, are seen throughont the vistas of the forest. After making the detour of these grounds, the drive may be continued to other interesting places in the neighborhood, among which is "Eagle Rock," a bold projecting portion of the cliff, commanding a wider scope of the horizon, and more nearly a birds-eye view of the landscape. Around this central tract, especially termed "the Park," the remainder of the property is divided into about fifty villa sites, of from three to ten acres each, the proprietors of which have a joint interest in and common access to the Park, but who possess the sole and unrestricted right to the lot which they may have selected. The fund for the purchase and embellishment of the Park is derived from an assessment on the surrounding sites, of one hundred dollars per acre; and for the maintenance of the Park, and future improvements, an annual assessment is made 



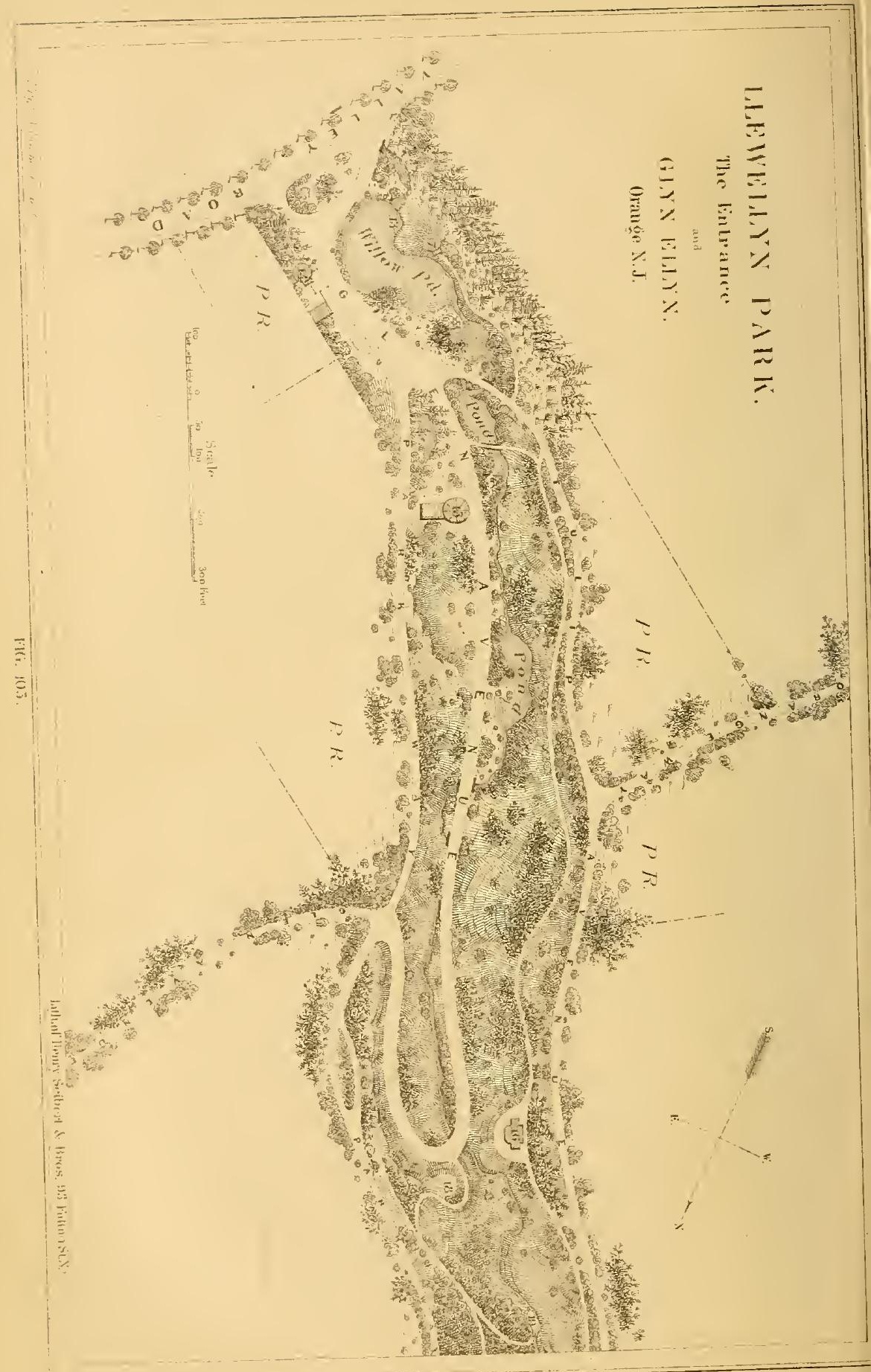




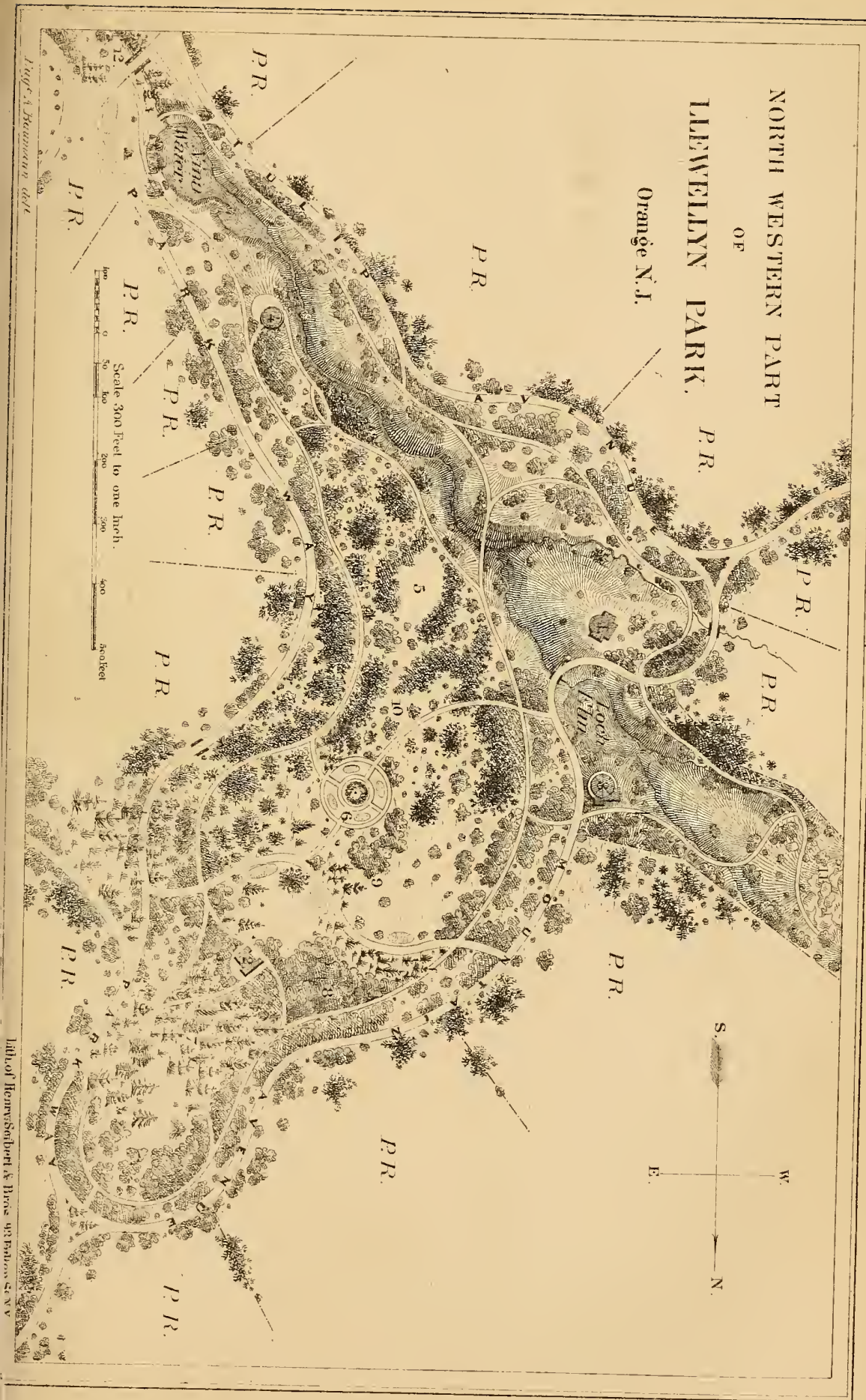



by the proprieturs, not to exceed ten dollar's per acre. The fee of the Park is in three trustees and their successors, and its care and embellishment is entrusted to a "Committee of Management," who are elected annually by the lot owners.

Some of the advantages which are aimed at, in what may be termed the social park, may be thins stated:

1. The securing a neighborhood free from nnisances and an inferior class of buildings.

2. The rural character of the grounds is preserved, instead of assuming the rectangnlar forms of a village, which are a repetition of city lots on an inferior scale.

3. The different places can be laid out with mutual reference to each other, so that the subdivisions are not apparent in a way detrimental to the general effect.

4. A fine entrance and approach road can be secured. even where the private grounds are small, and the amount appropriated to these embellishments limited.

5. The Park affords extensive drives and walks for the exclusive use of the proprietors, with a variety in the ornamental grounds unattainable on places of ordinary magnitude.

To illustrate the general mode of treatment of the private grounds adjoining the Park, we give, in Figs. 10 T and $10 \mathrm{~s}$, plans of one of the sites of five acres. It is situated on a gentle knoll, and the honse, which is in the Tuscan manner, occupies the summit, and commands fine distant views in all directions. The place is laid out in the natural style, by that very clever Landscape Gardener, Mir. Bauman, and an appropriate connection between the house and the surrounding grounds is maintained by an artificial terrace, fifteen feet wide at the top, and ornamented with vases, ete.

The plans may serve, also, to show the method of gronping the trees-their positions, and the varieties used, being given in the Table of References, page 573.

Another phase of improvement in our r'ural taste is the increasing care and attention bestowed upon the 
grounds attached to our colleges, hospitals, and other public buildings.

Mr. Downing, we think, did much to derelop this in the taste he displayed in the arrangement of the grounds attached to the Smithsonian Institute and La Fayette Square, in Washington. We are rapidly passing from the straight, formal walks, and the rectangular plantations of the past, into the more harmonions and pleasing arrangements of the modern school. Clinton Park and Botanic Garden, which contains within its limits Hamilton College, at Clinton, N. Y., is a very successful illustration of this improvement. Fifteen or twenty acres have been enclosed within the College Park, and entirely laid out in the most skillful and artistic manner. Broad and extensive lawns are divided by graceful walks throughout the whole extent; trees and shrubs, of every description flourishing in this climate, have been planted in groups, masses, or as single specimens.

A section of the ground will be used as a Botanic Garden, in which trees, shrubs, and flowers will be arranged according to their several families.

The humanizing influence of harmonious and beantiful surroundings upon erery one, is beyond all question; and it was truly said by the Rev. Mr. Gridley, to whose taste and energy much of the suecess of the Clinton Park is due, that "it is no vain thing to suppose that the minds and hearts of students will be benefited by daily walks through such grounds, and in view of snch a varied and wide-spread landscape: these peaceful shades and sunny slopes and langhing streams-this hum of cheerful industry-the music of distant church bells, and the glimpses and echoes here caught of the great thoroughfares of business and travel that mark the great world without-these skies, ever changing and ever beautiful, and the seasons rolling through themwhat mind can be brought into the midst of snch scenes without deriving fion them essential profit ?" 



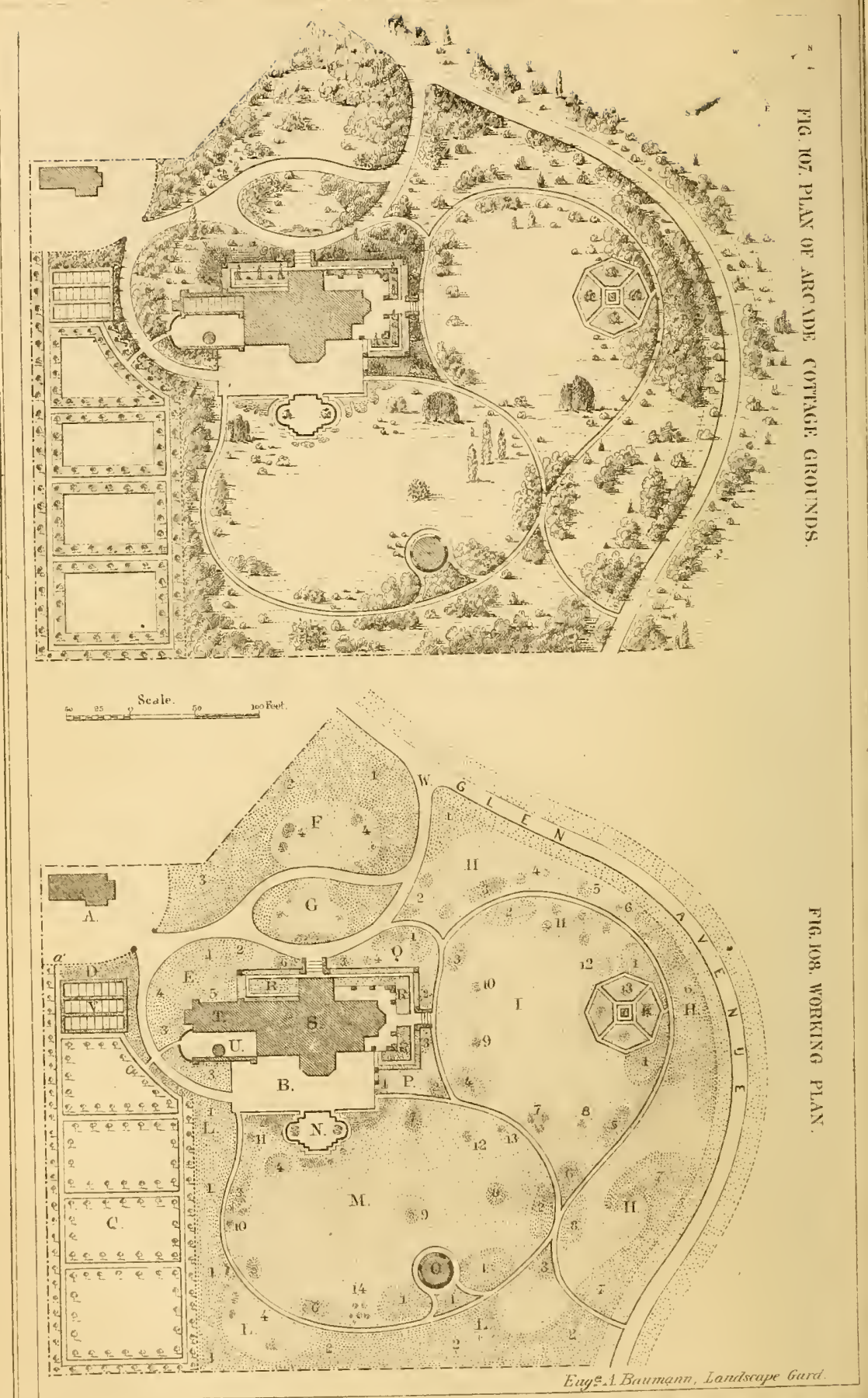




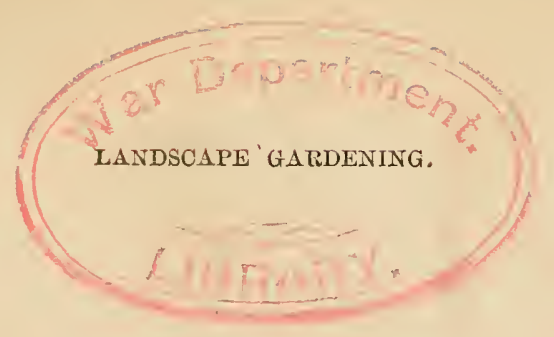

\section{RE F E E N C E S.}

\section{HXPLANATION OF REFERENCES FOR FIGURES 105 \& $10 \%$.}

No. 1. Lycenm.

"2. The Wigwam.

"3. Summer-house.

"4. 4 .

" 5. Children's Play-ground.

"6. Social Circle.

"7. The Evergreens.

"8. The Hickories.

* 9. The Chestuuts.

" 10. The Oaks.

"11. The Rocks.

\author{
No. 12. Stone Bridge on Oak Bend. \\ "13. The Caseade \\ "14. Gate-lodge. \\ " 15. Conservatory and Propagating \\ liouse. \\ "16. Prospect Tower. \\ "6 17. The Kiosk. \\ "18. Roekwork. \\ "19. Raviue Spring. \\ $P$. R. Private Pesidences.
}

\section{TABLE OF REFERENCES FOR FIGURES 107 \& 108.}

S. The House.

T. The Conservatory.

R. Grass Terrace.

$B$. Fravelled Terrace.

W. Approach.

N. Fountain and Jet d'eau, surrounded with beds of flowers.

0 . Kiosk, from which is the best view of the house.

I. Rnsery, in the centre of which is a suitable place for a statuc or vase.

A. Cosch-house and Stable.

$C$ Kitchen-garden, separated from the lawn by a belt of trees, $D L L$.

$E$ 1. Sugar Maple.

2. Silver"

3. Norway"

4. Lombardy Poplar.

כ. Screen of Ameriean Arbor Vitæ.

6. Group of Rhododendrons.

F1. Group of White Pines.

2. Lofty growing trees, near the boundary, Oaks, Maples, and Tulips.

3. Chinese double-tlowering Apple, Kentueky Coffee tree, and Kölreuteria.

$\Pi 1,6$, \& 7. A large group of trees, both Evergreen and Deciduous, planted on the outskirts of the place.

2. Acacia Bensoniana.
3. Group of Euonymus (purple-leaved).

4. Austrian Pine and Pinus exeelsa.

5. European Weeping Ash.

l 1. Group of low evergreen trecs, Yew \& Arbor Vitæ.

2. Group of Mountain Laurels.

3. "6 of Mahonias.

4. " of Bohemian Olives.
5. Thrija TVarreana.

6. Syringa Chinensis.

7. Group of Lindens.

8. A Weeping Willow.

9. Red Flowering Horse-chestnut.

10. Double-white " "

11. Hemlock, European Silver Fir, Irish Juniper, and Pieea Webbiana, planted singly.

12. Pyrus Japonica.

$\not I 1$. Groups of Evergreen Trees.

2. Syringa grandifiora, Forsythia Viridissima and Kerria Japonica.

3. Berberis purpurea, Amygdalus pumila, Calicanthus lævigatus, andl Deutzia gracilis.

4. Double-flowering Cherry.

5. Three single Ameriean Silver Firs.

6. Juniperus communis.

7. American Weeping Willow.

8. Magnolia tripetala.

9. Magnolia Soulangiana.

10. Deciduous Cypress and Ginko.

11. Purple-leared Beeeh.

12. Paulownia imperialis,

13. Judas Tree and Amer. Nettle Tree. 14. Spireas.

$P$ 1. Group of six Mahonias. 2. " " of Khododendrons,
3. "Enias and Epigea ro.

Q 1. Group of Roses, Spireas, and Weige. lias.

2. Azalias

3. Rhododendrons.

4. Magnolia purpurea.

U Fard and Woll. 


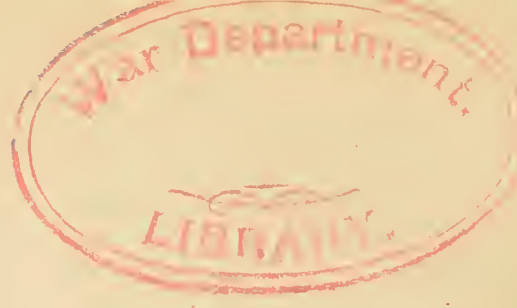

GENERAL INDEX.

$\Delta$ lites....................256, 484

"6 bracteata................. 508

• densa ................. 511

" Fraseri................... 508

". Kæmpferi............242,506

" nobilis................... 509

" pinsapo....................... 511

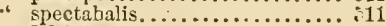

Vebbiana ..................... 511

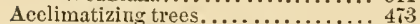

Acer..................... 165, 455

Acacia, three thorned................. 172

Esculus.................. 155, 457

Afriean Cyprus.................... 535

Ailanthus....................... . . 202

Alder .................... 163, 459

Alderthorpe, residence of J. F. Fisher 555

Alnus................. 163, 459

$\Lambda$ merican Silver Fir................ 256

Ampelopsis hederacea............. 2Ts

Aneient Style, plantations in ....... T5

Arabia........................ 470

Araucaria.................... $48 s$

Arbor vitæ............ 257, 459, 529

" broad-lcared............ 529

"6 Don's................... 507

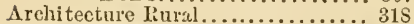

Aristolochia sipho............... 250

Appendix....................... 413

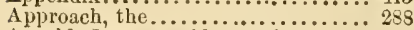

$\Lambda$ ruold, James, residence of.......... 41

$\Lambda$ sh, the ............121, $13 \mathrm{~s}, 462,463$

Aspinwall, $i$ i. ii, residenee of..... 36

Balm of Gilead ............... 256

billsam Fir. ................... 256

baltimore, residences nloitul........ 556

bartram Garden............... 56

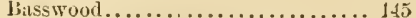

Benchelytie ................... 550

Beautiful, in Landseape Gardening.. 51

Beautiful, planting to produce...... 80

beech, the................ 1 147,461

Belmont...................... 3s, 158

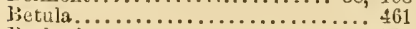

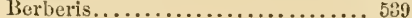

Bignonia........................ 280

Bireh, the..................... 158,460

black Gum..................... 216

Blithew ood .................... 30

Boston, residences around.......... 549

Brookwood, residence ot C. II Fisher 555

Brooks, treatment of ............ 313

Broussonetia................ 186

Brown, Alex, residence of.......... 43

Bridges......................... 599

Buttonwood, the................ 134

California Nutmeg. . . . . . . . . . . 583

California Redwoud............... 527

Camac, Mrs., residence of',.......... 42

Carpinus. ............... 150, 462

Carioll Mano2. ............... 539

Carya........................... 194

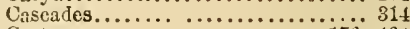

Castanea................... 176, 460

Catalpa.....................212

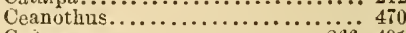

Cedars..................... 266,491

Cedar, Incense................. 506

Cedar, Japaı........... . . . . . . . . . 495

Cedar of Lebanon.................. 262

Cedar, the White................ 495

Cedrus.......................... 491

Celastrus seandens.................. 279

Cemeteries, ruinl.............. 559, 561

Central Park, N. I.............. 562

Cereis.................. 174, 461

Cephalotaxus................ 494, 528

Chamacyparis........................ 555

Champlust, residence of U. P. Fox... 5.6

Chestuut.................... 176

Chiuese rice paper plant... ........ . 470

Chinensis procumbens........... $49 \pi$

Chinquapin .................... 180

Clematis............................. $2 s 1$

Clifton Park, residence of $\mathrm{Mr}$.

Hopkins.................. 557

Clintun Park, Clinton, N. Y........ 57.

Compost for Rhododendrons, \&c.... 537

Cornus..................... 2t9

Cornus variegata...............440

Conservatory.................. 886

Cotonenster........................ 536

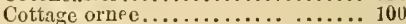

Country place, how to make....... 437

Cratregus...................... 21s

Cryptomerias..................... 49.5

Cunninghamia................ 496

Currant, flowering ............. 471

Cushing, J. P., residence of. .......... Cupressus.............. $233,497,527$ Cypress .................... 234

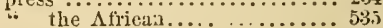

" Deeiduous ............... $52 \pi$

" the True................. 497

Dacrydium....... ......... 498

Daphne atro puxpureum............ 471

Deciduous Shrubs................ 469

Diospyros.................... 214

Deutzias.............................. 471 Devonshire, resilence of $\mathrm{M}$ ir. Blight 556 Dogwood..................... 229

". Variegated-leaved.........440

Dive, the.................. 293

Elder, black........ .........4 471

Ellerstie....................... $8 * 3$

Elm, the ..................... 128, 469

Embellishmients............... 362

Emmet, Wril, residence of........ 34 
English Cottage Style............ 349 Entrance Lodges......... . . . . . . . . 356 European Silver Fir.............. 257 Expression in Architecture......... 32. Evergreen trees.................. 246 Evergreen shrubs. newer......... 4sEvergreens, transplanting......... $\$ 19$

Fagus................ 117, 461 Farmlands, residence of Mr. Lurman 556 Fences...................... 295 Ferme ornec................... 99 Fern-Hill, residence of J. P. ג'Këin 555 liirs........................ 256 Fir, the American Silver............. European Silver............. 257

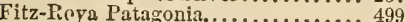

Flower Garden, architectural....... 371 " "6 English............ 376 " " at bropmore........ "6 "6 French............ 374 .6 " irregular........... 373

Flowers, introduction of............. 490 Forsy thia viridissima............... 47 I

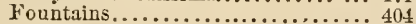
Fraxinus................... 133,462

Gardiner, J.L., residence of . . . . . . 549

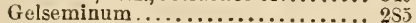

Geometric gardening................. 72

Ginko.................. 26, $23 \mathrm{I}$

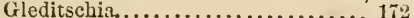

Glycine........................ 282

Glyptostrobus.................... 499

Gothic Style for Domestic Architec-

ture....................... 341

Green House........................... 356

Ground, treatment of................. 2st

Grouping of trees..............

Gymnocladus................... 204

Hamilton, Wm., residence of.... ... 25

Hampton, residence of Mr. Ridgley . 557 Harmony between House and Grounds................... 327

Ilarmony in Landscape Gardening....................... 66

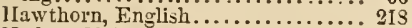

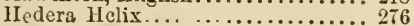

Hedges, trees suitable for .......... 296

IIercules' Club ................. 470

IIistorical Notices............... 17, 546

IIilllouse, James, residence of .... 37

Hickory. Tree .................... 194

ILoles for Trees.................... 418

IIolly ..... .................... 270

IIoneysuckle..................... 283

llornbeam................ 150,462

Horse Chestnut. . ............ 155, 457

II udson. River, residences on....... 552

IIunter's Island................ 36

IIunnewell, H. H., residence of...... 442

Idlewild.. .................. 554

Ilex...................... 270

Ilex laurifulia.....................

Illinois, Mr. Edwards' Report on

Evergreens in.............. 560

Irving, Washington, residence of. 35,353

Ironwood . ............... 1 . 0

Islands, formation of.................. 30 .

I talian Scenery................. . 451

Italian Garlen................... 44
Jessamine.................... 295

Judias Tree.......................... 174

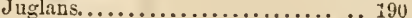

Junipers.................... 26\%, 500

Landscape Gardening........1\%, 45, 67 Do. progress ill. . . . . . . . . . 42

Lakes in Landscape Gardening....... 30 . Lalch, the.................238, 506 Larix....................... 238 Latimer, J. R., residence of .......... 43 Laurus.......................... 211 Lawn, treatment of................... 421 "6rass Seed for . ........... 12. " Mowing Machine........... 42 "T'op Dressing for.............. 42t Lee, Thowas, residence of........... 40 Lemon Hill. . . . . . . . . . . . . . . . . . .

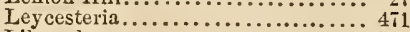
Libocedrus..................... 506 Ligustrum.................. 471 Liriodend $l^{\circ}$. . . . . . . . . . . . . . . . . . . . . . . Linden, the ................... 148, 469 Linmele, residence of in. S. Fay.... 119 Lime Tree................... 143, 464

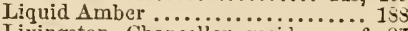
Livingston, Chancellor, residence of 27 Livingston, Manor of.............. 30 Llewellyn Park, Orange, … J......... 56 Locust, the.................... 170 Lonicera................................ Ludlow, $T$. W., residence of......... 35 Lyman, Theo., " Lyndhurst, residence of R. Johnsun... 55'

Machine for Mowing Lawns.... 41i, 422 Maclura..................... 18 Magnolia.... ................ 330,461 Mahonia................... 530 Malbone Place, residence of $\mathrm{J}$. Pres-

cott Hall, Esq..................550 Mammoth Tree, the.................. 534 Maple, the.................. 1605,455 Margins of Water.................. 315 Marine Residences.................. 549 Minturu, Robert B ................ $36^{\circ}$ Modern Style, plantations in ........ 76 Monroe, James, residence of......... 86 Mondawnin.................... 55s Montgomery Place................ 31 Morus $. \ldots \ldots \ldots \ldots \ldots \ldots \ldots \ldots \ldots \ldots, 184$ Mountain $\Lambda$ sh................. 190,467 Mowing Lawns.................... 42. Mulberry.................... 184

Newport, residences around........ 5.50 Norway spruce................... 257 Nyssa.........................

Oak, the ................. 11 $i, 46:$ Ohio, Landseape Gardening in...... 5̃ s Ornamental P'lantations .......... 91 Ostrya......................... 150 Osage Orange.................... 181 Outline of Water................... 304

Park, treatment of.............. ss

Parks............................ 569 Paulownia..................... 245 Pavia................... 157, 458 Peach, White tlowering............. 4T1 Periploca.................... 285 Perkins, Col., residence of............ 3s Persica vulgaris, flore pleno alba.... 4i 
PAGE

Persimon, the................214

Peters, Judge, residence of......... 26

Peperidge, the..................210

Philadelphia, residences around.... 555

Picea.................... 507

Picturesque in Landscape Gard..... 51

Picturesque, plantiug to produce.... 81

Pine, the................ 5ii, 246

Pine, Chili...................... 499

"6 Norfolk Islind................ 489

Pine-Bank.................. 89

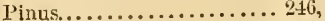

. cedrus.................... 493

"6 deodara.................... 491

" Fraseri................... 508

" Krempferi................. 506

"6. Iasiocalpa................. 507

" pinsapo................ 511

4. plpiata $\ldots \ldots . . .511$

6. Siberica.................... 510

Pipe vine.................... 280

Pits for wintering plants.......... 482

Plane tree...................... $18 t$

Plantanus..................... 137

Plants, half-.iardy ............... 47

Podocarpus .................... 525

Poplar, the...................228, 150

Populus....................... 150

Porch, explession of............. 325

Prairies, evergreens on the......... 560

Privet ...................... 471

Prospect tower................ 397

Pseudo larix Kæmpferi. . . . . . . . . . 506

Pyrus........................ 198

Quercus..................117, 465

Tathbone J., residence of........ 34

Tathbone J., residence of............ 434

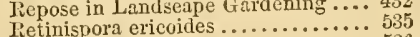

rietinispora ericoides ................ 5836

libes sanguineum flore pleno........ 471

Rifer side villa, illustration of....... 97

Roads, coustriction of............ 288

Robiner..........................

Roseneath, resideuce of C. M. Wol- 554

cott.............................. 554

Roses............................... 281

liock-work..................... 400

Tockwood. .................... 550

linstic work, fences of............ 297

Salisburia................. 26, 231

Salix....................... 207, 460

Sambucus flore pleno..............4 471

Sargent, H. W., resideuce of...... 439, 34

sassafras tree................... 211

Saxe Guthan conspicua............. 526

Service tree ............... 201

Seats, open and eorered............... 392

Sequoia gigantea ............... 53

is sempervireis...........5527

Silver fir.................... 507

Sheaff, G., residence of........... 41

Sheldon, Mr., residence of.......... 354

Shrubbery, the................. 350

Shrubs, Lvermeun................ 535

sophora...................... 467

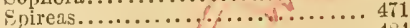

spruce Firs................... 454

Stakes, use of, in planting.......... 443

Statues..................... 368
PagR

Stenton........................ 43 Supplement to Landscape Gardening 425 Survilliers, Count de, residence of... 41 Sweet Gum tree................. 1 ss Syringa Josikma................ 472

Tabular view of evergreens........ 540 Tamarix Africana. .................4 479

Taxus.....................272,528

" Montani.......................

"Lambertiana............... 511

Taxodium .................. 234 " pendulum............... 500 " distichum................. 527

" Japonicum............... 499

" sempervilens........... 527

Terrace, to conuect house and grounds 363 Thayer, J. E., residence of.......... 549 Thuiopsis.................. 497,529 Thuja..................... 499, 529

" Anstralis...................., 491

Thorn tree.................... 218 Tilia....................... 143, 468 Transportiug trees.............4 413, 417

Trees, choice of ................... 415

" expression iu............... 112

"4 druoping................ 109

". management of, in Landscape. 69

"6 round headed................. 103

" spiry top....................... 105

"6 oblons beaded.............. 108

Trumpet creeper.................. 2>0 Torreya....................... 53: Tupelo..................... 217 Tulip tree...................... 2225

Clmus.................... 128, 470 Unity in Landscaje Gardening...... 64

Tariety in Landscape Gardening.... 66

Vines........................ 275

Virginia creeper.................. 278

Virgilia lutea..................... 243

Wadsworth, 0 , residence of....... 37

Walks, construction of.............. $28 s$

Waltham Ifouse.................. 28

Walnut tree..................... 198

Warren, Mr., residence of........... 351

Wasen, tronia girantea................584

Water, treatment of ............... 29y

Waterfills....................... 314

Watering trees when planting....... 418

Wellingtonia giganten.............. 534

White beam, the................ 201

White wood....................... 245

Widdriugtouia .................. 535

Willow.....................207, 460

wistarin....................... 282

Tood, management of ....... $70,87,410$

Woodbine.....................2 28\%

Woodfield, residence of $\mathrm{il}$. Swift... 25

Woodlawn...................... 556

Wodenethe.................... 31

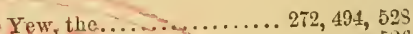

Yew, the..... Ifbert'.............. 526

"s stiuking.................. $58 \pm$

Vases....................... 363

Verandah......................... 326 



| 1 n n =

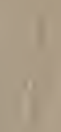




\section{LIBRARY OF CONGRESS

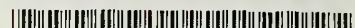

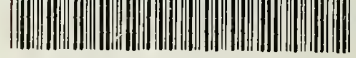 \\ 0000.9 4 4 ? ? ?}

